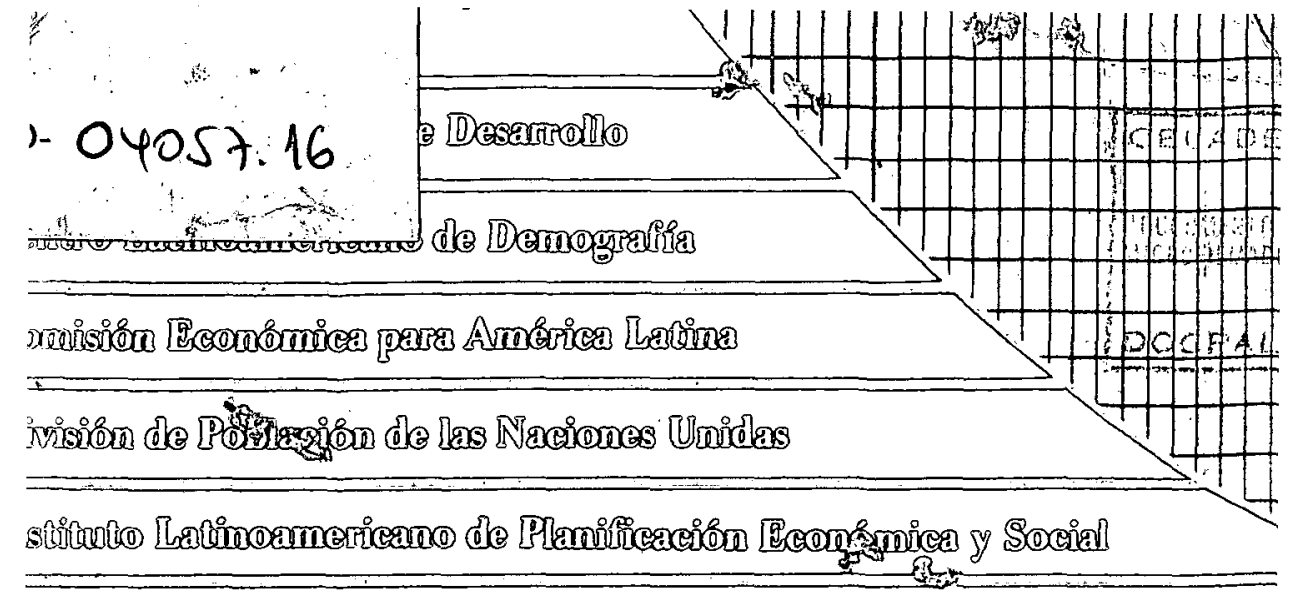

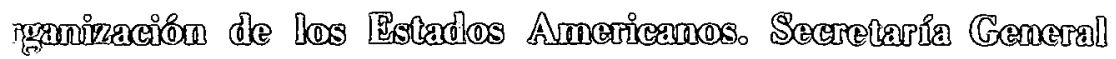

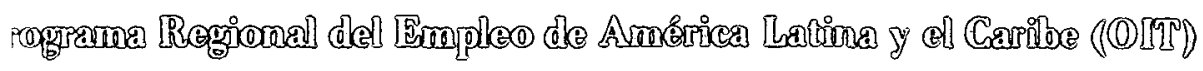

\title{
LOS ESTUDIOS
}

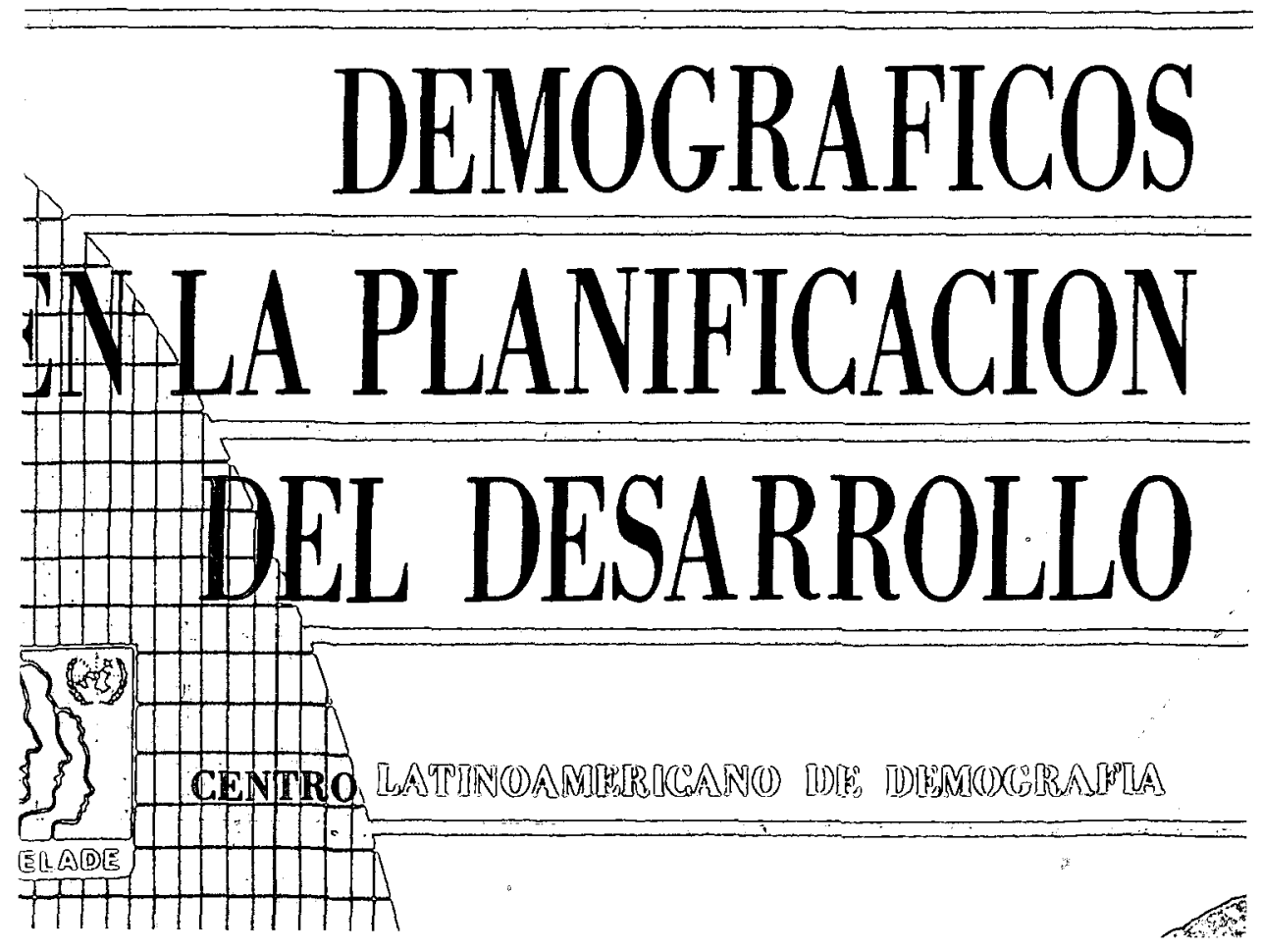


$\hat{z} \cdot \cdots$ 


\title{
LOS ESTUDIOS DEMOGRAFICOS
}

\section{en la}

\section{PLANIFICACION DEL DESARROLLO}

\author{
Banco Interamericano de Desarrollo \\ Centro Latinoamericano de Demografía \\ Comisión Económica para América Latina \\ División de Población de las Naciones Unidas \\ Instituto Latinoamericano de Planificación Económica y Social \\ Organización de los Estados Americanos. Secretaría General \\ Programa Regional del Empleo de América Latina y el Caribe (O IT)
}
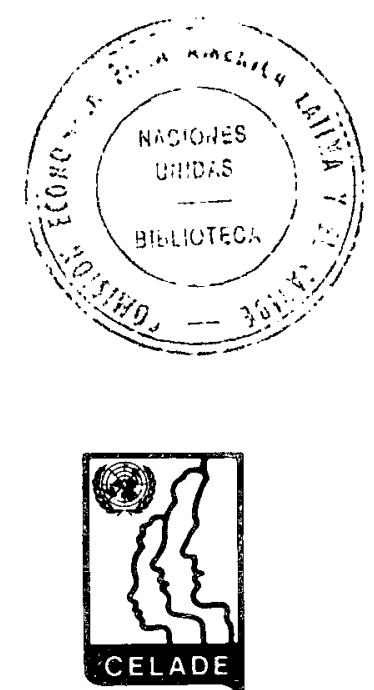

CENTRO LATINOAMERICANO DE DEMOGRAFIA

Santiago de Chile, 1975 
Centro Latinoamericano de Demografia

CELADE: J.M. Infante 9. Casilla 91. Teléfono 257806 Santiago (Chile)

CELADE: Ciudad Universitaria Rodrigo Facio

Apartado Postal 5249

San José (Costa Rica)

(c) Centro Latinoamericano de Demografía, 1975

Serie $E, N^{\circ} 12$ 


\section{LOS ESTUDIOS DEMOGRAFICOS}

EN LA PLANIFICACION DEL DESARROLLO 

El Banco Interamericano de Desarrollo, el Centro Latinoamericano de Demografía, la Comisión Económica para América Latina, la División de Población de las Naciones Unidas, el Instituto Latinoamericano de Planificación Económica y Social, la Secretaría General de la Organización de los Estados Americanos y el Programa Regional dell Empleo de América Latina y el Caribe, auspiciaron el seminario sobre Utilización de Estudios y Datos Demográficos en la Planificación, que se realizó en Santiago de Chile, del 23 al 29 de agosto de 1971.

El objetivo del seminario fue el de examinar con planificadores de los paises de la región, los aspectos sustantivos y metodológicos de las interrelaciones de la población y el desarrollo, así como discutir las perspectivas del uso de los estudios y datos demográficos en la planificación económica y social.

En esta publicación se presentan reunidos los documentos que sirvieron de base para las labores del seminario. Ellos fueron preparados, con este propósito, por las oficinas pertinentes de algunos países y por los organismos internacionales que le prestaron su auspicio. Pese al tiempo transcurrido, la vigencia del interés de su contenido justifica el esfuerzo de ponerlos al alcance de un círculo mayor de científicos sociales y otros especialistas en estas materias.

El material incluido toca temas de indudable relevancia en las actuales orientaciones de la planificación, poniéndose énfasis en los relativos a la planificación económica, de la salud y de la educación. Otros documentos presentan las experiencias nacionales en este campo, señalándose de paso las principales deficiencias de las estadísticas disponibles. Por último se incluye el informe final del seminario, en español y en inglés, el qque, aparte de recoger las conclusiones más importantes, es una exposición sumaria de los principales problemas que enfrenta la consideración de las variables demográficas en la planificación económica y social.

Centro Latinoamericano de Demografía 
. 


\title{
INDICE
}

\author{
Página \\ LOS ESTUDIOS DEMOGRAFICOS EN LA PLANIFICACION DEL DESA- \\ RROLLO, Instituto Latinoamericano de Planificación Económica \\ y Social - Centro Latinoamericano de Demografía ......... \\ I. Introducción $\ldots \ldots \ldots \ldots \ldots \ldots \ldots$ \\ II. Influencias recíprocas entre desarrollo y variables \\ demográficas .................. 5 \\ III. La experiencia en la planificación en América Latina .. 11 \\ IV. Perspectivas y programas $\ldots \ldots \ldots \ldots \ldots \ldots \ldots$ \\ 1 \\ POSIBILIDADES Y PERSPECTIVAS DEL USO DE LOS DATOS Y ESTU. \\ DIOS DEMOGRAFICOS, Instituto Latinoamericano de Planifi- \\ cación Económica y Social - Centro Latinoamericano de \\ Demografía ........................ \\ OBJETIVOS SOCIALES Y VARIABLES DEMOGRAFICAS EN LA PLA- \\ NIFICACION ECONOMICA, Alejandro Foxley .......... 23

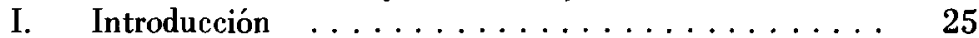 \\ II. Primera fase: metas y recursos globales . . . . . . 27 \\ III. Segunda fase: metas sectoriales y coherencia global-sec- \\ torial .................... 30 \\ IV. Metas regionales y coherencias sectorial-regional $\ldots \ldots \quad 55$ \\ RELACIONES ENTRE VARIABLES ECONOMICAS Y DEMOGRAFICAS. \\ Ensayo de un modelo, Angel Fucaraccio y Carmen Arretx . . . . .

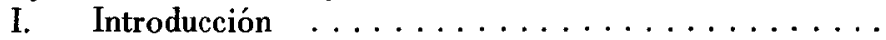 \\ II. Algunas asociaciones entre status socio-económico de la \\ población, fecundidad y participación femenina en \\ América Latina . . . . . . . . . . . . . . 69 \\ III. Visión sintética del modelo y las hipótesis . . . . . . 90 \\ IV. Los resultados y su significación para la planificación ... 105 \\ Anexo I. Niveles de consumo y de fecundidad ..... 111 \\ Anexo II. Ecuaciones del submodelo demográfico .... . 119* \\ Anexo III. El programa de cómputo . . . . . . . . 132 \\ Bibliografía de referencia . . . . . . . . . . . 149
}


SECUENCIA DEL PROCESO DE FORMULACION DE METAS DE EMPLEO EN LA PLANIFICACION, Esteban Lederman . . . . . . . .

I. Introducción $\ldots \ldots \ldots \ldots \ldots \ldots \ldots$

II. Disponibilidades de recursos humanos . . . . . . . . . 157

III. Determinación de las metas de creación de puestos de

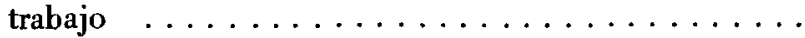

IV. Determinación de las metas de crecimiento económico .

V. Determinación de la estructura productiva y ocupación en los sectores rurales .................

VI. Determinación de la estructura productiva y ocupación en los sectores urbanos . . . . . . . . . . . .

VII. Asignación y distribución de los recursos humanos ....

VIII. Compatibilización macroeconómica de las diversas

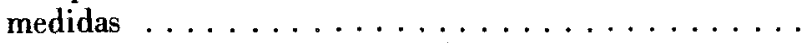

LA UTILIZACION DE LOS DATOS DEMOGRAFICOS Y EL TRATAMIENTO DE LAS VARIABLES DE LA POBLACION EN PLANIFICACION DE LA SALUD, Dr. Raúl Vargas . . . . . . . . . .

I. Influencias recíprocas entre población y salud .......

II. Situación actual del uso de los datos demográficos en

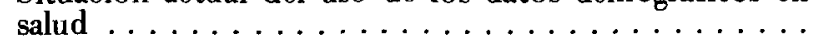

III. El uso deseable de las variables y datos demográficos en la planificación en salud ................

ASPECTOS DEMOGRAFICOS DE LA PLANIFICACION DE LA EDUCA-

CION, Jorge Arévalo e Iris Corbalán . . . . . . . . . . .

Introducción

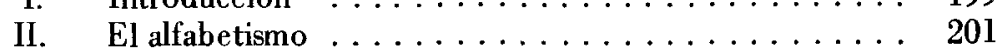

III. Migración interna, urbanización y nivel de instrucción . 208

IV. Recapitulación ................... 212

EL USO DE DATOS Y ESTUDIOS DEMOGRAFICOS EN LA PLANIFICACION DEL DESARROLlO REGIONAL, Comisión Económica para

América Latina . . . . . . . . . . . . . . . . .

Primera parte. Las variables demográficas en la planificación

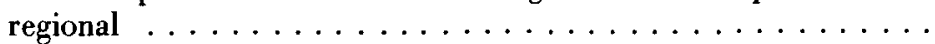

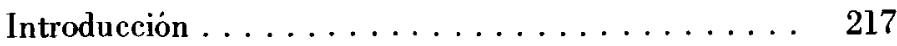

Segunda parte. El caso concreto del Perú . . . . . . . . . . 225

I. La situación actual y los fundamentos estratégicos . . . 226

II. Los cambios fundamentales en la ocupación del espacio 239

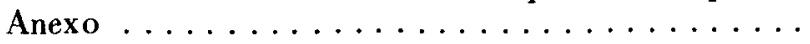

PROGRAMA DE ADIESTRAMIENTO SOBRE POBLACION Y PLANIFICACION DEL DESARROLLO, Luis Olivos y Luis Ratinoff.

I. Antecedentes ...................

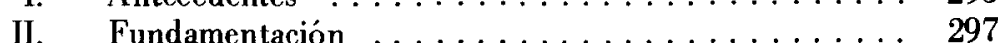

III. Contenido provisorio del curso ... . . . . . . . . 304 
GUIA BIBLIOGRAFICA DE ESTADISTICAS DEMOGRAFICAS Y SOCIA-

LES, Comisión Económica para A mérica Latina . . . . . . . . . . . .

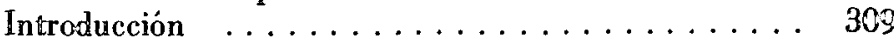

Anexo I. Simbología utinizada . . . . . . . . . . . 345

Bibliografía internacional ............. 346

Bibliografía nacional .............. 348

Anexo II. Información adicional sobre las principales publicaciones estadisticas internacionales y nacionales en los campos demogzáfico y

social $\ldots \ldots \ldots \ldots \ldots \ldots$

LA INFORMACION Y LOS ESTUDIOS DEMOGRAFICOS EN AMERICA

LATINA, Carmen Arretx . . . . . . . . . . . . . . . .

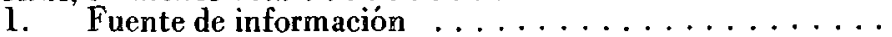

2. Técnicas de análisis demográfico utilizadas en los países de América Latina . . . . . . . . . . . . . . . . . . .

3. Necesidades de estudios de población para los fines de la programación del desarrollo económico y social . . . . .

4. Ejemplo ilustrativo de utilización de datos censales. Estimación del subempleo . . . . . . . . . . . 366

UTILIZACION DE LOS DATOS DEMOGRAFICOS EN EL PROCESO DE PLANIFICACION. EL BALANCE DE RECURSOS HUMANOS, Boris

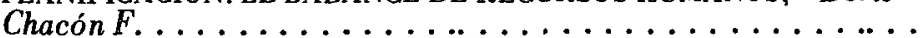

El balance de recursos humanos $\ldots \ldots \ldots \ldots \ldots \ldots \ldots$

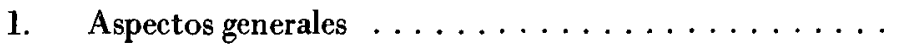

2. Tipos de balances $\ldots \ldots \ldots \ldots \ldots \ldots \ldots$

3. Tareas en la preparación de los balances ..........

EXPER IENCIA ECUATORIANA, Dr. Néstor Vega Moreno ...... 383

I. Conceptos básicos ................. 385

II. Experiencia en el Ecuador en la utilización de datos y estudios demográficos en la planificación . . . . . . . 388

III. Nueva estrategia para la planificación del desarrollo . . 392

IV. Conclusión .....................

USO DE DATOS Y ESTUDIOS DEMOGRAFICOS EN LA PLANIFICA CION ECONOMICA Y SOCIAL DE HONDURAS, Lic. Conrado Osorio

Generalidades .................... 397

Honduras: Proyecciones existentes en uso . . . . . . . 398

Determinación del crecimiento demográfico . . . . . . 399

Honduras: Crecimiento estimado para $1969 \ldots \ldots$

Honduras: Población por grupos de edades . . . . . . . 401

Honduras: Población Urbana y rural . . . . . . . . 401

Uso de datos demográficos en la planificación regional . 402

Industria, comercio, servicios y centros urbanos . . . . 403 
ALGUNOS MODELOS SENCILLOS PARA EL ANALISIS DE LAS INTER. DEPENDENCIAS ENTRE LOS CAMBIOS ECONOMICOS Y LOS DEMO-

GRAFICOS, Lic. Eliézer Tijerina Garza . . . . . . . . . . .

El análisis de las interacciones de los factores económicos y demográficos regionales en México .... Descripción del método de componentes principales . . El desarrollo económico global y el crecimiento de la producción y ocupación sectoriales .......... El análisis estadístico de los cambios regionales y sectoriales en la ocupación de la mano de obra ..... .

OBJETIVOS DE LAS POLITICAS DE DESARROLLO ECONOMICO, Lic. Luis de Pablo Serna . . . . . . . . . . . . . . . . . . .

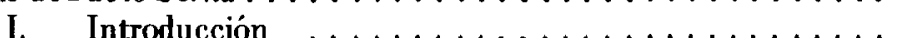

Pobreza ...................... 437

Desocupación y subempleo . . . . . . . . . . 437

Distribución del ingreso $\ldots \ldots \ldots \ldots \ldots \ldots 47$

Estructura de desigualdades . . . . . . . . . . 437

II. Pobreza . . . . . . . . . . . . . . . . . 439

LA EXPERIENCIA VENEZOLANA SOBRE USO DE DATOS Y ESTUDIOS DEMOGR AFICOS EN LA PLANIFICACION, Dirección de Planificación Social y Cultural, Oficina Central de Coordinación y Planificación, República de Venezuela. ................... Advertencia $\ldots \ldots \ldots \ldots \ldots \ldots \ldots$ Uso de las proyecciones $\ldots \ldots \ldots \ldots \ldots \ldots \ldots$

Anexo. Indicadores estadísticos utilizados en los análisis de recursos humanos, fuentes que los suministran y observaciones sobre su confiabi-

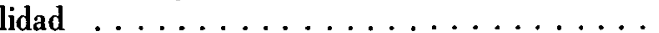

INFORME FINAL. VERSION DEFINITIVA $\ldots \ldots \ldots \ldots \ldots \ldots . \ldots 47$

Introducción $\ldots \ldots \ldots \ldots \ldots \ldots \ldots \ldots \ldots$

Primera parte ...................... 475

1. Disponibilidad y uso de los datos demográficos . . . . . 475

2. La elaboración estadística .............. 476

3. Necesidad de estudios sobre interrelaciones . . . . . 477

4. Las variables demográficas incorporadas a los planes como datos exógenos . . . . . . . . . . . . . . 477

5. Necesidad de intensificar la colaboración entre economistas y demógrafos . . . . . . . . . . . . .

6. Desagregación necesaria para el tratamiento de las relaciones entre variables demográficas $y$ aspectos sociales y económicos del desarrollo ..........

7. Capacitación de profesionales .............

8. Unidades de análisis demográfico en oficinas de

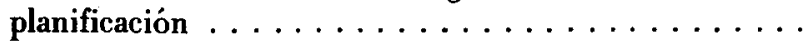


Segunda parte $\ldots \ldots \ldots \ldots \ldots \ldots \ldots \ldots \ldots \ldots$

1. Objetivos sociales y variables demográficas en la planificación ...................

2. Relaciones entre variables económicas y demográficas: Ensayo de un modelo . . . . . . . . . . . . . .

3. Secuencia del proceso de formulación de metas de empleo en la planificación ................

4. La utilización de datos demográficos y el tratamiento de las variables de la población en planificación de Ja salud

5. Aspectos demográficos de la planeación de la educación

6. El uso de datos y estudios demográficos en la planificación del desarrollo regional $\ldots \ldots \ldots \ldots \ldots$

7. Programa de adiestramiento sobre población y planificación del desarrollo . . . . . . . . . . . . . .

8. Guía bibliográfica de estadísticas demográficas y sociales y la información demográfica y los estudios demográficos en la América Latina . . . . . . . . . . . . .

Anexo 1. Exposición del señor Carlos Quintana, Secretario Ejecutivo de la Comisión Económica para América Latina, hecha en el acto inaugural del Seminario sobre utilización de estudios y datos demográficos en la

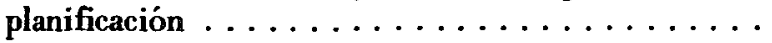

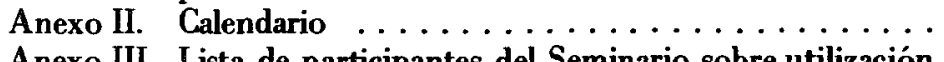

Anexo III. Lista de participantes del Seminario sobre utilización de estudios y datos demográficos en la planificación . 507

Anexo IV. Lista de documentos ............. 514

SEMINAR ON THE UTILIZATION OF STUDIES AND DEMOGRAPHIC DATA IN PLANNING. FINAL REPORT . . . . . . . . . Introduction $\ldots \ldots \ldots \ldots \ldots \ldots \ldots \ldots$

Part one . . . . . . . . . . . . . . . . . 521

1. Availability and use of demographic data ... . . . . 521

2. The statistical elaboration .............. 522

3. Necessity of studies on interrelations . . . . . . . . . 522

4. The demographic variables incorporated to plans as external data ................... 523

5. Necessity of intensifying the collaboration between economists and demographers $\ldots \ldots \ldots \ldots \ldots$

6. Necessary disaggregation for the treatment of the interrelations between the demographic variables and the social and economic aspects of development ... . . . 524

7. Training of professionals . . . . . . . . . . . 525

8. Units of demographic analysis in planning bureaus ... 525 
Part two ........................ 526

1. Social goals and demographic variables in planning .... 526

2. Relations between economic and demographic variables: Attempt at a model . . . . . . . . . . . . . . . 529

3. Sequence of formulating employment objectives in

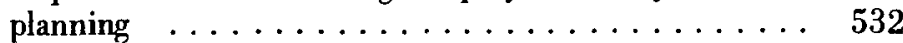

4. The use of demographic data and treatment of population variables in health planning $\ldots \ldots \ldots .533$

5. Demographic aspects of education planning ...... 536

6. The use of demographic data and studies in regional development planning $\ldots \ldots \ldots \ldots \ldots \ldots . \ldots 538$

7. Training programme on population and development planning $\ldots \ldots \ldots \ldots \ldots \ldots \ldots$

8. Bibliographical guide to demographic and social statistics and demographic information and demographic studies in Latin America . . . . . . . . . . . . . . . . .

Appendix I. Statement by Mr. Carlos Quintana, Executive Secretary for the Economic Mission in Latin America, delivered in the opening of the Seminar on: "The use of demographic studies and data in planning" .................. 546

Appendix II. Part one of the seminar . . . . . . . . . . 549

Appendix III. Participants of the . seminar on the use of demographic studies and data in planning . . . . 551

Appendix IV. List of documents . . . . . . . . . . . 558 
LOS ESTUDIOS DEMOGRAFICOS EN LA PLANIFICACION DEL DESARROLLO

BASE DE DISCUSION

Instituto Latinoamericano de Planificación
Económica y Social.
Centro Latinoamericano de Demografia 


\section{INTRODUCCION}

La necesidad de intensificar y perfeccionar el uso de datos y estudios demográficos en la planificación económica y social es cada vez más evidente. Las Naciones Unidas, a través de su División de Población, han promovido la realización de tres seminarios $\underline{1}$ sobre este tema y otros relativos a sectores específicos de la planificación. Tanto la CEPAL como el ILPES y el CELADE, a través de documentos, conferencias, docencia, investigación y asistencia técnica, han llevado adelante una actividad que ha estimulado la consideración de estos aspectos por parte de planificadores y demógrafos. La OEA y el BD han impulsado actividades con propósitos muy semejantes y han examinado la posibilidad de organizar programas destinados al estudio de las relaciones mutuas entre demografía y planificación del desarrollo. Por su parte, el ṔREALC hace hincapié en la necesidad de no perder de vista las relaciones mutuas entre población y empleo.

Estas coincidencias impulsaron a la División de Población de las Naciones Unidas, la Secretaría General de la Organización de los Estados Americanos a través del Departamento de Asuntos Sociales, en conjunción con el Programa Regional del Empleo para América Latina y el Caribe (OIT), el Banco Interamericano de Desarrollo, la Comisión Económica para América Latina, el Instituto Latinoamericano de Planificación Económica y Social y el Centro Latinoamericano de Demografía a patrocinar este Seminario.

Se definieron los siguientes objetivos:

a) Discutir con funcionarios responsables de los programas de planificación nacional, las posibilidades y perspectivas del uso de los estudios y datos demográficos en la planificación del desarrollo;

b) Discutir los aspectos sustantivos y metodológicos del sisterna de interrelaciones entre demografía y planificación y los métodos y técnicas requeridos para incorporar las variables demográficas en la planificación;

c) Discutir en líneas generales el contenido de un programa de enseñanza de dichos métodos y técnicas.

Aun cuando se reconocen las dificultades que presentan objetivos

1/ Addis Abeba, Etiopía, julio de 1969; Kiev, Ucrania, septiembre de 1969 y Beirut, Líbano, noviembre de 1970. 
tan ambiciosos, se cree también que el aumento de conocimientos y el ensanchamiento de objetivos que han tenido lugar en la última década permiten encarar esta tarea con razonables posibilidades de éxito.

La mayor cantidad de información de la que actualmente se dispone en los países de Ainérica Latina, unida al nacimiento y desarrollo de centros de investigación, enseñanza y asesoría nacionales e internacionales, públicos y privados, han permitido llevar adelante estudios e investigaciones sobre diferentes aspectos teóricos y prácticos desde el punto de vista particular de cada disciplina. La suma de estos conocimientos y el creciente interés de los especialistas por incursionar en lo que hasta no hace mucho tiempo se consideraba como ajeno a sus actividades, han permitido sentar las bases para establecer relaciones interdisciplinarias.

En el caso de los demógrafos ese interés se ha puesto de manifiesto en la ejecución de estudios e investigaciones que son de utilidad para planificadores globales de los recursos humanos, de la educación, de la salud, etc. En el de los planificadores es posible verificar que, a la luz de los enfoques más modernos, los planes de desarrollo de la última década elaborados por las oficinas nacionales, incluyen en mayor o menor grado las variables demográficas y diferentes aspectos de la composición de la población.

Hoy es posible y oportuno reunir a jefes de oficinas nacionales de planificación $y$ especialistas de diferentes instituciones para iniciar en América Latina un diálogo que habrá de redundar en provecho de todos. Se espera que esta reunión aporte bases concretas para un mejor conocimiento de las relaciones mutuas entre el comportamiento demográfico y los efectos de un programa de desarrollo económico social. 


\section{INFLUENCIAS RECIPROCAS ENTRE DESARROLLO . Y VARIABLES DEMOGRAFICAS}

\section{INFLUENCIA DEL DESARROLLO}

Es posible distinguir dos grandes líneas de relaciones entre desarrollo y población. Ambos tipos de nexos, aunque complejos, pueden ser esquematizados en alguna medida.

Uno de los vínculos más nítidos es la relación entre la tecnología y la situación demográfica latinoamericana. En esta materia puede discernirse la presencia dominante de la tecnología médica y farmacéutica en las campañas contra enfermedades endémicas y epidémicas y en general, el logro de mejores condiciones sanitarias a través de obras de infraestructura. No todos estos elementos provinieron de América Latina. La fuente principal de este tipo de cambios parece, pues, ser externa a la región.

Esta clase de influencias técnico-económicas, con fuerte efecto demográfico, se ha venido asimilando en diversos países de la región con cierto grado de independencia respecto a su etapa de desarrollo o a las modalidades económicas del mismo, fueran éstas de exportación primaria o de industrialización sustitutiva.

De todos modos, el efecto ha sido notable en la reducción de la mortalidad, y en las últimas décadas han ocurrido cambios significativos al respecto. Para el futuro, el propio éxito que lograron esos instrumentos limita su posible efecto. Si bien es cierto que aún hay campo para avanzar en sanidad, en infraestructura vinculada y disponibilidad de medicinas y hospitales, asi como en cultura sobre salud, los efectos difícilmente podrán alcanzar la misma importancia del pasado, aunque en términos regionales y para algunos países, todavía revistan gran importancia.

La segunda línea de relaciones es más el fruto de la situación actual del desarrollo latinoamericano y parece estar ligada a las nuevas modalidades que éste adopte. Al mejorar el ingreso de la población latinoamericana, se produce también un incremento de la demanda y un conjunto de cambios entre los que se encontrará muy probablemente una reducción de la fecundidad. Si ese incremento, como ha ocurrido en el pasado, se produce sin cambios significativos en la distribución del ingreso, el efecto del mayor ingreso sobre la reducción de la fecundidad se producirá seguramente de manera bastante lenta, pues los grupos de 
bajos ingresos, que son los que reúnen los atributos más típicos del subdesarrollo, requieren un cambio importante del ingreso para alcanzar patrones económico-culturales que usualmente corresponden a una fecundidad menor.

Los efectos del desarrollo sobre las variables demográficas serán más intensos en los grupos más bajos, que constituyen un 40 por ciento de la población de América Latina (con consumo de unos 73 dólares al año por persona), ya que en términos de sanidad, infraestructura, acceso a servicios médicos y medicinas, cultura en salud, ocupación, educación y capacitación, los niveles de este gran grupo de la población latinoamericana son actualmente sumamente reducidos.

Más que la influencia del desarrollo, en general, sobre la situación demográfica, los cambios significativos en esta última se producirán fuertemente asociados con lo que ocurra con las condiciones de vida, el grado de ocupación, la distribución del ingreso y las posibilidades ocupacionales para los estratos de bajo ingreso; es decir, que las características de ese desarrollo revestirán seguramente una importancia decisiva.

En consecuencia, se aprecia cómo, en gran medida, la influencia del desarrollo sobre las variables demográficas dependerá de las modalidades que los propios latinoamericanos impriman al proceso.

\section{INFLUENCIA DE LA SITUACION Y LA DINAMICA DEMOGRAFICA}

El proceso de desarrollo económico, especialmente en lo que él supone en cuanto a cambios en el nivel de vida de importantes sectores de la población, tiene, como se ha señalado, incidencia en el comportamiento de las variables demográficas. A su vez, el tamaño, composición y distribución de la población, así como también la dinámica demográfica que las determina, tienen influencia en la marcha del proceso de desarrollo económico, lo que hace aconsejable su consideración dentro de los esquemas de planificación.

Por obvio, no sería quizás necesario señalar que se planifica para una población determinada que en el punto de partida del plan tiene un tamaño dado, está distribuida en el territorio siguiendo un cierto patrón y posee estructuras propias en cuanto a edad, sexo, estado civil, educación y actividad económica. Estas caracteristicas, consideradas aun en un contexto puramente estático, están contribuyendo a determinar en el momento inicial, entre otras, variables tan importantes desde el punto de vista económico como tamaño potencial del mercado, nivel de consumo efectivo, composición de la demanda efectiva, tamaño, localización, calificación y composición por edad y sexo de la fuerza de trabajo y, en cierta medida, la localización geográfica de la actividad económica. 
Sometidas a la influencia de la dinámica de la fecundidad, la mortalidad y la migración, tanto interna como in ternacional, las características iniciales de la población se van modificando, fenómeno que a su vez afecta el proceso de desarrollo económico. El saldo neto de los nuevos contingentes que se agregan a la población está obviamente determinado por la operación de los componentes del cambio demográfico antes citado, pero los efectos sobre el sistema económico serán diferentes según se combinen dichos componentes. Una población que aumenta por una combinación de crecimiento vegetativo $e$ inmigración internacional plantea a la economía requerimientos distintos de otra que crece principal, o exclusivamente, por la acción del saldo entre fecundidad y mortalidad. Aparte de que la segunda forma tendrá una mayor proporción de menores que impondrán al sistema ciertas características en las estructuras de las demandas de servicios, contará además, proporcionalmente, con una fuerza de trabajo menor. Ahora bien, un mismo crecimiento vegetativo puede darse como resultado de la combinación de distintos niveles de fecundidad y mortalidad. Según sea esta combinación, se afectará no sólo el propio proceso de desarrollo sino también, claro está, las decisiones de política que se adopten en la esfera de la planificación. Una tasa baja de crecimiento de la población, que sea resultado de una fecundidad y una mortalidad de niveles reducidos (que determinan una estructura por edad en que los menores de 15 años representan aproximadamente una cuarta parte de la población total), tiene consecuencias diferentes en cuanto a estructura del consumo y en cuanto a demanda de inversiones en general y, en particular, en vivienda, educación y fuerza de trabajo, a las de una tasa de igual magnitud resultante de niveles altos de fecundidad y mortalidad (que determinan que la mitad de la población, aproximadamente, esté por debajo de los 15 años).

Examinando aún en mayor detalle la estructura de la fecundidad en cuanto a su composición por edad y por grupos sociales y su nivel diferencial según área geográfica, es posible observar que puede darse un mismo o parecido valor de la fecundidad total con un comportamiento muy variado de diversos grupos sociales, regiones, etc., que forman parte de ese total. Esta diversidad tiene diferentes consecuencias en la distribución del ingreso, en la demanda de ciertos servicios sociales y en la asignación de recursos por áreas geográficas del país.

La mortalidad es diferencial en cuanto a su intensidad y a las causas de muerte no sólo por edad y por grupos sociales, sino también por área geográfica. Distintas estructuras en cuanto a las primeras características y distintas distribuciones espaciales de la mortalidad determinarán decisiones diferentes, entre otros aspectos, en la asignación de recursos en el área de salud y en el de infraestructura sanitaria (acueductos, alcantarillados, etc.). 
Finalmente, la distribución de la población en el territorio puede modificarse por la acción exclusiva o combinada de un crecimiento vegetativo diferencial por áreas y por la migración interna $\mathrm{e}$ internacional. La redistribución de la población, que en América Latina reviste caracteres de gran dinamismo, es parte del proceso de desarrollo economico y cambio social, del cual es a su vez causa y efecto.

La afirmación general anterior no impide reconocer que distintas tendencias de evolución en cuanto a la distribución geográfica de la población comportan efectos diferenciados en la marcha de la economía y deberian determinar la adopción de políticas diferentes en concordancia con las metas que se pretenda lograr. Elevada y continua concentración en una o pocas ciudades, en oposición a la existencia de un número mayor de ciudades grandes en procesos de expansión; migración rural-urbana predominante, en lugar de que la misma sea acompañada también de importantes movimientos entre áreas rurales y entre ciudades de diferente tamaño; tendencia al asentamiento de núcleos de población extranjera en ciertos polos de atracción del pais, a diferencia de la no existencia de inmigración internacional de alguna importancia, son fenómenos que influirán de muy diversa manera en el proceso de desarrollo económico y que incidirán en la formulación de los planes de desarrollo regional, en la utilización de la mano de obra disponible, en la asignación de recursos para programas de viviendas e infraestructura física, etc.

\section{UN CAMPO IMPORTANTE DE INFLUENCIAS RECIPROCAS MIGRACIONES INTERNAS. DISTRIBUCION GEOGRAFICA DE LA POBLACION Y URBANIZACION}

Los aspectos relativos a la regionalización de los planes de desarrollo, las migraciones internas y la urbanización constituyen un área de problemas que son sumamente importantes para los paises de América Latina y que tienen estrecha vinculación con la demografía.

Estos procesos de migración interna son inseparables del cambio y del desarrollo. Las corrientes migratorias tienen como uno de sus motivos principales la obtención de mejores oportunidades económicas y de condiciones sociales y niveles de vida más deseables. Estas distintas condiciones económicas y sociales tienen, a su vez, una expresión en distintos comportamientos demográficos (diferentes patrones y niveles de fecundidad). Las mejores oportunidades económicas frecuentemente se ligan no sólo a las posibilidades de obtener un mayor ingreso, sino también a la mayor diversificación de posibilidades de empleo.

Los problemas y posibilidades del crecimiento económico y la atención de las demandas sociales que corresponden a la radicación de la población están, entonces, estrechamente relacionados entre sí. La creación de empleos y la elevación del nivel de actividad económica 
requieren esfuerzos de provisión de infraestructura y de inversión en actividades productivas. La población que obtiene un sustento de estas actividades, a su vez tiene necesidades de vivienda, salud, educación, servicios sanitarios, etc., que también caen bajo la atención directa de los planificadores.

Por otra parte, los problemas regionales y de distribución geográfica : de la población y de las actividades económicas plantean el problema de la relación entre los recursos humanos y la población, los recursos naturales y los recursos de capital. En muchos de los paises de América Latina se detectan situaciones de concentración muy alta de población en zonas de recursos naturales relativamente escasos, con el consiguiente nivel de vida más bajo $y$, por otra parte, de regiones ricas en recursos naturales y relativamente vacías en cuanto a población.

Esta relación entre recursos naturales y de capital y recursos humanos también plantea problemas relativos a las calificaciones especificas que se requieren para aprovechar estos recursos.

Uno de los casos en que son más claros los desequilibrios que se producen a raiz de las migraciones internas se relaciona con la urbanización. Los grandes déficit de servicios urbanos, los crecimientos posiblemente excesivos de las principales ciudades de algunos países de América Latina, aun el hecho de que el proceso de urbanización no se corresponda estrictamente en todos los casos con la creación de oportunidades de ocupación productiva manifestada en la concentración de mano de obra en actividades de baja productividad y en servicios y en los problemas de marginalidad que áquel tiene conexos son, entre otros, algunos de los problemas vinculados con este proceso de urbanización que, además de exigir una gran disponibilidad de recursos de inversión para atender las correspondientes necesidades, crea también problemas sociales sumamente importantes.

En el campo del desarrollo regional, las migraciones internas y la urbanización plantean una serie de aspectos de gran interés tanto para los planificadores como para los demógrafos. Aunque se ha avanzado en la elucidación de las causas que producen estas migraciones internas, que las aceleran o retardan y que definen su dirección, es todavia necesario continuar profundizando en el conocimiento de este campo. El conocimiento de estas causas es esencial para poder actuar sobre tales desplazamientos orientándolos de acuerdo con las necesidades del desarrollo. También se requiere mayor conocimiento acerca del tipo de personas que forman parte predominante de tales migraciones; sus motivaciones, sus calificaciones, el periodo de adaptación a los nuevos sistemas de vida urbana, si mantienen o no aspectos importantes de su modo de vida rural en el medio urbano, los tipos de ocupaciones para los cuales tienen predisposición y las que encuentran, su demora en adquirir las calificaciones que requieren en las nuevas tareas, etc. También los cambios en el comportamiento demográfico que inducen 
estas migraciones representan un área insuficientemente explorada y conocida: la magnitud y rapidez de los cambios inducidos en la fecundidad, la mortalidad, la tasa de participación en el mercado de trabajo, etc. 


\section{LA EXPERIENCIA EN LA PLANIFICACION EN AMERICA LATINA}

En el decenio de los años 50 se elaboraron una serie de estudios sobre el desarrollo económico de los países, que contribuyeron a perfeccionar técnicas y métodos en la medida en que se iban presentando enfoques alternativos.

En esos trabajos se estableció que el proceso de planificación comprende aproximadamente tres etapas: el diagnóstico, la definición de objetivos y metas y la determinación de las necesidades de expansión tanto global como sectorial de la economía, con el auxilio de modelos pertinentes.

Interesa, pues, hacer una breve referencia a las bases metodológicas elaboradas para la planificación, a sus requerimientos de datos demográficos y al uso que de ellos se ha hecho en los planes latinoamericanos.

En la etapa del diagnóstico es donde se ha utilizado una mayor cantidad de información demográfica, la que generalmente se refiere al tamaño de la población, su distribución por edad, la tasa de crecimiento, la distribución regional de la población, los niveles de fecundidad y mortalidad, la mortalidad infantil, los niveles de analfabetismo, las tasas de participación en la actividad económica, las estimaciones sobre el tamaño de la fuerza de trabajo, etc.

En esta etapa del diagnóstico es donde el uso de los datos demográficos adquiere actualmente una mayor dimensión. De un lado, la caracterización e identificación de los problemas actuales obliga a investigar las características de la población, v.g., el número de niños que no están atendidos por el servicio educativo, el número de personas que no dispone de servicios para eliminar las aguas residuales, el número de personas que no tiene abastecimientos controlados de agua potable, la clasificación de la población infantil según las causas de morbilidad y mortalidad, la población que se encuentra con un déficit de viviendas, para lo cual se hace necesaria la estimación del tamã̃o medio de la familia.

Del otro lado, el examen del tipo de problemas que se pueden dilucidar a partir de la proyección de las tendencias económicas actuales obliga a los planificadores a disponer de proyecciones de población. La utilidad de las mismas radica en el hecho de que ofrecen una base adecuada para el análisis de algunos sectores, en particular aquéllos que 
se refieren al aspecto social (educación, salud, vivienda), e infraestructura de igual índole, tal como agua potable y alcantarillado.

En la etapa de definición de objetivos y metas, en la medida en que ciertas características de la población hayan intervenido en el diagnóstico y se hayan mostrado como problemas, pasarán explícita o implícitamente a formar parte de los objetivos y metas que el proceso de desarrollo deberá superar. Un ejemplo relativo a la esfera social es que si el plan contempla una reducción de la mortalidad infantil como un objetivo deberá hacer uso de la proyección demográfica para establecer las metas cuantitativas de tal reducción. Otro ejemplo relativo a la parte global del plan es que si éste contempla un mejoramiento en los niveles de vida de la población será necesario que se incorporen los datos de distribución del ingreso según tramos de población para permitir cuantificar el objetivo que el plan desea lograr. En el mismo campo global de análisis se podría mencionar el objetivo de reducir la desocupación, por ejemplo, para lo cual se requiere una proyección de la disponibilidad de mano de obra a partir de la proyección de la población para contrastarla con los puestos de trabajo ofrecidos por la economía.

En la tercera etapa, en la que. se definen las orientaciones de la política de desarrollo y sus modalidades y requisitos de implementación, se requiere disponer de una mayor cantidad de elementos metodológicos que permitan establecer vinculaciones más claras y operativas de aspectos demográficos con los de desarrollo.

En general, si bien se trata de un campo en el cual existen continuas innovaciones, la práctica común ha consistido en realizar un planteamiento global que permitiera dar una primera idea acerca del conjunto de las variables macroeconómicas más importantes $y$, en forma paralela, efectuar desagregaciones sectoriales hasta Hegar al nivel de los proyectos. El modelo global daría el marco de referencia mientras que las desagregaciones sectoriales constituirían subdivisiones de aquellas proyecciones globales.

Una característica general que se puede encontrar en los textos metodológicos, cualquiera que sea el grado de complejidad de los modelos que se presentan, radica en el hecho de que estos modelos no incorporan sistemáticamente la variable demográfica o, si la incorporan, es sobre la base de tomar a la población como un dato.

Los análisis y proyecciones efectuados por los demógrafos son utilizados como "datos" para la consideración de problemas relativos a ocupación, recursos humanos, educación y salud, evolución del ingreso per cápita, nivel de vida, etc. Frecuentemente las proyecciones suministradas por los demógrafos presentan más de una hipótesis, que suelen recibir el carácter de supuestos alternativos dentro de un rango máximo y mínimo. Precisamente el hecho de que se presente más de una hipótesis obedece a la circunstancia de que el tamaño y 
composición de la población estarán influidos por el comportamiento -no totalmente determinado- de algunas variables económicas y sociales, por la forma en que evolucione el proceso de desarrollo y la influencia que tenga sobre la mortalidad, la fecundidad, los procesos de migración interna, etc. Los supuestos relativos al cambio económico y social que tienen detrás estas proyecciones y análisis demográficos generalmente no se hacen explícitos por falta de elementos de juicio que permitan definir y concretar esos supuestos.

En esta forma, no es posible considerar el grado de coherencia que hay entre las políticas y cambios previstos en los planes, y las proyecciones demográficas de que se parte. Por ejemplo, en caso de que se definan políticas que cambien en forma sustancial el nivel de vida de la población, sobre todo de los estratos de ingresos más bajos, tales cambios podrán influir a su vez sobre el comportamiento de la mortalidad y de la fecundidad de estos grupos. En caso de que las políticas de desarrollo amplíen sustancialmente las oportunidades de ocupación, probablemente se alterará el comportamiento de la población en edad activa, particularmente de las mujeres, que podrán buscar trabajo remunerado con mayor intensidad. En caso de que como parte de la política de desarrollo se realicen esfuerzos de gran envergadura para descentralizar la actividad económica y social del país, creando nuevos centros dinámicos de crecimiento, los desplazamientos internos de población podrán su frir una modificación inducida por las variaciones producidas en la distribución geográfica de las actividades económicas.

Los ejemplos que se han enunciado apuntan hacia el hecho de que no es apropiado considerar las variables demográficas como "datos", partiendo de ellas para analizar sus implicaciones en cuanto al desarrollo económico y social, sin considerar a su vez la influencia que este último tendrá sobre el comportamiento de algunas de las principales variables demográficas.

Cuando se considera solamente la confección de los planes a mediano plazo, de cuatro a cinco años de duración, suele considerarse no totalmente correcto, pero aceptable, este procedimiento de considerar como datos las variables demográficas. En efecto, la influencia que el desarrollo puede ejercer sobre el comportamiento de estas variables toma tiempo; las variables demográficas generalmente tienen un comportamiento bastante estable.

Pero la esencia de la planificación, que consiste en definir metas de más largo plazo para la evolución económica, social y política, y en establecer las políticas apropiadas para cumplir dichas metas, requiere también considerar, como parte de los procesos de planificación, visiones de más largo plazo que los cuatro o cinco años que generalmente corresponde a cada plan, de modo que estos últimos sean definidos en el contexto de una visión de perspectiva más amplia. Y si 
se consideraran estos plazos más largos, es claro que no debe desconocerse el cambio que el desarrollo económico y social puede producir sobre la población. Para poder definir cuáles de las proyecciones elaboradas por los demógrafos (las "máximas" o las "mínimas") se corresponden mejor con las orientaciones de desarrollo elaboradas por los planificadores, y discutir el grado de coherencia que hay entre la evolución prevista de las variables demográficas y el cambio en la ocupación, el nivel de vida, etc., es necesario discutir estas proyecciones demográficas despojándolas de su carácter de "datos" y examinando su interdependencia con el resto de los análisis efectuados. En este examen, el tamaño de la población, su estructura por edades, su distribución geográfica dentro del país, su comportamiento respecto a mortalidad y natalidad, etc., no pueden tomarse hacia el futuro solamente sobre la base de tendencias del pasado; es preciso penetrar analíticamente en los hechos que pueden modificar este comportamiento histórico, y en particular en la forma en que dicho comportamiento puede resultar afectado en uno $u$ otro sentido por los esfuerzos de desarrollo que se prevén.

Es preciso tener en cuenta que no solamente se toma a la población como un dato en los planes de mediano plazo, sino que suele emplearse un procedimiento análogo con otros elementos que también cambian lentamente, tales como la tecnología, la infraestructura y los patrones de demanda para consumo. Esto no implica, sin embargo, desconocer la importancia que puede tener el cambio de estos elementos, ni el hecho de que uno de los objetivos de la planificación consiste en prever o incorporar dichos cambios a las políticas de desarrollo. En estas polític as se opera, precisamente, sobre todos estos elementos de cambio lento; muchas de las acciones que, en todos estos aspectos, se pueden realizar en el corto y en el mediano plazo, madurarán completamente en un período más largo, tal como puede esperarse de las variables demográficas. Los proyectos de gran envergadura, vinculados con inversiones de infraestructura y con sectores productivos básicos, suelen producir sus efectos completos también en un plazo muy extendido. El desarrollo de las ciudades, sus planes de suministro de energía y agua, los componentes troncales de la red de transportes, la apertura de nuevas regiones geográficas de un país, los planes de reforma agraria, el desarrollo de industrias básicas, tampoco tienen efectos que puedan considerarse dentro de los estrechos límites de un plan de mediano plazo. Algo similar ocurre con la educación, que suele producir sus efectos completos realmente al cabo de una generación.

Puede decirse que toda politica de desarrollo representa un esfuerzo para modificar las tendencias del pasado que condicionan fuertemente el presente. Para diseñar estas políticas no sólo debe tenerse una visión de largo plazo, sino que, además, es preciso contar con elementos de juicio que permitan cuantificar y precisar los cambios posibles. Las 
proyecciones demográficas no pueden entonces ser simples extrapolaciones de tendencias observadas ni parece conveniente que sean hechas sin analizar su relación con los grandes cambios que constituyen el desarrollo ec nómico, social y político. En el pasado se ha observado cambios importantes en la evolución demográfica en América Latina, de modo que aun para interpretar inteligentemente los hechos del pasado y prever las consecuencias de su posible evolución futura, se necesita un minimo de conocimiento analítico. Si se hubieran proyectado las tendencias demográficas antes de la introducción de las obras de agua y desague o de las campañas contra el paludismo, de la disponibilidad de antibióticos, etc., se hubieran obtenido proyecciones muy deficientes en caso de que no se hubieran introducido estos nuevos elementos.

En sintesis, aunque la planific ación opera, en gran medida, a base de $-:$ planes de mediano y corto plazo, requiere una visión más integral y de más largo plazo que permita observar el comportamiento de las variables demográficas a compás con las modificaciones de los otros aspectos del desarrollo. En este caso, es demasiado limitado el procedimiento de tomarlas como datos exógenos. 


\section{PERSPECTIVAS Y PROGRAMAS}

En el campo del estudio de la población se ha avanzado en el conocimiento de las variables demográficas y de sus factores determinantes y se ha logrado cierta madurez y solidez en cuanto a los métodos y procedimientos utilizados.

Se ha acentuado la necesidad de la realización de estudios que no sólo se refieran a las variables demográficas, sino que además expliquen los cambios de las mismas dentro del contexto económico y social en que evoluciona la población. Se comprende que la realización de este tipo de estudios exige la coordinación de esfuerzos y el trabajo conjunto de profesionales de diferentes disciplinas. En esta dirección se encaminan algunas de las actuales investigaciones demográficas. Por otra parte, los organismos internacionales se encuentran preocupados por llevar adelante esfuerzos que conducen a una in tegración de los estudios económicos y sociales, lo que se trasunta en diversos trabajos, por ejemplo, el realizado por ILPES-CELADE y en la tendencia a formar grupos interdisciplinarios en algunos organismos.

De estos comentarios trascienden por lo menos dos hechos igualmente importantes: la necesidad de formar especialistas que integren las diferentes disciplinas y la necesidad de aumentar los esfuerzos dirigidos al estudio de las relaciones entre el comportamiento demográfico y variables de otras ciencias sociales que intervienen en el proceso de planificación. Cada una de estas necesidades requiere, indudablemente, diferentes modos de ser enfrentada y, también, cierta prioridad.

Parece obvio decir que para formar especialistas que integren las diferentes disciplinas debe existir un cuerpo de conocimientos que sea su patrimonio. Ese cuerpo de conocimientos es todavia muy pequeño y para formarlo se requiere una gran cantidad de estudios $e$ investigaciones interdisciplinarias. De ahi que resulte evidente la necesidad de aumentar los esfuerzos que permitan avanzar en ese campo, considerando la utilidad de formar grupos interdisciplinarios nacionales o internacionales, en los que intervengan las instituciones públicas y privadas interesadas, especialmente las oficinas nacionales de planificación y las universidades. Trabajando en estrecho contacto, estas instituciones pueden dar a las investigaciones un carácter que se adapte a los requerimientos más inmediatos de los países, al mismo tiempo que el más alto nivel científico. 
La prioridad de que se habló más arriba parece rigurosamente lógica, pero, desde un punto de vista práctico, no lo es tanto. Los países tienen urgencia por disponer de profesionales que tengan esa formación y no pueden darse el lujo de esperar a que exista un cuerpo de conocimientos considerable para formarlos adecuadamente. Los necesitan ahora. En el período de transición podrían, tal vez, utilizar profesionales que provinieran de uno de los campos científicos involucrados pero que adquirieran formación adicional en otro.

Deberían considerarse tres aspectos: a) los campos de procedencia de los candidatos; b) el contenido que deberá dársele a la enseñanza, y c) cuáles serán los sistemas formales responsables de la formación de los especialistas.

En principio, parecería que los especialistas de cualquiera de las disciplinas involucradas reunirían los requisitos que se exigirían a los candidatos, que podrían ser planificadores, médicos, economistas, sociólogos, demógrafos, maestros, etc.

En lo que al contenido se refiere, deberían contemplarse las necesidades más inmediatas de los países, que seguramente darán las pautas según el acento que pongan en los diferentes sectores de la planificación.

Los sistemas responsables de la formación de los especialistas podrían ser, básicamente, las universidades y los departamentos, instituciones o centros, dependientes de las universidades o no, que estén directamente interesados en la planificación del desarrollo o en la demografía. También, como en lo que a investigaciones se refiere, deberían formular sus programas en estrecha consulta con las oficinas nacionales de planificación. 
POSIBHLIDADES Y PERSPECTIVAS

DEL USO DE $\mathbb{L O S}$ DATOS Y ESTUDDOOS TBRINOGRAFICOS

ALGUNOS PUNTOS DE DISCUSION

Instituto Latinoamericano de Planificación

Económica y Social

Centro Latinoamericano de Demografía 

Tanto las modalidades del desarrollo económico-social adoptadas en América Latina, como las influencias externas que se han experimentado en las últimas décadas, han influido en el comportamiento demográfico. ¿Cómo conciben los participantes que se presentarán la intensidad y las características de las relaciones entre el desarrollo económico-social y la dinámica de la población?

Los datos y estudios demográficos cumplen algunos requisitos de los planes de desarrollo económico y social. Se reconoce, sin embargo, que se debe avanzar mucho más.

¿Qué aspectos, en términos de datos y estudios demográficos, se consideran más importantes en relación con:

a) la concepción que se tiene en su pais de la planificación a distintos plazos,

b) los problemas y sectores principales de la planificación?

En relación con la pregunta anterior, ¿qué datos o estudios juzgaría usted necesario conocer con mayor profundidad para satisfacer o complementar la concepción de la planificación global y sectorial aludida?

En la formulación de planes regionales de desarrollo, el planificador, en general, dispone de escasas informaciones de índole económica a ese nivel geográfico. Se ha podido observar que las características demográficas y sociales de la población se asocian a etapas determinadas del proceso de desarrollo económico.

a) ¿Hasta qué punto podría aceptarse que las informaciones y estudios demográficos regionales reemplacen o complementen las escasas estadísticas económic as regionales?

b) ¿Qué requisitos deberian tener los datos y estudios demográficos regionales para satisfacer las necesidades de este tipo de planificación?

Los planificadores y demógrafos, en general, tienen conciencia de la interdependencia de las condiciones económico-sociales y demográficas; sin embargo, no ha sido frecuente que los estudios de unos y otros se hayan llevado a cabo en forma conjunta. Con el fin de alcanzar esa coordinación en forma sistemática y eficiente,

a) ¿en qué forma podrían abordar este problema las oficinas de planificación y los demógrafos?

b) ¿de qué manera pueden contribuir las universidades y otros organismos nacionales o internacionales a dilucidar los interrogantes que plantea la interdependencia de la evolución económica 

demográfico en la planificación?

Con el propósito de avanzar en la integración de los datos y estudios demográficos con la planificación del desarrollo,

a) ¿qué lagunas, en términos de investigación sobre interrelaciones de variables económicas y demográficas, sería indispensable llenar en el futuro?

b) ¿convendria capacitar especialistas con formación distinta a la que hasta ahora se ha impartido en la región?

c) ¿qué contenido sería recomendable sugerir para un programa de este tipo?

d) ¿qué instituciones podrían tomar a su cargo la realización de estos programas de formación de especialistas en los países? 


\title{
OBJETIVOS SOCIALES Y VARIABLES DEMOGRAFICAS EN LA PLANHFICACION ECONOMICA
}

\author{
Alejandro Foxley
}

\begin{abstract}
Preparado especialmente para el Departamento de Asuntos Sociales de la OEA con el objeto principal de ser usado como "documento de trabajo" en los seminarios que este Departamento organiza con la colaboración de organismos gubernamentales de los países sobre el tema Población y Planificación del Desarrollo.

El autor es Director del Centro de Estudios de Planificación (CEPLAN) de la Universidad Católica de Chile.

Los puntos de vista expresados por el autor no comprometen a las instituciones mencionadas.
\end{abstract}





\section{INTRODUCCION}

La elaboración de planes económicos por parte de los paises latinoamericanos ha sufrido una constante evolución desde los primeros intentos de planificación. Las diferencias más marcadas entre esa primera etapa y la actual se encuentran en los objetivos considerados, en la importancia que se atribuye a los diferentes recursos necesarios para el plan $y$, por último, en la metodología de elaboración de los planes.

Respecto a los objetivos, los primeros planes concentraban su atención casi exclusivamente en las metas de crecimiento del producto geográfico, sin una preocupación muy marcada por los que en este trabajo llamamos objetivos sociales. Entre ellos consideramos especialmente la redistribución del ingreso, la satisfacción de necesidades básicas de consumo para toda la población, la provisión por parte del Estado de servicios adecuados de salud, educación, vivienda y seguridad social (particularmente para los estratos de bajos ingresos) y la creación de niveles aceptables de empleo para la fuerza de trabajo disponible. Los esfuerzos más recientes en la planificación tratan de dar énfasis a este tipo de metas, además de las ya tradicionales, lográndose un mejor equilibrio entre los objetivos económicos y sociales del plan. En segundo lugar, con referencia a los recursos, los planes tradicionalmente consideraban un recurso escaso el capital, y los esfuerzos se volcaban hacia la determinación de la tasa de inversión necesaria para sostener un determinado ritmo de crecimiento del producto y hacia las fuentes de financiamiento, interno o externo, de esa inversión. Actualmente se da mucho mayor importancia a los recursos humanos, su cantidad y calidad, como factores determinantes del crecimiento económico $y$, por lo tanto, del cumplimiento de las metas del plan.

En tercer lugar, las metodologias originales de planificación distinguían entre etapas de elaboración muy claramente diferenciables: la planificación global, como primera etapa; la planificación por sectores, a continuación; el estudio de proyectos, en tercer lugar; y terminaban con una etapa de revisión y síntesis que partía de los proyectos, reformulaba los planes sectoriales y permitía así fijar las metas globales definitivas.

En algún momento de este proceso se insertaban elementos de planificación regional cuya integración al resto del esquema de 
planificación era usualmente insatisfactoria e incompleta. Recientemente estos aspectos metodológicos también han evolucionado, especialmente con el desarrollo de modelos de planificación cada vez más complejos, en los que es posible ir integrando distintos aspectos de la planificación global, sectorial y regional, haciendo que la separación de la planificación en etapas se haga cada vez menos marcada. Esto no implica, naturalmente, que los modelos sustituyan a la planificación global, sectorial o regional; sólo que desde el punto de vista metodológico es ahora posible tratarlos en forma mucho más integrada.

El objetivo del presente trabajo es justamente in tentar describir una metodología general de planificación que, junto con incorporar desarrollos recientes en el campo de los modelos, ponga especial énfasis en aspectos relativamente olvidados en los planes tradicionales, como son los que se señalaban más arriba: tratamiento metodológico adecuado para los objetivos sociales, esto es, aquellos más directamente vinculados a las necesidades de la población, e incorporación explicita de los recursos humanos, como un factor de producción escaso que debe ser suministrado en proporciones adecuadas para el cumplimiento de las metas del plan.

Estos dos aspectos están en directa relación con las variables poblacionales y de ocupación, por lo que en el resto de este trabajo se hará un esfuerzo para describir con cierto detalle la interrelación entre este tipo de variables y aquellas otras más tradicionales, como son los niveles y estructura de la producción, el consumo, la inversión y otras.

La metodología se resume en los cuadros 1 y 2 . 


\section{PRIMERA FASE: METAS Y RECURSOS GLOBALES}

Dado el marco de referencia fundamental del plan por parte de la autoridad política, la primera fase de elaboración propiamente técnica consiste, en una especificación en términos cuantitativos de las metas y una verificación de su consistencia global con los recursos disponibles. If

La aceleración de la tasa de crecimiento del PGB la redistribución de ingresos, la disminución del desempleo, alcanzar niveles aceptables de consumo para toda la población y la reducción de la dependencia externa son los objetivos usualmente aceptados en la actualidad. En el proceso de cuantificación al nivel global, la meta más explícita es la de crecimiento del producto.

Normalmente, en esta primera etapa se han utilizado variedades del modelo básico de Harrod-Domar en el que, a partir de un objetivo para el crecimiento del Producto Geográfico Bruto, se determina la inversión requerida para sostener ese ritmo de crecimiento $y$, como residuo, los niveles de consumo a que la población puede aspirar sin que se dificulte el cumplimiento de los objetivos de crecimiento.

Más recientemente se han comenzado a utilizar en esta fase los llamados modelos de brechas, en los que partiendo de una proyección exógena de la tasa de crecimiento del PGB, de las exportaciones y de algunos componentes de la inversión, es posible determinar la magnitud de los desequilibrios estructurales previsibles desde el punto de vista de los recursos para lograr una tasa de crecimiento dada. 2]

En este método se determinan dos brechas: la de financiamiento interno, definida como el déficit entre requerimientos de inversión y ahorro interno probable, y la de comercio exterior, definida como la diferencia entre importaciones más remesas al exterior y las exportaciones. Calculada la magnitud de las brechas mediante un

1/ Véase el cuadro I,

2/ Véase Chenery, H. y Strout, A., "Foreign Assistance and Economic Development", en American Economic Review, septiembre de :956; Chenery, H. y Eckstein, P., Development Alternatives for Latin America, trabajo presentado a la Conferencia sobre Problemas de Política Económica en América Latina, Chicago, 1966; Chenery, H. y Mc. Ewan, A., "Optimal Patterns of Growth and Aid over Time", en Pakistan Development Review, verano de 1966; Beca, R. "El Modelo de las Dos Brechas", Mimeo, Odeplan, Chile; A. Foxley Infante, Corbo R. y Gómez, M., "Desequilibrios de financiamiento en el proceso de desarrollo", en Cuadernos de Economia No 19 , diciembre de 1969. 
modelo de Cuentas Nacionales de unas 30 o 40 ecuaciones, es necesario analizar a partir de ellas algunas primeras cuestiones de gran importancia para el resto de la elaboración del plan.

Lo primero es la determinación de cuál es la brecha dominante en el periodo del plan, esto es, si acaso será el ahorro interno o las divisas extranjeras el factor que limitará más fuertemente el crecimiento. Si la brecha interna es la dominante y no se toman las medidas de política que puedan reducirla drásticamente, la economía se caracterizará por una gran dificultad para financiar la inversión con alto componente nacional (vivienda, obras públicas, construcciones sanitarias o educacionales) y, en cambio, mostrará una tendencia al incremento de las reservas internacionales y a un aumento en la tasa marginal de importaciones. Esto último se traducirá en incrementos en las importaciones de bienes de consumo, entre los que puedan contarse los alimentos.

$\mathrm{Si}$, a la inversa, la brecha dominante es la de comercio exterior, la economía tendrá que recurrir con toda probabilidad al racionamiento de importaciones, con eventuales dificultades para reducir el déficit de alimentos mediante esta vía y con restricciones en la capacidad de importar bienes de capital. La composición de la inversión se alterará, por lo tanto, aumentando su componente nacional, lo que posibilitará, probablemente, inversiones significativas en vivienda y otros asectores sociales, como educación y salud.

Determinada la brecha dominante y los posibles efectos que tendría en la economía, es necesario formular alternativas de ajuste entre las brechas. Es bien conocido que ambas brechas siempre se igualarán ex-post. Lo que interesa es analizar cuál podría ser un ajuste óptimo entre ellas. Por ejemplo, si la brecha de financiamiento interno es mayor que la de comercio exterior, una alternativa de ajuste seria reducir la brecha mayor aumentando el ahorro o bajando la inversión. Supongamos que pareciera factible un aumento del ahorro interno, entonces el plan podría señalar la tasa de ahorro requerida para igualar en forma optima, sin sacrificar crecimiento, ambas brechas y el nivel de consumo resultante de este tipo de ajuste. Como éste, habría otro número de posibilidades de ajuste que habría que analizar.

Lo que nos interesa, sin embargo, es vincular la discusión anterior con el problema de las metas sociales y las variables demográficas. Desde el punto de vista metodológico, el estudio de cuál es la brecha dominante y sus efectos probables, que se ha descrito anteriormente, da algunas luces para decidir la estrategia más adecuada para el cumplimiento de objetivos sociales como la redistribución de ingresos. Es claro que en una situación de brecha interna dominante $y$, por lo tanto, relativa "abundancia" de divisas, será posible concebir una redistribución significativa del ingreso por la vía directa (política de salarios) puesto que se dispondrá de los medios para abastecer la 
demanda adicional de alimentos y bienes de consumo habitual que esta política genera, a través de las importaciones. Será más difícil, en estas condiciones, la redistribución indirecta del ingreso a través de inversiones en vivienda, educación y salud puesto que el ahorro interno será muy escaso. La estrategia inversa, de redistribución preferentemente indirecta, será recomendable cuando la brecha dominante sea la de comercio exterior.

Supongamos ahora que del análisis de las brechas se decide un tipo de ajuste entre ellas que se considera óptimo. De éste se desprende una cierta tasa de ahorro y un nivel de consumo global. Corresponde analizar en este momento el significado de ese nivel de consumo en términos de estándar de vida de la población.

Un primer indicador adecuado, aunque incompleto, es el consumo per cápita, cuál es su nivel y cuánto crece con respecto al periodo inmediatamente anterior al plan. Su cálculo supone conocer el tamaño de la población y su probable crecimiento durante la aplicación del plan. El ritmo de crecimiento resultante en el consumo per cápita da una idea de la factibilidad de implementar las tasas de ahorro deducidas del ajuste de brechas. Si el consumo por habitante en el plan fuera, por ejemplo, inferior al del periodo anterior a éste, es obvio que el logro de la meta de ahorro puede hacerse imposible. Es difícil todavía, sin embargo, avanzar en el análisis del contenido de la cifra global de consumo en términos de consumo probable por tramos de ingreso o por tipo de bienes. Por lo tanto, aún no se pueden sacar conclusiones referentes a grado de satisfacción de las necesidades de consumo de los distintos grupos de la población. Esto se examinará en etapas posteriores.

Finalmente, a este nivel global, es importante una primera verificación de los niveles de empleo de la mano de obra que resultan de las metas de crecimiento. Este cálculo se hará normalmente sobre la base de la estimación de un coeficiente medio de productividad de la mano de obra, basándose en cifras históricas, y de una comparación entre empleo y población activa, lo que da una primera medición de la tasa global de desocupación. Los aspectos vinculados a las proyecciones y políticas de empleo se discutirán en detalle más adelante. 


\section{SEGUNDA FASE: METAS SECTORIALES Y COHERENCIA GLOBAL-SECTORIAL}

El ajuste de las brechas señala los montos de ahorro interno y divisas necesarias para mantener una cierta tasa de crecimiento. También se conoce la población y la fuerza de trabajo disponible $\mathrm{y}$, por lo tanto, los recursos básicos con que se cuenta para implementar el plan, además de los recursos naturales, que son fijos.

Es necesario, entonces, prever el nivel y la composición sectorial de la demanda para calcular qué niveles de producción, inversión, exportaciones e importaciones sectoriales son compatibles con los recursos disponibles y satisfacen las demandas específicas generadas por los distintos agentes económicos (las personas, el gobierno, las unidades de producción).

El procedimiento empleado en esta fase se ilustra en el cuadro 1 y consiste en la utilización de una matriz de insumo-producto, previa especificación de los principales componentes de la demanda sectorial (consumo privado y del gobierno, exportaciones, etc.). Mediante distintos tipos de modelos, ya sea la simple inversión de la matriz de insumo-producto dada una estructura de la demanda exógenamente, o un modelo del tipo dinámico de Leontief, o un modelo multisectorial de optimización, se obtienen niveles de producción, importaciones e inversión por sectores (las exportaciones son generalmente exógenas). 3 J

En este trabajo supondremos la utilización de un modelo de optimización multisectorial. 4 / Este tiene la gran ventaja de determinar simultáneamente el potencial máximo de crecimiento de la economía, compatible con las restricciones de recursos disponibles y con la estructura de demanda y relaciones interindustriales, entregando,

3/ Para una discusión de los distintos tipos de modelos disponibles véase Chakravarty, S. y Eckaus, R. S., "An Appraisal of Alternative Planning Models", en Capital Formation and Economic Development, P.N. Rosenstein-Rodan, editor, MIT Press, 1964.

4/ Sin embargo, en las próximas secciones hemos mantenido la descripción metodológica a un nivel suficientemente general como para ser también aplicable dentro del marco de modelos de consistencia, como el dinámico de Leontief u otros. 
además, los niveles de producción, empleo, inversión e importaciones ( $y$ su grado de sustitución) por sectores. 5 J

Formalmente es posible, entonces, alimentar el modelo multisectorial con los resultados del modelo de brechas (montos de ahorro, divisas, etc.) y obtener rápidamente un cuadro de compatibilidad global-sectorial. 6 -

\section{DETERMINACION DE LA DEMANDA FINAL}

La resolución del modelo sectorial, cualquiera que él sea, supone comenzar por la especificación de los componentes de la demanda final. De éstos, las exportaciones son fijadas exógenamente y no tiene mayor interés, desde el punto de vista de este trabajo, el entrar en mayor detalle sobre el método para determinarlas.

Desde el punto de vista de la interrelación entre variables económicas y variables sociales y demográficas, los componentes de importancia son el consumo de las personas, el consumo del gobierno y las inversiones.

\section{A. El consumo privado}

El nivel global de consumo de las personas se determina ya sea exógenamente a partir del resultado del análisis global (primera fase) o endógenamente en la función de maximización, si el modelo sectorial que se usa es de optimización. Cualquiera que sea el método, lo que más interesa especificar es la distribución sectorial del consumo. Esta es una función de la elasticidad-ingreso de la demanda por tipo de bien, del tamaño de la familia, del gasto en consumo per cápita y de la distribución del ingreso.

5/El uso de estos modelos en la planificación se ha incrementado sustancialmente tanto en países capitalistas y de economía mixta, como en los del área socialista. Véase Bruno, M., "A Programming Model for Israel" y Manne, A., "Key Sectors of the Mexican Economy, 1962-1972", ambos en Adelman, I. y Thorbecke, E., "The Theory and Design of Economic Development", The Johns Hopkings Press, Baltimore, 1966; Eckaus, R. y Parikn, K., Planning for Growth, Multisectoral Intertemporal Models Applied to India, MIT Press, Cambridge; Clark, P. B., Planning Import Substitution, North Holland Press, forthcoming. Para aplicaciones en el área socialista véase Hejl, Lubos et al, "Macroeconomic Decision Model for the Medium-term Optimal Planning", en Czechoslovak Economic Papers, Praga, 1969; Porwit, K., Central Planning Evaluation of Variants, Pergamon Press, Oxford, 1968. Una descripción más general de modelos de planificación de óptima categoría se encuentra en Kantorovich, L. V., "La Asignación Optima de los Recursos Económicos", Ariel, 1968. Para la economía chilena, véase Foxley, A., "Desequilibrios estructurales y alternativas de crecimiento para la economía chilena, 1970-1980", tesis doctoral, Universidad de Wisconsin, 1970.

6) Este procedimiento ha sido desarrollado detalladamente por el autor del presente trabajo en Desequilibrios estructurales y alternativas de crecimiento para la economía chilena, 1970-1980, Tesis Doctoral Universidad de Wisconsin, 1970. 


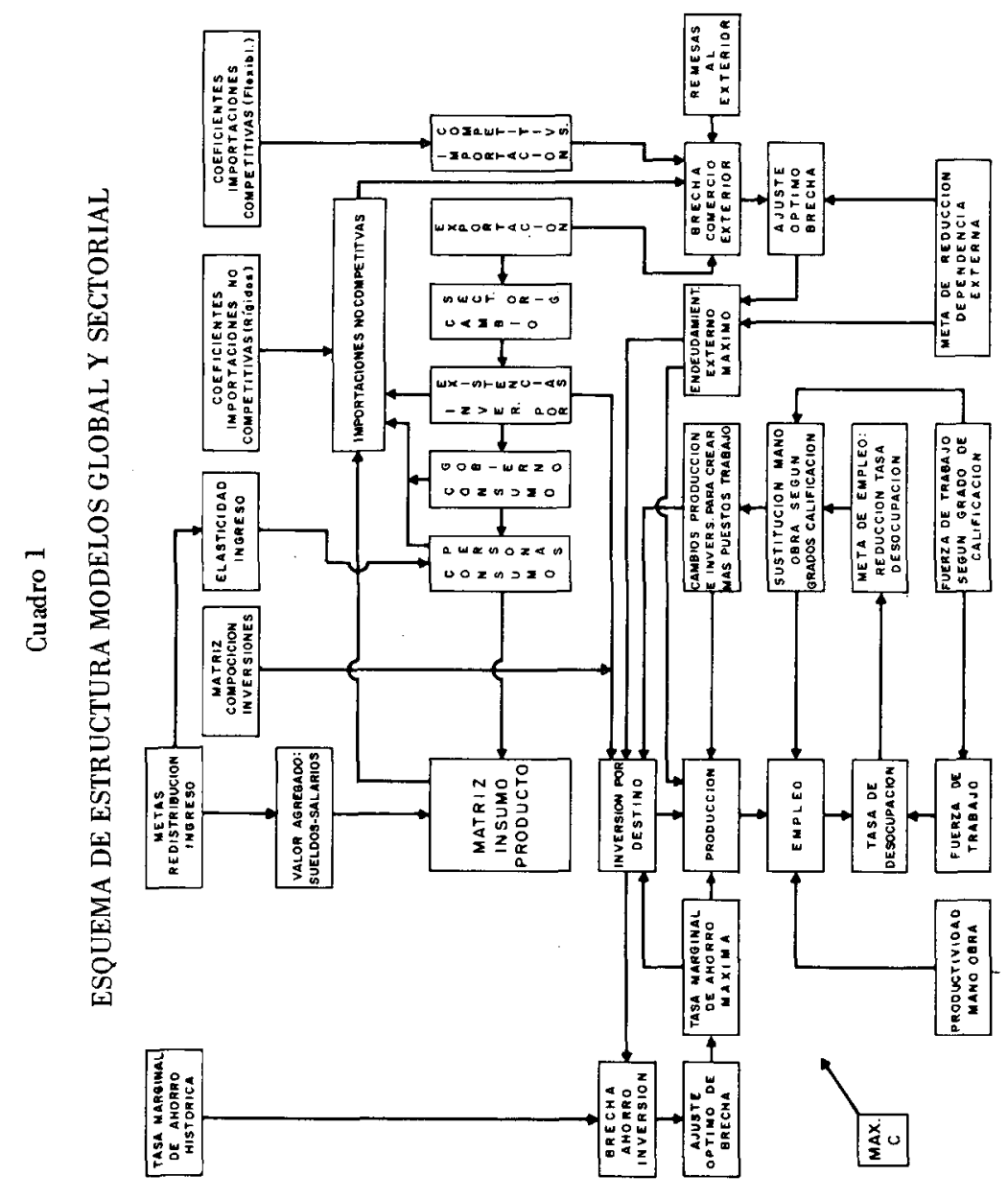


La elasticidad-ingreso de la demanda debe ser estimada para cada grupo de bienes a partir de información estadística: encuesta de presupuestos familiares o análisis de series de tiempo de consumo.

En cualquiera de los dos casos, la utilización adecuada de la elasticidad supone el llegar a una buena predicción del tamaño de la familia y del número de familias en el periodo del plan.

Esto requiere de un conjunto de datos demográficos que son fundamentales para reducir el margen de error de la proyección.

Se hace necesario en esta etapa contar, al menos, con los siguientes datos: la estructura de la familia por sexo, edad y número de personas y su cambio a través del tiempo. ?]

Para predecir correctamente el número de familias, hay que disponer de información acerca de jefes de hogar por sexo y grupo de edades, la edad al casarse, la frecuencia de divorcios, el celibato, etc. El cálculo del número de familias usualmente consiste en extrapolar, basándose en un índice que mide la relación entre el número de jefes de hogar por sexo y grupo de edades y la población total de ese sexo y grupo de edades. Multiplicando el índice por el crecimiento esperado de la población se obtiene una estimación del número de familias.

La otra variable importante en la determinación de la estructura sectorial del consumo privado es el nivel de consumo per cápita, que está afectado por el ritmo de crecimiento de la población. Es conveniente detenerse a examinar esta última variable más detalladamente, por cuanto influye no sólo en el nivel de consumo promedio a que cada persona puede aspirar durante la aplicación del plan, sino en un gran número de relaciones que irán apareciendo posteriormente en el proceso de su elaboración.

En el contexto presente, nos interesa el volumen de la población y su ritmo de crecimiento como demandantes de bienes y servicios que el plan debe suministrar. Un crecimiento excesivamente rápido de la población puede obligar a destinar recursos en abundancia para el consumo, a expensas de las posibilidades de ahorro y capitalización. De esta forma, se resentiría el potencial de crecimiento y de ocupación que a futuro la economia puede generar. A la inversa, un estancamiento de la población puede provocar problemas de escasez de mano de obra con lo que el ritmo de crecimiento económico también podría verse afectado. Cuál es el tamaño óptimo de la población para un país en

7/ Véase, por ejemplo, Naciones Unidas Principios Generales para los Programas Nacionales de Proyecciones de Población como Ayuda a la Planificación del Desarrollo, Estudios sobre Población N $N^{0} 38, p p .29$ y siguientes. 
proceso de desarrollo es una cuestión extensamente discutida en la literatura y en la cual no queremos entrar aquí. 8

Nos interesa más bien enfatizar aquí el aspecto metodológico. Las estimaciones del crecimiento de la población no podrán ser, normalmente, una simple extrapolación de tendencias históricas. Es imprescindible contar con buenas estimaciones de las tasas de fecundidad, de la mortalidad, de la emigración e inmigración internacional. Para ello, será imprescindible formular hipótesis razonables referentes a los factores que influyen en cada una de estas variables.9/ Por ejemplo, si se reconoce la influencia que el nivel de ingreso personal y el grado de educación y de urbanización tienen en la fecundidad, habrá que medir la relación entre ésta y esas variables, sabiendo que la dirección es la de una relación inversa en el caso del ingreso y directa en los otros dos, 10 / que será necesario determinar empiricamente aunque sea en forma aproximada.11/ Hecho este estudio, podrán formularse hipótesis sobre el comportamiento probable de las tasas de fecundidad en el periodo del plan. Un análisis semejante habrá que hacer sobre los cambios probables en la tasa de mortalidad y los niveles de emigración e inmigración.

Es importante comprender también que estas distintas variables tienen un efecto combinado sobre la población, que se adiciona a cada uno de los efectos considerados individualmente. Por ejemplo, si se dan conjuntamente altas tasas de fecundidad y rápidos descensos en la nortalidad, además de expresarse esto en ritmos acelerados de crecimiento de la población en el corto y mediano plazo, resulta que la estructura de la población comienza a cambiar con un predominio de los jóvenes, lo que a su vez permite predecir un rápido aumento en la tasa bruta de natalidad en el largo plazo.12/ Este resultado, si bien es posible que no se haga sentir en el período del plan, es importante

8/ Para una excelente discusión de este punto véase López, Alvaro, Temas sobre población y desarrollo económico en América Latina, Trabajo presentado a la Conferencia Regional Latinoamericana de Población, México, D.F., 17 al 22 de agosto 1970. Véase también León Tabah, "Demographic and Economic Interrelationship in the Developing World", U.N. Expert Group Meeting on the Application of Demographic Data and Studies in Development Planning, Beirut, Diciembre 1970.

9/ Un lúcido análisis de estas relaciones y su significación empírica para distintos países latinoamericanos puede encontrarse en CEPAL, "Tendencias Demográficas y Opciones para Politicas de Población en América Latina", Decimocuarto Periodo de Sesiones, CEPAL, Santiago, abril 1971, pp. 3-13.

10/ CEPAL, op. cit.

11/ CEPAL, op. cit.

12/ Véase CEPAL, op. cit. 
tenerlo presente puesto que debería influir indirectamente en éste en lo que se refiere a la decisión de consumo presente versus consumo futuro, es decir, la decisión entre consumo y ahorro. En efecto, una población cuyo crecimiento se acelera durante el periodo del plan y aún más después de éste, obliga a los planificadores a considerar un mayor sacrificio de la generación presenté a través del ahorro para lograr ingresos y consumo satisfactorios para las generaciones futuras.

Una última variable de importancia fundamental en la determinación de la estructura sectorial del consumo es la distribución del ingreso. En la medida en que distintos grupos de la población manifiesten elasticidades-ingreso de la demanda, significativamente diferentes para los mismos bienes, la distribución del ingreso por grupos no será neutral en la determinación de la estructura sectorial del consumo. Si se aceptara, por ejemplo, la hipótesis tradicional, aunque insuficientemente comprobada, de una mayor elasticidad de la demanda de bienes durables en los grupos de ingresos altos que en los estratos medios o bajos, podria deducirse que una redistribución regresiva del ingreso en el período del plan provocaría un mayor crecimiento en la demanda de durables que si el ingreso se redistribuyera más progresivamente. En estas últimas alternativas se produciría, por el contrario, un mayor consumo de bienes tradicionales (alimentos, vestuario, etc.) 13 /

Con el objeto de predecir la dirección y magnitud del cambio en el consumo sectorial causado por la redistribución del ingreso, se hace necesario conocer o estimar las elasticidades-ingreso de la demanda por categoría de ocupación, rama de actividad o tramos de ingreso. Para esto debe contarse con información demográfica referente a 1) las proporciones de la población en cada categoría, rama de actividad o tramo de ingreso; 2) el crecimiento demográfico por grupos; 3) la distribución por edad y sexo en cada grupo; 4) el tamaño de la familia y el número de familias.

A partir de estos datos, es posible determinar elasticidades diferenciadas por tramos y proyectar la estructura de la población por categoría de ocupación, rama de actividad o tramo de ingreso en el período del plan. Conociendo la estructura de la población por tramos de ingreso y las elasticidades de la demanda para cada tramo, es posible examinar el efecto de políticas alternativas de distribución del ingreso. Para esto, se desagrega la columna de consumo de personas en la matriz de insumo-producto, de tal modo que genere una columna para cada grupo o tramo de ingreso. Es necesario, a continuació a, determinar la proporción del gasto total de las familias en consumo de cada tipo de bien en cada tramo de ingreso en el año inicial del plan. Por último, hay que presentar en forma explícita la hipótesis de redistribución en el

13/ El desarrollo de esta hipótesis aparece, por ejemplo, en P. Vusković. "Distribución del ingreso y opciones de desarrollo" en Cuadernos de la Realidad Nacional, Santiago, Chile, Septiembre, 1970. 
plan, indicando la participación porcentual relativa que tendrá cada grupo en el ingreso total que se generará a través de éste. Con todos estos antecedentes, no hay dificultad en resolver el modelo sectorial (de cualquier tipo que sea) asegurando la coherencia entre los objetivos de crecimiento del producto y la redistribución, por una parte, y entre estructura productiva, estructural de consumo y composición del ingreso, por otra.

Un último aspecto que hay que enfatizar para un tratamiento adecuado de la variable distribución del ingreso y su relación con el consumo es que, tal como el comportamiento económico de distintos? grupos o tramos puede ser diferente (manifestado a través de elasticidades diferenciadas), su comportamiento demográfico también puede serlo. Las tasas de fecundidad, por ejemplo, son usualmente más altas en los grupos de bajos ingresos, lo que hace que el crecimiento de la población sea más acelerado en estos grupos. Naturalmente que esta propensión tiende a aumentar la regresividad en la distribución del ingreso, a igualdad de los otros factores. Por esto, antes de la formalización en el modelo de los objetivos globales de distribución entre tramos, es indispensable conocer en detalle la información demográfica por tramos y poder proyectar tendencias a partir de ella. Es conveniente recalcar esto una vez más.

\section{B. Consumo del gobierno /}

El gasto en bienes y servicios de consumo por parte del gobierno tiene por objeto, básicamente, asegurar un nivel minimo de satisfaccción de 7 necesidades para toda la población. Por esto, si se analiza la composición sectorial de este gasto, se observará que tiende a concentrarse en demanda de alimentos y de servicios como educación y salud públicas. En la determinación de cada una de estas demandas interviene un número de factores entre los cuales los demográficos son de la mayor importancia. Analicemos separadamente los tres casos.

a) Educación pública

Es un sector en el cual son importantes los gastos en consumo del gobierno. La demanda privada por educación puede estimarse usando elasticidades-ingreso tal como en el caso de otros bienes y servicios de consumo personal. La demanda de educación pública sería, en ese caso, igual a la diferencia entre las necesidades totales de educación y los servicios suministrados por el sistema de educación privada. Naturalmente, el orden en que se determina la magnitud de ambos programas puede alterarse si uno de los objetivos del plan fuera, por ejemplo, que el Estado proveyera toda la educación o la mayor proporción posible dentro de su restricción presupuestaria. En ese caso 
de limitación de "la soberanía del consumidor", los programas de educación privada se determinarían como residuo entre requisitos totales y programas de educación pública.

Una buena especificación de los gastos públicos en educación tiene que comenzar por un amplio análisis de la extensión y calidad de los servicios educacionales prestados antes del plan y su relación con las necesidades totales de la población. 14/ Para esto se requiere un estudio riguroso de los datos censales de población por edad y sexo, grado de alfabetización y nivel de instrucción por edad y sexo al comenzar el plan. Es conveniente, a continuación, hacer hipótesis alternativas sobre las tendencias de estas variables en el futuro con el objeto de determinar los efectos que el crecimiento de la población y su cambio de estructura tendrían sobre los requisitos globales de servicios educacionales que el Estado debe proveer.15

Es importante, además, hacer el análisis anterior, por regiones, puesto que el déficit educacional es usualmente muy diferente en distintas zonas del país. Por ejemplo, tiende a ser muy al to en las zonas urbanas de migración reciente. En las zonas rurales, en cambio, aun cuando a veces el déficit no es cuantitativamente tan alto, si lo es desde el punto de vista de la calidad de los servicios prestados. Este último factor, que establece un desequilibrio de magnitud en la calidad de la educación entre las zonas urbanas y rurales, se convierte en determinante de la aceleración de la migración a zonas urbanas por parte de los estratos medios de la población rural. Precisamente, estos grupos medios son los que podrían ser importantes en el sector agrícola para la elevación de la productividad del sector, a través de su mayor capacidad de innovación. 16

14/ Para detalles de cómo utilizar los datos demográficos en este sector véase Naciones Unidas, Principios generales para los programas nacionales de proyecciones.., op. cit; y Naciones Unidas, "Utilización de los programas nacionales de análisis de los datos de los censos de población en la formulación de planes y políticas", Estudios sobre Población $N^{\circ} 36$.

15/ Hay que hacer notar que la relación entre crecimiento de la población y magnitud de los servicios educacionales opera en los dos sentidos. Es decir, también parece ser válida la hipótesis de que a mayor nivel de educación tiende a bajar la fecundidad y así, a disminuirse el ritmo de crecimiento de la población. Véase L. Olivos Factores demográficos $y$ análisis de sectores sociales, trabajo presentado a la Conferencia Regional Latinoamericana de Población, México D.F. agosto de 1970.

16/ La medición de los distintos niveles de calidad de la educación en diferentes zonas plantea problemas metodológicos difíciles, por lo que, usualmente, en esta segunda fase de la planificación no son considerados explícitamente, aunque sí en la posterior elaboración detallada del programa sectorial de educación. 
Establecido el diagnóstico de la situación educacional, es imprescindible contrastarlo con las necesidades educacionales a futuro. $\}$ Estas pueden dividirse en dos aspectos: primero, asegurar un nivel general de instrucción lo más alto posible a través del aparato formal de educación (básica y media fundamentalmente); segundo, satisfacer requerimientos de fuerza de trabajo según categoría ocupacional, grado de calificación y sector de actividad. Este último aspecto, que considera la educación en función de la mano de obra como un recurso productivo, corresponde a la planificación de recursos humanos y será tratado más adelante. En esta sección nos interesa medir la demanda de educación desde el punto de vista del servicio prestado por el gobierno a la población (podríamos decir, al consumidor). Puede identificarse entonces con la aspiración de la población por el mayor grado de instrucción posible.

En este último sentido, la metodología se orienta a fijar metas de / escolaridad por edades $\mathbf{y}$ por niveles en la educación básica y media. Estas metas se miden por porcentaje de absorción dentro del sistema $\curvearrowleft$ educacional de la población en los respectivos tramos de edad. Así, por ejemplo, se puede establecer una meta de escolaridad del 100 por ciento entre los 6 y los 13 años, de un 80 por ciento entre los 13 y los 15 y de un 50 por ciento entre los 15 y los 19 años. Hay que hacer notar en este punto que la meta de escolaridad está sujeta a dos tipos derestricciones: la primera, es la capacidad instalada o infraestructura existente (más las inversiones que se puedan hacer a través del plan); la segunda, es la capacidad de absorción de servicios educativos por parte de los educandos. En efecto, los estratos de bajos ingresos, por ejemplo, se caracterizan por altas tasas de fecundidad, exhiben problemas serios de desnutrición y viven en condiciones de hacinamiento. Todos estos factores, que atentan contra su capacidad de aprender, se suman a la presión económica que los obliga a trabajar prematuramente. Por lo tanto, la capacidad de incorporación a niveles cada vez más altos del sistema educacional por parte de estos grupos, en el corto plazo, puede verse limitada. De allí la necesaria interrelación entre la expansión del sistema educacional y los programas de nutrición, vivienda y
redistribución de ingresos.

Una vez que se han fijado metas (provisionales) para la educación básica y media, se hace necesario estimar la expansión de gastos en el sistema universitario y en los programas de capacitación. Para el sistema universitario se procede, en esta etapa, en forma similar a la educación básica y media. Se fijan metas preliminares de porcentaje de absorción de egresados de la enseñanza media. El análisis más detallado, en etapas posteriores, de la elaboración del plan, hará que esas metas se revisen desde el punto de vista de la demanda de recursos humanos específicos requeridos para el cumplimiento del plan. Lo mismo ocurre con los programas de capacitación. 


\section{b) Salud pública}

Cinco son los aspectos más importantes a considerar en la. determinación de los gastos públicos de salud.

Primerò, la reducción de la tasa de mortalidad. Este, que es un', objetivo central en cualquier programa de salud, requiere para su cuantificación el que se determinen las tasas de mortalidad por edad y sexo y la posible influencia del incremento demográfico sobre los cambios en estas tasas por edad y sexo. Es indispensable, también, identificar los factores específicos que influyen en las tasas de mortalidad, tales como las condiciones sanitarias generales, epidemias, desnutrición infantil, deficiente atención médica o enfermedades particulares. A partir de este análisis, es posible diseñar programas detallados para reducir la incidencia de cada uno de estos factores en la mortalidad. Se obtiene como resultado una estimación de la reducción posible de la mortalidad y de los gastos en salud, necesarios para lograr esa meta.

: Un segundo aspecto se refiere a las demandas específicas de servicios de salud por distintos grupos de la población. Uno de ellos, explicado por la usualmente alta tasa de crecimiento demográfico, se refiere a los servicios pediátricos. La demanda de estos servicios tiende a ser. preponderante sobre otros, existiendo a menudo una significativa demanda insatisfecha. Esta es una función, en definitiva, de las condiciones generales de vida de la población, entre las que se cuentan la alimentación, las condiciones sanitarias, las deficiencias habitacionales, etc. Todos estos factores afectan especialmente a la población infantil, que además crece numéricamente en forma más rápida que otros estratos. Es imprescindible entonces proyectar la población infantil a futuro $y$, mediante índices de incidencia de distintas enfermedades en este grupo de edades, estimar la demanda probable de servicios en el período del plan.

Otra demanda específica de importancia se refiere a la atención. maternal, que puede ser medida en función del porcentaje de la población, que estará constituido por mujeres en edad de procrear.

El otro sector de demandas especificas es el de la población en edad $\checkmark$ avanzada. Para estimarla, se requiere contar con estimaciones de esperanza de vida, las que serán una función, entre otras cosas, de las tasas de mortalidad. También influirá en la importancia relativa de estos servicios, la composición por edades de la población y su tasa de crecimiento.

El tercer aspecto de importancia en la determinación de los gastos en salud pública está constituído por el estudio de las tasas de morbilidad por_categoría ocupacional y tipo-de actividad. Es necesario establecer de algún modo la relación entre éstas y los niveles de productividad de la mano de obra. El plan, en una etapa posterior de su formulación, 
determinará los incrementos de productividad requeridos. Los programas de salud deberán contribuir a mantener o aumentar los niveles de productividad, especialmente en los sectores y tipos de actividad en los que las condiciones ambientales implican deterioros importantes de la salud, con el consiguiente descenso en el rendimiento de la mano de obra. Hay que estudiar en esta etapa, por lo tanto, el costo de programas para reducir la incidencia de las llamadas enfermedades profesionales, costo que será un elemento de importancia en los planes de salud pública.

Un cuarto aspecto está dado por la determinación del déficit global, por sectores y por regiones, en la capacidad de atención sanitaria. Es necesario contar con indicadores tales como el numero de personas atendidas por médico, el número de pacientes por cama, etc. Las proyecciones demográficas permitirán medir el déficit probable a futuro, a partir del cual habrá que establecer las metas cuantitativas que impliquen el mejoramiento de esas relaciones, para una mejor atención sanitaria de la población.

Finalmente, un dato fundamental será la distribución geográfica de $>$ los servicios sanitarios, comparándola con la distribución de la población y la tendencia de los flujos migratorios. De este modo será posible detectar desequilibrios entre demanda y capacidad instalada que habrá que subsanar a través de una mayor productividad de los servicios existentes y a través de nuevas inversiones.

\section{c) Demanda de productos alimenticios}

La demanda de productos agrícolas y alimenticios por parte del gobierno está determinada por la necesidad de proveer de alimentos que aseguren un nivel básico de salud y nutrición a toda la población. Esta demanda toma usualmente la forma de programas alimenticios subsidiarios de carácter gratuito. En la medida en que favorecen preferentemente a los grupos de ingresos reducidos constituyen otra forma de redistribución de la renta nacional.

La magnitud del gasto en estos programas descansa en una estimación de los requerimientos de la dieta alimenticia en calorías, proteínas, etc. Estos requerimientos dependen de la edad, sexo y tipo de actividad de los distintos grupos de la población ya sean urbanos o rurales. Hay que hacer notar que la dieta alimenticia mínima varía también según el grado de urbanización y de industrialización del país, por cuanto estos factores cambian la actividad física de estratos importantes de la población. Los requerimientos alimenticios mínimos, sumados para toda la población, dan el consumo total básico que el plan debe satisfacer. Es necesario, entonces, considerar que, dada la desigual distribución del ingreso, el consumo de los grupos cuyo ingreso está sobre el nivel de subsistencia tenderá a ser mayor que el consumo 
básico. Cuantificando los requisitos de consumo básico para el estrato de menores rentas, se pueden plantear hipótesis alternativas sobre la proporción de este consumo básico que sería entregado en forma gratuita por el gobierno. Este tipo de programa es sólo uno de los posibles cursos a seguir para asegurar niveles aceptables de alimentación. No es necesariamente el más eficiente. Más simple puede ser una política de crecientes subsidios gubernamentales a los grupos de bajos ingresos según el tamaño de su familia, su composición por edades, etc., más un subsidio por cesantía.

Los programas de nutrición a veces toman formas mucho más específicas como, por ejemplo, los de alimentación para la población en edad escolar o para las madres en períodos pre y post-natal. El cálculo; del gasto en estos programas se determinará proyectando el número de niños entre determinadas edades y las tasas de fecundidad por edades para el período del plan.

\section{La inversion}

Dentro de nuestra descripción metodológica de la fase de la planificación sectorial, hemos abarcado, hasta ahora, la especificación de dos de los componentes de la demanda final: el consumo privado y. el consupa de gobierno. Corresponde entrar ahora en el análisis de la inversión, tercero de esos elementos, de importancia en la demanda final desde el punto de vista de los objetivos sociales y las variables demográficas.

La inversión es un elemento importante por el tipo de demanda de bienes que genera, demanda que influye en el nivel de actividad económica en el período en que se efectúa; por la creación de capacidad productiva en diferentes sectores de actividad económica, y por la creación de ocupaciones. En esta sección veremos especialmente el primer aspecto.

Uno de los problemas de los modelos de planificación sectorial consiste en el logro de consistencia entre la inversión requerida desde el punto de vista de la expansión de capacidad y la inversión considerada como componente de la demanda final. En los distintos procedimientos empleados para buscar la consistencia, es corriente distinguir entre componentes autónomos e inducidos de la inversión. Los primeros se especifican exógenamente, de acuerdo con programas del gobierno que responden a objetivos explícitos del plan. Tal vez el más importante de : estos programas sea el de vivienda. Ciertamente, así lo es desde el punto de vista social y demográfico y concentraremos, por lo tanto, la atención en los métodos para determinar la inversión en este sector.17]

17) Un ejemplo puede encontrarse en ODEPLAN El desarrollo Económico y Social de Chile en la Década 1970.1980, Santiago, Chile, agosto de 1970, Tomo 1, Volúmen 1, págs. 104-110. 
¿El valor que se obtenga para la vivienda se introducirá exógenamente en el sector demanda final correspondiente a la inversión.

La medición del déficit con respecto a la población actual, constituye el primer problema del programa de vivienda. Para esto se estima, usualmente a través de datos censales, la disponibilidad de vivienda en metros cuadrados y de metros cuadrados por habitante $y$ por familia. Se establece una primera meta provisional del número de $>$ metros cuadrados por familia, que será preciso asegurar a través del plan. Multiplicando ese número de metros cuadrados por el número de familias se obtiene una medición de los requerimientos. Si se comparan éstos con la provisión existente, se llega a una primera medición del déficit (el que no considera todavía las viviendas para nuevas familias y para reposición).

En seguida se hace necesario proyectar los requerimientos para las nuevas familias. Se proyecta, en primer lugar, el número de familias, que depende, entre otros factores, del número de adultos en cierto rango de edad y sexo y del crecimiento de la población. El cálculo aquí es el mismo que se describia en la metología de determinación del consumo privado a través de las elasticidades y no es necesario repetirlo.

Establecido el número de familias, hay que relacionarlo al número de hogares, para lo cual deben usarse datos censales acerca de la estructura de los hogares por sexo, edad, número de personas y grado de? parentesco entre ellas. Es posible relacionar, además, todas estas; variables con la tasa de crecimiento de la población y su estructura. Hay, por ejemplo, una vinculación obvia entre un incremento rápido de la población, un cambio en su composición hacia los estratos de menor edad, el incremento en el tamaño de la familia y el aumento del número de familias. Todas estas variables están relacionadas directamente a través de efectos que no son instantáneos sino que se hacen sentir después de un periodo perfectamente determinable.

Agregadas las nuevas familias a las existentes, es posible determinar, 7 a través de su tamaño promedio y del número total, los requerimientos netos de metros cuadrados a construir. A esto hay que sumar la reposición de viviendas en mal estado o destruidas. Este cálculo descansa usualmente en informaciones censales sobre el estado de las viviendas, complementado con alguna hipótesis de depreciación de la existencia conocida de viviendas. A menudo se considera una depreciación lineal, con lo que la tasa de depreciación es inversamente proporcional a la vida útil de la vivienda. Si nos ponemos como objetivo el reponer la existencia en igual magnitud a su depreciación, es posible, a través de cálculos sencillos, determinar la inversión requerida. La inversión de reposición más la inversión neta da la inversión total en vivienda, expresada en metros cuadrados.

En este punto se hace necesario precisar los programas específicos de vivienda, indicando qué proporción de los metros cuadrados totales se 
construirá en viviendas de qué tamaño. Esto es importante tanto para adecuarse a las demandas especificas de las familias, como para una correcta estimación del gasto total de inversión, puesto que el costo de los distintos tipos de vivienda es diferente. Luego, para determinar los programas según tipo de vivienda hay que contar con información sobre la distribución de las familias por tamaño y su posible composición en el futuro.

Diseñados los programas específicos, se obtiene el total de viviendas por cada tipo y sólo resta determinar el ritmo de iniciación por año, el que dependerá del monto total de recursos disponibles anualmente para la inversión en el plan y del periodo de maduración de la inversión, es decir, el tiempo promedio requerido para construir las viviendas de cada tipo.

\section{DEMANDA INTERMEDIA, PRODUCCION E INVERSIONES}

En las secciones anteriores hemos descrito un método de especificación de la demanda final por sectorees, destacando aquellos aspectos más vinculados a los objetivos sociales del plan. La especificación queda completa si se introducen exógenamente, las exportaciones por sectores y si se hace que el cambio de existencias sectoriales sean una función de. los cambios esperados en los niveles de producción.

Especificada la demanda final, se establecen las ecuaciones de balance sectorial en las que la producción más las importaciones se hace 'igual a la demanda final más la demanda intermedia. Esta parte del modelo sectorial se simplifica si se cuenta con una matriz de insumo-producto. Invirtiendo esta matriz es posible determinar los niveles y composición de la producción por sectores a partir de la demanda final. Sin embargo, el procedimiento requiere también calcular simultáneamente los incrementos de capacidad productiva sectorial compatibles con los niveles de producción determinados a través de la matriz de relaciones inter-industriales. Estos incrementos requeridos de capacidad determinan, a través de coeficientes de capital-producto sectoriales, la inversión por sectores de destino. Mediante una matriz de composición promedio de la inversión, se convierte ésta en inversión por orígen, la que debe ser idéntica a la que aparece como componente del vector sectorial respectivo en la demanda final. Esto se logra por la resolución iterativa del conjunto de ecuaciones simultáneas que representan las relaciones antedichas.

El resultado, sin embargo, en términos de los niveles de producción e inversión sectoriales, está estrechamente ligado, además, a la estructura de la oferta, particularmente a los márgenes de sustitución de importaciones probables en el período del plan. La determinación de la sustitución de importaciones requiere distinguir en el modelo entre importaciones competitivas y no-competitivas por sectores y por tipo 
de bien (bienes de capital, intermedios, de consumo). Las primeras se definen como aquéllas que al mismo tiempo que son importadas se $J$ producen también internamente.

Finalmente, como las expansiones en la producción, las importaciones o la inversión están condicionadas por la disponibilidad de recursos, es necesario evaluar si el uso de divisas, ahorro interno y mano de obra está enmarcado dentro de las cantidades máximas disponibles de estos recursos en el período del plan. Esta evaluación es' equivalente a las de las brechas que ảiscutíamos en el análisis global, sólo que ahora se hace por sectores y que el ajuste de las brechas se efectúa en forma automática de acuerdo con las pautas obtenidas del estudio global.

\section{EMPLEO}

En el aspecto del uso de recursos nos interesa especialmente el problema de los niveles de empleo. Como decíamos, la resolución del modelo_sectorial implica no usar más divisas, ahorro interno o mano de obra que los disponibles. Lo mas probable es que los primeros resultados de la compatibilidad sectorial indiquen la necesidad de usar todas las divisas y el ahorro interno, pero dejando un porcentaje de la fuerza de trabajo sin ocupación. Precisamente, a causa de esta característica, que en cierto sentido mide la tendencia espontánea de la economía, los planes deben centrar en forma preferente su atención sobre los problemas de empleo de la fuerza de trabajo. Este es un objetivo de tipo social, aunque_también económico, de una importancia equivalente al del incremento de la producción. $\bar{D}$ e allí que nos interese concentrarnos en él en las secciones siguientes.

El problema del empleo tiene dos aspectos: el primero, ya mencionado, es la probable ocurrencia de una tasa de desocupación a nivel global incompatible con los objetivos del plan. El segundo, no contradictorio con el primero, es que, a pesar de haber una tasa global de desocupación, es posible que cuando se determinan las necesidades de mano de obra (y de ocupación, por lo tanto) en forma más desagregada, distinguiendo entre distintos tipos y niveles de calificación, se detecten déficit en la disponibilidad de algunos tipos de mano de obra que dificulten el logro de las metas de crecimiento. Cuando se habla de empleo, por lo tanto, se incluyen ambas tareas: reducción de la tasa global de desocupación y adecuación de los recursos humanos disponibles para las necesidades del plan mediante programas de capacitación $u$ otros que permitan eliminar cuellos de botella en el) proceso productivo.

El nivel de empleo generado en el plan depende del volumen y estructura de la producción y de la productividad de la mano de obra por sectores. La fuerza de trabajo a la que es necesario dar ocupación está determinada por la magnitud de la población activa. 


\section{a) Proyección de población activa}

La proyección de la población activa estará directamente relacionada"? con el ritmo de crecimiento de la población y la tasa de actividad por sexo y grupo de edades. Como sabemos, el ritmo de crecimiento de la población depende de las funciones biométricas, de las que resultará una determinada tasa de incorporación de jóvenes a la fuerza de trabajo. Las tasas de actividad, por otra parte, serán una función de a) los deseos de trabajar, b) las oportunidades de trabajo (función del crecimiento de la economía y que tienden a aumentar las tasas de actividad), c) la extensión de los programas educacionales (que hacen más lentas las nuevas incorporaciones a la fuerza de trabajo), d) los cambios en la cobertura del sistema de seguridad social (por ejemplo, las jubilaciones a más temprana edad reducirán las tasas de actividad), e) el promedio de vida activa (que influye la tasa de cese en el trabajo) y otros.

La precisión en los valores proyectados para la población activa es fundamental si se quiere hacer una correcta producción de la tasa global de cesantía y definir, por consecuencia, las políticas para reducirla. La proyección de población activa debe incluir a los inactivos con deseos de trabajar. De este modo se evita la subestimación de esta variable $y$, consiguientemente del desempleo, en que a menudo se incurre en proyecciones de este tipo.

Por las razones anteriores, es conveniente realizar varias proyecciones alternativas de la población activa. En una primera alternativa, se puede suponer una evolución en las tasas de actividad masculina y femenina igual a la histórica. Se puede, después, agregar a la cifra así obtenida a los inactivos con deseos de trabajar. En una tercera proyección, se plantearian cambios significativos en patrones culturales que motiven cambios en la natalidad $y$ en la tasa de actividad femenina (posiblemente un rápido incremento en esta última). Se tendrían así tres proyecciones para la población activa, entre las cuales habrá que seleccionar, en etapas posteriores, la que parezca más razonable.

\section{b) Producción y productividad por sectores}

Las variables que determinan el empleo son el nivel y estructura de la $\zeta \neq$ producción, y la productividad por sectores.

El nivel de producción está condicionado por el volumen y composición de la demanda, por la disponibilidad de recursos escasos y sus usos alternativos y por los objetivos explícitos del plan, como son el crecimiento del producto geográfico, la redistribución del ingreso, el

, alto nivel de ocupación y otros. De estos aspectos nos hemos ocupado anteriormente.

Respecto a la relación entre el nivel de ocupación y la productividad del trabajo por sectores, hay que hacer notar que normalmente ésta se 
hace explícita a través de la productividad media, medida como el valor bruto de la producción generado-por persona. En esta etapa de la elaboración del plan, se considera todavía a la fuerza de trabajo como homogénea, sin distinguir por tipos de calificación.

La proyección de las productividades puede tener varias alternativas. La primera y más obvia es la utilización de tendencias históricas mediante un análisis de regresión. Los coeficientes así obtenidos servirán para indicar una especie de prognosis de la situación ocupacional. En un análisis más refinado de las productividades, sin embargo, es posible distinguir entre sectores tradicionales y dinámicos. En los primeros habrá poca influencia de proyectos nuevos como para alterar significativamente los coeficientes de productividad (los coeficientes marginales serían semejantes a los medios) y se pueden mantener, para la proyección, las tendencias históricas. En los sectores dinámicos, por otra parte, es usual que el cambio tecnológico implicado? por nuevos proyectos sea significativo y tienda a aumentar la productividad de la mano de obra por sobre las tendencias observadas anteriormente. La expansión directa del empleo por el efecto de estos sectores puede ser reducida. Sin embargo, el efecto total no se podrá determinar mientras no se mida (a través de la matriz de insumo-producto) cuál es el efecto derivado, en términos de ocupaciones, que resulta del incremento en el ingreso y la producción, asociados al crecimiento de los sectores dinámicos. Luego, con el objeto de determinar adecuadamente el cambio en la productividad de los sectores dinámicos, habrá que contar con información de proyectos específicos en el sector. Sólo así se podrá medir la divergencia entre coeficientes medios y marginales y proyectar la nueva tendencia de la productividad en esos sectores.

\section{c) Proyección de la tasa de desocupación}

Lo que normalmente ocurre al hacer una primera proyección con los datos tal como se han descrito en el párrafo precedente, es que el empleo crece muy poco en los sectores dinámicos, y bastante más ( rapidamente en los sectores tradicionales, pero aun así la tasa de\} desempleo resultante es relativamente alta.

El crecimiento de la ocupación en los sectores tradicionales, por otra parte, tiende a concentrarse en los sectores agrícola y de servicios. 18 /

Típicamente, la baja en la productividad agricola resultante del alto empleo en el sector se convierte, finalmente, en una presión que acelera la migración a las áreas urbanas con la consiguiente aparición de

18/ Este resultado no debería sorprender. Si los coeficientes están bien medidos, éste es el tipo de resultado que tiene que entregar al modelo, puesto que corresponde al proceso real por el que han pasado y pasan las economías latinoamericanas. 
bolsones de desocupación en las ciudades. En éstas el sector servicios es el que tiende a sobreextenderse, absorbiendo grandes volumenes de la población migrante.

Este tipo de comportamiento del sector servicios puede comprobarse observando una tendencia negativa en su productividad al examinar un período suficientemente largo. La sobreextensión del sector servicios. introduce un desequilibrio estructural en la economía de efectos negativos en el crecimiento. Además, dificulta la reducción de los márgenes globales de comercialización en la economía, repercutiendo esos altos márgenes en un deterioro de la capacidad de compra de la . población. La posibilidad de modificar el ritmo del flujo migratorio rural-urbano y de incrementar la productividad de los servicios descansa en la posibilidad de absorber productivamente mano de obra en el sector industrial. Esto, a su vez, depende del grado de dinamismo que pueda imprimirse al crecimiento del sector industrial y de la adecuada selección de tecnologías en dicho sector, de tal modo que los coeficientes mano de obra-capital tiendan a elevarse.

Los argumentos anteriores plantean un cierto conflicto entre el proceso de modernización industrial (que parece requerirse para, entre otras cosas, reducir el estrangulamiento en el comercio exterior) y los requisitos de ocupación global de la economía. Si este conflicto se traduce o no en una estrategia consciente de dualismo tecnológico es algo que tiene que discutirse en esta etapa de la elaboración del plan, a la luz de las líneas gruesas de la estrategia industrial y de los proyectos específicos de que se disponga.

Sintetizando, podría decirse que con la fuerza de trabajo y las productividades estimadas como se ha descrito y una vez que se conocen los niveles de producción, se obtiene una medición de la demanda total de mano de obra, la que comparada con la población activa, resulta en una cierta tasa de desocupación, la que puede ser mayor o menor que la tasa máxima permisible como objetivo del plan.

d) Reducción del desempleo bajo supuestos de homogeneidad en la fuerza de trabajo.

Debemos llamar la atención en este punto sobre algunos supuestos metodológicos del procedimiento que se ha estado describiendo. El primero de ellos es que al trabajar con la matriz de insumo-producto y con coeficientes constantes de productividad para la mano de obra estamos aceptando un tipo de función de producción en que es cero la elasticidad de sustitución entre factores, sean insumos intermedios, mano de obra o capital. Esto quiere decir que en un sector en particular, el capital se usa siempre en proporciones fijas (determinadas por el coeficiente de capital-producto), y la mano de obra también, de acuerdo con el valor del coeficiente de productividad constante. 
La economía, tal como estaría representada en este modelo, no tendria un margen de ajuste interno en cada sector de tal modo de tender a usar más del factor abundante (mano de obra) y menos del factor escaso (capital). El problema de si este tipo de representación de la economía se ajusta o no a la realidad es empírico y ha recibido amplia atención en la literatura, pero sobre él no hay aún respuestas categóricas. 19] Hay, en todo caso, aquí, un amplio campo de investigaciones abierto para los grupos que trabajan en la elaboración de material básico de sustentación para el plan. Nos referimos a la experimentación empírica con distintos tipos de funciones de producción, a través de las cuales es posible llegar a una medición de la elasticidad efectiva de sustitución entre factores para una economía determinada. Todo lo que aquí puede adelantarse a' nivel de la generalidad de esta discusión, es que el resultado obtenido a través del modelo que se describe tiende a reflejar una situación extrema, en la que la excesiva rigidez en el uso de recursos hace aparecer una tasa de desempleo probablemente exagerada. 20

En todo caso, si aceptamos provisionalmente el supuesto de rigidez en el uso de factores como uno no muy distante de la realidad empírica, corresponde tomar la cifra de desempleo entregada por los cálculos y ver la forma de reducirla hasta los niveles aceptables según los objetivos del plan. Esto puede hacerse usando el mismo aparato metodológico que hemos descrito. En efecto, si bien es cierto que, según los supuestos del modelo, la sustitución entre factores dentro de un sector no es posible, sí lo es entre sectores. A través de un cambio en la composición de la producción o de la inversión por sectores es posible utilizar may or proporción de un factor (mano de obra) y menos del otro (capital). Esto es asi puesto que los coeficientes de capital-producto y dell capital-mano de obra son distintos para los diferentes sectores. Iguali; nivel de producción total puede representar, por lo tanto, variadas composiciones sectoriales de esa producción $y$, consecuentemente, grados diversos de uso de los factores productivos.

Entonces, lo que corresponde es estudiar una reasignación sectorial de la producción, de tal modo que se desarrollen más aquellos sectores

19/ Para evidencia empírica sustentando la tesis de alta sustitución véase, por ejemplo, S. Bowles "The Aggregation of Labor Inputs in the Study of Growth and Planning: Experiments with a Two Level CES Function", Economic Development Report No 122, Center for International Affairs, Harvand University, Nov. 1968. La tesis de escasa sustitución, particularmente en el sector industrial fue sustentada por R.S. Eckaus "The F actor Proportions Problem in Underdeveloped Areas" en Azarwala y Singh "The Economics of Underdevelopment", Oxford, 1963.

20. Notemos, sin embargo, que ese sesgo puede desaparecer o aun cambiar de signo si pudiéramos medir el desempleo disfrazado existente especialmente en el sector agricola y sumarlo a la tasa de desempleo obtenida con el modelo. 
que pueden emplear o retener mano de obra en mayor proporción. Estos son usualmente la agricultura, la construcción y los servicios. Al producirse el cambio en la composición de la producción, cambia también la estructura sectorial de la inversión, y se expande más la capacidad productiva en los sectores intensos en el uso de mano de obra. Desde el punto de vista del comercio exterior, este tipo de cambio estructural implica, además, una sustitución forzosa de importaciones, la que genera nuevas ocupaciones a través de la mayor actividad productiva interna y libera divisas que permiten importar más bienes de capital, que se utilizan en la expansión de capacidad interna de producción.

Todos estos cambios pueden cuantificarse usando un modelo multisectorial de optimización, al cual se le pone como restricción el reducir la tasa de desempleo con respecto a la "tasa espontánea" obtenida en una primera solución del modelo. $21 /$

Al comparar la solución original con la que incluye la restricción de empleo, se observarán cambios en la producción, las inversiones y el comercio exterior, como los que se señalaban en el párrafo anterior. Desde el punto de vista global, podrá también medirse el costo social implicado por una política de absorción de desempleados a través del menor crecimiento en el producto que resulta al forzar a la economía a darles ocupación. Este costo social es equivalente al subsidio que el gobierno debe dar a los productores para que empleen más mano de obra. El crecimiento resultante en el producto geográfico bruto es menor por cuanto los recursos destinados exclusivamente a reducir el desempleo tienen menor productividad en este caso que si se asignaran libremente con propósitos puramente de crecimiento en la, producción. $\underline{22}$

e) Reducción del desempleo bajo supuestos de sustitución entre distintos grados de calificación de la mano de obra.

Hay otro curso de acción posible para reducir el desempleo, que hasta ahora no se ha detectado en nuestra metodología, justamente por supuestos restrictivos del modelo que hemos estado usando. En efecto, dijimos que el modelo no consideraba la sustitución entre factores, excepto en la medida en que se altera la composición de la producción. Este supuesto alcanza también a los distintos tipos de mano de obra, que hasta ahora se ha supuesto homogénea. Sin embargo, ésta está, en

21/ Este es, exactamente el procedimiento seguido en P.B. Clark y A. Foxley, Sub-optimal Growth: The Social Cost of Make-Work Employment Policies, Trabajo presentado al II Congreso Mundial de Econometria, Cambridge, Inglaterra, Septiembre de 1978.

22/ P.B. Clarck y A. Foxley, op. cit. 
realidad, compuesta por grupos de muy diferentes niveles de calificación. Alguna evidencia empírica parece indicar que el grado de sustitución entre distintos niveles de calificación puede ser significativo. 23/ La elasticidad de sustitución tiende a ser mayor que uno, en, prácticamente, todos los casos. 24/ A causa de esta realidad empírica, un tercer tipo de ajuste para reducir el desempleo puede consistir en reasignar la mano de obra no sólo entre sectores sino aun dentro de un mismo sector. Si es posible, por ejemplo, sustituir un trabajador con nivel al to de calificación por dos de nivel medio, el efecto neto de la sustitución en el empleo es positivo.

Metodológicamente, no es fácil medir el porcentaje de absorción posible por este camino. Tal vez el principal problema en la mayoría de los países sea el de la escasa información. Se hace necesario conocer a través de datos censales o de alguna muestra, la población activa y la población ocupada según sectores de actividad, tramos de ingreso y niveles educacionales. Deben conocerse también los niveles medios de ingresos para cada subclasificación. Estos pueden obtenerse dividiendo el ingreso total del subgrupo por el número de personas empleadas de ese subgrupo. Si se supone que las diferencias en ingresos medios reflejan diferencias en productividad y éstas corresponden a distintos niveles educativos, es posible asignar, dentro de cada sector de actividad, productividades diferenciadas para eada nivel educacional. Con estos datos se proyecta la demanda de mano de obra por grado de calificación y sector de actividad. Sumando en todos los sectores, se puede obtener el total de requerimientos en cada nivel educacional.

Es necesario comparar a continuación esa demanda con la oferta previsible de mano de obra según grados de calificación. Además, es necesario conocer hasta qué punto pueden ser satisfechos los requisitos para determinado tipo de mano de obra mediante otra clase de fuerza de trabajo. En otras palabras, hay que determinar la elasticidad de sustitución entre distintos tipos de mano de obra, la que puede estimarse econométricamente a partir de datos de series de tiempo a corte transversal. La estimación de la elasticidad implica definir la forma de una función de producción que agrega los distintos tipos de mano de obra en un función oferta de trabajo. La tasa global de desempleo que se desea reducir aparecerá a través de estos cálculos desagregada por grado de calificación. Al forzar la reducción del desempleo, obligamos, un tipo de ajuste entre demanda y oferta de mano de obra en la que la función de producción opera en el sentido de sustituir mano de obra muy calificada (escasa) por otra de menores

23/ S. Bowles, op. cit.

24/ S. Bowles, op. cit. 
niveles de educación (abundante). El efecto neto debería ser una disminución del desequilibrio a nivel global, es decir, una menor tasa de desempleo. $\underline{25}$

\section{ESTIMACION DE LOS RECURSOS DISPONIBLES \\ PARA EL PLAN}

Habiamos dicho en la primera parte de este trabajo que de un estudio de los desequilibrios de financiamiento $\mathrm{y}$ su posible ajuste se podían deducir montos máximos de endeudamiento externo y de ahorro interno disponibles para el plan. La población activa establecía, por otra parte, el límite en la disponibilidad de mano de obra. Estos tres factores son, junto a los recursos naturales, los que determinan el potencial de crecimiento en la economía. Después del análisis global, se hace necesario examinar en más detalle la factibilidad de obtener los recursos de ahorro y divisas y de ocupar adecuadamente a la mano de obra. Lo haremos brevemente en esta sección.

\section{a) Los recursos humanos}

El reverso del problema que discutíamos al tratar el tema del empleo es el que nos interesa ahora. En otras palabras, se trata de detectar a. tiempo qué tipos de mano de obra serán deficitarios con respecto a la . demanda previsible en el plan. El déficit se entiende después de todas. las sustituciones posibles entre distintos tipos de mano de obra. Esto es lo que usualmente se entiende como la planificación de los recursos humanos. 26]

Determinado un cierto déficit para distintos niveles de calificación, hay que examinar detalladamente la oferta de trabajo, incluyendo las. posibles "reservas" de mano de obra existentes y las disminuciones por retiro de la vida activa. A partir de este estudio se pueden especificar el tipo y magnitud de los distintos programas educacionales, tanto en el sistema formal de educación, como en los cursos de capacitación y en el entrenamiento en los lugares de trabajo requeridos por el plan. La, celeridad con que el aparato educacional pueda adaptarse a los requerimientos de mano de obra (que van cambiando) es el que determina el ritmo en que es posible la desaparición de los "cesantes calificados" y de las rentas excesivas en las profesiones en que la oferta es escasa.

25/ Véase P.B. Clark A. Foxley, op. cit.

26/ Un buen artículo que se refiere a estos aspectos es el de Jean Monly "La Integración de la Planificación de los Recursos Humanos en la Planificación del Desarrollo Económico", en Revista Internacional del Trabajo, Vol. $72, \mathrm{~N}^{\circ} 3$, Septiembre 1965. 
Hay un conjunto de medidas que pueden facilitar el ajuste entre oferta y demanda de recursos humanos. En ellas, son importantes las que aseguren una mejor organización del mercado de trabajo, aumentando la movilidad en las ocupaciones; las que ayuden a una mejor organización del trabajo dentro de la empresa, lo que debería resultar en un mejor aprovechamiento de la mano de obra más escasa: las que permitan una aceleración en la formación profesional especializada, y las que impliquen un aumento en la productividad de la educación tradicional, mejorando los métodos de enseñanza. 27/ El equilibrio que se busca entre oferta y demanda de trabajo debe, en todo caso, producirse para cada nivel de calificación no sólo globalmente sino también por regiones y sectores de actividad económica.

b) El ahorro interno

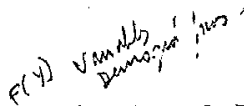

El ahorro intemo puede generarse a nivel de las personas o familias, de las empresas y del gobierno.

El ahorro que se puede generar a través de las personas dependerá, en primer lugar, del ingreso y estará relacionado con variables demográficas entre las cuales una de las más importantes parece ser el tamaño de la familia o el número de hijos, cuya influencia en el ahorro prersonal no está suficientemente clarificada. Depende, entre otras cosas, de cuál es para las personas "el residuo" cuando se toman decisiones que se refieren a cómo disponer del ingreso, si lo es el consumo personal o el ahorro. Esto, a su vez, está relacionado con la forma en que se consideran los hijos en la familia. 28/ En algunas sociedades son vistos como futuros factores de producción para la unidad familiar, ya que asegurarian un mayor ingreso futuro para la familia sin necesidad de ahorrar en el presente. A mayor número de hijos mayor consumo presente, por lo tanto, no sólo porque hay mayores necesidades objetivas de consumo en la familia al aumentar su número, sino también porque a mayor número de hijos, existe mayor seguridad de contar con ingresos más altos en el futuro por el aporte productivo de éstos. A la inversa, si los hijos aparecen como demandantes de consumo creciente a través del tiempo, lo más probable es que el mayor número de hijos

27) Véase J. Monly, op. cit.

28/ Véase H. Leibenstein, Economic Backwardness and Economic Growth, J. Wiley, 1957. El desarrollo de un modelo matemático con hipótesis alternativas sobre la relación entre variables demográficas y ahorro puede encontrarse en W.H. Somermeyer, Efectos Demográficos sobre el Ahorro, Trabajo presentado a la Conferencia Regional Latinoamericana de Población, México, agosto 1970. Para una excelente discusión de tipo más general en torno a la relación entre fecundidad, ahorro e inversión, véase A. Fucaraccio, El Control de la Natalidad y el Argumento del Ahorro y la Inversión, Documento presentado a la misma Conferencia de México. 
incentive un mayor sacrificio presente en términos de ahorro para asegurarles un futuro adecuado. La clasificación adecuada de este tipo de relaciones es indispensable para determinar el potencial de ahorro de la población bajo ciertas previsiones demográficas.

El otro aspecto que debe dilucidarse es la propensión a ahorrar de distintos grupos de la población, sean tramos de ingreso o categorías ocupacionales. Sin esta información es imposible verificar la coherencia entre objetivos como la redistribución de ingresos y la elevación de la tasa de ahorro. Es indispensable, además, para la formulación de las políticas de ahorro. Si los datos indican, por ejemplo, una reducida potencialidad de ahorro en los grupos de bajos ingresos, una alternativa puede ser la de buscar para estos grupos aquéllas formas de ahorro más atractivas desde el punto de vista de sus necesidades inmediatas. Una posibilidad es el ahorro en vivienda.

Finalmente, el ahorro de las personas puede verse afectado en forma? diferente ante estímulos semejantes según el estrato al cual las personas pertenezcan. Pensemos, por ejemplo, en el efecto probable de una baja en la tasa de natalidad. Es posible que ésta no afecte al ahorro en los grupos de más bajos ingresos en la medida en que el menor número de hijos permita elevar el consumo de la familia desde niveles de subsistencia; es posible que afecte positivamente el ahorro de grupos medios; y que no afecte el de los grupos altos, por cuanto en éstos podrían ser otros los factores relevantes en la determinación del ahorro.

El_ahorro de las empresas se ve influido por un gran número de variables. Desde el punto de vista demográfico, probablemente la más influyente es el aumento de población, que afecta positivamente al ahorro por la vía de incremento de utilidades en la medida en que las economias de escala sean importantes para la empresa en cuestión y . negativamente si el aumento demográfico repercute en una presión para la empresa para elevar su contratación de mano de obra a un costo fijo por sobre los niveles óptimos. Los mayores costos implicados en esta política resultarían en menores utilidades, y por lo tanto, menor capacidad de ahorro.

En el sector gobierno, el ahorro depende, obviamente, del nivel de

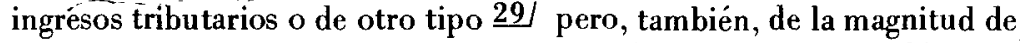
los gastos corrientes que como es bien sabido, son muy poco elásticos.' Influyen en forma determinante los gastos en seguridad social, estrechamente vinculados a variables demográficas como tasas de natalidad, vida activa y otras. Influyen también los gastos en remuneraciones. Como veiamos anteriormente, si hay un crecimiento demográfico rápido y un crecimiento industrial insuficiente, es el sector servicios uno de los que se convierte en absorbedor de mano de obra

29/ Véase J. Arrate y L. Geller "Economic Surplus and the Budget" en K. Griffin, editor Financing Development in Latin America, Mac Millan, 1971. 
desocupada. Dentro de los servicios, es el gobierno el que tenderá a absorber la mayor proporción. De esta forma, los gastos en sueldos y salarios de la burocracia pública aumentan muy rápidamente, a f expensas del potencial de ahorro. Otro aspecto del mismo problema se refiere a la inter-relación entre crecimiento de la población y gastos en servicios que el gobierno debé suministrar_a_ésta,_como salud, educación, etc. A mayor tasa de natalidad, mayor proporción de los gastos totales debe dedicarse a la atención de la población, a expensas , del ahorro para inversión reproductiva.

Estas son, someramente, algunas de las relaciones que es necesario considerar en la determinación del potencial de ahorro interno de la economía en el período del plan. El tema está lejos de ser agotado.

\section{c) Las divisas extranjeras}

La capacidad de generación de divisas está limitada por la dificultad de la mayoría de los países en desarrollo para expandir sus exportaciones 30/ y por el_al to nivel de endeudamiento externo de arrastre, que hace difícil contar con recursos sustanciales del exterior para financiar el plan. Ambos factores deben examinarse cuidadosamente. El primero, a través de un estudio, producto por producto, de las condiciones del mercado externo y la capacidad interna de expandir la exportación. El segundo, contrastando el monto $\left(c^{\prime}\right.$ de la deuda pública acumulada y su tendencia probable a futuro con los objetivos del plan de reducir la dependencia externa. De estos dos tipos: de estudios debería surgir una idea concreta acerca del monto total de divisas con que es posible contar para la aplicación del plan.

\section{RECAPITULACION}

Hemos hecho hasta ahora un recuento detallado de los distintos elementos que intervienen en la elaboración del plan durante la fase de planificación sectorial y de compatibilidad global-sectorial.

Todos los elementos señalados se incorporan en un marco coherente de análisis (o modelo), que puede ser resuelto el número de veces que sea necesario a medida que la información se va enriqueciendo, a través de la discusión con los especialistas sectoriales.

Las otras fases que se distinguen usualmen te en un plan, como son la de los proyectos y la de revisión final de las metas sectoriales, tienden a confundirse con una sola en la medida en que el modelo multisectorial sirva como marco de referencia para flujos iterativos de información que van y vuelven desde el nivel global hasta el de los proyectos.

30/ Véase K. Griffin "The Role of Foreign Capital" en K. Griffin op, cit., y A. Foxley, M. Gómez y R. Infante "Desequilibrios de financiamiento en el proceso de desarrollo", en Cuadernos de Economía, No 19, Santiago, Chile. 


\section{METAS REGIONALES Y COHERENCIA SECTORIAL-REGIONAL}

\section{METAS REGIONALES}

Los objetivos del desarrollo regional ponen especial énfasis en lo que habiamos definido al comienzo de este trabajo como objetivos sociales del plan. 31

En efecto, la planificación regional busca una distribución igualitaria del ingreso per capita y de las oportunidades de empleo entre las diversas regiones que componen el país. A estos objetivos fundamentales se agregan otros como la integración interna del territorio, tanto física como económica y socio-política; la descentralización en los mecanismos de decisiones públicas y privadas (redistribución del poder) y otros.

Usualmente, estas metas de carácter general adquieren una mayor explicitación a través de estrategias de desarrollo para cada región, en las que se incorporan objetivos adicionales que dependen de las caracteristic as de cada una de ellas. $\underline{32 /}$

Asi por ejemplo, en regiones con alta diversificación económica, al to produc to per cápita y alta tasa de crecimiento. la planificación regional tiende a producir un ordenamiento y racionalización en el crecimiento para evitar los problemas asociados a un crecimiento urbano excesivo.

En las regiones con alguna diversificación, producto per cápita promedio y lento crecimiento, se tiende a asociar la economía regional a las actividades más dinámicas, y se busca una integración de éstas en los centros metropolitanos de la región mediante el fortalecimiento de los sistemas urbanos.

En regiones con al to producto per cápita, pero con predominio de un solo sector productivo, se tiende a obtener una diversificación en la estructura productiva con el objeto de lograr su desarrollo más equilibrado y una mayor integración con respecto a las otras regiones.

Por último, en aquellas regiones de menor desarrollo relativo que se caracteriza usualmente por lento crecimiento y poca diversificación en

31/ Agradezco la colaboración de María Luisa Duerr en esta parte del trabajo.

32/ Véase, por ejemplo, Odeplan, El desarrollo económico y social de Chile en la década 1970-1980, Tomo II, Volumen I, Santiago, agosto de 1970. 
la producción, los objetivos son los de dar una mayor sustentación a la economía regional basándose en la explotación integral de sus recursos naturales, abordando la industrilización de éstos en todos los rubros en que sea posible.

El resultado final de la implementación de estas estrategias debería ser el de un desarrollo más equilibrado entre las regiones, el de una distribución más igualitaria del ingreso entre personas que viven en distintas regiones y el de la desaparición de recursos sin utilizar en zonas determinadas (particularmente la mano de obra).

\section{COHERENCIA SECTORIAL-REGIONAL}

Las metas regionales deben, necesariamente, hacerse compatibles con los objetivos globales y sectoriales del plan.

En términos metodológicos se trata de obtener una asignación óptima de los recursos entre regiones y entre los diversos sectores productivos de cada región, teniendo presentes ciertas condicionantes dadas por la planificación global-sectorial, como la tasa global de crecimiento de la economía y los crecimientos sectoriales, además de las condicionantes propias impuestas por los objetivos específicos del desarrollo regional, como son el empleo y la redistribución de ingreso entre regiones.

Las metas regionales deben hacerse compatibles en dos sentidos (véase el cuadro 2):

\& a) La producción, inversión y empleo global y por sectores deben resultar iguales a la suma de las mismas variables entre regiones, globalmente y para cada sector. En este sentido, la planificación regional toma como un dato la producción, inversión y empleo por sectores.

b) La existencia de metas regionales que impliquen redistribución del ingreso per cápita y de oportunidades de empleo entre regiones pueden afectar los resultados del programa global-sectorial. Lo mismo puede ocurrir si otros objetivos se hacen explícitos, tales como la incorporación de territorios no colonizados, la creación de polos de desarrollo, etc. En todos estos casos deben revisarse, a partir de los resultados de la planificación regional, las metas de crecimiento de la producción, inversión y empleo globales y por sectores. 33 /

A Cabe destacar, finalmente, el papel básico que debe jugar la política

33/ Un modelo que enfatiza los aspectos de empleo es el de ILPES Modelo $G P C-2$, Un instrumento de aproximación cuantitativa para la selección de alternativas de estrategia de desarrollo con objetivos de empleo, junio de 1970. 


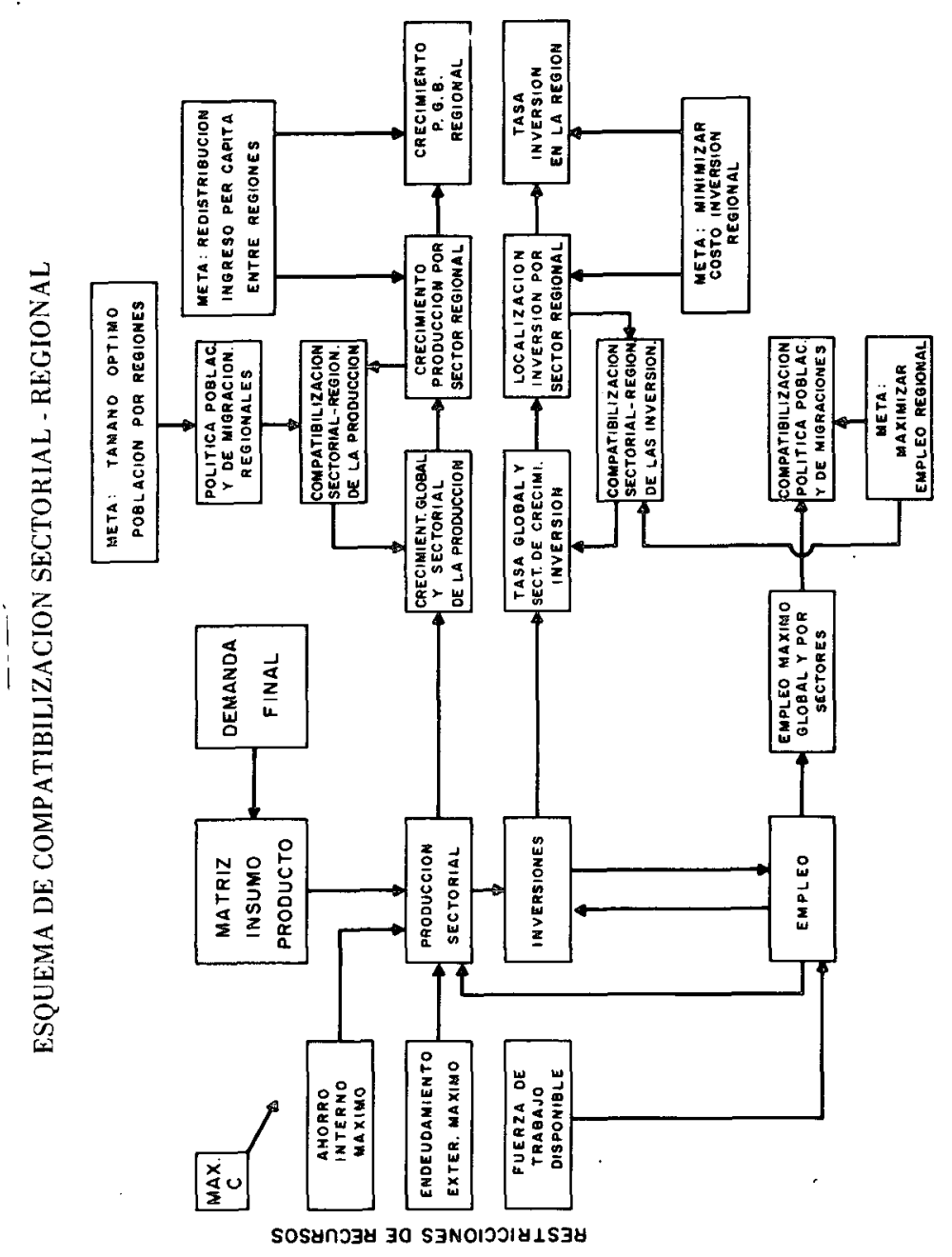


de migración al hacer compatible la planificación regional con las metas globales y sectoriales. 34

En efecto, hechos todos los ajustes en las metas de producción e inversión por sectores y regiones con el objeto de lograr una mejor distribución regional del ingreso per cápita y una mayor ocupación, es posible que los resultados no sean aún satisfactorios de acuerdo con los objetivos deseados en el plan. En este caso, es imprescindible actuar sobre las variables que regulan el crecimiento de la población y los flujos de migración entre regiones, de tal modo de lograr una óptima distribución territorial de la población. Esta distribución óptima debería traducirse en un menor crecimiento de la población en las regiones de lento crecimiento económico de tal modo que facilite en ellas la elevación del ingreso per cápita y la reducción de las tasas de desocupación. Lo inverso debería decirse con respecto al incremento de la población en las regiones más dinámicas.

La política de migración debe tomar en consideración, también, los problemas de distribución de ingresos y empleos entre las zonas urbanas y rurales dentro de una región determinada. Es corriente que en muchas regiones tanto el ingreso como las oportunidades de ocupación tiendan a concentrarse en las áreas urbanas. Una adecuada regulación de los flujos migratorios de las zonas rurales a las urbanas puede tener un efecto beneficioso en el ingreso per cápita y los niveles de desocupación rurales.

34/ Véase ILPES, op. cit., y Naciones Unidas, Estudios sobre Población, No 36, Nueva York, 1964. 


\title{
RELACIONES ENTRE VARIABLES ECONOMICAS Y DEMOGRAFICAS. ENSAYO DE UN MODELO
}

\author{
Angel Fucaraccio \\ Carmen Arretx
}

\begin{abstract}
Este trabajo ha sido preparado en estrecha colaboración con el equipo ILPES/CELADE y como parte del trabajo "Elementos para la elaboración de una política de desarrollo con integración para América Latina".

Los autores forman parte del plantel del CELADE y agradecen los comentarios e ideas del señor Norberto González del ILPES, recogidas en este trabajo. Se agradecen también los comentarios de Juan Carlos Elizaga y Carmen A. Miró, del CELADE. El señor Gérard Fichet del ILPES y Agustín Garcia del $C E L A D E$ han colaborado en este trabajo.
\end{abstract}





\section{INTRODUCCION}

Tal como se ha desarrollado la planificación económica y social -sobre todo cómo se ha ejecutado técnicamente hasta el presente, al menos en muchos de los países latinoamericanos- las variables demográficas han sido tomadas básicamente como datos dados por los demográfos.

Las proyecciones demográficas, a su vez, se apoyan tanto en las tendencias pasadas de la fecundidad, la mortalidad y las migraciones como en la evolución que se pueda esperar de las mismas a la luz de la experiencia de otros países que se encuentran en una etapa más adelantada de evolución demográfica.

En la práctica, corrientemente se adoptan supuestos alternativos sobre los cambios esperados en los niveles de mortalidad y fecundidad, de manera tal que se definen límites máximos y mínimos dentro de los cuales puede evolucionar la población. Dado que el margen de error de cualquier estimación de la fecundidad en el futuro puede ser relativamente grande, cuando ésta es alta, como ocurre en la generalidad de los países latinoamericanos, las proyecciones de población varían unas de otras dependiendo de los supuestos que se hayan adoptado con respecto a su evolución. En otras palabras, se trata de acotar el nivel de la fecundidad entre un máximo (por ejemplo, manteniendo constante el nivel presente durante todo el período de la proyección) y un mínimo (por ejemplo, suponiendo variaciones que involucrarian cambios importantes en el comportamiento reproductivo de la población ya sea en forma espontánea o inducida).

Precisamente, el hecho de que se trate de acotar la evolución de la fecundidad se debe a la circunstancia de que como ésta está determinada por las condiciones económicas, sociales y culturales de la población y como no se conoce con precisión su evolución, se hace necesario considerar diversas alternativas.

Sin embargo, lo que hay que destacar es que queda la incógnita de cuál es la proyección que se debe elegir en la planificación ante una determinada hipótesis de desarrollo; se hace necesario, entonces, vincular más estrechamente las proyecciones demográficas con las proyecciones económicas.

A su vez, los planificadores y los gobiernos han formulado planes que muchas veces no van más allá de un horizonte de cinco o seis años, en el cual existe el consenso de que el comportamiento de las variables demográficas está determinado y es prácticamente inmodificable. Sin 
embargo, es útil efectuar un análisis de más largo plazo en el cual los planes sufrirían modificaciones a causa de cambios en el comportamiento demográfico, consecuencia, a su vez, del proceso de desarrollo económico y social.

Un ejemplo concreto que las relaciones entre los factores demográficos y los factores económicos no son explícitas se refleja en el documento en que se describe el Modelo GPC21/, preparado para el Consejo de Planificación del Estado de Minas Gerais, Brasil. En este modelo se pueden identificar, a nivel muy general, un área de política económica junto con relaciones económicas interdependientes, que en el gráfico l llamamos "modelo económico", y un área de población y disponibilidad de mano de obra, que en este gráfico llamamos "modelo demográfico". La característica más general de este modelo, en términos del asunto que nos ocupa, es la desconexión entre el modelo demográfico y el modelo económico. En otras palabras, a pesar que se trata de evaluar alternativas de estrategia que modificarán sustancialmente el funcionamiento del sistema económico, el modelo no intenta incorporar el comportamiento demográfico. Por ejemplo, el modelo económico, a pesar de determinar el volumen de personas que migran del campo a la ciudad que reconocen niveles de fecundidad diferentes, no modifica los niveles globales de fecundidad y, por lo tanto, no modifica el comportamiento demográfico visto a través de la tasa de crecimiento de la población, que es lo único que el modelo incorpora. La población para este modelo es un parámetro fijado desde afuera.

Gráfico 1.

Modelo GPC 2

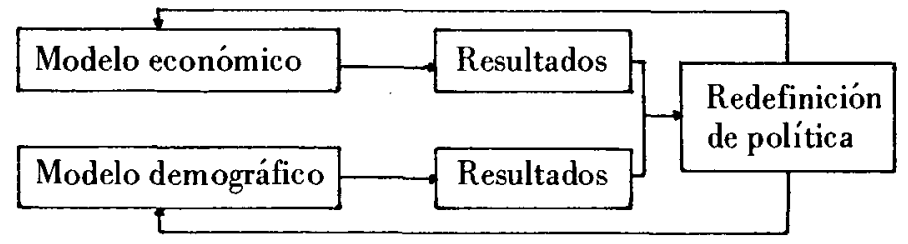

Para este modelo la única manera de influir sobre el movimiento de la población sería a través de medidas directas según se ha formulado el modelo, aunque esta modificación tampoco repercutiría sobre el comportamiento económico.

1/ "Modelo GPC2": Un instrumento de aproximación cuantitativa para la selección de alternativas de estrategia de desarrollo con objetivos de empleo, ILPES-CELADE, ILPES, Santiago, mayo de 1970. 
Sin embargo, en el contexto de la planificación del desarrollo, en la cual se tenga como objetivo acelerar acentuadamente el ritmo de crecimiento económico, producir mejoramientos sustanciales en los niveles materiales de vida de la población, mejorar sus niveles educativos, proveer a la población de mayores servicios médicos y mejores condiciones habitacionales, establecer nuevas industrias en localizaciones específicas y las acciones aplicadas al sector agricola, debe terminar, si es que la política tiene éxito, por cambiar el comportamiento de las personas no sólo en sus funciones como agentes de producción y consumo, sino también en aquella parte que dice relación con su comportamiento reproductivo y en la formación de hogares, en sus niveles de mortalidad y patrones de migración. En otros términos, la política de desarrollo ha de producir cambios en el comportamiento de las variables demográficas. Este cambio, a su vez, puede afectar en aspectos específicos a los planes mismos, lo cual podría conducir a cambios en la política de desarrollo.

Este enfoque de interdependencia ha servido de guía a los trabajos del grupo ILPES-CELADE, que han consistido en vincular tres áreas de problemas y, por lo tanto, de variables: las demográficas, las de ciertas políticas económicas que pueden constituirse en elementos de una política de desarrollo y ciertos problemas básicos del desarrollo latinoamericano como son los de la desocupación (incluida la desocupación estructural) y el estrangulamiento externo. Estos estudios dieron lugar, entre otros documentos, al informe que trata sobre algunos elementos para la elaboración de una política de desarrollo con integración de 1968. 2 J

Sin embargo, los análisis efectuados en ese y en otros trabajos, han consistido preliminarmente en suponer que la evolución demográfica es invariable ante cambios en las condiciones económicas. Este ha sido un primer paso efectuado en términos de etapas de trabajo y ahora se trata de ilustrar acerca de las posibles variaciones en el comportamiento demográfico ante cambios en las condiciones económicas.

El esquema de referencia, que ha servido de guía para esta nueva versión, se puede apreciar en el gráfico 2 . Allí las acciones que se toman en la esfera económica tienen repercusiones en la esfera demográfica y, a su vez, los cambios demográficos repercuten en el área económica. En sintesis, el trabajo ha consistido en un ensayo de ligar variables económicas con variables demográficas.

2/ "Elementos para elaboración de una política de desarrollo con integración para América Latina", ILPES-CELADE, Santiago, 1968. 
Gráfico 2.

Modelo de referencia del ILPES-CELADE

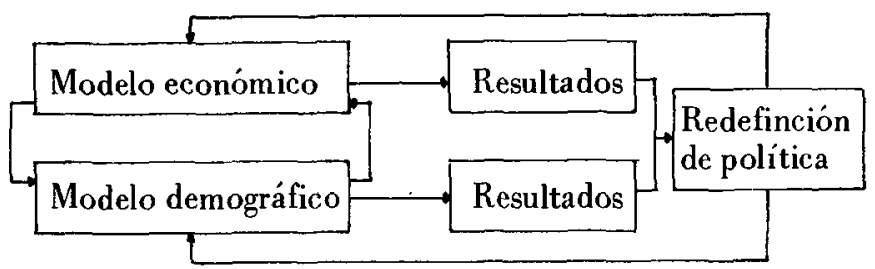

Resulta conveniente presentar algunos ejemplos para ilustrar lo anterior:

a) Los recursos destinados a la salud pública, cuyo objetivo fundamental es mejorar las condiciones de salud de la población, tienen un efecto directo sobre los niveles de mortalidad y sobre la composición en términos de causas por muertes. Sin embargo, cabe pensar que el mismo proceso de desarrollo, en forma independiente de los fondos específicos destinados a la salud, afectará los niveles de mortalidad.

En este sentido, RAO3/ ha efectuado una análisis de correlación de factores sociales, económicos y de salud relacionados con la esperanza de vida para América Latina y ha llegado a la conclusión de que "el alfabetismo parece ser el factor más importante que afecta a la mortalidad, excepto la mortalidad de la vejez", y ha encontrado que la mortalidad está asociada también con los niveles de industrialización, el grado de urbanización, la prestación de servicios médicos, el consumo de calorías, el ingreso per cápita y factores sanitarios. Con las reservas ' con que hay que tomar estos estudios de correlación, debido al hecho de que algunas de las variables explicativas pueden estar correlacionadas entre si $y$ porque se trata de indicadores muy agregados, parece razonable pensar que en América Latina han de existir diferenciales de mortalidad según el status socioeconómico y según las áreas de residencia de la población. Es probable que lòs patrones de mortalidad de los sectores de más altos ingresos de América Latina no difieran del que prevalece en los países económicamente más desarrollados, no sólo desde el punto de vista de los niveles de mortalidad, sino también con respecto a las causas de muerte.

Si se tiene en cuenta que en América Latina el 44 por ciento de las muertes ocurren en los menores de 5 años de edad, cabe pensar que el proceso de desarrollo contribuirá por si mismo a disminuir la mortalidad en forma adicional al esfuerzo médico que se adopte en el plan de desarrollo.

3/ S.L.N. RAO, Factores socioeconómicos y de salud públicá que afectan a la mortalidad por edades en A mérica Latina, Conferencia Regional Latinoamericana de Población, México, agosto de 1970, Sesión 1: Mortalidad. 
Consideraciones análogas se pueden hacer con respecto al esfuerzo educativo dado que en los mayores niveles de instrucción del conjunto de la población pueden contribuir a disminuir la mortalidad por ciertas causas de muerte en la medida en que la población cambie sus pautas de conducta por otras de mayor higiene, mejor calidad de alimentación y mejores cuidados en los primeros tiempos de vida del niño.

El planificador y el demógrafo tendrán que tener en cuenta y evaluar el efecto del proceso de desarrollo sobre la mortalidad y de este modo el efecto sobre el volumen, tasa de crecimiento y estructura por edad de la población. Estas modificaciones, a su vez, pueden conducir a una reducción o reorientación de los fondos destinados a la salud pública, aceptando que la mortalidad en América Latina se debe a los problemas derivados de la pobreza.

El mejoramiento en las condiciones de salud puede afectar también a los niveles de productividad cuando ésta es baja, a causa de la reducción del ausentismo por enfermedad. Un ejemplo que ya ha pasado a ser clásico es el del control de la malaria, aplicado en un distrito de Pakistán, que no sólo disminuyó la mortalidad infantil, sino que permitio aumentar la producción de arroz en un 15 por ciento, sin mejorar los métodos de cultivo ni la variedad del arroz, debido a que disminuyó el ausentismo de la mano de obra en las épocas críticas de siembra y cosecha. 4 .

b) Los fondos destinados a la salud pública pueden influir también sobre los niveles de fecundidad en la medida en que en el plan de salud estén incluidos programas que, atendiendo al problema de salud materno-infantil, contemplen la difusión de métodos anticonceptivos como medio para reducir el aborto inducido.

A su vez, el éxito en la reducción de la mortalidad infantil también puede alterar los niveles de fecundidad si es que altera la actitud de las familias. Así, una comunidad cuyo consenso fija en cuatro, por ejemplo, el número de niños, requerirá, digamos, siete u ocho niños para alcanzar efectivamente el número de cuatro niños sobrevivientes a la edad adulta. De esta manera, la reducción de la mortalidad infantil puede provocar una disminución de la fecundidad.

Del mismo modo, los gastos públicos destinados a la educación pueden tener influencia en los niveles de fecundidad. Tanto la enseñanza formal como la informal constituyen el vehículo de transmisión de los valores generados por la organización social y en la medida en que ésta genera ideas con respec to al tamaño de la familia, el planificador y el demógrafo han de tener en cuenta, al formular el plan, la repercusión que estos elementos tendrán sobre la fecundidad a través del sistema educativo.

4) Preliminary Report on the World Social Situation, Naciones Unidas, Nueva York, 1952, pág. 36. 
Si las condiciones de vida en la ciudad, por ejemplo, son tales que han generado valores por los cuales la población tiende a reducir el tamaño de la familia, ya sea porque la vida en la ciudad impone una reducción del tamaño de la vivienda que no permite tener muchos niños, porque se abren oportunidades de trabajo para la mujer que reducen el tiempo que puede dedicar al cuidado de los hijos, o porque los medios de comunicación de masas introducen aspiraciones de consumo que hacen competitivo tal consumo con el hecho de tener niños y pasan a ser elementos que pueden conducir a la gente a desear una familia más reducida. Y si al mismo tiempo la enseñanza contiene elementos informativos de cómo controlar la concepción, este hecho tenderá a reforzar los elementos valorativos generados por el sistema.

c) Las acciones de política previstas en el plan pueden significar cambios en los patrones migratorios y en sus características socio-económicas. Si el plan conlleva mayores grados de urbanización, la fecundidad de todo el país tenderá a disminuir con mayor rapidez que en el pasado, siempre que las personas que migren de las áreas rurales, con niveles más altos de fecundidad, asimilen las pautas reproductivas de la ciudad que reconocen niveles más bajos.

d) Cambios en los niveles de vida, vistos a través de mayores niveles educativos, mejores condiciones habitacionales, elevación de los niveles de ingreso per cápita, mejoras en las condiciones de salud y reducciones de la mortalidad, pueden significar disminuciones de fecundidad, sobre todo cuando aquellas mejoras se registran en los grupos sociales de fecundidad más elevada. Si, al mismo tiempo, el proceso de desarrollo abre posibilidades de trabajo para la mujer, ello puede reforzar el efecto antes mencionado de disminución de la fecundidad. A su vez, esta disminución, que dejará tiempo libre a la mujer en las tareas del cuidado de los niños, puede aumentar el deseo de las mujeres de participar en actividades fuera del hogar y aumentar así la oferta de mano de obra femenina en el mercado de trabajo.

Al planificar los puestos de trabajo que se crearán a raíz del proceso de desarrollo se tienen que tomar en cuenta estos hechos, no sólo por el cambio de volumen de oferta de mano de obra, sino porque las actividades económicas en que participan las mujeres son cualitativamente distintas de aquéllas en las que participan los hombres.

Cambios en la fecundidad y en la mortalidad, asociados a las acciones implícitas y explícitas del plan, producirán cambios en el crecimiento de la población y en su composición por edad en comparación con una proyección en la que sólo se tuviera en cuenta la extrapolación de la tendencia del pasado.

$\mathrm{Si}$ el proceso de desarrollo cambia los niveles de fecundidad, repercutirá cambiando la cantidad de niños que son los que demandan servicios educativos. El plan educativo debe tener en cuenta este hecho pues de otro modo se produciría una sobre dimensión en términos de 
los requerimientos futuros de aulas y maestros. Del mismo modo, el plan de salud debe considerar explícitamente el cambio cuantitativo de los niños al formular las asignaciones específicas en los distintos tipos de atenciones que el servicio debe prestar.

Al formularse el plan de vivienda y servicios urbanos, a más largo plazo, debe considerarse también el cambio en el tamaño de la población que al afectar el número de nuevos hogares conducirá a una estimación distinta del número de viviendas requeridas por la población.

A largo plazo, la disminución de la fecundidad produce un cambio en la estructura por edad con un envejecimiento de la población que puede tener influencia sobre el sistema productivo en el sentido de que una población relativamente envejecida puede dificultar la introducción de las nuevas técnicas a causa de la obsolescencia de la educación de la población activa y su menor movilidad comparada con una población más joven.

Muchos autores mencionan con frecuencia el conjunto de relaciones enunciadas anteriormente a título de ejemplo, pero no ha sido medido con suficiente rigurosidad hasta el presente, ni tampoco han sido discutidos los diversos contextos socio-económicos en los cuales tienen vigencia. Es ésta una tarea que se encuentra pendiente de realización, no tanto por la falta de datos, como por deficiencias en las técnicas de evaluación del impacto de una determinada medida sobre la variable específica, cuando en la determinación de ésta están obrando diversos factores.

En este trabajo, como se dijo anteriormente, se ha efectuado un primer ensayo de ligar algunas variables económicas con otras demográficas. En la parte II se intenta ligar el status socio-económico con los niveles de fecundidad y la participación femenina en las actividades económicas.

Se ha centrado la atención en la fecundidad porque hacia el futuro el comportamiento de la tasa de crecimjento de la población dependerá fundamentalmente de la evolución que registre esta variable en comparación con la que podría registrar la mortalidad, la que se considera que ha llegado, para amplios sectores de la población, a niveles cuya disminución implicaría superar los problemas derivados de la pobreza. Y se ha centrado la atención en la participación femenina porque la que se registra en América Latina es baja en comparación con la de los países más desarrollados y porque cabe pensar que si se encara un proceso de desarrollo que brinde oportunidades de trabajo para la mujer, ésta tenderá a participar en mayor medida que en la actualidad.

Las relaciones encontradas en la parte II se incorporan al modelo demográfico que se presenta en la parte III y se elaboran hipótesis de fecundidad ligadas a hipótesis de nivel de vida las cuales se relacionan también con hipótesis de participación femenina. 
En la parte IV se presentan resultados que muestran la necesidad de que los planificadores y los demógrafos, en una visión de más largo alcance, incorporen las mutuas relaciones entre los aspectos demográficos y los económicos. 


\section{ALGUNAS ASOCIACIONES ENTRE STATUS \\ SOCIO-ECONOMICO DE LA POBLACION, FECUNDIDAD Y PARTICIPACION FEMENINA EN AMERICA LATINA}

\section{STATUS SOCIO-ECONOMICO Y LA FECUNDIDAD}

Muchos han sido los trabajos en los cuales se ha llamado la atención acerca de los diferenciales de fecundidad entre diversos grupos de la población de un país, aunque generalmente estos estudios han estado referidos a los países más desarrollados.

En América Latina existen algunos estudios que asocian, mediante comparación internacional, niveles de ingreso y de educación y grado de industrialización con los niveles de fecundidad. Pocos son los datos y los estudios que se vinculan al status socio-económico, dentro de cada país con los niveles de fecundidad. El Programa de Encuestas Comparativas de Fecundidad en América Latina (PECFAL urbano), efectuadas en siete ciudades capitales en 1963/1964, brinda algunos datos estadísticos que permiten relacionar el status socio-económico de la población y la fecundidad. No es que no se tuviera conocimiento de que niveles más altos de fecundidad se registran en aquellos sectores de la población de más bajo nivel de vida porque esto se puede visualizar con sólo observar nuestra realidad circundante.

Las encuestas antedichas permiten ahora hacer alguna cuantificación al respecto, aunque, sin embargo, es necesario destacar que no se intenta aquí describir relaciones causales sino más bien indagar acerca de asociaciones estadísticamente significativas.

En primer lugar, aquellas asociaciones indicadas desde hace algún tiempo acerca de que mayores niveles de analfabetismo se encuentran asociados con mayores niveles de fecundidad, a través del estudio de un corte trasversal en un punto del tiempo mediante comparación internacional, también se verifican cuando nos introducimos al interior de un país. Los mayores niveles de fecundidad, según se puede apreciar en el cuadro 1, corresponden, para las ciudades capitales investigadas, a las mujeres que tienen menor nivel educativo. Si se piensa que los matrimonios tienden a producirse, en la generalidad de los casos, entre personas de una misma clase social, cabría esperar también una asociación entre la educación del marido y la fecundidad de las mujeres. En el cuadro 2 se puede observar que esta asociación existe en algunas de las capitales latinoamericanas investigadas. En otras palabras, a menor nivel educativo del marido mayor es la fecundidad de las mujeres. 
Cuadro 1

PROMEDIO DE HIJOS POR MUJER ACTUALMENTE CASADA AL

TERMINO DE SU EDAD FERTIL a/ Y SEGUN SU

NIVEL DE EDUCACION, AÑO 1963-1964.

\begin{tabular}{|c|c|c|c|c|c|c|}
\hline $\begin{array}{c}\text { Educación } \\
\text { de la } \\
\text { mujer }\end{array}$ & $\begin{array}{l}\text { Argentina } \\
\text { (Bs. Aires) }\end{array}$ & $\begin{array}{l}\text { Brasil } \\
\text { (Rio) }\end{array}$ & $\begin{array}{l}\text { Colombia } \\
\text { (Bogotá) }\end{array}$ & $\begin{array}{l}\text { Costa Rica } \\
\text { (San José) }\end{array}$ & $\begin{array}{c}\text { México } \\
\text { (Capital) }\end{array}$ & $\begin{array}{c}\text { Venezuela } \\
\text { (Caracas) }\end{array}$ \\
\hline $\begin{array}{l}\text { Sin } \\
\text { educación } \\
\text { Primaria } \\
\text { Secundaria } \\
\text { Universitaria }\end{array}$ & $\begin{array}{l} \\
3,3 \\
2,3 \\
1,9 \\
\text { ria } \\
\ldots\end{array}$ & $\begin{array}{l}5,4 \\
3,8 \\
2,4 \\
2,0\end{array}$ & $\begin{array}{l}7,9 \\
5,1 \\
4,2 \\
3,8 b\end{array}$ & $\begin{array}{l}6,0 \underline{b} / \\
6,3 \\
3,9 \\
3,7\end{array}$ & $\begin{array}{l}6,3 \\
5,4 \\
3,3 \\
3,9\end{array}$ & $\begin{array}{l}5,6 \\
5,0 \\
3,2 \\
1,0\end{array}$ \\
\hline Total & 2,1 & 3,2 & 4,9 & 5,2 & 5,0 & 4,4 \\
\hline $\begin{array}{ll}\text { a/ } & D \\
\text { b/ } / & D\end{array}$ & $\begin{array}{l}\text { CELADE, } \\
\text { América La } \\
135 \text { x } 14 \text { x } \\
\text { De } 45 \text { a } 49 \\
\text { De } 35 \text { a } 39\end{array}$ & $\begin{array}{l}\text { grama d } \\
\text { a, zona } \\
\text { Inédito } \\
\text { s. } \\
\text { s. }\end{array}$ & $\begin{array}{l}\text { Encuest } \\
\text { urbana. }\end{array}$ & $\begin{array}{l}\text { omparat } \\
\text { po de }\end{array}$ & $\begin{array}{l}\text { de F } \\
\text { oulacio }\end{array}$ & $\begin{array}{l}\text { nndidad en } \\
4 \text { (cruce }\end{array}$ \\
\hline
\end{tabular}

Cuadro 2

PROMEDIO DE HIJOS POR MUJER ACTUALMENTE CASADA

AL CABO DE SU EDAD FERTIL SEGUN NIVEL

DE EDUCACION DEL MARIDO, AÑO 1963-1964

\begin{tabular}{lccccc}
\hline $\begin{array}{c}\text { Educación } \\
\text { del } \\
\text { marido }\end{array}$ & $\begin{array}{c}\text { Argentina } \\
\text { (Bs. Aires) }\end{array}$ & $\begin{array}{c}\text { Brasil } \\
\text { (Río) }\end{array}$ & $\begin{array}{c}\text { Colombia } \\
\text { (Bogotá) }\end{array}$ & $\begin{array}{c}\text { México } \\
\text { (Capital) }\end{array}$ & $\begin{array}{c}\text { Venezuela } \\
\text { (Caracas) }\end{array}$ \\
\hline $\begin{array}{l}\text { Sin } \\
\text { educación }\end{array}$ & 3,7 & 5,6 & $8,7 \underline{a} /$ & 6,2 a/ & 6,7 \\
$\begin{array}{l}\text { Primaria } \\
\text { completa }\end{array}$ & 1,7 & 3,3 & 5,0 & 4,9 & 3,4 \\
$\begin{array}{l}\text { Secundaria } \\
\text { completa }\end{array}$ & 1,3 & 2,3 & 4,4 & 4,4 & 3,5 \\
\hline
\end{tabular}

Fuente: CELADE, PECFAL urbano, Programa de Encuestas Comparativas de Fecundidad en América Latina, Zona urbana (cruce 135 x 22 × 14) a) 40-44 años.

Otro indicador que con frecuencia se utiliza para mostrar el status socio-económico de la población se refiere a la ocupación. Se puede observar, en el cuadro 3 , que a medida que se asciende en la escala 
social, medida en términos ocupacionales, el nivel de fecundidad disminuye. En el cuadro se muestra el número de hijos por mujer casada al cabo de su vida fecunda (45-49 años) según la ocupación de su marido. Las ocupaciones se han clasificado en cuatro categorías: la primera se refiere a ocupaciones de "manuales no especializados", que puede considerarse como una de las categorías de más bajos niveles de ingresos. La segunda corresponde a la de "manuales especializados"; la tercera, a una categoría intermedia de "no manuales" y la cuarta a un estrato que normalmente en América Latina tiene altos niveles de ingresos como los profesionales, directores y gerentes. A través de las cifras del cuadro se puede observar que el comportamiento reproductivo de las mujeres cuyos maridos trabajan en actividades "manuales no especializadas" varía entre los distintos países. Así se puede observar que la fecundidad en Buenos Aires, para esta categoría ocupacional, es decididamente menor que en la de las otras ciudades capitales. Estas diferencias se explican por el diferente contexto económico, social y cultural propio de cada uno de los países.

Cuadro 3

PROMEDIO DE HIJOS POR MUJER ACTUALMENTE CASADA AL CABO DE SU VIDA FERTIL SEGUN OCUPACION DEL MARIDO, AÑO 1963-1964,

\begin{tabular}{|c|c|c|c|c|c|c|}
\hline $\begin{array}{c}\text { Ocupación } \\
\text { del } \\
\text { marido }\end{array}$ & $\begin{array}{c}\text { Argentina } \\
\text { (Bs. Aires) }\end{array}$ & $\begin{array}{l}\text { Brasil } \\
\text { (Río) }\end{array}$ & $\begin{array}{c}\text { Colombia } \\
\text { (Bogotá) }\end{array}$ & $\begin{array}{l}\text { Costa Rica } \\
\text { (San José) }\end{array}$ & $\begin{array}{l}\text { México } \\
\text { (Capital) }\end{array}$ & $\begin{array}{l}\text { Venezuela } \\
\text { (Caracas) }\end{array}$ \\
\hline $\begin{array}{l}\text { Manuales no } \\
\text { especializados }\end{array}$ & 3,2 & 4,5 & 5,8 & 6,5 & 6,3 & 5,4 \\
\hline $\begin{array}{l}\text { Manuales espe- } \\
\text { cializados }\end{array}$ & 2,0 & 3,3 & 5,3 & 6,0 & 5,1 & 5,0 \\
\hline $\begin{array}{l}\text { No manuales } \\
\text { de categoría } \\
\text { intermedia }\end{array}$ & 1,9 & 3,3 & 5,4 & 4,6 & 5,5 & 3,3 \\
\hline $\begin{array}{l}\text { Profesionales, } \\
\text { directores, } \\
\text { gerentes y } \\
\text { supervisión } \\
\text { elevada }\end{array}$ & 1,8 & 2,3 & 3,5 & 3,2 & 4,0 & 3,2 \\
\hline Promedio & 2,1 & 3,2 & 4,9 & 5,2 & 5,0 & 4,4 \\
\hline
\end{tabular}


Un indicador más sintético que dice relación con el status socio-económico de la población son sus niveles de consumo per cápita. Sobre la base de las encuestas PECFAL urbano se ha efectuado un análisis de regresión y correlación $\mathbf{5}$ entre los niveles de consumo per cápita y el número de hijos en cada edad específica de la mujer. A continuación se presentan los ajustes lineales en los valores absolutos, efectuados entre la fecundidad, los niveles de consumo per cápita y la edad de la mujer.

Cuadro 4

REGRESIONES LINEALES ENTRE FECUNDIDAD, CONSUMO PER CAPITA Y EDAD DE LA MUJER

\begin{tabular}{|c|c|c|c|c|c|}
\hline \multirow[b]{2}{*}{ País } & \multirow[b]{2}{*}{ Constante } & \multicolumn{2}{|c|}{$\begin{array}{c}\text { Cocficientes de las } \\
\text { variables } \\
\text { independientes }\end{array}$} & \multirow[b]{2}{*}{$\mathrm{R}^{2}$} & \multirow{2}{*}{$\begin{array}{l}N^{\circ} \text { de } \\
\text { obser- } \\
\text { vacio- } \\
\text { nes b/ }\end{array}$} \\
\hline & & Consumo & Edad & & \\
\hline $\begin{array}{l}\text { Argentina } \\
\text { Error estándar }\end{array}$ & 0,4873 & $\begin{array}{c}0,00008 \mathrm{a} / \\
(0,00014)\end{array}$ & $\begin{array}{l}(0,3230 \\
(0,0366)\end{array}$ & 0,7010 & 35 \\
\hline $\begin{array}{l}\text { Brasil } \\
\text { Error estándar }\end{array}$ & 1,778 & $\begin{array}{l}-0,0019 \\
(0,0005)\end{array}$ & $\begin{array}{c}0,3987 \\
(0,0422)\end{array}$ & 0,6662 & 54 \\
\hline $\begin{array}{l}\text { Colombia } \\
\text { Error estándar }\end{array}$ & 1,2028 & $\begin{array}{l}-0,0004 \mathrm{a} / \\
(0,0004)\end{array}$ & $\begin{array}{c}1,0061 \\
(0,0692)\end{array}$ & 0,8501 & 40 \\
\hline $\begin{array}{l}\text { Costa Rica } \\
\text { Error estándar }\end{array}$ & 2,0532 & $\begin{array}{l}-0,00067 \\
(0,00033)\end{array}$ & $\begin{array}{c}0,6460 \\
(0,0733)\end{array}$ & 0,6756 & 42 \\
\hline $\begin{array}{l}\text { México } \\
\text { Error estándar }\end{array}$ & 1,646 & $\begin{array}{l}-0,0010 \\
(0,0004)\end{array}$ & $\begin{array}{c}0,9456 \\
(0,0612)\end{array}$ & 0,8675 & 40 \\
\hline $\begin{array}{l}\text { Panamá } \\
\text { Error estándar }\end{array}$ & 2,2039 & $\begin{array}{l}-0,0013 \\
(0,0004)\end{array}$ & $\begin{array}{c}0,5415 \\
(0,0727)\end{array}$ & 0,6349 & 40 \\
\hline $\begin{array}{l}\text { Venezuela } \\
\text { Error estándar }\end{array}$ & 1,8113 & $\begin{array}{l}-0,00156 \\
(0,00056)\end{array}$ & $\begin{array}{c}0,7437 \\
(0,0790)\end{array}$ & 0,7777 & 30 \\
\hline
\end{tabular}

Fuente: Anexo 1.

a/ No significativamente distinto de cero a nivel del 95 por ciento de confiabilidad.

b/ Indica el número de puntos utilizados en el ajuste lineal. Los valores de recundidad son promedios extraidos a partir de la muestra completa.

En primer lugar, cabe mencionar que los signos de los coeficientes que se aplican al consumo son, con la excepción del de la Argentina, negativos; es decir, tienen el signo que cabia esperar a priori, en el sentido de que la fecundidad es más alta en los sectores de más bajo nivel de vida y disminuye en aquellas familias de más alto nivel de

5/ Una discusión más amplia sobre cuestiones metodológicas se puede ver en el Anexo 1. 
consumo. El signo de los coeficientes que se refieren a la edad son todos positivos, que también es un resultado que cabía esperar anticipadamente.

Los números que se encuentran entre paréntesis abajo de la ecuación son los errores estándares del coeficiente respectivo. Como se puede observar, tanto el coeficiente que se aplica al consumo como aquéllos que se refieren a la edad, son estadísticamente significativos a nivel del 95 por ciento de significación, con la excepción de la Argentina y Colombia.

En otras palabras, con un 95 por ciento de probabilidad, los coeficientes de regresión son significativamente distintos de cero. En los gráficos 1 a 5 se ha dibujado la fecundidad según los niveles de consumo para cada una de las edades de la mujer, para los distintos países, y se ha superpuesto la ecuación ajustada.

Fn definitiva, los datos sugieren que la fecundidad disminuye a medida que aumentan los niveles de vida de la población. Utilizando los datos de la Argentina, la conclusión aparente es que el consumo no tiene influencia sobre los niveles de fecundidad; aunque, sin embargo, hay que destacar el hecho de que los niveles de consumo per cápita relevados en la encuesta de la Argentina son notablemente superiores a los del resto de los países. Esto podría significar que, alcanzado un cierto nivel de vida, relativamente al to, el comportamiento reproductivo de las mujeres se rige por otros hechos que no tienen relación con el nivel de vida mismo. $6 /$ Estos resultados contradicen aparentemente a aquéllos que ligan la posición ocupacional con la fecundidad.

Para finalizar, caben algunas observaciones en relación con los niveles educativos, las posiciones ocupacionales y los niveles de vida. En primer lugar, aunque los niveles de vida permanezcan constantes, la fecundidad puede cambiar según cambien los niveles educativos. Así por ejemplo, una política educativa pública gratuita que abarque una gran proporción de la población que en la actualidad permanece al margen del sistema educativo puede provocar una disminución en la fecundidad latinoamericana; aunque, no cabe desconocer que tal política educativa debe ser consideada como un mejoramiento en el nivel de vida, aunque no tenga una traducción monetaria en el sentido de elevar los niveles de consumo per cápita.

Téngase en cuenta, además, que el análisis de regresión y correlación se ha hecho para distintos grupos de población en un mismo punto del tiempo.

Si estas conclusion es se quisieran extender como para que abarquen una pauta temporal habría que hacer la hipótesis de que a medida que aumenta el nivel de vida, las clases más pobres, tienden a adquirir las

6' Una discusión sobre este asunto se puede ver en Judith Blake, "Income and Reproductive Motivations", Population Studies, noviembre de 1967. 


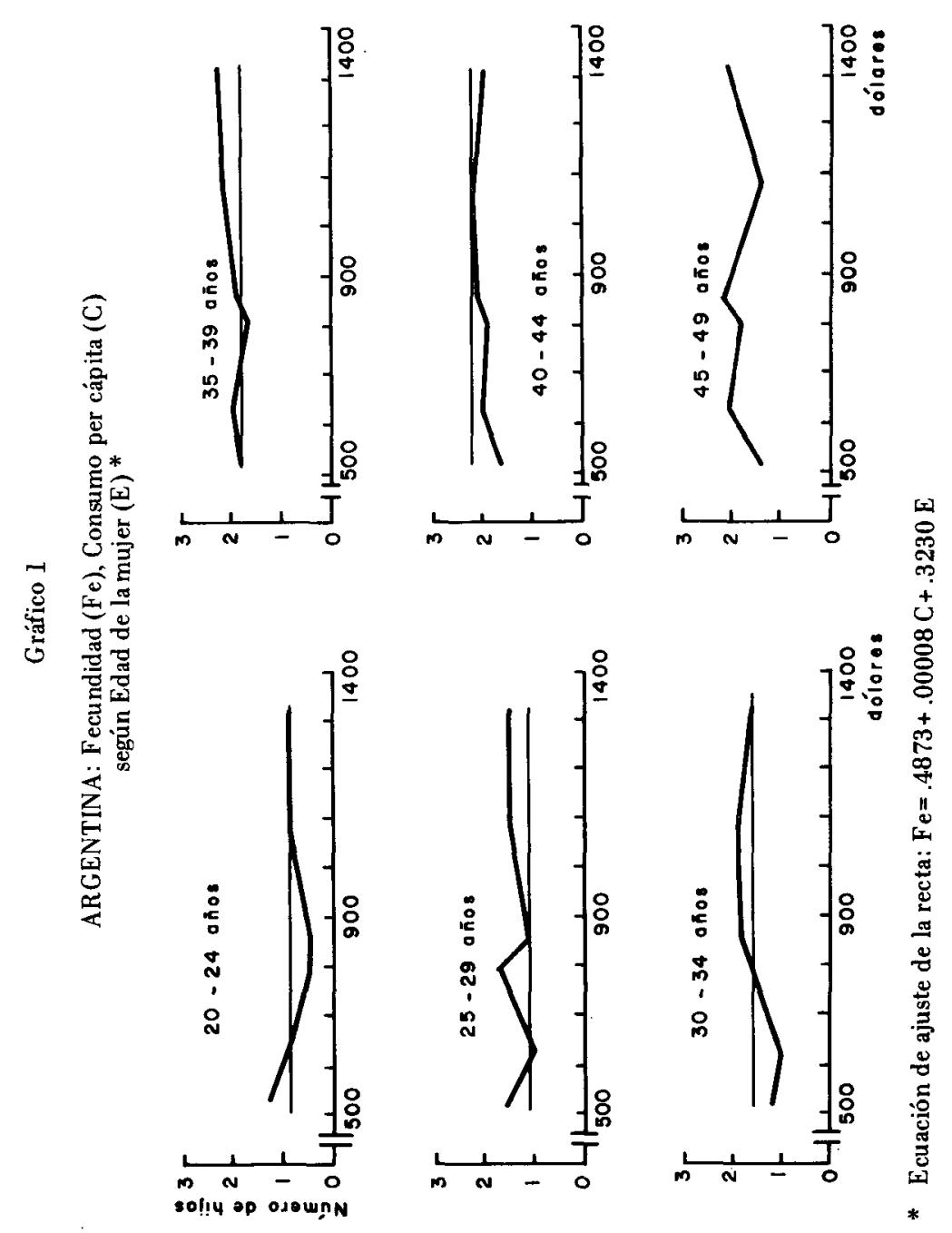




\section{Gráfico 2}

BRASIL: Fecundidad (Fe), Consumo per cápita (C) según Edad de la mujer (E)
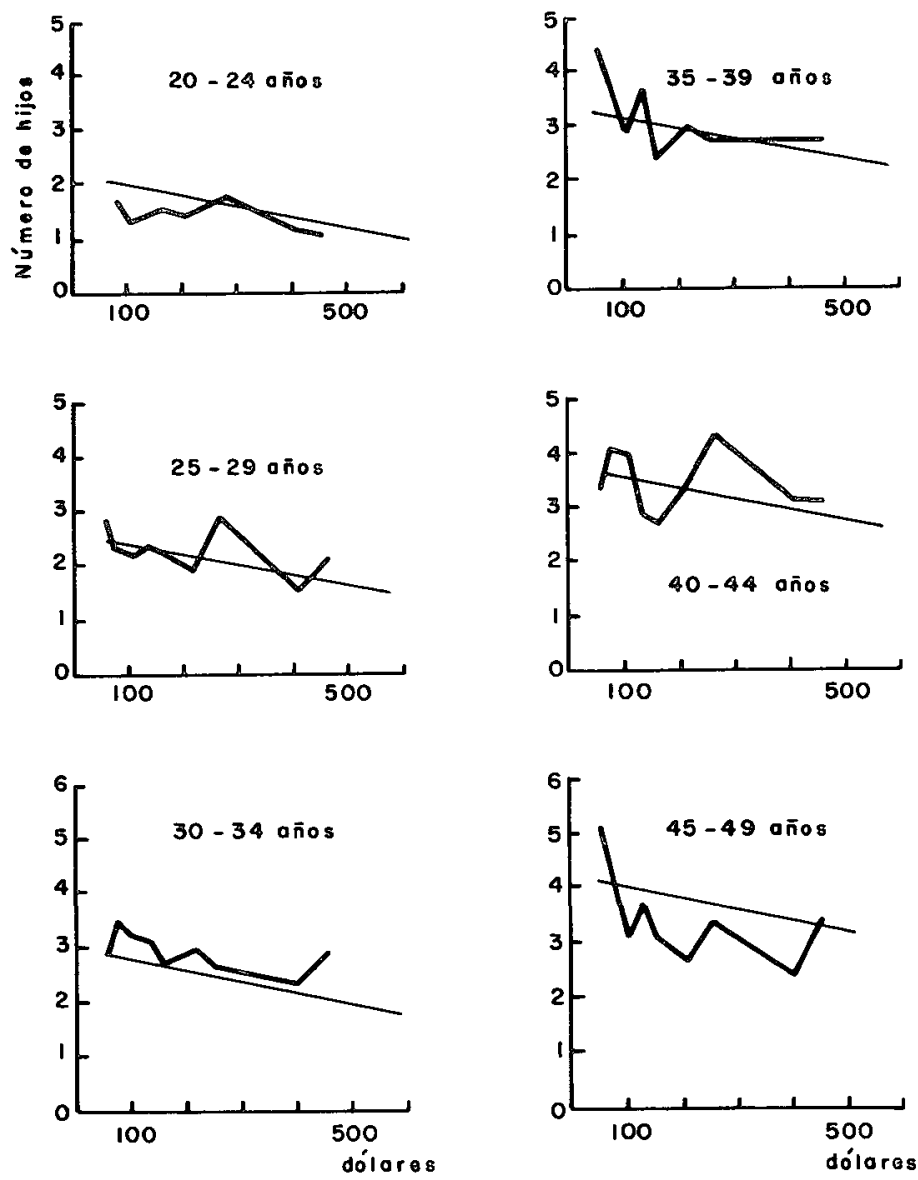

\footnotetext{
* Ecuación de la recta de ajuste: $\mathrm{Fe}=1.778 \cdot .0019 \mathrm{C}+.3987 \mathrm{E}$
} Fuente: Encuesta PECFAL-u (cruce 135 x 40 x 14) 
Gráfico 2 (continuación)

Fecundidad ( $\mathrm{Fe}$ ), Consumo per cápita (C) según Edad de la mujer $(E)$ *
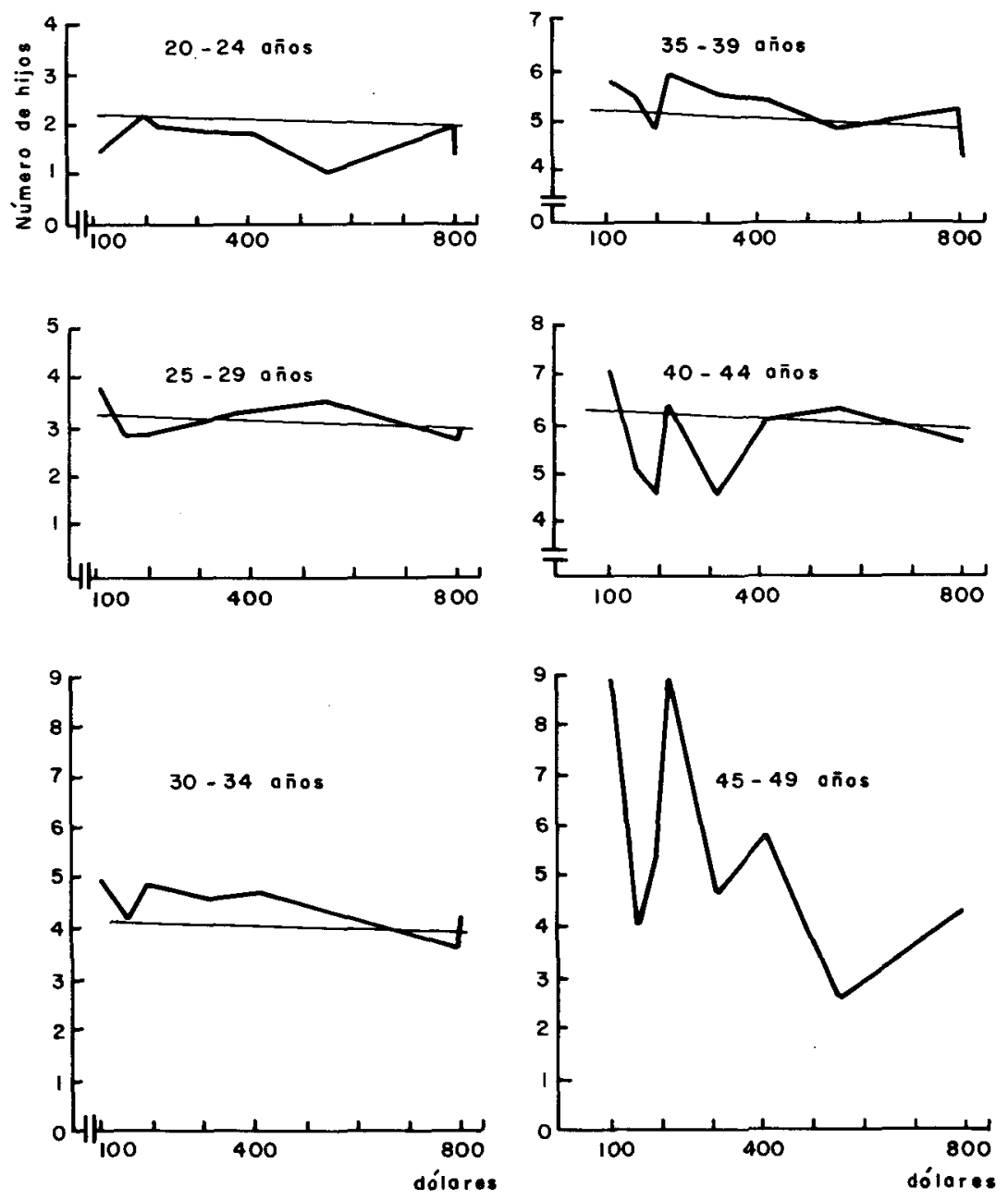

* Ecuación de la recta de ajuste: $\mathrm{Fe}=1.2028-.0004 \mathrm{C}+1.0061 \mathrm{C}$ 


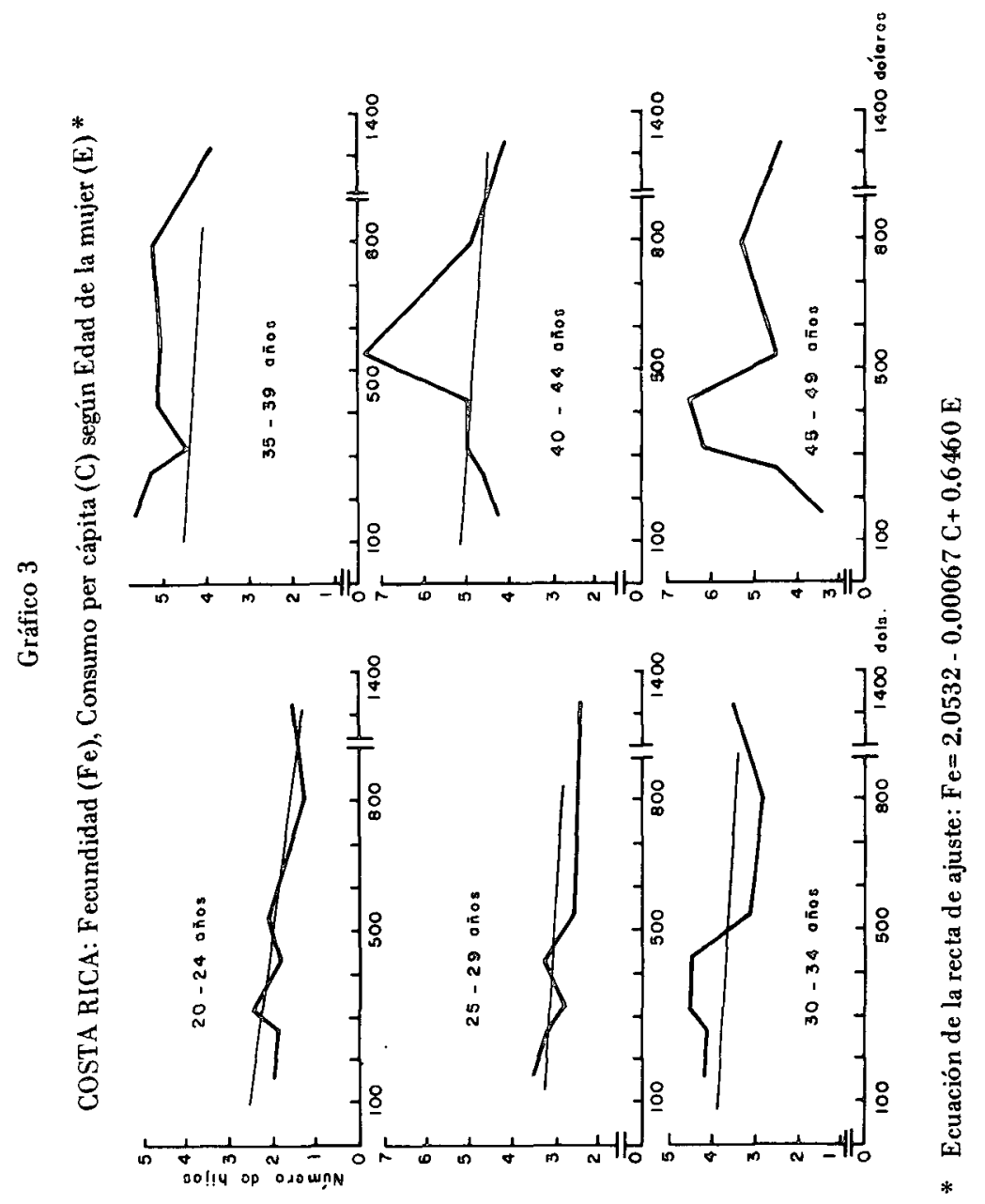




\section{Gráfico 3 (Continuación)}

Fecundidad ( $\mathrm{Fe}$ ), Consumo per cápita $(\mathrm{C})$ según Edad de la mujer (E) *
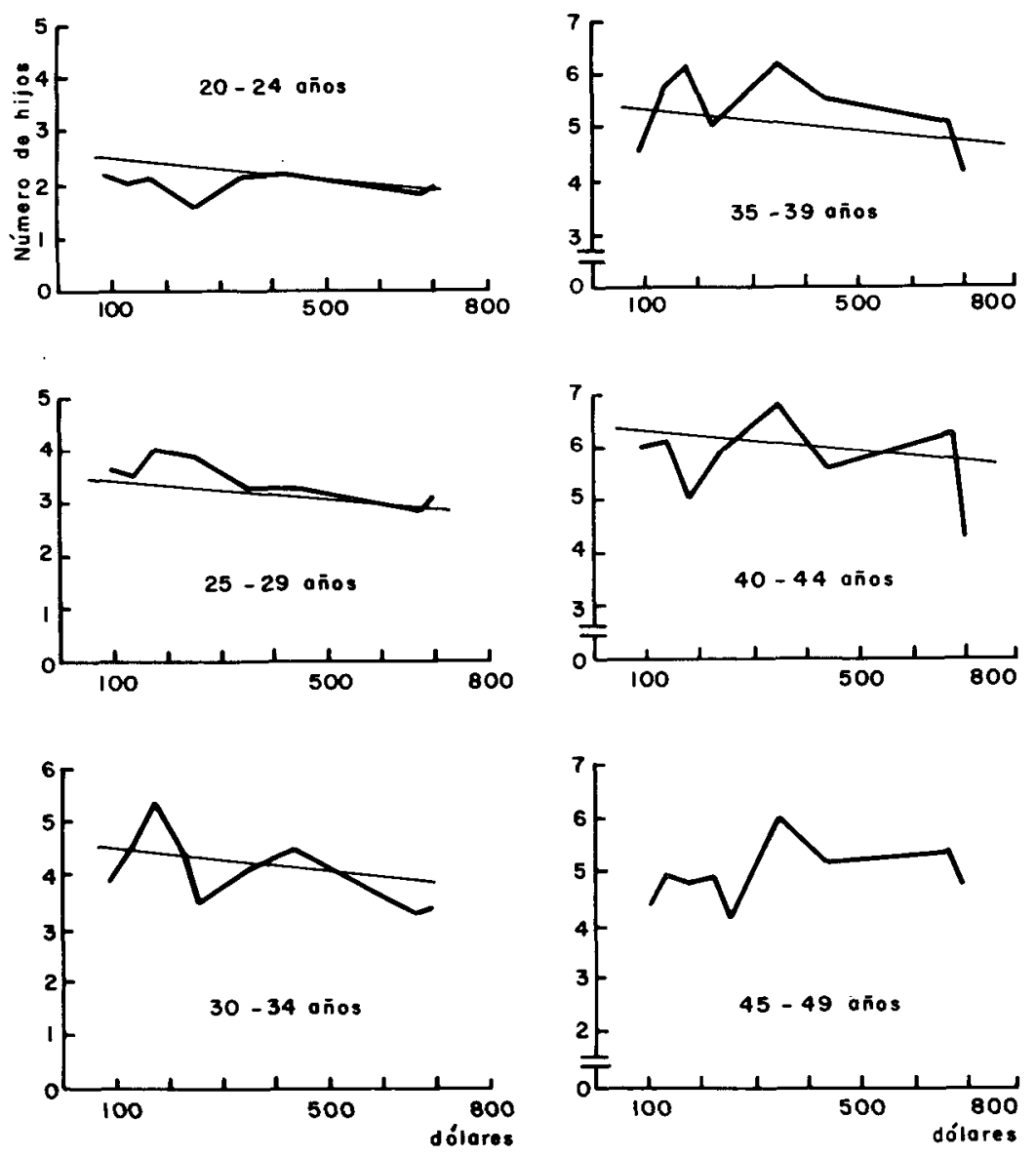

* Ecuación de ajuste de la recta: $\mathrm{Fe}=1.646 \cdot .0010 \mathrm{C}+.9456 \mathrm{E}$ 


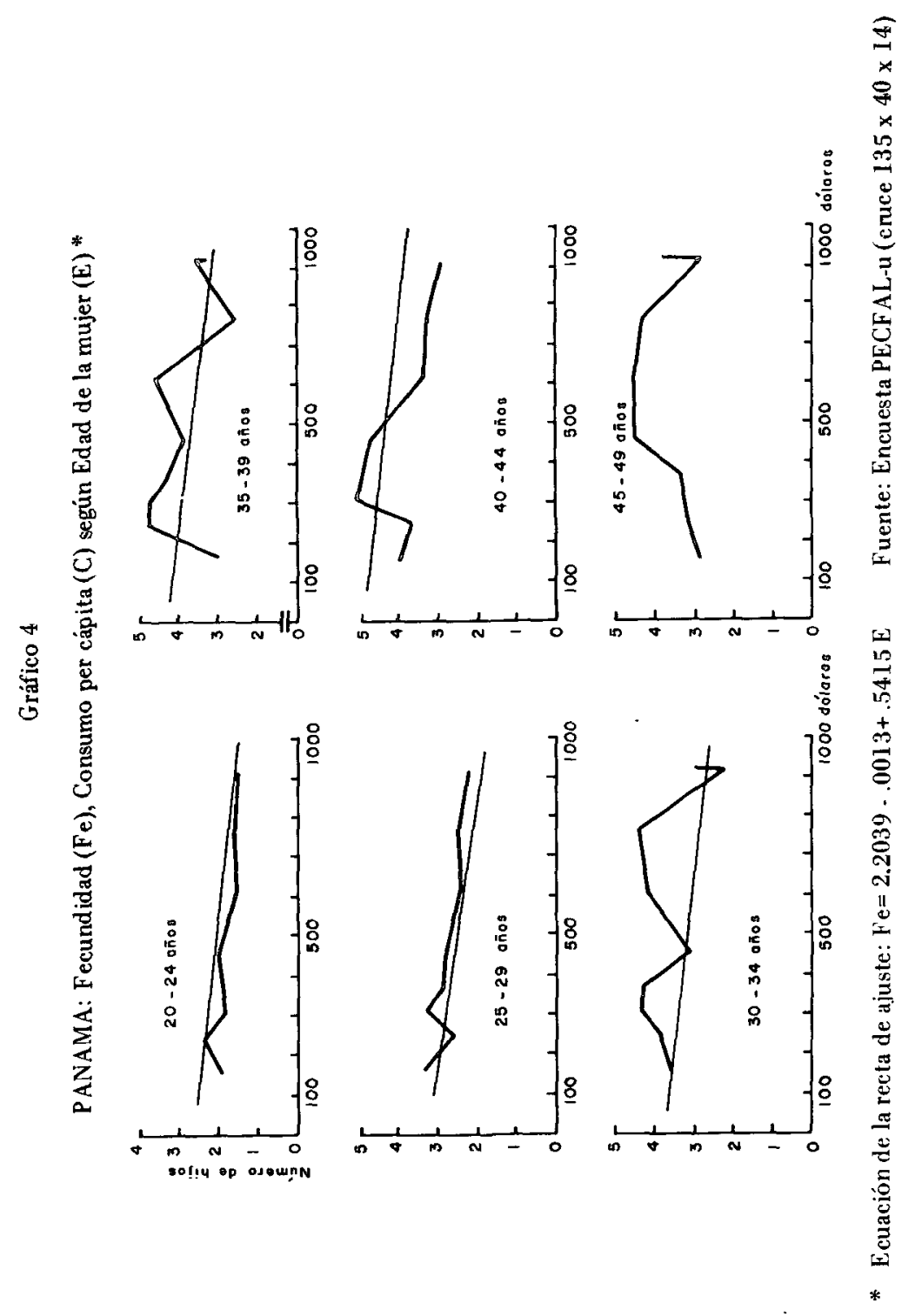


Gráfico 5

VENEZUELA: Fecundidad (Fe), Consumo per cápita (C) según Edad de la mujer (E) *
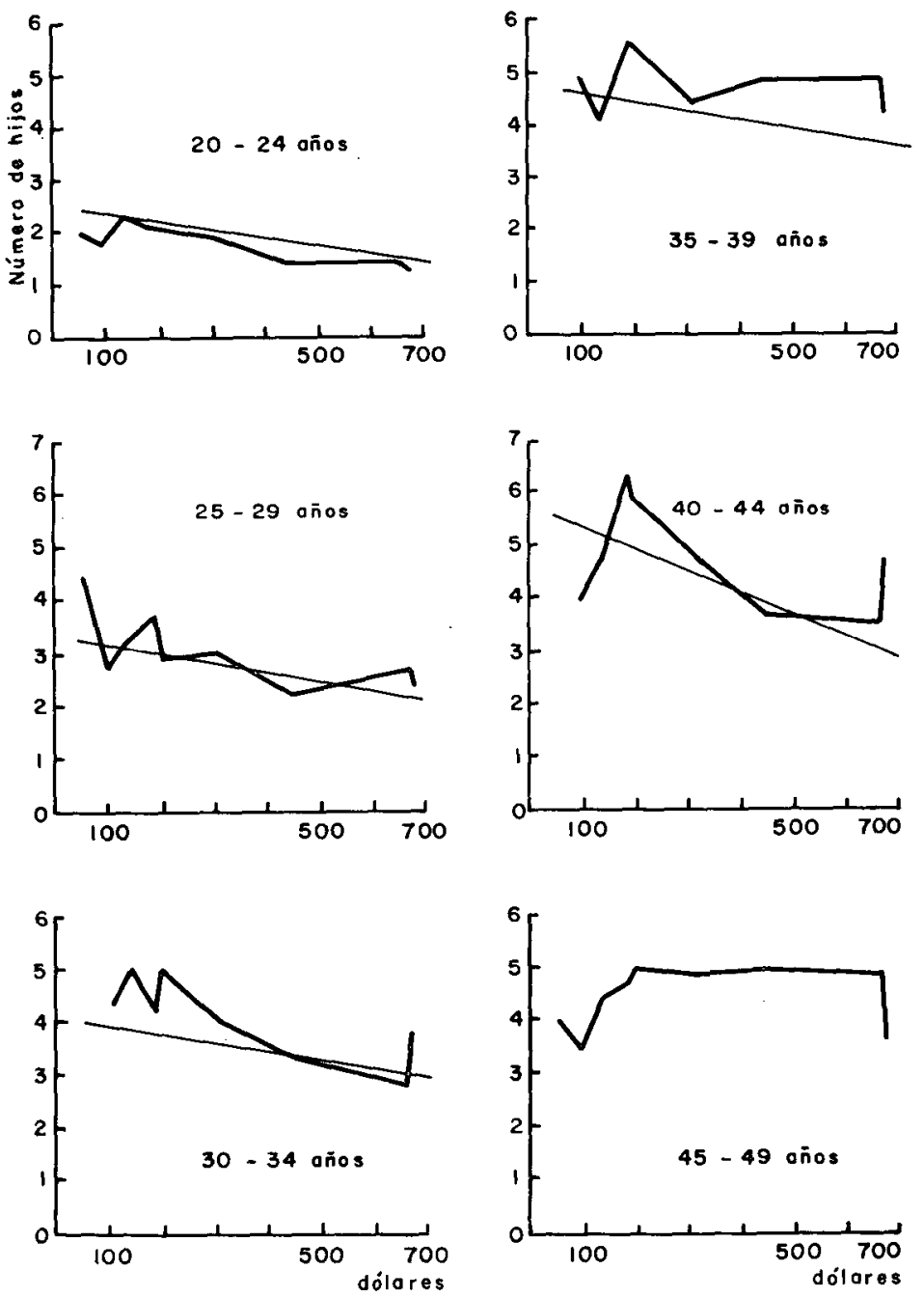

* Ecuación de la recta de ajuste: $\mathrm{Fe}=1.8113-.00156 \mathrm{C}+.7437 \mathrm{E}$ Fuente: Encuesta PECFAL-u (cruce 135x40x 14)

80 
pautas de conducta de las clases más acomodadas de la sociedad. Si bien esto parecería ser claro en todo aquéllo que se refiera a gastos en artículos de consumo, no hay una evidencia clara acerca de que el comportamiento reproductivo de las clases de más bajos ingresos pueda tender a semejarse a aquellas otras de más altos niveles de ingreso.

Para terminar con esta secciór, es interesante comprobar las diferencias entre la fecundidad según la zona de residencia. La fecundidad urbana siempre es menor que la fecundidad rural según se puede apreciar en el cuadro 5.

Cuadro 5

PROMEDIO DE HIJOS NACIDOS VIVOS POR MUJER

AL TERMINO DE SU EDAD FERTIL, SEGUN LUGAR DE RESIDENCIA

\begin{tabular}{lccccc} 
País & Año & Grupo de edad & Total & Urbana & Rural \\
\hline Brasil & 1950 & $45-49$ & 6,2 & 4,9 & 7,3 \\
Cuba & 1953 & $45-49$ & 3,9 & $\mathbf{3 , 1}$ & 5,8 \\
México & 1960 & $40-49$ & 5,0 & 4,4 & 5,7 \\
Panamá & 1950 & $45-49$ & 5,0 & 3,6 & $\mathbf{6 , 1}$ \\
Argentina & 1895 & $15-59$ & 4,2 & 3,9 & 4,5 \\
Argentina & 1947 & & 3,5 & 3,0 & 4,6 \\
Argentina & 1960 & & 2,7 & 2,1 & $\mathbf{3 , 1}$ \\
\hline
\end{tabular}

Fuente: Elementos para la elaboración de una política de desarrollo con integración para América Latina, capítulo II, cuadro 15, ILPES-CELADE, Santiago, 1968. Los datos para Argentina se tomaron de Evolution of Fertility in Argentina and Uruguay. Ana María Rothman Mimeografiado, pág. 12. Los datos se refieren a las mujeres casadas.

No existen estudios que evalúen el efecto que tiene el proceso migratorio sobre la fecundidad urbana. Dado que la fecundidad de las áreas rurales es más alta que la de las zonas urbanas se puede levantar el interrogante de si el migrante que llega a la ciudad continuará con su comportamiento reproductivo rural o adoptará las pautas de conducta reproductiva urbana. Esta cuestión no se encuentra totalmente aclarada a causa del complejo de situaciones que involucran al migrante. Esta asimilación de pautas reproductivas propias de la ciudad, dependerá en gran proporción de la edad a la cual el migrante llega y de si el medio urbano lo absorbe en actividades productivas que eleven su nivel de vida o no.

\section{LA PARTICIPACION EN EL TRABAJO}

Hay que destacar que la participación de la población latinoamericana en actividades económicas presenta las características propias de los 
páses en proceso de desarrollo. En el caso de los hombres, la participación de los niños en las actividades económicas, en las edades de 10 a 14 años, es cinco veces mayor que la que muestran los páses industrializados. En tanto que la de 65 años y más es aproximadamente dos veces superior a la de los paises industrializados.

La participación de los niños en las actividades económicas es el resultado, en gran medida, de las condiciones económicas en que se desenvuelve una gran masa de latinoamericanos ubicados en los estratos de más bajos ingresos. Se trata de perceptores secundarios de ingresos que complementan aquéllos aportados a la familia por el jefe de la misma.

En el caso de las mujeres, la participación femenina en los países más desarrollados es superior a la que presenta América Latina en su conjunto. La diferencia más notable se presenta en el grupo de 20 a 24 años de edad, donde en los países industrializados trabajan dos mujeres por cada una de la misma edad de los países latinoamericanos. Debe tenerse en cuenta que esta mayor participación se reconoce como una tendencia de largo plazo. Parecería ser que en los países desarrollados, como tendencia de largo plazo, la misma dinámica del desarrollo ha creado oportunidades de trabajo para la mujer, ha estimulado las ideas acerca de la igualdad de los sexos, ha elevado los niveles de instrucción y, en definitiva, ésto ha tenido repercusiones sobre los niveles de participación femenina en el trabajo. Cabe hacer notar aquí que muchos han sido los trabajos que tratan de explicar las variaciones cíclicas de corto plazo en la participación femenina en el trabajo. Dos hipótesis se han elaborado al respecto: aquélla que dice relación con el "trabajador adicional", que postula que a medida que la tasa de desempleo aumenta la participación en el trabajo en su conjunto tiende a aumentar, a causa de que un jefe de familia desempleado se ve compensado por la entrada a la fuerza de trabajo de perceptores secundarios de ingreso ya sean éstos la esposa o los varones menores que ahora trabajan para sumplementar el ingreso familiar; y la otra es la hipótesis del "trabajador desalentado", que postula que la participación en la fuerza de trabajo cae a medida que la tasa de desempleo sube, porque, una persona que se encuentra desempleada durante un tiempo prolongado se desalienta y se retira de la fuerza de trabajo. Una conclusión, que se ha obtenido para los Estados Unidos de Norte América, es que las familias no-blancas con marido y mujer vivos tienden a escapar de la pobreza durante los tiempos prósperos, convirtiéndose en familias con múltiples perceptores de ingresos; 0 sea, que las mujeres casadas entran al mercado de trabajo para asegurarse una ocupación -tanto si es a tiempo parcial o a tiempo completo. Se llegó también a la conclusión que el efecto "trabajador desalentado" es más fuerte para las mujeres casadas no-blancas que para todas las 
mujeres no-blancass? Se ha encontrado también que "si la esposa tiene una larga historia de trabajo, ello se asocia con menor cantidad de hijos, aunque esta relación es más imporrante al comienzo de la vida fértil que en las últimas etapas de la misma. 8 /

Al nivel de algunos países desarrollados se verifica una asociación negativa entre indicadores más globales como los niveles de tasas de participación femenina y las tasas brutas de natalidad. Sin embargo, en esta asociación no se puede decir con seguridad cuál es la causa y cuál el efecto; $o$, en otros términos, se podria argumentar que en este tipo de asociación existe un conjunto de otros factores que explican ambos movimientos al mismo tiempo. Para algunos países latinoamericanos esta asociación se verifica también como puede verse en el cuadro 6 . En este cuadro se presentan los datos de tasa bruta de participación femenina y los de la tasa bruta de natalidad para algunos países seleccionados durante un período aproximado de 10 años. Como se puede apreciar a medida que la tasa de participación aumenta, la tasa de natalidad disminuye.

Cuadro 6

TASA BRUTA DE PARTICIPACION FEMENINA EN EL TRABAJO Y TASA BRUTA DE NATALIDAD

\begin{tabular}{lcccccc}
\hline & & & \multicolumn{3}{c}{$\begin{array}{c}\text { Tasa bruta de } \\
\text { participación }\end{array}$} & \multicolumn{2}{c}{$\begin{array}{c}\text { Tasa bruta de na- } \\
\text { talidad (por mil) }\end{array}$} \\
& año & año & añoa/ & añob/ & añoc/ & añoc/ \\
País & $(1)$ & $(2)$ & $(1)$ & $(2)$ & $(1)$ & $(2)$ \\
\hline Argentina & 1947 & 1960 & 16,6 & 17,2 & 25,1 & 22,5 \\
Colombia & 1951 & 1964 & 12,4 & 11,6 & 37,4 & 42,4 \\
Venezuela & 1950 & 1961 & 12,2 & 11,4 & $\mathbf{4 3 , 5}$ & $\mathbf{4 5 , 2}$ \\
Costa Rica & 1950 & 1963 & 10,4 & 9,6 & 48,7 & 50,5 \\
Nicaragua & 1950 & 1963 & $\mathbf{8 , 6}$ & $\mathbf{1 2 , 3}$ & 42,1 & 40,0 \\
Japón & 1955 & 1965 & $\mathbf{3 4 , 2}$ & $\mathbf{3 7 , 5}$ & $\mathbf{1 9 , 4}$ & $\mathbf{1 6 , 9}$ \\
U.S.A. & 1950 & 1960 & $\mathbf{2 1 , 8}$ & $\mathbf{2 4 , 6}$ & $\mathbf{2 4 , 5}$ & $\mathbf{2 3 , 7}$ \\
Canadá & 1951 & 1961 & $\mathbf{1 6 , 9}$ & $\mathbf{1 9 , 7}$ & $\mathbf{2 7 , 3}$ & $\mathbf{2 6 , 0}$ \\
\hline
\end{tabular}

Fuente:

a/ Naciones Unidas, "Demographic Aspects of Manpower", Report 1, Population Studies, No 33, 1962 (ST/SOA/Ser.A/33), pág. 8.

b/ Yearbook of Labour Statistics, OIT, 1967.

c) Demographic Yearbook, Naciones Unidas, 1962.

7] "Urban poverty and labor force participation", Joseph Mooley. American Economic Review, marzo de 1967.

B/ Deborah S. Freedman "The Relation of Economic Status to Fertility". American Economic Review, junio de 1963. 
Sobre la base de los datos de este cuadro se ha procedido a hacer un ajuste lineal obteniéndose un coeficiente de correlación $R^{2}=0,72$ y como se puede observar en la siguiente ecuación el coeficiente que multiplica a la tasa bruta de natalidad es significativamente distinto de cero al nivel de 95 por ciento de confiabilidad. La ecuación ajustada es:

participación femenina $=0,646$ tasa de natalidad $+38,9 ; R^{2}=0,72$

De este modo, cuando la tasa bruta de natalidad disminuye la participación femenina aumenta. Decíamos anteriormente que debe existir una constelación de otros factores que explican ambos movimientos al mismo tiempo. Sin embargo, algunos autores argumentan que cuando la fecundidad disminuye y el tamaño de las familias es pequeño las obligaciones maternales son menores; $y$, suponiendo que el sistema económico permite empleos para la mujer, ésta puede tender a entrar en una mayor proporción a la fuerza de trabajo. En el sentido inverso otros autores han propuesto como una cuestión de alta prioridad en la estrategia de desarrollo el hecho que se induzca a las mujeres a entrar a la fuerza de trabajo en mayor número con lo cual se ayudarían a una disminución en la fecundidad. $2 /$

\section{ALGUNAS CARACTERISTICAS ECONOMICAS DE LA POBLACION}

Dado que en este estudio que pretende hacer un análisis cruzado entre las característic as demográficas de la población y las condiciones del desarrollo, ello implica que necesariamente haya que detenerse en algunos aspectos relacionados con la posición económica de los grupos sociales latinoamericanos.

Se ha visto anteriormente que la fecundidad está ligada con el nivel de vida de la población, y hubo de analizarse principalmente la fecundidad, por ser ésta la variable de que dependerá con mayor intensidad el futuro crecimiento de la población. El nivel de vida depende fundamentalmente de la distribución del ingreso y de las oportunidades ocupacionales que brinda la economía latinoamericana por lo cual se hace necesario referirse a estos dos aspectos, aunque se hará muy brevemente. 10 /

En primer lugar cabe observar que entre la población latinoamericana existe una muy desigual distribución del ingreso y, por lo tanto, de los niveles de vida; y que una buena porción de la misma se encuentra en condiciones de desocupación y subocupación.

\footnotetext{
9/ Bernard Berelson, "Beyond Family Planning", Studies in Family Planning, No 38 , febrero de 1969 .

10/ Lo que aquí se expone en forma resumida se puede ver más in extenso en la publicación "Elementos para la elaboración de una política de desarrollo con la integración", ILPES-CELADE, 1968.
} 
En efecto hacia 1960, un 40 por ciento de la población, o sea, 100 millones de personas recibían el 9 por ciento del ingreso latinoamericano; esto es, cada uno de estos habitantes disponía en el año de 77 dólares. Una gran proporción de este amplio sector estaba compuesto fundamentalmente por población rural, la parte urbana de ohreros industriales ocupados en los sectores artesanales, las personas ocupadas en el servicio doméstico y los vendedores ambulantes, es decir, en gran medida, por lo que podría denominarse la mano de obra activa subutilizada o marginada del mercado de trabajo. Cada una de estas personas disponía de apenas 9 dólares anuales para dedicarlos a otro gasto que no fuera el de alimentación, vestuario y servicios y su ahorro era nulo según se puede apreciar en el cuadro 7. Téngase en cuenta que, según se ha visto en la sección anterior, éstos son los grupos que tienen una más alta fecundidad y presumiblemente los menores niveles educativos.

Cuadro 7

AMERICA LATINA: DISTRIBUCION CONJETURAL DEL INGRESO 1960 Y DE LA FECUNDIDAD 1960-1970

\begin{tabular}{|c|c|c|c|c|c|c|c|c|}
\hline \multirow[b]{2}{*}{ Categoría } & \multicolumn{2}{|c|}{ Porcentaje de } & \multirow[t]{2}{*}{$\begin{array}{l}\text { Promedio de } \\
\text { ingreso perso- } \\
\text { nal, dólares } \\
\text { anual } \\
\text { per cápita }\end{array}$} & \multicolumn{3}{|c|}{$\begin{array}{l}\text { Destino del ingreso } \\
\text { personal en porciento }\end{array}$} & \multicolumn{2}{|c|}{$\begin{array}{l}\text { Número de } \\
\text { hijos por } \\
\text { mujer al cabo } \\
\text { vida fértil }\end{array}$} \\
\hline & Población & $\begin{array}{l}\text { Ingreso } \\
\text { personal }\end{array}$ & & Consumo & Tribut. & Ahorro & Total & Urbana \\
\hline I & 40 & 9 & 77 & 90 & 10 & - & 6,2 & 5,1 \\
\hline II & 20 & 10 & 179 & 80 & 20 & - & 5,8 & 4,5 \\
\hline III & 35 & 50 & 497 & 77 & 20 & 3 & 4,9 & 4,1 \\
\hline IV & 5 & 31 & 2190 & 57 & 25 & 18 & 3,7 & 2,5 \\
\hline Total & 100 & 100 & & & & & 5,5 & 4,5 \\
\hline
\end{tabular}

Fuente: Distribución del ingreso y su destino: ILPES. Fecundidad: elaborado sobre la base de los datos de la sección B.

Una segunda categoría, en la que quedan incluidos obreros de la industria fabril con escasa calificación, pequeños comerciantes con cierto grado de organización y parte del personal administrativo de los sectores público y privado, representa el 20 por ciento de la población y tiene un ingreso de alrededor de 180 dólares anuales. Este grupo tampoco tiene capacidad de ahorro.

Conviene retener este hecho de profunda significación: el 60 por ciento de la población latinoamericana percibe ingresos inferiores a los 180 dólares anuales; que estos grupos no sólo no tienen capacidad de ahorro sino que tampoco tienen ingresos como para satisfacer las 
necesidades más elementales que se han estimado como mínimo en 190 dólares;11 que éstos son los grupos en los que se registra la más alta fecundidad, la más alta mortalidad infantil y los menores niveles educativos.

Una tercera categoría de población, que abarca al 35 por ciento de la misma, tiene un ingreso aproximado de 500 dólares anuales y el 5 por ciento restante percibe alrededor del 31 por ciento del ingreso latinoamericano con un promedio per cápita de 2200 dólares. En estas dos últimas categorías quedan incluidos obreros altamente calificados, la parte más alta del personal administrativo de los sectores público y privado, los empresarios, técnicos y profesionales del sector industrial y los profesionales independientes. De paso hay que mencionar que estas dos últimas categorías son las que constituyen el mercado sobre el cual operan la mayor parte de las firmas industriales y son los sectores de población que tienen capacidad de ahorro y que registran niveles inferiores de fecundidad.

Este fenómeno de tan desigual distribución del ingreso está asociado, de un lado, al papel que han desempeñado los distintos sectores económicos en la absorción de mano de obra; y, del otro, a la dinámica misma del proceso de desarrollo y a la tecnología utilizada.

La otra faceta a través de la cual se puede analizar esta cuestión de la distribución del ingreso es a través de la desocupación.

En los países subdesarrollados la característica principal con que se manifiesta la subutilización de la mano de obra es en términos de subocupación o desocupación disfrazada, además de la desocupación abierta. En los países subdesarrollados las personas, en general, tratan de no permanecer inactivas, sino que, al no encontrar una ocupación estable, tienden a tomar trabajos temporarios, a tiempo parcial, o durante períodos inferiores al nominal de trabajo o a ocuparse en unidades económicas que actúan con niveles de productividad anormalmente bajos o en servicios que existen sólo como forma de obtener un ingreso aunque éste no cubra satisfactoriamente las necesidades minimas socialmente aceptables.

Se ha estimado que en 1960 las personas que se hallaban afectadas por esta situación representaban algo más del 40 por ciento de la mano de obra activa. $Y$, si se computa la proporción promedio en cada una de ellas se encontraba subutilizada y se determina sobre esa base la cantidad equivalente de personas totalmente desocupadas, conténida en el grupo de subutilizados, resulta que el 27,4 por ciento de la población activa se encontraba en 1960 totalmente desocupada, en América Latina. Además, los elementos de juicio con que se cuenta con respecto al comportamiento de la economía con posterioridad a esa fecha,

11/ Véase "Elementos para la elaboración de una politica de desarrollo con integración para América Latina", ILPES-CELADE, 1968, pág. II-56. 
señalan que en sus características fundamentales esta situación sigue vigente en la actualidad, aunque con tendencia levemente creciente.

Se puede presumir que una gran parte de estas personas se encuentran incluidas en los tramos más bajos de ingreso, aunque en todos los casos esta relación no es estrictamente necesaria. A pesar de la baja productividad algunas personas reciben ingresos con niveles bastante significativos y aun están incorporadas a sistemas regulares de previsión y de servicios sociales. Por ejemplo, en algunos casos en que el sector servicios ha absorbido mano de obra en forma excesiva, como en el sector gobierno, la productividad escasa o nula que corresponde a cierta proporción de la mano de obra ocupada en los mismos, no impide que las personas correspondientes reciban un ingreso regular de bastante signific ación. En otros casos, la asociación es más directa y evidente como por ejemplo el caso de los vendedores ambulantes y los lustrabotas que aparecen en las ciudades.

Esta situación debe relacionarse con aquella fecundidad que se mostró en la sección 2 anterior. Como se recordará las mujeres cuyos maridos ocupaban puestos manuales no especializados eran las que tenían más alta fecundidad.

\section{ALGUNAS REFLEXIONES}

A modo de síntesis de lo que se ha visto anteriormente en el curso de este trabajo, se pueden elaborar algunas reflexiones.

El fenómeno que se presenta en América Latina de bajos niveles de vida, alta proporción de gente subocupada, una muy desigual distribución del ingreso, altos niveles de fecundidad, bajas tasas de participación femenina en las actividades económicas, altas tasas de participación masculina en las edades extremas, altos niveles de mortalidad infantil, está ligado al ritmo de desarrollo logrado por América Latina y al estilo particular con que se ha llevado a cabo el crecimiento económico,

No se trata en esta sección de hacer un estudio exhaustivo en relación al estilo particular de desarrollo de América Latina y al ritmo con que ésta ha crecido, sino más bien entregar a la discusión algunos elementos esenciales, a nuestro parecer, que tienen relación con los aspectos demográficos antes mencionados.

El ritmo con que ha crecido el producto latinoamericano ha sido insuficiente para absorber en ocupaciones productivas $y$ bien remuneradas al creciente contingente de personas resultante del aceleramiento en el crecimiento de la población. Se generan así amplios sectores de población que si bien pueden quedar desocupados temporalmente, más bien tienden a tomar ocupaciones aunque sea a tiempo parcial, o durante períodos inferiores al nominal de trabajo; a ocuparse en unidades económicas que trabajan con niveles de 
productividad anormalmente bajos y en servicios de bajos ingresos cuya naturaleza no requiere adiestramiento ni la disponibilidad de bienes de capital. Son éstas las familias que registran los más altos niveles de fecundidad, de mortalidad infantil, y donde se encuentra la mayor participación de los niños fundamentalmente para complementar los ingresos familiares y de mujeres sobre todo en el sevicio doméstico y en otros sevicios.

Esta insuficiencia en el crecimiento económico resulta agravada por el vacío de desarrollo tecnológico en los países del área latinoamericana. De hecho, los países latinoamericanos deben importar la tecnología desde los países más desarrollados; y, dado que éstos tienden a adoptar tecnologías ahorradoras de mano de obra, que son trasplantadas a la América Latina, de un lado refuerza la concentración del ingreso y del otro tiende a ocupar relativamente menos mano de obra. Altos ingresos concentrados en pocas manos de un lado, e ingresos de subsistencia para una gran masa de población por el otro, aunque con una cierta gama de variación, produce una especie de círculo vicioso que tiende a generar y perpetuar la situación de bajos niveles de vida y alta fecundidad. Los grupos de más altos ingresos tienen una demanda diversificada y sofisticada dirigida a aquellos productos que tienen poco contenido de mano de obra, en términos relativos. Los estratos de más bajos ingresos participań en muy poca medida en el mercado industrial. Su demanda de bienes industriales es lo suficientemente reducida como para que los sectores de más alto contenido en mano de obra no pueden avanzar más allá de un aumento meramente vegetativo, que resulta insuficiente para absorver el creciente número de personas aptas para trabajar. Estos focos de "modernismo" en que se desenvuelve una minoría de altos ingresos y de baja fecundidad, por el modo particular de funcionamiento del sistema económico, no se expande al resto dé las clases sociales más bajas con lo cual se perpetúan los altos niveles de fecundidad de las mismas. En estos sectores es donde también se encuentran las altas tasas de mortalidad infantil ligada fundamentalmente a problemas de nutrición, condiciones de vivienda y al medio ambiente en el cual se encuentra radicada la población.

Sin embargo, cabria consignar que una política de desarrollo que se propusiera aumentar el ritmo de crecimiento de la economía latinoamericana y elevar significativamente el nivel de vida de esa gran porción de gente, podría traer como consecuencia una disminución de la fecundidad de los grupos de más bajos ingresos. Pero esta disminución de fecundidad a través de mejores niveles de vida no puede esperarse que tenga efecto significativo sobre el tamaño de la población en un plazo de diez años. El efecto más significativo puede reflejarse, en ese plazo, en el número de puestos de trabajo que demanda el sistema económico, ya que el aumento de poder adquisitivo de los grupos de 
bajos ingresos se destinaría con una alto grado de probabilidades, principalmente a la compra de bienes industriales que por sus características tienen un alto contenido relativo de mano de obra (alimentos industrializados y vestuario).

A más largo plazo, la disminución de de la fecundidad afectará el tamaño de la población y por lo tanto a uno de los elementos que constituyen la dimensión del mercado el que influye sobre la demanda de trabajo por un lado, y la oferta de trabajo resultará influenciada, por el otro, en la medida en que un menor número de niños signifique horas libres para la mujer que pueden ser ocupadas en tareas fuera de la casa. En otras palabras, a más largo plazo la disminución de la fecundidad puede significar una reducción de la demanda de trabajo (por la disminución relativa del tamaño del mercado) y un aumento de la oferta de trabajo, aunque a priori resulta difícil hacer una afirmación categórica a este respecto porque los efectos cuantitativos han de depender de la naturaleza y magnitud del proceso.

Las mejoras en los niveles de vida significarán aumentos en los niveles educativos que pueden reforzar la caída de la fecundidad y reducciones en la mortalidad infantil que a su vez pueden determinar aumentos en la oferta de trabajo femenino. Estas y otras cuestiones relacionadas se analizan cuantitativamente más adelante. 


\section{VISION SINTETICA DEL MODELO Y LAS HIPOTESIS}

El modelo demográfico que vamos a utilizar en la actualidad, es una versión simplificada de aquél que se presentara en 1968 en el documento ya citado del ILPES-CELADE, "Elementos para la elaboración de una política de desarrollo con integración para Ámérica Latina", aunque, a diferencia de aquél, éste permite interrelacionar los movimientos económicos con los movimientos demográficos y viceversa. En este trabajo el análisis se realiza en un solo sentido: variaciones económicas producen efectos sobre aspectos demográficos, pero éstos por ahora, no repercuten sobre el comportamiento económico. El análisis de la influencia de la población sobre las variables económicas no se considera en este documento.

El modelo demográfico elabora proyecciones de población total y de la población económicamente activa (PEA), por sexo, edades individuales, para las zonas urbanas y rural. En este trabajo se han introducido los datos de América Latina en su conjunto, para los años calendarios del periodo 1970-2000, considerando el conjunto de las 20 repúblicas latinoamericanas que se consideran en los estudios del CELADE.

Debido a la limitación de la información disponible y a la complejidad de las interrelaciones entre variables económicas y demográficas, se introducen en el modelo sólo las relaciones que se han podido cuantificar, según se pudo ver en el capitulo anterior. En la medida en que se desarrollen estudios más profundos sobre la naturaleza y alcance de la dependencia mutua de variables económicas y demográficas, podrá mejorarse el modelo que se presenta en esta oportunidad.

Se han elaborado dos alternativas de proyección: la primera, implica una evolución de la mortalidad y fecundidad que sigue la tendencia observada en las décadas pasadas. Esta evolución demográfica resulta de suponer una evolución económico-social, que sigue la tendencia histórica; es decir, el crecimiento del producto per cápita continúa al mismo ritmo que en el pasado y la distribución del ingreso se mantiene constante. La segunda alternativa de proyección de la población implica una evolución de la fecundidad diferente: un descenso más acentuado, que está en relación con un incremento mayor del producto per cápita y con una redistribución de los niveles de consumo. 
En estas alternativas se supone que tanto la mortalidad como el grado de urbanización tendrán en el futuro un comportamiento similar al registrado en el pasado, respectivamente. Cabe señalar que la primera alternativa de proyección es aproximadamente la implícita en la del CELADE, la cual se explica de un lado por la evolución del nivel de vida en las hipótesis que las condiciones económicas continúen como en el pasado, y, del otro lado, por "otros factores" que fueron incorporados implícitamente en la hipótesis de la evolución de la fecundidad efectuada por CELADE. Estos "otros factores" podrían interpretarse como un efecto adicional sobre la fecundidad de la "modernización", introducidos a través de los múltiples mecanismos sociales como, por ejemplo, los modelos de comunicación masivos y otros factores exógenos como la educación.

La segunda alternativa de proyección demográfica contempla el mismo efecto, en términos proporcionales, como se verá más adelante, de los "otros factores" sobre la fecundidad, pero ahora ésta se ve afectada en mayor intensidad por una hipótesis de crecimiento más fuerte del ingreso per cápita y por una redistribución de los niveles de consumo.

Con el propósito de comprender la estructura del modelo se presenta a continuación una visión sintética del mismo pero el lector no interesado puede omitir sin pérdida esta parte. En la parte B se efectía una explicación detallada de las hipótesis de evolución de la mortalidad, fecundidad, migraciones rural-urbana y participación de actividades económicas.

\section{VISION SINTETICA DEL MODELO}

El modelo opera con la población según área de residencia (urbano-rural), por sexo y por edad detallada entre 0 y 70 años. Calcula además población económicamente activa con la misma clasificación.

(a) $\mathrm{N}(\mathrm{J}, \mathrm{I})=\mathrm{Fl}(\mathrm{N}(\mathrm{J}-1, \mathrm{I}-1), \mathrm{FE}(\mathrm{J}, \mathrm{I}), \mathrm{P}(\mathrm{J}, \mathrm{I}), \mathrm{CE}(\mathrm{J}, \mathrm{I}))$

La población $\mathrm{N}$ por edad $\mathrm{J}$ en el periodo $\mathrm{I}$ es una función $\mathrm{Fl}$ que depende de la población que en el periodo anterior (I-1) tenía un año menos (J-1), de la fecundidad por edad (FE), de las relaciones de supervivencia $(P)$, y de los coeficientes de emigración del campo a la ciudad (CE). El cálculo se hace por sexo, edad y urbano-rural.

(b) PEA (J,I) $=$ F2 (N (J,I), CA (J,I))

La población económicamente activa (PEA) es una función $\mathrm{F} 2$ de la población por edad $\mathrm{N}$ y de los coeficientes de actividad (CA).

(c.1) FET (I) $=$ F3 (S(I)

(c.2) FET (I) = Exógeno

(c.3) FET (I) = F4 (S(I), Exógeno) 
Para la fecundidad total (FET) (número medio de hijos por mujer al cabo de su vida fértil) hay tres formas alternativas de operación:

La primera que sea función (F3) de las condiciones socioeconómicas de los grupos sociales (S). Estas condiciones surgen como resultado del modelo económico.

La segunda alternativa es que la fecundidad se de exógenamente, desde afuera del modelo, sobre la base de un estudio específico de posible variación de la fecundidad.

La tercera alternativa es una combinación de factores sociales y exógenos que determinan el nivel de fecundidad total. Es esta forma de cálculo la que se adop tó en nu estro trabajo.

(d) $\mathrm{FE}(\mathrm{J}, \mathrm{I})=\mathrm{F} 5(\mathrm{FET}$ (I))

La distribución de fecundidad (FE) por edades, depende o es función del nivel de fecundidad total (FET)

(e.1) PT (I) $=$ F6 (S(I))

(e.2) PT (I) = Exógeno

(e.3) PT (I) = F7 (S(I), Exógeno)

La relación total de supervivencia (PT) (suma de las relaciones de supervivencia por edad) se puede determinar con las tres alternativas indicadas para la fecundidad. En este trabajo hemos adoptado la modalidad e.2.

(f) $\mathrm{P}(\mathrm{J} ; \mathrm{I})=\mathrm{F} 8(\mathrm{PT}(\mathrm{I}))$

La distribución por edades de las relaciones de supervivencia (P) depende del nivel de la relación de supervivencia total (PT)

(g.1) $\operatorname{CAT}(\mathrm{I})=$ F9 $(\mathrm{FET}(\mathrm{I}))$

(g.2) CAT (I) $=$ Exógeno

(g.3) $\mathrm{CAT}(\mathrm{I})=$ F 10 (FET (I), S(I), Exógeno).

Al igual que en el conjunto de ecuaciones (c) los coeficientes de actividad (CAT) presentan tres alternativas de cálculo, cada una de ellas para la clasificación por sexo y por área de residencia. La primera depende del nivel de fecundidad total. La segunda se considera exógena; $y$, en la tercera se combinan dichos elementos. En el modelo se adoptan para dos alternativas diferentes las dos primeras modalidades.

(h) $\mathrm{CA}(\mathrm{J}, \mathrm{I})=\mathrm{F} 11(\mathrm{CAT}(\mathrm{I}))$

La distribución de las tasas de actividad por edades (CA) depende del nivel absoluto de la tasa de participación total (CAT).

Una visión más detallada del modelo demográfico y sus interrelaciones con el modelo económico se puede apreciar en el gráfico 6. 


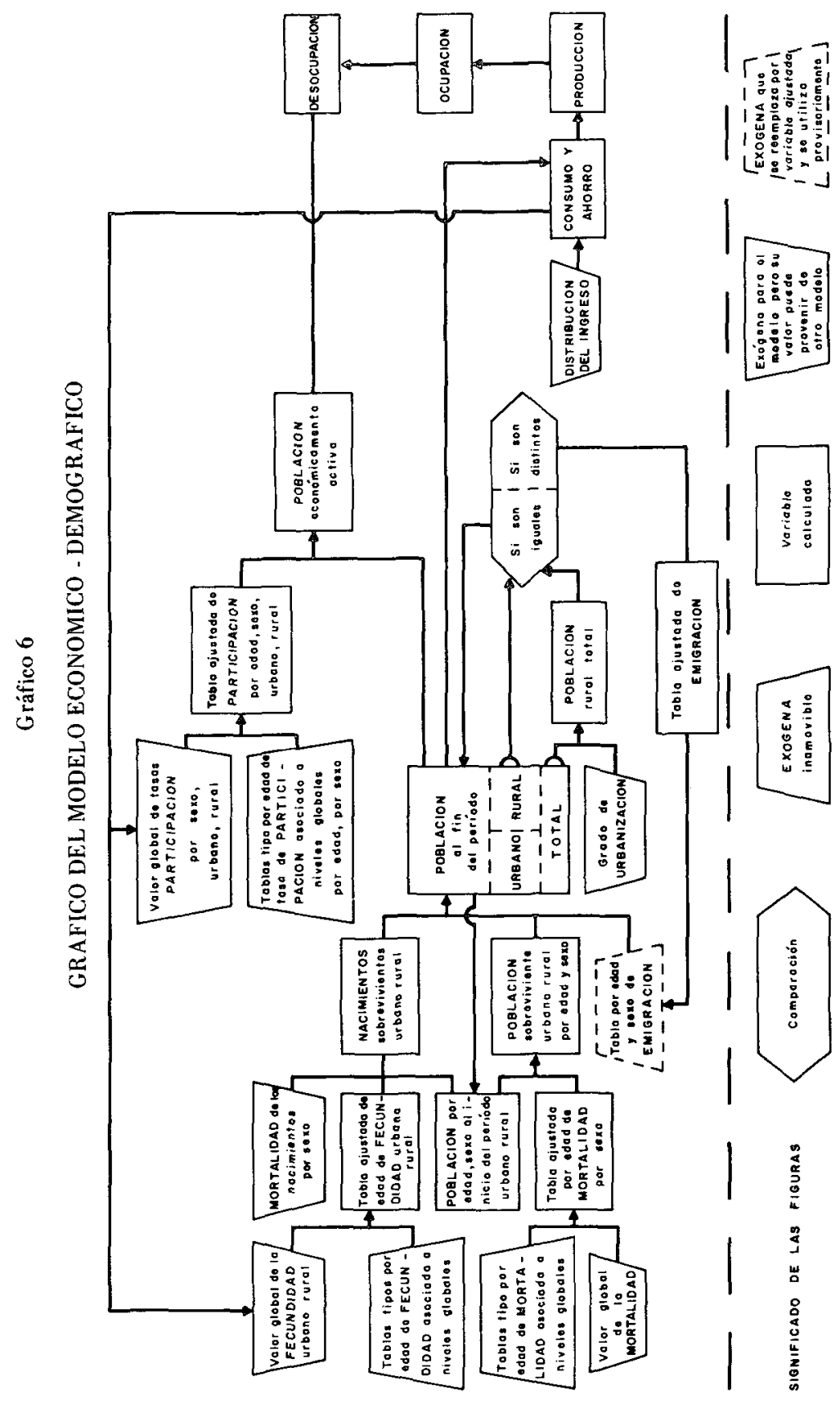


En primer lugar, el modelo recibe los siguientes datos básicos:

a) La población del período inicial, por sexo, por edad y por zona de residencia.

b) Tablas tipo de fecundidad por edades que corresponden a las de tres modelos diferentes: a) alta fecundidad con cúspide dilatada, cuya suma es 6,2 hijos por mujer al cabo de su vida fértil; b) alta fecundidad con cúspide temprana cuya suma es 4,5 hijos: c) baja fecundidad con cúspide temprana, cuya suma es 3,7 hijos por mujer al cabo de la vida fertil.

c) Tablas tipos de mortalidad por edad y por sexo asociados a ciertos niveles globales de la misma. No se diferencia la mortalidad por área de residencia.

d) Tablas tipos de tasas de participación por sexo y edad, asociados a niveles globales de participación.

e) Tablas por sexo y edad de emigración deste el campo hacia las zonas urbanas.

Estas tablas tipos se han introducido para hacer manejable el modelo en términos del volumen de información a suministrarle. Por ejemplo, una proyección a 30 años con 70 edades individuales por área de residencia, requeriria de 4,200 datos de fecundidad, igual cifra para mortalidad y para migraciones, y 8600 datos de participación. En total, 21200 datos para producir una única proyección.

Con estos valores básicos el modelo opera de la siguiente forma:

i) A partir de la población inicial, momento I-1, (urbana, rural, por sexo y edad detallada) y las relaciones de supervivencia, se calculan los sobrevivientes clasificados según las mismas variables.

ii) A partir de la fecundidad urbana y rural global -derivada de la fecundidad total proveniente del modelo económico- si el programa de cómputo elige o interpola una tabla por edad y por área de residencia que corresponde al valor global dado para la fecundidad en el año correspondiente. Con las tasas de fecundidad asi calculadas y la población femenina, el momento inicial (I-l) y sus sobrevientes al momento (I), se calculan los nacimientos según área de residencia.

ii) Se calculan los sobrevivientes de los nacimientos utilizando la relación de supervivencia correspondiente al nivel de mortalidad propio del periodo I-1 a I.

iv) La población al momento I, por áreas de residencia se obtiene aplicando a la población obtenida en 1 y a los sobrevivientes de los nacimientos obtenidos en iii), la tabla de tasas de emigración (exógena al modelo) rural-urbana.

v) El modelo luego compara, utilizando el grado de urbanización (exógeno al modelo demográfico) de población rural que surge según tal grado de urbanización con la población rural obtenida en 4. Si la población rural que resulta de iv) es igual que la que resultaría de aplicar el grado de urbanización, queda terminada la proyección para el 
momento I. Si ambos valores de población rural son distintos, se ajusta la tabla de tasas de emigración de manera que se obtenga una emigración rural-urbana que resulte en el grado de urbanización postulado desde afuera del modelo. De esta manera quedan terminada tanto la población rural como la urbana.

Esta población interviene en la determinación de los niveles de consumo total mediante la aplicación de la población a los consumos per cápita que resultan de la distribución del ingreso. Los niveles de consumo y el resto de la demanda final, determinan los niveles de producción y éstos, a su vez, mediante la aplicación de coeficientes de trabajo variables en el tiempo, da origen al número de puestos de trabajo que ofrece la economía.

vi) La distribución del ingreso permite obtener una distribución de consumo según grupos sociales, a los cuales se encuentran asociados niveles de fecundidad promedio para el país. Esta fecundidad promedio se abre luego en urbano y en rural y este valor es el que entra en el cálculo del segundo año de la proyección.

vii) El valor global de las tasas de participación puede provenir de una estimación que se entrega exógenamente al modelo, o sea, las variaciones temporales de la misma están dadas desde afuera del modelo mismo; y, la otra alternativa es que el valor global de las tasas de participación femenina dependa del valor de la fecundidad. En cualquiera de los dos casos, dado el valor global de las tasas de participación, el computador elige una tabla por edad, por sexo, por zona urbana y rural, ajustada a los valores totales de participación. Sobre la base de esta tabla ajustada de tasas de participación se calcula la población económicamente activa que comparada con el número de puestos de trabajo da la magnitud de la desocupación.

\section{LAS HIPOTESIS DE TRABAJO}

\section{A. Población inicial de las proyecciones}

Se considera como población inicial la de América Latina, recomendada por CELADE para 1970 (Boletín Demográfico No 4). Se la distribuye por área urbana y rural de acuerdo al nivel de urbanización estimado para ese mismo año para la región: 54,4 por ciento de la población viviría en núcleos de más de 2000 habitantes en 1970. La estructura por sexo y edad que se adopta corresponde a la de algunos países con niveles de urbanización semejantes. En el cuadro 8 se presenta la población por sexo, grupos quinquenales de edades en las zonas urbana y rural, que se adopta como población inicial; en este mismo cuadro se incluyen las estructuras por edades. A partir de esta población inicial 
por grupos quinquenales de edades utilizando un procedimiento de interpolación, 12 se calculó la población por edades detalladas.

\section{B. Hipótesis de evolución futura de la mortalidad, fecundidad, migración rural-urbana y participación en actividades económicas}

\section{a. Mortalidad}

Se establece una hipótesis única de evolución de la mortalidad, esto es, la mortalidad tiene el mismo nivel e igual tendencia en la zona urbana y rural aunque diferenciada por sexo. Se podría introducir en el futuro, niveles diferenciales de mortalidad para ambas zonas, y acaso vincular la tendencia con algunas características del modelo económico. El modelo aunque no considera esta posibilidad, es lo suficientemente flexible como para introducirla más adelante cuando se tengan mejores conocimientos sobre este aspecto.

La mortalidad adoptada en el momento inicial corresponde a que reflejan las tablas de vida para la región para el periodo 1965-1970 13/ con esperanzas de vida al nacer de 58,9 años para los hombres y 63,6 años para las mujeres. Se supone que las relaciones de supervivencia, derivadas de esas tablas, evolucionarán de manera que hacia el año 2000 se habrá alcanzado el nivel de mortalidad que expresan las relaciones de supervivencia de las tablas de vida de los Estados Unidos para $1960, \underline{14}$ / con esperanzas de vida al nacer de 66,8 años para los hombres y de 73,2 años para las mujeres, cuyos niveles son cercanos a las estimaciones que se han hecho para América Latina en el año 2000.

Para facilidad de los cálculos en el computador, se ha definido como indicador de la mortalidad total, la suma de las relaciones de supervivencia. Se han introducido cuatro tablas de relaciones de supervivencia: dos para mujeres y dos para hombres. Para los años calendarios intermedios se calcula, mediante interpolación, el nivel de la mortalidad total y la correspondiente estructura por edad de las relaciones de supervivencia como se indicó anteriormente.

$12 /$ Multiplicadores de Beers.

13/ La mortalidad en el periodo 1965.1970 de América Latina, por C. Arretx y J. Pujol, documento presentado a la Conferencia Regional de Población, México, 1970.

14/ United States Life Tables 1959-1960, U.S. Department of Health, Education and Welfare, vol. 1, N$^{\circ} 1,1964$. 
Cuadro 8

POBLACION DE AMERICA LATINA EN 1970, POR SEXO, GRUPOS OUINQUENALES DE EDAD, Y ZONAS URBANA Y RURAL (Cifras absolutas en miles y estructura por edad en porcentaje)

(Población Masculina)

\begin{tabular}{|c|c|c|c|c|c|c|}
\hline \multirow{2}{*}{$\begin{array}{c}\text { Grupos de } \\
\text { edades }\end{array}$} & \multicolumn{2}{|c|}{ Urbana } & \multicolumn{2}{|c|}{ Rural } & \multicolumn{2}{|c|}{ Total } \\
\hline & $\begin{array}{l}\text { Pobla- } \\
\text { ción }\end{array}$ & $\begin{array}{c}\text { Estruc- } \\
\text { tura }\end{array}$ & $\begin{array}{l}\text { Pobla- } \\
\text { ción }\end{array}$ & $\begin{array}{l}\text { Estruc- } \\
\text { tura }\end{array}$ & $\begin{array}{l}\text { Pobla- } \\
\text { ción }\end{array}$ & $\begin{array}{l}\text { Estruc- } \\
\text { tura }\end{array}$ \\
\hline 0.4 & 12183 & 16,29 & 10848 & 17,19 & 23031 & 16,70 \\
\hline 5.9 & 10489 & 14,02 & 8901 & 14,11 & 19390 & 14,06 \\
\hline $10 \cdot 14$ & 8881 & 11,87 & 7932 & 12,57 & 16813 & 12,19 \\
\hline 15.19 & 7596 & 10,15 & 6649 & 10,54 & 14. 245 & 10,33 \\
\hline $20 \cdot 24$ & 6441 & 8,61 & 5341 & 8,46 & 11782 & 8,34 \\
\hline $25-29$ & 5588 & 7,46 & 4253 & 6,74 & 9841 & 7,14 \\
\hline $30-34$ & 4664 & 6,24 & 3727 & 5,91 & 8391 & 6,08 \\
\hline $35-39$ & 4137 & 5,53 & 3089 & 4,89 & 7226 & 5,24 \\
\hline $40 \cdot 44$ & 3546 & 4,74 & 2799 & 4,44 & 6345 & 4,60 \\
\hline 45.49 & 2891 & 3,86 & 2462 & 3,90 & 5353 & 3,88 \\
\hline $50-54$ & 2330 & 3,12 & 1981 & 3,14 & 4311 & 3,13 \\
\hline 55.59 & 2020 & 2,70 & 1505 & 2,38 & 3525 & 2,56 \\
\hline $60-64$ & 1556 & 2,08 & 1251 & 1,98 & 2807 & 2,04 \\
\hline $65-69$ & 1052 & $1,4.1$ & 1008 & 1,60 & 2060 & 1,49 \\
\hline $70 y+$ & 1435 & 1,92 & 1358 & 2,15 & 2793 & 2,02 \\
\hline Total & 74809 & 100,00 & 63104 & 100,00 & 137913 & 100,00 \\
\hline
\end{tabular}

(Población Femenina)

\begin{tabular}{|c|c|c|c|c|c|c|}
\hline \multirow{2}{*}{$\begin{array}{c}\text { Grupos de } \\
\text { edades }\end{array}$} & \multicolumn{2}{|c|}{ Urbana } & \multicolumn{2}{|c|}{ Rural } & \multicolumn{2}{|c|}{ Total } \\
\hline & $\begin{array}{l}\text { Pobla- } \\
\text { ción }\end{array}$ & $\begin{array}{l}\text { Estruc- } \\
\text { tura }\end{array}$ & $\begin{array}{l}\text { Pobla- } \\
\text { ción }\end{array}$ & $\begin{array}{l}\text { Estruc- } \\
\text { tura }\end{array}$ & $\begin{array}{l}\text { Pobla- } \\
\text { ción }\end{array}$ & $\begin{array}{l}\text { Estruc- } \\
\text { tura }\end{array}$ \\
\hline 0.4 & 11756 & 15,16 & 10508 & 17,67 & 22264 & 16,25 \\
\hline 5.9 & 10219 & 13,18 & 18613 & 14,48 & 18832 & 13,74 \\
\hline $10-14$ & 8965 & 11,56 & 7333 & 12,33 & 16298 & 11,89 \\
\hline $15-19$ & 7879 & 10,16 & 6064 & 10,20 & 13943 & 10,18 \\
\hline 20.24 & 6682 & 8,62 & 5015 & 8,43 & 11697 & 8,54 \\
\hline $25-29$ & 5844 & 7,54 & 4,004 & 6,73 & 9848 & 7,19 \\
\hline $30 \cdot 34$ & 4944 & 6,38 & 3407 & 5,86 & 8431 & 6,15 \\
\hline $35 \cdot 39$ & 4347 & 5,60 & 2932 & 4,96 & 7299 & 5,33 \\
\hline $40 \cdot 44$ & 3826 & 4,93 & 2604 & 4,38 & 6430 & 4,69 \\
\hline $45-49$ & 3238 & 4,18 & 2214 & 3,72 & 3452 & 3,98 \\
\hline $50-54$ & 2644 & 3,41 & 1826 & 3,07 & 470 & 3,26 \\
\hline $55-59$ & 2221 & 2,86 & 1457 & 2,45 & 3678 & 2,68 \\
\hline 60.64 & 1739 & 2,24 & 1192 & 2,01 & 2931 & 2,14 \\
\hline $65-69$ & 1283 & 1,65 & 906 & 1,52 & 2189 & 1,60 \\
\hline $70 y+$ & 1961 & 2,53 & 1304 & 2,19 & 3265 & 2,38 \\
\hline Total & 77548 & 100,00 & 59479 & 100,00 & 137027 & 100,00 \\
\hline
\end{tabular}




\section{b. Fecundidad}

Se considera que existen diferenciales de fecundidad según áreas de residencia. Es decir, existe una fecundida urbana y otra rural, cuya evolución es diferente. Como medida de fecundidad se utilizan tasas de fecundidad por edad detallada de las mujeres, entre 15 y 49 años, y como indicador resumen, que se denomina en lo sucesivo fecundidad total, se utiliza el número medio de hijos por mujer al cabo de su vida fértil (suma de las tasas de fecundidad por edades invidivuales).

Se han introducido tablas tipo, por edades de las tasas de fecundidad correspondientes a las de tres modelos diferentes: (i) alta fecundidad con cúspide dilatada, con FT $=6,2$ hijos; (ii) alta fecundidad con cúspide temprana, $\mathrm{FT}=4,5$ hijos y (iii) baja fecundidad con cúspide temprana, $\mathrm{FT}=3,7$ hijos. 15 /

Con respecto a la evolución de la fecundidad global (para el conjunto de áreas urbana y rural) se han elaborado dos hipótesis: una, que en adelante llamaremos FEl, se elaboró bajo la hipótesis de que el ritmo de crecimiento del producto latinoamericano es como en el pasado $(2,1$ por ciento per cápita anual) y que por lo tanto el nivel de vida (consumo) de los cuatro grupos sociales considerados en el cuadro 9 crecen a la misma tasa. La otra, que en adelante llamaremos FE2 y que se presenta en el cuadro 10 , se elaboró bajo la hipótesis de que el producto latinoamericano crece de tal forma que partiendo en 1971 con la tasa histórica llega a 1980 , en forma creciente, al cinco por ciento anual. De ahí en adelante continúa creciendo con la misma tasa.

En la primera parte del cuadro 9 se incluye la evolución del consumo per cápita, bajo la hipótesis de que éste crece como en el pasado histórico. En la segunda parte del mismo cuadro se presentan los valores de fecundidad. Para el año 1970, éstos son los mismos presentados en el cuadro 7. Para el resto de años, los valores surgen mediante interpolación de los valores de fecundidad de 1970 para el nivel de consumo correspondiente. $O$ sea, el valor de fecundidad de 5,82 para el año 2000 surge de interpolar entre los valores de 6,20 y 5,80 (año 1970), y el valor de 140 dólares de consumo del año 2000 es el que se encuentra entre 73 y 145 dólares en 1970.

15/ N.U., Boletín de población, № 7. 
Cuadro 9

PROYECCION DE PROGNOSIS (FE1). CONSUMO PER CAPITA

EN DOLARES Y FECUNDIDAD

\begin{tabular}{|c|c|c|c|c|c|c|c|c|c|}
\hline \multirow{2}{*}{$\begin{array}{l}\text { Tramo } \\
\text { de } \\
\text { ingreso }\end{array}$} & \multirow{2}{*}{$\begin{array}{l}\text { Por ciento } \\
\text { de } \\
\text { población }\end{array}$} & \multicolumn{4}{|c|}{$\begin{array}{l}\text { Consumo per cápita } \\
(2,1 \text { por ciento })\end{array}$} & \multicolumn{4}{|c|}{$\begin{array}{l}\text { Fecundidad. Número de hijos } \\
\text { por mujer al cabo edad fértil }\end{array}$} \\
\hline & & 1970 & 1980 & -1990 & 2000 & 1970 & 1980 & 1990 & 2000 \\
\hline $\begin{array}{l}\text { J } \\
\text { II } \\
\text { III } \\
\text { IV }\end{array}$ & $\begin{array}{r}40 \\
20 \\
35 \\
5\end{array}$ & $\begin{array}{r}73 \\
145 \\
410 \\
1576\end{array}$ & $\begin{array}{r}90 \\
178 \\
502 \\
1920\end{array}$ & $\begin{array}{r}112 \\
220 \\
618 \\
2367\end{array}$ & $\begin{array}{r}140 \\
275 \\
775 \\
2969\end{array}$ & $\begin{array}{l}\mathbf{6 , 2 0} \\
\mathbf{5 , 8 0} \\
\mathbf{4 , 9 0} \\
\mathbf{3 , 6 9}\end{array}$ & $\begin{array}{l}6,10 \\
5,61 \\
4,61 \\
3,69\end{array}$ & $\begin{array}{l}5,98 \\
5,48 \\
4,34 \\
3,69\end{array}$ & $\begin{array}{l}5,82 \\
5,31 \\
3,98 \\
3,69\end{array}$ \\
\hline Total & 100 & & & & & 5,54 & 5,36 & 5,19 & 4,97 \\
\hline
\end{tabular}

En el cuadro 10 se presentan los valores del consumo suponiendo que el ingreso crece hasta llegar a 5 por ciento per capita en 1980 y sus correspondientes valores de fecundidad. Esta hipótesis incluye además supuestos diferenciales con respecto al crecimiento de cada grupo social. Asi, el consumo del Grupo I y II crecen al 3,9 por ciento por año; mientras que los grupos III y IV crecen, respectivamente, al 2,7 y 1,7 por ciento por año. Esta hipótesis, como se comprenderá, abarca no sólo un aumento del producto per cápita más rápido que en el pasado, sino también una redistribución en los niveles de vida. 16 ]

Cuadro 10

PROYECCION DE POLITICA (FE2). CONSUMO PER CAPITA EN DOLARES Y FECUNDIDAD

\begin{tabular}{|c|c|c|c|c|c|c|c|c|c|}
\hline \multirow{2}{*}{$\begin{array}{l}\text { Tramo } \\
\text { de } \\
\text { ingreso }\end{array}$} & \multirow{2}{*}{$\begin{array}{c}\text { Por ciento } \\
\text { de } \\
\text { población }\end{array}$} & \multicolumn{4}{|c|}{$\begin{array}{c}\text { Consumo per cápita } \\
\text { (5 por ciento diferencial) }\end{array}$} & \multicolumn{4}{|c|}{ Fecundidad } \\
\hline & & 1970 & 1980 & 1990 & 2000 & 1970 & 1980 & 1990 & 2000 \\
\hline $\begin{array}{l}\text { I } \\
\text { II } \\
\text { III } \\
\text { IV }\end{array}$ & $\begin{array}{r}40 \\
20 \\
35 \\
5\end{array}$ & $\begin{array}{r}73 \\
145 \\
410 \\
1576\end{array}$ & $\begin{array}{r}107 \\
211 \\
525 \\
1835\end{array}$ & $\begin{array}{r}178 \\
345 \\
863 \\
2850\end{array}$ & $\begin{array}{r}289 \\
571 \\
1420 \\
4425\end{array}$ & $\begin{array}{r}6,2 \\
5,8 \\
4,9 \\
3,69\end{array}$ & $\begin{array}{l}\mathbf{6 , 0 1} \\
\mathbf{5 , 5 0} \\
\mathbf{4 , 5 5} \\
\mathbf{3 , 6 9}\end{array}$ & $\begin{array}{l}5,61 \\
5,09 \\
3,78 \\
3,69\end{array}$ & $\begin{array}{l}5,26 \\
4,44 \\
3,69 \\
3,69\end{array}$ \\
\hline Total & 100 & & & & & 5,54 & 5,28 & 4,78 & 4,47 \\
\hline
\end{tabular}

En el cuadro 11 se presentan los valores que resultan del cuadro 9 y los proyectados por el CELADE.

16/ El cuadro 10 ha sido tomado del documento "Transformación y desarrollo. La gran tarea de América Latina", en lo que se refiere a la hipótesis de redistribución de los niveles de vida. Los niveles de fecundidad constituyen una elaboración nuestra. 
Cuadro 11

NUMERO DE HIJOS POR MUJER AL CABO DE LA EDAD FERTIL

\begin{tabular}{lccc}
\hline Año & $\begin{array}{c}\text { Proyección } \\
\text { CELADE } \\
(1)\end{array}$ & $\begin{array}{c}\text { Resultados del } \\
\text { cuadro } 9 \\
(2)\end{array}$ & $\begin{array}{c}\text { Discrepancia } \\
(3)=1 / 2\end{array}$ \\
\hline 1970 & 5,50 & 5,54 & 0,99278 \\
1980 & 5,10 & 5,36 & 0,95149 \\
1990 & 4,60 & 5,19 & 0,88632 \\
2000 & 4,00 & 4,97 & 0,80483 \\
\hline
\end{tabular}

Como se puede apreciar, la hipótesis de que la economía crece como en el pasado arroja valores de fecundidad decrecientes con el correr del tiempo, y más elevados que la proyección efectuada por CELADE. Se interpreta que la discrepancia se debe al hecho de que nuestra proyección (la del cuadro 9) se obtiene a partir de una única variable explicativa: los niveles de vida medidos a través del consumo; y que no incluye otro conjunto de variables como cambios en las pautas de conducta, así como los mayores niveles educativos cuya intensidad, en cuanto a disminuir los niveles de fecundidad, puede no ser la misma que el efecto medido a través de los mayores niveles de consumo.

Por lo tanto, la discrepancia será considerada como el "resto de factores" no incluídos en el consumo, que intensifican la caída de la fecundidad.

Este coeficiente de discrepancia se aplica a la fecundidad promedio del cuadro 9 y del cuadro 10 , obteniéndose de este modo las dos hipótesis de fecundidad antes mencionadas.

Una vez obtenidos los valores de la fecundidad global, según las dos hipótesis, fue necesario derivar de ellos los correspondientes a la fecundidad rural y urbana para esos mismos años. Se estableció en primer término que la fecundidad total es resultante de un promedio de la fecundidad urbana y rural ponderadas por las respectivas proporciones de población urbana y rural. En símbolos:

(1) $\mathrm{FET}=\mathrm{GU}$ 的 FEU + (1-GU) के FER

donde FET simboliza la fecundidad total, número medio de hijos por mujeres, obtenida anteriormente.

GU representa a la proporción de población urbana, dentro del total; varía de acuerdo a la tendencia supuesta en las estimaciones de CELADE como se señala más adelante (véase el cuadro 13 ).

FEU simboliza la fecundidad urbana, que se trata de calcular. 
Cuadro 9

PROYECCION DE PROGNOSIS (FE1). CONSUMO PER CAPITA EN DOLARES Y FECUNDIDAD

\begin{tabular}{|c|c|c|c|c|c|c|c|c|c|}
\hline \multirow{2}{*}{$\begin{array}{c}\text { Tramo } \\
\text { de } \\
\text { ingreso }\end{array}$} & \multirow{2}{*}{$\begin{array}{l}\text { Por ciento } \\
\text { de } \\
\text { población }\end{array}$} & \multicolumn{4}{|c|}{$\begin{array}{l}\text { Consumo per cápita } \\
\text { ( } 2,1 \text { por ciento) }\end{array}$} & \multicolumn{4}{|c|}{$\begin{array}{l}\text { Fecundidad. Número de hijos } \\
\text { por mujer al cabo edad fértil }\end{array}$} \\
\hline & & 1970 & 1980 & -1990 & 2000 & 1970 & 1980 & 1990 & 2000 \\
\hline $\begin{array}{r}\text { I } \\
\text { II } \\
\text { III } \\
\text { IV }\end{array}$ & $\begin{array}{r}40 \\
20 \\
35 \\
5\end{array}$ & $\begin{array}{r}73 \\
145 \\
410 \\
1576\end{array}$ & $\begin{array}{r}90 \\
178 \\
502 \\
1920\end{array}$ & $\begin{array}{r}112 \\
220 \\
618 \\
2367\end{array}$ & $\begin{array}{r}140 \\
275 \\
775 \\
2969\end{array}$ & $\begin{array}{l}6,20 \\
5,80 \\
4,90 \\
3,69\end{array}$ & $\begin{array}{l}6,10 \\
5,61 \\
4,61 \\
3,69\end{array}$ & $\begin{array}{l}5,98 \\
5,48 \\
4,34 \\
3,69\end{array}$ & $\begin{array}{l}5,82 \\
5,31 \\
3,98 \\
3,69\end{array}$ \\
\hline Total & 100 & & & & & 5,54 & 5,36 & 5,19 & 4,97 \\
\hline
\end{tabular}

En el cuadro 10 se presentan los valores del consumo suponiendo que el ingreso crece hasta llegar a 5 por ciento per cápita en 1980 y sus correspondientes valores de fecundidad. Esta hipótesis incluye además supuestos diferenciales con respecto al crecimiento de cada grupo social. Asi, el consumo del Grupo I y II crecen al 3,9 por ciento por año; mientras que los grupos III y IV crecen, respectivamente, al 2,7 y 1,7 por ciento por año. Esta hipótesis, como se comprenderá, abarca no sólo un aumento del producto per cápita más rápido que en el pasado, sino también una redistribución en los niveles de vida. 16/

\section{Cuadro 10}

PROYECCION DE POLITICA (FE2). CONSUMO PER CAPITA EN DOLARES Y FECUNDIDAD

\begin{tabular}{|c|c|c|c|c|c|c|c|c|c|}
\hline \multirow{2}{*}{$\begin{array}{c}\text { Tramo } \\
\text { de } \\
\text { ingreso }\end{array}$} & \multirow{2}{*}{$\begin{array}{c}\text { Por ciento } \\
\text { de } \\
\text { población }\end{array}$} & \multicolumn{4}{|c|}{$\begin{array}{l}\text { Consumo per cápita } \\
\text { (5 por ciento diferencial) }\end{array}$} & \multicolumn{4}{|c|}{ Fecundidad } \\
\hline & & 1970 & 1980 & 1990 & 2000 & 1970 & 1980 & 1990 & 2000 \\
\hline $\begin{array}{l}\text { I } \\
\text { II } \\
\text { III } \\
\text { IV }\end{array}$ & $\begin{array}{r}40 \\
20 \\
35 \\
5\end{array}$ & $\begin{array}{r}73 \\
145 \\
410 \\
1576\end{array}$ & $\begin{array}{r}107 \\
211 \\
525 \\
1835\end{array}$ & $\begin{array}{r}178 \\
345 \\
863 \\
2850\end{array}$ & $\begin{array}{r}289 \\
571 \\
1420 \\
4425\end{array}$ & $\begin{array}{c}6,2 \\
5,8 \\
4,9 \\
3,69\end{array}$ & $\begin{array}{l}6,01 \\
5,50 \\
4,55 \\
3,69\end{array}$ & $\begin{array}{l}\mathbf{5 , 6 1} \\
\mathbf{5 , 0 9} \\
\mathbf{3 , 7 8} \\
\mathbf{3 , 6 9}\end{array}$ & $\begin{array}{l}\mathbf{5 , 2 6} \\
4,44 \\
\mathbf{3 , 6 9} \\
\mathbf{3 , 6 9}\end{array}$ \\
\hline Total & 100 & & & & & 5,54 & 5,28 & 4,78 & 4,47 \\
\hline
\end{tabular}

En el cuadro 11 se presentan los valores que resultan del cuadro 9 y los proyectados por el CELADE.

16/ El cuadro 10 ha sido tomado del documento "Transformación y desarrollo. La gran tarea de América Latina", en lo que se refiere a la hipótesis de redistribución de los niveles de vida. Los niveles de fecundidad constituyen una elaboración nuestra. 
Cuadro 11

NUMERO DE HIJOS POR MUJER AL CABO DE LA EDAD FERTIL

\begin{tabular}{lccc}
\hline Año & $\begin{array}{c}\text { Proyección } \\
\text { CELADE } \\
(1)\end{array}$ & $\begin{array}{c}\text { Resultados del } \\
\text { cuadro } 9 \\
(2)\end{array}$ & Discrepancia \\
\hline 1970 & 5,50 & 5,54 & $(3)=1 / 2$ \\
1980 & 5,10 & 5,36 & 0,99278 \\
1990 & 4,60 & 5,19 & 0,95149 \\
2000 & 4,00 & 4,97 & 0,88632 \\
\hline
\end{tabular}

Como se puede apreciar, la hipótesis de que la economía crece como en el pasado arroja valores de fecundidad decrecientes con el correr del tiempo, y más elevados que la proyección efectuada por CELADE. Se interpreta que la discrepancia se debe al hecho de que nuestra proyección (la del cuadro 9) se obtiene a partir de una única variable explicativa: los niveles de vida medidos a través del consumo; y que no incluye otro conjunto de variables como cambios en las pautas de conducta, así como los mayores niveles educativos cuya intensidad, en cuanto a disminuir los niveles de fecundidad, puede no ser la misma que el efecto medido a través de los mayores niveles de consumo.

Por lo tanto, la discrepancia será considerada como el "resto de factores" no incluídos en el consumo, que intensifican la caida de la fecundidad.

Este coeficiente de discrepancia se aplica a la fecundidad promedio del cuadro 9 y del cuadro 10 , obteniéndose de este modo las dos hipótesis de fecundidad antes mencionadas.

Una vez obtenidos los valores de la fecundidad global, según las dos hipótesis, fue necesario derivar de ellos los correspondientes a la fecundidad rural y urbana para esos mismos años. Se estableció en primer término que la fecundidad total es resultante de un promedio de la fecundidad urbana y rural ponderadas por las respectivas proporciones de población urbana y rural. En símbolos:

(1) $\mathrm{FET}=\mathrm{GU}$ FEU + (1 - GU) \& FER

donde FET simboliza la fecundidad total, número medio de hijos por mujeres, obtenida anteriormente.

GU representa a la proporción de población urbana, dentro del total; varía de acuerdo a la tendencia supuesta en las estimaciones de CELADE como se señala más adelante (véase el cuadro 13).

FEU simboliza la fecundidad urbana, que se trata de calcular. 
Cuadro 9

PROYECCION DE PROGNOSIS (FE1). CONSUMO PER CAPITA

EN DOLARES Y FECUNDIDAD

\begin{tabular}{|c|c|c|c|c|c|c|c|c|c|}
\hline \multirow{2}{*}{$\begin{array}{c}\text { Tramo } \\
\text { de } \\
\text { ingreso }\end{array}$} & \multirow{2}{*}{$\begin{array}{l}\text { Por ciento } \\
\text { de } \\
\text { población }\end{array}$} & \multicolumn{4}{|c|}{$\begin{array}{l}\text { Consumo per cápita } \\
(2,1 \text { por ciento })\end{array}$} & \multicolumn{4}{|c|}{$\begin{array}{l}\text { Fecundidad. Número de hijos } \\
\text { por mujer al cabo edad fértil }\end{array}$} \\
\hline & & 1970 & 1980 & -1990 & 2000 & 1970 & 1980 & 1990 & 2000 \\
\hline $\begin{array}{l}\text { I } \\
\text { II } \\
\text { III } \\
\text { IV }\end{array}$ & $\begin{array}{r}40 \\
20 \\
35 \\
5\end{array}$ & $\begin{array}{r}73 \\
145 \\
410 \\
1576\end{array}$ & $\begin{array}{r}90 \\
178 \\
502 \\
1920\end{array}$ & $\begin{array}{r}112 \\
220 \\
618 \\
2367\end{array}$ & $\begin{array}{r}140 \\
275 \\
775 \\
2969\end{array}$ & $\begin{array}{l}\mathbf{6 , 2 0} \\
\mathbf{5 , 8 0} \\
\mathbf{4 , 9 0} \\
\mathbf{3 , 6 9}\end{array}$ & $\begin{array}{l}6,10 \\
5,61 \\
4,61 \\
3,69\end{array}$ & $\begin{array}{l}5,98 \\
5,48 \\
4,34 \\
3,69\end{array}$ & $\begin{array}{l}\mathbf{5 , 8 2} \\
\mathbf{5 , 3 1} \\
\mathbf{3 , 9 8} \\
\mathbf{3 , 6 9}\end{array}$ \\
\hline Total & 100 & & & & & 5,54 & 5,36 & 5,19 & 4,97 \\
\hline
\end{tabular}

En el cuadro 10 se presentan los valores del consumo suponiendo que el ingreso crece hasta llegar a 5 por ciento per cápita en 1980 y sus correspondientes valores de fecundidad. Esta hipótesis incluye además supuestos diferenciales con respecto al crecimiento de cada grupo social. Así, el consumo del Grupo I y II crecen al 3,9 por ciento por año; mientras que los grupos III y IV crecen, respectivamente, al 2,7 y 1,7 por ciento por año. Esta hipótesis, como se comprenderá, abarca no sólo un aumento del producto per cápita más rápido que en el pasado, sino también una redistribución en los niveles de vida. $16 /$

Cuadro 10

PROYECCION DE POLITICA (FE2). CONSUMO PER CAPITA EN DOLARES Y FECUNDIDAD

\begin{tabular}{|c|c|c|c|c|c|c|c|c|c|}
\hline \multirow{2}{*}{$\begin{array}{c}\text { Tramo } \\
\text { de } \\
\text { ingreso }\end{array}$} & \multirow{2}{*}{$\begin{array}{c}\text { Por ciento } \\
\text { de } \\
\text { población }\end{array}$} & \multicolumn{4}{|c|}{$\begin{array}{c}\text { Consumo per cápita } \\
\text { (5 por ciento diferencial) }\end{array}$} & \multicolumn{4}{|c|}{ Fecundidad } \\
\hline & & 1970 & 1980 & 1990 & 2000 & 1970 & 1980 & 1990 & $\overline{2000}$ \\
\hline $\begin{array}{l}\text { II } \\
\text { III } \\
\text { IV }\end{array}$ & $\begin{array}{r}40 \\
20 \\
35 \\
5\end{array}$ & $\begin{array}{r}73 \\
145 \\
410 \\
1576\end{array}$ & $\begin{array}{r}107 \\
211 \\
525 \\
1835\end{array}$ & $\begin{array}{r}178 \\
345 \\
863 \\
2850\end{array}$ & $\begin{array}{r}289 \\
571 \\
1420 \\
4425\end{array}$ & $\begin{array}{c}6,2 \\
5,8 \\
4,9 \\
3,69\end{array}$ & $\begin{array}{l}\mathbf{6 , 0 1} \\
\mathbf{5 , 5 0} \\
\mathbf{4 , 5 5} \\
\mathbf{3 , 6 9}\end{array}$ & $\begin{array}{l}\mathbf{5 , 6 1} \\
\mathbf{5 , 0 9} \\
\mathbf{3 , 7 8} \\
\mathbf{3 , 6 9}\end{array}$ & $\begin{array}{l}5,26 \\
4,44 \\
3,69 \\
3,69\end{array}$ \\
\hline Total & 100 & & & & & 5,54 & 5,28 & 4,78 & 4,47 \\
\hline
\end{tabular}

En el cuadro 11 se presentan los valores que resultan del cuadro 9 y los proyectados por el CELADE.

16/ El cuadro 10 ha sido tomado del documento "Transformación y desarrollo. La gran tarea de América Latina", en lo que se refiere a la hipótesis de redistribución de los niveles de vida. Los niveles de fecundidad constituyen una elaboraciön nuestra. 
Cuadro 11

NUMERO DE HIJOS POR MUJER AL CABO DE LA EDAD FERTIL

\begin{tabular}{lccc}
\hline Año & $\begin{array}{c}\text { Proyección } \\
\text { CELADE } \\
(1)\end{array}$ & $\begin{array}{c}\text { Resultados del } \\
\text { cuadro } 9 \\
(2)\end{array}$ & Discrepancia \\
\hline 1970 & 5,50 & 5,54 & $(3)=1 / 2$ \\
1980 & 5,10 & 5,36 & 0,99278 \\
1990 & 4,60 & 5,19 & 0,95149 \\
2000 & 4,00 & 4,97 & 0,88632 \\
\hline
\end{tabular}

Como se puede apreciar, la hipótesis de que la economía crece como en el pasado arroja valores de fecundidad decrecientes con el correr del tiempo, y más elevados que la proy ección efectuada por CELADE. Se interpreta que la discrepancia se debe al hecho de que nuestra proyección (la del cuadro 9) se obtiene a partir de una única variable explicativa: los niveles de vida medidos a través del consumo; y que no incluye otro conjunto de variables como cambios en las pautas de conducta, así como los mayores niveles educativos cuya intensidad, en cuanto a disminuir los niveles de fecundidad, puede no ser la misma que. el efecto medido a través de los mayores niveles de consumo.

Por lo tanto, la discrepancia será considerada como el "resto de factores" no incluídos en el consumo, que intensifican la caida de la fecundidad.

Este coeficiente de discrepancia se aplica a la fecundidad promedio del cuadro 9 y del cuadro 10 , obteniéndose de este modo las dos hipótesis de fecundidad antes mencionadas.

Una vez obtenidos los valores de la fecundidad global, según las dos hipótesis, fue necesario derivar de ellos los correspondientes a la fecundidad rural y urbana para esos mismos años. Se estableció en primer término que la fecundidad total es resultante de un promedio de la fecundidad urbana y rural ponderadas por las respectivas proporciones de población urbana y rural. En símbolos:

(1) $\mathrm{FET}=\mathrm{GU}$ \& $\mathrm{FEU}+(1-\mathrm{GU})$ \& FER

donde FET simboliza la fecundidad total, número medio de hijos por mujeres, obtenida anteriormente.

GU representa a la proporción de población urbana, dentro del total; varía de acuerdo a la tendencia supuesta en las estimaciones de CELADE como se señala más adelante (véase el cuadro 13).

FEU simboliza la fecundidad urbana, que se trata de calcular. 
(I-GU) representa la proporción de población rural, dentro del total; es en consecuencia complemento al de $u$.

FER simboliza la fecundidad rural, que se trata de calcular.

Para resolver la relación (1) es preciso introducir un supuesto adicional, sea relativo al diferencial de fecundidad urbano-rural o a cualquier otro tipo de relación entre FET, FEU y FER. Se ha observado en varios países, y a través del tiempo, que la diferencia entre los niveles de fecundidad urbano y rural, varía según el nivel de fecundidad global sin que la variación se ajuste a un patrón general, alcanzando en promedio una discrepancia de 1,46: esto es, la fecundidad rural es 1,46 veces la fecundidad urbana. Este diferencial fue adoptado en este trabajo y se aplicó tanto a la hipótesis FE1 como en la FE2 de evolución de la fecundidad total.

La segunda condición expresada en símbolos es, por lo tanto:

(2) $\mathrm{FER}=\mathrm{d}$ \& FEU, donde $d$ representa el diferencial rural urbano de fecundidad. Es fácil deducir de las relaciones (1) y (2) el valor que toma ya sea FEU o FER, ya que se conoce FET y GU. Se tiene por ejemplo:

$\mathrm{FEU}=\mathrm{FET} / \mathrm{GU}+\mathrm{d}$ 的 $(\mathrm{I}-\mathrm{GU})$

que permite calcular la fecundidad urbana. Iuego, a través de la relación (2) se obtiene la fecundidad rural. Los resultados aparecen en el cuadro 12 .

Cuadro 12

EOVLUCION DE LA FECUNDIDAD URBANA Y RURAL, SEGUN LAS HIPOTESIS FE1 Y FE2 DE FECUNDIDAD TOTAL

\begin{tabular}{|c|c|c|c|c|c|c|}
\hline \multirow[b]{3}{*}{ Año } & \multicolumn{6}{|c|}{ Número medio de hijos por mujer } \\
\hline & . & \multicolumn{2}{|c|}{ ipótesis FE1 } & \multicolumn{3}{|c|}{ Hipótesis FE2 } \\
\hline & Total & Urbana & Rural & Total & Urbana & Rural \\
\hline 1970 & 5,5 & 4,53 & 6,66 & 5,50 & 4,53 & 6,66 \\
\hline 1980 & 5,1 & 4,30 & 6,32 & 5,02 & 4,24 & 6,23 \\
\hline 1990 & 4,6 & 3,94 & 5,79 & 4,24 & 3,63 & 5,34 \\
\hline 2000 & 4,0 & 3,45 & 5,07 & 3,60 & 3,10 & 4,56 \\
\hline
\end{tabular}

c. Migraciones rural-urbanas

Teniendo en cuenta la tendencia de la urbanización de América Latina, estimada por CELADE (Boletín Demográfico № 3 ), se establece que el volúmen de migrantes rural-urbanos debe alcanzar una cifra tal que la urbanización (porcentaje de la población urbana con respecto a la 
población total) resultante, siga esa tendencia. Para obtener una distribución por sexo y edad de los migrantes se utilizan las tasas de migración rural-urbanas, por sexo y edad, estimadas para Chile para el período 1952-1960.17 Aplicando dichas tasas a la población cerrada rural, obtenida para un momento dado (sobrevivientes de la población rural del periodo anterior, más los nacimientos ocurridos entre la población rural durante el periodo), se obtienen los migrantes netos por sexo y edad, cuyo número total se ajusta al grado de urbanización que se ha adoptado. En el cuadro 13 se presentan las cifras sobre evolución del porcentaje de población que se han adoptado en estas proyecciones.

Cuadro 13

EVOLUCION DEL PORCENTAJE DE POBLACION URBANA

EN AMERICA LATINA

\begin{tabular}{cc}
\hline Años & Porcentaje \\
& \\
1970 & 54,4 \\
1980 & 60,7 \\
1990 & 63,4 \\
2000 & 66,0 \\
\hline
\end{tabular}
d. Hipótesis sobre participación de la población en actividades
económicas.

Se han adoptado dos hipótesis sobre participación de la población en actividades económicas: la primera supone que las tasas de participación por sexo y edad, permanecen constantes a lo largo de los treinta años de proyección, de acuerdo a prácticas que son comunes en la estimación de oferta de mano de obra. Esta hipótesis se combina con las dos proyecciones de la población total provenientes de las dos hipótesis de fecundidad, la FEl y la FE2.

En la segunda hipótesis se supone que la participación por sexo y edad es variable en el tiemppo.

Se observa, en general, sin discriminar zonas de residencia que la participación femenina en su conjunto aumenta a medida que la fecundidad disminuye y que se abren oportunidades de trabajo para ellas. Sin embargo, ello no implica aumentos en todas las edades: ocurre que en el primer tramo de edades, 10 a 14 años, las tasas de participación pueden disminuir cuando hay cierto desarrollo debido a la extensión e intensificación de los servicios educativos.

17/ Proyección de la población urbana y rural de Chile, 1960-1980, por J. Pujol y J. Vidal (CELADE, inédito). 
Por otro lado, la participación masculina en actividades económicas se comprime, en general, frente a mejoramientos económicos y sociales, en particular en los tramos marginales de edad: menores de 15 años y mayores de 60 .

Este comportamiento es diferencial con respecto a las zonas rurales en comparación con las zonas urbanas, aunque con seguridad estos cambios se operan con mayor intensidad en las zonas urbanas. Por otro lado, muchos autores señalan que la captación censal de la participación en el campo es muy deficiente; apoyando la tesis que en las zonas 'rurales la participación se acerca al 100 por ciento, tanto en hombres como en mujeres.

Sobre esta base, algunos autores señalan que el proceso de desarrollo tendería a hacerla disminuir. Debido a estos problemas y al hecho de no haberse podido indagar en profundidad acerca de los posibles errores contenidos en las tasas de participación rural, a los fines de este trabajo, para las dos alternativas de fecundidad analizadas, se ha adoptado el criterio de que tanto la participación femenina como la masculina, en zonas rurales, se mantiene constante a lo largo del período de proyección.

Con respecto a la participación femenina urbana, se usó la ecuación de regresión, obtenida en el capítulo II, cuyo nivel depende de la tasa bruta de natalidad y por lo tanto, la participación resulta endógena al modelo. Con respecto a la participación masculina urbana se efectuó una hipótesis en la cual se verifica una disminución de la misma.

En forma similar al tratamiento dado a la mortalidad y fecundidad, se ha introducido en el modelo como índice sintético de participación, que facilita la operabilidad del modelo, la suma de las tasas de participación por edad. En el cuadro 14'se presentan en forma resumida las cifras correspondientes a las hipótesis sobre actividad.

Cuadro 14

NIVELES DE ACTIVIDAD POR SEXOS Y AREAS DE RESIDENCIA URBANA Y RURAL

(Suma de tasas por edad)

\begin{tabular}{|c|c|c|c|c|c|}
\hline \multirow{3}{*}{ Años } & \multicolumn{3}{|c|}{ Actividad constante } & \multicolumn{2}{|c|}{ Actividad variable urbana } \\
\hline & \multicolumn{2}{|c|}{ Rural } & Urbana & FE1 & FE2 \\
\hline & $\begin{array}{l}\text { Hom- } \\
\text { bres }\end{array}$ & $\begin{array}{l}\text { Muje- } \\
\text { res }\end{array}$ & $\begin{array}{l}\text { Hom- Muje- } \\
\text { bres res }\end{array}$ & $\begin{array}{l}\text { Hom- Muje- } \\
\text { bres res }\end{array}$ & $\begin{array}{l}\text { Hom- Muje- } \\
\text { bres res }\end{array}$ \\
\hline $\begin{array}{l}1970 \\
2000\end{array}$ & $\begin{array}{l}60,7 \\
60,7\end{array}$ & $\begin{array}{l}7,00 \\
7,00\end{array}$ & $\begin{array}{ll}44,70 & 14,45 \\
44,70 & 14,45\end{array}$ & $\begin{array}{lll}44,70 & 14,45 \\
44,70 & 18,58\end{array}$ & $\begin{array}{ll}44,70 & 14,45 \\
42,00 & 20,00\end{array}$ \\
\hline
\end{tabular}


En el caso de la actividad constante, los valores se dieron exógenamente y para los años intermedios de la proyección el modelo calculó, por interpolación, los valores del índice sintético. En el caso de actividad variable de los hombres, los valores también se dieron exógenamente. En cambio, los valores de la actividad femenina urbana, el modelo los calculó internamente según los niveles de tasa bruta de natalidad. Por tal razón, los valores para la hipótesis de FE2 son más altos que los que corresponden a la de FEl.

Se efectuaron proyecciones de población con dos hipótesis distintas de fecundidad, FE1 y FE2. Cada una de estas proy ecciones se combinó con las posibilidades de participación constante y variable, femenina y masculina de zonas urbanas. 


\section{LOS RESULTADOS Y SU SIGNIFICACION PARA LA PLANIFICACION}

En el punto anterior se han establecido dos hipótesis básicas para la proyección de la población y dos hipótesis acerca del comportamiento de la población económicamente activa, cuya combinación dio lugar a las proyecciones que ahora se pasan a comentar.

\section{LA POBLACION TOTAL}

Como se recordará, se establecieron dos hipótesis de variación de la fecundidad: en una primera, la fecundidad varía asociada a una hipótesis de que las condiciones económicas continúan como la tendencia del pasado. En términos de la planificación, esta hipótesis correspondería a las tareas previas a la formulación del plan en el cual se trata de determinar la magnitud y calidad de los problemas; es decir, a aquellas tareas que dicen relación con el diganóstico.

La segunda hipótesis de fecundidad está asociada a una evolución económica que supone la aplicación de una determinada política para alcanzar las metas que se propuso el plan. Supone una etapa más avanzada del proceso de planificación, en el cual se han definido las metas y algunas acciones de política y es necesario evaluar las repercusiones de la misma. En ambas proyecciones de la población, el resto de las variables demográficas (mortalidad, grado de urbanización) han seguido la misma evolución, en términos numéricos, en una y otra proyección. Este procedimiento se ha adoptado para evaluar, en forma aislada, el efecto de cambios en la fecundidad sobre el comportamiento demográfico y su posible repercusión en el proceso de planificación.

Hay que hacer notar que la diferencia de fecundidad global entre ambas alternativas, es al cabo de los treinta años de sólo 0,4 hijos: en la primera alternativa la fecundidad bajaría de 5,5 hije; promedio por mujer a 4,0 hijos; en la segunda alternativa, el descenso sería desde un promedio de 5,5 hijos por mujer a 3,6 hijos. Sin embargo, este descenso sería más importante de haberse hecho una hipótesis más fuerte con respecto a los niveles de vida de los estratos de más bajos ingresos. Estos alcanzan los 180 dólares de consumo anual per cápita, en esa hipótesis, recién hacia el año 1990 . Ese nivel puede considerarse un mínimo, 
incluso en términos de los patrones actuales ${ }^{*}$ y la política de desarrollo tendría que contemplar para esos grupos una superación más rápida en términos de sus niveles de vida. La disminución de 0,4 hijos por mujer, aunque pequeña, al cabo de los 30 años de la proyección, significa 20 millones de personas menos.18/ En otros términos, si en el plan se hubiera adoptado una única proyección de población, la primera, y no se hubiera adoptado una visión de largo plazo como esta de 30 años, se hubieran contemplado acciones dentro del plan para 20 millones de personas más que las que resultarian de una aproximación más realista al ligar el movimiento de la fecundidad con los cambios económicos. Además de la cifra anterior, 18 millones son niños (edad 0 a 14 años) con lo cual la visión del sector educación y salud infantil cambiaría sustancialmente.

También cambiaría la visión acerca del tamaño y composición de la demanda en el sentido de que si el plan se hubiera quedado con la primera alternativa de fecundidad habría calculado los requerimientos para un número de niños superior en un 7,5 por ciento.

Las diferencias entre la población que correspondería a la hipótesis del diagnóstico (FE1) y aquella que resultaría de la aplicación de una política de desarrollo (FE2) se puede apreciar en el cuadro 15.

Cuadro 1.3

AMERICA LATINA: DIFERENCIAS ENTRE LA POBLACION CON FEI Y LA POBI.ACION CON FE2

\begin{tabular}{ccc}
\hline Años & $\begin{array}{c}\text { Diferencia absoluta } \\
\text { (En iniles) }\end{array}$ & $\begin{array}{c}\text { Relación entre } \\
\text { población FE I y FE2 }\end{array}$ \\
\hline 1970 & 0,0 & 1,0000 \\
1975 & 108,3 & 1,0003 \\
1980 & 594,6 & 1,0016 \\
1985 & 1967,3 & 1,0047 \\
1990 & 5443,0 & 1,0113 \\
1995 & 11587,7 & 1,0211 \\
2000 & 20003,1 & 1,0322 \\
\hline
\end{tabular}

* "Elementos para la elaboración de una política de desarrollo con integración para América Latina", ILPES-CELADE, Santiago, 1968.

18/ Si se hubiera supuesto que la población del tramo I de la distribución de ingresos llegara a 180 dólares de consumo per cápita en el año 1980, en lugar de alcanzar esa cifra en el año 1990 , la proyección conduce a una estimación de 34 millones menos de personas en comparación con la proyección efectuada con la primera hipótesis de fecundidad FE 1 . 
La reducción más rápida de la fecundidad en la segunda alternativa, como cabía esperar al cabo de 30 años, no alcanza a influir en el numero de las personas de 65 años y más, mientras que los grupos de 15 a 64 años disminuyen en unos 2 millones de personas.

En consecuencia, la estructura por edad de la población sufre un pequeño envejecimiento en la segunda alternativa en comparación con la primera, como puede verse en el cuadro 16.

Cuadro 16

ESTRUCTURA DE LA POBLACION POR GRANDES GRUPOS DE EDADES (Cifras por cien habitantes)

\begin{tabular}{crrr} 
& 1970 & \multicolumn{2}{c}{2000} \\
$\begin{array}{c}\text { Grupos de } \\
\text { edades }\end{array}$ & & Población con fecundidad \\
\hline 0 - 14 & & FE1 & FE2 \\
$15-64$ & 42,42 & 40,01 & 38,39 \\
$65 y+$ & 53,83 & 56,14 & 57,63 \\
\hline
\end{tabular}

\section{LA POBLACION ECONOMICAMENTE ACTIVA}

Como se ha dicho anteriormente, en la proyección de la población económicamente activa, la práctica corriente ha consistido en man tener fijas las tasas específicas de participación o, si se trata de la población masculina, suponer un cierto descenso en las edades extremas. Fn esta oportunidad, se han incorporado las relaciones entre niveles de fecundidad y tasas de participación femenina aplicadas al área urbana.

i) En primer lugar, si en el proceso de diagnóstico (FEl) se hubiera supuesto que las tasas específicas de participación fueran constantes a lo largo del período de proyección, en desacuerdo con el supuesto de que al disminuir la fecundidad aumenta la participación femenina, al menos en las áreas urbanas, se hubiera estimado que la economía debe ofrecer en el año $2000,8,3$ millones de puestos de trabajo menos que los que las hipótesis más realistas indica. En otros términos, el tamaño de la oferta de trabajo con actividad constante es de 217,5 millones de personas, mientras que con participación femenina urbania variable, esta oferta alcanza la cifra de 225,8 millones de personas, como se pude ver en el cuadro 17.

Hay que destacar que este aumento de 8,3 millones de mujeres que se incorporarían a las actividades económicas plantea problemas distintos a los que supondria ocupar personas del sexo masculino. Las 
actividades en que intervendrían las mujeres serian distintas, tanto en términos de asignaciones sectoriales como en términos de los trabajos específicos a los que se dedicarían.

Cuadro 17

AMERICA LATINA: POBLACION ECONOMICAMENTE ACTIVA CON FECUNDIDAD FE 1 ACTIVIDAD CONSTANTE Y VARIABLE (En miles de personas)

\begin{tabular}{lrcc}
\hline & Total & Hombres & Mujeres \\
Actividad femenina urbana variable & 225842,5 & $\mathbf{1 7 0 4 8 2 , 6}$ & $\mathbf{5 5 3 5 9 , 9}$ \\
Actividad constante & 217538,3 & $\mathbf{1 7 0} 482,6$ & $\mathbf{4 7 0 5 5 , 7}$ \\
Diferencia & $\mathbf{8 3 0 4 , 2}$ & -- & $\mathbf{8 3 0 4 , 2}$ \\
\hline
\end{tabular}

ii) Las consideraciones efectuadas anteriormente son también relevantes en términos de la necesidad de incorporar más explicitamente las influencias recíprocas entre los aspectos económicos y los demográficos en el proceso de planificación y toma de decisiones, si se tienen en cuenta los siguientes elementos: Si el demógrafo hubiera supuesto una declinación más fuerte de la fecundidad, como la que se registra en la hipótesis FE2 comparada con la FE1, y se hubiera proyectado la población económicamente activa con participación constante, se concluiría que habría un millón de personas menos para ocupar puestos de trabajo, como se puede apreciar en el cuadro 18. Esta conclusión proviene justamente del hecho de haber supuesto una declinación más rápida de la fecundidad manteniendo constante, como muchas veces es la práctica, las tasas de participación.

Cuadro 18

AMERICA LATINA: POBLACION ECONOMICAMENTE ACTIVA EN DOS HIPOTESIS DE FECUNDIDAD (FE1, FE2), CON PARTICIP ACION CONSTANTE

(Miles de personas)

\begin{tabular}{crrr}
\hline Hipótesis de fecundidad & Total & Hombres & \multicolumn{1}{c}{ Mujeres } \\
\hline FE 1 & 217538,3 & 170482,6 & 47055,7 \\
FE 2 & 216442,9 & 169698,9 & 46744,0 \\
Diferencia & 1095,4 & 783,7 & 311,7 \\
\hline
\end{tabular}

De incorporarse la hipótesis más realista de' que el proceso de desarrollo, al menos para el área urbana, al inducir cambios en la 
fecundidad inducirá también aumentos en la participación femenina, se habrian obtenido unos requerimientos de puestos de trabajo mucho mayores, en lugar de una diminución de los mismos, con lo cual la visión cambia radicalmente. Ahora los 8,3 millones más de personas para ocupar puestos de trabajo se transforman en 10,6 millones adicionales de mujeres. En el cuadro 19 se pueden ver estos resultados.

Cuadro 19

AMERICA LATINA: POBLACION ECONOMICAMENTE ACTIVA CON FECUNDIDAD FE2, ACTIVIDAD CONSTANTE Y VARIABLE (Miles de personas)

\begin{tabular}{lrcc}
\hline & Total & Hombres & Mujeres \\
\hline Actividad femenina urbana variable & 226994,1 & 169698,9 & 57295,2 \\
Actividad constante & 216442,9 & 169698,9 & 46744,0 \\
Diferencia & 10551,2 & - & 10551,2 \\
\hline
\end{tabular}

iii) Para no recargar demasiado con el mismo tipo de efectos que implica el uso de una u otra hipótesis, se hará referencia por último a una comparación entre la primera al ternativa de fecundidad (FEl) con participación constante y la alternativa segunda de fecundidad 9FE2) con participación variable. Téngase en cuenta que hasta ahora se ha hecho variar la participación femenina urbana y mantenido constante la pariticipación de los hombres. Sin embargo, si es que se ha de producir un proceso de desarrollo, en el plan se habrán planteado metas con respecto a la educación, por un lado, y a los retiros por vejez, por el otro. Es de suponer que muchos de los niños (menoresde 14 años que trabajan como ocurre en la actualidad pasarán al sistema educativo y que muchos de los viejos (65 y más años de edad) en lugar de estar participando en las actividades económicas, estarán amparados por el sistema de seguridad social. Si éste es el caso, la hipótesis de mantener constante la actividad de los hombres en las zonas urbanas, aparece como incorrecta $y$ se hace necesario cuantificar el efecto de su disminución con lo cual se vuelve a cambiar nuevamente la visión del futuro incorporada en el plan.

En efecto, suponiendo que la participación de los hombres de las áreas urbanas disminuye y que la participación femenina aumenta como en los ejercicios anteriores, se llega a la conclusión que el plan debe contemplar 3,6 millones más de puestos de trabajo que los resultarán de una hipótesis de fecundidad no ligada al proceso de desarrollo (FEl) y tasas de actividad constantes. 
Cuadro 20

AMERICA LATINA: POBLACION ECONOMICAMFNTE ACTIVA

EN DOS HIPOTESIS DE FECUNDIDAD (FE] Y FE2) Y EN DOS

HIPOTESIS DE PARTICIPACION

(CONSTANTE Y VARIABIE)

(Miles de personas)

\begin{tabular}{lrrr}
\hline & Total & Hombres & Mujeres \\
\hline FE2, actividad urbana y variable & & & \\
para hombres y mujeres & 221183,9 & 163888,7 & 57295,2 \\
FE1, actividad constante & 217538,3 & 170482,6 & 47055,7 \\
Diferencia & 3645,6 & $-6593,9$ & 10239,5 \\
\hline
\end{tabular}

En apariencia, la cifra parece insignificante en términos cuantitativos y se podría decir que no sería necesario tanto refinamiento para llegar a una magnitud que difiere muy poco de la obtenida por un método menos sofisticado. Sin embargo, tal juicio no es cierto: la economía deberá suministrar 10,2 millones de puestos de trabajo a las mujeres y arbitrar los medios necesarios para retirar 6,6 millones de las actividades económicas. Esto, ciertamente, significa un cambio cualitativo muy importante que el planificador debe introducir explícitamente en su plan y que el demógrafo debe incorporar a sus proyecciones específicas para la planificación. 


\section{ANEXO 1 \\ NIVELES DE CONSUMO Y DE FECUNDIDAD 19/}

En el programa de Encuestas Comparativas de Fecundidad de América Latina para la zona urbana efectuada en 1963/64 se hace una pregunta acerca del monto de consumo familiar. Existe una tabulación que cruza el consumo de la familia con los niveles de fecundidad, definido como el número de hijos tenidos por la mujer en la edad de la misma en el momento de la entrevista. $\mathrm{La}$ pregunta “ ¿cuánto gasta semanalmente?", para relevar los niveles de consumo familiares es bastante vaga a pesar de que se pide que se excluy an los gastos que se refieren al arriendo. Es probable que, tal como está formulada la pregunta, los gastos declarados por unas y otras mujeres no sean comparables por la inclusión o no de algunos tipos de gastos. Esto es importante en lo que se refiere a los gastos de consumo en bienes durables. Por ejemplo, si alguna familia hizo un gasto en durables de consumidor en la fecha de la encuesta, es probable que esté incluido en la respuesta dada. Esto de por si no sería correcto, puesto que lo que hubiera correspondido sería repartir proporcionalmente ese gasto y otros durante todo el año imputando a la semana sólo la parte proporcional. Si al mismo tiempo otras familias no han hecho un gasto en durables de consumidor y a su vez, no han imputado la parte proporcional que corresponde a los mismos, comprados en otras fechas, se plantea el problema de que los tramos de consumo pueden aparecer distorsionados en sus valores absolutos. Así, una familia que normalmente tiene bajos niveles de ingreso y por lo tanto de consumo, puede aparecer en esta encuesta con niveles altos.

El segundo tipo de porblema que se presenta para el análisis de estos datos radica en el hecho de que el tamaño medio de la familia no necesariamente es creciente a medida que crecen los gastos de consumo familiares; $y$, el hecho de que el dato de consumo se refiere al de la familia plantea una serie de dificultades para analizar los valores de la fecundidad que arroja la encuesta ya que no se preguntó el tamaño medio de la familia.

Por otra parte, los tramos de ingreso familiar de un país con otro no son comparables puestos que éstos definieron al nivel de cada país. Se

19/ En esta parte del trabajo colaboró el señor Gérard Fichet del ILPES. 
consideró el nivel de consumo más bajo arrojado por la encuesta y el nivel más alto, y sobre esta base se construyeron nueve tramos de consumo mediante una interpolación a intervalo constante entre el más bajo y el más alto.

Quedan plantea planteados en la encuesta dos tipos de homogeneizaciones a los efectos de la comparabilidad: uno, llevar los datos a una base per cápita; dos: llevarlos a una base monetaria común. Para ello se hace necesario combinar información de tamaño medio de la familia según tramo de consumo y transformar los valores monetarios nacionales en una unidad monetaria común, o sea, dólares de Estados Unidos. En las tablas siguientes se muestran las hipótesis de tamaño medio de familia que hemos utilizado para cada uno de los tramos individuales de las encuestas y los tipos de cambio de paridad que se usaron para transformar en dólares a las unidades monetarias nacionales. 


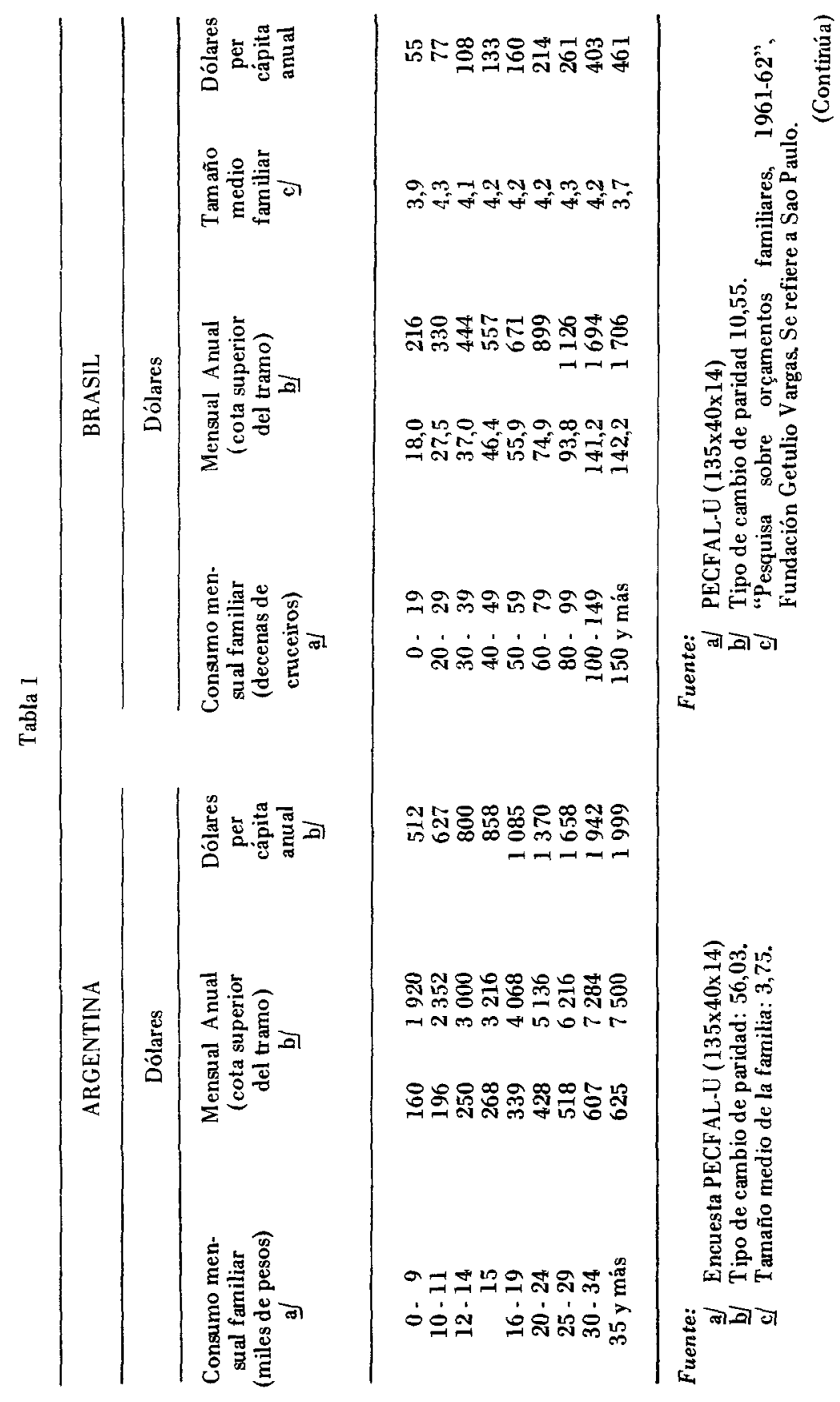




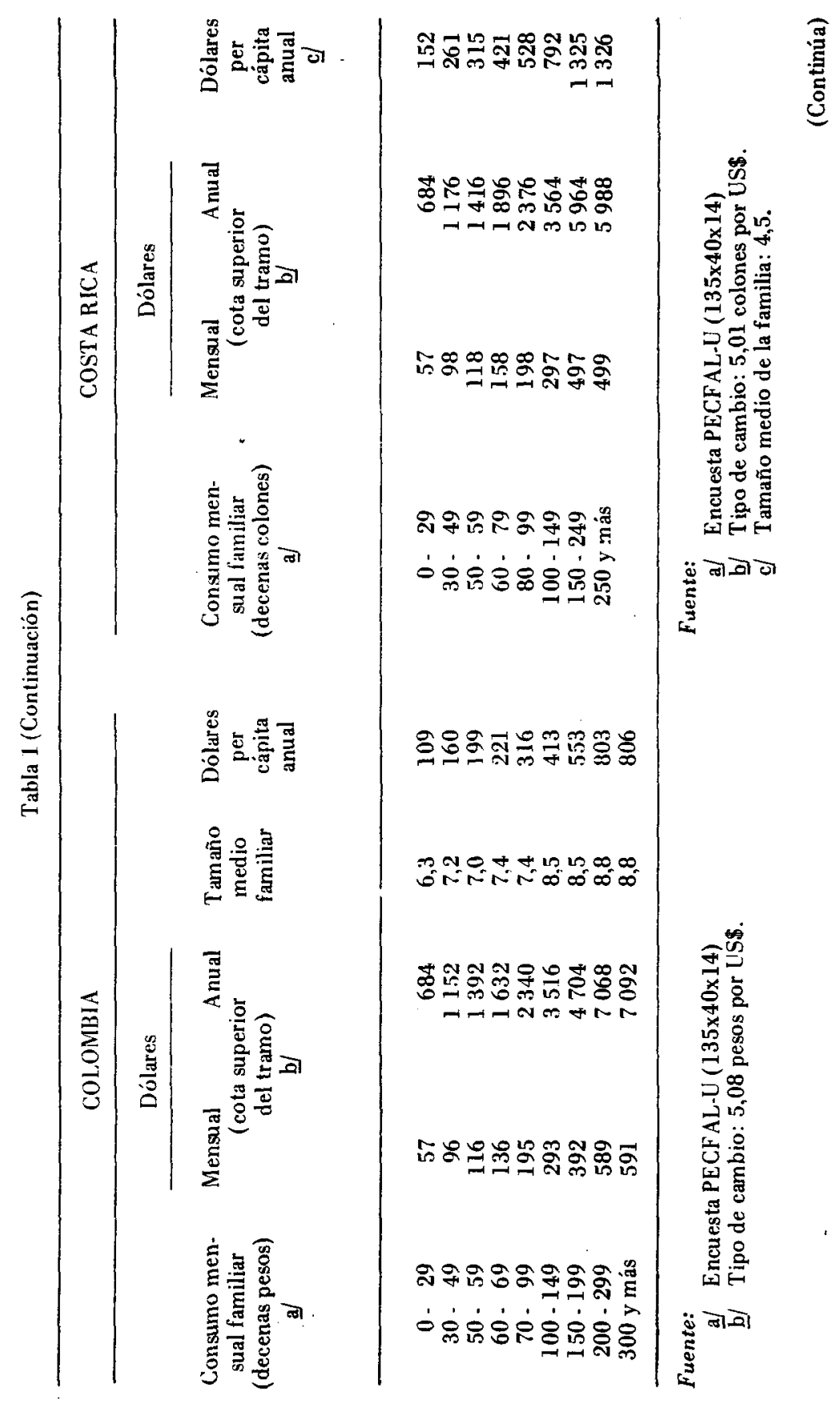

114 


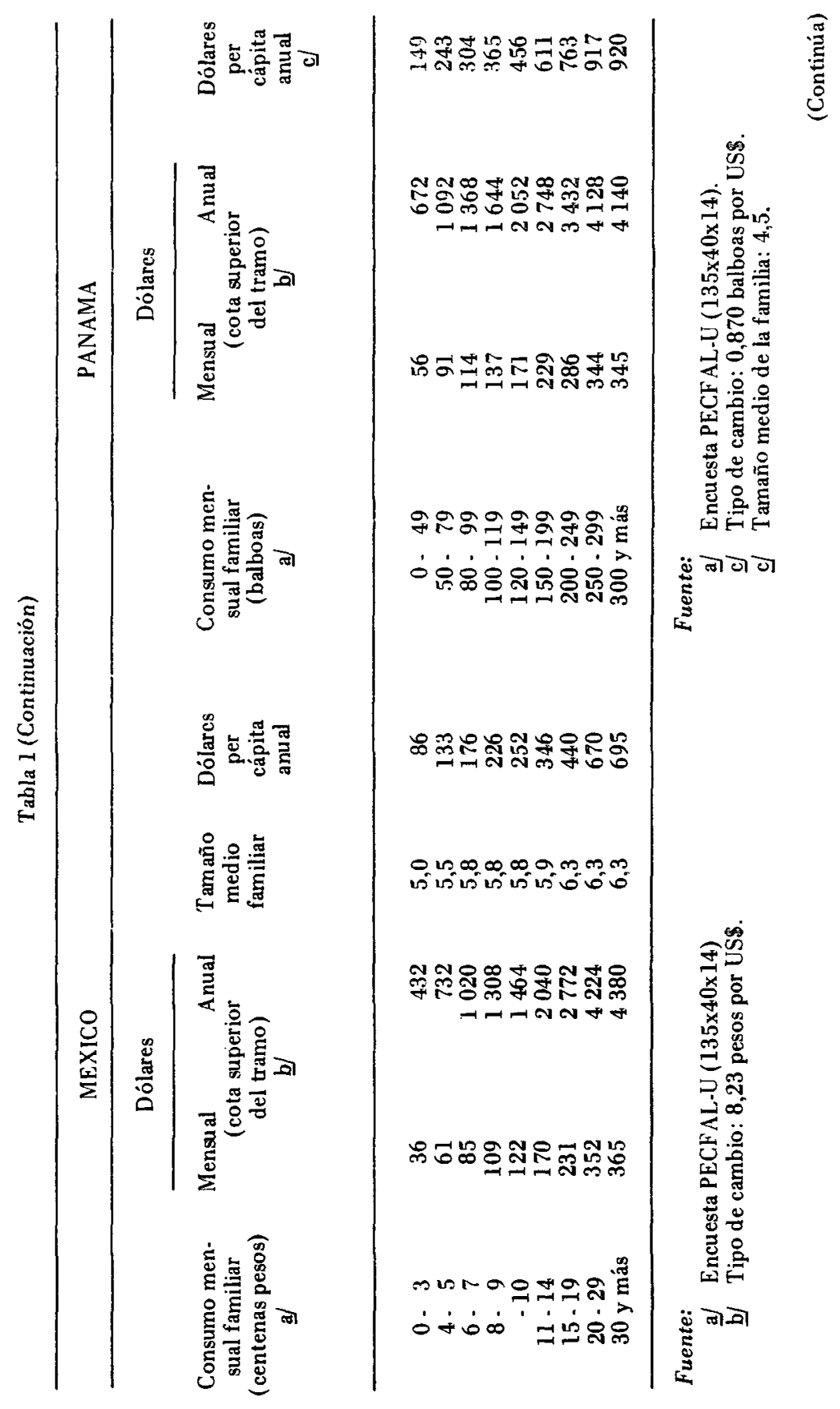


Tabla 1 (Conclusión)

VENEZUELA

\begin{tabular}{|c|c|c|c|c|}
\hline \multirow{2}{*}{$\begin{array}{l}\text { Consumo mensual } \\
\text { familiar } \\
\text { (centenas de } \\
\text { bolívares) } \\
\text { a }\end{array}$} & \multicolumn{2}{|l|}{ Dólares } & \multirow{2}{*}{$\begin{array}{l}\text { Tamaño } \\
\text { medio } \\
\text { familiar }\end{array}$} & \multirow{2}{*}{$\begin{array}{l}\text { Dólares } \\
\text { per } \\
\text { cápita } \\
\text { anual }\end{array}$} \\
\hline & $\begin{array}{l}\text { Mensual } \\
\text { (cota superior del } \\
\text { b/ }\end{array}$ & $\begin{array}{l}\text { Anual } \\
\text { (tramo) }\end{array}$ & & \\
\hline $0-9$ & 195 & 2340 & 4,5 & 52 \\
\hline $10 \cdot 19$ & 412 & 4944 & 5,2 & 95 \\
\hline $20-29$ & 629 & 7548 & 5,5 & 137 \\
\hline $30-39$ & 846 & 10152 & 5,4 & 187 \\
\hline $40-49$ & 1063 & 12756 & 6,4 & 199 \\
\hline $50-69$ & 1497 & 17964 & 5,8 & 310 \\
\hline $70-99$ & 2148 & 25776 & 5,8 & 444 \\
\hline $100-149$ & 3232 & 38784 & 5,8 & 668 \\
\hline 150 y más & 3254 & 39048 & 5,8 & 673 \\
\hline
\end{tabular}

Fuente:

a/ Encuesta PECFAL-1! (135x40x 14)

b) Tipo de cambio: 4,61 bolivares por US\$.

Los consumos per cápita así obtenidos, reemplazaron a los valores originales de la encuesta PECFAL-Urbano. Estos y los datos de fecundidad por edad de la mujer entrevistada se presentan en el apéndice.

Tabla 2

CORRELACIONES ENTRE FECUNDIDAD Y CONSUMO PER CAPITA Y EDAD DE LA MUJER

\begin{tabular}{|c|c|c|c|c|c|}
\hline \multirow[b]{2}{*}{ Pais } & \multicolumn{3}{|c|}{ Variable explicativa } & \multirow[b]{2}{*}{$\mathrm{R}^{2}$} & \multirow[b]{2}{*}{$\begin{array}{l}\mathrm{N}^{6} \\
\text { Obser }\end{array}$} \\
\hline & Constante & Consumo & Edad & & \\
\hline $\begin{array}{l}\text { Argentina } \\
\quad \text { error estándar }\end{array}$ & 0.6570 & $\begin{array}{c}0,00012 \\
(0,00015)\end{array}$ & $\begin{array}{c}0,2335 \\
(0,0325)\end{array}$ & 0,5703 & 42 \\
\hline $\begin{array}{l}\text { Brasil } \\
\quad \text { error estándar }\end{array}$ & 1,778 & $\begin{array}{l}-0,0019 \\
(0,0005)\end{array}$ & $\begin{array}{c}0,3987 \\
(0,04,22)\end{array}$ & 0,6662 & 54 \\
\hline $\begin{array}{l}\text { Colom bia } \\
\text { error estándar }\end{array}$ & 1,9770 & $\begin{array}{l}-0,00122 \\
(0,00074)\end{array}$ & $\begin{array}{c}0,7940 \\
(0,0947)\end{array}$ & 0,6175 & 48 \\
\hline $\begin{array}{l}\text { México } \\
\quad \text { error estándar }\end{array}$ & 2,2421 & $\begin{array}{l}-0,00063 \\
(0,00062)\end{array}$ & $\begin{array}{c}0,6409 \\
(0,0714)\end{array}$ & $0,64,26$ & \\
\hline $\begin{array}{l}\text { Panamá } \\
\quad \text { error estándar }\end{array}$ & 2,3811 & $\begin{array}{l}-0,0008 \\
(0,0004)\end{array}$ & $\begin{array}{c}0,3713 \\
(0,0646)\end{array}$ & 0,4447 & 48 \\
\hline $\begin{array}{l}\text { Venezuela } \\
\quad \text { error estándar }\end{array}$ & 2,1848 & $\begin{array}{l}-0,00118 \\
(0,00062)\end{array}$ & $\begin{array}{c}0,5466 \\
(0,0719)\end{array}$ & 0,6493 & 36 \\
\hline
\end{tabular}

Fuente: Datos de Encuesta PECFAL-U (cruce 135x40x14), todas las edades. 
Sobre la base de los mismos, se procedió a ajustar por mínimos cuadrados una recta de regresión en los valores naturales, cuya variable dependiente es la fecundidad y las variables explicativas son los niveles de consumo per cápita en dólares y la edad. El resultado de las regresiones por paises se puede ver en la tabla 2 .

En primer lugar, cabe observar que, con la excepción de la Argentina, los coeficientes que multiplican al consumo per cápita son negativos y los que multiplican a la edad de la mujer son positivos, como cabía esperar.

Los coeficientes que multiplican a la edad de la mujer son todos significativamente distintos de ccero al nivel 99 por ciento de confianza. En cambio, los coeficientes que multiplican al consumo per cápita no son significativamente distintos de cero, al nivel del 95 por ciento de confianza. La única excepción es la del Brasil, cuyo coeficiente del consumo es significativamente distinto de cero.

Observando los datos de la encuesta se puede ver que en las edades de 45 a 49 años el número de hijos, en la generalidad de los casos, es menor que en las edades de 40 a 44 años. En otros términos, la distribución de frecuencias acumuladas para cada nivel de consumo presenta una caída en la edad de 45 a 49 años.

Por ejemplo, en el caso de México, la distribución de frecuencias acumuladas alcanza un valor de seis hijos para la edad de 40 a 44 años, mientras que para las edades de 45 a 49 cae a cuatro hijos. Esta caida podría dar lugar a dos tipos de consideraciones. Una, que las mujeres de 45 a 49 años han olvidado parte de los hijos que han tenido en su vida reproductiva; $y$, la otra, que el punto de cuatro hijos corresponde a una distribución de frecuencia acumulada que reconoce una pauta distinta a la de las mujeres de 40 a 44 años. Esta última hipótesis significaría que la fecundidad en México ha ido creciendo a través del tiempo. Sin embargo, esta hipótesis parece difícil de sostener dado que la fecundidad de México ha sido elevada, según los conocimientos que se tiene acerca de ellas en el pasado, y que resulta difícil justificar un cambio tan notable en la fecundidad de mujeres que sólo difieren en 5 años en promedio de edad.

Consideraciones similares se pueden hacer para el resto de los países en aquellos casos en que la distribución de frecuencias acumuladas registra variaciones que no se pueden explicar, salvo por deficiencias en la captación de la encuesta.

Sobre la base de estas consideraciones hemos procedido a rehacer las regresiones elimeliminando el último tramo de edad (45 - 49 años), excepto para Brasil en que, como se vio anteriormente, la correlación es estadísticamente significativa.

Como se puede observar, el coeficiente de correlación $\left(\mathrm{R}^{2}\right)$ aumenta notablemente en todos los países, cuando se elimina la edad 45 a 49 años. En los casos de México, Panamá y Venezuela, los coeficientes que 
multiplican al consumo per cápita tienen signo negativo y son significativamente distintos de cero al nivel de 95 por ciento de confiabilidad. En los casos de Colombia y Argentina, tales coeficientes no son significativamente distintos de cero.

En resumen, sólo en dos de los seis países analizados no se verifica la reiación esperada entre fecundidad y niveles de consumo. En el caso de la Argentina, se puede deber al hecho de que los niveles de consumo que relevó la encuesta son altos (el tramo inferior es hasta 512 dólares) y que ya a esos niveles no se verifica la relación negativa entre fecundidad y nivel de vida.

Tabla 3

CORRELACIONES ENTRE FECUNDIDAD, CONSUMO PER CAPITA Y EDAD DE LAS MUJERES

\begin{tabular}{|c|c|c|c|c|c|}
\hline Pais & Constante & Consumo & Edad & $\mathrm{R}^{2}$ & $\begin{array}{l}N^{\circ} \\
\text { Observ. }\end{array}$ \\
\hline $\begin{array}{l}\text { Argentina } \\
\quad \text { error estándar }\end{array}$ & 0,4873 & $\begin{array}{c}0,00008 \\
(0,00014)\end{array}$ & $\begin{array}{c}0,3230 \\
(0,0366)\end{array}$ & 0,7010 & 35 \\
\hline $\begin{array}{l}\text { Colombia } \\
\quad \text { error estándar }\end{array}$ & 1,2028 & $\begin{array}{l}-0,0004 \\
(0,0004)\end{array}$ & $\begin{array}{c}1,0061 \\
(0,0692)\end{array}$ & 0,8501 & 40 \\
\hline $\begin{array}{l}\text { México } \\
\quad \text { error estándar }\end{array}$ & 1,646 & $\begin{array}{l}-0,0010 \\
(0,0004)\end{array}$ & $\begin{array}{c}0,9456 \\
(0,0612)\end{array}$ & 0,8675 & 40 \\
\hline $\begin{array}{l}\text { Panamá } \\
\quad \text { error estándar }\end{array}$ & 2,2039 & $\begin{array}{l}-0,0013 \\
(0,0004)\end{array}$ & $\begin{array}{c}0,5415 \\
(0,0727)\end{array}$ & 0,6349 & 40 \\
\hline $\begin{array}{l}\text { Venezuela } \\
\quad \text { error estándar }\end{array}$ & 1,8113 & $\begin{array}{l}-0,00156 \\
(0,00056)\end{array}$ & $\begin{array}{c}0,7437 \\
(0,0790)\end{array}$ & 0,7777 & 30 \\
\hline
\end{tabular}

Fuente: Datos de Encuesta PECFAL-U (cruce $135 \times 40 \times 14$ ), eliminando la edad de 45 a 49 años. 


\section{ANEXO II \\ I. ECUACIONES DEL SUBMODELO DEMOGRAFICO 20}

En la parte A se establecen las convenciones para ser utilizadas en la formación de las palabras con que se designan los nombres de las variables. En la parte $B$ se presenta el modelo demográfico en forma resumida para facilitar una pirmera visión del mismo. En la parte $\mathrm{C}$ se describen las ecuaciones de que consta el modelo demográfico y en la parte $\mathrm{D}$ se describe la manera de operarlo.

\section{A. Convenciones a utilizar}

a) Las palabras se formarán con las siguientes letras básicas
1. $\mathrm{N}=$ población, en número de personas
$2.1 \mathrm{~F}=$ femenino
$2.2 \mathrm{M}=$ masculino
$3.1 \mathrm{U}=$ urbano
$3.2 \mathrm{R}=$ rural
4. $\mathrm{E}=$ emigración
5. $\mathrm{C}=$ coeficiente o tasa
6. $\mathrm{J}=$ edad
7. $\mathrm{I}=$ tiempo
8. $\mathrm{P}=$ relación de supervivencia
9. $\mathrm{PB}=$ relación de supervivencia de los nacimientos
10. $\mathrm{FE}=$ fecundidad
11. Il $=$ año final de la proyección
12. $\mathrm{J} 5=$ edad final considerada
i3. $\mathrm{PEA}=$ población económicamente activa
14. $\mathrm{T}=$ total

Por convención la edad cero se toma como edad uno.

Para formar las palabras, las letras se ordenan, en general, de la siguiente forma: la primera letra será $\mathrm{N}$; la segunda $\mathrm{F}$ ó $\mathrm{M}$ según corresponda; la tercera $U$ ó $\mathrm{R}$ y la última, E. Cuando se trata de un coeficiente, la letra $\mathrm{C}$ se antepone al concepto que designe.

20/ Una visión gráfica del modelo y sus interrelaciones con el modelo económico se puede apreciar en el gráfico 1 . 
Las letras I, J, Il y J5 son subíndices y por convención se colocarán al lado de la palabra entre paréntesis separadas por coma. Los conceptos $P, P B$ y FE se anteponen al nombre que designen. Así, PBMR significa: relación de supervivencia $(\mathrm{PB})$, masculina $(\mathrm{M})$, de área rural $(\mathrm{R})$.

b) El orden en que están escritas las ecuaciones es importante. La convención que se hace es que se comienza por calcular la ecuación 1 para el año 1 y se continúa calculando la ecuación 2 para el mismo año, hasta terminar con todas las ecuaciones. En el período siguiente se vuelve a comenzar por la ecuación 1 hasta calcular la última ecuación y así sucesivamente. En otras palabras el cálculo es secuencial.

De este modo cuando, por ejemplo, aparece una variable a la izquierda de un signo de igualdad, que no tiene subíndice de tiempo, ello significa que el valor que esa variable tenía en el periodo anterior o en alguna ecuación anterior, es reemplazado por el valor que adquiere en el momento presente del cálculo.

c) En algunos casos, a los fines de no repetir ecuaciones cuya única diferencia reside en un simple cambio de nombre procederemos a escribirlas en forma general indicando en cada caso las categorias de clasific ación a las que se aplican.

Supongamos que se quiera efectuar la siguiente operación

$$
A=(B+C) / D
$$

varias veces cambiando de una a otra vez sólo el nombre de las variables. En este procedimiento entran las variables A, B, C, D y para dejar indicado esto, a las mismas se las coloca entre paréntesis separadas por comas. 0 sea,

(al) $(\mathrm{A}, \mathrm{B}, \mathrm{C}, \mathrm{D}) \mathrm{y}$

(a2) $A=(B+C) / D$ es la forma genérica de definir un procedimiento de cálculo

Cuando hay a necesidad de cambiar los nombres de las variables bastará indicarse en la forma al. Así, si se quieren usar las variables $E$, $\mathrm{F}, \mathrm{G}, \mathrm{H}$, éstas se indican entre paréntesis.

(a'l) $(E, F, G, H)$ y (a'2) automátic amente quedará escrita $E=(F+G) / H$

En la forma al el orden es importante: indica también el lugar que las variables ocupan en la ecuación a2. Las variables que ocupan el segundo y tercer lugar se suman, la cuarta es un divisor y la primera el lugar donde se coloca el resultado de la operación.

\section{B. Resumen del modelo demográfico}

A continuación se presenta el modelo demográfico en forma resumida para facilitar una primera visión panorámica del mismo. La definición y contenido de cada una de las variables se expone en la parte de definición de datos. 
(a) $\quad N(J, I)=F 1(N(J-1, I-1), F E(J, I), P(J, I), C E(J, I))$

La población $N$ por edad $J$ en el período I es una función $\mathrm{Fl}$ que depende de la población que en el periodo anterior tenía un año menos, de la fecundidad por edad ( $F E$ ), de las relaciones de supervivencia $(\mathrm{P})$, y de los coeficientes de emigración del campo a la ciudad (CE). El cálculo se hace por sexo, edad y urbano-rural.

(b) $P E A(J, I)=F 2(N(J, I), C A(J, I))$

La población económicamente activa (PEA) es una función $\mathrm{F} 2$ de la población por edad $\mathrm{N}$ y de los coeficientes de actividad (CA)

(c.1) $F E T(I)=F 3(S(I))$

(c.2) FET (I) =Exógeno

(c.3) $F E T(I)=F 4$ (S ( $)$, Exógeno)

Para la fecundidad total (FET) hay tres formas alternativas: la primera que sea función (F3) de las condiciones socio-económicas de los grupos sociales (S). Estas condiciones surgen como resultado del modelo económico.

La segunda alternativa es que la fecundidad se dé exógenamente, desde afuera del modelo, sobre la base de un estudio específico de variación posible de la fecundidad.

La tercera al ternativa es una combinación de factores sociales y exógenos que determinan el nivel de fecundidad total.

(d) FE $(J, I)=F 5(F E T$ (I))

La distribución de fecundidad, por edades, depende $o$ es función del nivel de la fecundidad total

(e.1) $P T(I)=F 6(S(I))$

(e.2) $P T(I)=$ Exógeno

(e.3) $P T(I)=F 7(S(I)$, Exógeno)

La relación total de supervivencia se determina de la misma forma indicada para la fecundidad. 
(f) $P(J, I)=F 8(P T(I))$

La distribución por edades de la relación de supervivencia depende del nivel de la fecundidad total

(g.1) $C A T(I)=F 9(F E T(I), S(I))$

(g.2) CAT $(I)=$ Exógeno

(g.3) CAT (I) =F10 (FET (I), S(I), Exógeno)

$\mathrm{Al}$ igual que en el conjunto de ecuaciones (c) los coeficientes de actividad total presentan tres alternativas de cálculo.

La primera depende del nivel de fecundidad total y de factores socio-económicos. La segunda se considera exógena; y, en la tercera se combinan ambos elementos.

(h) $\quad C A(J, I)=F 11(C A T(I))$

La distribución de las tasas por edades depende del nivel absoluto de la tasa de participación total.

\section{Las ecuaciones especificas del modelo demográfico}

A grandes rasgos el cálculo comprende cuatro etapas. La primera etapa tiene por objeto calcular la población cerrada (ecuaciones 1, 2, 3, 4, 5 y 6). El cálculo se hace por edad, sexo y \%ona de residencia urbano-rural aunque en esta etapa se supone que no hay emigraciones del campo a la ciudad.

Las migraciones internas, del campo a la ciudad, se calculan por medio de las ecuaciones 7 a 13, y la población abierta en las ecuaciones 15 a 20 . Finalmente, en las ecuaciones 21 a 25 , se calcula la población cconómicamente activa.

\section{(i) Población cerrada}

En las tres ecuaciones (1), (2) y (3) se usa el nombre genérico $\mathrm{N}$ pero el cálculo se hace por separado por sexo (el cálculo de las mujeres se hace primero) clasificado por zona de residencia (urbano-rural). Las variables genéricas que se utilizan en las tres ecuaciones son:

(A) $(N, P, F E, P B, C O, N F)$

(1) $N(J, I)=N(J-1, I-1)$ 的P(J-1,I-1) J $=2, \ldots, J 5-1$

La población $\mathrm{N}$ de edad $\mathrm{J}$ en el período 1 es el número de personas 
que tenían en el periodo anterior un año menos de edad multiplicado por la relación de supervivencia $P$.

Esta ecuación se aplica para las edades comprendidas entre 2 y $\mathrm{J} 5-1$.

Las edades 1 y $\mathrm{J} 5$ se calculan en las dos ecuaciones siguientes

(2)

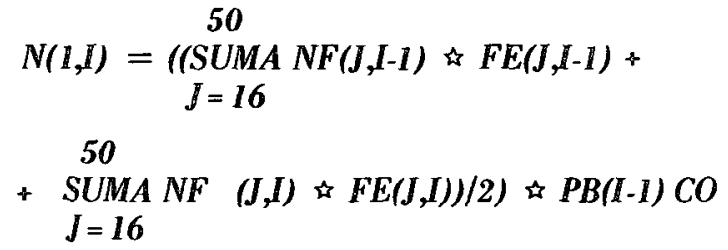

El número de nacimientos $(\mathrm{N}(1))$ de un año I se obtiene sumando los productos de las tasas de fecundidad por edad (FE) de las mujeres en edad fértil (entre 16 y 50 años o edades entre 15 y 49). Los nacimientos de un período I, I+ 1 resultan como promedio de los ocurridos entre I y en I+ 1. Los sobrevivientes de los nacimientos con edad entre 1 y 2 (edades 0-1) se obtienen multiplicando los nacimientos de un período por la relación de supervivencia de los nacimientos (PB). El coeficiente CO separa los hombres de las mujeres.

(3) $N(J 5, I)=N(J 5-1, I-1)$ मे $P(J 5-1, I-1)+N(J 5, I-1)$ के $P(J 5, I-1)$

Las personas $\mathbf{N}$ de edad $\mathrm{J} 5$ se obtienen sumando a los supervivientes de la edad anterior, aquellos que sobreviven de la edad J5. Este procedimiento se adopta porque lo que se ha denominado edad $J 5$ es edad $J 5$ y más.

Para el cálculo efectivo, las variables genéricas definidas en (A) adquieren las siguientes expresiones:

(B) (NFU, PF, FEU, PBF, 0,4878, NFU)

(C) (NMU, PM, FEU, PBM, 0,5122, NFU)

(D) (NFR, PF, FER, PBF, 0,4878, NFR)

(E) (NMR, PM, FER, PBM, 0,5122, NFR) 
Asi el reemplazo.de los nombres que figuran en (A) por los que figuran en (B) y su correspondiente reemplazo en las expresiones (1), (2) y (3) permite calcular la población femenina urbana (NFU). Para ello se utiliza la relación de supervivencia propia de las mujeres (PF) que se supone igual para el área rural y el área urbana, la fecundidad urbana (FEU) y la relación de supervivencia de los nacimientos femeninos (PBF) donde tampoco se distingue diferenciales urbano-rurales. Similarmente se opera con B, C y D, calculándose, de este modo la población masculina urbana(NMU), la población femenina rural (NFR) y la población masculina rural (NMR).

La población total se puede calcular ahora por simple suma:

(4) $\quad N F(J, I)=N F R(J, I)+N F U(J, I)$

(5) $\quad N M(J, I)=N M R(J, I)+N M U(J, I)$

$J 5 \quad J 5$

(6) $N(I)=$ SUMA NF(J,I) + SUMA NM(J,I)

$$
J=1 \quad J=1
$$

\section{ii) Migraciones internas}

La población así calculada supone que no hay emigraciones del campo a la ciudad, debiendo enseguida procederse a efectuar este ajuste que sólo es válido para la distribución rural-urbana pero no para la población total pues se supone que la migración internacional es nula.

(7) NFRE $(J)=N F R(J, I)$ \& $C F R E(J, I)$

La población femenina rural por edad que emigra a la ciudad (NFRE) es igual a la población femenina rural por edad (NFR) multiplicada por la tasa femenina de emigración CFRE.

(8) $\quad N M R E(J)=N M R(J, I)$ \& $C M R E(J, I)$

La población masculina rural que emigra del campo a la ciudad (NMRE) resulta de multiplicar la población masculina rural (NMR) por sus correspondientes coeficientes de emigración (CMRE).

En este punto del cálculo pueden ocurrir dos opciones: una, que los coeficientes de emigración por edad se consideren, en términos conceptuales, como la probabilidad que tiene una persona de emigrar. En este caso, los valores absolutos de dichas tasas se consideran que 
lienen validez. El grado de urbanización dependerá entonces del valor absoluto que tengan los coeficientes de emigración.

La otra opción consistiría en fijar desde afuera del modelo el grado de urbanización global esperado y suponer entonces que los coeficientes de probabilidad de emigrar del campo a la ciudad sólo tienen validez en sus valores relativos pero no en su valor absoluto como en el caso anterior. Cuando se trata de la primera opción, después de calcular la ecuación (8) se salta a la ecuación (15).

Las ecuaciones (9) a (14) entran en el cálculo sólo en aquellos casos en que el grado de urbanización se fije desde afuera, como un dato exógeno. En este caso, resulta evidente que sólo por casualidad el grado de urbanización que se obtiene de aplicar a la población el valor absoluto de los coeficientes de emigración será igual a aquel postulado como hipótesis desde afuera del modelo demográfico. En este caso se hace necesario ajustar el grado de urbanización, que surge de las tasas, al nivel de la urbanización postulada desde afuera, para lo cual sólo interesan los valores relativos de los coeficientes de emigración.

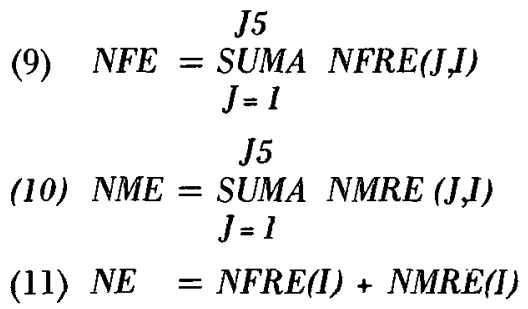

En las ecuaciones (9), (10) y (11) se calcula, respectivamente, el total de población femenina rural que emigra (NFE), el total de población masculina que emigra (NME) y el total de hombres y mujeres que emigran (NE) del campo a la ciudad.

(12) $N R I=(1-G U(I))$ is $N(I)$

La población rural (NR1) se obtiene multiplicando la población total (N) por el complemento a uno del grado de urbanización (GU).

J5

(13) $N F R E(J)=N F R E(J) / N E$ « $(S U M A N F R(J, I)+$ $J=1$

J5

$+S U M A N M R(J, I)-N R l)$

$J=1$ 
La población femenina rural que emigra (NFRE) resulta de multiplicar un conjunto de coeficientes que distribuyen el total de migrantes según sexo y edad (NFRE(J)/NE) (ecuaciones 7 y 11) por la diferencia entre la población total y rural sobreviviente (SUMA NFR(J)+SUMA NMR(J)) (Ecuaciones, 1, 2 y 3 ) y la población rural estimada con el grado de urbanización (ecuación 12) NR1.

El ajuste consiste, por lo tanto, en igualar el total de emigrantes ruralurbanos obtenidos en la ecuación (11), con el de emigrantes que surgen de comparar la población rural cerrada con la rural estimada de acuerdo al grado de urbanización.

En la ecuación siguiente se calcula la emigración del campo a la ciudad de los hombres, para lo cual vale la misma explicación dada aqui, con el cambio correspondiente de nombres. $J 5$
(14) $N M R E(J)=N M R E(J) / N E$ \& $(S U M A N F R(J, I)+$ $J=1$
$J 5$
+ SUMA NMR $(J, I)-N R 1)$
$J=1$

iii) Población abierta

(15) $N F R(J, I)=N F R(J, I)-N F R E(J)$

La población femenina rural se obtiene restando a la población cerrada el número de mujeres que emigran.

(16) $N M R(J, I)=N M R(J, I)-N M R E(J)$

La explicación anterior es válida con el cambio apropiado de nombres.

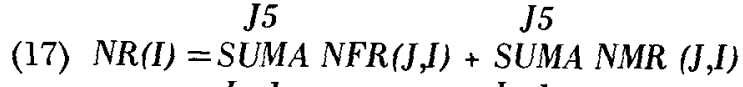


La población rural total surge sumando la población femenina y la masculina.

(18) $N F U(J, I)=N F(J, I)-N F R(J, I)$

La población femenina urbana se obtiene por diferencia entre la población femenina total (NF) y la ubicada en áreas rurales (NFR).

(19) $N M U(J, I)=N M(J, I)-N M R(J, I)$

Con el cambio de nombre la explicación anterior es válida.

$J 5 \quad J 5$

(20) $N U(I)=$ SUMA NFU(J,I) + SUMA NMU(J,I)

$J=1 \quad J=1$

La población urbana es la suma de la población femenina y masculina radicada en zonas urbanas.

iv) Población económicamente activa

(21) $\operatorname{PEAFR}(J, I)=N F R(J, I)$ \& $\operatorname{CAFR}(J, I)$

La población económicamente activa femenina residente en zonas rurales (PEAFR) resulta de aplicar a la población femenina rural las tasas de participación en la actividad económica.

(22) PEAMR (J,I) = NMR $(J, I)$ के $C A M R(J, I)$

(23) $P E A F U(J, I)=N F U(J, I)$ मे $C A F U(J, I)$

(24) PEAMU'(J,I) =NMU(J,I) \& CAMU $(J, I)$

En estas tres últimas ecuaciones se calcula la población económicamente activa masculina rural, femenina urbana y masculina urbana.

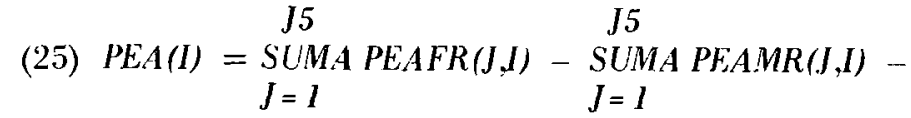

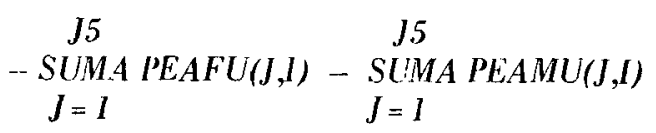


Con esta ecuación se calcula la población económicamente activa total, como suma de las ecuaciones anteriores.

\section{Modo de operar}

\section{a) Los datos básicos}

El modelo recibe los siguientes datos básicos:

i) la población, por sexo, por edad y por zona de residencia (urbano, rural) para el año inicial de la proyección;

ii) tasas específicas de fecundidad, de mortalidad y de participación en actividades económicas para cada uno de los años de la proyección y diferenciadas según zona de residencia y sexo.

A partir de estos datos básicos y a través de las ecuaciones descritas anteriormente, se efectúa la proyección de la población, por sexo, por edad y por zona de residencia. Estos resultados son la base del cálculo de la población económicamente activa.

Sin embargo, el hecho de que se introduzcan tasas específicas para cada uno de los años de la proyección, haría imposible el uso del modelo. En primer lugar, porque significaría manejar un gran volumen de información. Por ejemplo, para una proyección a 20 años, con 70 edades individuales requeriría de 1400 datos para fecundidad; de 2800 datos para mortalidad y de 4800 datos para tasas de participación.

En segundo lugar, se crearian excesivas dificultades para interrelacionar el modelo demográfico con el económico, pues éste debería generar anualmente las tasas específicas.

Una forma de subsanar la dificultad del gran volumen de información podría consistir en entregar al computador las tasas específicas iniciales y las del año final de la proyección y para el periodo intermedio generar esa información en la máquina a través de una interpolación. Sin embargo, este procedimiento se torna bastante inflexible tanto para la pauta fija de variación en el tiempo de las tasas especificas como porque dicha rigidez dificulta interrelacionar el modelo demográfico con el económico.

Por esta razón se ha decidido entregar en forma exógena al modelo demográfico dos conjuntos de datos:

1) Las series de tiempo de los coeficientes globales que pueden estar definidas como la suma de las tasas específicas (ejemplo para fecundidad: número de hijos por mujer al cabo de su edad fértil) o como un promedio ponderado de las mismas (ejemplo para fecundidad: tasa bruta de natalidad). Estos datos son los que se van a variar de una proyección a otra. 
2) Se entregará como dato algunas tablas de tasas especificas para cada uno de los conceptos (fecundidad, mortalidad, participación). A cada una de estas tablas corresponderá un valor determinado y sólo uno del coeficiente global.

Cuando algún valor de la serie temporal no corresponda con el coeficiente global de la tabla, se procede a interpolar entre las tablas más cercanas.

Por ejemplo, supongamos que para cierto concepto de tasas especificas utilizamos tres tablas: $\mathrm{T} 1, \mathrm{~T} 2, \mathrm{~T} 3$ a las cuales corresponden los coeficientes globales G1, G2, G3 y supongamos que la serie temporal del coeficiente global es $G(\mathrm{I}) \mathrm{I}=1,2, \quad \ldots$.. $\quad \mathrm{Si}$ $G 1<G(I)<G 2$; o sea, si en algún periodo $G$ está comprendido entre G1 y G2 la tabla que se va a utilizar es la interporlada entre T1 y T2 para el valor $\mathrm{G}$.

Este procedimiento permite introducir de una vez para siempre tablas que reflejen situaciones típicas incluso muy extremas. El hecho de que en alguna proyección se utilice alguna tabla ha de depender de los valores que tomen los coeficientes globales mencionados en párrafos an teriores.

Sin embargo, los valores absolutos de las tablas interpoladas no reproducirán necesariamente el valor del coeficiente global que es el dato que puede variar entre una proyección y otra. Para resolver esta cuestión se adopta un criterio similar a aquel adoptado para el caso de la emigración: se considera a la tabla interpolada como representativa en sus valores relativos de modo tal que sus valores absolutos se ajusten perfectamente al valor global entregado desde afuera.

Este procedimiento no sólo reduce considerablemente el volumen de la información sino que también facilita la interrelación con el modelo económico. Este entregaría, sobre la base de indicadores económicos, los niveles globales de fecundidad, mortalidad y participación, sobre cuya base se ajustarían las tablas típicas dadas.

\section{b) Procedimiento}

El procedimiento se divide en dos partes: i) uno aplicable a aquellos indicadores globales cuyo valor es independiente de la estructura por edad; ii) el otro procedimiento se aplica a aquellos indicadores cuyo nivel total no es independiente de la estructura for edad de la población.

i) Proceso 1: Indicador global independiente de la estructura por edad.

Las ecuaciones las escribiremos suponiendo que se ha definido un indicador de fecundidad, independiente de la estructura por edad. El uso de la fecundidad es sólo a título de ejemplo. 
Uitilizaremos las variables genéricas y luego se explicitan los argumentos que reemplazan a tales variables. Los argumentos genéricos son:

(F) (LI, L2, FE, FET, EE)

donde $\mathrm{L} 1$ y $\mathrm{L} 2$ son los coeficientes globales de las distribuciones $\mathrm{EE}$; FE es la fecundidad por edad; FET es el nivel total de la fecundidad; $y$, EE son distribuciones de fecundidad por edad.

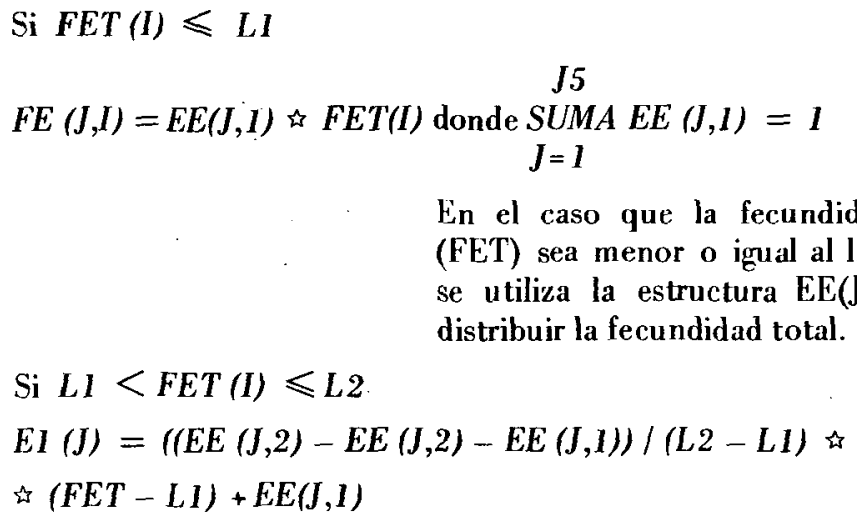
distribuir la fecundidad total.

Si $L I<F E T(I) \leqslant L 2$

$E I(J)=((E E(J, 2)-E E(J, 2)-E E(J, 1)) /(L 2-L 1)$ 宁 的 $(F E T-L I)+E E(J, I)$

En el caso que la fecundidad total (FET) sea menor o igual al límite L1 se utiliza la estructura $\mathrm{EE}(\mathrm{J}, \mathbf{l})$ para

Con esta ecuación se interpolan los valores intermedios entre la distribu. ción $\mathrm{EE}(\mathrm{J}, 1)$ y EE $(J, 2)$. Los valores interpolados (E1) no han de sumar necesariamente uno. Para cumplir con este requisito se hace el cálculo siguiente, donde directamente se distribuye la fecundidad total para obtener la fecundidad por edades

$$
\begin{aligned}
& J 5 \\
& F E(J, I)=(E I(J) / S U M A E 1(J)) \text { 方FET (I) } \\
& J=1
\end{aligned}
$$

Si $L 2 \leqslant F E T$ (I)

$F E(J, I)=E E(J, 2)$ \& FET (I)

En este caso se ha explicitado el procedimiento para dos distribuciones $\mathrm{EE}$.

Proceso 2: Indicador global dependiente de la estructura por edad.

Los argumentos se escriben de manera genérica y tienen la forma I siguiente. Se supone ahora que el indicador de fecundidad total se define como un promedio ponderado de las tasas especificas. 
(I) (L1, FE, FET, EE, N)

Si $F E T(I) \leqslant L 1$

$F E(J, I)=E E(J, 1)$ \& $F E T(I) / F E T I$
$J 5 \quad J 5$
donde FET1 = SUMA $(E E(J, 1)$ 出 N(J,I-1)) / SUMA N(J,I-1) $J=1 \quad J=1$
La distribución EE se corrige por la discrepancia entre FET (dado exógena- mente) y el promedio ponderado de las tasas específicas (FET1). Se utiliza la población del periodo anterior como ponderada.

Si $L 1<P T \leqslant L 2$

$E 1(J)=((E E(J, 2)-E E(J, I)) /(L 2-L I))$ 公 $(P T-L I)+E E(J, I)$

Con esta ecuación, al igual que en el proceso 1 , interpola en dos distribuciones $\mathrm{EE}$. En la ecuación siguiente se calcula el coeficiente total que resulta del promedio ponderado con la población.

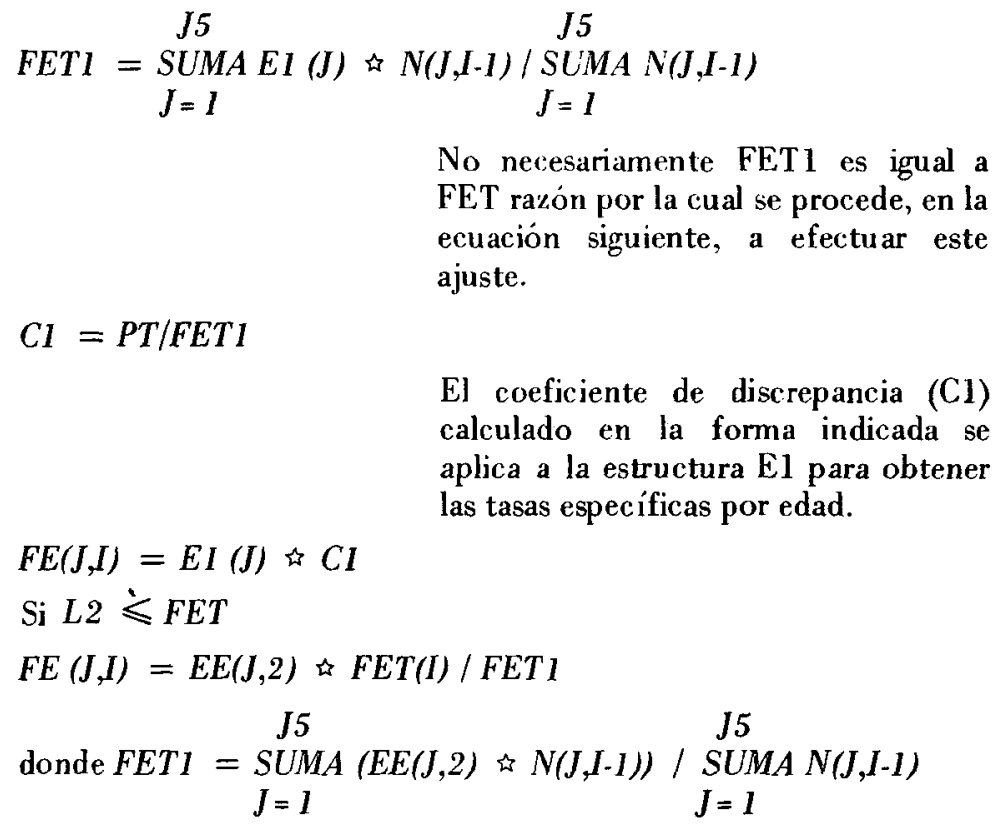

No necesariamente FET 1 es igual a FET razón por la cual se procede, en la ecuación siguiente, a efectuar este ajuste.

$C 1=P T / F E T I$

E] coeficiente de discrepancia (Cl) calculado en la forma indicada se aplica a la estructura El para obtener las tasas específicas por edad.

$F E(J, I)=E I(J) \& C I$

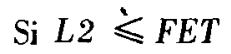

$F E(J, I)=E E(J, 2)$ \& $F E T(I) / F E T I$

donde FETI $=\underset{J=1}{S 5}(E M A(E E(J, 2)$ \& $N(J, I-1)) / \underset{J=1}{J 5}$ SUMA $N(J, I-1)$ 


\section{ANEXO III}

\section{EL PROGRAMA DE COMPUTO}

El modelo anteriormente descrito ha sido programado en lenguaje FORTRAN. Se compone de 10 partes a saber

i) Subrutina POB1 donde se encuentran programadas las ecuaciones 1,2 y 3 del modelo.

ii) Subrutina POB2. Esta parte calcula las migraciones y la población abierta (ecuaciones 7 a 20 ).

iii) Subrutina PEAl donde se calcula la población económicamente activa (ecuaciones 21 a 25).

iv) Subrutina ELEC1. Calcula las tasas específicas (fecundidad, mortalidad y participación) para los valores totales prefijados exógenamente al modelo. Esta parte tiene dos opciones: una, donde el valor total es independiente de la estructura por edad; $y$, otra que depende de la estructura por edad de la población.

v) Subrutina INTER. Se utiliza para interpolar la forma lineal.

vi) Subrutina PORCEN, que sirve para calcular estructuras relativas.

vii) Subrutina ESC1, Subrutina ESC2, Subrutina ESC3. En esta parte se maneja la salida de resultados.

viii) Subrutina LECT1. Esta parte del programa lee aquellos datos que van a variar de un experimento a otro. Permite leer tanto los datos de todos los años de la proyección, así como el dato inicial, el final y el programa automáticamente interpolado.

ix) Subrutina SUM2. Permite calcular sumas.

x) Finalmente la parte denominada $M A I N$ es aquella que ordena la secuencia de lectura, de cálculo y de la impresión de resultados.

A continuación se indica la forma de entregar los datos; y en la parte $B$, se muestra una salida del programa.

\section{A. Entrada de datos}

Tarjeta 1 y 2 : título resumido de variables

Tarjeta 3 : formato con el que se va a leer la tarjeta siguiente.

Tarjeta 4 : especifica la edad límite, el número de años de la proyección y el año a partir del cual empieza la proyección. 


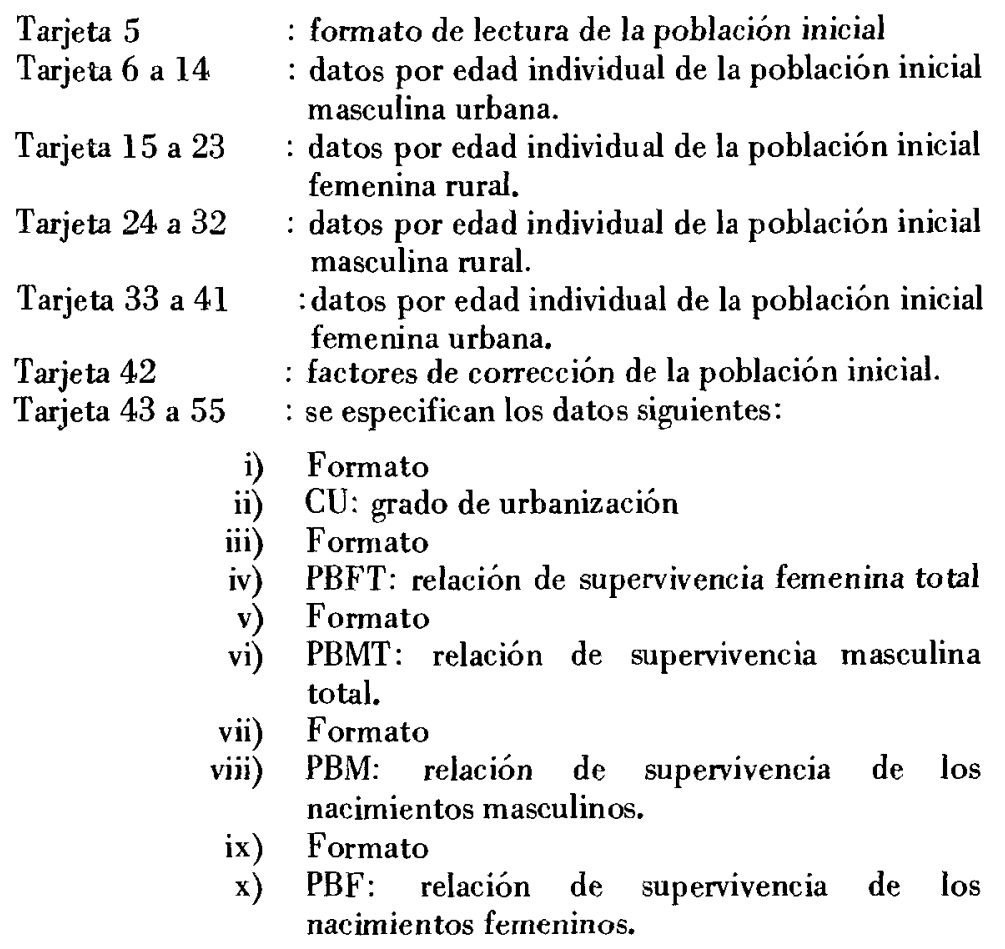

Como podrá observarse, antepuesto a cada una de las variables antedichas, se coloca siempre una tarjeta de formato que permite leer los datos que le siguen.

La lectura de estas variables se hace con la Subrutina LECTI que permite las siguientes facilidades:

i) leer anualmente los datos.

ii) leer el dato del año inicial y del año final. El programa se encarga de interpolar linealmente.

iii) leer el dato del año inicial, de años intermedios y del año final.

El programa se encarga de interpolar linealmente entre cada punto. Para que el computador efectúe esta operación se le introducen tres parámetros que entran como datos en las columnas 1-2, 11-12, 21-22.

Ejemplificaremos esto con el grado de urbanización $\mathrm{GU}$ y con la relación de supervivencia femenina total (PBFT).

Caso 1: Lectura del dato inicial y del dato final.

Este es el caso de la relación de supervivencia (PBFT). El año inicial, en este caso 1970, se indentifica dentro del programa con el número 1 y 
el año final (año 2000) con el número 31. La PBFT varía de 70.31112 en 1970 a 70.57192 en el año 2000 . El programa se encarga de interpolar los 30 años intermedios. Este último valor también debe entregarse. El conjunto de datos se especifica en la tarjeta de la siguiente manera.

Columna número

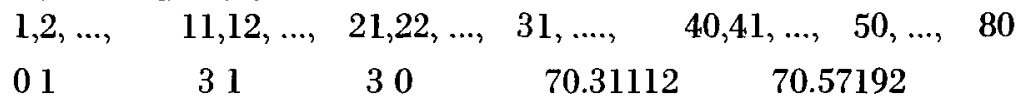

Caso 2: Lectura de datos anuales.

Con el mismo criterio anterior, la primera tarjeta contiene los siguientes datos

Columna número

$$
\begin{array}{llll}
1,2, \ldots, & 11,12, \ldots, & 21,22 \\
01 & 31 & 0 & 1
\end{array}
$$

Lo cual para el programa signific a que los datos que se van a entregar parten del año 1, llegan al año 31 y se van a leer datos de uno en uno. El 1 en la columna 22 hace que el programa lea los datos antedichos. A continuación de la columna 22 se colocan los 31 datos que se han de leer.

Caso 3: Lectura de datos en año seleccionados.

Este es el caso de la variable grado de urbanización (GU). Se han entregado datos para los años 1970,1975, 1980, 1985 y 2000 . En el programa los años se encuentran numerados desde 1, 2, ... hasta Il. El año 1970 corresponde a 1 ; el año 1975 al número 6; el año 1980 al número 11 ; el año 1985 al número 16 y el año 2000 al número 31 . Eśto se especifica en tres tarjetas de la forma siguiente:

\begin{tabular}{|c|c|c|c|c|c|c|}
\hline Tarjeta 1 & 01 & 0 & 6 & 0 & Dato 1 & Dato 2 \\
\hline Tarjeta 2 & 06 & 1 & 1 & 0 & Dato 2 & Dato 3 \\
\hline Tarjeta 3 & 11 & 1 & 6 & 0 & Dato 3 & Dato 4 \\
\hline Tarjeta 4 & 16 & 3 & 1 & 1 & Dato 4 & Dato 5 \\
\hline
\end{tabular}

\section{Columna} $1,2, \ldots, 11,12, \ldots \quad 21,22, \ldots, 31, \ldots, 40,41, \ldots 50, \ldots 80$

El programa lee la primera tarjeta y ubica el primer dato (columna 31 a 40) en el año 1 , el segundo dato (columnas 41 a 50) en el año 6 e interpola entre estos años. Lee la segunda tarjeta, ubica el dato 2 en el año 6 y el dato 3 en el año 11 e interpola. Como no ha llegado a completar los 31 años de la proyección, pide leer una nueva tarjeta. Lee entonces de la tarjeta 3 el dato 3 que lo ubica en el año 11 (este es el 
año inicial de la nueva interpolación) y el dato 4 que lo coloca en el año 31 ; con estos datos procede a interpolar. Como ya tiene completos todos los años no pide leer una nueva tarjeta para este mismo dato.

Tarjeta $56 \quad$ : Formato de entrada de los datos de las tarjetas siguientes

Tarjeta 57 a 74 : Se ocupan para entregar la información sobre tasas específicas de fecundidad (EEF).

El primer número que aparece ubicado en la columna 1 de la tarjeta 57 indica el número de distribuciones que se han de suministrar. Las nueve columnas siguientes se utilizan para comentario y a continuación se escriben los datos de las distribuciones.

Tarjeta 75 : Formato de entrada de los datos de las tarjetas siguientes

Tarjeta 76 a 97 : Se usan para entregar la información sobre las tasas específicas de emigración masculina $\mathrm{y}$ femeninas (CME y CFE)

Tarjeta 98 : Formato de entrada de los datos siguientes

Tarjeta 99 a 128 : Se registra la ifnormación sobre tasas específicas de participación tanto femeninas como masculinas (EEAF y EEAM)

Tarjeta 129 y 130 : Formato de entrada de los datos de las tarjetas siguientes

Tarjeta 131 a 174 : Se registra la información sobre tasas específicas de supervivencia masculinas $y$ femeninas (EEPM y EEPF).

Tarjeta 176 a 181 : Se leen los siguientes datos

i) formato

ii) AMRT: actividad masculina rural total

iii) formato

iv) AFRT: actividad femenina rural total

v) formato

vi) AFVT: actividad femenina urbana total

Tarjeta 182 y 183 : Título del experimento.

Tarjeta 184 a 193 : Se usa para leer la fecundidad rural total (FERT) y la fecundidad urbana total (FEUT).

Tarjeta 194 : Esta es una opción para indicar al programa si la participación femenina urbana es constante o si es variable.

Tarjeta 195 : Indica al programa si va a leer nuevos datos o finaliza el trabajo.

A continuación se presenta un listado de los datos tal como se han entrado en el ejercicio que se comenta en el capítulo II. 


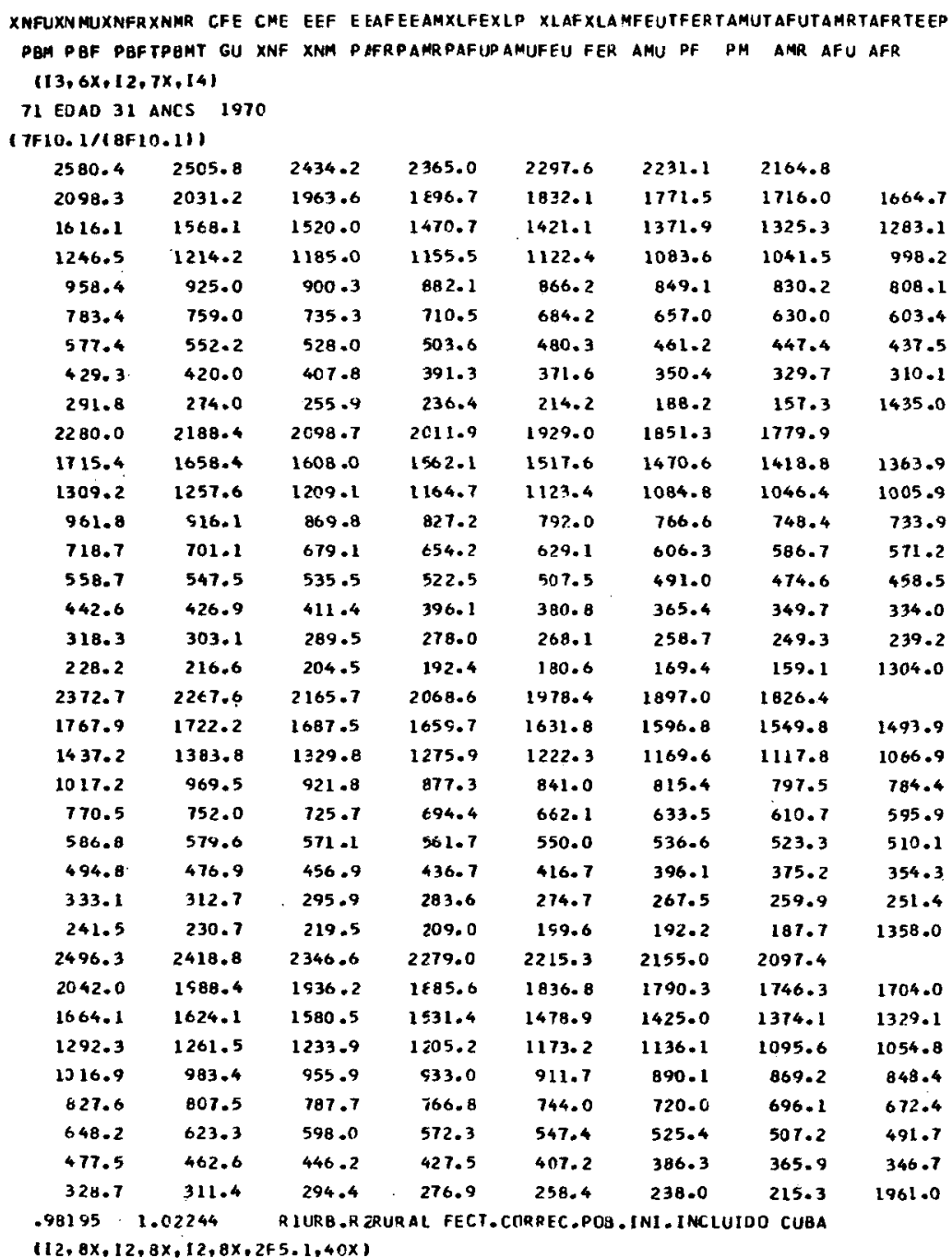




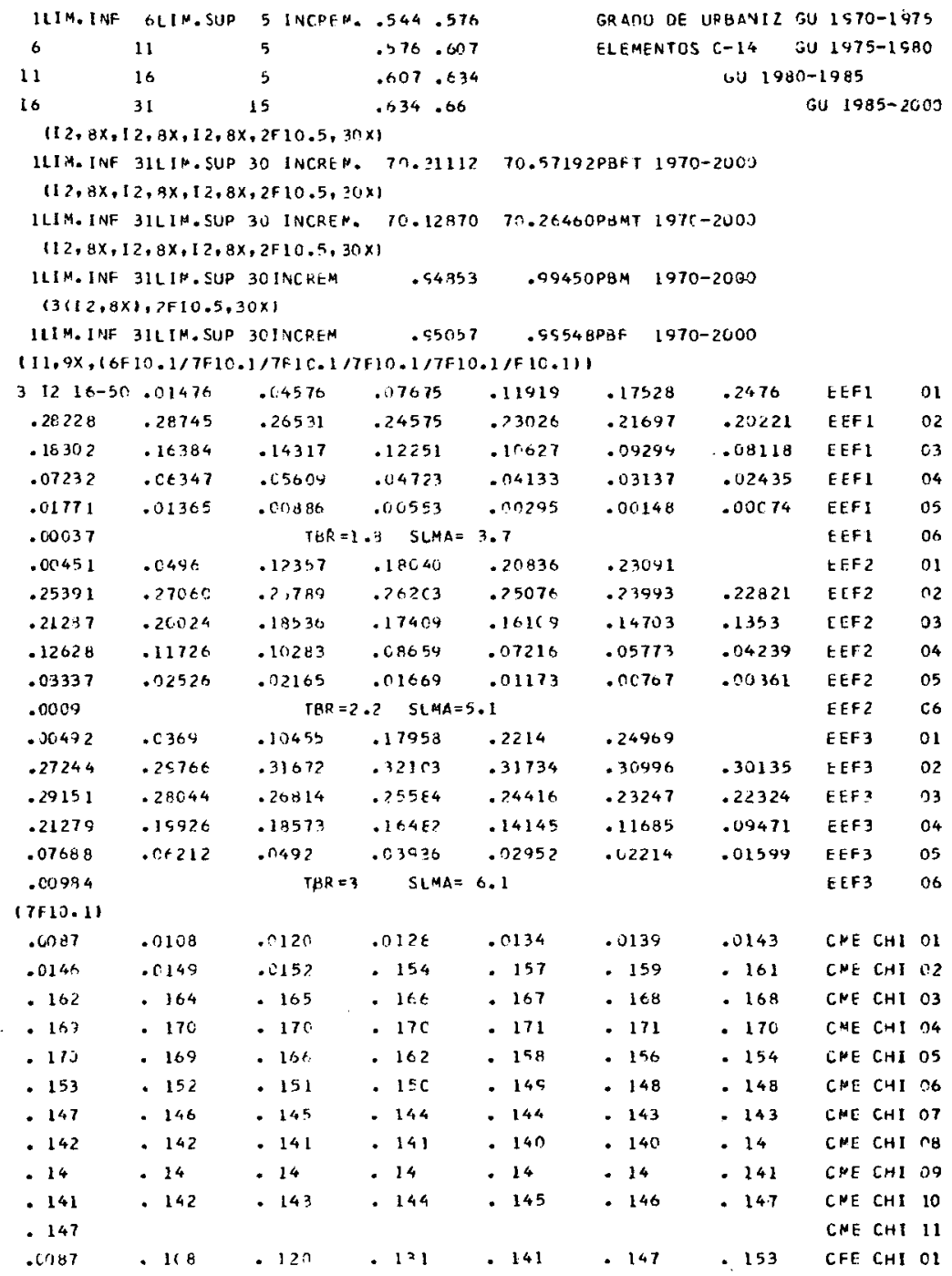




\begin{tabular}{|c|c|c|c|c|c|c|c|c|}
\hline - 158 & . 162 & .165 & - 168 & . 170 & - 173 & . 175 & CFE & CHI \\
\hline$\cdot 177$ & - 180 & . 181 & . 183 & .183 & . 183 & . 183 & CFE & $\mathrm{CHI}$ \\
\hline - 182 & - $|B|$ & . 180 & .179 & - 177 & . 175 & . 168 & CFE & $\mathrm{CHI}$ \\
\hline . 164 & - 161 & . 159 & . 15e & .157 & . 156 & . 155 & CFE & CHI \\
\hline .154 & . 153 & .153 & - 153 & . 153 & - 153 & .153 & CFE & $\mathrm{CHI}$ \\
\hline .154 & . 154 & . 154 & . 154 & . 154 & . 154 & . 154 & CFE & $\mathrm{CHI}$ \\
\hline . 154 & - 154 & - 154 & - 155 & .155 & - 156 & . 156 & CFE & $\mathrm{CHI}$ \\
\hline .155 & .156 & .156 & . 156 & .156 & .156 & . 157 & CFE & $\mathrm{CHI}$ \\
\hline - 157 & . 157 & .157 & .157 & .156 & .156 & .155 & CFE & $\mathrm{CHI}$ \\
\hline . 147 & & & & & & & CFE & $\mathrm{CHI}$ \\
\hline
\end{tabular}

(11,9X, (12F5.3/14F5.3/14F5.3/14F5.3/7F5.3))

$\begin{array}{llllllllllllll}313 & 11-71 & .008 & .026 & .048 & .068 & .095 & .117 & .139 & .155 & .167 & .174 & .170 & .158 \text { EEAF } 1 \text { GUA1 }\end{array}$ $.144 \cdot 139.135 \cdot 131 \cdot 129.128 \cdot 127 \cdot 126.125 \cdot 124 \cdot 123 \cdot 122 \cdot 121 \cdot 121$ EEAF1GUA2 $.120 .119 .119 .120 .121 .123 \cdot 125 \cdot 127.130 .131 .132 \cdot 133.133 .132$ EEAF1GUA3 $.131 .130 .125 \cdot .127 \cdot 125 \cdot 123 \cdot 121 \cdot 117.115 \cdot 113 \cdot 110 \cdot 108 \cdot 105 \cdot 102$ EEAFIGUA4 .098 .095 .093 .068 .085 .082 .05 SUMA $=713$ TASA 11.53 EEAFIGUAS $\begin{array}{lllllllllllll}.066 & .02 & .04 & .073 & .12 & .175 & .24 & .301 & .357 & .39 & .412 & .422 & .42\end{array}$ EEAF2CR 1

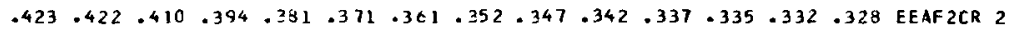
$\begin{array}{llllllllllllllllll}.326 & .323 & .318 & .314 & .310 & .365 & .298 & .292 & .285 & .277 & .270 & .261 & .25 & .24 & \text { EEAF2CR } 3\end{array}$ $.232 .223 .213 .205 \cdot 197.190 .183 .178 .170 .163 .157 \cdot 150.142 \cdot 135$ EEAF 2 CCR 4

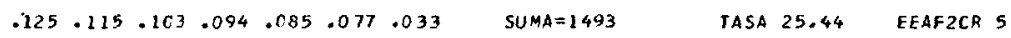
$.003 .008 .017 .035 .060 .098 .175 .368 .485 .502 .505 .500 \quad 000$ EEAF4USAL $\begin{array}{llllllllllllllll}.483 & .458 & .435 & .410 & .390 & .378 & .37 & .365 & .365 & .37 & .376 & .382 & .392 & .400 \text { EEAF } 4 \text { USAL }\end{array}$

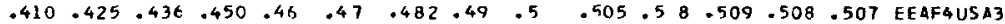

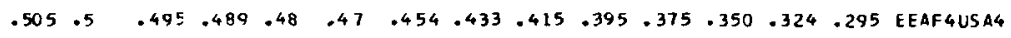
$.265 .228 .205 .182 .167 .15 \quad .054$ SUMA 2222 TASA 37.28 EEAF4USA5 $\begin{array}{lllllllllllllll}3 & 14 & 11-71 & .005 & .025 & .05 & .08 & .13 & .195 & .28 & .395 & .54 & .77 & .82 & .855 \text { EEAM1USA }\end{array}$

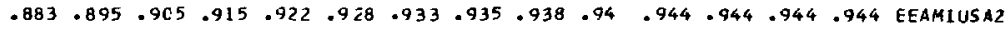

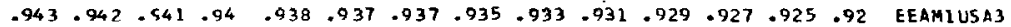

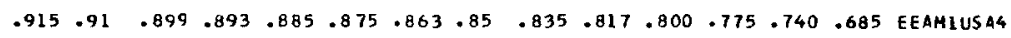

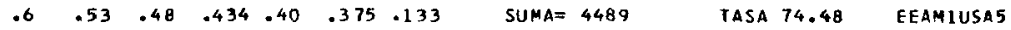

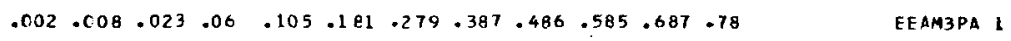
$\begin{array}{llllllllllllllll}.068 & .904 & .522 & .932 & .940 & .947 & .951 & .954 & .956 & .958 & .959 & .96 & .96 & .96 & \text { EEAM3PA } 2\end{array}$

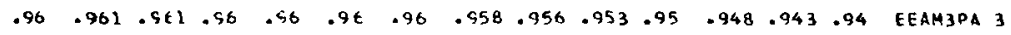

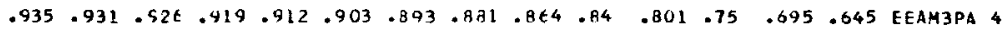
$.600 .515 .474 .400 .350 .300 .110 \quad$ SUMA $44<769$ EEAM3PA 5

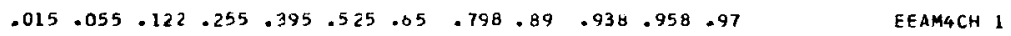
$.975 .98 \quad .922 \quad .983 .984 \quad .984 \quad .984 .984 .984 \quad .984 \quad .984 \quad .984 .984 \quad .984$ EEAM4CH 2

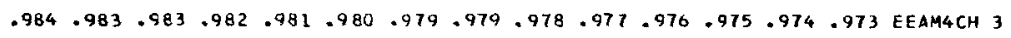
$\begin{array}{llllllllllllll}.97 & .965 & .9 t 2 & .956 & .95 & .944 & .939 & .933 & .925 & .92 & .915 & .910 & .9 & .99 \\ \text { EEAM4CH } 4\end{array}$ $.88 .865 .845 .825 .81 \quad .785 .427$ SUMA $=5255$ TASA 78.46 EFAM4CH 5 111.9K.16F10.1/7F10.1/7F16.1/7F1n.1/7F10.1/7F10.1/7F10.1/7F10.1/7F10.1/7F10.1/2F 10.111 


\begin{tabular}{|c|c|c|c|c|c|c|}
\hline $151-71$ & .94853 & .98885 & .59301 & .9966 & .99822 & .99836 EEPAI \\
\hline .99837 & .99837 &.$\$ 9837$ &.$\$ 9715$ & .95926 & .9991 & $.99865 E$ EPMI \\
\hline .99826 & .99835 & .99848 & .99825 & .99794 & .99768 & .99756 EEPA1 \\
\hline .99749 & .99734 & .99720 & .99707 & .99691 & .99681 & .99681 EEPHI \\
\hline .99685 & .95684 & .99673 &.$\$ 9655$ & .95637 & .99616 & .99595 E EPथ 1 \\
\hline .99571 & .95551 & .99535 &.$\$ 9520$ & .99499 & .99466 & .99427 EEPHI \\
\hline .99393 & .99357 & .59313 & .59263 & .99202 & .99129 & . 99046EEPHI \\
\hline .98961 & .98882 & .588 & .98705 & .98602 & .98495 & . 98388EEPH1 \\
\hline .98275 & .98151 & .98018 & .57878 & .97732 & .97550 & $.97338 E$ EPAI \\
\hline .97123 & .96892 & .96653 & .96396 & .96124 & .95840 & .95545 EEPHI \\
\hline .95230 & .90554 & \multicolumn{2}{|c|}{ SUMA $=70.12871$} & & & EEPAI \\
\hline .99450 & .99852 & .99900 & .99917 & .99932 & .9993 & EEPA2USA \\
\hline .99943 & .95947 & .99951 & .99954 & .99956 & .99952 & .99944E EPH2USA \\
\hline .99930 & .95912 & .99896 & .59877 & .99862 & .99850 & . 9983НE EPMZUSA \\
\hline .99825 & .99816 & .99814 & .59816 & .95823 & .99828 & .99832E EPAHZUSA \\
\hline .99832 & .95929 & $.998 \leq 2$ &.$\subseteq 9814$ & .99807 & .99796 & . 99783 EEPAZZUSA \\
\hline .99768 & $.957 \leq 1$ & .59731 & .59704 & .99677 & .99645 & .99607 EEPAZUSA \\
\hline .99566 & .79523 & .09472 & .99423 & .99366 & .99298 & . 99225EEPALUSA \\
\hline .99134 & .99038 & .98933 & .58827 & .98719 & .98613 & .98507EEPHZUSA \\
\hline .98391 & .98262 & .58109 & .57939 & .97750 & .97550 & $.97339 E E P M Z U S A$ \\
\hline .97123 & .96892 & .96853 & .56396 & .96124 & .95840 & . 95545EEPA2USAI \\
\hline .95230 & .90554 & \multicolumn{2}{|c|}{ SUPA $=70.26460$} & & & EEPR2USA I \\
\hline .95057 & .98928 & .99338 & .59688 & .99840 & .99868 & EEPF 3 \\
\hline .99860 & .95868 & .99869 &.$؟ 975$ & .99958 & .9994 & .99893 EEPF 3 \\
\hline .99858 & .95864 & .99880 & .59865 & .59843 & .99825 & .99816FEPF3 \\
\hline .99811 & $.9 \$ 802$ & .99793 & .99785 & .99773 & .99764 & .99761 EEPF 3 \\
\hline .99761 & .95757 & .99748 & .59732 & .95714 & .99693 & $.99672 E$ EPF 3 \\
\hline .99654 & .99638 & .99620 & .99602 & .99582 & .99556 & $.99532 E^{2}$ PPF 3 \\
\hline .99514 & .95498 & .99476 &.$\$ 9441$ & .99400 & .99361 & .99317 EEPF 3 \\
\hline .99269 & .95218 & .99158 & .99083 & .98999 & .98915 & .98830 EEPF 3 \\
\hline .78751 & .98675 & .98599 & .98511 & .98405 & .98281 & $.98142 E E P F 3$ \\
\hline .9799 & .57829 & .97659 & .9748 & .97289 & .97087 & .9687 EEPF3 \\
\hline .93463 & .92036 & \multicolumn{2}{|c|}{$S U A_{A}=70.31112$} & & & EEPF3 \\
\hline .99548 & .55875 & .99917 & .99935 & .99945 & .9995 & EEPF \&USA \\
\hline .99959 & .99962 & .99967 & .99969 & .99969 & .99971 & .99968 EEPF4USA \\
\hline .99964 & .99959 & .99953 & .99947 & .99944 & .99939 & .99938 EEPF 4 USA \\
\hline .99935 & .95932 & .99928 &.$\$ 9925$ & .99923 & .99919 & $.99916 E$ EPF4USA \\
\hline .99910 & $.9 \subseteq 505$ & .55858 & .59891 & .99882 & .99873 & $.99865 E$ EPF 4 USA \\
\hline .99854 & .99843 & .99830 & .99817 & .99798 & .9978 & $.99761 E$ EPF4USA \\
\hline .99736 & .95715 & .9969 &.$\$ 9663$ & .99633 & .99602 & .99567 TEPF4USA \\
\hline .99525 & .99484 & .99435 & .99385 & .99291 & .99241 & $.99188 E$ EPF4USA \\
\hline .99124 & .55046 & .98957 & .58847 & .98733 & .98611 & $.98486 E E P F 4 U S A$ \\
\hline .98356 & .98218 & .98068 & .97893 & .97695 & .97462 & . 97209EEPF4USA10 \\
\hline .96926 & .92036 & SUMA & 0.57192 & & & EEPF4USA1: \\
\hline
\end{tabular}




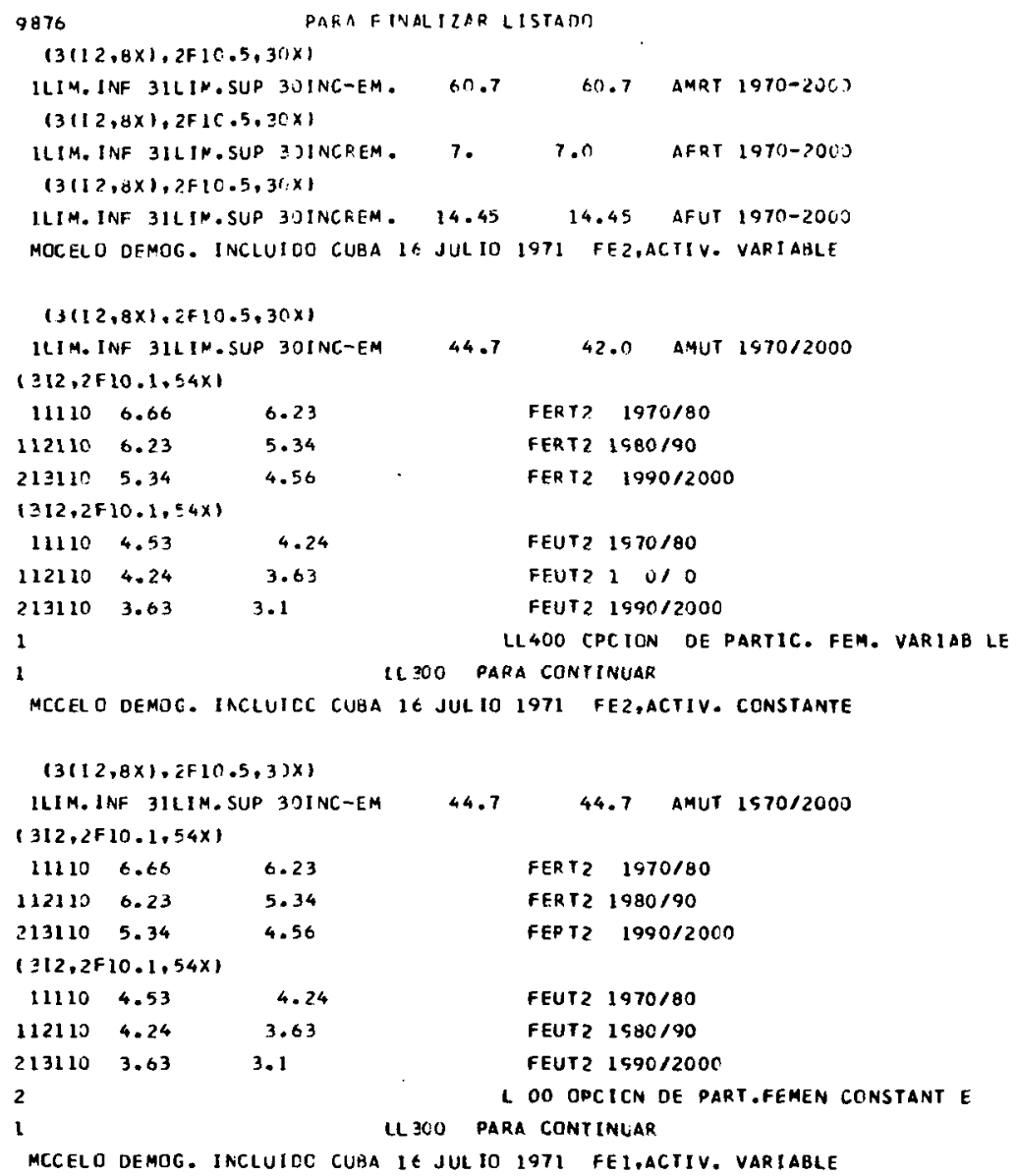




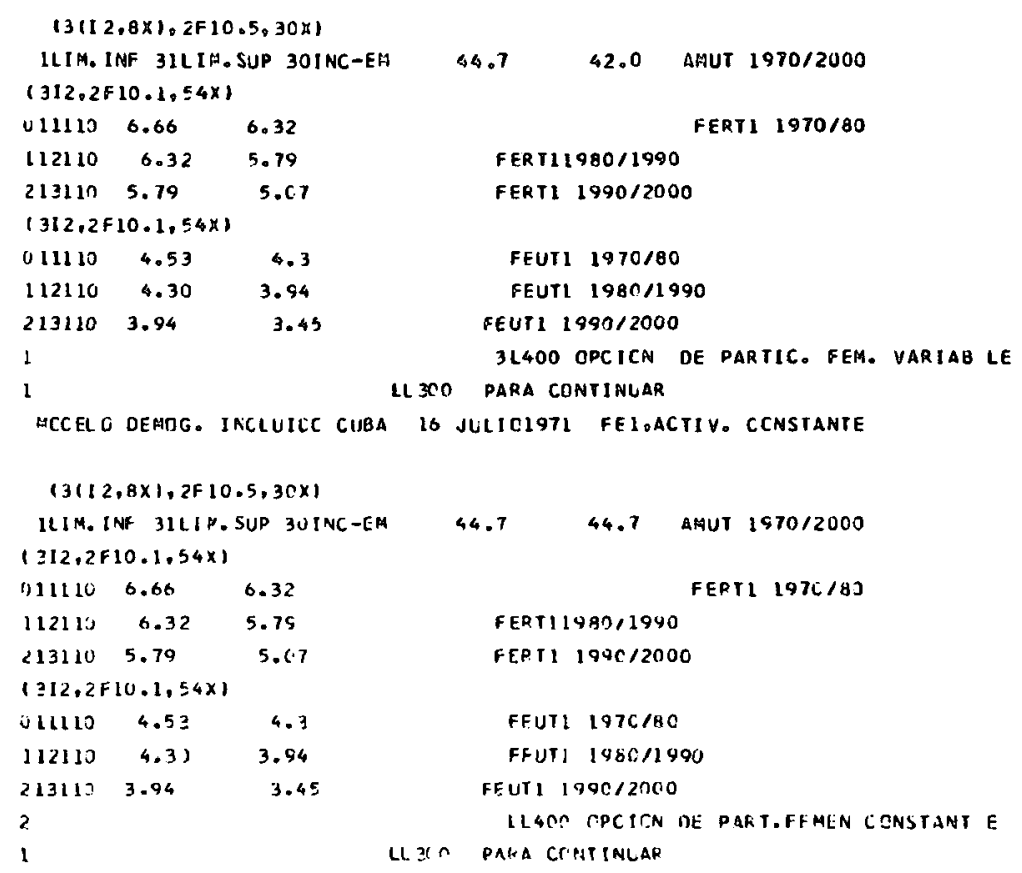




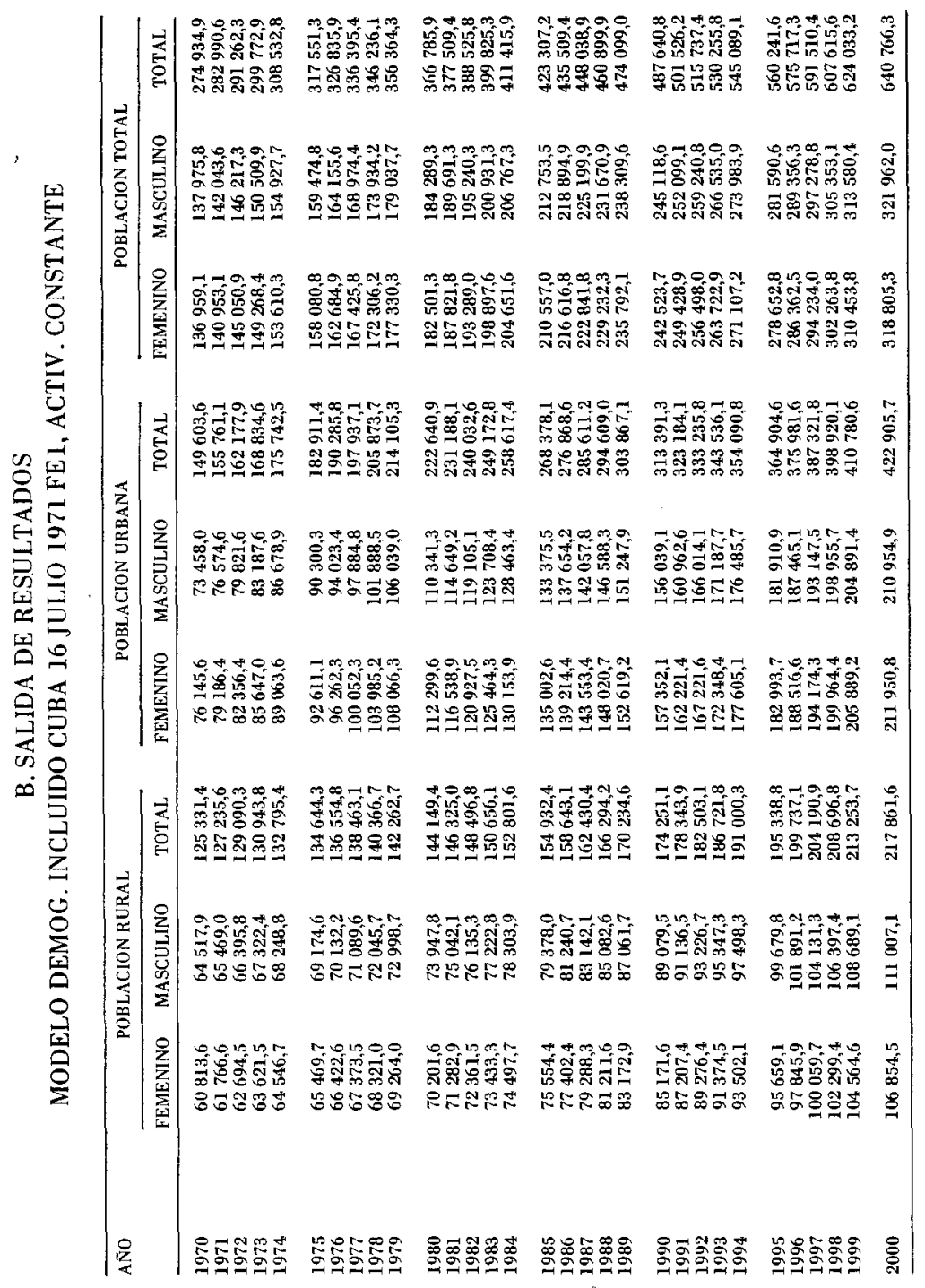

142 


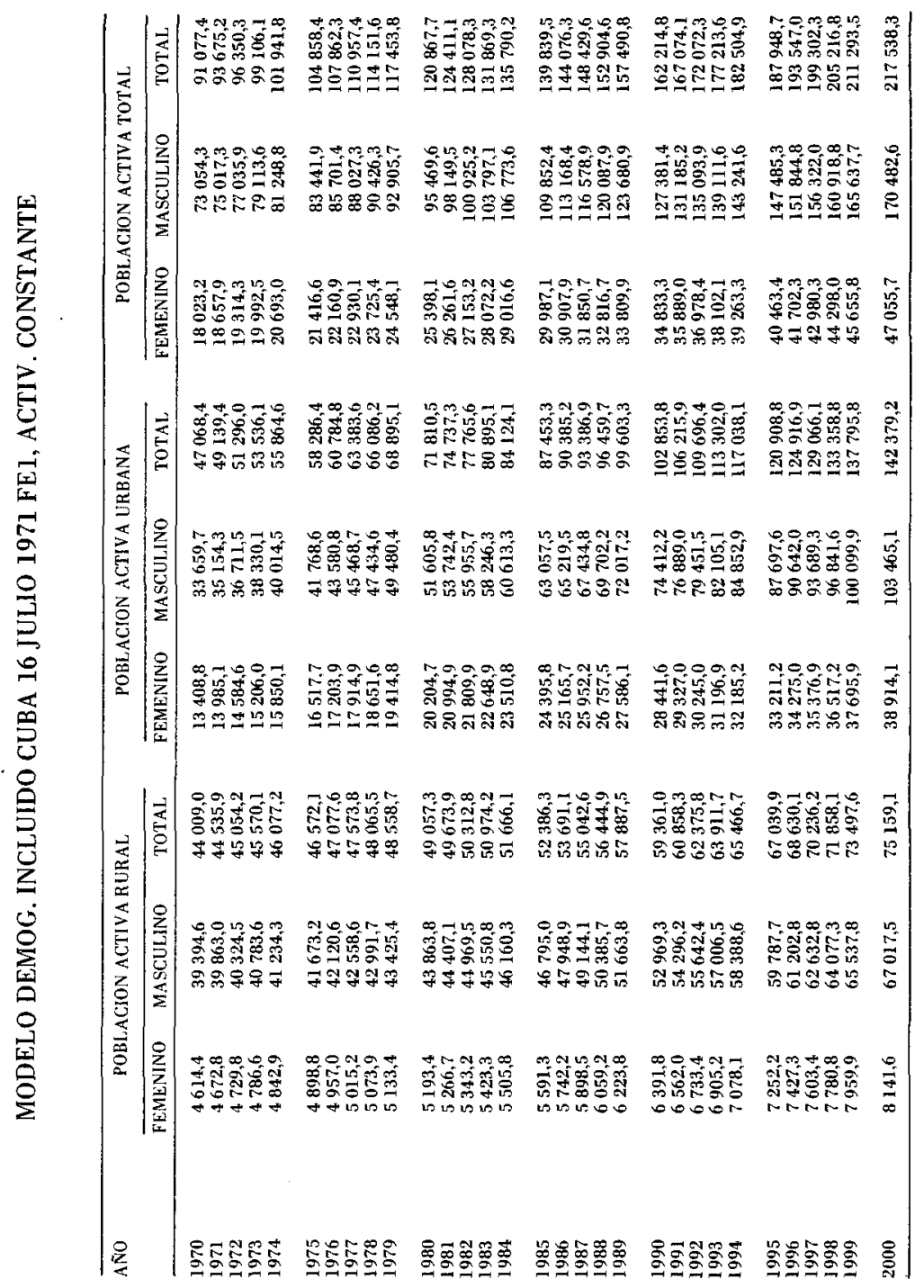




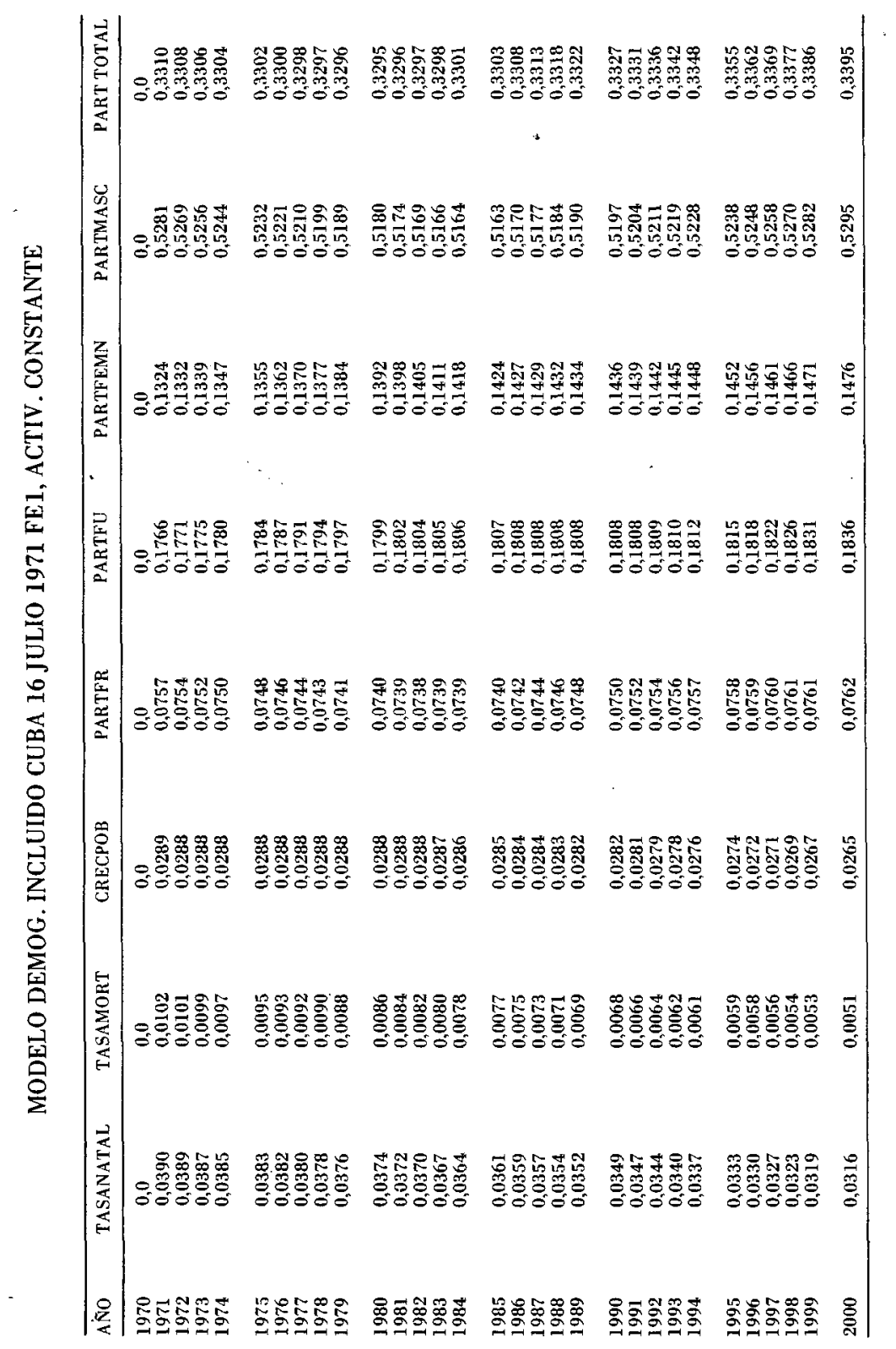

144 


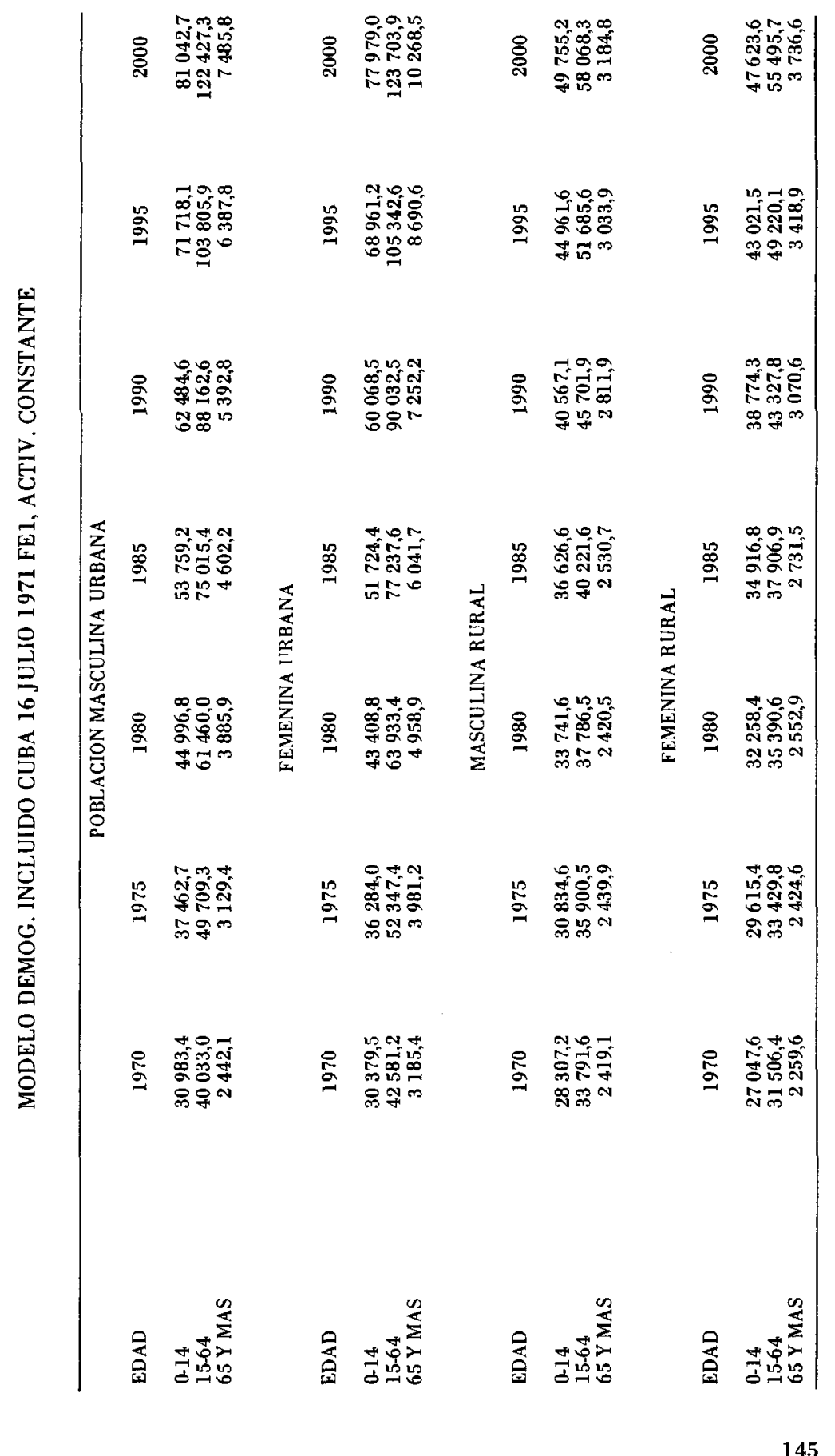




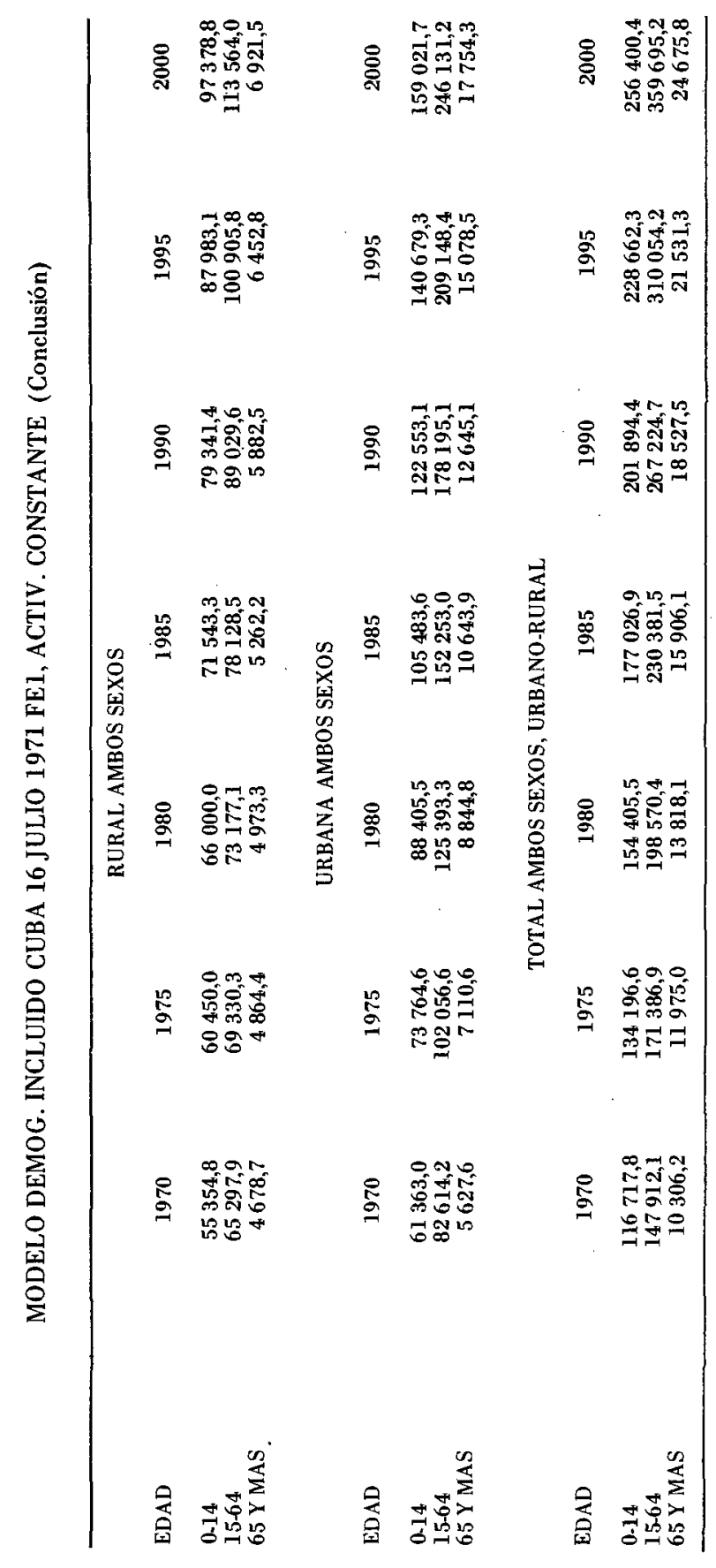

146 


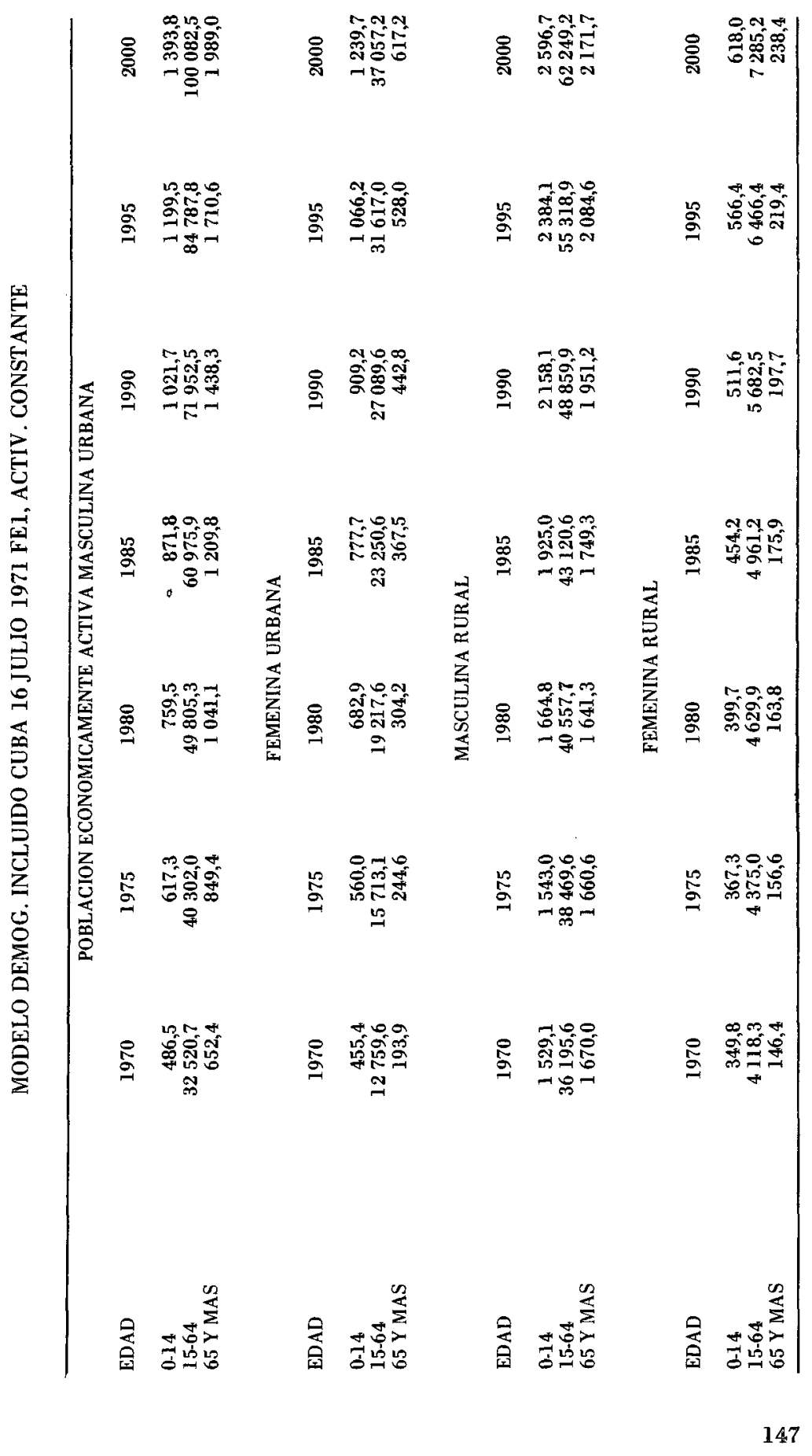




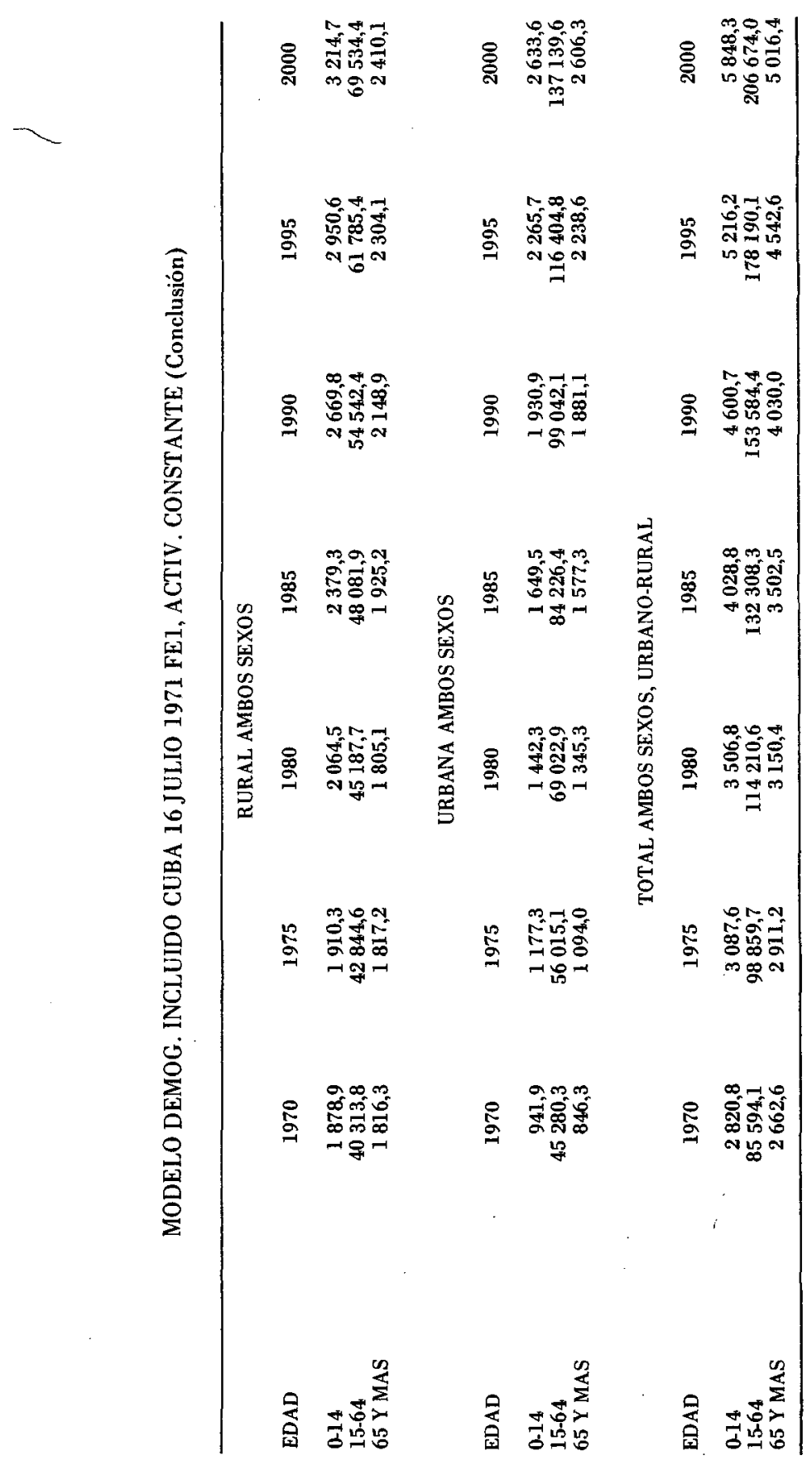

148 


\section{BIBLIOGRAFIA DE REFERENCIA}

1. Berelson, Bernard "Beyond family Planning", studies in Family Planning, No 38 , febrero 1969.

2. Blake, Judith, "Income and Reproductive motivation", en Population Studies, Noviembre, 1967.

3. Freedman S., Deborah, "The relation of Economic Status to fertility", American Economic Review, Junio, 1963.

4. ILPES-CELADE, Elementos para la elaboración de una política de desarrollo con integración para América Latina, ILPES, Santiago, 1968 y revisiones efectuadas en 1969.

5. Meade y otros, "Demography and Economics", Supplement to Population Studies, May, 1970.

6. Mooley, Joseph, "Urban Poverty and labor force participation", en American Economic Review, Maroco, 1967.

7. Pujol J. y Vidal J., Proyección de la población urbana y rural de Chile, 1960-1980, inédito.

8. Prebisch, Raúl, Transformación y Desarrollo: La gran tarea de A mérica Latina, ILPES, Santiago, 1970.

9. Rothman, Evolution of fertility in Argentina and Uruguay. Mimeografiado.

10. United States Life Tables 1959-1960, Vol. 1, No 1, 1964, U.S. Department of Health, Education and Welfare. 
 \\ SECUENCTA DEL PROCESO DE FORMULACION DE METAS DE EMPLEO \\ EN LA PLANIFICACION
}

\author{
Esteban Lederman
}

El presente documento es un avance de un trabajo más amplio, actualmente en elaboración, para ser presentado en el Seminario de Desarrollo, Empleo y Población, en Lima, Perí (8 al 12 de noviembre de 1971). organizado por la Oficina Internacional del Trabajo, a través del Programa Regional del Empleo para América Latina y el Caribe, y el Departamento de Asuntos Sociales de la Organización de Estados Americanos, con la colaboración del Instituto Latincamericano de Planificación Económica y Social. Colaboraron en la preparación los señores Paulo Renato de Souza y Fernando Ordóñez. 



\section{INTRODUCCION}

El carácter integral e interrelacionado de la estructura económica requiere que la planificación también lo sea y que abarque a toda la economía. El plan de una actividad exige el conocimiento de cómo se desarrollarán los demás sectores de la economía, con los que directa e indirectamente se encuentra enlazada.

Este fenómeno se da no sólo desde el punto de vista de la "sectorialización" del plan sino también desde el punto de vista global. Así no es posible planificar por separado la producción, las inversiones, los recursos humanos, etc.; es necesario realizarla en forma conjunta,

Para la formulación del programa de producción se precisa conocer las disponibilidades de las diversas categorias de mano de obra' y los programas de inversiones, así como para la elaboración de los programas de inversiones se necesita conocer el de producción y para éste se requiere conocer los objetivos en materia de utilización de los recursos humanos.

En los programas de producción habrán de ser contemplados las necesidades de insumos y recursos humanos para la fabricación de los bienes necesarios para la inversión; pero tampoco se podrá determinar exactamente el plan de producción si no se conocen sus posibilidades de crecimiento debido a las inversiones en bienes de capital y las condiciones del comercio exterior. Es decir, la disyuntiva es por dónde empezar a elaborar el programa, por la producción o por las inversiones, por los objetivos de empleo o por las posibilidades de comercio exterior. La respuesta a estas interrogantes está en que la planificación debe realizarse en forma simultánea e integral, contemplando conjuntamente tanto los planes de producción como los de inversión. De igual manera habrá de trabajarse simultáneamente el número de personas ocupadas, los ingresos y los niveles de demanda. De ahí que todos los aspectos del plan deben estar entrelazados orgánicamente entre sí.

En estas notas se pretende, teniendo en cuenta esa interrelación dialéctica, presentar la secuencia de la planificación global, teniendo como punto de referencia los objetivos de mejorar la utilización de los recursos humanos en virtud de tres consideraciones principales:

1) La subutilización de los recursos humanos o el desempleo, subempleo y creciente marginalización de vastos sectores de la población latinoamericana es uno de los problemas que requieren una mayor prioridad. 
2) En los esfuerzos de planificación el gran olvidado, como objetivo explícito, ha sido la mejor utilización de los recursos humanos, a lo más, mencionada como manifestación de intenciones o como una referencia con carácter de subproducto de una estrategia o plan ya formulado o adoptado.

3) La magnitud y atributo de los recursos humanos se determinan, en última instancia, por la característica de la población y su comportamiento demográfico como síntesis de su interacción con las condiciones económicas y sociales del propio proceso de desarrollo.

De manera que las presentes consideraciones se basan en el supuesto de la existencia de un diagnóstico, cuyo carácter es el de revelar las condiciones de la utilización de los recursos humanos y de sus potencialidades en el proceso de desarrollo económico y social de un pais.

Por lo demás, diversos estudios han permitido señalar que las características del subdesarrollo de América Latina se manifiestan especialmente a través de los indicadores que muestran la evidente subutilización de los recursos, no solamente humanos sino también naturales y de capital. Valga como ejemplo el hecho de que a la par de los niveles de desocupación y subocupación existentes en los países, también se encuentra una subutilización de la capacidad industrial utilizada y de las tierras agrícolas. $\underline{1}$

De manera que en estas consideraciones se intenta hacer explícita la secuencia metodológica de la planificación cuando uno de los objetivos estratégicos del desarrollo es el de empleo o de utilización de los recursos humanos. Es decir, en lo concreto esto se traduce en la búsqueda de aquella estrategia de desarrollo que esté adecuada a los objetivos ocupacionales que se fije un país. En consecuencia, cada uno de los pasos metodológicos de la secuencia en el proceso de formulación de planes significará una evaluación de la creación de ocupaciones y su consiguiente compatibilidad con las metas previamente fijadas. Este proceso de hacerlos compatibles se manifiesta en forma de ciertos hitos en la secuencia, a los cuales denominaremos "focos de concentración problemática". En estos focos se requiere un proceso de decisiones continuas para adecuar los objetivos de utilización de recursoshumanos, los factores que inciden en el proceso de desarrollo y los demás obje tivos de dicha planificación. La determinación de estos hitos es importante,

1/ Véase ILPES/CELADE, "Aprovechamiento de la capacidad instalada en el sector industrial", capitulo III de Elementos para la elaboración de una política de desarrollo con integración para América Latina, presentado en el Seminario sobre Desarrolllo Nacional con Integración (México, 4 al 8 de agosto de 1969). Solon Barraclough y Arthur Domike, "La estructura agraria en siete paises de América Latina", en El Trimestre Económico No 130, Fondo de Cultura Económica (México, 1966). 
pues señala los puntos a los cuales deberá dedicarse mayor atención y donde se requeríán más investigaciones y estudios y, en general, la may or cantidad de informaciones que permitan tomar las decisiones políticas pertinentes. Por lo tanto, estos focos son fundamentales por el carácter que adquieren en los hechos, al concentrar los elementos alternativos de las decisiones económicas y políticas que le darán la característica definitiva a la estrategia.

Hasta el presente se puede señalar que en la mayoría de los esfuerzos de planificación de América Latina se ha carecido de un tratamiento explícito de la utilización de recursos humanos. $2 /$ Es preciso reconocer que la preocupación sobre estos problemas se ha ido extendiendo y acentuando en la medida en que se han agudizado las condiciones de marginalidad ocupacional de una proporción creciente de la población. Sin embargo, en el terreno en que más se avanzó es en la definición de ciertos elementos de diagnóstico, estudios, recopilación de antecedentes que señalan la gravedad del problema y sus perspectivas de empeoramiento. $\underline{3}$ / En algunos casos se han hecho intentos de estudiar las repercusiones de los planes ya formulados en términos de recursos humanos u ocupacionales. En todo caso, lo que se podria decir es que el tratamiento de los problemas ocupacionales en los más de los casos ha sido el de un subproducto de planes ya formulados en función de otros objetivos globales, como es la tasa de crecimiento, el comercio exterior y las inversiones. 4

2/ Véase OIT, Planificación de la mano de obra y política de empleo para el desarrallo económico, Octava Conferencia de los Estados de América Miembros de la OIT (Ottawa, septiembre, 1966), p. 133 s.s. CEPAL/ILPES, Formación de los recursos humanos en el desarrollo económico y social de América Latina, presentado en la Conferencia de Ministros convocada por UNESCO y CEPAL (Buenos Aires, junio, 1966.), p. 12 s.s.

3/ Los ejemplos recientes más elocuentes de ello son: Raúl Prebisch, Transformación y desarrollo: la gran tarea de América Latina, Fondo de Cultura Económica y Banco Interamericano de Desarrollo (1970). ILPES/CELADE, "Ocupación, población y distribución del ingreso", capitulo II de Elementos para lo planificación ... (op.cit.. PREALC/OIT, Estudios sobre la situación del empleo en Perú y Chile (todavia no publicados) y Esteban Lederman, Los recursos humanos en el desarrollo de América Latina, Cuadernos de ILPES, Serie II No 9. (octubre, 1969).

4) Entre los intentos para cambiar esa orientación metodológica pueden señalarse: SIECA, Bases para un estrategia centroamericana de desarrallo, Guatemala, 1967, (mimeografiado). Secretaría Técnica de Planificación, La planificación de los recursos humanos en el Paraguay - Bases para una estrategia futura, Asunción, 1966. CONADE, Plan nacional de desarrollo y seguridad, 1971-1975, Buenos Aires, 1971; Ministerio de Planificación y coordinación de Bolivia, Estrategia socioeconómica del desarrollo nacional La Paz, 1970; y especialmente CED, Bases para una estrategia de desenvolvimiento del Estado de Minas Gerais, Belo Horizonte, 1969. 
El esquema de trabajo aquí adoptado considera un proceso cuya esencia está en la evaluación de las necesidades sociales y de las perspectivas de los recursos de que se dispone, de modo de lograr balances entre los objetivos, es decir utilización de los recursos y la disponibilidad de ellos. Ese esquema está basado en el concepto de que la planificación, en última instancia, es el medio para lograr la mejor forma de utlización de los recursos disponibles para satisfacer lo más ampliamente posible las necesidades de todos los integrantes de la sociedad. 5

5) Véase CED, op.cit.; Minas Cerais. Perspectivas e directrizes 1971.1975 (Belo Horizonte, 1971); y especialmente ILPES, Modelo GPC-2. Un instrumento de aproximación cuantitativa para la selección de alternativas de estrategia de desarrollo con objetivos de empleo (Santiago, Junio 1970). Para un esquema de la secuencia analizada en este documento, aplicado en los trabajos del Estado de Minas Gerais, véase infra anexo. 


\section{II.DISPONIBILIDADES DE RECURSOS HUMANOS}

La formulación general de un plan en el que uno de los objetivos principales es la utilización de recursos humanos parte de las condiciones actuales expresadas en un balance sobre la utilización de estos recursos. Ello requiere conocer, por un lado, las disponibilidades que de ellos tiene el país y sus perspectivas futuras y, por otra parte, la utilización que de ellos se ha hecho en el pasado y en la actualidad. Con estos antecedentes, la formulación del plan proyecta hacia el futuro los balances de recursos humanos que permitirán confrontar y evaluar las necesidades y demanda de mano de obra de la economía, por un lado, y las disponibilidades de recursos humanos por otro, y tomar decisiones sobre una asignación apropiada de ellos.

De ahí que el primer paso metodológico esté en determinar las disponibilidades de recursos humanos que el país tendrá en el futuro, basándose en el desenvolvimiento histórico y actual de ellos. Sin embargo, para tal logro es preciso definir el tamaño, estructura y característica de la población, que es el marco de referencia mediante el cual es posible conocer la parte que será apta para el trabajo o económicamente activa. Sólo a partir del conocimiento cuantitativo y cualitativo de la parte de la población en condiciones para el trabajo es posible definir una política de utilización de recursos humanos y consiguientes objetivos ocupacionales. El comportamiento demográfico de la población, en función de su estructura por sexo y edades, señalará los límites de las disponibilidades de fuerza de trabajo. Deberá quedar especificada la composición de la población por tramos de edades y sexos atendiendo a sus condiciones de activos e inactivos. En última instancia, habrá de quedar claro cuál es la población apta para el trabajo, deducidos los inhabilitados física o mentalmente y los estudiantes, ya sea en edad activa o no activa, y cuál es la parte de ella que integra la fuerza de trabajo. Habrá que tomar en cuenta que los factores demográficos y económicos que en ella influyen son dependientes del proceso de desarrollo que se está planeando. Habrá que distinguir, de acuerdo con el período de referencia, aquellos elementos que influyen en la estructura y tasa de crecimiento de la población y cuáles se convierten en variables y aquéllos que constituyen parámetros. La tasa de crecimiento de la población, en el hecho, es, a corto y mediano plazo, un parámetro, en la medida en que su comportamiento ya está determinado en la actualidad y que las 
migraciones no jueguen un papel significativo. En efecto, en ese caso depende fundamentalmente de las tasas de fecundidad y mortalidad, las que determinan la estructura por edades, a la vez que son una función de ellas. Así, por ejemplo, la actual estructura por edad de América Latina permite prever que la tasa de natalidad seguirá siendo alta en los próximos años. Al mismo tiempo es dable esperar un decrecimiento de la tasa global de mortalidad en la región por la existencia de factores que aún no han sido atendidos plenamente en términos de las condiciones de salud. Es cierto que existen algunos otros elementos que juegan en el sentido contrario, es decir, elementos tales como el aumento de los niveles de participación femenina pueden traducirse en caidas de la tasa de natalidad. Además, el mismo comportamiento de la relación urbana o rural tiene influencia sobre las tasas de fecundidad, dado que dichas tasas son menores en la ciudad que en el campo.

De ahí que cualquier definición que se tome en el proceso de planificación sobre el de urbanización tendrá efecto sobre las tasas de fecundidad de la población.

En consecuencia habrá que determinar las disponibilidades de recursos humanos, en términos de los factores que inciden en el crecimiento y estructura de la población, y en seguida en los que inciden en la entrada y salida de población de la fuerza de trabajo. Con ello, el estudio de las tasas de participación de la población ocupa un papel importante en la determinación de las disponibilidades.

Es preciso analizar estas tasas de participación, separadamente por grupos de edades, para la población masculina y femenina. Especialmente el comportamiento de la participación femenina puede transformarse en un objetivo de la política de desarrollo, si se considera la baja tasa actual $y$, en consecuencia, las reservas potenciales de recursos humanos que ella significa. En la medida en que el proceso de desarrollo social aumenta, se dan condiciones objetivas que actúan sobre la participación femenina. De ahí que una política de desarrollo tiene que contemplar en la definición de cada periodo cuáles son los objetivos en términos de integrar recursos humanos actualmente inactivos.

En el corto y mediano plazo también pueden tener importancia aquellas partes de la población que se encuentran en la fuerza de trabajo, pero que es preciso transferirlas a inactivas. 'Tal es el caso de menores de edad que trabajan y cuya integración a la educación puede ser un objetivo del plan. 


\section{DETERMINACION DE LAS METAS DE CREACION DE PUESTOS DE TRABAJO}

Una vez determinadas las disponibilidades de recursos humanos para el período que se planifica, el paso siguiente es fijar los objetivos preliminares de ocupación.

Este proceso está estrechamente relacionado con las decisiones políticas que significan fijar la imagen objetiva a largo plazo que se pretende en la estrategia de desarrollo que el país piensa aplicar. Es decir, a este nivel, teniendo en cuenta el grado de utilización actual de los recursos humanos, se habrá de tomar la decisión en cuanto a qué habrá de pasar en el futuro. Ello se expresa cuantitativamente en definir un valor permisible de desocupación en la economía para el periodo del plan, desocupación que representa el excedente de disponibilidades de mano de obra en relación a los puestos de trabajo, lo que estará expresado en términos tanto de desocupación abierta de la fuerza de trabajo disponible, como en un equivalente de la subocupación. Esta medida tiene importancia, pues permite determinar, tanto en el diagnóstico como en las proyecciones, los objetivos de creación de puestos de trabajo, que es la tarea fundamental del proceso de planificación y con los cuales se entra a considerar la situación en el área rural donde a su vez se fijarán las metas correspondientes. Por diferencia, quedarán determinados los requisitos de creación de puestos de trabajo en los sectores de actividad urbana. 6

Queda la interrogante de si se debe comenzar en las actividades rurales o urbanas. En los hechos se trabaja simultáneamente en ambas áreas, sólo que en el momento de hacerlas compatibles es necesario comenzar con una, lo que puede adecuarse a las condiciones del país en que se planifica en relacion al papel que desempeñan los sectores. Sin embargo, puede señalarse que, en general, parece más conveniente comenzar por el sector rural, por las condiciones del proceso histórico de desarrollo de América Latina y de otros países del mundo, referidas a las reservas potenciales de mano de obra que existen en el sector rural para ser iransferidas a los sectores urbanos vía incremento de la productividad agrícola.

6/ En este trabajo, con fines de simplificación, se identifica por rural a las actividades agropecuarias, y por urbano a las no agropecuarias. 


\section{DETERMINACION DE LAS METAS DE CRECIMIENTO ECONOMICO}

Aqui, a la par que se fijan las metas ocupacionales y en función de las definiciones políticas que han permitido conformar un objetivo-imagen de la estretegia adoptada, es posible expresar todo ello en un indicador global de crecimiento económico, necesario como referencia para adecuar el nivel y la estructura productiva. Esta determinación no es arbitraria, pues nace de las potencialidades evidenciadas en el diagnóstico.

Al igual que en el caso de las consideraciones sobre los objetivos preliminares ocupacionales, en este caso se podría comenzar por fijar las condiciones y estructura de la producción de los sectores urbanos pero, por las mismas razones anteriores, parecería conveniente comenzar por los sectores rurales. Además, porque las actividades rurales, que son esencialmente agrícolas, dependen fundamentalmente de la cantidad, calidad y potencialidad de los recursos humanos existentes. De ahí que al comenzar el tratamiento rural se puede clarificar prontamente por el lado de las potencialidades, los objetivos de condiciones de vida, traducidos en términos de ingreso por habitante rural aspecto importante si se consideran los bajos niveles de vida y productividad de la mano de obra en las actividades agrícolas, lo que permite determinar los incrementos de productividad $y$, en consecuencia, los desplazamientos de mano de obra que habrá que considerar de las actividades rurales a las urbanas. 


\section{DETERMINACION DE LA ESTRUCTURA PRODUCTIVA Y OCUPACION EN LOS SECTORES RURALES}

Los factores principales que determinan las condiciones de producción agrícola son, además de la potencialidad de los recursos naturales, la relación hombre-tierra, la estructura del uso de la tierra, la tecnología y la demanda agrícola.

Aquí cabe considerar de qué manera la estructura de propiedad actual obstaculiza la posibilidad de materializar las potencialidades detectadas y si un cambio en ella la facilita y de qué manera. Estas son interrogantes que en lo específico podrán responderse en cada caso concreto.

En lo que se refiere a la demanda, habrá que calcular las elasticidades correspondientes, considerando preliminarmente objetivos de redistribución de ingresos, de acuerdo con las metas de crecimiento global fijadas anteriormente. Estas elasticidades habrán de ser revisadas en una segunda etapa cuando se hay a llegado a una distribución del ingreso como resultado de los objetivos ocupacionales. Hechos los estudios correspondientes respecto a los factores citados, de acuerdo con la cantidad de tierra disponible y la composición de esos suelos, es posible determinar la estructura de cultivos que se adoptará. En función de la tecnología utilizada, es posible determinar la productividad física de cada cultura y de acuerdo con sus niveles de producción se obtienen las necesidades de mano de obra. El total de mano de obra requerida en el sector agrícola será el resultado de la agregación de la de todas las explotaciones.

A lo anterior habrá que sumar las demás actividades rurales, especialmente la ganadería. Asimismo habrá que considerar, por ejemplo, la pesca, la silvicultura, etc. En el caso de la ganadería, se parte tambien de los recursos naturales y de su potencialidad y en función de la tecnología empleada se llega a una superficie de la tierra necesaria por cabeza de ganado y a una producción pecuaria en función de esa masa ganadera. En este caso, los requerimientos de mano de obra estarán relacionados por una norma de manejo de masas ganaderas, es decir, por la relación entre masa ganadera y mano de obra requerida. En el caso agrícola, la relación está dada por el tipo de producción y la productividad de ella, es decir, mano de obra requerida por unidad de producto de cada tipo de cultivo. 
De esta manera se tendrán los puestos de trabajo o los requerimientos de mano de obra deducidos de las condiciones de producción. Con ellos se habrá llegado a un primer "foco de concentración problemática". A este nivel habrá que hacer compatibles los requerimientos de mano de obra deducidos de las condiciones de producción con las metas iniciales de puestos de trabajo que se habian fijado a partir de las disponibilidades. Este proceso significa un conjunto de decisiones políticas. Como probablemente en un primer intento habrá una diferencia entre lo que se fija como objetivo y lo que resulta de la producción, ello requerirá, en consecuencia, ya sea revisar los objetivos de producción o los de ocupación. Este proceso puede tener en teoría infinidad de soluciones, ya sea que los requerimientos resulten inicialmente mayores o menores que los objetivos preliminares de creación de puestos de trabajo.

Los objetivos preliminares ocupacionales rurales dependen de los siguientes factores: los limites de las tasas de desocupación abierta y equivalente, la relación de la población rural a la urbana (coeficiente de ruralización), la tasa de participación de la fuerza de trabajo y la tasa de crecimiento de la población. Por otra parte, los requerimientos de mano de obra dependen de las potencialidades del sector rural, del producto obtenido, de la productividad y de la estructura de cultivos y tipos de explotaciones.

De ahí que el proceso podría lograrse ajustando uno o varios de los factores mencionados; sin embargo, en cada caso específico las alternativas se reducen a unos pocos. Asi, si tomamos, por ejemplo, las condiciones generales de América Latina, puede observarse que si los requisitos resultan mayores que los puestos de trabajo, la alternativa obvia es revisar las tasas limites de desempleo fijadas, pues significa que en esos límites se aceptaron tasas grandes que hicieron que los objetivos ocupacionales fuesen modestos. Si se tratase de un país con escasez de mano de obra, habrá que realizar el ajuste por medio del incremento de la productividad y consiguiente mecanización. En otros términos, habrá que proceder a alterar la tecnología para que no sean perjudicadas las metas del producto. A su vez habrá que evaluar este proceso de mecanización y de cambio tecnológico en términos de financiamiento, lo que a su vez habrá que hacer compatible mas adelante cuando se vean los problemas de ahorro e inversión globales.

Otro caso que puede producirse es que al reducir la tasa de desocupación rural, las metas de creación de puestos de trabajo se transforman en mayores que los requisitos de mano de obra. En este caso, la solución estará en encontrar tal magnitud intermedia permisible de tasa de desocupación que las metas de creación de puestos de trabajo se igualen con los requisitos de mano de obra del plan.

Aun dentro de esta alternativa hay una decisión de política a considerar, y ella es: ¿qué convendría minimizar dentro de la tasa 
global de desempleo resultante, la de desempleo abierto o de desocupación equivalente?. En principio, parece ser aconsejable eliminar al mínimo el desempleo abierto y solamente considerar desocupación equivalente. Es preferible y, además la tendencia, que durante el período en que aún se mantenga el desequilibrio entre disponibilidad y puestos de trabajo, ello se ajuste mediante la subocupación, ya que significa realizar algún tipo de actividad. Más adelante se verá el tratamiento que se da a esos subocupados.

Otra posibilidad se verifica cuando la ocupación neta del sector rural excede a las necesidades de mano de obra del plan agropecuario. Una alternativa de solución frente a ello será, en consecuencia, revisar por el lado de la producción, partiendo de la base de que los objetivos de puestos de trabajo, por el lado de las disponibilidades, ha sido más bien una decisión de índole política. Generalmente ello es muy difícil, pues teniendo un buen diagnóstico, la fijación de los niveles iniciales de producción ha partido del hecho de intentar el máximo, dadas las potencialidades agropecuarias. La otra alternativa sería la de reducir la productividad de la mano de obra rural, lo que aumentaría los requisitos de mano de obra en términos de puestos de trabajo por unidad de producto. Tal al ternativa, sin embargo, significaría reducir aún más el ingreso por habitante rural, lo que a menudo es poco viable.

La otra solución estaría por el lado de revisar las metas iniciales de ruralización hasta que se produzca la igualdad, es decir, transferir objetivos de puestos de trabajo del sector rural al sector urbano. Habrá que analizar este nuevo nivel de ruralización a la luz del comportamiento histórico y de los estudios sociológicos relativos a las migraciones y a las diversas potencialidades económicas, pues puede llegarse a requisitos de aceleramiento de la migración rural-urbana o de un nivel de urbanización que no sea viable para el proceso de desarrollo que se está planeando para el país. Si es así, esto lleva a revisar las bases y definiciones politicas iniciales que dieron origen a la estretegia del plan. 


\section{DETERMINACION DE LA ESTRUCTURA PRODUCTIVA Y OCUPACION EN LOS SECTORES URBANOS}

El hecho de hacer compatibles los requerimientos y las disponibilidades de mano de obra rural implica no sólo el ajuste cuantitativo del nivel de empleo con la mano de obra disponible, sino la necesaria coherencia entre objetivos, metas y medios. De esta forma, las condiciones que de esta situación se deriven para el caso urbano tienen su origen en una situación rural viable. Con ello, los objetivos de creación de puestos de trabajo en el conjunto de los sectores urbanos quedan determinados, en primera instancia, al fijarse preliminarmente para el conjunto de la economía y para los sectores rurales y con la correspondiente revisión posterior.

Para el tratamiento de los sectores urbanos habrá que distinguir dos grupos: los de la esfera de producción material o de bienes y los de la esfera no material o de servicios. La esfera naterial estará constituida por aquellas actividades cuyo resultado tenga una expresión física y, en consecuencia, cuyo rendimiento pueda también apreciarse físicamente. Aquellas actividades de servicios que por su naturaleza o sus rendimientos no pueden asociarse directamente a un producto físico y cuyas formas de prestación están mas bien asociadas a ciertas normas, constituirán los sectores de la esfera no material.

Entre las primeras estarán las actividades manufactureras, de construcción, mineras, de servicios básicos y de comercio de mercaderías. Entre las segundas estarán las actividades de administración del gobierno, servicios sociales, como educación y salud, y los diversos servicios personales.

De esta manera, en la esfera material la determinación de la ocupación se obtendrá por la relación entre producción y productividad; en cambio, en servicios, los requisitos de mano de obra se obtendrán a partir de normas de prestación correspondiente.

En cuanto a la esfera de producción material o de bienes, como lo han recalcado varios estudios al respecto, el nivel de capacidad ociosa, especialmente en las industrias latinoamericanas, es bastante alto. $7 / \mathrm{La}$ consideración del problema es importante, pues parte del mayor

7 ‘ “ ( . . ) el problema de la subutilización de capacidad productiva en América Latina no es, en esencia, un problema coyuntural. Se trata, indudablemente, de algo mucho más profundo y permanente que constituye un aspecto propio de la 
producto y ocupación comtemplados en el plan puede lograrse con un mínimo de inversión. Metodológicamente, por lo tanto, conviene establecer en términos sectoriales cuáles serían los niveles de producto y ocupación compatibles con el uso pleno de la capacidad instalada, y a partir de ahi, establecer las necesidades de inversión y estudiar las alternativas tecnológicas que se presentan por sus implicaciones en la productividad.8] Conviene analizar cuáles serían los principales condicionantes estructurales que restringen el horizonte de alternativas para el planificador en esta etapa del plan. Los determinantes generalmente señalados son la distribución del ingreso y las formas de absorción de tecnología.

En general, en la literatura económica corriente en América Latina se señala la vinculación entre tipos de industria y la tecnología disponible. Se habla, por ejemplo, de que las industrias productores de bienes de consumo duradero, en general las llamadas industrias dinámicas suelen usar técnicas de producción mucho más intensivas en capital que las tradicionales (productoras de bienes de consumo no durables). Frente a ello, la concentración del ingreso explicaria los bajos niveles de empleo que han caracterizado el proceso de industrialización de América Latina. En ese sentido, una política de redistribución del ingreso haría aumentar la demanda por determinados tipos de bienes, cuya producción suele exigir más mano de obra que la de bienes durables. Si ello fuera cierto, el radio de maniobra con que se contaría en esta etapa de la elaboración del plan estaría en alguna medida delimitado por la distribución del ingreso que resulte de la aplicación del plan.

Es conveniente confrontar la validez de esa interpretación con las formas de absorción tecnológica que los países subdesarrollados han utilizado a lo largo de su proceso de industrialización.

La tesis central es que la tecnología utilizada en cada industria corresponde a la técnica de producción más moderna disponible en los países industrializados en la época de su instalación en nuestros países.

De otra parte, la evolución tecnológica en los países centrales se ha caracterizado por avances en el ahorro de insumos, mano de obra y capital, por unidad de producto mediante la introducción de técnica cuyo efecto en el empleo es cada vez más reducido.

Por lo tanto, la ampliación de las industrias tradicionales tiende a verificarse con procesos de absorción de técnicas similares a las de los países industrializados y cada vez más sustitutivas de mano de obra.

\footnotetext{
modalidad de desarrollo industrial latinoamericano, por lo tanto que se encuentra implícito en las actuales tendencias económicas y que se autoperpetúa."

(ILPES/CELADE, “A provechamiento de la capacidad. ..”, op.cit.,p.29.)

8/ Con más razón si recordamos que nos estamos refiriendo a la productividad técnica de cada puesto de trabajo.
} 
Esta tesis se conforma en algunos países de la región (verbigracia en el Brasil) en los que se ha verificado recientemente un proceso de modernización de algunas ramas tradicionales con efectos negativos sobre el empleo.9/En estas condiciones, la redistribución del ingreso. como medida aislada no tiene efectos positivos sobre el empleo y, por lo tan to, restringe la posibilidad de solucionar el desempleo mediante el uso de tecnologías alternativas. 10 /

Por otra parte, no sólo la productividad suele ser distinta para cada tecnologia, sino que la calidad de los bienes producidos también lo es. Agréguese el hecho que para los bienes más modernos, sencillamente no hay alternativa de técnica más antigua.

Por otra parte, optar por una tecnología más antigua puede significar mayor empleo, pero también destinar mayores recursos para la inversión en equipos y obtener índices de productividad inferiores. Este último problema puede ser crucial en el caso de sectores donde la producción es competitiva con el mercado internacional (por ejemplo, sectores productores de insumos para la agricultura exportadora, o sectores directa o potencialmente exportadores).

Una u otra vía de solución envuelve problemas políticos que deben ser previamente definidos. Se refiere al destino y uso del excedente creado en el proceso productivo. Si el planificador dispone de medios de manipular dicho excedente, o actúa en un modelo político que lo permite, las repercusiones del problema tecnológico en el empleo asumen un aspecto secundario..

Convendría, en ese caso, utilizar tecnología moderna en algunos sectores definidos en la estrategia, logrando con ello crear una masa considerable de excedente que se utilizaría en el financiamiento de otras actividades, las cuales requerirían utilizar mano de obra en gran escala. Se garantiza así, de un lado, la competitividad de algunos sectores estratégicos, $\mathrm{y}$ de otro, un elevado nivel ocupacional.

Otro aspecto que no se puede olvidar en el análisis de los sectores es la capacidad de multiplicación de ocupaciones que posee cada sector (o sea, la relación que hay entre creación de empleos directos e indirectos, hacia atrás o hacia adelante) y verificar hasta qué punto el empleo indirecto es, de hecho, generado dentro del país y no en el exterior, para poder evaluar el efecto de los distintos sectores sobre el empleo.

Un segundo orden de problema a nivel de los sectores es la estructura de la demanda compatible con los niveles de ingreso planeados. La

9/ Véanse los datos en: IPEA, Anexo estadistico Industrias tradicionais: $U_{n}$ reexame crítico $\mathrm{R}$ io de $\mathrm{J}$ aneiro, 1969, mimeografjado.

10/ Para el planificador, sin embargo, puede ser importante analizar cuál es el real impacto sobre el empleo de un proceso de redistribución del ingreso, principalmente en actividades ya instaladas, sobre todo si este análisis se efectúa paralelamente con el del aprovechamiento de la capacidad ociosa antes referida. 
utilización de los coeficientes de elasticidad-ingreso por tipo de bienes es ahora importante. Cabe de nuevo señalar que dichos coeficientes no son independientes de la distribución del ingreso, lo que implica establecer para ellos valores que contemplen esta particularidad y revisarlos cu ando se haga la "compatibilización" final.

Definidos el nivel de producción por sectores, el uso de la capacidad actual, la estructura productiva la tecnología empleada en las nuevas inversiones, se llega a los requisitos de mano de obra en términos de puestos de trabajo para los sectores industriales y de servicios básicos.

En el caso de la esfera de servicios, no es posible encontrar una relación directa de productividad, con lo que el procedimiento se vincula a ciertos objetivos de esos servicios y normas de su prestación, como ser número de alumnos atendidos por el sistema escolar y número de docentes por alumnos en cada tipo de enseñanza, o también número de camas hospitalarias, de acuerdo con los objetivos de mejoramiento en las condiciones de salud y la relación de personal médico para su atención. Para otros servicios, las normas podrán fijarse en su relación con la evolución de los sectores productores de bienes, en el comportamiento histórico o en comparaciones internacionales.

Conviene también complementar las consideraciones y análisis anteriores a la luz de indicadores globales sobre el comportamiento histórico de la estructura de ocupaciones del país y de otras experiencias. Estos análisis basados en métodos globales de correlaciones, pueden ser útiles como marco de referencia y, más de una vez, un primer paso preliminar de determinación cuantitativa para vislumbrar órdenes de magnitud, hasta que las programaciones sectoriales se efectúen y permitan hacer la "compatibilización". Para ello es posible, teniendo presente la experiencia histórica, en una primera aproximación, relacionar el nivel del ingreso por persona en la zona urbana con una estructura del producto urbano compatible.

Estos elementos son, en cierta medida, independientes de la estrategia de desarrollo adoptada. Pero, como se señalaba, la eștructura del producto urbano habrá de irse conformando en forma compatible con la estrategia a nivel sectorial. De esta manera, se habría llegado a otro "foco de concentración".

Al igual que en el caso agrícola, una vez determinados los requisitos de mano de obra urbanos, hay que proceder a hacerlos compatibles con las metas de empleo antes establecidas, en términos de puestos de trabajo.

En el caso de que los requisitos de mano de obra sean mayores que las metas de ocupación, el procedimiento es, en líneas generales, idéntico al usado en el caso rural. Solamente cabe observar que si se mantienen los requisitos mayores, una vez reducida a un minimo la tasa de desocupación, el análisis para disminuir los requisitos de la mano de obra habrá de comenzar en la revisión de las normas de prestación en la esfera de servicios. 
Si los requisitos de mano de obra son menores que las metas de ocupación, la solución estará en aumentar la tasa de desempleo equivalente hasta lograr la "compatibilización", dado que ya lo están las metas de ocupación rural.

En suma, si bien los problemas de "compatibilidad" se resuelven en forma similar al caso rural, es preciso tener presente que para este ajuste existen menos grados de libertad, debido, precisamente, a que los niveles a los que se logre la compatibilidad en el sector rural se convierten en parámetros para el sector urbano.

El ajuste descrito, si bien asegura una compatibilidad cuantitativa global, nada dice respecto a la composición cualitativa tanto de las necesidades como de las disponibilidades.

La consecución de los objetivos de desarrollo económico plantea, a lo menos, dos exigencias en términos de recursos humanos. La primera es que se satisfagan plenamente los requerimientos cuantitativos de mano de obra derivados, como se ha visto, de las metas de producción de las diferentes actividades, mediante las productividades medias de los puestos de trabajo o de las normas de prestación de servicios, según sea el caso. Esta exigencia se satisface al lograr la compatibilidad ya descrita.

La segunda exigencia se refiere a la necesaria concordancia entre el perfil de capacitación de la fuerza de trabajo con la estructura de habilidades de la mano de obra requerida por las tecnologías implícitas en los objetivos propuestos. 11

En la práctica, lo más probable es que existan déficit de capacitación de la fuerza de trabajo en función de ciertos objetivos de desarrollo. Será materia del programa de educación o capacitación cubrir dichos déficit; claro que, como la capacitación no es instantánea, existirá un periodo de maduración durante el cual el desajuste permanecerá inalterado.

Estas consideraciones son importantes, por cuanto introducen la necesidad de revisar los objetivos a la luz de esta nueva restricción y a la vez entregan antecedentes para la reformulación de aquellas tareas del sector educación que incidan directamente sobre la capacitación de la fuerza de trabajo actual y para el ajuste de los programas de estudios de la población en edad escolar.

11/ Recuérdese que la tecnología se introduce explícitamente mediante la determinación de los niveles de productividad media de los puestos de trabajo en el caso de la esfera de producción material y de las normas de prestación de servicios en las actividades de la esfera no material. 


\section{ASIGNACION Y DISTRIBUCION DE LOS RECURSOS HUMANOS}

Hasta la etapa anterior se logra tener los puestos de trabajo disponibles, pero no como se asignarán los recursos humanos. Por lo tanto, la atención se debe ahora volver a la determinación de la población ocupada $; \underline{12 /}$ a la división entre personas plenamente ocupadas y subocupadas; $y$ a la determinación del producto generado por cada uno de esos grupos. El procedimiento debe ser aplicado para los sectores rurales y urbanos independientemente.

En caso de existir subocupación, se presenta el hecho de que un mayor número de personas producen la misma cantidad de bienes y servicios. Esto trae como consecuencia que la productividad media desciende, pero en la práctica se puede constatar que en un sector de actividad, al existir más trabajadores que los necesarios, a pesar de bajar la productividad media, se encuentran estratos plenamente ocupados y otros cuya productividad es casi nula. Esta situación obliga a distinguir entre los trabajadores a aquéllos que aún permanecerán subocupados y darles un tratamiento diferencial.

Dado que se conoce el número en términos de su equivalencia a número de desocupados abiertos, el primer paso en la determinacion de la generación del producto por estrato de ocupación consiste en la cuantificación de las personas en condiciones de subocupacion. A causa de que la desocupación se refiere tanto a aquellas personas que trabajan una jornada inferior a la normal como a los que por insuficiencia de conocimientos o habilidades. o bien por falta de equipos adecuados, tienen una productividad inferior a la normativa, se concluye que en todos los casos se puede caracterizar la subocupación por presentar productividades bajas, lo que se traduce en un requerimiento de mano de obra por unidad de producto, superior al normativo.

La división entre ocupados y subocupados se hace mediante la productividad "normativa" (o sea, la productividad mínima bajo la cual

12 La población ocupada es la suma de los puestos de trabajo y la desocupación equivalente. Dados los altos niveles de productividad en el sector pecuario en relación al agrícola, podría ser conveniente considerar los puestos de trabajo en el sector pecuario igual a la población ocupada, o, lo que es lo mismo, considerar inexistente el subempleo en la ganadería. Caso contrario, hay que hacer todo el cálculo de la desocupación equivalente para los dos sectores independientemente, igual modo como se procedería después en el caso de los sectores urbanos. 
se considera que la mano de obra es subocupada) y la productividad promedio de estos últimos.

El total de ocupados plenos se determina por diferencia entre la población ocupada efectiva y los subocupados. Cabe destacar que, existiendo desocupados equivalentes, el número de ocupados plenos será inferior al número de puestos de trabajo, ya que, por definición, el resto de dichos puestos será ocupado por los subocupados en una proporción de más de una persona por ocupación.

En el caso urbano, en que se tienen metas sectoriales y totales de producto y puestos de trabajo, la desocupación equivalente determinada a nivel global se distribuye en los sectores de acuerdo con el papel que se le asigne a cada actividad en la política de absorción de la desocupación para la consecución de los objetivos de la estrategia de desarrollo.

Este tratamiento de la subocupación es útil, pues como su absorción es gradual persistirá durante algín tiempi, aunque disminuyendo en forma progresiva, y de esta forma se podrán reservar algunos sectores para que lleven el peso de dicha absorción, sin comprometer la eficiencia operativa de aquellos otros que serán más estratégicos desde el punto de vista del desarrollo. 


\section{COMPATIBILIZACION MACROECONOMICA DE LAS DIVERSAS MEDIDAS}

Determinado el nivel de población ocupada global y sectorial, la desocupación, las personas en condiciones de subocupación y, por diferencia, los ocupados plenos, es posible cuantificar el producto generado tanto por los subocupados como por los ocupados plenos mediante las productividades medias respectivas. Este cálculo debe hacerse a nivel de cada sector. Con ello se está en condiciones de analizar la distribución de ingreso generado como resultado de un proceso productivo establecido para cumplir los objetivos ocupacionales..

\section{Apropiación del producto y distribución del ingreso}

Para efectos de introducir el estudio de la apropiación del producto en esta estrategia de desarrollo, como requisito básico se debe contar con una definición por parte de la autoridad política del criterio que se adoptará en la materia. Esto es importante por cuanto determina el tipo de herramienta a utilizar en las correcciones de las desviaciones del proceso distributivo. Asi, si se mantiene la estructura de apropiación del producto derivado del sistema de propiedad y de la estructura de salarios y utilidades prevalecientes, los ajustes deberán hacerse principalmente por vías indirectas tales como tributación y subsidios. Por otra parte, si la estrategia pretende cambiar sustancialmente la estructura del sistema socioeconómico vigente y con ello llegar a una distribución del ingreso más pareja, será necesario cambiar previamente el sistema de apropiación, vía transferencia de la propiedad de los medios de producción, y conseguir una redistribución entre las personas y dejar el ajuste de las desviaciones menores a los mecanismos indirectos.

Una vez decididos esos elementos, es posible distribuir los ocupados plenos en tantos tramos de ingreso como sea relevante para efectos de la estrategia, manteniendo a los subocupado como un estrato más .

Todo el estudio de apropiación del producto habrá de hacerse a nivel de cada sector de actividad, por lo tanto se tiene una cuantificación del producto correspondiente a cada estrato de población en cada uno de los sectores.

Teniendo el cuadro de distribución del producto o ingreso generado, se introducen los elementos preliminares de la política de redistribución, 
a base de los mecanismos que permiten pasar de la apropiación del producto a la distribución del ingreso disponible. 13 /

En los hechos, esto llevará a otros problemas importantes y en relación a los sistemas y políticas de remuneraciones de algunos estratos, dado que las medidas de carácter general, tales como los salarios mínimos, parecen no tener vigencia como medida homogeneizadora de las remuneraciones en toda la economía.

Conviene destacar que éste todavía no es el ingreso personal disponible, pues no se ha aislado la parcela correspondiente a las utilidades. Dado el procedimiento que se adoptará en la determinación del ahorro personal, asociándolo a distintos niveles de ingreso, conviene, por ejemplo, determinar de antemano el monto de ganancias retenidas por estratos sectoriales de apropiación del producto. Esto se hará por dos razones principales: las utilidades retenidas de hecho no pueden ser consideradas ingreso de los propietarios y las decisiones respecto a su monto no es individual sino que generalmente los establecen las empresas mismas, en función de sus políticas de largo plazo.

El procedimiento alternativo de considerar a todas las utilidades como ingreso y posteriormente a la parcela retenida como ahorro de los propietarios, además de metodológicamente incorrecto, dificultaría formalmente la determinación de los coeficientes de ahorro según

13/ Ello se hace para cada estrato de ingreso y pueden utilizarse métodos de cálculo matricial, en base, por ejemplo, de los siguientes elementos:

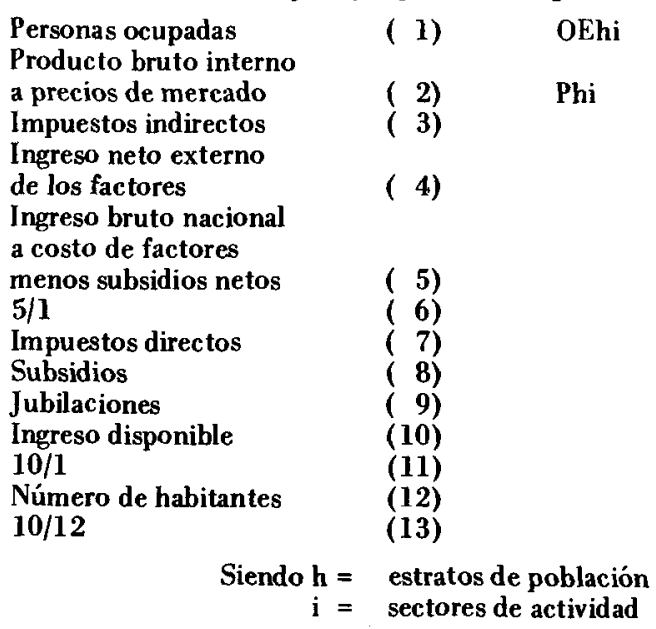

Es decir, metodológicamente conviene también partir de la apropiación del producto bruto a precios de mercado según estratos de apropiación y deducir (o agregar) en cada uno de ellos las respectivas parcelas hasta llegar al ingreso disponible en cada estrato de apropiación. Véase el Modelo GPC-2, op. cit. 
tramos de ingreso al mezclar decisiones de tipo personal - teóricamente aceptables en cuanto a la correlación con el nivel de ingreso- con desiciones de las empresas, que dependen de otro tipo de factores.

\section{Consumo e inversión}

Una vez determinada la apropiación del producto y correspondiente distribución del ingreso según los estratos de los respectivos sectores, es necesario determinar el ahorro y el consumo y su estructura.

El ahorro y la estructura de consumo están relacionados con el nivel de ingreso per cápita independientemente del sector en el cual se haya generado. Para llegar al ahorro privado, se asocia a cada estrato de ingreso por persona un coeficiente de ahorro, compatible con los hábitos de la población y los cambios en ellos, eventualmente previstos en la estrategia.

El ahorro privado será, pues, la suma de las ganancias retenidas y el ahorro personal, lo que después deberá ser agregado al ahorro público y externo para hacer compatible la cuenta ahorro-inversión.

En cada estrato de apropiación del producto, el consumo resulta de la diferencia entre el ingreso total y el ahorro antes determinado. Con ello se está en condiciones de determinar el consumo por persona de cada estrato de ingreso.

La determinación de la estructura de consumo obedece a una técnica similar a la utilizada en el caso del ahorro. Se asocian distintas estructuras de consumo compatibles con distintos niveles de consumo por persona. Estas estructuras se aplican al consumo de cada estrato de apropiación del producto, según sus respectivos niveles de ingreso por persona, quedando con ello determinada la estructura y el nivel del consumo total segin sectores de origen.

Establecido asi el consumo personal total de la economía, procede la determinación del consumo del gobierno. En este caso, habrá primero que estimar la evolución del producto del sector público considerando factores tales como las necesidades determinadas por la evolución económica general definida por el plan, la tasa de urbanización y la necesidad de expansión de los servicios públicos, etc. La compra de bienes y servicios no personales del gobierno puede ser estimada luego mediante su relación al producto total del sector.

El siguiente componente de la demanda final que debe ser establecido es la inversión. En buena medida, este componente estará determinado a nivel sectorial desde que se determinó el producto y las funciones de producción sectoriales.

Distinto tratamiento debe tener el cálculo de la inversión del gobierno dado su carácter peculiar en la mayoría de los casos. Está generalmente determinada por otros factores que no son los criterios privados de asignación de recursos. Pero, tambien es verdad que se 
puede establecer una cierta relación entre la inversión del gobierno y la de los demás sectores o "privada". Ambos montos suelen tener un comportamiento relacionado, dado quie la inversión pública, en una gran parte de los casos, es complementaria de la inversión "privada". 14/ Por ello, el procedimiento más sencillo consiste en determinar (basado en las series históricas disponibles y en algunas de las definiciones de la estrategia de desarrollo) el correlato de ambas magnitudes. Determinadas las inversiones sectoriales, queda definida la del gobierno.

\section{Comercio exterior, brecha de ahorro y producto total}

Las importaciones totales deben ser calculadas a base de las necesidades de bienes de consumo final, de capital y de bienes intermedios. Los primeros serán dados por las necesidades de abastecimiento resultantes de la estructura de consumos determinada anteriormente. El resto se define en cada caso por los componentes importados de cada uno de esos agregados a nivel sectorial. Por supuesto que el análisis del comportamiento histórico de la economía es importante para la determinación de esos coeficientes de importación, pero se debe tener presente que la estrategia de desarrollo puede contemplar algunas metas de sustitución de importaciones que deben ser consideradas en cada caso.

Las exportaciones son un componente exógeno de la demanda final en el sentido de que su determinación es independiente de la demanda interna y están vinculadas esencialmente con las oportunidades del mercado internacional. Pero si se dan las condiciones de demanda, la capacidad de respuesta de la economía depende esencialmente de la política de exportaciones definida por la estrategia de desarrrollo.

El radio de maniobra con que contará el planificador no será tan estricto entonces, dado que puede manipular las condiciones de oferta al marco de la demanda externa. El cálculo de las potencialidades de exportación debe, por lo tanto, contemplar esos dos aspectos del problema y corresponder a una estrategia dada de exportaciones. Se debe tener presente, sin embargo, que las exportaciones pueden ser un elemento de ajuste en la "compatibilización" final, en el sentido de que una adecuada redefinición de la política de exportaciones puede contemplar la inclusión de otros productos que antes no se exportaban, aprovechando algunos sectores de comercio potencial, además de los que habían sido inicialmente definidos en la estrategia.

Con ello se llega a otro "foco de concentración problemática". En efecto, el producto por el lado de la demanda quedó determinado por medio del consumo personal y del consumo público, la inversión

14. Vale recordar que lo que se indica aquí como inversión privada incluye también a la de las empresas públicas. 
"privada" y del gobierno, las importaciones y las exportaciones. Habrá que hacer compatible este agregado con el producto inicialmente fijado, por el lado de la oferta productiva, como resultado de los objetivos de empleo.

En el caso de que se produjeran discrepancias entre los totales, se podrá buscar la "compatibilización" por medio de un ajuste (brecha comercial) en las necesidades de importaciones, en las estrategias de exportación o en el movimiento de capitales, de acuerdo con la política de comercio exterior y deuda externa que se elabore como reflejo de la estrategia general de desarrollo.

La solución alternativa será la de mantener el desequilibrio hasta que se elaboren las cuentas de ahorro y determinar entonces la brecha de ahorro. Tiene ese último procedimiento la ventaja de mantener inalteradas las metas del plan y tratar. de definir el monto de las deficiencias en el ahorro. Podrá eso determinar políticas específicas de contratación de financiamientos externos o de alteración en el ahorro interno. Este último procedimiento implica hacer compatible nuevamente la estructura de consumo de la población. 

ESQUEMA DE UNA SECUENCIA DEL PROCESO DE FORMULACION DE METAS DE EMPLEO EN LA PLANIFICACION *

Distribución de la desocupación equivalente urbana

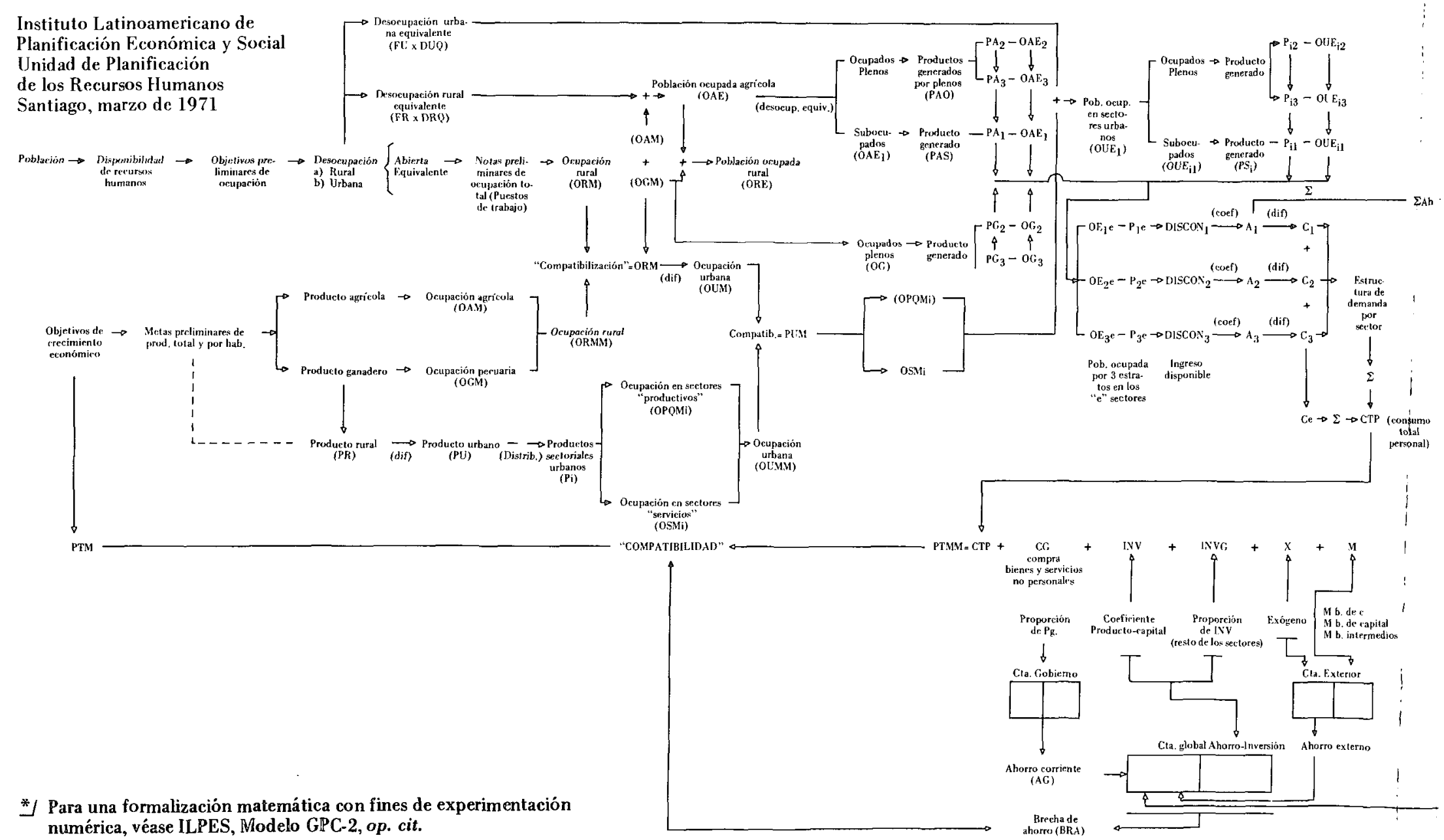




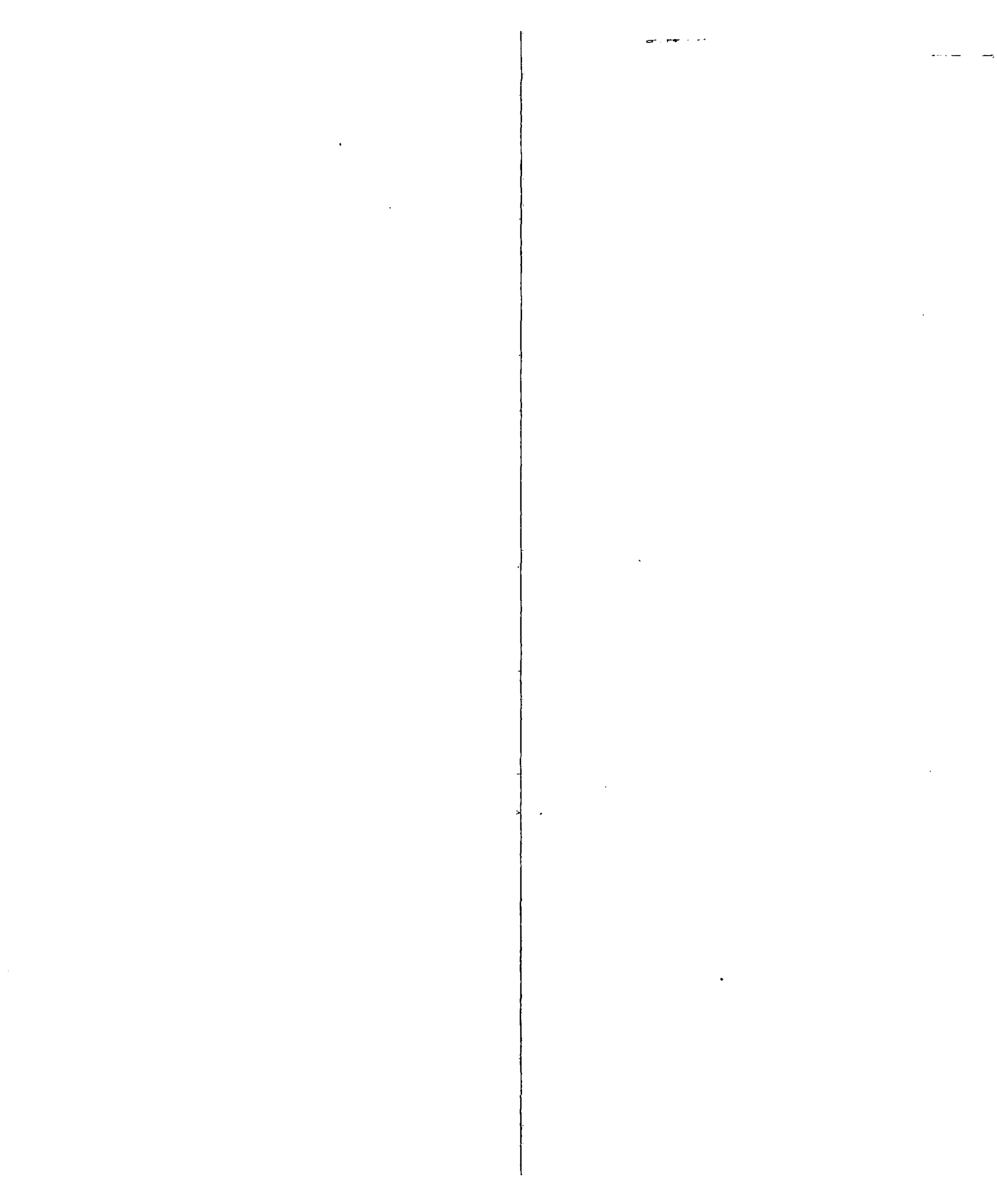


LA UTILIZACHON DE LOS DATOS

DEMOGRAFICOS $Y$ EL TRATAMIENTO

$\mathbb{D E E}$ LAS VARIABLES DE $L A$ POBLACION

EN PLANIFICACION DE LA SALUD

\author{
Dr. Raúl Vargas
}

Documento preparado por el Centro Panamericano de

Planificación de la Salud. Organización Panamericana de la Salud. 



\section{INFLUENCIAS RECIPROCAS ENTRE POBLACION Y SALUD}

\section{INFLUENCIA DE LAS VARI ABLES DEMOGR AFICAS SOBRE LA SALUD}

Es conveniente establecer una diferencia entre dos aspectos en los que las variables demográficas pueden tener influencia sobre la salud: uno es el relacionado con la asociación existente entre la población y la salud misma; y, el otro, aquél que presenta a la población como sujeto para la provisión de los servicios que brinda el sector. En otras palabras, examinaremos la población y las variables demográficas en cuanto ellas determinan o condicionan ciertas necesidades de salud y también en cuanto ellas condicionan la oferta de servicios.

\section{a) Influencia sobre la salud}

No es fácil explicar la existencia de una relación de causa-efecto entre las características de la población que se consideran tradicionalmente "demográficas" y la salud, a pesar de las evidentes asociaciones que se encuentran en los estudios epidemiológicos que se llevan a cabo. Es posible que la mayor parte de correlaciones encontradas sean de tipo espurio y que las características demográficas sean en realidad variables intermedias. Ello no invalida su gran utilidad como indicadoras de situaciones en las que se podría hallar a los verdaderos agentes etiológicos.

Examinaremos brevemente las características demográficas más comunes.

i) El tamaño de la población por sí solo puede ser difícilmente asociado con la presentación de diferencias en niveles de salud. Desde luego que si se liga a otras características, sobre todo a las modificaciones que su dinámica introduce en el medio ambiente, podría pensarse en la existencia de una mayor asociación. Son conocidos en el reino animal los ejemplos de los mecanismos por los cuales el crecimiento acelerado de una especie modifica el medio ambiente, altera su ecología y cambia sus condiciones de vida. Tales mecanismos son también ciertos en la especie humana aunque ellos se encuentran controlados por la densa utilización de la tecnología, la que introduce posiblemente modificaciones mucho más drásticas en el ambiente que las causadas por el crecimiento de la población. 
En general, es muy poco lo que se conoce al respecto, ya que no es sencillo aislar los efectos del tamaño de la población ni los de su dinámica numérica. Es insostenible un punto de vista puramente malthusiano así como también el suponer la existencia de un tamaño "óptimo" para un nivel de salud dado, lo cual no podría ser aceptado sin la demostración de alguna relación de causalidad entre ambos factores.

ii) La distribución geográfica de la población implica la existencia de distintos grupos de población expuestos a diversos riesgos ambientales $y$, por lo tanto, la presencia de diferenciales en niveles y estructura de salud. Dentro de esta característica demográfica vale la pena señalar la importancia que tiene el concepto de densidad de población, el cual, simplemente por la proximidad física que en algunos casos representa, puede condicionar la "trasmisibilidad" de ciertas enfermedades. Si a tal concepto le agregamos el de "densidad social" hallaremos elementos explicativos para muchas otras enfermedades tales como las mentales y los desarreglos de la conducta.

Como en el caso del tamaño de la población y sobre todo en sus aspectos dinámicos (migraciones) que implican la modificación de la densidad, la concentración, el hacinamiento, etc., la distribución geográfica actúa indirectamente a través de la modificación del ambiente físico, biológico y social, aumentando, disminuyendo o generando nuevos riesgos sin constituir una causa directa de los diversos estados de salud, Además las migraciones significan el movimiento de gente que tiene ciertas características de salud ya adquiridas y que al trasladarse a otras áreas pueden introducir en ellas cambios en la estructura de la morbilidad. Así, por ejemplo, son conocidos los casos de migrantes de áreas rurales a urbanas que llevan consigo enfermedades inexistentes en estas últimas, introduciendo de este modo una nueva patología en el conjunto (enfermedad de Chagas y otras). Igualmente son notables los rápidos procesos de tuberculización en ciertas áreas debido a la llegada de población residente en zonas donde abunde esa enfermedad. En sentido contrario, se da el caso de migrantes susceptibles que, siendo residentes en áreas de baja exposición a una endemia, al ponerse en contacto con poblaciones que llegan con alto índice de tuberculización, adquieren rápidamente la enfermedad y con ello elevan súbitamente los índices de prevalencia. Parecería obvio volver a mencionar casos de epidemias generadas por la movilidad geográfica de la población.

iii) En cuanto, a la composición de la población, puede decirse que en general, la pertenencia de un individuo a un grupo dado de población le determina un cierto grado de susceptibilidad y de exposición a riesgos para la salud, que son inherentes a dicho grupo. Esto puede verse muy claramente en la distribución por sexo y por edad cuando se examinan las tasas específicas de morbilidad y de mortalidad por un gran número 
de enfermedades. Algunas de éstas atacan indistintamente a cualquier edad, aunque también es común que hay a diferencias muy marcadas, indicando así una desigual proclividad de los distintos grupos de edades y sexos a la presentación de ciertas enfermedades. Así, la estructura por sexo y por edad, al estar asociada con las diversas intensidades de ataque de las enfermedades configura lo que puede llamarse la "susceptibilidad básica" de la población a tales enfermedades. Ella brinda importantes elementos explicativos de la situación de salud, es un factor condicionante de ésta, y, al estimarse y proyectarse al futuro, provee de elementos para basar hipótesis y previsiones acerca del nivel y estructura de la salud con respecto a muchas enfermedades.

La composición económica, laboral, educacional, social y cultural de la población cuya información se obtiene en los censos, por lo cual son designadas como características demográficas, se presentan en grupos de población asociados a distintas formas de vida y de comportamiento social. Por lo tanto, pueden ser considerados como grupos que tienen también distintos grados de exposición a los diversos riesgos de enfermar y de morir. Así, puede concebirse la existencia de diferencias importantes en el nivel y estructura de la salud entre una población cuya actividad económica primordial es la agricultura y otra cuya actividad más importante es la minería, o bien entre profesionales y obreros, etc. De este modo, la composición de la población según diversas características aporta elementos explicativos de la situación de salud, desde el momento en que tales características son indicadores de formas de vida y de comportamiento social y entrañan exposiciones distintas a los diversos riesgos.

\section{b) Influencia sobre los recursos para la salud}

Si se observa la distribución geográfica de los recursos de salud en un país cualquiera, puede advertirse que sigue de cerca la de su población, aunque con frecuencia las facilidades sanitarias se presentan con más altos índices de concentración. Por consiguiente, las áreas urbanas más densamente pobladas y cuyos habitantes tienen mayor acceso a las fuentes de trabajo, de ingreso económico, de educación, de cultura y de esparcimiento, son también las más favorecidas con la disponibilidad de recursos.

La distribución geográfica de la población es posiblemente la característica demográfica de mayor gravitación en la distribución de los recursos de salud, siguiendo consideraciones parecidas a las que rigen el "mercado" de la industria de la salud. Esta situación se altera en parte por la intervención de los servicios oficiales de salud, especialmente cuando éstos programan sus actividades dentro de una política destinada a brindar una mejor salud a los sectores más desamparados, conforme a una política de justicia distributiva y 
absorbiendo por ello el mayor costo que significa. A pesar de esto y de lo drástica que pueda ser dicha política, el factor predominante en la distribución de los recursos seguirá siendo la distribución geográfica de la población, en su sentido de accesibilidad física a los servicios de salud. e

Por esta mísma razón, la dinamica migratoria, que altera la distribución geográfica de la población, tiene importantes repercusiones sobre los recursos de salud. Exige una respuesta inmediata de oferta, la que estará condicionada, además, por las variaciones que el fenómeno introduce en el estado de salud. Es bien conocido el hecho de que la urbanización en América Latina ha introducido presiones importantes sobre los servicios públicos en general y, por lo tanto, sobre los servicios de atención médica, de provisión de agua potable, de disposición de excretas y basuras, etc. La intensidad de la dinámica migratoria ha rebasado en ciertos casos la capacidad de producción de dichos servicios y ha obligado a incrementar los rendimientos hasta niveles que podrían hacer presumir un posible deterioro en su calidad.

$\mathrm{La}$ infraestructura de salud, que incluye principalmente los recursos humanos y la capacidad instalada, tiene un cierto límite en su flexibilidad y en sus posibilidades de adaptación. Por ello, no siempre es posible satisfacer en forma inmediata una demanda cuyo incremento no se ha previsto con la suficiente anticipación que permita, entre otras cosas, la formación de nuevos recursos o la modificación de los existentes en número y configuración.

A causa de la asociación que existe entre las categorías de la población por grupos de edades y sexo y grupos socio-económicos, por una parte, y los problemas de salud, expresados generalmente en términos de enfermedades, lesiones y condiciones orgánicas y funcionales anormales, por otra, la estructura de la población condiciona de cierta manera el tipo de recursos, como, por ejemplo, en el ' caso de las especialidades médicas. Una población con alta proporción de niños explica una proporción más elevada de pediatras y de obstetras; en cambio, una población envejecida explica la presencia de cancerólogos, cardiólogos, etc.

Debe mencionarse nuevamente que en estos casos no son las características demográficas las que determinan el tipo y número de recursos y de servicios de salud, sino la estrecha relación entre ellas y la patología a la que se encuentran asociadas.

\section{INFLUENCIA DE LAS ACCIONES DE SALUD SOBRE LAS VARIABLES DEMOGRAFICAS}

\section{a) Sobre la mortalidad}

El descenso de la mortalidad, que inició la transición demográfica en los países de Europa Occidental donde ha sido posible estudiar este 
fenómeno, reconoce una causalidad múltiple. No es fácil aislar el efecto que tuvieron las actividades de salud propiamente dichas del obtenido como consecuencia de la elevación de los niveles generales de vida. Los estudiosos del problema están más dispuestos a señalar este último fenómeno como el de mayor importancia en la explicación de la reducción de la mortalidad.

Es muy posible que en los países que actualmente se hallan en vías de desarrollo los descensos importantes de la mortalidad tengan alguna may or relación de causalidad con acciones desarrolladas para prevenir la enfermedad y la muerte, puesto que tales paises han tenido acceso al uso de tecnologías de salud mucho más avanzadas que aquéllas que dispusieron los países europeos durante su transición. A este respecto pueden mencionarse la existencia y uso de antígenos y vacunas, de drogas y medicamentos, de antibióticos, etc. Además de un conocimiento más ajustado de la patología y etiología, de la ciencia médica en general y de procedimientos más perfeccionados de administración, aplicables a la atencion médica y al saneamiento ambiental. Todo ello ha permitido una más racional utilización de los recursos de salud.

Tal vez la posiblidad de seguir obteniendo logros espectaculares en términos de subsiguientes reducciones de la mortalidad no sea muy grande en el futuro. Por ello no es raro que en algunos casos se disminuya la importancia del sector salud en favor de la influencia de otros sectores del desarrollo económico y social. A estas conclusiones se llega, sobre todo, cuando se estudia la asociación entre la mortalidad y las características económicas y sociales. En efecto, parece existir una íntima relación entre ambos factores, aunque no deben tomarse estas conclusiones muy a la ligera, pues no debe ignorarse que así como han evolucionado las características económicas y sociales también ha evolucionado la eficiencia del sector salud.

Podría ser interesante estimar cuáles serían los niveles de mortalidad de una comunidad si se paralizaran por un tiempo todas las actividades de salud, dando libre juego a la letalidad natural de las enfermedades. La diferencia entre la mortalidad estimada de este modo y la observada en la realidad representaría la mortalidad evitada por las actividades del sector. Todo parece indicar que dicha mortalidad evitada se estaría incrementando en el tiempo a pesar de que la mortalidad observada puede permanecer constante o siga un lento proceso de disminución, sobre todo si se tienen en cuenta los cambios en la estructura de la mortalidad y los incrementos en la esperanza de vida la nacer.

b) Sobre la fecundidad

Hay algunas acciones del sector que, a pesar de no ser orientadas por consideraciones de caracter demográfico y estando destinadas a lograr 
un mejor estado de salud de las personas, a prevenir la enfermedad y evitar la muerte, tienen, sin embargo, un efecto sobre la fecundidad. El control de gestantes, la atención hospitalaria del parto, el tratamiento de la esterilidad, la prevención del aborto espontáneo, etc., son actividades realizadas con un propósito de salud pero cuyo subproducto, su efecto sobre la fecundidad, es de carácter incremental. Este efecto es tal vez sólo marginal y de reducidas proporciones puesto que no ha sido posible observar, durante los períodos que muestran descensos de la mortalidad por éstas y otras actividades, la existencia de un ascenso de la fecundidad.

Por un fenómeno de crecimiento de la demanda, e independientemente de propósito de control demográfico, el sector salud se ha venido ocupando de otras acciones destinadas a prevenir la concepción, cuando ello reporta riesgos de salud para las madres o las familias. Alli donde no existen políticas oficiales expresamente orientadas al control demográfico, las actividades del sector se han llevado a cabo dentro de las tipicas relaciones individuales de médico-paciente. El efecto neto de estas acciones tiene que hallarse en una reducción de la fecundidad; sin embargo, no es fácil evaluar la magnitud de tal efecto y lo probable es que no sea de significativa magnitud, dada la asociación de estas actividades con la demanda, la que a su vez tiene características especiales. Es posible que las mujeres o las familias que buscan tales servicios pertenezcan a grupos económicos y sociales en los que ya existen bajos niveles de fecundidad y que la demanda, en su mayor parte, esté representada por personas que utilizando ya ciertos medios de control de natalidad, buscan solamente substituirlos por otros más efectivos.

El verdadero impacto sobre la fecundidad se ha de producir en el momento en que las acciones de regulación de la natalidad sean realizadas atendiendo a la demanda de los grupos de más alta fecundidad. Esto significa, por supuesto, la adopción de decisiones importantes de política demográfica para un país, las que tendrían que culminar en programas dirigidos a tal propósito y que contengan acciones masivas de promoción de la demanda. Hay que advertir que en situaciones de este tipo, la motivación del sector no se halla dentro del campo mismo de la salud, o por lo menos, esta ubicación no se encuentra completamente aclarada. La conducción de los programas se encarga a los servicios de salud, esencialmente por la naturaleza biológica del acto de interferencia con la concepción o gestación, en previsión de los riesgos que ello puede acarrear a la salud y, finalmente, por la familiaridad con que el sector salud puede desempeñarse en la conducción de los programas. 


\section{c) Sobre el crecimiento y estructura de la población}

Parecería obvio señalar que el efecto neto de las acciones del sector salud sobre el crecimiento y la composición etaria de la población depende exclusivamente del efecto sobre la mortalidad y la fecundidad, ya que no es posible visualizar efecto alguno sobre la movilidad espacial. Sin embargo, la consideración del efecto total disimula algunas diferencias que son dignas de mencionar. Así, por ejemplo, se sabe que las disminuciones de la mortalidad con mantenimiento del nivel de fecundidad aceleran el crecimiento de la población; pero teniendo presente que las mayores reducciones se obtienen en aquellas subpoblaciones que tienen altos niveles de mortalidad, las que a su vez tienen niveles altos de fecundidad que se mantienen, tiene que estarse produciendo un crecimiento diferencial muy importante en estas subpoblaciones. En el caso hipotético de dos subpoblaciones de igual tamaño en un determinado momento y con igual tasa de crecimiento natural, pero una con tasas bajas de natalidad y de mortalidad y la otra con tasas altas, el efecto de la misma política de salud hacia la reducción de la mortalidad causará un crecimiento demográfico mucho mayor en la segunda que en la primera, ya que en aquélla los logros pueden ser espectaculares.

Se sabe que el mantenimiento de un nivel de fecundidad, con reducciones no muy drásticas en la mortalidad, en la práctica mantiene también la estructura por edades de la población estable resultante. Ello no quiere decir que no puedan presentarse alteraciones transitorias muy marcadas, principalmente cuando la política de salud se orienta a dar atención preferencial a ciertos grupos de edades. Por ejemplo, en el caso antes mencionado de las dos subpoblaciones hipotéticas, puede esperarse que las reducciones más violentas de la mortalidad se presenten en la población infantil y de niños, con lo cual puede darse un rejuvenecimiento casi instantáneo de la población, cuyas consecuencias estarán presentes por muchos años antes de la recuperación de la estructura etaria inicial.

En sintesis, el efecto de las acciones de salud sobre las características de la población no puede ser despreciado, sobre todo cuando se tienen presentes los efectos parciales de las políticas de salud aplicadas a algunas subpoblaciones. 


\section{SITUACION ACTUAL DEL USO DE LOS DATOS DEMOGRAFICOS EN SALUD}

\section{DATOS QUE SE UTILIZAN}

El trabajo en salud pública no es posible si no se tiene presente en todo momento que la saluủ es un fenómeno que acontece en una población." Es inconcebible la actividad de un planificador o administrador de salud que no haya tenido en cuenta las características de la población, a lo largo de todas las fases de los procesos planificador y administrativo. En el diagnóstico, tanto el tamaño como la distribución geográfica y la estructura de la población son elementos esenciales para la determinación del estado de salud y de los factores que la condicionan. El cálculo de tasas generales y específicas que se usan con tal propósito requiere de la estimación de poblaciones y subpoblaciones en las que se presentan los fenómenos de salud con diversas intensidades. Más adelante, las mismas poblaciones y subpoblaciones, estimadas o proyectadas, se utilizan para llevar a cabo previsiones con diversas alternativas de cambios en los niveles y estructura de la salud.

Simultáneamente con el diagnóstico y pronóstico de la situación de salud, se lleva a cabo el análisis de los recursos y de las actividades producidas por el sector. Ambos se hallan condicionados, en cierta forma, por la situación de salud que muestra la población y por la política en este campo. Asimismo, la asignación de recursos y actividades sigue muy de cerca aunque de manera imperfecta, al tipo y magnitud de las necesidades, las que a su vez tienen una asociación muy marcada con las características de la población. Una práctica muy corriente en la planificación de la salud es aquélla que conduce a lograr niveles "útiles" de cobertura, los cuales deben establecerse contanto previamente con el conocimiento de las poblaciones y subpoblaciones hacia las que van dirigidas las actividades.

Algunos ejemplos pueden ilustrar estos aspectos. El diagnóstico de la situación de salud puede mostrar que el sarampión es un problema importante y que las tasas de morbilidad y de mortalidad por esta causa o por sus complicaciones son elevadas entre los niños menores de 6 años. Se decide organizar un programa de vacunación inmediata para este grupo y de mantenimiento del nivel inmunitario para el 80 por ciento de este mismo grupo. En primer lugar, se observa que la identificación del sarampión como problema importante tiene que 
haber surgido del estudio y la comparación de las tasas de morbilidad y de mortalidad de la población de menores, la que, por lo tanto, tiene que ser conocida. En segundo lugar, una vez dispuesta la acción, tienen que calcularse los recursos necesarios, los cuales deben ser asignados no solamente de manera global sino teniendo en cuenta las formas de acceso a la población de niños que debe ser vacunada. Esto significa que deberá saberse tanto el número de los niños, con el fin de evaluar la cobertura que se ha establecido como objetivo, como el tiempo y el espacio en los que se los puede localizar. Este ejemplo es prácticamente válido para todas las actividades de tipo preventivo, que requieren del conocimiento de la población en la fase de identificación del problema, en la de programación de las actividades mismas y en la de evaluación de los resultados obtenidos.

Otros ejemplos muy simples: el estudio de las tasas de morbilidad y de mortalidad por algunos tumores nos revelan no sólo su nivel de incidencia sino también su distribución por áreas geográficas y por grupos de edades y sexos. La situación nos plantea una determinada demanda de ciertas características, que requiere del uso de algunos recursos especiales tales como cirujanos, patólogos, radiólogos, equipos de radioterapia, etc. Dada la estrecha relación que existe entre las características de la población y la incidencia de tumores (mayor incidencia a mayor edad, o los diferenciales por residencia) es posible prever las necesidades para la atención de esta demanda si se dispone de estimaciones y previsiones de cambios en el tamaño y la estructura de la población causados por envejecimiento y por migración. En todos los casos, si se sabe utilizar la asociación de las características de la salud y las de la población, la previsión de modificaciones en esta última permite visualizar probables cambios en la salud.

Las acciones de salud pública se dirigen tanto a la atención de las personas a través de medidas preventivas, curativas y de rehabilitación, como a influir sobre el medio ambiente mediante actividades que tratan de proteger al individuo de los agentes externos. En este último caso se encuentran las actividades destinadas a proveer de agua potable a las comunidades, los servicios de control de vectores, roedores, de disposición de excretas y de basuras, de control de contaminación del agua, del aire y del suelo, etc. Desde luego, la planificación de tales servicios requiere del conocimiento del tamaño, la distribución geográfica y de las correspondientes estimaciones y proyecciones de la población que permiten medir los servicios y estimar las fuentes de financiamiento de las obras.

Así, el proceso de planificación de la salud, en todas sus etapas y fases, implica la utilización de datos acerca de la población y de las previsiones demográficas. Los datos más utilizados se refieren al tamaño, la distribución geográfica y la composición por sexo y por edad. 


\section{a) Tamaño de la población}

EI tamaño está presente en cualquier actividad de planificación del sector, no solamente en la formulación de políticas y estrategias sino también a niveles más concretos de programación de detalle. La dificultad más notable en la utilización del tamaño de la población es la falta de disponibilidad de la información, sobre todo cuando se trata de obtenerla para pequeñas áreas. Es posible que los paises cuenten con estimaciones nacionales, pero, muchas veces la confiabilidad de tales estimaciones para las áreas administrativas mayores no es aceptable, principalmente por la escasa información de que se dispone acerca de las migraciones internas. El problema se agudiza cuando se trata de obtener estimaciones para áreas más pequeñas, como las que serían necesarias para determinar la población de localidades y de las áreas de influencia de los establecimientos de salud (hospitales y otras unidades operativas) que deben programar sus actividades.

Hay un desbalance en el uso que se hace de la información acerca del tamaño de la población en la planificación y operación de los programas de salud. Mientras en algunos casos es suficiente una aproximación, en otros se requiere prácticamente lo que podría equivaler a un registro de población. Tal es, por ejemplo, el caso de las actividades de atención materno-infantil: para una buena programación y operación se necesitará contar con el registro de toda gestante y de todo nacimiento. Ello ha generado a veces la organización de sistemas de información para la salud paralelos a los de estadísticas vitales. También se ha dado el caso que, al no contar el sector con estimaciones de población adecuadas parà las comunidades a las que sirve, se procure sus propios datos por medio de censos o encuestas especiales.

\section{b) Distribución urbano-rural}

El sector salud ha utilizado tradicionalmente la dicotomia urbano-rural para poner de manifiesto diferenciales importantes en los niveles de salud. También la utiliza para establecer diferencias en la composición de las prestaciones y en el tipo de recursos humanos y materiales utilizados para producirlas. Existen en estos casos los mismos problemas de disponibilidad de información; sin embargo, algunos servicios procuran su propia información para poder actuar, alcanzando en algunos casos las características de un registro de población. Tales son, por ejemplo, los programas de salud pública rural, de erradicación de la malaria, etc.

\section{c) Composición por sexo y por edad}

La información demográfica más corrientemente utilizada es la composición de la población por sexo y por edad. Ella es empleada en la 
programación de la mayoría de las actividades de salud: para la medición de las diferenciales en incidencia y prevalencia de muchas enfermedades, para orientar la acción de los servicios, y para evaluar las coberturas, rendimientos y efectos obtenidos.

La estructura de la población por edad y sexo está asociada muy frecuentemente con la presencia de ciertas enfermedades que muestran diferencias notables de incidencia y prevalencia y cuyas tasas específicas por edad son utilizadas como indicador de lo que ha dado en llamarse "susceptibilidad básica". Por ejemplo, dado el hecho que los casos de poliomielitis se dan casi en su totalidad por debajo de los seis años de edad, este grupo de población puede considerarse como "susceptible" y las campañas de vacunación tienen que ser dirigidas a este grupo. Vacunar a otras edades sería un esfuerzo inútil. En el otro extremo se da el caso del cáncer de pulmón, donde el 90 por ciento de los casos corresponde a adultos de más de 45 años de edad. Entonces, cuando se formulan programas para la atención de la demanda por cáncer pulmonar debe tenerse en cuenta la magnitud de dicha población y los casos esperados según las tasas observadas.

\section{d) Otras composiciones de la población}

Otros aspectos de la composición de la población son escasamente empleados en la planificación y administración en salud, aunque su uso se va haciendo cada vez más frecuente en investigaciones epidemiológicas y en programas muy especiales, sobre todo cuando se trata de identificar algunas subpoblaciones de alto riesgo. Tal es el caso de la estructura ocupacional en programas de higiene y seguridad industrial.

\section{e) Mortalidad y morbilidad}

Cuando se planifica y se está en la etapa de diagnóstico, se procura evaluar la situación de salud, en su nivel y estructura, así como explicar el por qué de tal situación a través de la determinación de los factores que la determinan y la condicionan. Es tan fácil entender por qué en esta etapa tenga que utilizarse la población como un elemento explicativo del estado de salud: el fenómeno de la enfermedad se da entre las personas y la manera de iniciar la acción sobre él es conociendo quiénes se enferman y de qué se enferman.

El estudio de la mortalidad y la morbilidad diferencial por edad, por sexo, por residencia y por una serie de características demográficas lleva a la identificación de las diversas subpoblaciones sometidas a los distintos riesgos. La epidemiología se encarga luego de explicar el mecanismo por el cual los riesgos y la susceptibilidad interaccionan para producir la enfermedad. 
A pesar de que la epidemiología utiliza la información demográfica, ésta se ha restringido, por lo general, a la relativa a edad, sexo y residencia. El futuro parece tener reservada una más profusa utilización de los datos para obtener elementos explicativos del fenómeno de la enfermedad en relación con otras características de la población, tales como la situación familiar, la educación, la condición laboral, económica y social. Esta afirmación puede hacerse considerando, sobre todo, que el proceso de desarrollo de los países ha de significar cambios importantes en las estructuras económicas y sociales y que el desarrollo de la salud, acompañando al desarrollo general, tendrá que prever, en su proceso sectorial de planificación, no solamente los cambios en salud producidos por la modificación de los factores condicionantes, sino también la inducción de cambios en éstos por las acciones de salud.

Vemos, pues, que se tendrá que disponer de información demográfica más abundante y de previsiones de cambios a través de los plazos que abarquen los planes de salud. Por supuesto, tales previsiones tendrán que hacerse con alternativas que incorporen los cambios previstos, tanto en el sector salud como en los otros sectores de la dinámica social. Debe tenerse presente también que la utilización de la información demográfica tendrá que ser efectuada con propiedad y que, por lo tanto, el sector salud requerirá del concurso de demógrafos capacitados para trabajar estrechamente con los epidemiólogos y administradores.

En la etapa del diagnóstico se explican también las características de la of erta de servicios para luego hacer las previsiones de cambios que deben ser introducidos en el tipo, número, organización $\mathrm{y}$ funcionamiento de los recursos del sector, dentro del marco que fije una política de salud, la cual a su vez debe ser compatible con las políticas de otros sectores, todo dentro del gran marco de referencia del desarrollo global. Por lo tanto, la asignación de recursos y actividades siguen criterios diversos entre los cuales el de tamaño, distribución y composición de la población son indispensables.

La determinación de niveles de oferta de servicios de salud tiende a seguir las características de las necesidades, tal como éstas son evaluadas por el sector. Aunque se procure que tal oferta cubra la totalidad de las necesidades, generalmente no se puede lograr. Uno de los objetos de la planificación es, precisamente, el asignar los recursos de tal modo que su utilización sea lo más eficiente posible, aunque suponga no poder atender algunas de las necesidades. Estas, por otro lado, son diferentes según sean determinadas por los técnicos del sector o apreciadas por la población que utiliza los servicios y, por lo tanto, debe hallarse en esta diferencia, así como en otros factores que no es del caso mencionar, la explicación de la demanda y la divergencia de ésta con los servicios ofrecidos y su utilización efectiva. 
Los últimos desarrollos metodológicos y conceptuales de la planificación en salud están indicando con mayor frecuencia la urgencia que se tiene por disponer de información respecto de las característic as de la demanda y de cómo y por qué se comportan las diversas subpoblaciones en la forma como lo hacen en la utilización de los servicios médicos y de salud. Para obtener dicha información ha de identificarse a dichas subpoblaciones y por lo tanto, en este aspecto debe también esperarse una mayor utilización de los datos demográficos. Sin embargo, hay cierta información de la que no se dispone porque no se obtiene en los censos de población y que deberá ser obtenida por medios propios del sector. Tal es el caso de la pertenencia de ciertos grupos de población a instituciones de seguridad social o la particpación de otros grupos en el financiamiento de la atención médica, las pautas de utilización de los servicios de salud, el gasto en salud, ciertas características de la familia, la accesibilidad a los servicios, etc. Es posible obtener esta información por medio de investigaciones especiales en la población utilizando técnicas de muestreo, cuyo diseño y realización están siendo encarados o efectuados en algunos paises como una extensión de los sistemas de información en salud. Estas investigaciones, además, suelen incluir aspectos de la morbilidad, con lo cual se evita la necesidad de estudiar estos últimos exclusivamente a través de los datos que se obtienen por la demanda atendida.

\section{EL TRATAMIENTO DE LAS VARIABLES DEMOGRAFICAS}

\section{a) La mortalidad}

Es la variable demográfica más íntimamente asociada a la salud. Tanto es así que se la toma como uno de los más importantes indicadores del estado de salud de la población. No ocurre lo mismo con la fecundidad y la migración, cuya relación con el campo de acción de la salud es marginal y son tomadas en cuenta por el sector solamente como elementos exógenos que tienen efecto sobre otros factores de la población y del ambiente.

El papel asignado por la sociedad al sector salud, en el sentido de preservar el capital humano que la compone, lo obliga a conocer profundamente la morfología y el funcionamiento de la sociedad a la que sirve, de la misma manera que el médico requiere de los conocimientos de anatomía y fisiología, entre otros, para arribar a un diagnóstico de enfermedad, a un pronóstico de evolución y luego a la prescripción de un tratamiento. Posiblemente, el conocimiento del tamaño, distribución y composición de la población sea el mecanismo más práctico para que el sector disponga de información respecto de la morfología social y tenga ciertos atisbos de su funcionamiento. La 
intima relación entre la configuración demográfica de la población y la salud lleva de inmediato a percatarse de la necesidad de observar continuamente la dinámica de los cambios en la población que son introducidos por la mortalidad, natalidad y migración, al mismo tiempo que la de los cambios en el medio ambiente, que en interacción con la población dan origen al fenómeno de la enfermedad sobre la cual actúa el sector. De este modo, tanto la configuración demográfica y su dinámica como su interrelación con el medio ambiente son elementos explicativos del fenómeno de la salud aunque externos al sistema. Ellos actúan independientemente, aun cuando sean afectados en parte por las acciones del sector.

Muchas acciones de salud tiene un efecto final sobre la mortalidad, aunque ésta, en los momentos actuales y como variable demográfica, puede haber dejado de constituir un elemento de gran dinámica. Ello, sin embargo, no es óbice para que el sector deje de tener una responsabilidad importante no solamente en la enunciación de las modificaciones que ha de introducir como efecto de sus propias acciones, sino por las que se puede prever como efecto de los factores externos. Esto es asi porque la mortalidad es una variable intrínseca de la salud y, por lo tanto, los planes deben contener previsiones e hipótesis con respecto a ella, basadas en el conocimiento más ajustado posible de los hechos, a través del uso de la epidemiología.

Las previsiones sobre niveles y características de la mortalidad así elaboradas tendrían que alimentar los modelos utilizados por la demografía en la elaboración de sus propias previsiones, porque solamente de esta forma podrían hacerse compatibles las metas enunciadas en los planes de salud con las características de las poblaciones esperadas para los plazos considerados en los planes.

No es fácil, en cambio, asociar temáticamente las acciones del sector salud con la fecundidad o con las migraciones. Ellas continúan siendo externas al campo de la salud, tal como pueden ser la movilidad social, los cambios en los niveles educacionales, la redistribución del ingreso, o cualquier otro aspecto de la dinámica social. Todos ellos pueden tener impactos importantes en la salud y es incumbencia del sector estimar su magnitud y, en función de ellos, reasignar recursos y actividades, pero tal hecho no confiere al sector salud una responsabilidad directa en el campo temático mismo.

La población, con sus características y variables demográficas, es un elemento exógeno del sector, que puede ser comprendido como uno de los más importantes factores condicionantes de la salud, pero cuyas modificaciones y tratamiento no caen dentro de la jurisdicción de la política sectorial, a menos que exista una política demográfica enunciada en cuya aplicación se haya dado participación al sector.

Esta es la forma como, en general, se concibe el tratamiento de las variables demográficas dentro del campo de la salud. En cuanto a la 
mortalidad, el sector tiene ingerencia directa y comparte responsabilidades con otros sectores de actividad de la sociedad. En cambio, frente a la dinámica de la fecundidad y las migraciones no tiene responsabilidad directa, por lo menos hasta hoy. 


\section{EL, USO DESEABLE DE LAS VARIABLES \\ Y DATOS DEMOGRAFICOS EN LA \\ PLANIFICACION EN SALUD}

El estado de salud de una población, cualquiera que sea su forma de expresión, es la consecuencia de la interacción entre factores propios de la población misma y factores del ambiente físico, biológico y social en el que ella se encuentra innersa. Los factores de la población son características genéticas o adquiridas, que trasuntan luego, en una expresión de "susceptibilidad" o "proclividad", a que dicha población sea afectada por los riesgos de enfermar y morir. Los del ambiente, además de representar riesgos, actúan modificando la susceptibilidad, al afectar las característic as de la población.

El sector salud tiene una finalidad asignada por la sociedad, cual es la preservación de su capital humano, haciendo que éste alcance los más altos niveles posibles de salud y contribuyendo de esta manera al logro del mayor bienestar. Dada la interdependencia entre los diversos sectores de la actividad de una sociedad, se supone que tales niveles de salud son alcanzables dentro de un desarrollo armonioso de dichos sectores y que la expresión "más alto nivel posible" significa precisamente que pueden señalarse cotas de factibilidad impuestas por el grado general de desarrollo económico y social. No se pueden aventurar teorias al respecto, pero es razonables pensar que, si bien los paises con un modesto nivel de desarrollo global no pueden pretender contar con un nivel muy elevado de salud, es muy probable que, dentro de límites compatibles con la realidad, puedan contar con una mejor salud que la que tienen en la actualidad, si se adoptan algunas técnicas y procedimientos que faciliten y perfeccionen el accionar del sector salud, uno de los cuales procura ser el llamado proceso de planificación de la salud.

La planificación en el campo de la salud debe ser considerada en dos ámbitos: uno, muy amplio, se refiere al fenómeno mismo y comprende a ésta y a todos los factores biológicos, sociales y culturales que la determinan; el otro, más restringido, se refiere al sistema de "servicios de salud" cuyos componentes se encuentran todos dentro del sector.

Siendo la salud un estado del sistema social determinado por una intrincada red de relaciones entre los múltiples elementos que constituyen tal sistema, su planificación es inseparable de la planificación social en su totalidad y sus objetivos deben ser propuestos 
no sólo atendiendo a lo que el sector salud esté en condiciones de lograr con sus actividades, sino también tomando en cuenta las situaciones de inercia que resultan de la interacción de todos los factores, aun cuando el sector no tenga ingerencia sobre muchos de ellos. Dado que planificar significa cierta previsión del futuro y que en el campo de la salud hay incógnitas importantes acerca de la manera como operan las fuerzas de inercia mencionadas, gran parte del proceso en este campo se reduciría a colaborar inteligentemente con lo inevitable, a menos que la planificación del desarrollo global contemple la introducción de cambios estructurales que puedan ser interpretados a nivel del sector salud.

En relación a los sistemas de salud, puede haber criterios más concretos y establecer metas en términos de actividades que se llevarán a cabo, y no necesariamente en términos de nivel y estructura de la salud. En este último caso pueden fijarse metas en relación a todos aquellos componentes de la patología para los que se conocen los efectos de las acciones. Así, por ejemplo, no es difícil considerar que, dado el conocimiento actual de las ciencias de la salud (la medicina, la epidemiología, la administración, etc.) se puedan establecer metas para la reducción o eliminación de ciertas enfermedades infecciosas y parasitarias, o de todos aquellos daños cuyos agentes etiológicos hayan sido identificados. Esto es posible cuando se conoce la forma como tales agentes operan, cuando se dispone de las técnicas para neutralizarlos o eliminarlos, y cuando existe la factibilidad de aplicación de dichas técnicas. Generalmente, estos daños son aquéllos que se atacan por prevención.

Por el contrario, no es tan fácil establecer el mismo tipo de metas para gran parte de la patologia restante, como tumores, enfermedades cardiovasculares, mentales, etc. Toda esa considerable parte de la patología donde el sector actúa cuando el daño se ha producido, las acciones corresponden a la medicina reparativa. Así pues, el tipo de metas que puede establecerse en estos casos no será de la misma naturaleza que la mencionada anteriormente, sino que, más bien, en términos de acciones médicas de restitución de la salud a una subpoblación enferma cuyo tamaño puede estimarse con anterioridad, pero cuya presencia, al no haber podido evitarse, adopta las características de "información" precursora de la decisión y de la acción del sector. No debe interpretarse con esto que no se pueda fijar objetivos en salud en estos casos, ya que ello depende de la manera como ésta haya sido definida. Es común utilizar para tal fin solamente la mortalidad como la inversa de la salud, con lo cual, a pesar de que se facilita el manejo de ciertos datos que existen, se restringe innecesariamente el planteamiento de objetivos en el sector a papeles tradicionalmente asignados a la práctica de la medicina: alivio del doliente, prevención de la enfermedad, curación del enfermo, 
rehabilitación del incapacitado, prolongación de la vida y promoción de una mejor salud.

En resumen, las características de la población y las variables demográficas son un insumo no solamente deseable sino requerido para un sistema de planificación de la salud y adquieren un particular relieve en las etapas del diagnóstico y del pronóstico. Tienen que ser consideradas en la formulación de políticas y juegan un papel importante en la conformación de estrategias. Son imprescindibles en la determinación de la demanda, en el establecimiento de objetivos y metas $\mathrm{y}$, por lo tanto, en la previsión de los recursos y actividades. Tienen que ser empleadas para la elaboración de los proyectos, para la programación de las actividades y para la evaluación de los programas.

La mortalidad es utilizada y deberá seguir siéndolo como la expresión del efecto esperado de las acciones del sector en ciertos campos de la patología, sin perjuicio de la expresión de otros efectos en términos de morbilidad.

Una consideración especial merece la fecundidad, que no constituye un efecto buscado por el sector salud, excepto de modo muy tangencial. Por lo tanto, su inclusión dentro de la planificación de la salud, de no mediar una política explícita y expresa, tiene las caracteristicas de ser informativa para la programación de actividades destinadas a la atención de la demanda espontánea. En cambio, de existir una política definida y una decisión adoptada para designar al sector como elemento instrumental de ella, las acciones de planificación de la familia deberán ser incluidas dentro del contenido de la planificación sectorial, no sólo como un insumo del sistema sino como un área para la cual tendrán que programarse actividades, fijarse metas y medirse efectos. 
ASPECTOS DEMOGRAFICOS DE LA PLANIFICACION $\mathbb{D E}$ LA EDUCACION

Jorge A révalo

Iris Corbalán 



\section{INTRODUCCION}

Puede decirse que desde el momento en que empezó a difundirse en la América Latina el interés por el planeamiento de la educación, interés que se tradujo en el desarrollo de métodos y su aplicación en diferentes países, se incluyó información demográfica en los planes. Diferentes instituciones, a través de cursos, seminarigs y otras actividades subrayaron los aspectos demográficos de la planificación educacional.

En la etapa del proceso de planificación en que ha llegado a hacerse más intensivo el uso de la información demográfica sobresale, sin duda, el diagnóstico. La intensidad de su utilización depende, además del desarrollo de los métodos, de las metas del plan y del grado de desagregación establecido. En esta utilización hay dos aspectos claramente diferenciados. Uno se refiere a la descripción de la situación actual y al examen del proceso histórico reciente. El otro se refiere al pronóstico. Estos aspectos plantean distintos niveles de dificultad. La mayor, que se presenta en el primer caso, es la disponibilidad de información. Si ésta es abundante y suficientemente detallada hay pocas difcultades en satisfacer la primera etapa del diagnóstico.Sin embargo, éste suele no ser el caso más frecuente y muchas veces se ha de recurrir a inferencias por métodos indirectos. En el segundo caso, el pronóstico, se presentan mayores dificultades pues además de requerir como base una buena elaboración de la primera etapa, se necesita conocer los factores determinantes de las tendencias para poder así extrapolarlas. La dificultad aumenta todavía si se tiene en cuenta que esos factores están generalmente interrelacionados y aún no se conocen lo suficiente como para poder establecer las relaciones de causa y efecto y medir su importancia. Esta etapa del diagnóstico es necesariamente más incierta y generalmente se sale del paso suponiendo que el valor de los indicadores utilizados permanecerá constante o variará como lo ha hecho en el pasado, como si los factores que lo determinan no cambiaran y siempre condujeran al mismo resultado. Las proyecciones de población escolar no escapan a la limitación señalada, tanto más cuanto mayor sea el nivel de desagregación de las mismas. Así pues son incluidos en un plan de expansión educacional como si fueran independientes de los resultados que se espera lograr mediante el plan, cuando en la realidad es muy probable que esos resultados afecten la dinámica demográfica y por consiguiente, las proyecciones. Y, como es evidente, las metas mismas pueden dejar de ser adecuadas. 
Podría pensarse, por ejemplo, en los efectos de un programa de desarrollo de la educación que abarcara a toda la población de un país. Es razonable esperar que haya cambios en las variables demográficas: mortalidad, natalidad y migración.

Un aumento en el nivel de instrucción puede traducirse en una disminución del nivel de mortalidad, pues en general las personas más instruidas tienen una mejor comprensión de las normas higiénicas y de la utilidad de su aplicación en la prevención de las enfermedades, principalmente las de la primera infancia.

La natalidad tal vez tienda a disminuir pues con la instrucción pueden transmitirse pautas culturales que estén en conflicto con el ideal de un número elevado de hijos.

La intensidad de las corrientes migratorias también podría sufrir la influencia de la expansión de la educación. Se ha observado que muchas veces los migrantes de las zonas rurales a las urbanas tienen un nivel de instrucción más alto que los no-migrantes rurales, lo que indicaría una may or propensión a migrar entre los más instruidos.

A su vez, los cambios en la mortalidad, la natalidad y la migración alteran el ritmo de crecimiento de la población, su distribución territorial y la composición de la misma. Estos cambios pueden afectar el proceso de planificación de la educación.

Un cambio en el ritmo de crecimiento de la población puede significar una variación en la proporción de recursos asignados al sector educacional dentro de un plan general de desarrollo. Puede hacer variar la asignación interna de recursos para la enseñanza primaria, secundaria y superior. Los cambios en la distribución territorial de la población afectan la localización de las escuelas y la distribución del personal docente. Los cambios en la composición de la población, principalmente por edad y nivel de instrucción, pueden afectar el logro de las metas.

Estas breves consideraciones intentan mostrar algunas debilidades del diagnóstico $y$, en particular, las relaciones con las variables demográficas.

A pesar del vacio actual de conocimientos que deberá llenarse mediante la colaboración de planificadores y demógrafos, se pretende en este informe ilustrar con unos pocos ejemplos los aportes que la demografia puede hacer al planeamiento de la educación en la fase del diagnóstico, algo diferentes de los requerimientos habituales que formula el planificador. Son ejemplos de utilización de ciertos datos de los censos de población que complementan la descripción de la situación actual y pasada ( $y$ que a veces dan la única descripción posible por falta de otras informaciones), y de algunas relaciones entre las variables demográficas y el nivel de instrucción de la población.

Para ilustar el tex to se utilizarán datos procedentes de los censos de población de Colombia de 1951 y 1964, publicados por el Departamento Administrativo Nacional de Estadística de Colombia. 


\section{EL ALFABETISMO}

A través de este atributo es posible hacer inferencias acerca del éxito o la capacidad del sistema educacional para lograr el objetivo que la población sepa leer y escribir. La medida más simple que resume esa capacidad es la tasa global de analfabetismo que resulta del cociente entre el número de personas analfabetas desde una cierta edad en adelante y el número total de personas que tienen desde esa edad en adelante en la población. Siempre se trata de escoger una edad a partir de la cual sea razonable esperar que las personas puedan haberse alfabetizado según el sistema establecido en el país. Con fines de comparación internacional la UNESCO ha recomendado partir de los 10 años y COINS desde los 15. Por "sistema educacional" entenderemos en este informe incluso los medios no formales y extraescolares, puesto que no se puede, con la información disponible, separar lo que es resultado del sistema formal de lo que no lo es.

La tasa global es sólo una medida muy gruesa de la capacidad del sistema. Un mismo valor puede ser el resultado de diferentes combinaciones según sexo, edad y lugar de residencia. Además resume simultaneamente la capacidad actual y la pasada. Conviene entonces distinguir la medida del analfabetismo según esos tres atributos.

Tal vez la distinción más simple según el lugar de residencia sea la clasificación de la población en urbana y rural (en Colombia es prácticamente equivalente la distinción entre "cabeceras de municipios" y "resto de municipio"). Se puede ver en el cuadro 1 que mientras la tasa global total de analfabetismo es en 1964 de alrededor del 27 por ciento, la urbana es de un 14 por ciento y la rural del 41 por ciento. Esta simple distinción indica el gran desdequilibrio existente en lo que a capacidad del sistema se refiere. Clasificaciones más detalladas por lugar de residencia permiten detectar con precisión los lugares en que la acción del sistema es más deficiente y, en consecuencia, los que un plan de alfabetización deberá tener más en cuenta.

La medida del analfabetismo por sexo y edades detalladas permite otros enfoques. Al distinguir por sexo se aprecia de qué manera puede ser discriminatorio el sistema. En el país que nos sirve de ilustración las tasas globales de hombres y mujeres no son muy diferentes, aun cuando los hombres se ven favorecidos. Sin embargo, cuando el exámen se hace por edad es notoria la diferencia, especialmente en las edades más avanzadas. Esta diferencia por edad está indicando por lo menos dos 


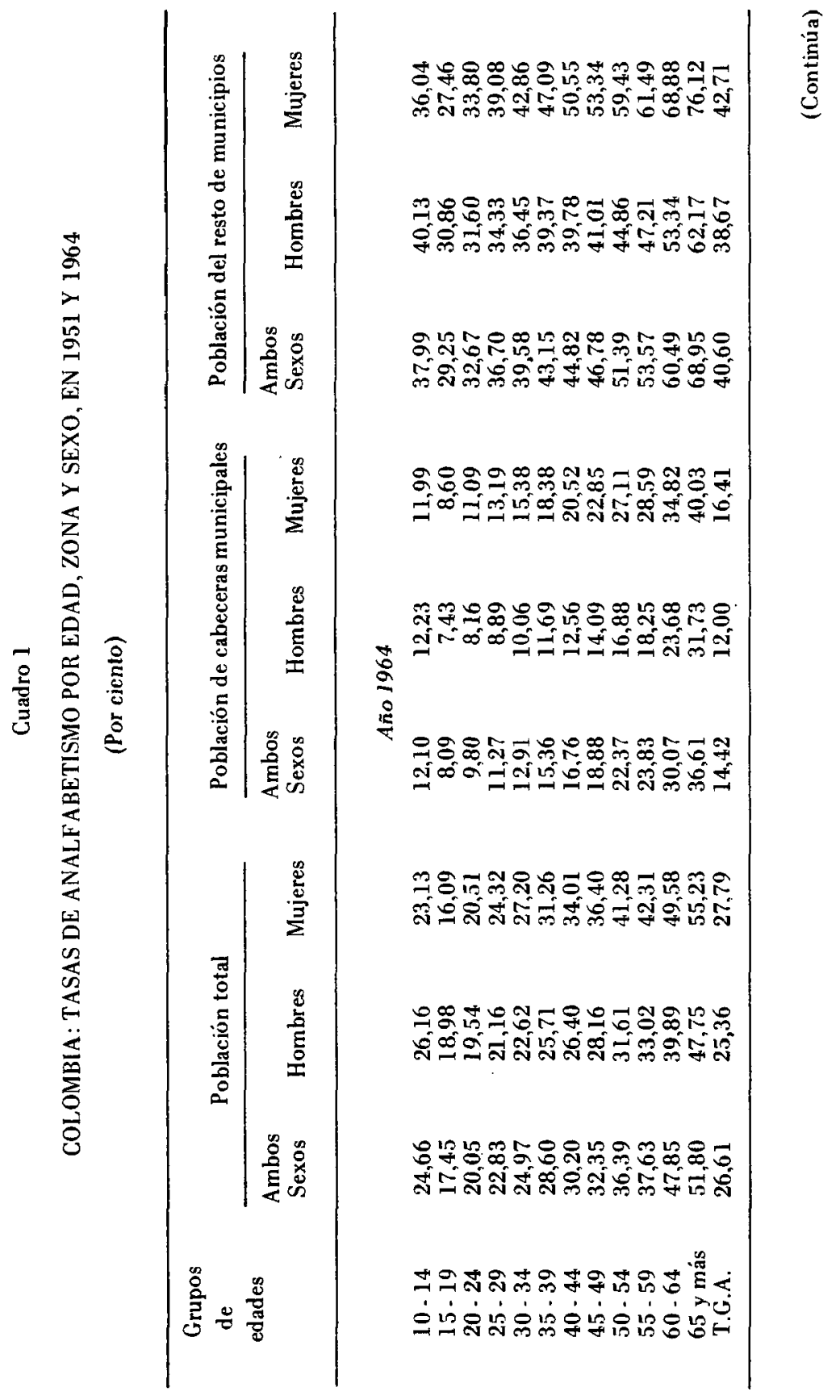


cosas: una efectiva discriminación por sexo y el resultado de la urgencia que la actividad económica impone a los hombre por alfabetizarse.

Este examen de las tasas por edad y sexo muestra también que la discriminación por sexo es cosa del pasdo pues el grupo de 15 a 19 años en que las tasas son más bajas, muestra una ligera ventaja a favor de las mujeres. Es decir, el sistema ha logrado equilibrar las oportunidades para hombres y mujeres.

Un plan de expansión educacional que tenga como objetivo la eliminación del analfabetismo debe incluir como una de sus metas, la de lograr mantener permanentemente un sistema formal que sea capaz de alfabetizar integramente a las generaciones sucesivas dentro de las edades más bajas, entre los 6 y 13 años, por ejemplo. Por esta razón es de la mayor importancia evaluar lo que el sistema educacional está produciendo actualmente, para medir el esfuerzo que habrá de realizar para lograr esa meta. Además, es indispensable para evaluar la tendencia, el conocimiento de lo que el sistema producía en el pasado. Si se acepta que en cada generación de personas, la gran mayoría de los que se alfabetizan lo logran en la niñez, es razonable suponer que después de los 10 o 15 años de edad la proporción de analfabetos de cada generación varía poco en el tiempo. De este modo, la tasa de analfabetismo de las personas de diferentes edades da la medida de la capacidad del sistema en diferentes épocas. Por ejemplo, se puede sostener que la tasa de los que tienen entre 15 y 19 años refleja la situación actual (en realidad, la situación en conjunto de los últimos 5 a 10 años). De la misma manera, la tasa de los que tienen entre 55 y 59 años reflejaría la situación de hace 40 años. En nuestro ejemplo, la tasa del primer grupo de edades, 17 por ciento, indica la proporción de población de las generaciones más jóvenes que el sistema no es capaz aún de alfabetizar. La tasa del grupo de 55 a 59 años, 38 por ciento, indica cuál era la situación hace 40 años. La comparación de estas dos tasas (y las de las edades intermedias) muestra el progreso que el sistema ha logrado en esos 40 años. Pero la tendencia progresista es lenta para el nivel actual de áspiraciones. Al ritmo de la tendencia, al cabo de 20 años contados desde 1964, el sistema estaria aún dejando fuera al 10 por ciento de personas de las generaciones más nuevas. Obviamente se requeriría poner en marcha un plan enérgico de alfabetización, el que deberia determinar la zona rural como de primera prioridad, cuya deficiencia es del 29 por ciento frente a la deficiencia urbana de sólo 8 por ciento (las tasas de analfabetismo de la población de 15 a 19 años de las zonas rural y urbana, respectivamente).

Sin embargo, el análisis de la tendencia histórica realizado de la manera comentada (con datos de un solo censo), tiene limitaciones. Se ha dicho anteriormente que de cada generación la mayor parte de los que se alfabetizan, lo logran en la niñez, y que, por ello, después de cierta edad varía poco la proporción de analfabetos de cada generación. 
Pero a veces, la variación es bastante apreciable. Esto resulta de la acción de dos factores, por lo menos. Uno de ellos es la alfabetización fuera de las edades consideradas de asistencia escolar. Los efectos más importantes resultan de la acción de las escuelas para adultos y de las campañas de alfabetización. En mucho menor grado influyen las acciones aisladas.

Un segundo factor es la mortalidad diferencial por nivel de instrucción. Aun cuando estas medidas específicas de la mortalidad faltan en la América Latina, investigaciones realizadas en otras partes indican que los menos instruidos tienen una mortalidad más alta que los más instruidos. Esta mortalidad diferencial tiende a disminuir más rapidamente el número de analfabetos que de alfabetos de cada generación, lo que repercute en una disminución de la proporción de analfabetos a través del tiempo, que es lo mismo que decir, a través de las edades.

Estas consideraciones nos permiten deducir que las tasas de analfabetismo de las personas de edades adultas avanzadas son, en realidad, estimaciones minimas de la deficiencia del sistema en el pasado, lo que nos conduce a afirmar que la tendencia al descenso del analfabetismo es más pronunciada de lo que parecería en un primer análisis.

Si se dispone de datos de dos censos no muy distanciados en el tiempo, es posible medir la variación intercensal de la proporción de analfabetos de cada generación o grupos de generaciones. Por ejemplo: la tasa de analfabetismo de las personas que en 1951 tenían entre 20 y 24 años era de 31,3 por ciento, y la tasa de los que tenían entre 33 y 37 años en 1964 (es la misma generación en dos fechas distintas) era de 27,1 por ciento. El grupo de generaciones del ejemplo disminuyó la proporción de analfabetos en los 13 años del período intercensal en un 13,4 por ciento. (Véanse los cuadros 2 y 3 ).

La estimación de las variaciones intercensales podría aplicarse sucesivamente a las diferentes generaciones hasta llegar a obtener una versión corregida de la proporción de personas en edad escolar que el sistema, en diferentes épocas, no alcanzaba a alfabetizar. 
Cuadro 2

COLOMBIA: TASAS DE ANALFABETISMO POR COHORTES Y ZONA EN 1951 Y 1964

(Por ciento)

\begin{tabular}{|c|c|c|c|c|c|c|c|}
\hline \multirow[b]{2}{*}{$\begin{array}{l}\text { Edad } \\
1951\end{array}$} & \multicolumn{3}{|c|}{ Tasas en $1951^{a}$} & \multirow[b]{2}{*}{$\begin{array}{l}\text { Edad } \\
1964\end{array}$} & \multicolumn{3}{|c|}{ Tasas en $1964, \underline{b}$} \\
\hline & Total & Urbana & Rural & & Total & Urbana & Rural \\
\hline \multicolumn{8}{|c|}{ Ambos sexos } \\
\hline $\begin{array}{l}10 \cdot 14 \\
15 \cdot 19 \\
20 \cdot 24 \\
25 \cdot 29 \\
30-34 \\
35 \cdot 39 \\
40-44 \\
45-49\end{array}$ & $\begin{array}{l}42,4 \\
31,4 \\
31,3 \\
32,8 \\
33,3 \\
38,1 \\
40,8 \\
42,8\end{array}$ & $\begin{array}{l}22,5 \\
15,8 \\
16,1 \\
16,5 \\
17,2 \\
21,3 \\
23,2 \\
25,5\end{array}$ & $\begin{array}{l}54,6 \\
42,5 \\
42,7 \\
44,6 \\
45,1 \\
50,0 \\
53,1 \\
55,3\end{array}$ & $\begin{array}{l}23-27 \\
28-32 \\
33-37 \\
38-42 \\
43-47 \\
48-52 \\
53-57 \\
58-62\end{array}$ & $\begin{array}{l}21,7 \\
24,0 \\
27,1 \\
29,7 \\
31,3 \\
34,8 \\
37,0 \\
43,7\end{array}$ & $\begin{array}{l}10,6 \\
12,2 \\
14,3 \\
16,2 \\
18,0 \\
21,3 \\
23,0 \\
27,3\end{array}$ & $\begin{array}{l}35,0 \\
38,5 \\
41,5 \\
44,3 \\
45,9 \\
49,7 \\
52,4 \\
57,7\end{array}$ \\
\hline \multicolumn{8}{|c|}{ Hombres } \\
\hline $\begin{array}{l}10-14 \\
15-19 \\
20-24 \\
25-29 \\
30-34 \\
35-39 \\
40-44 \\
45-49\end{array}$ & $\begin{array}{l}44,2 \\
32,8 \\
30,4 \\
30,2 \\
29,3 \\
33,7 \\
35,1 \\
37,8\end{array}$ & $\begin{array}{l}23,0 \\
14,3 \\
13,5 \\
12,6 \\
12,6 \\
15,5 \\
16,5 \\
19,1\end{array}$ & $\begin{array}{l}55,9 \\
43,5 \\
41,2 \\
41,1 \\
40,0 \\
44,2 \\
46,6 \\
49,2\end{array}$ & $\begin{array}{l}23-27 \\
28-32 \\
33-37 \\
38-42 \\
43-47 \\
48-52 \\
53-57 \\
58-62\end{array}$ & $\begin{array}{l}20,3 \\
21,8 \\
24,3 \\
26,2 \\
27,4 \\
30,1 \\
32,1 \\
36,6\end{array}$ & $\begin{array}{r}8,7 \\
9,7 \\
11,2 \\
12,3 \\
13,3 \\
15,7 \\
17,7 \\
21,4\end{array}$ & $\begin{array}{l}33,2 \\
35,3 \\
38,4 \\
39,8 \\
40,3 \\
43,2 \\
46,3 \\
50,4\end{array}$ \\
\hline \multicolumn{8}{|c|}{ Mujeres } \\
\hline $\begin{array}{l}10-14 \\
15-19 \\
20-24 \\
25-29 \\
30-34 \\
35-39 \\
40-44 \\
45-49\end{array}$ & $\begin{array}{l}42,0 \\
30,1 \\
32,1 \\
35,2 \\
37,5 \\
42,3 \\
46,6 \\
47,8\end{array}$ & $\begin{array}{l}22,0 \\
16,9 \\
18,2 \\
19,6 \\
21,3 \\
25,9 \\
29,1 \\
30,7\end{array}$ & $\begin{array}{l}53,1 \\
41,4 \\
44,4 \\
48,1 \\
50,7 \\
55,4 \\
60,7 \\
62,3\end{array}$ & $\begin{array}{l}23-27 \\
28-32 \\
33-37 \\
38-42 \\
43-47 \\
48-52 \\
53-57 \\
58-62\end{array}$ & $\begin{array}{l}22,6 \\
25,8 \\
29,8 \\
33,0 \\
35,3 \\
39,1 \\
41,7 \\
50,0\end{array}$ & $\begin{array}{l}12,3 \\
14,4 \\
17,2 \\
19,6 \\
22,0 \\
25,4 \\
27,7 \\
32,4\end{array}$ & $\begin{array}{l}37,0 \\
41,3 \\
45,5 \\
49,3 \\
52,1 \\
56,7 \\
60,6 \\
65,7\end{array}$ \\
\hline
\end{tabular}

Fuente: Censos de población de 1951 a 1964.

a/ Tasas observadas en 1951.

b) Tasas leídas en gräfico basado en las observadas en 1964. 
Cuadro 3

COLOMBIA: VARIACION DE LA PROPORCION DE ANALF ABETOS POR COHORTE, SEXO Y ZONA ENTRE 1951 y 1964

(Por ciento)

\begin{tabular}{|c|c|c|c|c|}
\hline $\begin{array}{c}\text { Edad } \\
\text { en } \\
1951\end{array}$ & Total & Urbano & Rural & $\begin{array}{c}\text { Edad } \\
\text { en } \\
1964\end{array}$ \\
\hline \multicolumn{5}{|c|}{ (Ambos sexos) } \\
\hline $\begin{array}{l}10 \cdot 14 \\
15-19 \\
20-24 \\
25-29 \\
30-34 \\
35-39 \\
40-44\end{array}$ & $\begin{array}{l}51,2 \\
76,4 \\
86,6 \\
90,5 \\
94,0 \\
91,3 \\
90,7\end{array}$ & $\begin{array}{r}47,1 \\
77,2 \\
88,8 \\
98,2 \\
104,7 \\
100,0 \\
99,1\end{array}$ & $\begin{array}{r}64,1 \\
90,6 \\
97,2 \\
99,3 \\
101,8 \\
99,4 \\
98,7\end{array}$ & $\begin{array}{l}23-27 \\
28-32 \\
33-37 \\
38-42 \\
43-47 \\
48-52 \\
53-57\end{array}$ \\
\hline \multicolumn{5}{|c|}{ (Hombres) } \\
\hline $\begin{array}{l}10-14 \\
15-19 \\
20-24 \\
25-29 \\
30-34 \\
35-39 \\
40-44\end{array}$ & $\begin{array}{l}45,9 \\
66,5 \\
79,9 \\
86,8 \\
93,5 \\
89,3 \\
91,5\end{array}$ & $\begin{array}{r}37,8 \\
67,8 \\
83,0 \\
97,6 \\
105,6 \\
101,3 \\
107,3\end{array}$ & $\begin{array}{r}59,4 \\
81,1 \\
93,2 \\
96,8 \\
100,8 \\
97,7 \\
99,4\end{array}$ & $\begin{array}{l}23-27 \\
28-32 \\
33-37 \\
38-42 \\
43-47 \\
48-52 \\
53-57\end{array}$ \\
\hline \multicolumn{5}{|c|}{ (Mujeres) } \\
\hline $\begin{array}{l}10-14 \\
15-19 \\
20-24 \\
25-29 \\
30-34 \\
35 \cdot 39 \\
40-44\end{array}$ & $\begin{array}{l}\mathbf{5 3 , 8} \\
\mathbf{8 5 , 7} \\
92,8 \\
93,8 \\
94,1 \\
92,4 \\
\mathbf{8 9 , 5}\end{array}$ & $\begin{array}{r}55,9 \\
85,2 \\
94,5 \\
100,0 \\
103,3 \\
98,1 \\
95,2\end{array}$ & $\begin{array}{r}69,7 \\
99,8 \\
102,5 \\
102,5 \\
102,7 \\
102,3 \\
99,8\end{array}$ & $\begin{array}{l}23-27 \\
28-32 \\
33-37 \\
38-42 \\
43-47 \\
48-52 \\
53-57\end{array}$ \\
\hline
\end{tabular}

Fuente: Cuadro 2.

Nota: Los porcentajes resultan de:

$$
\frac{a_{x+13}^{64}}{a_{x}^{5 !}} \cdot 100
$$

donde $a_{x}^{51}$ es la tasa de analfabetismo de las personas de edad $x$ en 1951, y $a_{x+13}^{64}$ es la tasa de analfabetismo de esa misma generación 13 años después. 


\section{MIGRACION INTERNA, URBANIZACION Y NIVEL DE INSTRUCCION}

a) Cuando se mide el nivel de instrucción de la población, por zonas, regiones, divisiones político-administrativas o cualquiera otra subdivisión territorial para efectuar el diagnóstico de la situación educacional que sirva a los propósitos de la planificación regional, debería tenerse en cuenta el efecto de la migración interna. Esa medida del nivel de instrucción cumple el doble objetivo de cvaluar la eficiencia del sistema en lugares geográficos definidos y de evaluar las necesidades que deberán ser satisfechas por la acción derivada del plan.

La migración interna afecta la evaluación porque es diferencial según el nivel de instrucción. Suele observarse, por ejemplo, que los migrantes de las zonas rurales a las urbanas tienen una proporción más alta de alfabetos que los que se quedan en el lugar de origen (rural), pero más baja que los del lugar de llegada (urbano). En el ejemplo que se está utilizando, Colombia, sucede asi. Si se examinan las proporciones de variación de las tasas de analfabetismo por generación (cohorte) entre 1951 y 1964 incluidas en el cuadro 3, puede apreciarse que casi sin excepción, el descenso de la proporción en las zonas urbana y rural es más pequeño que si se considera el país en conjunto. La única explicación razonable de esta aparente anomalía en que la mejora del nivel de alfabetismo para el total de la población es mayor que la de los componentes urbano y rural es la dada anteriormente. De hecho, el deterioro que produce la migración interna excede la ganancia que se obtuvo en el período intercensal en algunos grupos de edades. Son aquellos casos en que el índice supera al 100 por ciento.

b) Una hipótesis que parece verificarse frecuentemente es que la concentración de población favorece, directa e indirectamente, la mejora del nivel de instrucción de la población. A mayor grado de urbanización, mayor nivel de instrucción. Obviamente, en especial con los sistemas tradicionales de enseñanza, el desperdigamiento de la población traba la transmisión de los conocimientos. Esto es tanto más cierto si nos referimos al nivel de instrucción medido en años de estudios aprobados, más que al anal fabetismo. Si se considera que para instalar una escuela se requiere un mínimo de personas reunidas en una localidad, en la medida que ese mínimo no se alcance difícilmente podrá impartirse instrucción. 


\section{Cuadro 4}

\section{COLOMBIA: TASAS DE ALFABETISMO DE LA POBLACION DE 7 AÑOS Y MAS Y PROPORCION DE LA POBLACION QUE VIVE EN CABECERAS MUNICIPLAES RESPECTO DEL TOTAL POR DEPARTAMENTOS. AÑOS 1951 y 1964 \\ (Por ciento)}

\begin{tabular}{|c|c|c|c|c|}
\hline \multirow[t]{2}{*}{ Departamentos } & \multicolumn{2}{|c|}{ Tasa de alfabetismo } & \multicolumn{2}{|c|}{$\begin{array}{l}\text { Proporción de población } \\
\text { que vive en cabeceras }\end{array}$} \\
\hline & 1951 & 1964 & 1951 & 1964 \\
\hline Antioquia & 68,5 & 75,3 & 40,9 & 53,4 \\
\hline Atlántico & 70,1 & 80,0 & 88,6 & 90,9 \\
\hline Bolivara/ & 38,2 & 52,2 & 40,5 & 44,5 \\
\hline Boyacá & 42,4 & 61,5 & 15,7 & 23,8 \\
\hline Caldas & 69,1 & 77,1 & 38,1 & 54,8 \\
\hline Cauca & 48,6 & 58,3 & 20,5 & 23,2 \\
\hline Cundinamarca $\mathrm{b} /$ & 65,7 & 80,6 & 52,8 & 70,4 \\
\hline Chocó & 27,3 & 40,8 & 14,8 & 23,4 \\
\hline Huila & 48,3 & 63,4 & 32,2 & 43,1 \\
\hline Magdalena & 45,7 & 58,4 & 37,8 & 42,0 \\
\hline Nariño & 50,8 & 60,9 & 24,5 & 30,4 \\
\hline Norte de Santander & 50,3 & 64,1 & 37,4 & 49,2 \\
\hline Santander & 47,5 & 65,2 & 32,5 & 43,9 \\
\hline Tolima & 50,4 & 64,9 & 29,5 & 42,1 \\
\hline Valle del Cauca & 70,3 & 78,4 & 49,7 & 70,4 \\
\hline
\end{tabular}

Fuente: Censos de Población de 1951 y 1964.

a) Incluye a Córdoba.

b) Incluye a Bogotá

En Colombia se verifica la asociación entre el grado de urbanización por una parte y el nivel de instrución (medido por la tasa de alfabetismo en el cuadro 4 y por el número medio de años aprobados en el cuadro 5) por la otra. Hemos medido la asociación a través del coeficiente de correlación por rangos de Spearman. La asociación entre la proporción de personas que vive en cabeceras municipales (consideradas urbanas) de carla departamento respecto de la población total del mismo (grado de urbanización), por un lado, y la tasa de alfabetismo, por el otro, da un valor de 0,64 en 1951 y de 0,85 en 1964. Si se tiene en cuenta que cuando este índice toma los valores de $+1 \dot{o}-1$ hay correlación perfecta y cuando el valor es 0 , la ausencia de correlación es total, podemos concluir que efectivamente hay asociación entre las variables consideradas, y que ésta era más estrecha en 1964.

El valor del coeficiente de Spearman es de 0,87 cuando se compara en 1964 el grado de urbanización y el número medio de años aprobados 
Cuadro 5

COLOMBIA: NUMERO MEDIO DE AÑOS DE INSTRUCCION

APROBADOS POR LA POBLACION DE 15 A 59 AÑOS

Y PROPORCION DE PERSONAS QUE VIVE EN

CABECERAS MUNICIPALES RESPECTO DE LA

POBLACION TOTAL, POR DEPARTAMENTO. 1964

\begin{tabular}{|c|c|c|c|c|}
\hline \multirow[b]{2}{*}{ Departamentos } & \multicolumn{3}{|c|}{ Número medio de años de instrucción } & \multirow[b]{2}{*}{$\begin{array}{l}\text { Proporción } \\
\text { de población } \\
\text { que vive en } \\
\text { cabeceras } \\
\text { municipales } \\
\text { (Por ciento) }\end{array}$} \\
\hline & $\begin{array}{c}\text { Población } \\
\text { total }\end{array}$ & $\begin{array}{l}\text { Población } \\
\text { de cabece- } \\
\text { ras muni- } \\
\text { cipales }\end{array}$ & $\begin{array}{l}\text { Población } \\
\text { del resto } \\
\text { de cabece- } \\
\text { ras munici- } \\
\text { pales }\end{array}$ & \\
\hline Antioquia & 3,32 & 4,37 & 2,11 & 53,4 \\
\hline Atlántico & 379 & 3.98 & 1.82 & 90,9 \\
\hline Bolivar & 2,45 & 3,41 & 1,35 & 526 \\
\hline Boyacá & 2,15 & 3,84 & 1,61 & 23,8 \\
\hline Caldas & 3,12 & 3,92 & 2,15 & 54.8 \\
\hline Cauca & 2,18 & 3,77 & 1,68 & 23,2 \\
\hline Córdoba & 1.78 & 299 & 124 & 30.7 \\
\hline Bogotá D.E. & 5,00 & 5,02 & 3,95 & 97,9 \\
\hline Cundinamarca & 2,56 & 3,79 & 2,05 & 28,9 \\
\hline Chocó & 1,43 & 2,94 & 0,99 & 23,4 \\
\hline Huila & 2,41 & 3,24 & 1,78 & 43,1 \\
\hline Magdalena & 2,40 & 3,46 & 1,64 & 420 \\
\hline Meta & 2,48 . & 3,27 & 1,83 & 47,0 \\
\hline Nariño & 2,39 & $\mathbf{3 , 8 0}$ & 1,78 & 30,4 \\
\hline Norte de Santander & 2,50 & 3,57 & 1,45 & 49,2 \\
\hline Santander & 2,46 & 3,68 & 1,52 & 43,9 \\
\hline Tolima & 240 & 3,33 & 1,70 & 421 \\
\hline Valle del Cauca & $3,4.1$ & 3,90 & 2,19 & 70,4 \\
\hline
\end{tabular}

Fuente: Censos de Población de 1964.

por la población de 15 a 59 años. Nos parece que estos resultados son concluyentes.

c) El grado de urbanización, medido como lo hemos hecho más atrás, no es necesariamente el mejor indicador del grado de concentración de la población. Hemos hecho otras mediciones en que el nivel de instrucción se compara con la proporción de personas que vive en cabeceras municipales de un cierto tamaño respecto del total de personas que vive en cabeceras. Hemos fijado diferentes tamaños en la comparación con el propósito de ver si la asociación es más marcada en algunos casos que en otros. Si así fuera estaríamos en condiciones de inferir que a partir de un cierto tamaño hacia arriba se acelera la mejora en el nivel de instrucción. Los distintos tamaños escogidos, 50000 y más, 20000 y más, 15000 y más, y 10000 y más no partecen establecer las 
diferencias buscadas. Pero queda en pie el hecho que la asociación entre dichas proporciones y el número medio de años aprobados por los habitantes de las cabeceras municipales es importante. Los coeficientes de Spearman dan los siguientes valores en el orden de los tamaños citados: 0,$78 ; 0,73 ; 0,72 ; 0,73$.

Nuevamente, entonces, queda en evidencia que, por lo menos con el sistema educacional tradicional, la concentración de la población favorece la adquisición de más altos niveles de instrucción.

\section{Cuadro 6}

COLOMBIA: NUMERO MEDIO DE AÑOS DE INSTRUCCION APROBADOS POR LA POBLACION DE 15 A 59 AÑOS DE LAS CABECERAS MUNICIPALES Y PROPORCION DE PERSONAS QUE VIVE EN CABECERAS DE $n$ HABITANTES Y MAS RESPECTO DEL TOTAL DE PERSONAS QUE VIVE EN CABECERAS , POR DEPARTAMENTO (Por ciento)

\begin{tabular}{|c|c|c|c|c|c|}
\hline \multirow{2}{*}{ Departamentos } & \multirow{2}{*}{$\begin{array}{l}\text { Número } \\
\text { medio años } \\
\text { instrucción } \\
\text { población } \\
\text { cabeceras }\end{array}$} & \multicolumn{4}{|c|}{ Proporción de personas que viven en cabeceras de: } \\
\hline & & $\begin{array}{c}50000 \\
\text { habitantes } \\
\text { y más }\end{array}$ & $\begin{array}{c}20000 \\
\text { habitantes } \\
\text { y más }\end{array}$ & $\begin{array}{c}15000 \\
\text { habitantes } \\
\text { y más }\end{array}$ & $\begin{array}{c}10000 \\
\text { habitantes } \\
\text { y más }\end{array}$ \\
\hline$\overline{\text { Antioquia }}$ & 4,37 & 65,4 & 68,5 & 73,6 & 75,4 \\
\hline Atlántico & 3,98 & 75,6 & $\mathbf{8 4 , 5}$ & 84,5 & 88,2 \\
\hline Bolívar & $3,4,1$ & 41,1 & 54,6 & 61,3 & 74,7 \\
\hline Boyacá & 3,84 & 41,6 & 41,6 & 48,3 & 527 \\
\hline Caldas & 8,92 & 58,0 & 69,1 & 71,1 & 83,1 \\
\hline Cauca & 3,77 & 41,6 & 41,6 & 41,6 & 60,3 \\
\hline Córdoba & 2,99 & 39,2 & 39,2 & 39,2 & 59,4 \\
\hline Cundinamarca & 4,53 & 87,1 & 89,3 & 90,2 & 90,7 \\
\hline Chocó & 2,94 & - & - & 46,9 & 46,9 \\
\hline Huila & 3,24 & 42,3 & 42,3 & $4,2,3$ & $\mathbf{5 5 , 0}$ \\
\hline Magadalena & 3,46 & 26,9 & 54,4 & $\mathbf{5 4 , 4}$ & 70,7 \\
\hline Meta & 3,27 & - & 58,2 & 58,2 & 58,2 \\
\hline Nariño & 3,80 & 38,5 & 61,1 & 61,1 & 66,1 \\
\hline Norte de Santander & er $\mathbf{3 , 5 7}$ & 55,9 & 76,2 & 76,2 & 76,2 \\
\hline Santander & 3,68 & 62,9 & 62,9 & 67,1 & 73,0 \\
\hline Tolima & 3,33 & 85,4 & 41,8 & 57,6 & 64,7 \\
\hline Valle del Cauca & 3,90 & 79,7 & 81,9 & 85,9 & 88,9 \\
\hline
\end{tabular}

Fuente: Censo de población de 1964. 


\section{RECAPITULACION}

Se ha tratado de mostrar, muy sintéticamente, algunos aportes que los demógrafos pueden hacer en el proceso de la planificación de la educación.

Uno de ellos tiene relación con una utilización más intensiva de los datos de los censos de población combinando el nivel de instrucción con algunos atributos demográficos: sexo, edad, distribución territorial de la población. El mismo esquema analítico ilustrado mediante el caso de las tasas de analfabetismo, puede aplicarse en medidas más apropiadas del nivel de instrucción, como el número de años de estudios aprobados, por ejemplo, y obtenerse parecidas conclusiones, aunque más específicas.

Se encuentra así que en Colombia, como en todas partes alguna vez en su historia, hubo discriminación según el sexo a favor de los hombres, pero que en la actualidad parece haber desaparecido. Se ha visto también que el lugar de residencia (urbana y rural) es un atributo sumamente importante respecto del alfabetismo. La tasa de analfabetismo rural es el triple de la urbana.

El examen por grupos de edades ha permitido evaluar la situación actual de la educación, como asimismo la pasada y la tendencia. De paso se señaló la implicación que una variable demográfica, la mortalidad, podía tener en la modificación de la proporción de analfabetos a través del tiempo.

Se puso en evidencia una implicación muy importante de otra variable demográfica, la migración interna, al descubrirse que el movimiento de la zona rural a la urbana deterioraba tanto el nivel de alfabetismo de la población de origen como de llegada. Además de la importancia del efecto percibido, debe señalarse un punto que puede llegar a tener gran trascendencia para el planificador de la educación y para el demógrafo.

Por alguna causa, una proporción importante de los más instruidos abandona el campo para ir a las ciudades (migración rural-urbana). Probablemente sea el mismo nivel de instrucción lo que genera o alimenta las motivaciones para migrar. Si el planificador se propone elevar el nivel de instrucción probablemente esté estimulando la migración en el sentido señalado. ¿¿Será este el efecto final deseado por el planificador? ¿De qué manera y hasta qué punto son compatibles los objetivos fijados por el planificador global del desarrollo con las 
consecuencias (no previstas) de las acciones derivadas del plan de educación?

Más todavía. Desde el punto de vista de la coherencia interna del propio plan educacional cabe hacer algunas reflecciones adicionales. Muchas veces se ha sostenido y aún se sostiene, al punto que se realizan todavía experimentos, que el contenido de la educación rural debe adaptarse a las condiciones del medio, esto es, debe acompañarse la enseñanza considerada básica con otras que capaciten a los jóvenes para las tareas agrícolas que se supone serán ejecutadas por ellos cuando lleguen a la edad de trabajar. Puesto que es un hecho incontrovertible el de la migración de las zonas agrícolas a las no-agricolas, ¿es pertinente plantear de esa manera el contenido de la eduación rural? ¿No debería tomarse en cuenta que se prepara a muchas personas para tareas que nunca realizarán y que deberán reajustarse ulteriormente o aceptar como una condena ejercer siempre los cargos más bajos en la escala ocupacional?

Estos y otros interrogantes deberán ser contestados para mejorar el proceso de la planificación educacional. Se abre así un campo fascinante para la investigación. 
$=\infty$ 
EL USO DE DATOS Y ESTUDIOS

DEMOGRAFICOS EN LA PLANIFICACION DEL DESARROLLO REGIONAL

Comisión Económica para América Latina 



\section{PRIMERA PARTE \\ LAS VARIABLES DEMOGRAFICAS EN LA PLANIFICACION REGIONAL $1 /$}

\section{INTRODUCCION}

1. Se han mencionado tres razones que aconsejan introducir, entre los objetivos de los programas de desarrollo, los relacionados con el desarrollo regional: 2 J

a) la necesidad de propender a la equidad social en la distribución de los frutos del desarrollo;

b) las presiones políticas derivadas de las condiciones desmedradas de algunas zonas con respecto a otras más privilegiadas, y

c) la preocupación por aprovechar más plenamente todos los recursos naturales y humanos para estimular la economia nacional y lograr la necesaria integración de todo el territorio.

2. La regionalización de los planes de desarrollo no debería solamente consistir en "una desagregación espacial hecha a posteriori de las metas y planes nacionales sino que se debería hablar de un proceso de planificación en el cual la variable espacial debe participar desde las primeras fases en la fijación de las metas que persigue el desarrollo y en la determinación de las líneas de estrategia general y sectorial". $\underline{3}$

$\mathrm{Al}$ igual que en el caso de las otras variables que se consideran en la planeación del desarrollo, las demográficas muestran diferentes niveles y tendencias en distintas áreas del territorio nacional. La población total de un país no se encuentra nunca distribuida uniformemente en su superficie. Además, y esto tal vez tenga aún más relevancia para el proceso de desarrollo y su planificación, las características demográficas, económicas, sociales y culturales de la población varían ampliamente según las áreas de asentamiento.

1] Esta primera parte ha sido preparada por César A. Peláez, demógrafo, funcionario de la División de Asuntos Sociales de la CEPAL.

2. CEPAL, Aspectos regionales del desarrollo en los países latinoamericanos, E/CN.12/896, pág. 1.

3/ Conclusiones del Segundo Seminario sobre Regionalización de las Políticas de Desarrollo en América Latina, Santiago, 8 al 12 de setiembre de 1969. Versión preliminar. 
3. En lo que sigue se considerarán solamente los datos y estudios demográficos que pueden ser necesarios para la planificación regional. 4/ Es evidente que tanto los tipos de datos demográficos, como las clasificaciones de las características (demográficas, económicas, sociales y culturales) de la población, las unidades territoriales a que deben referirse y la frecuencia con que esa información debería proporcionarse, dependen de los modelos y métodos que se utilicen en el proceso de planificación. Cuanto más complejos y detallados sean éstos últimos, tanto más compleja y detallada será la información demográfica requerida. En vista de que en este documento no se hace referencia a un proceso concreto de planificación, se adoptará un criterio amplio en ese respecto, aunque de ningún modo se pretende hacer un inventario completo de los posibles usos de la información y los estudios demográficos en la planificación regional.

4. La información y los estudios demográficos son necesarios para la planificación regional porque ellos son importantes elementos tanto para la caracterización de las unidades territoriales (estructura intrarregional) como para el análisis de los flujos de factores de producción entre esas unidades (relaciones interregionales). Esto ocurre, en mayor o menor medida, en todas las etapas de un plan regional, desde el diagnóstico inicial, hasta la evaluación y control de su realización.

\section{La estructura y tendencias demográficas como elementos para delimitar o definir las regiones}

5. Sea cual fuere el criterio que se siga para determinar las regiones de planificación, 5 / la información y los estudios demográficos son de gran utilidad para caracterizar las áreas. Sin embargo, la información censal y la de los sistemas de estadísticas vitales se refiere siempre a unidades territoriales creadas en el pasado con fines político-administrativos. De este modo, muy rara vez ocurrirá que alguna de esas áreas coincida con la que correspondería a una región definida con algún criterio

4/ Para un estudio del enfoque analítico y de la estructura conceptual que deberían tenerse en cuenta en la organización de un sistema de información para la planificación del desarrollo regional, véase Tormod Hermansen, Sistemas de información para el control del desarrollo regional. Documento E/4 del Curso de Planificación Regional del Desarrollo, Santiago, 1970.

5/ El problema de la delimitación de las regiones ha sido muy discutido. Véase, por ejemplo, Informe final. Grupo de Trabajo sobre la Sociología del Desarrollo Regional, Ginebra, noviembre de 1968. (Documento de referencia No 16 del Seminario sobre Aspectos Sociales del Desarrollo Regional; Santiago, noviembre de 1969), y Conclusiones del Segundo Seminario sobre Regionalización de las Políticas de Desarrollo en América Latina, Santiago, setiembre de 1969. 
pertinente para los fines de la planificación económica y social. Esto sin tener en cuenta que, en la teoría y la práctica de la planificación regional, podría considerarse más adecuado tomar en cuenta regiones cuyos límites cambien a medida que cambien la distribución espacial de la población y la actividad económica.

Por otra parte, es notoria la escasez de información existente sobre los cambios de la estructura económica y social en las diferentes áreas o regiones de un país. Esa información puede ser complementada, y aún substituida en algunos casos, con información demográfica que, desde hace ya bastante tiempo, es recopilada para un gran número de divisiones administrativas mayores y menores.

Como en el caso de los otros tipos de estadísticas necesarios para la planificación del desarrollo regional, es conveniente que la información demográfica tenga el mayor grado de desagregación espacial posible. Las unidades territoriales consideradas podrán ser luego reagrupadas para formar regiones de planificación, que puedan ser distintas de las divisiones administrativas mayores y que, además, podrán variar por la redistribución de las áreas administrativas menores.

6. En la etapa del diagnóstico previo a la planificación del desarrollo regional deberá hacerse un estudio, lo más completo posible de la situación y tendencias demográficas que incluya:

i) El crecimiento de la población total y su redistribución geográfica. Evaluación y análisis de la información censal disponible para mostrar el tamaño y ritmo de crecimiento de la población de las distintas unidades territoriales. Tendencias de la redistribución de la población. Areas de atracción y de repulsión.

ii) Componentes del cambio demográfico. En esta parte se analizarán los niveles y tendencias de las variables demográficas que determinan el crecimiento de la población (natalidad, mortalidad y migración) al nivel de cada unidad territorial. Ese análisis deberá ser precedido de una evaluación de las estadísticas vitales. En los análisis comparativos de la fecundidad y la mortalidad deberán utilizarse métodos de tipificación para eliminar el efecto que tiene sobre esas variables la diferente estructura demográfica (sexo, edad, estado civil, etc.) de las unidades territoriales consideradas. 6 / La información censal sobre migración interna disponible para la mayoría de los países de América Latina sólo ha permitido un análisis muy limitado de esta componente que es el factor fundamental del crecimiento diferencial de las distintas áreas. Las estimaciones disponibles se basan generalmente en métodos indirectos que toman en cuenta la estructura por sexo y

6/ Sobre la tipificación por edad de las tasas brutas de mortalidad véase, J.C. Elizaga, Métodos demográficos para el estudio de la mortalidad, CELADE, Santiago de Chile, 1969. El uso de la tipificación en el análisis de la fecundidad puede verse en R.O. Carleton, Aspectos metodológicos y sociológicos de la fecundidad humana, CELADE, Santiago de Chile, 1970. 
edad de la población de las distintas áreas y las estadísticas vitales o relaciones de sobrevivencia de tablas de mortalidad. 2/ Es probable que en el futuro los censos proporcionen información que permita medir directamente la magnitud de las corrientes migratorias y la estructura por sexo y edad de los migrantes, $\underline{8}$ pero el conocimiento de otros aspectos de la migración tan importantes para la planificación como las características económicas y sociales de los migrantes, sus motivaciones para cambiar de residencia y el proceso de asimilación cultural en las áreas receptoras, dependerá en gran medida de la realización de estudios especiales por muestreo. $9 /$

El estudio de la migración hacia las áreas urbanas tiene especial significación para la planificación del desarrollo regional. Aunque, en general, se considera que ese tipo de migración favorece la modernización y la elevación del nivel de vida de la población, estos resultados dependen en gran medida del equilibrio entre el desarrollo industrial de las áreas urbanas y la modernización de la agricultura y de la posibilidad de que las áreas urbanas puedan absorber esa migración.

En las áreas urbanas, el rápido crecimiento de la población hace muy difícil la asimilación de los migrantes proveyéndoles empleo, vivienda adecuada y otros servicios públicos; en las áreas rurales, los cambios en la estructura por sexo y edades y la composición según características socio-económicas de la población tienen generalmente consecuencias desfavorables ya que la población que emigra se compone de adultos jóvenes en edad de trabajar y de los que son más emprendedores y capaces.

En general, hay acuerdo para considerar que las posibilidades de empleo, el nivel del ingreso y la alta tasa de crecimiento natural de la población rural son las variables más importantes para explicar la

7/ Sobre métodos para estimar la migración interna véase, Naciones Unidas, Manual VI. Methods of Measuring Internal Migration (ST/SOA/Series A/47), New York, 1970

8/ Para una discusión de la experiencia de los países de América Latina en cuanto a tabulaciones censales sobre migración, véase Censos de población de América Latina (1960-64): Examen critico y sugerencias, CELADE, Serie $A$, No 78 , octubre 1967.

Las siguientes tabulaciones deberían ser incluidas en los censos, como de primera prioridad:

1. Población por tiempo de residencia en el área de empadronamiento, por lugar de residencia anterior, edad y sexo.

2. Población económicamente activa, por tiempo de residencia, categoría de ocupación, edad y sexo.

3. Población de 10 años y más de edad por tiempo de residencia en el área de empadronamiento, nivel de instrucción, edad y sexo.

9/ Un ejemplo de este tipo de estudios puede verse en J.C. Elizaga, Migraciones a las áreas metropolitanas de América Latina, CELADE, Santiago de Chile, 1970. 
migración rural-urbana. También se está de acuerdo en que existe un conjunto de factores no económicos que contribuyen a motivar la migración rural-urbana como, por ejemplo, la atracción de la recreación que puede encontrarse en las ciudades y la posibilidad que existe en ellas de romper con la tradición y escapar a las rígidas barreras sociales característic as de una comunidad rural.

En la actualidad se habla cada vez más de la necesidad de que en las políticas nacionales de desarrollo se consideren especialmente los problemas planteados por la migración interna y se incluyan, entre otras cosas, medidas tendientes a aliviar los problemas derivados de la rápida urbanización. La idea de que las regiones atrasadas deberian industrializarse en la medida en que sea económicamente posible, se está aceptando más cada día. En particular, la descentralización de la actividad industrial, concentrada en las metrópolis de los países de América Latina, puede producir resultados muy beneficiosos. Sin embargo, contrariamente al caso de la migración internacional, el control de los movimientos migratorios internos presenta serias dificultades de orden práctico e institucional. Es posible que esos movimientos puedan ser influenciados mediante la aplicación de diversas medidas o planes de acción que incluyan incentivos y restricciones de carácter económico y social, pero los conocimientos actuales respecto a los factores que determinan las migraciones son muy incompletos como para permitir estimar cuantitativamente sus efectos.

$\mathrm{Al}$ investigar los factores que determinan la migración, deberá siempre tenerse en cuenta que ésta es un proceso demográfico cuya función es intentar el restablecimiento de un equilibrio o provocar un cambio económico o social importante. En la práctica, la dirección, las características del proceso y los factores determinantes pueden variar ampliamente según las épocas y países. De ahi que los determinantes y consecuencias de las tendencias de la migración deben estudiarse para cada país en particular y aún así, cualquier predicción de la migración futura deberá considerarse como una proyección ilustrativa de lo que ocurrirá si se verifican determinadas hipótesis.

iii) La estructura por sexo y edad de la población en diferentes áreas y localidades. La composición por sexo y edades tiene importantes consecuencias económicas y sociales ya que ella es un factor determinante de la proporción de habitantes que participan en la actividad económica, atienden el sistema educativo, necesitan viviendas, asistencia médica, servicios de seguridad social, etc. 10/

La estructura por edad de una población depende de las tendencias de las componentes del crecimiento (natalidad, mortalidad y

10/ Un análisis teórico básico de las causas e implicaciones de los cambios en la estructura por edad de una población puede verse en The aging of Populations and its Economic and Social Implications, (Population Studies, No 26) United Nations, New York, 1956. 
migración). Los cambios en esas variables provocan cambios en la estructura por edad cuya magnitud es diferente según la variable de que se trate.

Si se considera la población total de un pais, reducciones de la mortalidad del orden de las que se han observado históricamente han modificado muy poco la estructura por edad, aumentando ligeramente la proporción de jóvenes. En cambio, la disminución de la fecundidad ha tenido efectos muy importantes, disminuyendo la proporción de jóvenes y aumentando la de personas de edades avanzadas. El efecto de la migración internacional sólo ha sido perceptible en los países donde alcanzó un gran volumen en relación a la población residente.

La situación cambia radicalmente cuando se considera la población de las diferentes áreas o regiones dentro de un pais. En este caso, la migración constituye el factor demográfico fundamental que determina la estructura por edad de las áreas o regiones.

iv) $E l$ proceso de urbanización. Al analizar el proceso de redistribución espacial de la población, la consideración de la dicotomía urbana-rural es esencial en relación con la planificación, particularmente con la planificación del desarrollo regional. Esos dos segmentos de la población difieren en sus modalidades de producción y consumo, las características de la vivienda y sus requerimientos de obras de infraestructura como redes de agua potable, alcantarillado, caminos y transporte público. También difieren usualmente en sus características ocupacionales, capacitación, movilidad, organización sindical, etc. Las características y las aspiraciones educacionales son también diferentes y deberán ser tomadas en cuenta para que la organización de las escuelas y otros servicios educacionales se adapte a las condiciones y necesidades de las áreas urbanas y rurales. Lo mismo puede decirse de los servicios de salud pública y otros servicios sociales. De hecho, difícilmente podría encontrarse algún área de actividad económica o social en la cual los segmentos urbano y rural de la sociedad no presenten diferentes características, necesidades y contribuciones para el desarrollo.

La población urbana y la rural deberían ser consideradas como variables endógenas en la planificación. El tamaño y las características de la población de ambas áreas constituyen una información básica para describir la situación en el momento de partida del plan. Lós cambios en la población urbana y la rural (y en la población total) están influenciados por las tendencias de la fecundidad y la mortalidad, pero fundamentalmente por la migración interna entre ambas áreas. Esa migración, debida principalmente al efecto de condiciones socio-económicas vigentes en el país, en ambas áreas, es en parte una variable independiente, en el sentido de que no está determinada solamente por las medidas que se toman para ejecutar el plan.

Pero, al mismo tiempo, un determinado nivel de urbanización puede ser una de las metas del plan y las medidas que se tomen para 
influenciar los desplazamientos de la población entre las áreas rurales y urbanas pueden ser muy importantes para su implementación.

v) Las formas de asentamiento de la población. El estudio de este tema está estrechamente vinculado al de la urbanización y la distribución geográfica de la población, y por consiguiente, los tres podrían ser tratados en forma conjunta. Para la planificación del desarrollo regional no es suficiente el conocimiento del tamaño y las características de la población de las diferentes regiones y subregiones de planific ación. La consideración de la población de las áreas urbanas y rurales permite profundizar el análisis, pero esa dicotomía es todavía una simplificación (muy burda para muchos propósitos de análisis) de lo que en realidad es un continuo, más o menos polarizado, según los países, entre la población dispersa y la del área metropolítana más populosa. 11/ Es necesario entonces estudiar la forma en que tanto la población, como las actividades económicas se organizan en localidades $o$ asentamientos de diferentes tamaños y características.

El estudio de las formas o patrones de asentamiento de la población deberá comenzar con un relevamiento de la información disponible sobre el crecimiento de la población de todas las localidades del país tomando en cuenta muy especialmente su localización geográfica. Esto permitirá describir la situación actual y las tendencias de la estructura espacial de la población urbana y rural.

Posteriormente, se deberá estudiar las estructuras demográficas, económicas y sociales que se observan en las localidades urbanas y rurales de diferentes tamaños, a fin de caracterizarlas en cuanto a sus funciones y potencialidades. De este modo las localidades se podrán clasificar en diferentes categorías que, en general, tendrán un mayor número de funciones, a medida que aumenta su tamaño. Estos resultados son de gran utilidad para la planificación del desarrollo regional, en tanto que ella generalmente contempla alguna reestructuración de los espacios urbano y rural.

vi) La participación en la actividad económica. La proporción de población económicamente activa en un país o región depende de dos factores: la estructura por sexo y edad de la población y la propensión a participar en la actividad económica, también de acuerdo con el sexo y la edad. Ambos factores, que dependen en última instancia de un

11/ Una discusión de la importancia del estudio de las formas de asentamiento de la población y la actividad económica para el desarrollo regional puede verse en: Design for a Worldwide Study of Regional Development. A report to the United Nations on a proposed research - training program. Resources for the Future, Inc., Washington D.C., 1966. Un enfoque sociológico del problema, puede verse en: Recent changes in urban and rural settlement patterns in Latin America, prepared by the Social Affairs Division of the Economic Commission for Latin America. Inter-Regional Seminar on Development Policies and Planning in Relation to Urbanization. Pittsburgh, U.S.A., United Nations, 1966. 
conjunto de valores culturales, actitudes psicológicas y condiciones económicas y sociales no son completamente independientes ya que la estructura por sexo y edad puede influir en la propensión a participar en la actividad económica. Pero no sólo importa conocer la magnitud de la población económicamente activa. Deberán también investigarse sus características: ocupación, rama de actividad económica, categorías ocupacionales, nivel de instrucción, empleo, etc. $12 /$

El estudio de las tendencias en el tamaño y la estructura de la PEA reviste especial importancia para la planificación del desarrollo regional, en vista de los diferenciales que se observan generalmente entre las diferentes áreas de un país en cuanto a su crecimiento y demás características y de que esa planificación procura promover una reestructuración espacial de la economía.

7. Los estudios que se han mencionado, además de su utilidad para el diagnóstico de la situación económica y social al nivel regional, constituyen la base indispensable para la preparación de un conjunto de proyecciones demográficas necesarias para la planificación del desarrollo regional. En primer lugar, la proyección de la población por sexo y grupos de edades para cada una de las áreas consideradas. Esta sirve como base para la preparación de otras proyecciones derivadas, que permiten evaluar las futuras necesidades $y$ potencialidades productivas de la población: también al nivel de las áreas consideradas proyecciones de la fuerza de trabajo, de la población de edad escolar y la que asiste a la escuela, del nivel de instrucción de la población, del número de hogares y familias, etc. $\underline{13}$

12/ Véase: Métodos de análisis de los datos censales relativos a las actividades económicas de la población, Naciones Unidas, Estudios Demográficos, No 43, Nueva York, 1969.

13/ Véase: Principios Generales para los programas nacionales de proyecciones de población como ayuda a la planificación del desarrollo, Naciones Unidas, Estudios sobre población No 38, Nueva York, 1966. 


\section{SEGUNDA PARTE}

\section{EL CASO CONCRETO DEL PERU 14}

Una de las características más sobresalientes del Plan Nacional de Desarrollo del Perú 1971-75, es la incorporación de la variable regional, la cual complementando los planteamientos nacionales clásicos globales y sectoriales, intenta planificar un proceso integral de transformaciones socio-económicas a través de una nueva política de "organización espacial del territorio". 15 /

Entre los males profundos de la realidad actual del Perú figuran los grandes desequilibrios regionales, no solamente en cuanto a la satisfacción de las necesidades de la población, sino también respecto a las condiciones de aprovechamiento de todos los recursos potenciales y a la utilización de los recursos humanos existentes. Una de las razones más importantes de estos desequilibrios reside en las condiciones de ocupación física del territorio y en las tendencias de los movimientos migratorios. Entre las soluciones adoptadas figura la promoción de importantes cambios en las condiciones de ocupación del espacio nacional que requerirán la adopción de complejas políticas específicas con el fin de enfrentar en el largo plazo grandes movimientos migratorios. Este complejo: "situación - estrategia - plan - redistribución territorial de la población", constituye el caso concreto del Perú que se estimó conveniente hacer conocer en oportunidad de este Seminario.

Es menestar precisar que la mayoría de los conceptos, ideas e informaciones presentadas y utilizadas en este documento, se derivan del trabajo conjunto con el equipo de funcionarios del área de programación regional del Instituto Nacional de Planificación del Perú y que todavía no han sido publicados oficialmente. Su presentación actual en este Seminario tiene solamente carácter ilustrativo, y fue posible por atención especial del Arquitecto Julio Ernesto Gianella, Director del Area de Programación Regional del Instituto, y de su principal colaborador el Ingeniero Edgardo Quintanilla.

14/ Esta segunda parte ha sido redactada por Henri Méot, Asesor Regional de la OTC en Planificación Regional, adscrito a la CEPAL.

15/ Se propone esta traducción castellana para el concepto francés "d'aménagement du territoire", considerando que lo refleja mejor que la traducción utilizada generalmente de "acondicionamiento del territorio". 


\section{LA SITUACION ACTUAL Y LOS FUNDAMENTOS ESTRATEGICOS}

Uno de los caracteres principales del desarrollo actual del Perú, que también se presenta en todos los países latinoamericanos, reside en los marcados y crecientes desequilibrios de toda índole, que se producen en el territorio y, que conducen a situaciones socio-económicas injustas para toda la población e impiden su verdadera participación en el esfuerzo nacional de desarrollo. Esta situación ha motivado la adopción por parte del Gobierno de una nueva estrategia territorial.

\section{A. Los desequilibrios socio-económicos en el territorio}

El estudio de los recursos humanos es, sin duda, uno de los más fundamentales para analizar la realidad socio-económica de un país. El concepto de desarrollo no puede ser desligado del hombre, como ser individual y como componente de la sociedad. Por ello cualquier análisis de situación y su diagnóstico correspondiente deben asentarse en el estudio estructural de las concentraciones territoriales de la población y de sus característic as principales.

a) Las condiciones actuales de ocupación física del territorio

En 1970, el Perú contaba con una población total del orden de los 13000000 de habitantes, que se reparten de modo muy desigual en los $330000 \mathrm{~km}^{2}$ aproximadamente de superficie realmente aprovechable (sólo un 25 por ciento de la extensión territorial total). El Gran Lima, por sí solo agruparía a unos 3000000 de habitantes (casi 1/4 de la población total), y su tasa anual de crecimiento demográfico según tendencias sería superior al 10 por ciento. El resto de la población tiene un crecimiento demográfico muy inferior, que en ciertas áreas es negativo, resultado de grandes movimientos migratorios centrípetos hacia el Gran Lima y otras pocas zonas urbanas de segunda importancia. Estos desequilibrios en el poblamiento del territorio deben ser caracterizados para poder entender la situación actual del país. 


\section{1) Metodologia utilizada}

La metodología utilizada 16 / está basada en la utilización de un nuevo indicador de medición del grado de concentración de la población que vive en las distintas unidades territoriales de análisis, con respecto a la población total. Aplicada sucesivamente a los espacios urbano y rural, la metodología suministra una imagen cuantificada de la repartición territorial de la población total, en esos espacios.

El indicador propuesto es el siguiente:

$$
\mathrm{I}_{\mathrm{i}}=\frac{\text { Densidad de la unidad territorial " } \mathrm{i} \text { " }}{\sum \text { densidades de las unidades territoriales }}=\frac{\mathrm{Di}_{\mathrm{i}}}{\sum \mathrm{D}_{\mathrm{i}}}
$$

Lo novedoso de este indicador, es su carácter independiente del tamaño de las unidades territoriales elegidas para el análisis, del valor absoluto de la población total y de los límites adoptados para las unidades territoriales. Sus propiedades permiten las condiciones relativas de ocupación física del territorio por la población. Además, si esos indicadores se multiplican por el número total de las unidades territoriales adoptadas para el análisis $(n)$, se obtienen indicadores semejantes ${ }_{n} I_{i}$ cuyos valores son independientes de $n y$, por consiguiente, permiten comparaciones entre países o, para el mismo pais, entre dos épocas distintas, cualesquiera sean las modificaciones adoptadas en los límites de las unidades territoriales.

Además se puede caracterizar:

i) El grado de heterogeneidad del espacio total: $n I=\frac{D}{\leqslant D_{i}}$

donde $D$ es la densidad del espacio total;

ii) El grado de heterogeneidad del espacio rural: $n I_{r}=\frac{D_{r}}{\frac{\sum D_{r i}}{n}}$

donde $D_{r}$ es la densidad del espacio rural total y $D_{r i}$ las densidades de los espacios rurales de las distintas unidades territoriales;

iii) El grado de heterogeneidad del espacio urbano: $n I_{u}=\frac{D_{u}}{\frac{\sum D_{u i}}{n}}$

16/ Véase CEPAL, "Aspectos regionales del desarrollo de los países latinoamericanos", Anexo B, documento de conferencia E/CN.12/986 preparado para el Décimocuarto período de Sesiones, 19 de marzo de 1971. 
donde $D_{u}$ y $D_{u i}$ son índices de la estructura de la concentración urbana en las áreas respectivas;

iv) El coeficiente urbano-rural de heterogeneidad: $K=\frac{\bar{D}_{u}}{\bar{D}_{r}}$

siendo $\bar{D}_{u}$ y $\bar{D}_{r}$ los promedios aritméticos de las $D_{u i}$ y $D_{r i}$, respectivamente.

De este modo es posible clasificar en forma relativa, a todas las unidades territoriales de análisis en tres grandes grupos:

i) Zonias de ocupación total, donde existe sobreocupación física relativa en los dos espacios urbano y rural;

ii) Zonas de ocupación parcial, con sobrepoblamiento relativo en uno solo de los espacios, clasificados en dos subgrupos: urbano y rural;

iii) Zonas de subocupación, que presentan una condición de subpoblamiento relativo total en ambos espacios y que, según el valor de la densidad rural con respecto al valor crítico de 1 habitante $/ \mathrm{km}^{2}, 17$ l pueden clasificarse en dos subgrupos: zonas de subocupación y zonas vacías.

Los valores de los indicadores $I_{i}$ cuy a suma es igual a 1 (ó 100 por ciento), muestran finalmente los grados relativos de concentración de la población del espacio analizado en cada una de las unidades territoriales.

\section{2) Las condiciones de ocupación física del territorio en 1961}

Aplicando la metodología antes señalada a los resultados del censo de 1961, se obtienen los indicadores de ocupación física del territorio vigentes en aquella época, que han servido de base al análisis de los desequilibrios socio-económicos existentes.

Previamente es importante señalar algunos aspectos metodológicos que inciden notablemente en el análisis de las condiciones de ocupación:

i) $\mathrm{Si}$ bien la elección de las unidades territoriales no tiene teóricamente mayor incidencia en la imagen lograda, en realidad la precisión de la imagen depende del tamaño promedio de las unidades. En la práctica, lo más adecuado sería elegir unidades territoriales que presenten en toda su extensión suficientes caracteres de homogeneidad para el análisis y que, al mismo tiempo, sean lo suficientemente numerosas como para representar las distintas realidades territoriales existentes.

17/ Este valor es evidentemente arbitrario, pero se considera que es característico de una zona sin población rural. 
En el Perú, donde existen tres grandes zonas geográficas - Costa, Sierra y Selva- que han determinado en gran medida la realidad socio-económica actual, se han adoptado como unidades territoriales de análisis los Departamentos subdivididos en sus zonas geográficas, (42 unidades en total, sin contar el Gran Lima).

ii) A fin de tener una imagen que sea lo más real posible, es necesario tomar en cuenta las superficies aprovechables 18 que, como se ha señalado anteriormente, representan sólo el 25 por ciento de la extensión territorial total del pais.

iii) La aplicación de la metodología supone la adopción previa de una clara definición de los espacios urbano y rural. Si se utilizan criterios universales o estructurales, los resultados permiten comparaciones entre países, si nó sirven solamente para el país considerado. Esta última situación es la encontrada en el Perú, cuyo espacio urbano corresponde muy aproximadamente a los centros poblados de 2000 habitantes y más.

iv) Finalmente y dada la gran concentración de población en el Gran Lima, es evidente que se debe excluir del análisis esta unidad territorial. 19/

En las tablas 1 y 2 del Anexo, se presentan los datos básicos para el cálculo y los valores de los indicadores semejantes para las unidades territoriales. El gráfico 1 permite clasificar estas unidades en las cinco zonas y subzonas de ocupación física. 20/

En sintesis, las condiciones globales de ocupación física del territorio en 1961, son las siguientes:

i) El Gran Lima concentra, en una superficie territorial mínima, el 19 por ciento de la población total del país y casi el 40 por ciento de la población urbana nacional (la población rural es despreciable).

ii) Las importancias relativas de las superficies aprovechables y de las poblaciones de las 3 zonas geográficas con respecto al total del país.

\footnotetext{
18/ El término "aprovechable" debe entenderse como la posibilidad para el hombre de ocupar el territorio con fines productivos o de asentamiento, con las técnicas actuales.

19/ No se debe olvidar que el análisis de las condiciones de ocupación física es un análisis relativo y que si existe una gran concentración poblacional en una unidad las demás unidades serian automáticamente clasificadas como subocupadas al no descartarse la primera.

20/ Cabe señalar que, en el gráfico, algunas unidades han sido af ectadas a una clase a la cual no deberían teóricamente pertenecer por los valores de sus indicadores; en realidad se trasgredió la norma fijada tomando en cuenta los efectos de límites de clase (valores muy próximos a los límites).
} 
Cuadro 1

PERU: CONDICIONES DE OCUPACION FISICA DEL

TERRITORIO. 1961

\begin{tabular}{lcccc}
\hline Zona geográfica & \multicolumn{4}{c}{ Porcentaje del total del país } \\
\cline { 2 - 5 } & $\begin{array}{c}\text { Superficie } \\
\text { aprovechable }\end{array}$ & $\begin{array}{c}\text { Población } \\
\text { total }\end{array}$ & $\begin{array}{c}\text { Población } \\
\text { urbana }\end{array}$ & $\begin{array}{c}\text { Población } \\
\text { rural }\end{array}$ \\
\hline Costa & 9 & 39 a & 64 b & 17 \\
Sierra & 48 & 52 & 30 & 72 \\
Selva & 43 & 9 & 6 & 11 \\
\hline
\end{tabular}

Fuente:

a) Incluyendo Lima; sin ésta sólo alcanza al 20 por ciento.

b/ Incluyendo Lima; sin ésta sólo llega al 25 por ciento.

Cuadro 2

PERU: IMPORTANCIA PORCENTUAL DE LAS TRES ZONAS DE OCUPACION Y SUS SUBZONAS CON RESPECTO AL PAIS

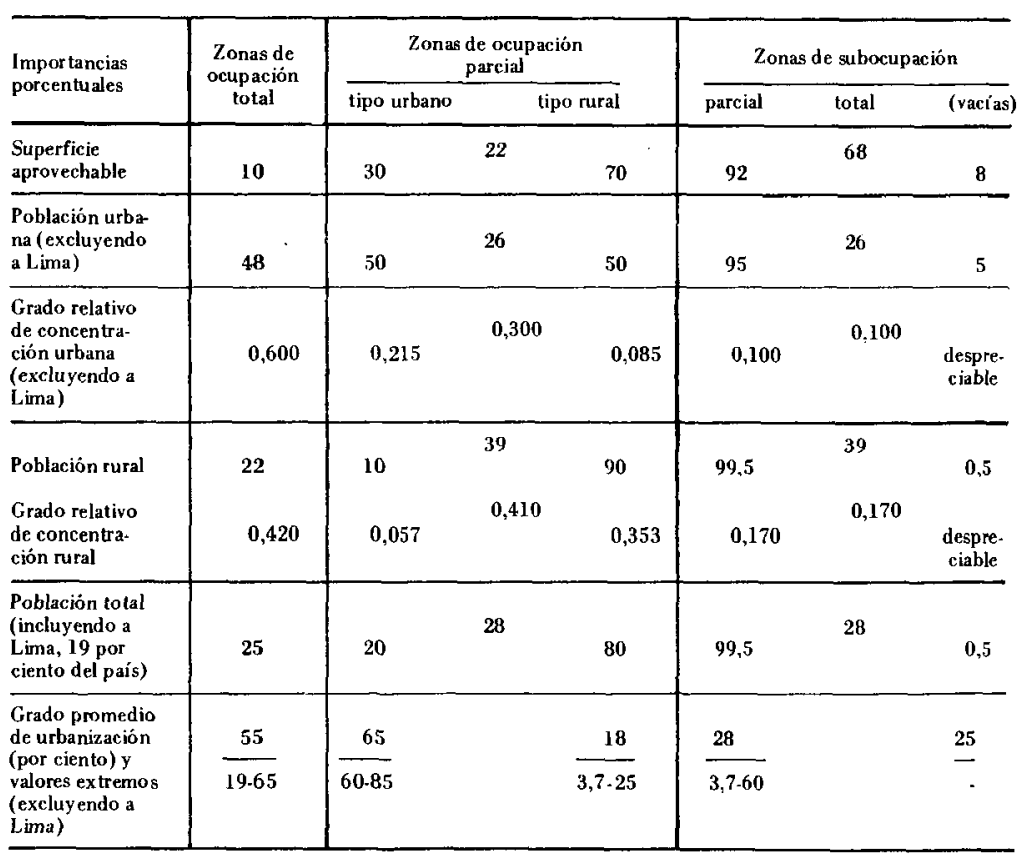



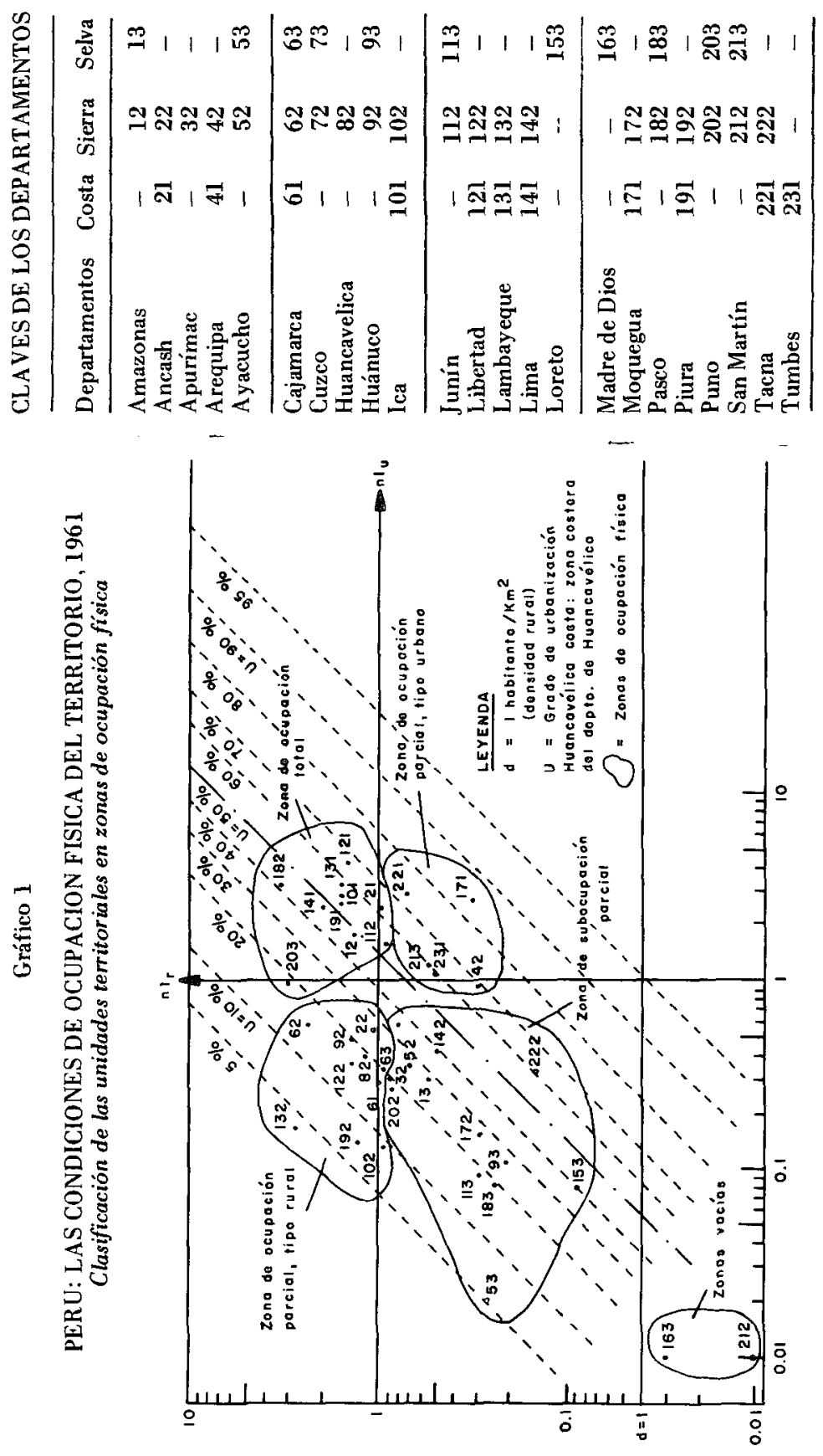
iii) Los indicadores de ocupación física para el país, sin tomar en cuenta el Gran Lima, son los siguientes:

grado de heterogeneidad del espacio urbano $=0,53$

grado de heterogeneidad del espacio rural $\quad=0,64$

coeficiente urbano-rural de heterogeneidad $\quad=0,68$

iv) Las importancias porcentuales de las tres zonas de ocupación física, y de sus respectivas subzonas con respecto al país. $\underline{21}$

v) Las importancias porcentuales de las zonas y subzonas de ocupación física en cada una de las 3 zonas geográficas, en 1961, figuran en la tabla 3 del anexo.

Estas condiciones globales se tipifican, en cada zona de ocupación física, mediante las densidades territoriales de la población rural y las modalidades de agrupación de la población urbana por clases de tamaño de los centros poblados.

La tabla 4 del anexo suministra las densidades territoriales por zonas geográficas. Además de los valores promedio, se han indicado los valores extremos existentes en cada tipo de zona, a fin de precisar el sentido del promedio zonal.

Antes de poder analizar las modalidades de agrupación de la población urbana, es preciso agrupar todos los centros poblados al nivel del pais en distintas clases homogéneas. Un primer análisis permite distinguir tres grandes grupos de centros poblados: los intermedios, los urbanos y el metropolitano. Los segundos, que tienen un tamaño bastante grande y son poco numerosos, son generalmente ciudades que tienen funciones múltiples. Por el contrario, los primeros, de tamaño más reducido y más numerosos, son centros cuyas funciones los asemejan bien sea a centros rurales, bien sea a centros urbanos, constituyéndose así en centros relé entre el espacio rural y el espacio urbano de las ciudades importantes.

La estructura nacional de los centros poblados del espacio urbano, en 1961, seria la siguiente:

21/Los porcentajes en las subzonas se expresan en relación a la zona correspondiente. Los grados relativos de concentración corresponden a la sumatoria de los indicadores de ocupación física. 
PERU: MODALIDADES DE AGRUPACION DE LA POBLACION URBANA AL NIVEL NACIONAL. 1961

\begin{tabular}{|c|c|c|c|c|c|}
\hline \multirow{2}{*}{$\begin{array}{c}\text { Categoria de centros } \\
\text { (grupos y clases por } \\
\text { tamaño) }\end{array}$} & \multirow[b]{2}{*}{$\begin{array}{l}\text { Tamaños } \\
\text { ex tremos }\end{array}$} & \multicolumn{4}{|c|}{ Características estructurales } \\
\hline & & $\begin{array}{l}\text { Námero de } \\
\text { centros }\end{array}$ & $\begin{array}{c}\text { Tamaño } \\
\text { promedio } \\
\text { a/ }\end{array}$ & $\begin{array}{c}\text { Población } \\
\text { por clase } \\
\text { b } /\end{array}$ & $\begin{array}{l}\text { Importan } \\
\text { cia por- } \\
\text { centual }\end{array}$ \\
\hline \multicolumn{6}{|l|}{$\begin{array}{l}\text { 1) Intermedios } \\
(2000-28000)\end{array}$} \\
\hline $\begin{array}{l}\text { muy pequeños } \\
\text { pequeños } \\
\text { medianos } \\
\text { grandes }\end{array}$ & $\begin{array}{r}2000 \cdot 4600 \\
5000 \cdot 9000 \\
10000 \cdot 16000 \\
20000 \cdot 28000\end{array}$ & $\begin{array}{c}\text { no se conoce } \\
50 \\
23 \\
16\end{array}$ & $\begin{array}{l}3300 \mathrm{c} \\
6000 \\
12000 \\
24000\end{array}$ & $\begin{array}{l}1189500 d / \\
308500 \\
280000 \\
368000\end{array}$ & $\begin{array}{r}25,0 \\
6,5 \\
6,0 \\
7,5\end{array}$ \\
\hline \multicolumn{6}{|c|}{$\begin{array}{l}\text { 2) Urbanos } \\
\{43000-150000)\end{array}$} \\
\hline $\begin{array}{l}\text { muy pequeños } \\
\text { pequeños } \\
\text { medianos }\end{array}$ & $\begin{array}{c}43000 \cdot 70000 \\
80000 \cdot 100000 \\
150000\end{array}$ & $\begin{array}{l}6 \\
3 \\
1\end{array}$ & $\begin{array}{r}60000 \\
90000 \\
150000\end{array}$ & $\begin{array}{l}348000 \\
270000 \\
150000\end{array}$ & $\begin{array}{l}7,5 \\
5,5 \\
3,0\end{array}$ \\
\hline $\begin{array}{l}\text { 3) Metropolitano } \\
\text { (Lima-Callao) }\end{array}$ & J 846000 & 1 & 1846000 & 1846000 & 39,0 \\
\hline Totales & - & $\begin{array}{l}100 \mathrm{de} \\
5000 \mathrm{y} \\
\text { más }\end{array}$ & - & 4760000 & 100,0 \\
\hline
\end{tabular}

a) Calculado por división de la población de la clase por el número de centros de la clase, y luego redondeado.

b) Calculado a partir de los tamaños y números de los centros existentes en cada clase.

c) Aproximadamente, corresponde a la mediana de la clase.

d/ Calculado por diferencia entre la población urbana del país y la de los centros de 5.000 y más habitantes.

El gráfico 2 visualiza estas estructuras nacionales (las demás informaciones serán analizadas más adelante).

Conociendo las estructuras al nivel del pais, es posible analizar las modalidades de agrupación de la población urbana por zonas geográficas y zonas de ocupación física, utilizando las mismas clases de tamaño. Se obtienen así las estructuras zonales que figuran en la tabla 5 del anexo.

b) Los desequilibrios resultantes

Todas las informaciones anteriores sobre las condiciones de ocupación física del territorio, subrayan los grandes desquilibrios que exitían en 1961 en el poblamiento del país. Pero como la actividad económica está generada por la del hombre y de las colectividades que ha formado, es de esperar que existan también grandes desequilibrios socio-económicos 


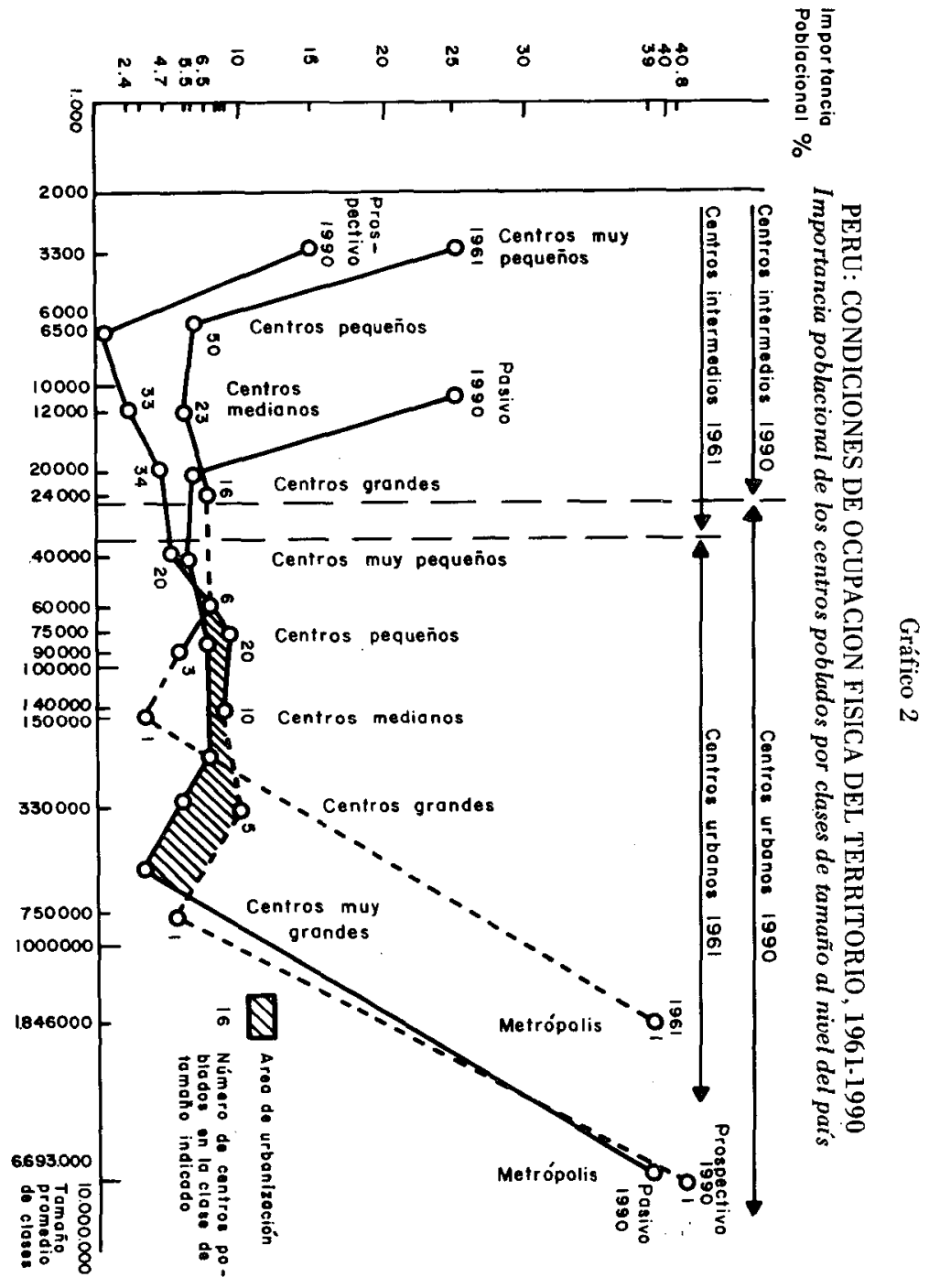


en todo el territorio. Hasta cierto punto, se puede afirmar que existe una relación de causa-efecto entre las condiciones de ocupación física del territorio y los distintos niveles socio-económicos de su población.

\section{LOS DESEQUILIBRIOS EN EL POBLAMIENTO DEL TERRITORIO}

Sin entrar en un análisis detallado de las distintas importancias porcentuales de las zonas de ocupación física y de las informaciones contenidas en las tablas 3 a 5 del anexo, es interesante subrayar los principales desequilibrios que existían, en 1961, en el poblamiento del territorio:

i) El pais, en su conjunto, es subpoblado $22 /$ y mal poblado, dada la elevada concentración existente en el Gran Lima y los coeficientes de heterogeneidad del resto de la población.

ii) $\mathrm{Si}$ bien la población total del país se reparte en forma aproximadamente igual entre el Gran Lima y los tres tipos de zonas de ocupación física, existen grandes diferencias en las condiciones de ocupación de los espacios urbano y rural (importancia poblacional de 1 a 2, grado de concentración de 1 a 6 y grado de urbanización de 1 a 3 ), aún más marcadas entre las subzonas de ocupación.

iii) Las condiciones de ocupación física también son muy dispares al nivel de las zonas geográfic as, siguiendo en cada una de ellas un patrón bien distinto.

iv) Los desequilibrios aparecen netamente en el espacio rural y en el urbano, tipificando los patrones anteriores: en la Costa, gran concentración urbana y rural en zonas de ocupación total relativamente estructuradas. En la Sierra, elevada concentración rural, a pesar de existir notables superficies subocupadas, con un espacio urbano mal estructurado. En la Selva, grandes superficies subocupadas o vacías, con concentraciones débiles de población.

\section{LOS DESEQUILIBRIOS SOCIO-ECONOMICOS EN EL TERRITORIO}

Además de los desequilibrios en el poblamiento del territorio existen también marcadas diferencias en los niveles socio-económicos de la población de las zonas de ocupación que reflejan las grandes disparidades en sus niveles de desarrollo. El documento de la CEPAL,

22/ Evidentemente, no es una novedad, pero se consideró importante subrayarlo para lograr esta observación con la nueva metodología utilizada. 
antes mencionado, ha presentado algunas informaciones al respecto para las zonas de ocupación física. $\underline{23}$ /

Esa información se resume en la tabla 6 del anexo, donde se presentan, para cada tipo de zona de ocupación, los valores de algunos indicadores sociales (mortalidad, camas hospitalarias, niveles de instrucción primaria y secundaria, asistencia escolar) y de otros económicos (producto bruto interno y su estructura sectorial, valor agregado y ocupación industrial, densidad territorial de las vías de comunicación, consumos de energía eléctrica global e industrial).

\section{B. La estrategia territorial}

Para remediar, en el largo plazo, las disparidades territoriales vigentes y aprovechar mejor todos los recursos naturales y humanos existentes, en beneficio del pais y de toda su población, el Perú adoptó una nueva estrategia territorial, que ha sido planteada en la estrategia del desarrollo nacional a largo plazo y, precisada en el plan nacional de desarrollo para 1971-1975. Las grandes opciones estratégicas adoptadas y la imagen-objeto fijada para los espacios urbano y rural son las piezas maestras de las nuevas condiciones de ocupación del territorio, deseadas para 1990.

\section{a) Opciones estratégicas}

Partiendo de la realidad socio-económica del país, la estrategia nacional, en sus grandes propósitos espaciales de desarrollo contempla: "Lograr una mejor distribución de la población dentro del espacio económico del país, evitando así las actuales tendencias de concentración creciente en la zona costera, particularmente en el centro metropolitano, mediante la formación de polos compensatorios de desarrollo en regiones estratégicas, en torno a una constelación de recursos naturales integrados. 24/ Se espera asi un mejor aprovechamiento de los recursos existentes de toda índole, al mismo tiempo que se modifiquen las tendencias migratorias hacia el Gran Lima en beneficio de nuevos centros dinámicos, juiciosamente repartidos en el territorio y capaces de generar demanda y excedentes.

23/ Es menestar señalar que el diseño de las zonas de ocupación, en este documento, no corresponde exactamente al analizado aquí, pero las diferencias son de poca magnitud y las conclusiones quedan válidas, a título de ilustración. E1 documento de la CEPAL trabajó al nivel de los Departamentos y de sus superficies totales, mientras que para este documento se han desglosado los departamentos en las 3 zonas geográficas y se han considerado las superficies aprovechables.

24/ Estrategia del Desarrollo Nacional a largo Plazo, resumen, Presidencia de la República, Lima, noviembre de 1968. 
El Plan Nacional de Desarrollo para $1971-1975$ (primer eslabón temporal de la estrategia de largo plazo), por su parte, ha precisado estos propósitos en su capítulo sobre "Política de acondicionamiento del territorio y del uso de lo recursos naturales". 25/ En particular, pone énfasis en la reducción de la población rural, particularmente en la zona de la Sierra, para obtener niveles racionales en la relación hombre-tierra aprovechable $y$ para mejorar las estructuras urbano-rurales, aprovechando y jerarquizando las reales posibilidades que existen en todo el territorio. Para eso, se ha diseñado en el país una serie de "zonas de acción concentrada", en donde, por existir mayor concentración poblacional y buenas posibilidades económicas, se adoptarán políticas específicas de inversiones y prioridades adaptadas a las vocaciones de las distintas zonas y al rol atribuido a cada una de ellas. Para jerarquizar las acciones de desarrollo a promover, se han clasificado estas zonas (que en conjunto comprenden un 80 por ciento de la población y un $\mathbf{3 0}$ por ciento de la superficie total) en cuatro categorias: zonas de ventajas comparativas, zonas de alto desarrollo relativo, zonas de saturación poblacional, zonas de frontera económica, además de zona metropolitana y el resto del país. En cada una de estas zonas, el plan define las grandes acciones a emprender, en un esquema espacial de interrelaciones.

Es interesante señalar que el diseño de las zonas de ocupación física del territorio es coherente con el diseño estratégico de las zonas de acción concentrada, encontrándose asi una justificación a posteriori, 26/ si fuera necesario, o demostrando la existencia de una cierta relación de causa-efecto entre las dos zonificaciones. Así, las zonas de ventajas comparativas y las de alto desarrollo relativo se corresponden muy bien con las zonas de ocupación total y de ocupación parcial de tipo urbano, que agrupan la mayor cantidad de la población nacional con las estructuras urbano-rurales más equilibradas.

\section{b) Imagen-objetivo}

A fines de precisar los objetivos fijados en la estrategia nacional y el primer plan quinquenal cuantificándolos en términos territoriales, el área de programación regional del Instituto Nacional de Planificación, inició el año pasado varios estudios socio-económicos. El propósito general es definir una imagen objetiva de los espacios urbano y rural del

25/Plan Nacional de Desarrollo para 1971.1975, Volumen I: Plan Global, Sistema Nacional de Planificación, Lima, mayo de 1971.

26/ El diseño de la zona de ocupación física ha sido posterior a la elaboración del plan. 
país, para el horizonte 1990,27 J en base a una serie de supuestos demográficos y económicos coherentes, que configuran los cambios fundamentales en la ocupación del espacio a conseguir en el largo plazo.

Un primer documento, todavía no publicado oficialmente pero destinado a servir de base y de marco general a las discusiones, ha presentado las primeras prospectivas, definiendo detalladamente la imagen-objetivo del espacio rural y esbozando la urbana, en términos coherentes. Dicho documento se expresa asi: "El problema de los cambios fundamentales en la ocupación del espacio económico abarca más de 40 variables, y cerca de 35 parámetros, y el tipo de análisis que se ha utilizado corresponde al de un modelo de planificación discrecional, es decir, que no está presentado en fórmulas matemáticas y que va tomando en cuenta los resultados, para ir superando las dificultades, la falta de información, etc. ... el documento es fundamentalmente normativo y voluntarista, en la medida en que se plantea una imagen futura de distribución racional de la población, pero que se cree perfectamente factible si se adoptan las políticas consiguientes y se canalizan los recursos humanos y financieros que se requieren para superar la extrema situación de desequilibrios en la ocupación del espacio económico que caracteriza al pais." 28/

En resumen, el modelo empleado para el análisis de la ocupación en el espacio rural ha permitido determinar en todo el territorio, y a nivel de los departamentos desglosados en sus 3 zonas geográficas, la futura fuerza de trabajo rural considerada óptima y posible de acuerdo a las potencialidades de los recursos existentes y a los principales factores, demográficos y económicos.

Luego de haber obtenido la imagen-objetivo del espacio rural, se ha empezado el estudio del espacio urbano, mucho más complejo por tener que satisfacer los objetivos estratégicos territoriales y absorber los excedentes netos de población rural a redistribuir. De los estudios realizados hasta la fecha, surge una imagen-objetivo que determina, en primera aproximación, la población prospectiva de todos los centros poblados de 2000 habitantes y más, en el horizonte 1990.

27 En realidad, todos los documentos se refieren al año 1988, o sea 20 años después de haberse aprobado la estrategia nacional pero la diferencia es mínima y en materia de prospectiva no tiene importancia.

28/ Los cambios fundamentales en la ocupación del espacio económico, Instituto Nacional de Planificación, Oficina Nacional de Evaluación de Recursos Naturales, Lima, octubre de 1970. (Documento no oficial). 


\section{LOS CAMBIOS FUNDAMENTALES EN LA OCUPACION DEL ESPACIO}

Cuando se examinan las condiciones de ocupación física del territorio, en su situación actual y en sus propias tendencias, a la luz de las grandes opciones estratégicas adoptadas, puede verse que, para alcanzar la imagen-objetivo en el largo plazo, el país deberá enfrentar, promover en forma planific ada y controlar importantes movimientos migratorios.

\section{A. Las consecuencias de las opciones estratégicas}

Traducir en términos territoriales cuantificados los diversos cambios a promover y sobre todo ligarlos en una dinámica espacial han sido los principales objetivos del documento, antes señalado, elaborado por el Instituto Nacional de Planificación sobre los cambios fundamentales en la ocupación del espacio económico. No se pretende aquí analizar este documento en forma detallada, sino más bien subrayar sus fundamentos en el marco territorial adoptado.

\section{a) Las distintas unidades territoriales de análisis}

Al nivel de un país, los estudios territoriales de prospectivas requieren la adopción previa de unidades territoriales de análisis que puedan constituirse en marcos de referencia y faciliten las sucesivas coherencias. Cuanto más grande sea el número de unidades elegidas, mejor se definirán en el territorio los cambios a promover. Pero muy rápidamente surgen importantes obstáculos como la falta de información adecuada y la creciente falta de confiabilidad de los datos existentes. En la práctica la selección definitiva se podrá lograr después de una serie de ensayos, sin perder de vista los objetivos perseguidos, las posibilidades y las necesarias coherencias territoriales.

En el caso concreto del Perú, se han adoptado varios niveles de análisis. E1 país constituye el marco general que permitió compatibilizar los resultados obtenidos al nivel de las cinco grandes regiones económicas y de planificación nacional: Norte, Centro, Sur, Oriente y Metropolitana. Estas regiones se las ha subdivido en sus respectivas zonas geográficas de Costa, Sierra y Selva, a fin de tener grandes unidades territoriales suficientemente homogéneas y de diversificación relativa, obteniendo así 11 unidades territoriales mayores de análisis. 
Además, en cada una de ellas (con excepción de la metropolitana) han sido desglosados los espacios urbano y rural.

Para poder precisar aún más la prospectiva, particularmente en el espacio urbano, y para disponer de una herramienta suplementaria de coherencia con los estudios de las condiciones de ocupación física del territorio, se ha realizado también el estudio de los cambios al nivel de los departamentos (unidad político-administrativa mayor del país) desglosados en sus respectivas zonas geográficas (42 unidades territoriales aparte del Gran Lima). Pero es necesario recalcar que se debe tener sumo cuidado en la utilización de estas unidades y en la interpretación de los resultados obtenidos, pues, a pesar de su mayor homogeneidad interna, su tamaño reducido hace que sean poco confiables algunos de los datos básicos utilizados.

\section{b) Los fundamentos del análisis}

El análisis de los cambios a promover en el espacio se ha fundamentado en la consideración de las proyecciones de las condiciones de ocupación física del territorio, las opciones estratégicas, particularmente las relativas al espacio rural, y un conjunto de supuestos básicos.

\section{LAS PROYECCIONES DE POBLACION}

A partir de los resultados de los censos de 1940 y 1961, el Instituto Nacional de Planificación ha elaborado proyecciones según tendencias de población, para las unidades territoriales adoptadas. La tabla 8 del anexo suministra las condiciones globales de ocupación física del territorio en 1961 y en 1990. Los cambios entre esas dos fechas demuestran la magnitud de los movimientos migratorios espontáneos y generalizados, y el consiguiente estancamiento, y aún dismunición de la población en las diversas unidades fuera de la metropolitana.

Paralelamente, se nota el proceso de urbanización $\mathrm{y}$, sobre todo, su similitud en las distintas regiones de planificación, con excepción de la región metropolitana

La confrontación de estas tendencias con las opciones estratégic as ha suministrado un cierto número de normas para orientar los cambios y su cuantificación.

\section{LA IMAGEN-OBJETIVO EN EL ESPACIO RURAL}

Merced a un conjunto de estudios, realizados con anterioridad, se disponia de la distribución de la fuerza de trabajo rural deseable en 
1990, al nivel de las unidades territoriales menores adoptadas. $\underline{29} /$ Esta imagen-objetivo ha sido la piedra angular, a partir de la cual se han desarrollado los demás estudios de los cambios a promover.

Es interesante señalar que, independientemente de la necesidad de redistribuir la población rural en el largo plazo, a pesar de la extensión prevista de la frontera agrícola, la imagen-objetivo conduce todavia a un excedente neto del orden de las 800000 personas sobre las proyecciones según tendencias de la población rural, que deben ser reubicadas en el espacio urbano.

\section{LOS SUPUESTOS BASICOS}

La complejidad del análisis, debida a la gran cantidad de variables y parámetros socio-económicos a tomarse en cuenta para reflejar mejor la realidad, se ha simplificado mediante la adopción de una serie de supuestos básicos demográficos, económicos y territoriales. Se podría pensar, que la utilización de esos supuestos resta validez a los análisis realizados. Sin embargo, no se debe olvidar que los objetivos fundamentales eran encontrar órdenes de magnitud de los cambios a promover, siempre y cuando éstos sean perfectamente compatibilizados entre sí. Además, los supuestos utilizados pueden clasificarse en dos categorías: los adoptados en primera aproximación para orientar lós cálculos y que los estudios de coherencia y de compatibilidad han mejorado o validado, y los básicos, generalmente de orden demográfico, cuya elasticidad es muy baja y, por ende, necesitan ser conocidos con una relativa precisión. Por último, se ha tratado siempre de utilizar, en forma concomitante, varios métodos independientes para verificar la validez de los supuestos, o se ha recurrido a varias fuentes de información para determinarlos.

Al nivel del país, los principales supuestos básicos han sido: i) considerar el espacio nacional como un universo cerrado, en el cual las migraciones externas no tienen importancia significativa; ii) adoptar las tasas de actividad promedio de las poblaciones total, urbana y rural, excluida la de Lima, y iii) conservar la población nacional proyectada para 1990, a pesar de su elevada tasa de crecimiento vegetativo (necesidad estratégica de poblamiento del pais). Para el Gran Lima se ha adoptado fundamentalmente la decisión estratégica de limitar su importancia poblacional, en 1990 , a un máximo de 30 por ciento de la población nacional, valor ligeramente inferior a las tendencias, y se ha fijado su futura tasa promedio de actividad. En las regiones, se han adoptado, en primera aproximación, las diferentes tasas de actividad, de crecimiento vegetativo y de urbanización que deberían verificarse en 1990.

29/ Esta imagen-objetivo permite equilibrar en todo el territorio la distribución de la población y los recursos potenciales agropecuarios, tomando en cuenta algunos supuestos económicos básicos. 


\section{B. Las metodologías utilizadas}

Para poder cumplir las opciones estratégicas adoptadas y atenerse a sus diversas consecuencias mediante adecuadas políticas de "organización espacial del territorio", $\underline{30 /}$ era imprescindible estudiar: i) las nuevas condiciones de ocupación física del territorio; ii) los movimientos migratorios que deberían realizarse, en las distintas unidades territoriales y entre ellas, para satisfacer la imagen, y iii) la naturaleza y magnitudes de estos movimientos deseables, en comparación con las tendencias.

\section{a) Principios metodológicos}

Para poder entender bien el modelo aplicado, es menester describir previamente las dos metodologías utilizadas, por lo menos en sus principios.

\section{LOS BALANCES DEMOGRAFICOS}

Aplicados al nivel de las distintas unidades territoriales de análisis, los balances demográficos permiten calcular las tasas medias anuales de migración neta y cuantificar los movimientos migratorios absolutos. Se basan en las dos ecuaciones fundamentales siguientes:

$$
\text { '(1) } r_{i}=V_{i} \pm m_{i}
$$

en la cual $r_{i}$ es la tasa media anual de crecimiento demográfico de la unidad espacio $i$ en un período determinado, $V_{i}$ la tasa media anual de crecimiento vegetativo de la misma unidad $i$ en el mismo período y $m_{i}$ la tasa media anual de migración neta positiva o negativa de la misma unidad en el mismo período.

$$
\text { (2) } A_{i}=V_{i} \pm M_{i}
$$

en la cual, para el mismo espacio $i$ y el mismo período determinado, $A_{i}$ es el aumento absoluto de población, $V_{i}$ es el crecimiento vegetativo absoluto de la población y $M_{i}$ es el número absoluto de migrantes (saldo migratorio neto, positivo o negativo).

La metodologia consiste en aplicar las dos ecuaciones básicas en todas las unidades de análisis, a partir de las situaciones 1940 y 1961 (censos de población) y en función de la imagen final de ocupación deseada para el largo plazo o de las tendencias pasivas. En estos dos casos, se pueden calcular las distintas tasas $r_{i} \mathrm{y}$, adoptando las tasas $V_{i}$

30/ Véase página 225, llamada $\underline{15}$. 
se obtienen las tasas $m_{\mathfrak{i}}$. Por aplicación de estas tasas a las poblaciones se pueden calcular las variaciones absolutas de población $\left(A_{i}, V_{i}\right.$ y $\left.M_{i}\right)$, que un estudio de coherencia y compatibilización, al nivel nacional, permite rectificar por aproximaciones sucesivas, en la hipótesis de que el saldo migratorio neto del país es nulo.

\section{LAS TASAS HIPERBOLICAS DE URBANIZACION}

Los estudios de los fenómenos globales de urbanización demuestran que los grados de urbanización de un territorio, o de sus distintas unidades territoriales, siguen una ley de variación en el tiempo, cuya forma general es única y que se define perfectamente por dos parámetros básicos: "el gradiente de urbanización, o su equivalente la tasa hiperbólica de urbanización", que caracteriza el dinamismo del fenómeno, y la "época crítica de urbanización, o su equivalente el coeficiente de urbanización al origen", que constituye la condición inicial del fenómeno. Dos observaciones solamente permiten definir sin ambigüedad estos parámetros característicos y, de ahí, calcular en cualquiera época los coeficientes y los grados de urbanización mediante las fórmulas siguientes:

$$
\begin{aligned}
& \text { (1) } C_{u}(t)=C_{u}(o)(l+e)^{t} \quad y \\
& \text { (2) } U=\frac{C_{u}}{1+C_{u}}
\end{aligned}
$$

en las cuales, para la unidad territorial considerada, $t$ es la variable tiempo, $\varrho$ es la tasa hiperbólica de urbanización, $C_{u}$ es el coeficiente de urbanización, o relación entre la población urbana y la rural, y $U$ es el grado de urbanización, o relación entre la población urbana y la total.

Además, existe entre las tasas anuales de crecimiento demográfico de los espacios urbano y rural $\left(\begin{array}{lll}r_{u} & \text { y } & r_{r}\end{array}\right)$ y la tasa hiperbólica de urbanización ( $e$ ) la relación fundamental siguiente:

$$
\text { (3) } r_{u}=r_{r}+\varrho
$$

que permite ligar los dos espacios en su dinámica.

b) El modelo

El análisis de la dinámica poblacional 1961-1990 ha sido llevado mediante la aplicación de la metodología de los balances demográficos en un modelo general, que luego ha sido perfeccionado utilizando un 
modelo auxiliar basado en las tasas hiperbólicas de urbanización. El esquema del modelo general figura en el gráfico 3 y el del modelo auxiliar en el gŕafico 4 .

Gráfico 3

PERU: LOS CAMBIOS FUNDAMENTALES EN LA OCUPACION DEL ESPACIO ECONOMICO

Esquema metodológico para el estudio de las migraciones I. esquema

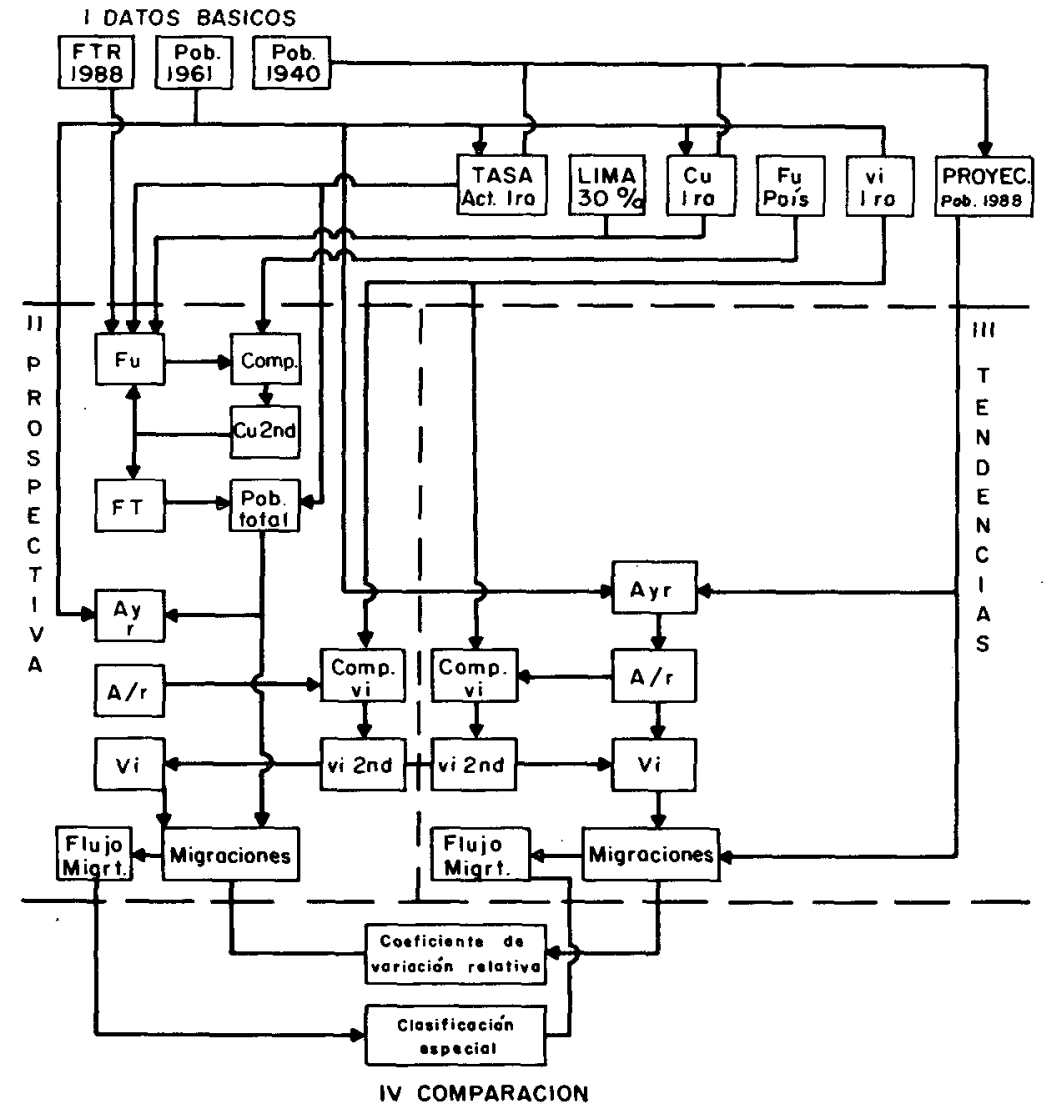

Fuente: Véase llamada 28/, página. 238. 
Gráfico 3 (continuación)

Nomenclatura del gráfico

DATOS BASICOS

FTR $1988 \ldots \ldots \ldots \ldots \ldots$ Fuerza de Trabajo Rural, 1988

Pob. $1961 \ldots \ldots \ldots \ldots \ldots$ Censo de Población, 1961

Pob. 1940 ............. Censo de Población, 1940

Tasa Act. 1ra. .......... Tasa de Actividad, primera aproximación

LIMA $30 \%$. ........... Relación de Población Lima/País

$C_{u}$ 1ra. .............. Relación Población Urbana/Población Rural,

$v_{i}$ lra. .............. primera aproximación

$v_{i}$ lra. ............... Tasa de crecimiento vegetativo, primera

Proyec. Pob. $1988 \ldots \ldots \ldots$. Proyección de la población, 1988

$F_{u}$ País $\ldots \ldots \ldots \ldots \ldots \ldots$ Fuerza de trabajo urbana del país

II PROSPECTIVA

$F_{u} \ldots \ldots \ldots \ldots \ldots \ldots$ Fuerza de Trabajo Urbana

FT $\ldots \ldots \ldots \ldots \ldots \ldots \ldots$ Fuerza de Trabajo Total

A y $\mathrm{r} \ldots \ldots \ldots \ldots \ldots \ldots$. Aumento absoluto de Población 1961-1988 y

Tasa de crecimiento demográfico

A/r ............... Relación: Aumento Absoluto de Población

1961-1988 a Tasa de crecimiento demográfico

$V_{i} \ldots \ldots \ldots \ldots \ldots$ Aumento vegetativo de la población en valor absoluto para el período 1961-1982

Comp ............. Compatibilización

$C_{s}$ 2nd $\ldots \ldots \ldots \ldots \ldots \ldots$ Coeficiente de Población Urbana/Población Rural, segunda aproximación

Flujo migrat Flujo migratorio

III TENDENCIAS

Idem que los anteriores

Gráfico 4

\section{PERU: LOS CAMBIOS FUNDAMENTALES EN LA OCUPACION DEL ESPACIO ECONOMICO}

Esquema metodológico auxiliar

Este esquema metodológico auxiliar completa el esquema del gráfico 3 y modifica el modelo en lo que se refiere al cálculo de los coeficientes de urbanización $C_{u}$. (lra y 2da).

1) Notaciones

$\begin{array}{ll}P_{r} & \text { población rural real, o normativa } \\ \boldsymbol{P}_{u} & \text { población urbana } \\ C_{u} & \text { coeficiente de urbanización } \\ r & \text { tasa de crecimiento demográfico nural } \\ \rho^{\prime} & \text { tasa hiperbólica de urbanización ( } 1^{\mathrm{a}} \text { y } 2^{\mathrm{a}} \text { aproximación) } \\ \boldsymbol{P}_{r} & \text { población rural según tendencias } \\ \Rightarrow & \text { aplicación al modelo general en el lugar del " } C_{u} \text { 2nd". }\end{array}$

2) Modelo

(Continúa) 


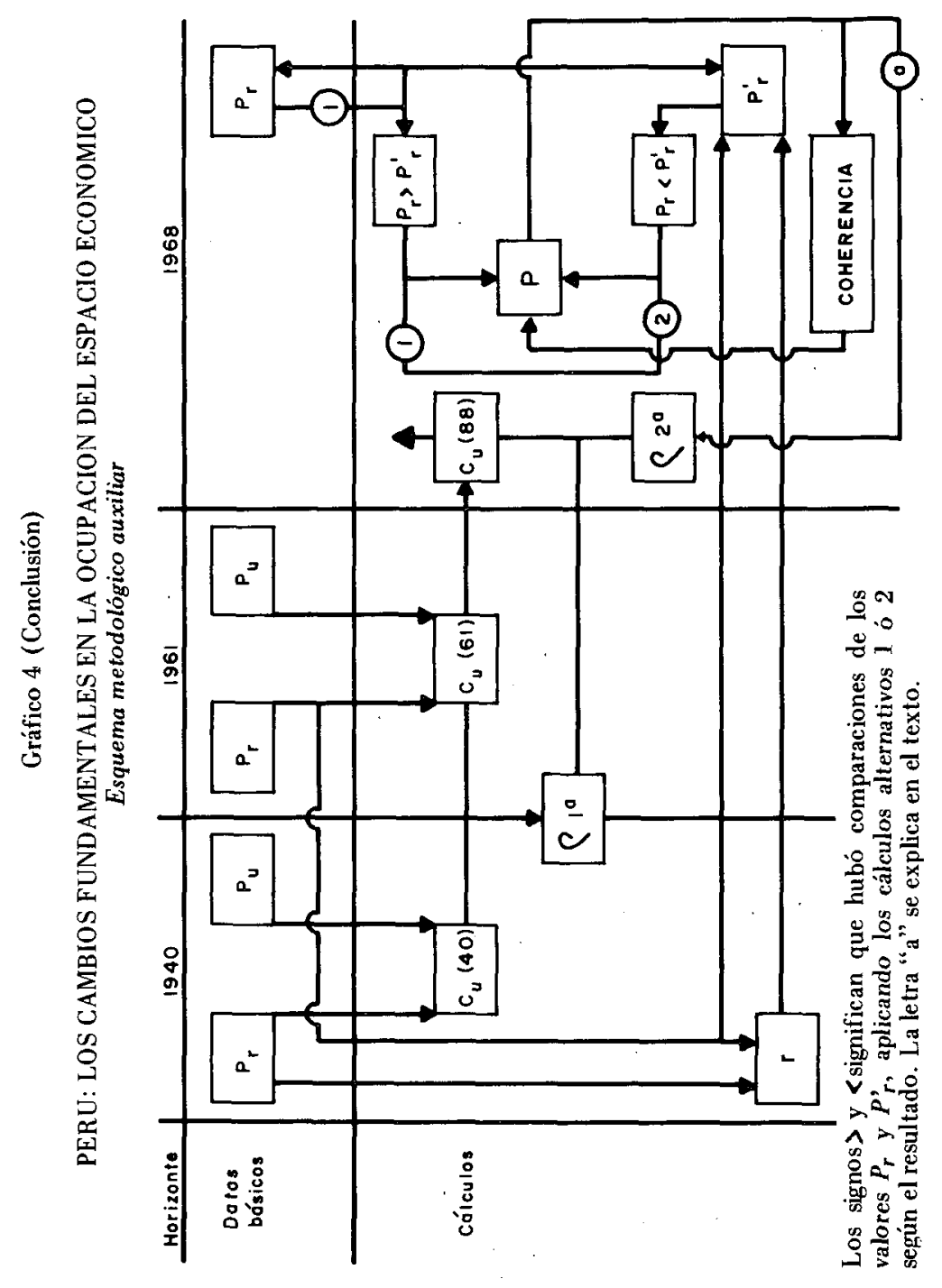




\section{PRINCIPIO DEL MODELO GENERAL}

Basado en las matrices de las unidades territoriales de análisis, el modelo parte de una triple serie de "datos básicos": i) los impuestos (fuerza de trabajo rural 1988, censos 1940 y 1961); ii) los datos e hipótesis fundamentales (peso poblacional de Lima, fuerza urbana de trabajo del país, proyección pasiva 1988 de la población), y iii) las hipótesis de primera aproximación (tasas de actividad, relaciones urbano-rurales, tasas de crecimiento vegetativo), que el modelo permite ajustar por aproximaciones sucesivas.

A partir de estos datos básicos, el modelo se desarrolla en dos ópticas paralelas: i) tendencia y ii) prospectiva, cuya comparación final conduce a la clasificación de las distintas unidades territoriales según la naturaleza y magnitud de sus movimientos migratorios.

En su aplicación práctica, el modelo sigue los sucesivos pasos siguientes: i) determinación de las migraciones (tasas y valores absolutos) para la imagen prospectiva, con los pasos intermedios: $F_{u}$, $F T$, población total, $A$ y $r$, compatibilidad, $C_{u}$, rectificaciones eventuales, $A / r$, compatibilidad $v_{i}, V_{i}$ y migraciones; ii) determinación de las migraciones (tasas y valores absolutos) según tendencias, con los pasos intermedios: $A$ y $r, A / r$, compatibilidad $v_{i}, V_{i}$ y migraciones, y iii) comparación de las migraciones según imagen normativa $y$ tendencias para caracterizar los procesos -migratorios prospectivos en cada unidad territorial y clasificarlos.

Es muy importante señalar las distintas "reacciones" que existen en este modelo y que actúan sobre los supuestos a corregir por aproximaciones sucesivas, mediante los estudios de coherencia y compatibilidad.

\section{PRINCIPIO DEL MODELO AUXILIAR}

Este modelo (véase gráfico 4) permite reemplazar las estimaciones de los diversos coeficientes de urbanización $C_{\boldsymbol{u}}$, hechas en forma subjetiva en la aplicación del modelo general, por cálculos prospectivos más rigurosos.

A partir de las situaciones 1940 y 1960 , se calculan el coeficiente prospectivo de urbanización y la población rural según tendencias para el año 1988. A esta altura, los estudios de coherencia al nivel del país han demostrado la necesidad de adoptar nuevos supuestos, para proseguir la aplicación del modelo, relativo a las estructuras urbano-rurales a promover. El primer supuesto deriva de la comparación de los valores normativos y pasivos de la población rural 1988: cuando la población normativa ha sido superior a la pasiva (efecto de colonización o disminución de las migraciones pasivas), se calculó la población urbana normativa a partir de la rural normativa, conservando 

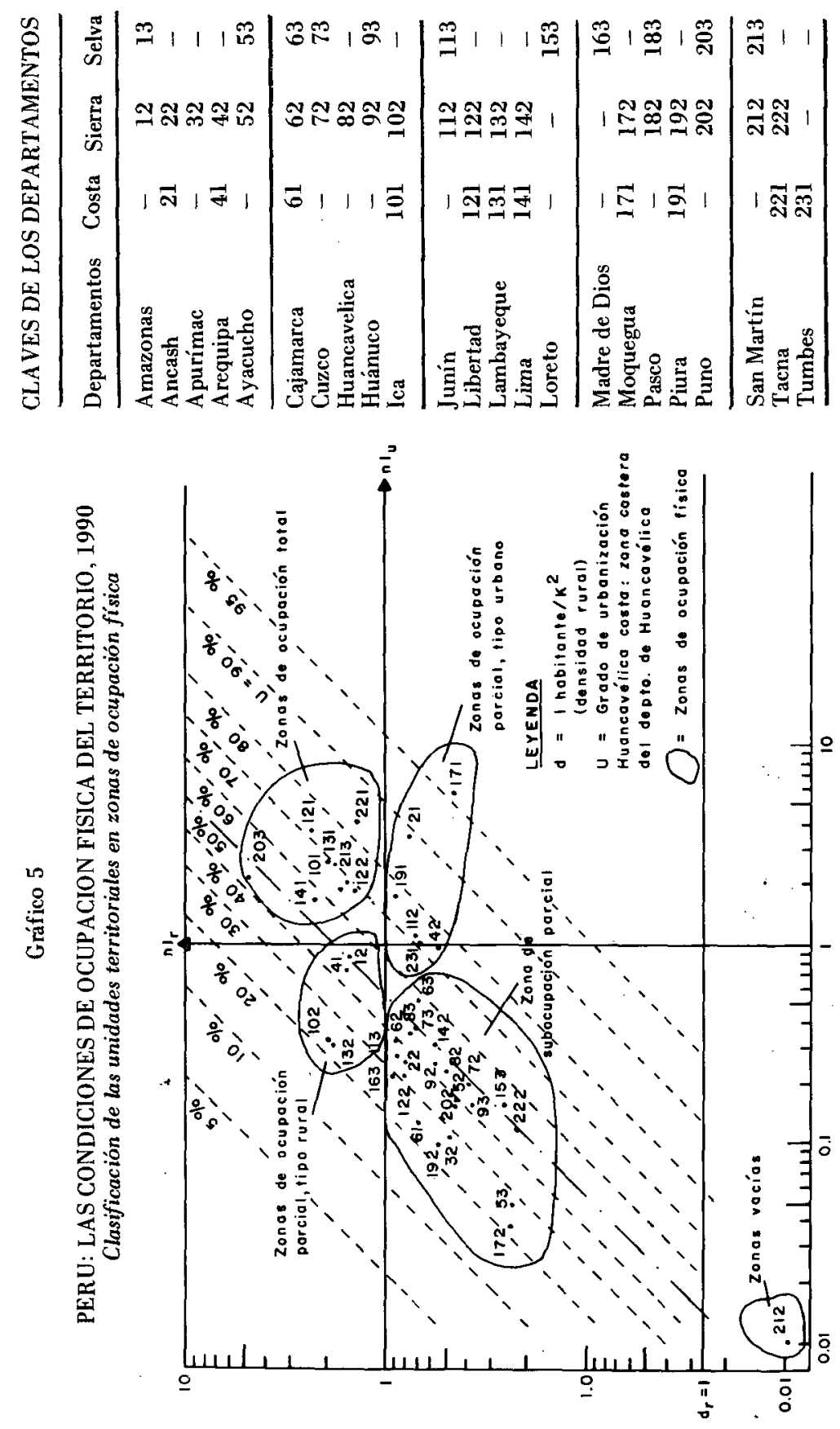
así sin modificaciones el fenómeno de urbanización observado; pero en caso contrario (redistribución de la población por aumento de las migraciones rurales), se calculó la población urbana normativa con la población rural pasiva, mejorando así en forma implícita el coeficiente de urbanización y por ende, las estructuras urbano-rurales de la unidad territorial. El segundo supuesto se refiere a las unidades territoriales que poseían una tasa negativa de urbanización 1940-1960, y consistió en calcular la población urbana normativa con el coeficiente de urbanización observado en $\mathbb{1 9 4 0}$ (recuperación de la situación perdida).

El cálculo de las poblaciones urbanas normativas según el modelo auxiliar permite aplicar, después de haber efectuado la coherencia nacional, los coeficientes definitivos de urbanización al modelo general y según la aplicación de este último (camino "a" del modelo auxiliar). Además, la aplicación del modelo auxiliar en las 42 unidades territoriales de análisis de las condiciones de ocupación física permitió obtener una mejor visión de los cambios futuros en el espacio urbano, por interesar unidades más homogéneas.

\section{Los resultados}

Tal como se lo presentía de antemano, las opciones estratégicas adoptadas conducen, en el largo plazo, a una modificación completa de los patrones vigentes en la distribución territorial de la población, a grandes migraciones de todo tipo y a una nueva repartición de los flujos migratorios, internos y externos a las distintas regiones. De ahi, la necesidad de prever, en el futuro, un conjunto de nuevas políticas, que permitan orientar adecuadamente estas migraciones y promover la debida organización espacial del territorio.

a) Los futuros cambios en la condición de ocupación física del territorio (1990)

Conociendo las poblaciones prospectivas de las distintas unidades territoriales de análisis, para el horizonte 1990 , en los espacios urbano y rural, se puede aplicar la metodología, antes señalada, para conocer las futuras condiciones de ocupación física del territorio. La tabla 9, indica los valores normativos de las futuras poblaciones y la tabla 10 entrega los valores de los indicadores de ocupación, que permiten clasificar las distintas unidades territoriales en las 5 zonas de ocupación física, mediante el gráfico 5. La comparación de estas nuevas condiciones con las vigentes en 1961 permite conocer los cambios a promover en el largo plazo. 


\section{NUEVAS CONDICIONES DE OCUPACION FISICA DEL TERRITORIO}

En síntesis, las nuevas condiciones globales y estructurales de ocupación física del territorio serán las siguientes:

i) El Gran Lima concentrará el 28 por ciento de la población total del país y un poco más del 40 por ciento de la población urbana nacional.

ii) Las importancias porcentuales de la población de las 3 zonas geográficas, con respecto al país, serán en números redondos:

Cuadro 4

PERU: NUEVAS CONDICIONES DE OCUPACION FISICA DEL TERRITORIO

\begin{tabular}{lccc}
\hline Con respecto al país & Costa & Sierra & Selva \\
\hline Población total con Lima & 52 & 28 & 20 \\
sin Lima & 24 & & \\
$\begin{array}{c}\text { Población urbana con Lima } \\
\text { sin Lima }\end{array}$ & 65 & 21 & 14 \\
Población rural & 24 & & \\
\hline
\end{tabular}

iii) Los indicadores de ocupación física para el país, sin tomar en cuenta el gran Lima serian:

grado de heterogeneidad del espacio urbano $\quad=0,45$

grado de heterogeneidad del espacio rural $\quad=0,61$

coeficiente urbano-rural de heterogeneidad $=1,75$

iv) Las importancias porcentuales de las tres zonas de ocupación física, y de sus respectivas subzonas, con respecto al país, serán las que figuran en el cuadro 5 .

Cabe aclarar que en el cuadro 5 , las importancias porcentuales de las subzonas son expresadas con respecto a la zona correspondiente y que los grados relativos de concentración corresponden a la sumatoria de los indicadores de ocupación física.

v) Las importancias porcentuales de las zonas y subzonas de ocupación física en cada una de las 3 zonas geográficas, en 1990, figura en la tabla 11, siguiendo los criterios adoptados en el cuadro 5, de resultados al nivel del país.

La tipificación de las condiciones globales, en cada zona de ocupación física, se realizó con los criterios adoptados para las condiciones 1961, y presentará los caracteres siguientes en 1990: 


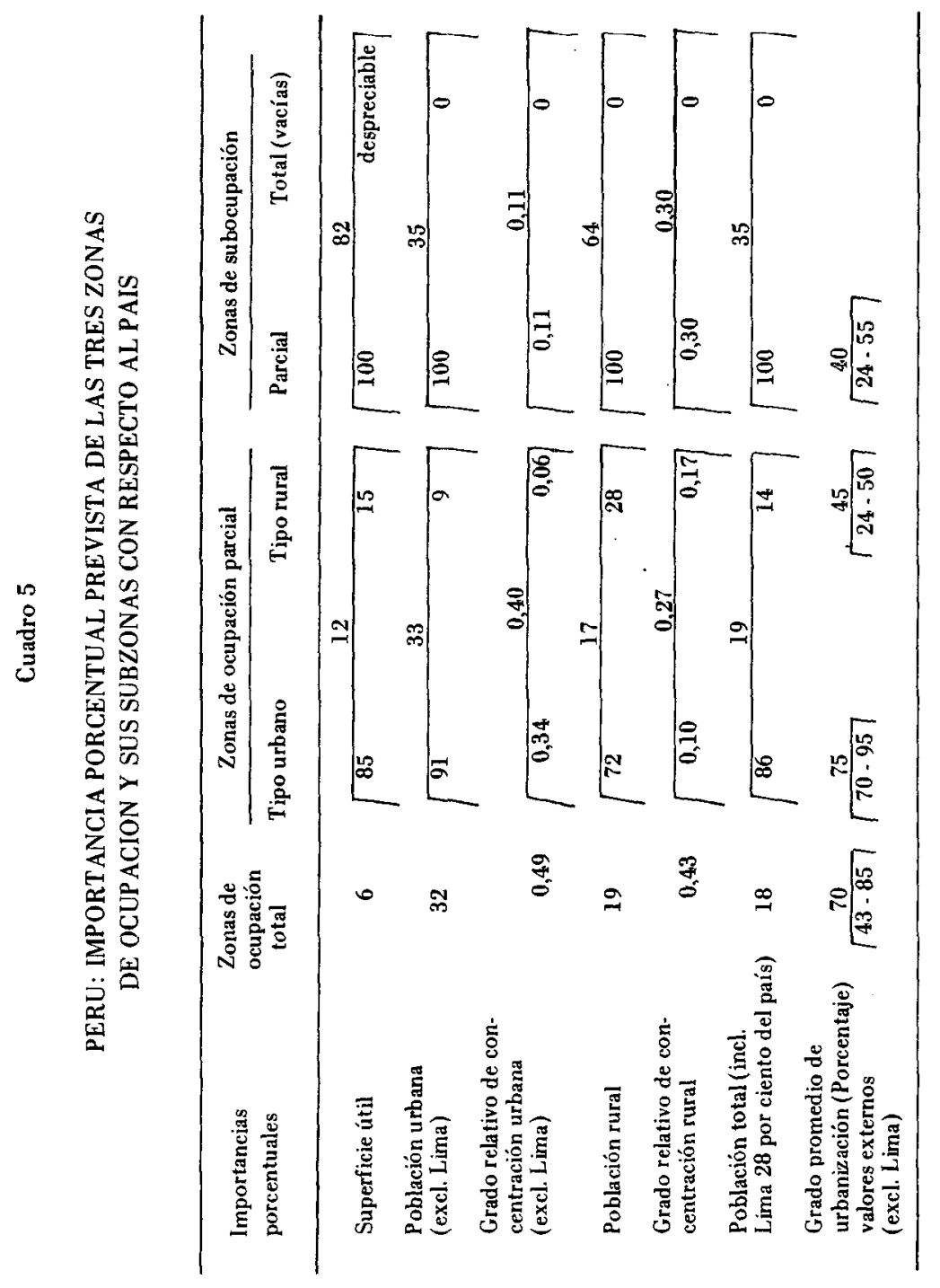


i) La tabla 12 del anexo indica las densidades territoriales en el espacio rural, que agrupa la población en centros de menos de 2000 habitantes.

ii) Para el país, la estructura nacional de los centros poblados del espacio urbano será la que se indica en el cuadro 6.

El gráfico 2 visualiza estas estructuras nacionales.

iii) Las modalidades de agrupación de la población urbana por zonas geográficas y zonas de ocupación física, utilizando las mismas clases de tamaño, figuran en la tahla 13 del anexo y merecen las mismas observaciones que las indicadas en el ii) anterior.

\section{LOS FUTUROS CAMBIOS}

Si se comparan las condiciones globales de ocupación física del territorio y sus caracteres específicos, vigentes en 1961 y las previstas para $1990,31 /$ se notan los grandes cambios que habrá que promover en todo el espacio nacional para satisfacer las opciones estratégicas adoptadas.

En síntesis, estos cambios son los siguientes:

i) Si bien la población del Gran Lima aumenta su importancia, con respecto a la población total del pais, en un 50 por ciento (fenómeno de metropolización que no se puede parar rápidamente), ésta no sobrepasa el 30 por ciento fijado, y más aún, su importancia en el espacio urbano no se modifica prácticamente.

ii) Al nivel de las tres zonas geográficas, se mejoran notablemente las estructuras urbano-rurales, en particular en la Sierra (descongestión poblacional) y en la Selva (colonización).

iii) Al nivel del pais los cambios son menos sensibles, salvo para el coeficiente urbano-rural de heterogeneidad que traduce las mejoras en las estructuras urbano-rurales. La heterogeneidad en los espacios urbano y rural no se puede corregir en forma sustancial por razones naturales (potencialidades de las tierras) y demográficas (subpoblación).

iv) Se observan notables cambios y mejores estructuras al nivel de las zonas de ocupación física del territorio y de las zonas geográficas.

v) El gráfico 2, que refleja las modalidades nacionales de agrupación de la población en el espacio urbano, indica también las mejoras prevista, pero deja entrever todavía algunos desequilibrios que los próximos estudios deberán corregir.

En dicho gráfico se ha diseñado, a título ilustrativo, la curva de las estructuras pasivas, en la hipótesis de un crecimiento demográfico parejo de todos los centros poblados (crecimiento del pais) y se han

31/Para 1961, véanse los cuadros 1,2 y 3 , las tablas 3, 4 y 5 del anexo, así como los gráficos 1 y 2 . Para 1990 ver los cuadros 4,5 y 6 , las tablas 11,12 y 13 del anexo, asi como los gráficos 2 y 5 . 
Cuadro 6

PERU: MODALIDADES DE AGRUPACION DE LA POBLACION URBANA AL NIVEL NACIONAL. 1990

\begin{tabular}{|c|c|c|c|c|c|}
\hline \multirow{2}{*}{$\begin{array}{l}\text { Categorías de } \\
\text { centros (grupos } \\
\text { y clases } \\
\text { por tamaño) }\end{array}$} & \multirow[b]{2}{*}{$\begin{array}{l}\text { Tamaños } \\
\text { extremos }\end{array}$} & \multicolumn{4}{|c|}{ Caracteristicas estructurales } \\
\hline & & $\begin{array}{l}\text { Número } \\
\text { por clase }\end{array}$ & $\begin{array}{c}\text { Tamaño } \\
\text { promedio } \\
\underline{a} /\end{array}$ & $\begin{array}{l}\text { Población } \\
\text { por clase } \\
\text { b] }\end{array}$ & $\begin{array}{l}\text { Importan } \\
\text { cia por- } \\
\text { centual }\end{array}$ \\
\hline \multicolumn{6}{|l|}{$\begin{array}{l}\text { 1) Intermedios } \\
(2000-24000)\end{array}$} \\
\hline $\begin{array}{l}\text { muy pequeños } \\
\text { pequeños } \\
\text { medianos } \\
\text { grandes }\end{array}$ & $\begin{array}{rr}2000- & 4600 \\
5000- & 8000 \\
9500- & 15000 \\
16000- & 24000\end{array}$ & $\begin{array}{c}\text { desconocido } \\
7 \\
33 \\
34\end{array}$ & $\begin{array}{l}3300 \mathrm{c} / \\
6500 \\
12000 \\
20000\end{array}$ & $\begin{array}{c}2508000 d] \\
44000 \\
396000 \\
680000\end{array}$ & $\begin{array}{r}15,0 \\
0,3 \\
2,4 \\
4,3\end{array}$ \\
\hline \multicolumn{6}{|c|}{$\begin{array}{l}\text { 2) Urbanos } \\
(28000-750000)\end{array}$} \\
\hline $\begin{array}{l}\text { muy pequeños } \\
\text { pequeños } \\
\text { medianos } \\
\text { grandes } \\
\text { muy grandes }\end{array}$ & $\begin{array}{r}28000-50000 \\
55000-100000 \\
110000-190000 \\
240000-400000 \\
750000\end{array}$ & $\begin{array}{r}20 \\
20 \\
10 \\
5 \\
1\end{array}$ & $\begin{array}{r}40000 \\
75000 \\
140000 \\
330000 \\
750000\end{array}$ & $\begin{array}{r}797000 \\
1400000 \\
1430000 \\
1620000 \\
750000\end{array}$ & $\begin{array}{r}5,0 \\
8,5 \\
9,0 \\
10,0 \\
4,5\end{array}$ \\
\hline $\begin{array}{l}\text { 3) Metropolitano } \\
\text { (Lima - Callao) }\end{array}$ & 6693000 & 1 & 6693000 & 6693000 & 41,0 \\
\hline Totales & & $\begin{array}{c}131 \mathrm{de} \\
5000 \text { y más }\end{array}$ & & 16318000 & 100,0 \\
\hline
\end{tabular}

a Calculado por división de la población de la clase por el número de centros de la clase, y luego redondeado.

b/ Calculado a partir de los tamaños y números de los centros previstos en cada clase.

c) Aproximadamente corresponde a la mediana de la clase.

d/ Calculado por diferencia entre la población urbana del país y la de los centros de 5000 y más habitantes.

indicado los tamaños de las localidades para las cuales se prevé una agudización del fenómeno de urbanización (zonas rayadas).

b) Las migraciones y los flujos migratorios

La aplicación del modelo general al nivel de las distintas regiones permite cuantificar las migraciones 1961-1990 en cada una de ellas y, mediante una serie de supuestos, determinar los posibles flujos migratorios. La comparación de los resultados de là imagen normativa y de la imagen según tendencias da una idea de la magnitud y diversidad de estos fenómenos.

\section{MIGR ACIONES 1961-1990}

La tabla 14 del anexo indica los saldos migratorios netos en los espacios urbano y rural de las distintas regiones, según las tendencias y en prospectiva. Naturalmente el saldo migratorio neto al nivel del país es 
nulo (hipótesis fundamental del modelo), pero la magnitud de los movimientos migratorios es grande, pues el saldo neto representa 19 por ciento del aumento vegetativo (o demográfico) del país, en el largo plazo, según las tendencias y 23 por ciento en la prospectiva, en números redondos. Eso significa que, al nivel del país durante el largo plazo, una persona de cada cuatro se desplazará o deberá ser desplazada. $\underline{32}$ / Además, se ve que las opciones estratégicas han reforzado las tendencias migratorias, pero que las migraciones están orientadas hacia una mejor ocupación física del territorio, (colonización de la Selva en detrimento beneficioso de la Costa y sobre todo de la Selva).

Es interesante comparar la magnitud de las migraciones según tendencias y prospectivas. Los coeficientes regionales de variación relativa porcentual de las migraciones (prospectiva - tendencia) son los siguientes:

tendencia

\begin{tabular}{|c|c|c|c|c|c|c|}
\hline \multirow{2}{*}{\multicolumn{2}{|c|}{$\begin{array}{l}\text { Regiones } \\
\text { geográficas }\end{array}$}} & \multicolumn{5}{|c|}{ Regiones de planificación } \\
\hline & & \multirow{2}{*}{$\begin{array}{r}\text { Norte } \\
\begin{array}{r}-8 \\
+40\end{array}\end{array}$} & \multirow{2}{*}{$\begin{array}{c}\begin{array}{c}\text { Centro } \\
\text { (salvo Lima) }\end{array} \\
+220 \\
+24\end{array}$} & \multirow{2}{*}{$\begin{array}{c}\text { Lima } \\
-\mathbf{3 3} \\
-\end{array}$} & \multirow{2}{*}{$\begin{array}{c}\text { Sur } \\
-\begin{array}{r}2800 \mathrm{a} / \\
-330 \mathrm{a} /\end{array}\end{array}$} & \multirow{2}{*}{ Oriente } \\
\hline Costa & $\begin{array}{l}\text { Urbano } \\
\text { Rural }\end{array}$ & & & & & \\
\hline Sierra & $\begin{array}{l}\text { Urbano } \\
\text { Rural }\end{array}$ & $\begin{array}{r}-33 \\
+260\end{array}$ & $\begin{array}{r}+160 \\
+70\end{array}$ & & $\begin{array}{r}.80 \\
+14\end{array}$ & \\
\hline Selva & $\begin{array}{l}\text { Urbano } \\
\text { Rural }\end{array}$ & $\begin{array}{l}+550 \\
-1500 \mathrm{a} /\end{array}$ & $\begin{array}{l}+370 \\
-600 a /\end{array}$ & & $\begin{array}{l}+1200 \\
-1200 \mathrm{a}\end{array}$ & $\begin{array}{r}+120 \\
+15\end{array}$ \\
\hline
\end{tabular}

a/ Unidad donde se invierte el sentido migratorio pasivo.

\section{FLUJOS MIGRATORIOS 1961-1990}

Si bien era interesante disponer de una visión territorial de las migraciones (localización y magnitud), lo era aún más conocer los posibles flujos migratorios espaciales, intra e interregionales. Para eso se tuvo que formular una serie de supuestos que permiten efectuar las debidas compensaciones migratorias. Es evidente que los flujos obtenidos dependerán en gran medida de los supuestos, pero no se debe olvidar que se trata de una prospectiva que las políticas a promover deberán satisfacer.

32/ En realidad los movimientos serán aún más importantes si se toman en cuenta las migraciones intrarregionales entre espacios urbano y rural. 
Los supuestos adoptados tienden esencialmente a minimizar los costos de traslado de los migrantes y los problemas socio-económicos planteados (en particular los problemas psico-sociales), han sido los siguientes:

i) En primer lugar, satisfacción de la demanda del espacio urbano de una región a partir de los emigrantes rurales de la misma.

ii) Luego, satisfacción de la demanda del espacio urbano de una región no satisfecha por la primera norma, con migrantes de origen preferentemente urbano.

ii) Reducción al máximo de las distancias de migración interregional.

Los gráficos 6 y 7 resumen la magnitud de las migraciones y visualizan los flujos migratorios en todo el espacio nacional, según tendencias y según la prospectiva. Su examen comparativo no necesita comentarios y demuestra, en síntesis, los grandes cambios a promover, en el largo plazo.

\section{c) Las futuras políticas a promover}

Es evidente que los grandes cambios a promover en la ocupación del espacio nacional requerirán la adopción de políticas específicas, cuidadosamente planificadas $\mathrm{e}$ instrumentadas, que los resultados anteriores permiten jerarquizar y precisar a grandes rasgos.

\section{CLASIFICACION ESPACIAL}

El modelo general utilizado (véase gráfico 3) conduce en definitiva a la siguiente clasificación espacial del país, que está basada en la naturaleza de las migraciones y de los flujos migratorios previstos.

i) Areas receptoras de población según tendencias, que se subdividen en:

áreas donde los flujos migratorios tradicionales deben ser disminuidos:

áreas donde los flujos migratorios tradicionales deben ser intensificados.

ii) Areas emisoras de población según tendencias, que se subdividen en:

áreas donde el sentido tradicional de los flujos migratorios debe ser invertido;

áreas donde los flujos migratorios tradicionales deben ser disminuidos:

áreas donde los flujos migratorios tradicionales deben ser intensificados. 
Gráfico 6

PERU; LOS CAMBIOS FUNDAMENTALES EN LA OCUPACION

DEL ESPACIO

Migraciones y flujos migratorios por regiones, según tendencias $1961-1988$

(Miles de habitantes)

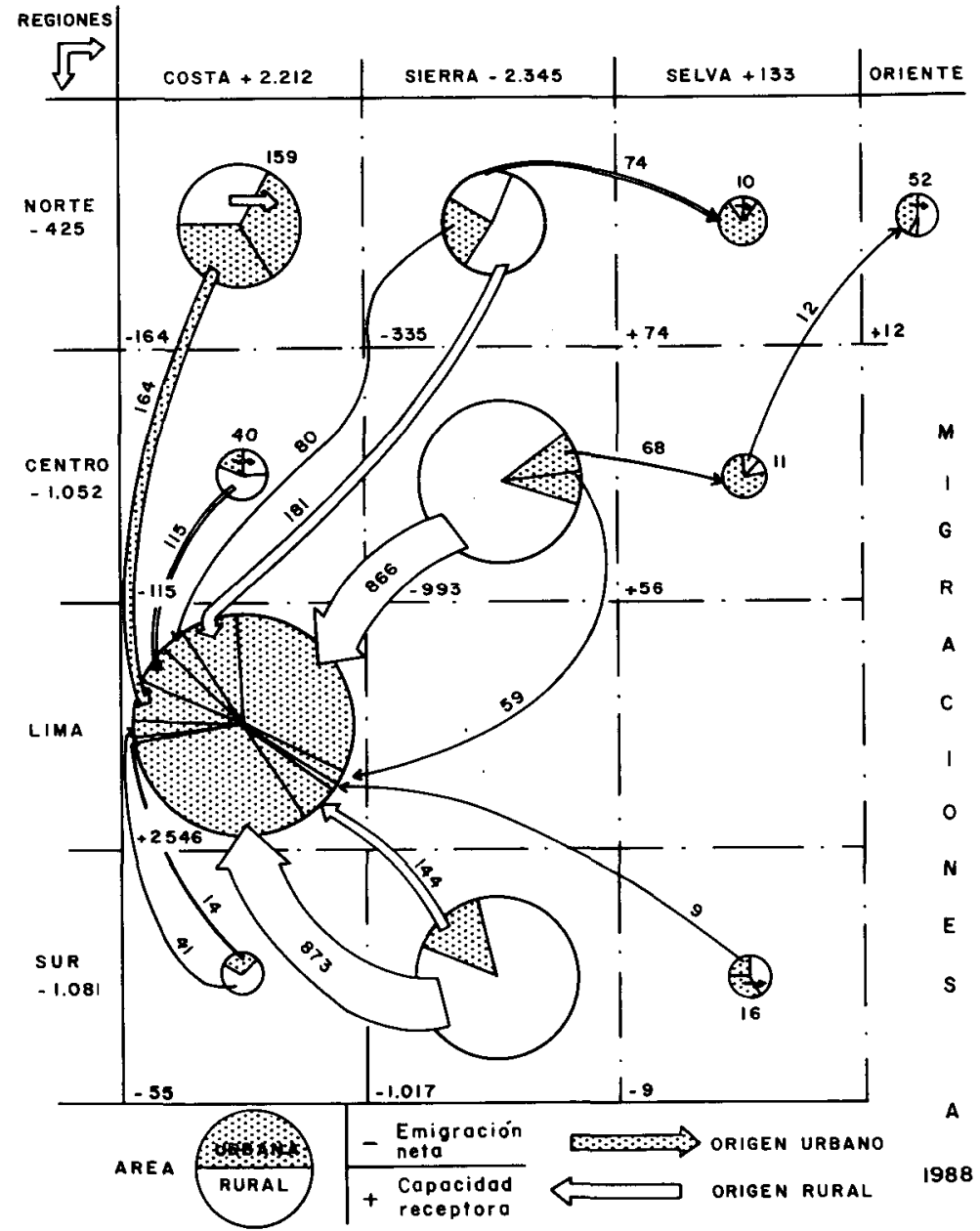

Fuente: Los cambios fundamentales en la ocupación del espacio económico, Instituto Nacional de Planificación y Oficina Nacional de Evaluación de Recursos Naturales, Lima, octubre de 1970. Documento no oficial. 
Gráfico 7

PERU: LOS CAMBIOS FUNDAMENTALES EN LA OCUPACION

DEL ESPACIO

Migraciones y flujos migratorios por regiones, según prospectiva $1961-1988$

(Miles de habitantes)

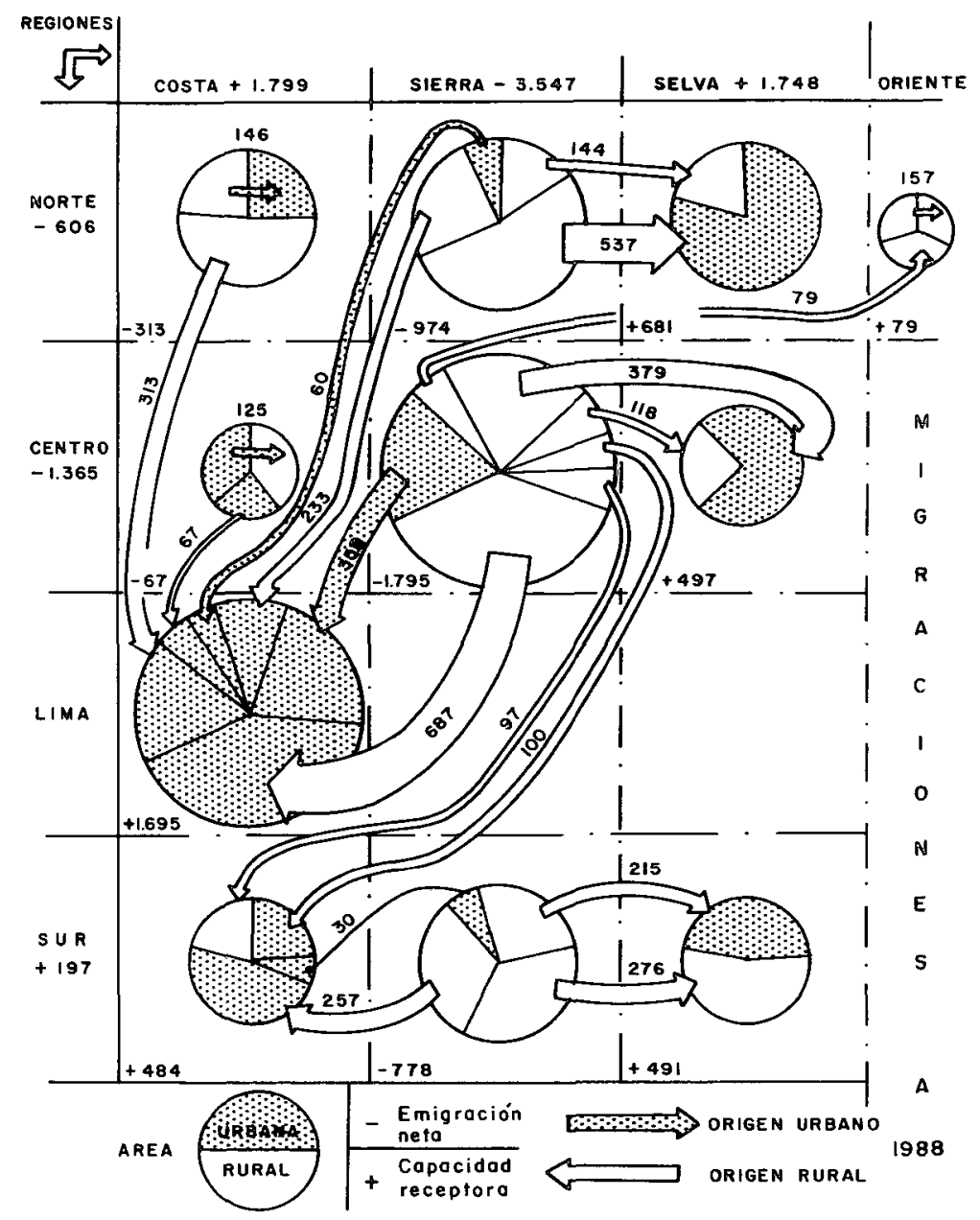

Fuente: Los cambios fundamentales en la ocupación del espacio económico, Instituto Nacional de Planificación y Oficina Nacional de Evaluación de Recursos Naturales, Lima, octubre de 1970. Documento no oficial. 


\section{POLITICAS A PROMOVER}

Si se toman en cuenta las variaciones relativas de los flujos migratorios según tendencias y prospectivas y las importancias poblacionales de las distintas regiones, en el marco de la clasificación anterior, se puede jerarquizar las regiones en función de la complejidad de las políticas a promover y de los grados de urgencia de su aplicación en el largo plazo. Por orden decreciente de la magnitud de los problemas migratorios a afrontar, las áreas se clasifican así:

i) Areas emisoras de población según tendencias, cuyos flujos emigratorios tradicionales deben invertirse para convertirlas en áreas recep toras;

ii) Areas receptoras de población según tendencias, cuyos flujos inmigratorios tradicionales deben ser aumentados;

iii) Areas emisoras de población según tendencias, cuyos flujos emigratorios tradicionales deben ser aumentados;

iv) Areas emisoras de población según tendencias, cuyos flujos emigratorios tradicionales deben ser frenados;

v) Areas receptoras de población según tendencias, cuyos flujos inmigratorios tradicionales deben ser frenados.

Las políticas a promover están siendo estudiadas detenidamente por el Instituto Nacional de Planificación, tanto en la perspectiva del largo plazo como para el mediano. Son políticas muy complejas que deberán no solamente interesar a los movimientos migratorios, sino también promover la integración de los migrantes a sus nuevos ambientes y la satisfacción de sus legítimas necesidades y aspiraciones. 


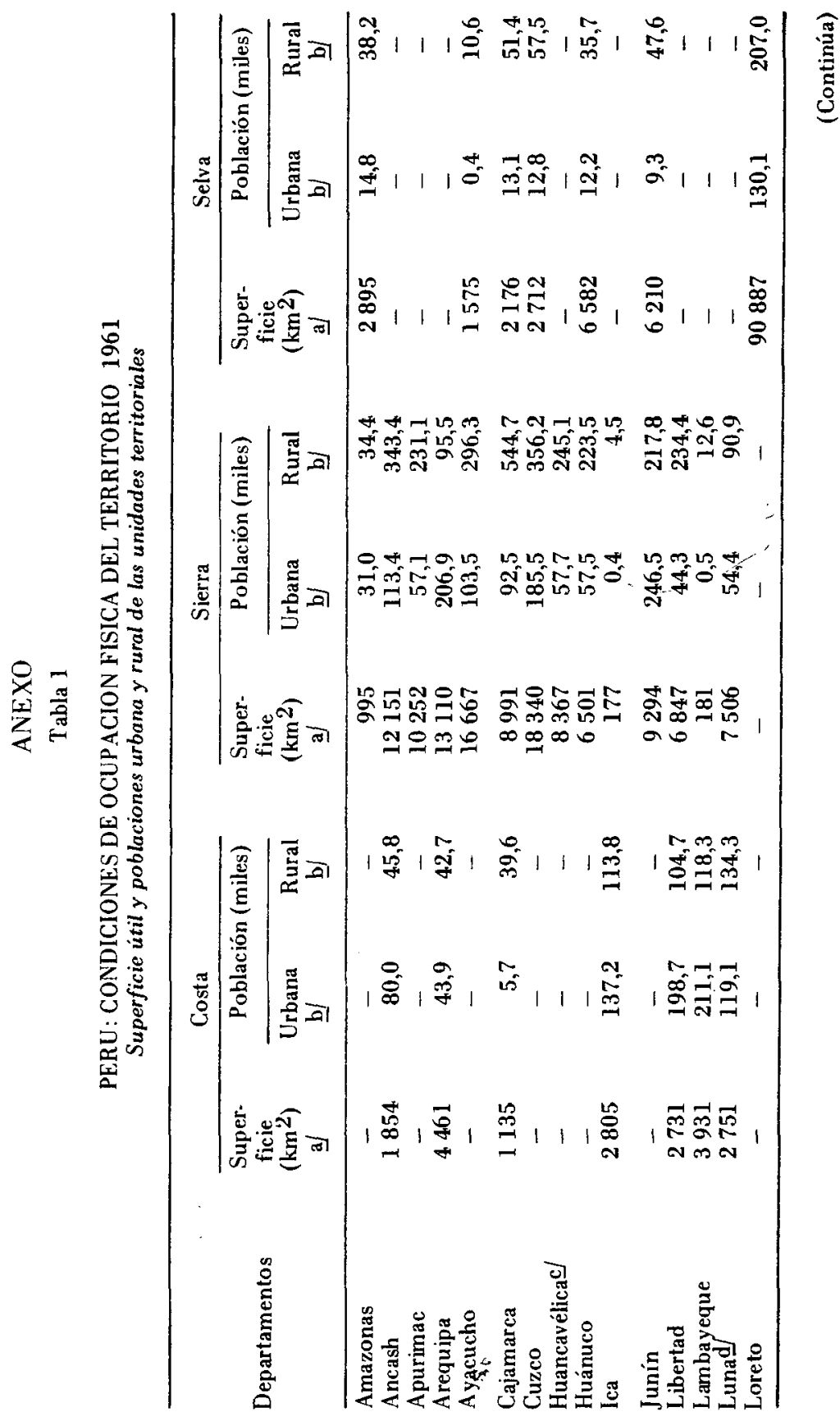




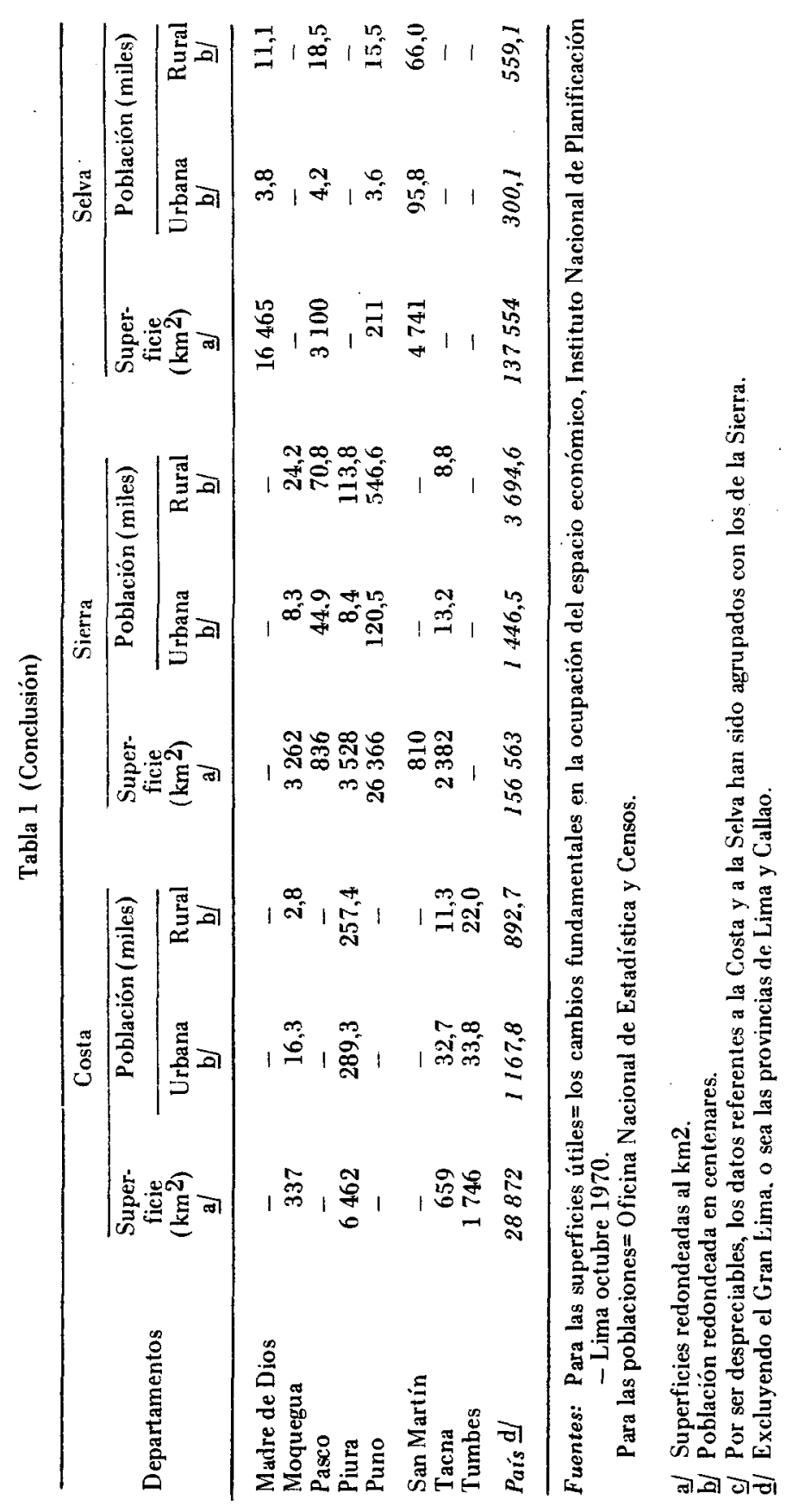


Tabla 2

PERU: CONDICIONES DE OCUPACION FISICA DEL TERRITORIO, 1961

Valores de los indicadores semejantes de ocupación urbana $y$ rural de las unidades territoriales $\mathrm{a}$

\begin{tabular}{|c|c|c|c|c|c|c|}
\hline \multirow{2}{*}{ Departamentos } & \multicolumn{2}{|c|}{ Costa } & \multicolumn{2}{|c|}{ Sierra } & \multicolumn{2}{|c|}{ Selva } \\
\hline & $\begin{array}{l}n I_{u} \\
\underline{\mathrm{b}} /\end{array}$ & $\begin{array}{l}n I_{r} \\
\underline{b}\end{array}$ & $n I_{u}$ & $n I_{r}$ & $n I_{u}$ & $n I_{r}$ \\
\hline Amazonas & - & - & 1,8 & $\overline{1,4}$ & 0,3 & 0,55 \\
\hline Ancash & 2,5 & 1,0 & 0,55 & 1,1 & - & - \\
\hline Apurimac & - & - & $\mathbf{0 , 3 3}$ & 0,9 & - & - \\
\hline Arequipa & 0,6 & 0,37 & 0,95 & 0,3 & - & - \\
\hline Ayacucho & - & - & 0,37 & 0.7 & 0,02 & 0,28 \\
\hline Cajamarea & 0,3 & 1,0 & 0,6 & 2,4 & 0,35 & 0,95 \\
\hline Cuzco & - & - & 0,6 & 0,8 & 0,28 & 0,85 \\
\hline Huancavélica & - & - & 0,4 & 1,2 & - & - \\
\hline Huánuco & - & - & 0,5 & 1,4 & 0,11 & 0,22 \\
\hline Ica & 2,8 & 1,6 & 0,13 & 1,0 & - & - \\
\hline Junín & - & - & 1,6 & 0,95 & 0,09 & 0,3 \\
\hline Libertad & 4,3 & 1,5 & 0,37 & 1,4 & - & - \\
\hline Lambayeque & 3,3 & 1,6 & 0,17 & 2,8 & - & - \\
\hline Luna & 2,5 & 2,0 & 0,43 & 0,5 & - & - \\
\hline Loreto & - & - & - & - & 0,08 & 0,09 \\
\hline Madre de Dios & - & - & - & - & 0,01 & 0,03 \\
\hline Moquegua & 2,8 & 0,33 & 0,15 & 0,3 & - & - \\
\hline Pasco & - & - & 3,3 & 3,3 & 0,08 & 0,24 \\
\hline Piura & 2,6 & 1,6 & 0,14 & 1,3 & - & - \\
\hline Puno & - & - & 0,28 & 0,85 & 1,0 & $\mathbf{3 , 0}$ \\
\hline San Martín & - & - & 0,0 & 0,0 & 1,2 & 0,55 \\
\hline Tacua & 3,0 & 0,7 & 0,33 & 0,15 & - & - \\
\hline Tumbes & 1,1 & 0,5 & - & - & - & - \\
\hline Totalc/ & 25,80 & 12,20 & 13,00 & 22,75 & 3,52 & 7,06 \\
\hline
\end{tabular}

a/ Calculados según la metodología expuesta en el texto y a parte de los datos del cuadro 1 . Los valores han sido redondeados al 5 por ciento.

b/ $n I_{u}$ es el indicador semejante para el espacio urbano y $n I_{r}$ es el del espacio rural $; n=42$ unidades territoriales de análisis.

c) La suma de los totales por espacio no es $\mathbf{4 2}$ debido a los redondeos. 


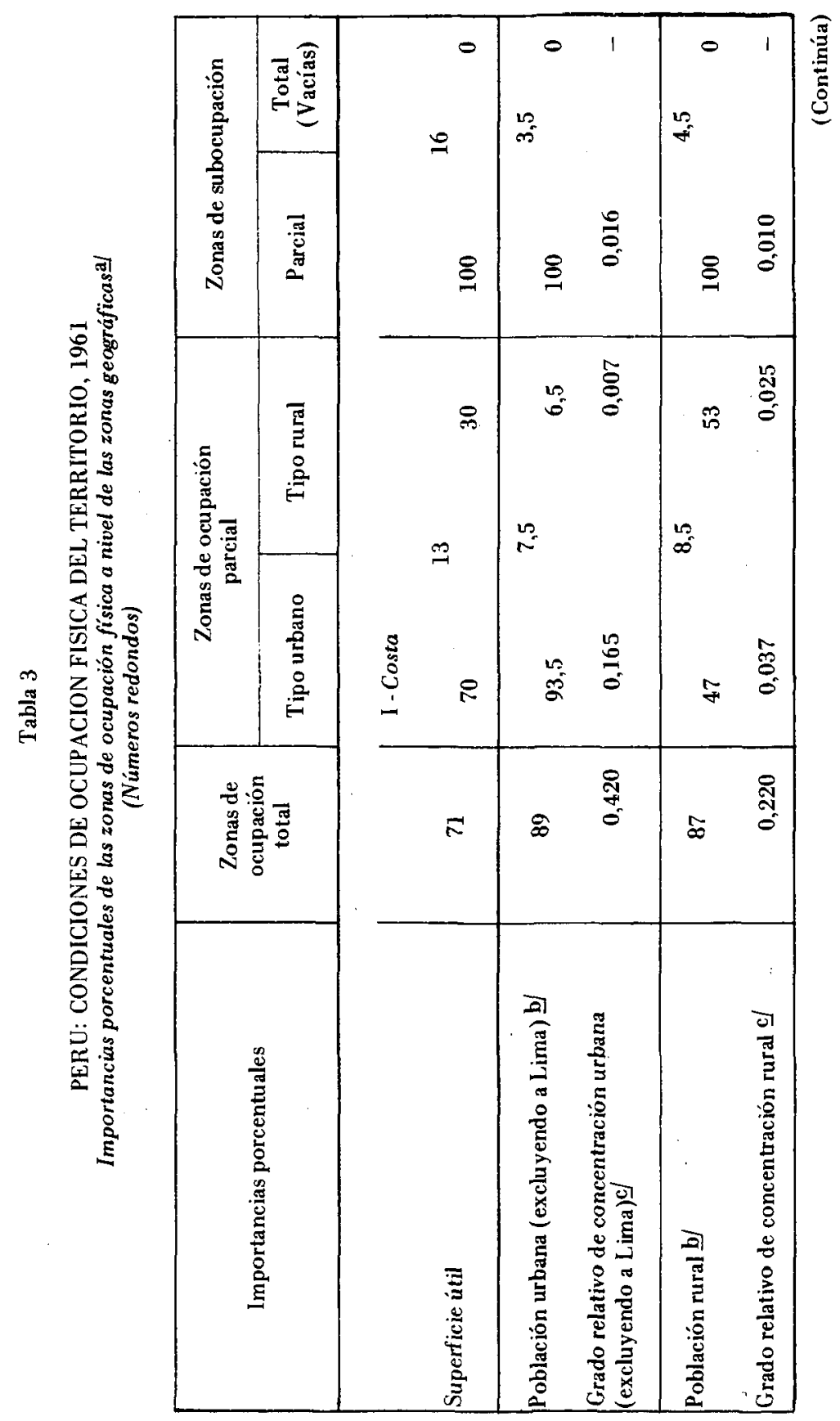

262 


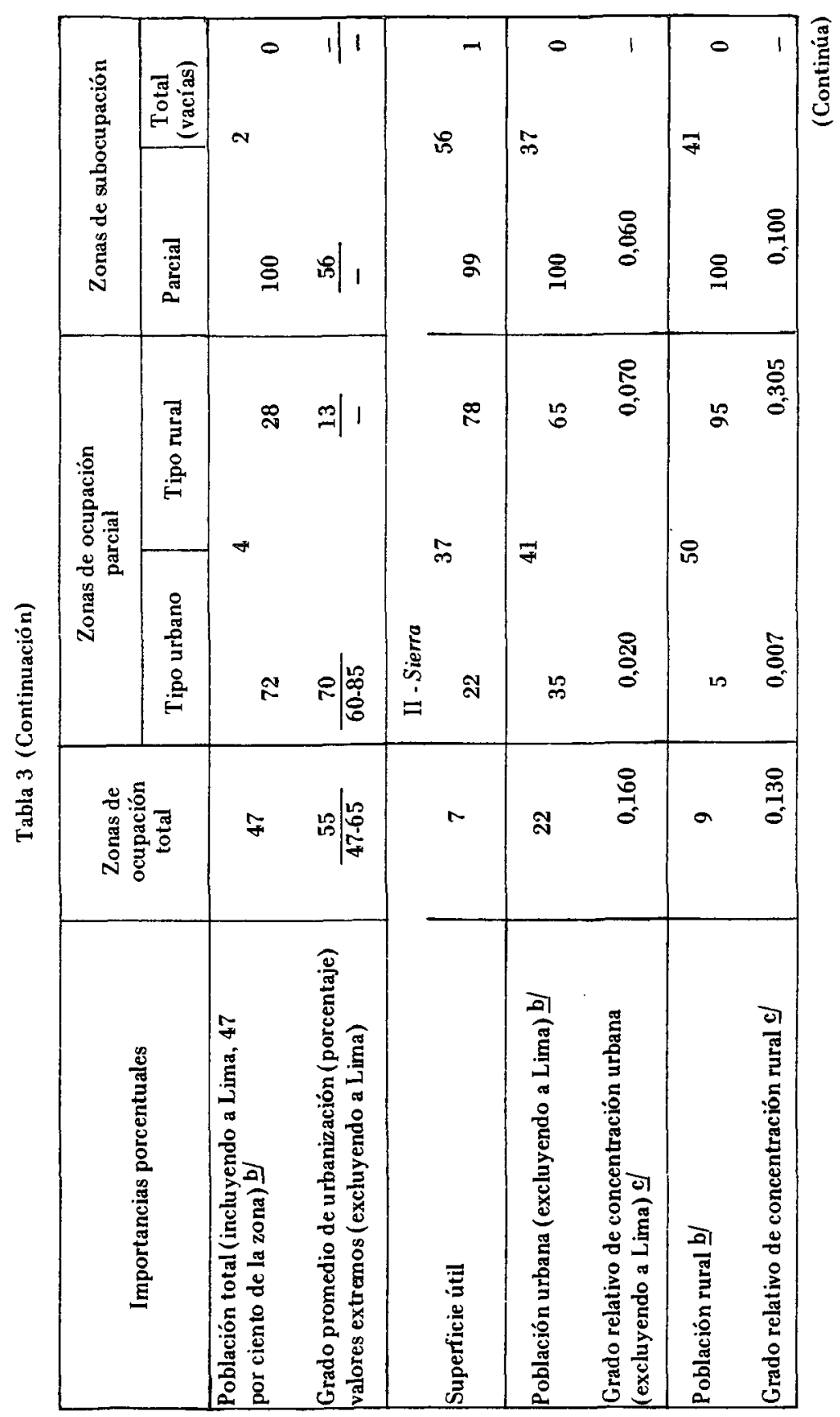




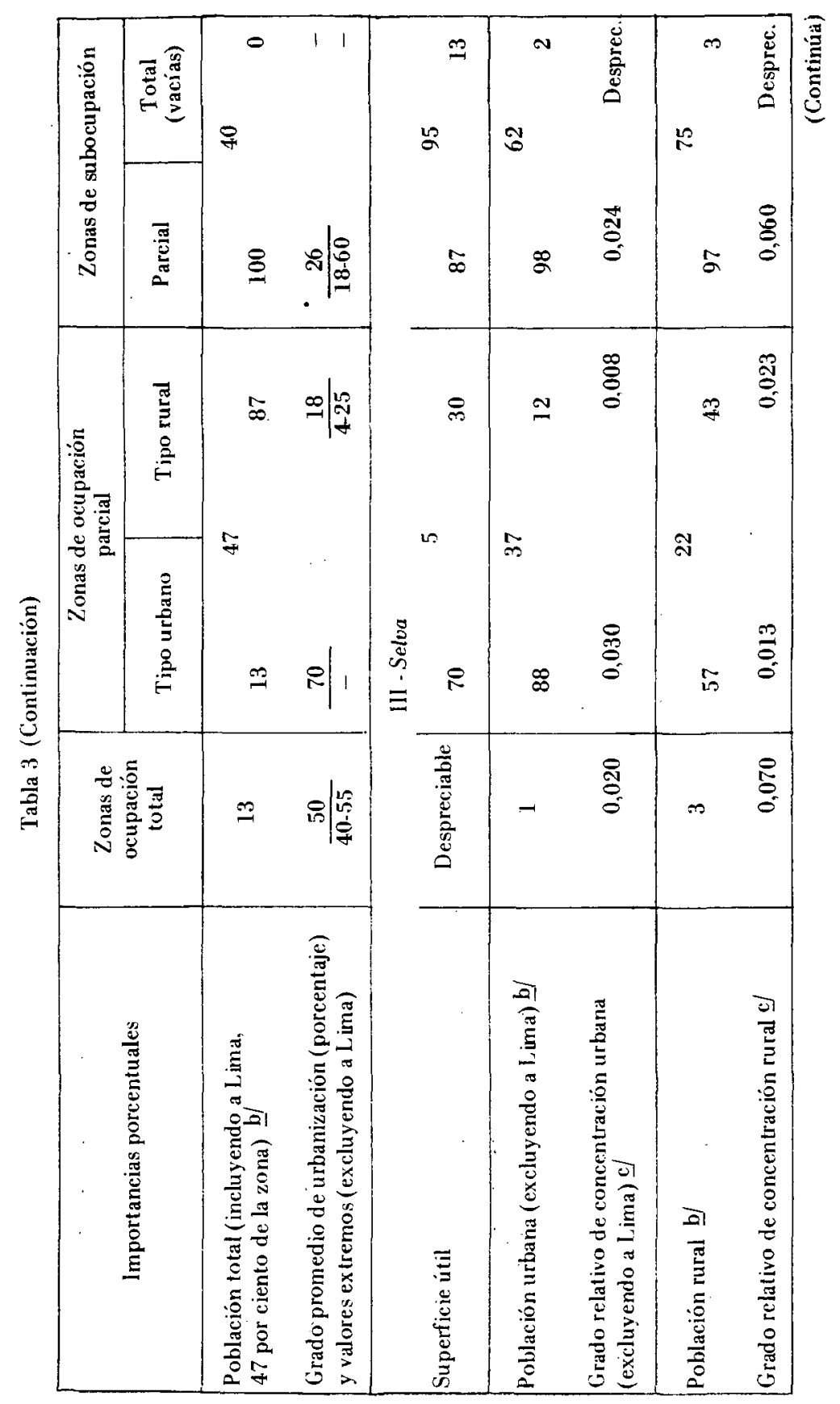




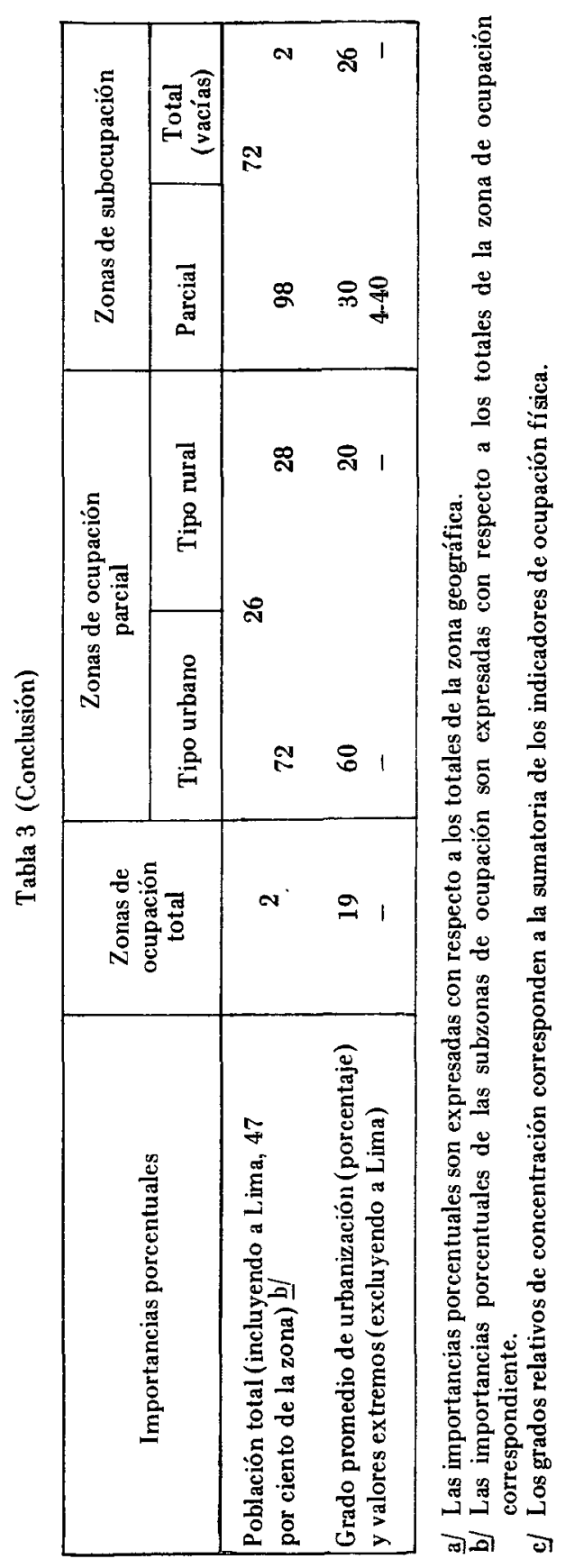


Tabla 4

PERU: CONDICIONES DE OCUPACION FISICA DEL TERRITORIO, 1961

Densidades territoriales de la población rural por zonas de ocupación física y zonas geográficas. Valores extremos a/

(Números redondos)

\begin{tabular}{|c|c|c|c|c|c|}
\hline \multirow{2}{*}{\multicolumn{2}{|c|}{ Zonas de ocupación física }} & \multicolumn{3}{|c|}{ Zonas geográficas } & \multirow{2}{*}{$\begin{array}{l}\text { Totales por } \\
\text { zonas de ocu- } \\
\text { pación (exclu- } \\
\text { yendo a Lima) }\end{array}$} \\
\hline & & Costa & Sierra & Selva & \\
\hline \multirow{2}{*}{\multicolumn{2}{|c|}{ Ocupación total }} & 3700 & 3000 & 7500 & 3500 \\
\hline & & $2500-5000$ & $2400-8500$ & - & $2400-8500$ \\
\hline \multirow{4}{*}{ Ocupación parcial } & \multirow{2}{*}{ Tipo urbano } & 1300 & 750 & 14,00 & 950 \\
\hline & & $850-1700$ & - & - & $750 \cdot 1700$ \\
\hline & \multirow{2}{*}{ Tipo rural } & 3500 & 3700 & 2400 & 3700 \\
\hline & & - & $2500 \cdot 7000$ & - & $2400-7000$ \\
\hline \multirow{4}{*}{ Subocupación } & \multirow{2}{*}{ Parcial } & 950 & 1800 & 370 & 1000 \\
\hline & & - & $370 \cdot 2200$ & $220 \cdot 2200$ & $370 \cdot 2200$ \\
\hline & \multirow{2}{*}{ Total (vacías) } & - & o & 65 & 65 \\
\hline & & - & - & - & - \\
\hline \multirow{2}{*}{\multicolumn{2}{|c|}{$\begin{array}{c}\text { Totales por zonas } \\
\text { geográficas } \\
\text { (excluyendo a } \operatorname{Lima} \text { ) }\end{array}$}} & 3000 & 2400 & 400 & 1500 \\
\hline & & $850-5000$ & $0-8500$ & $65-7500$ & 0.8500 \\
\hline
\end{tabular}

a/ La población rural es la que vive en centros poblados de aproximadamente menos de 2000 habitantes. Las densidades territoriales se expresan en habitantes por $100 \mathrm{~km} 2$ de superficie útil. 


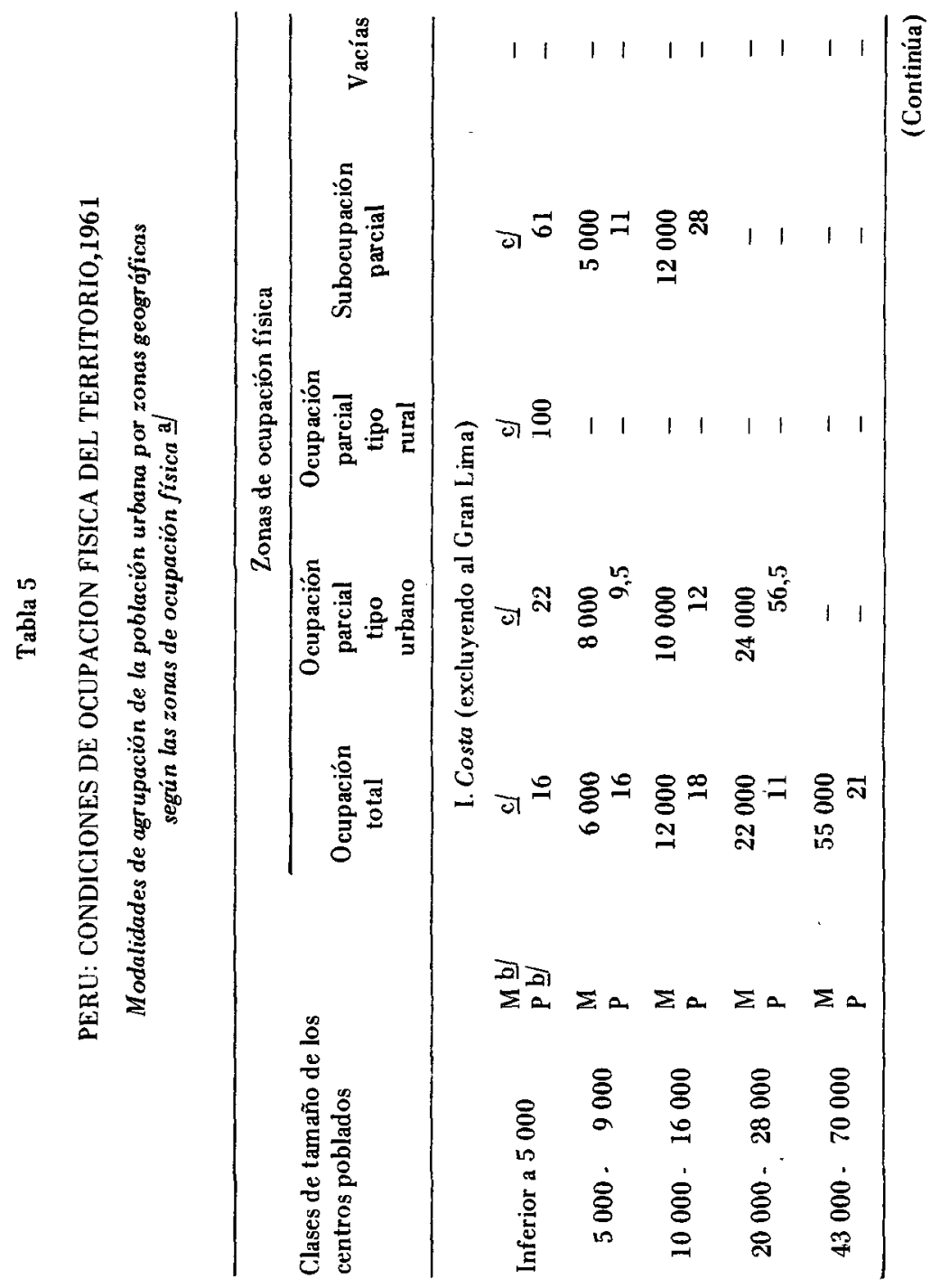




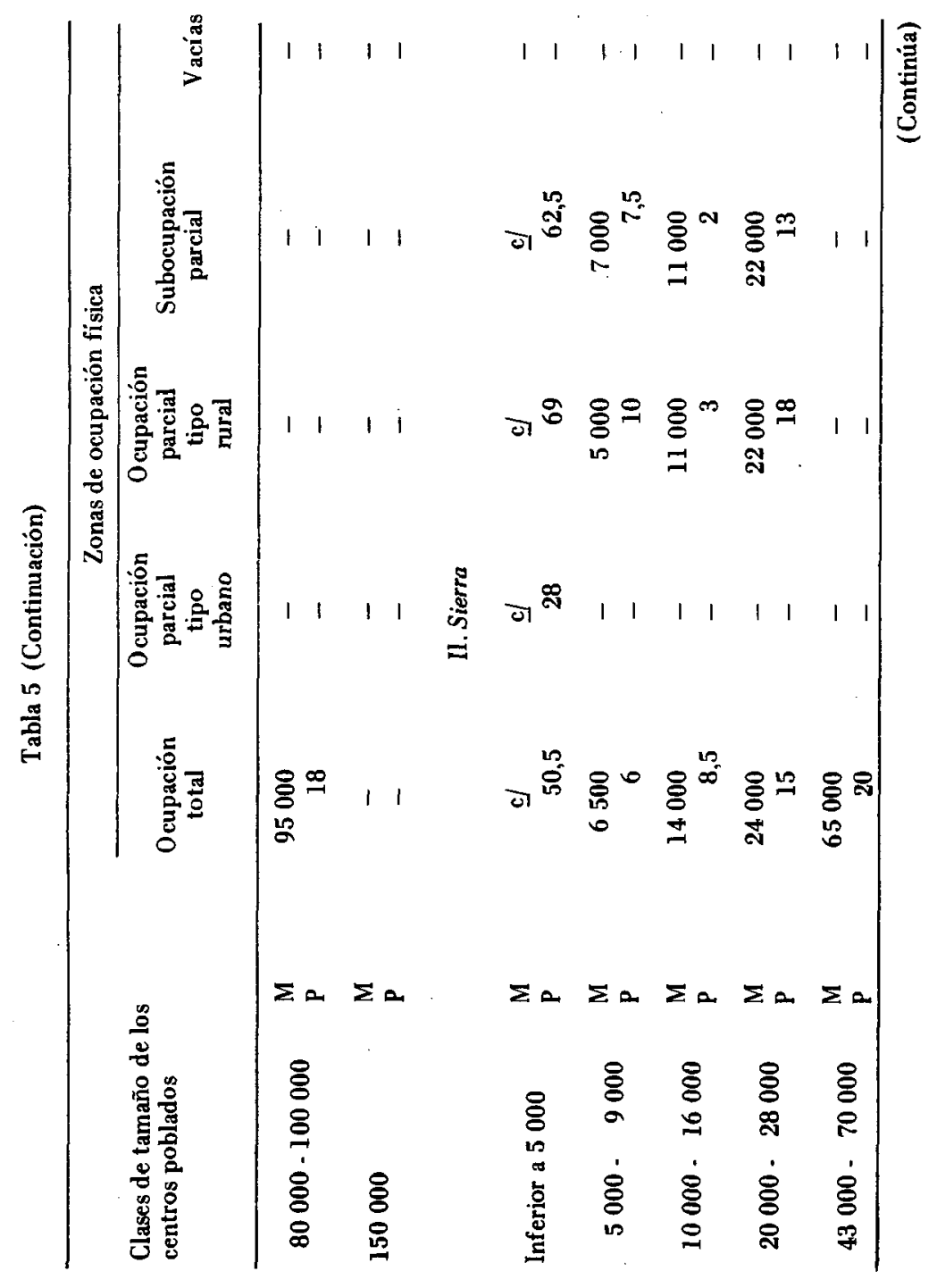




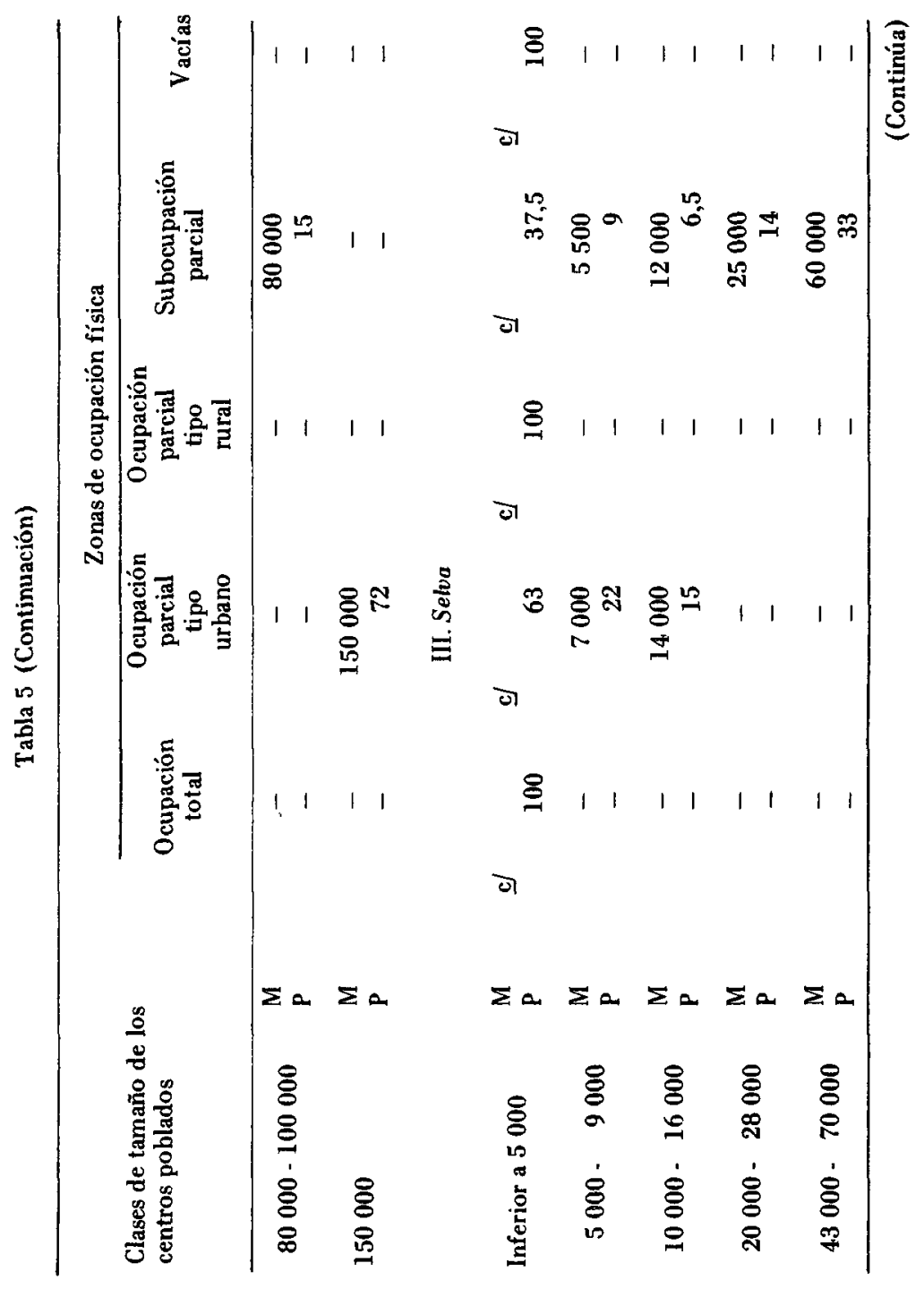




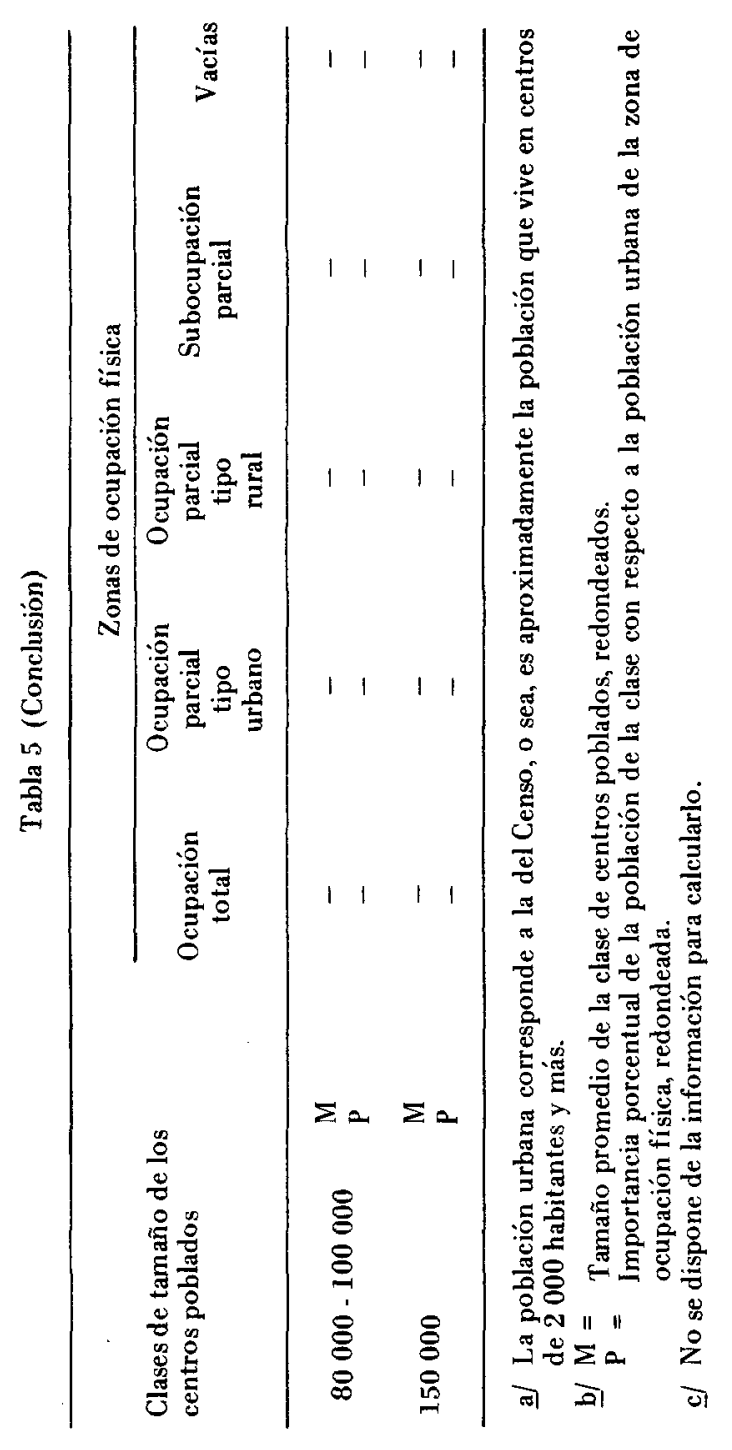

270 


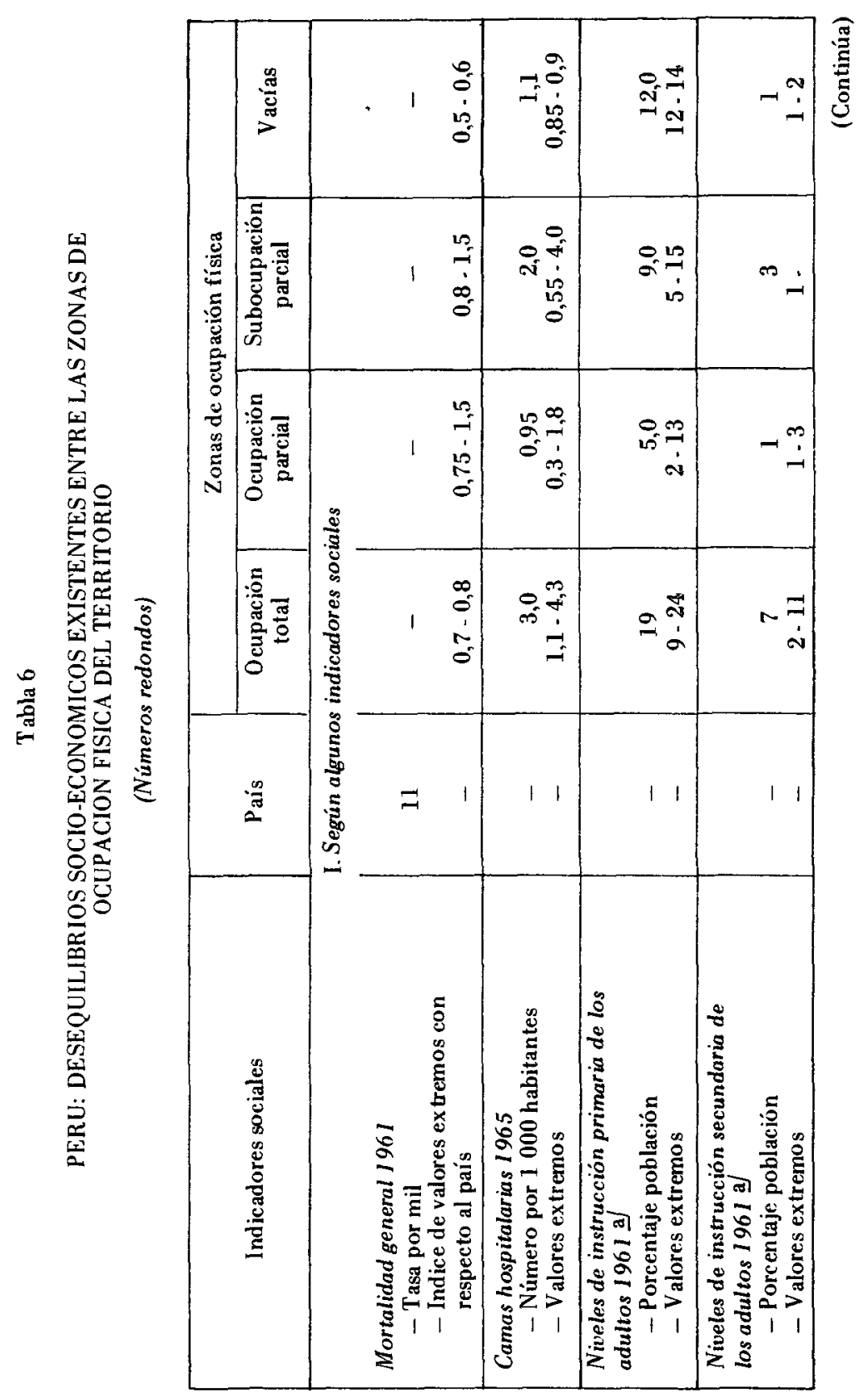

271 


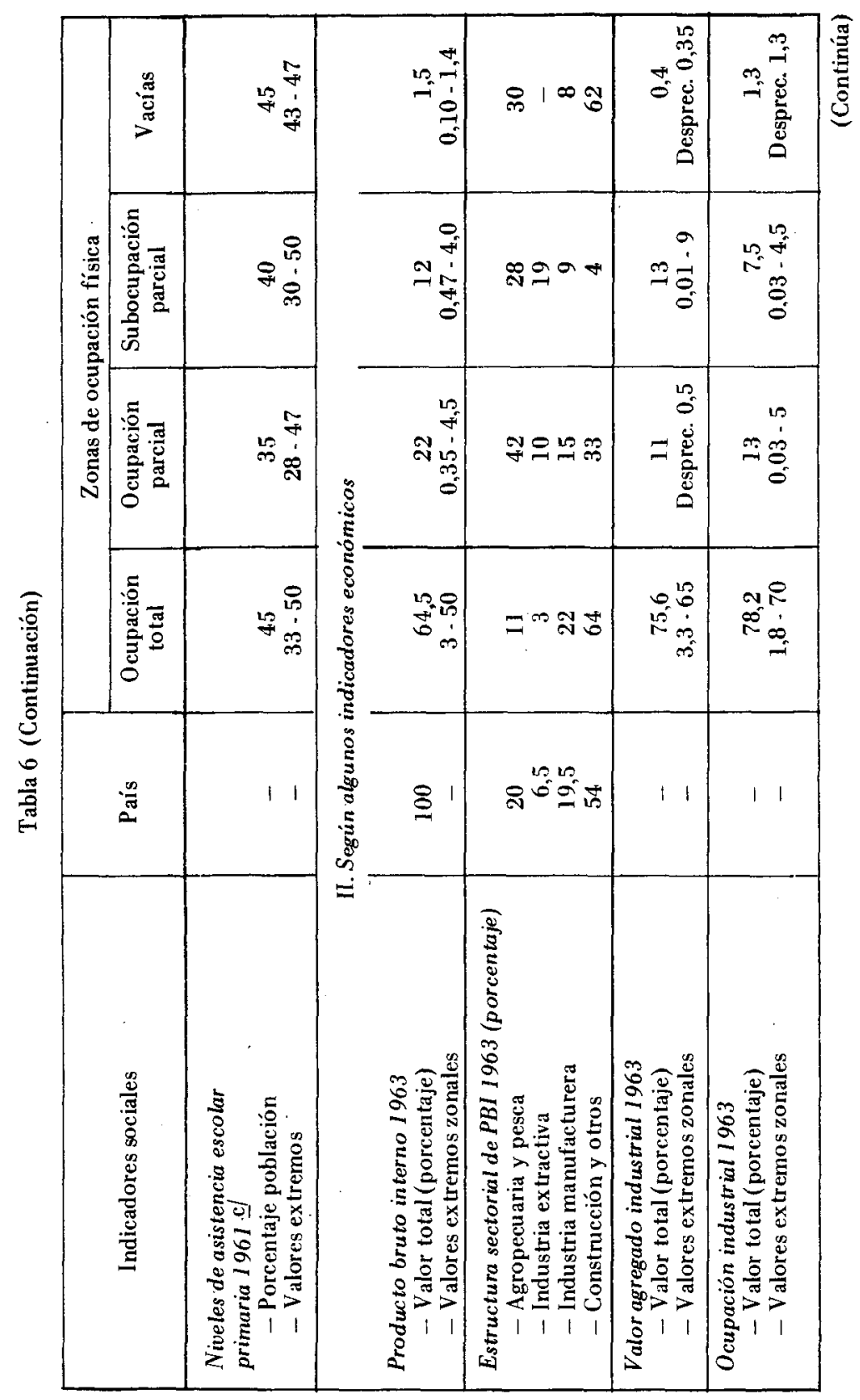

272 


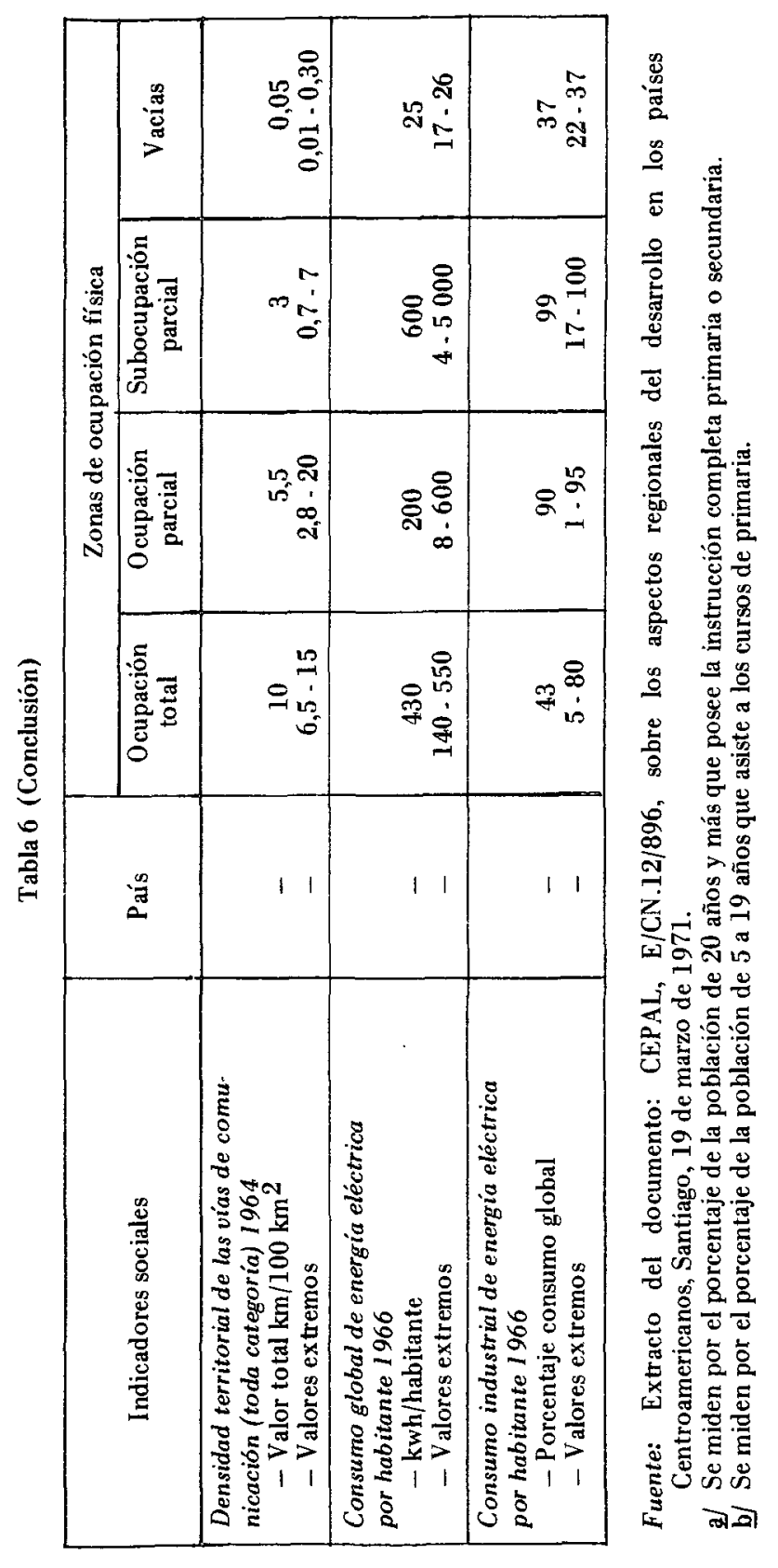


Tabla 7

PERU: LOS CAMBIOS FUNDAMENTALES EN LA OCUPACION DEL ESPACIO

Matriz de las unidades territoriales de análisis

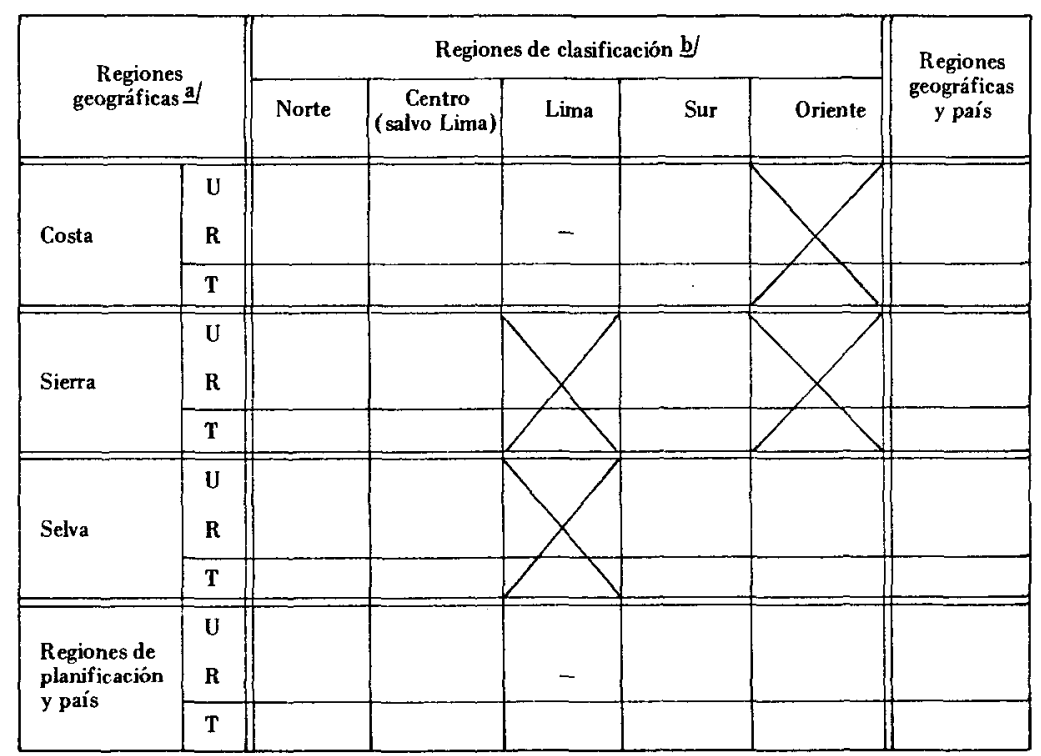

Fuente: Instituto Nacional de Planificación y Oficina Nacional de evaluación de recursos naturales. Los cambios fundamentales en la ocupación del espacio económico. Lima, octubre de 1970. Documento no oficial.

a/ Las letras significan: $\mathrm{U}=$ espacio urbano, $\mathrm{R}=$ espacio rural y $\mathrm{T}=$ espacio total.

b/ El guión significa que no existe el espacio considerado y la cruz que no existe la zona geográfica. 


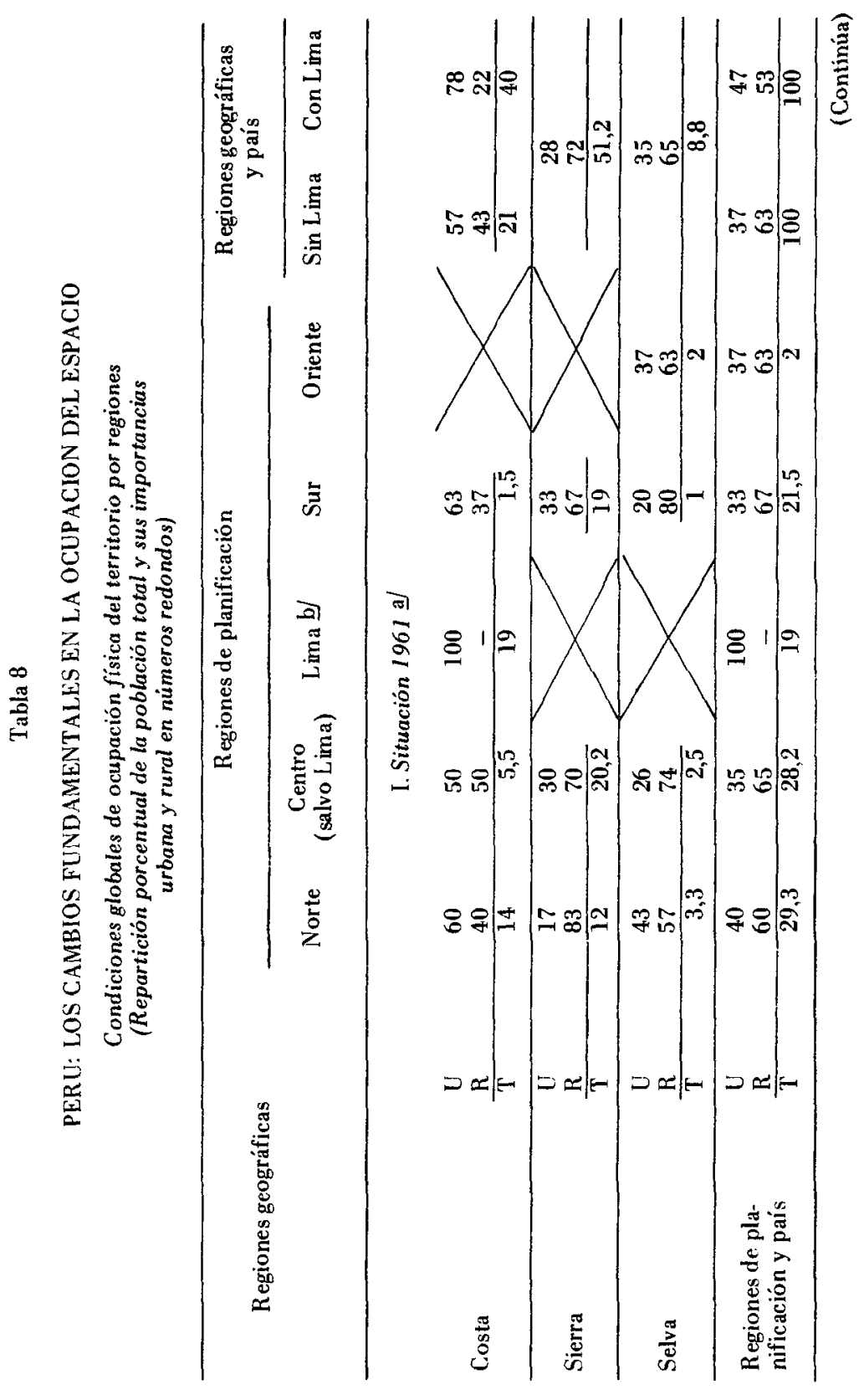




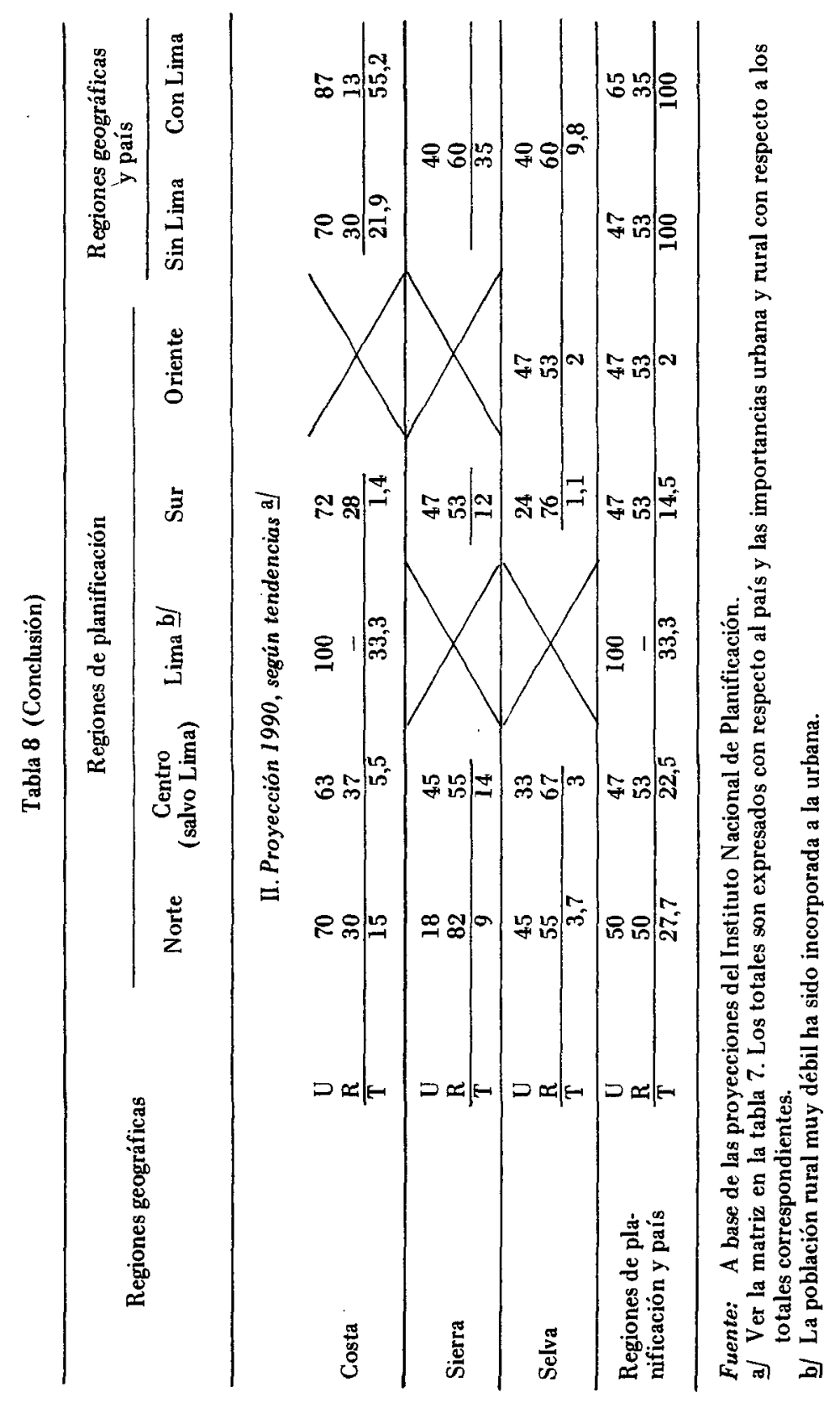




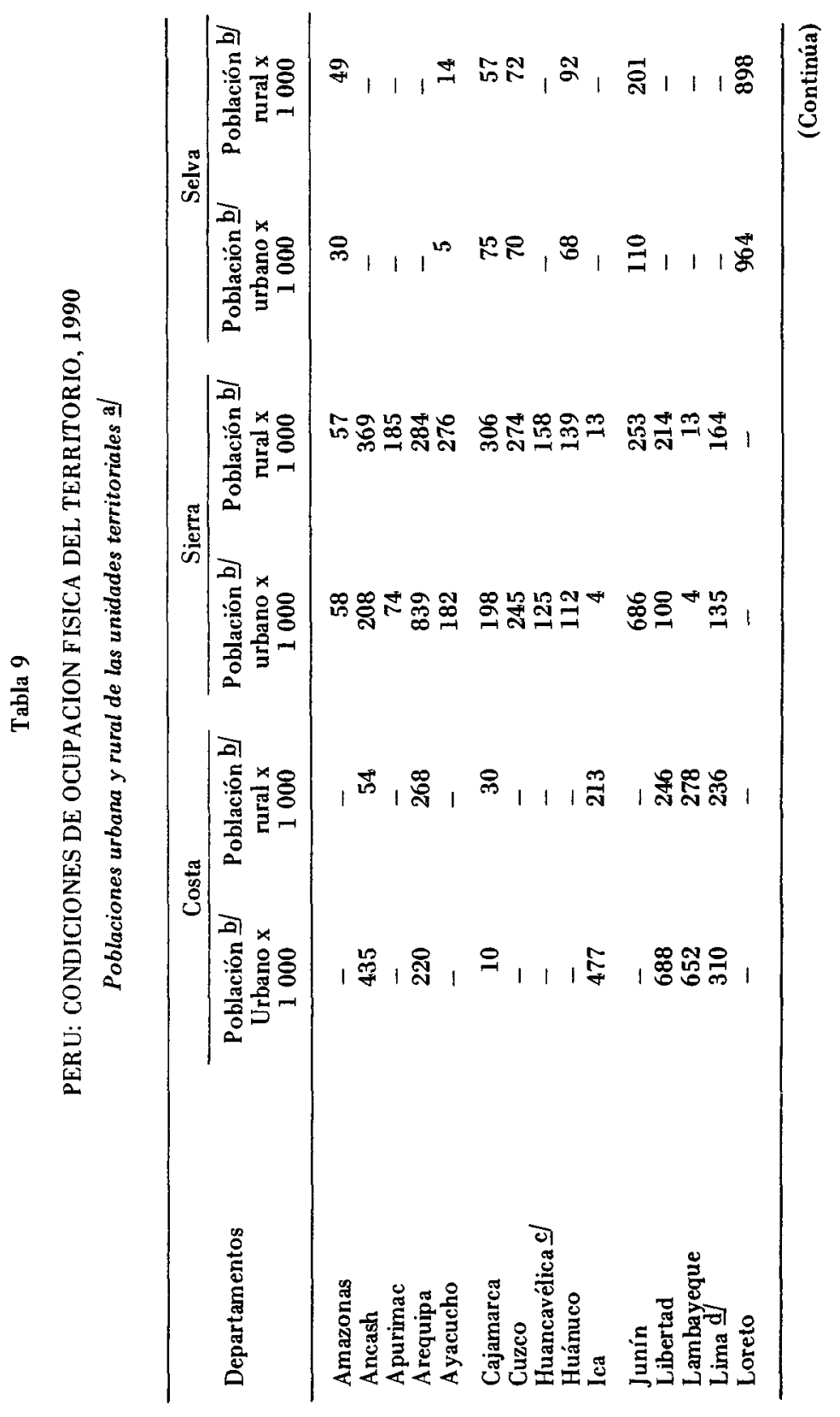




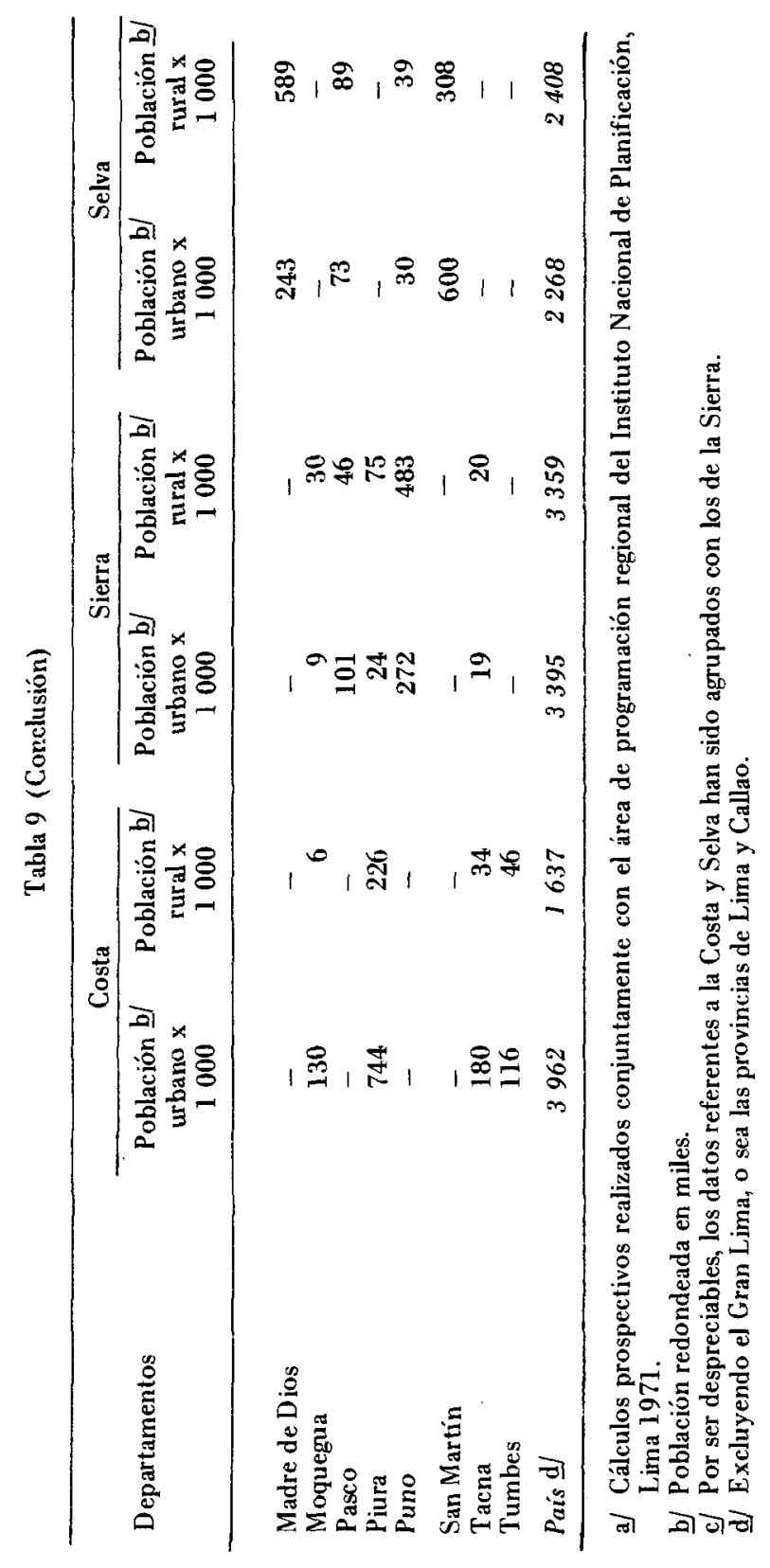

278 


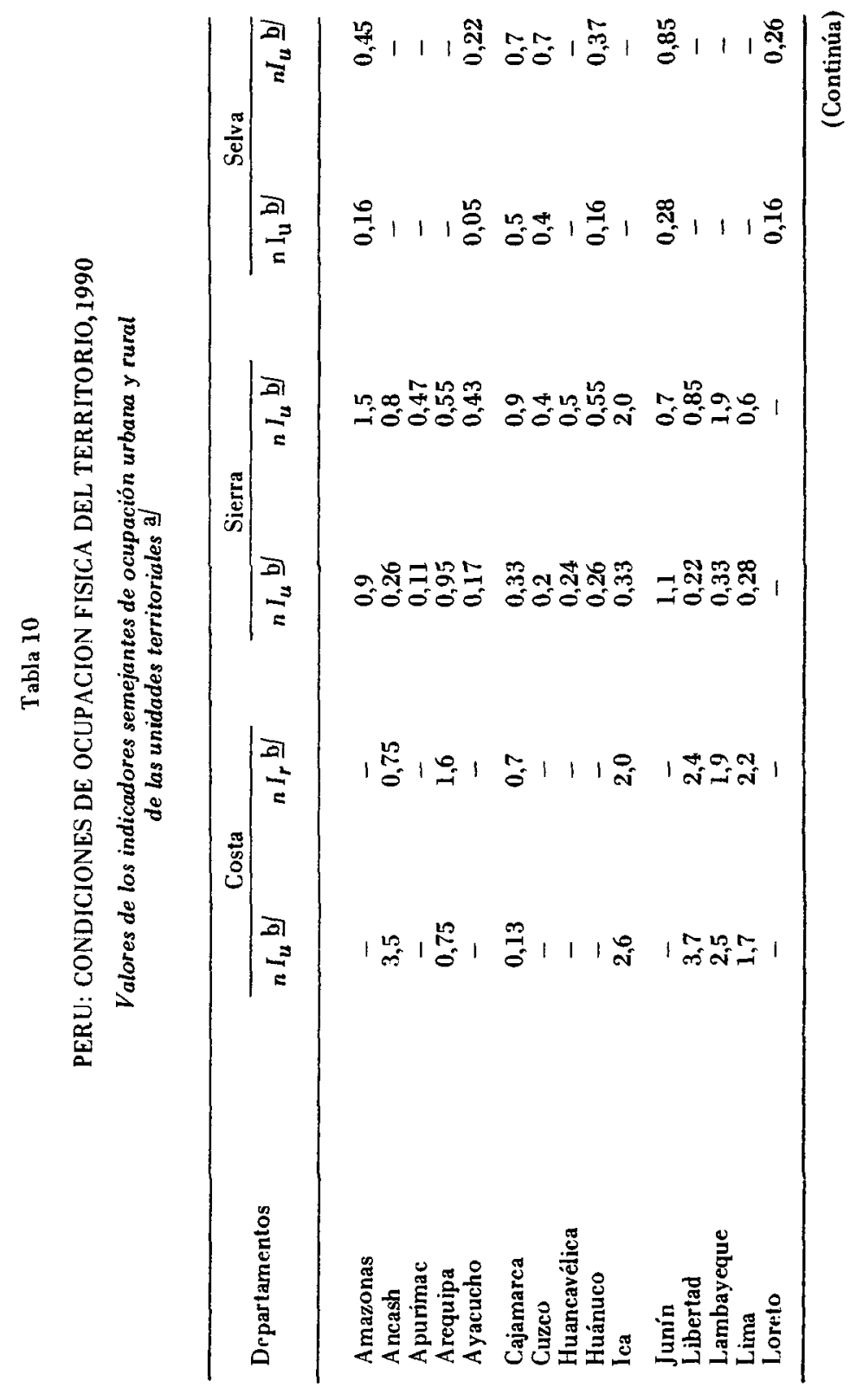




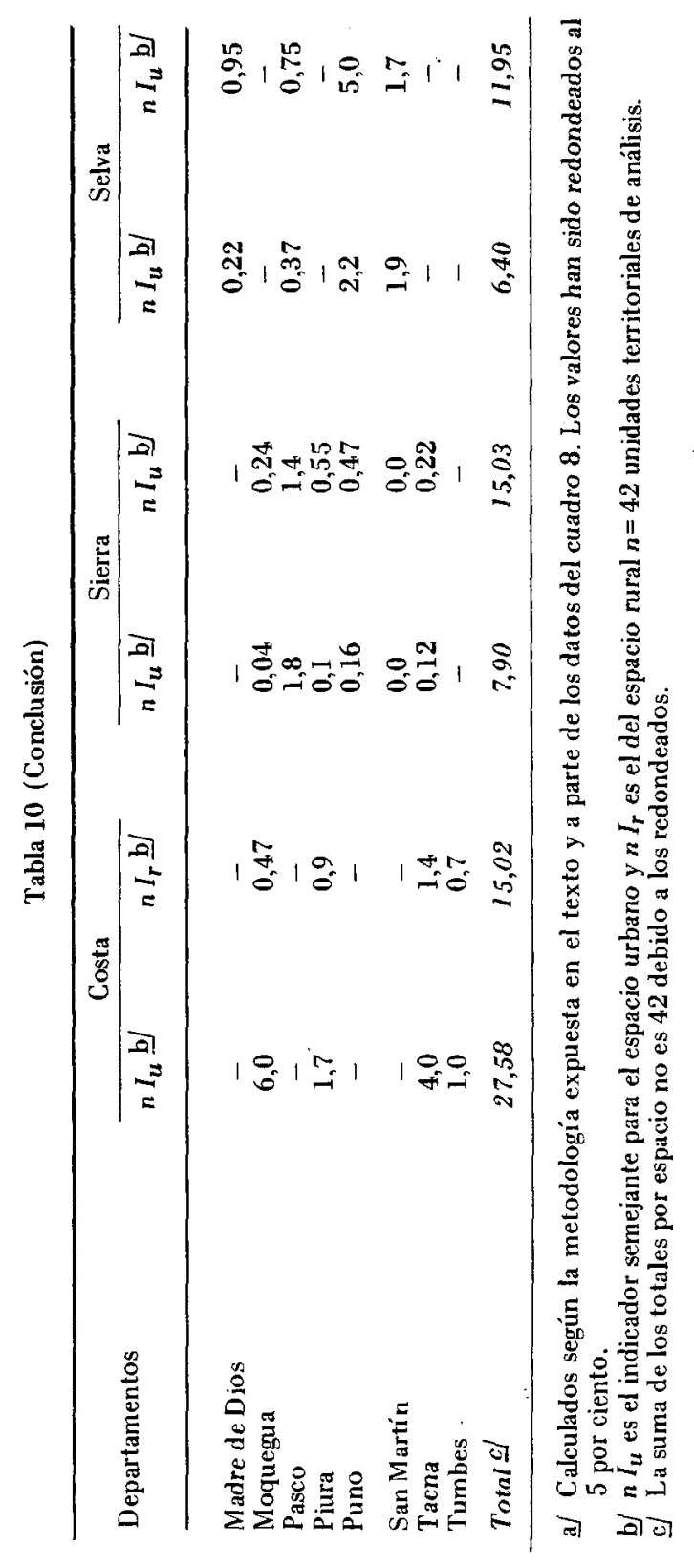




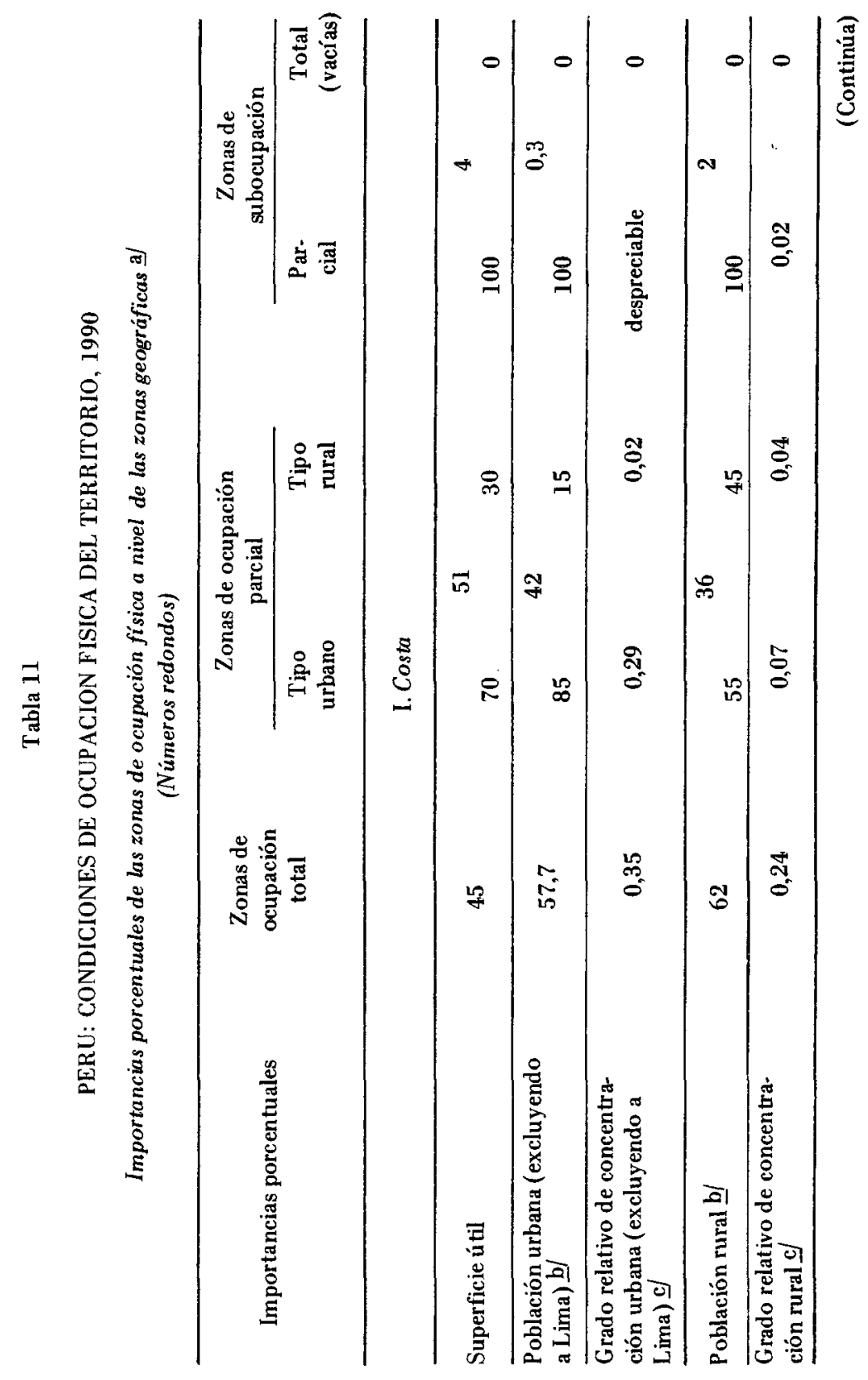




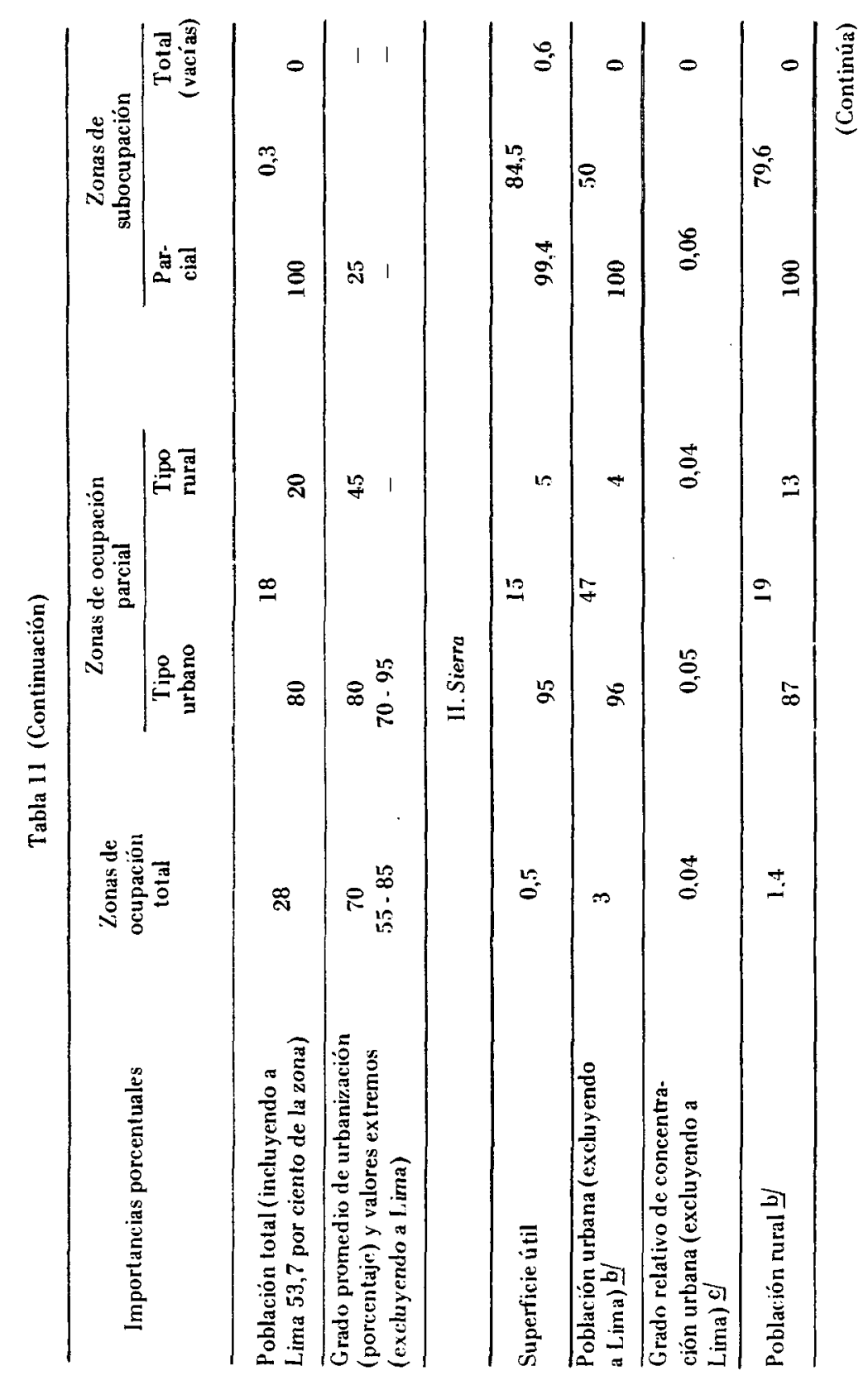

282 


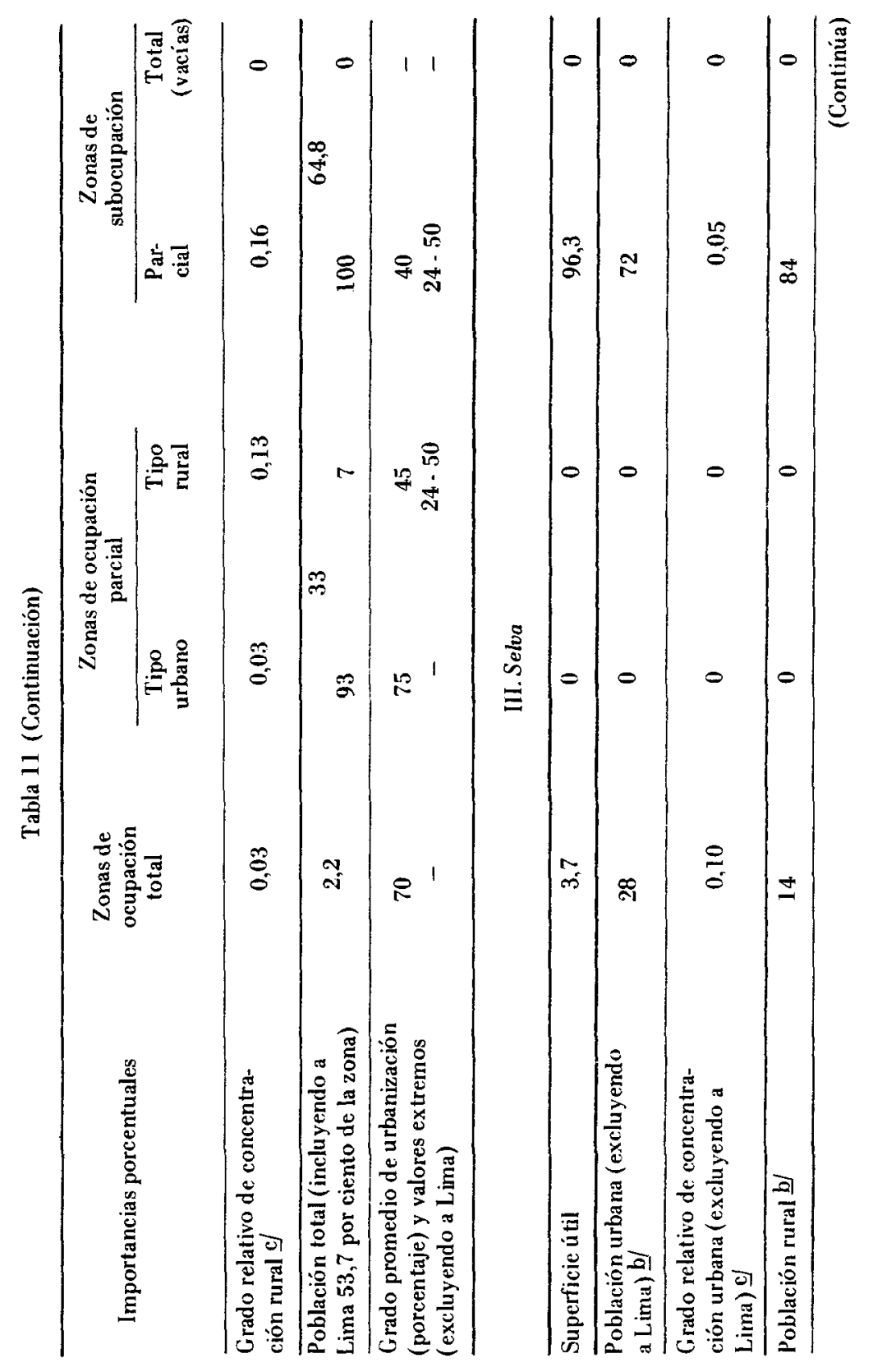




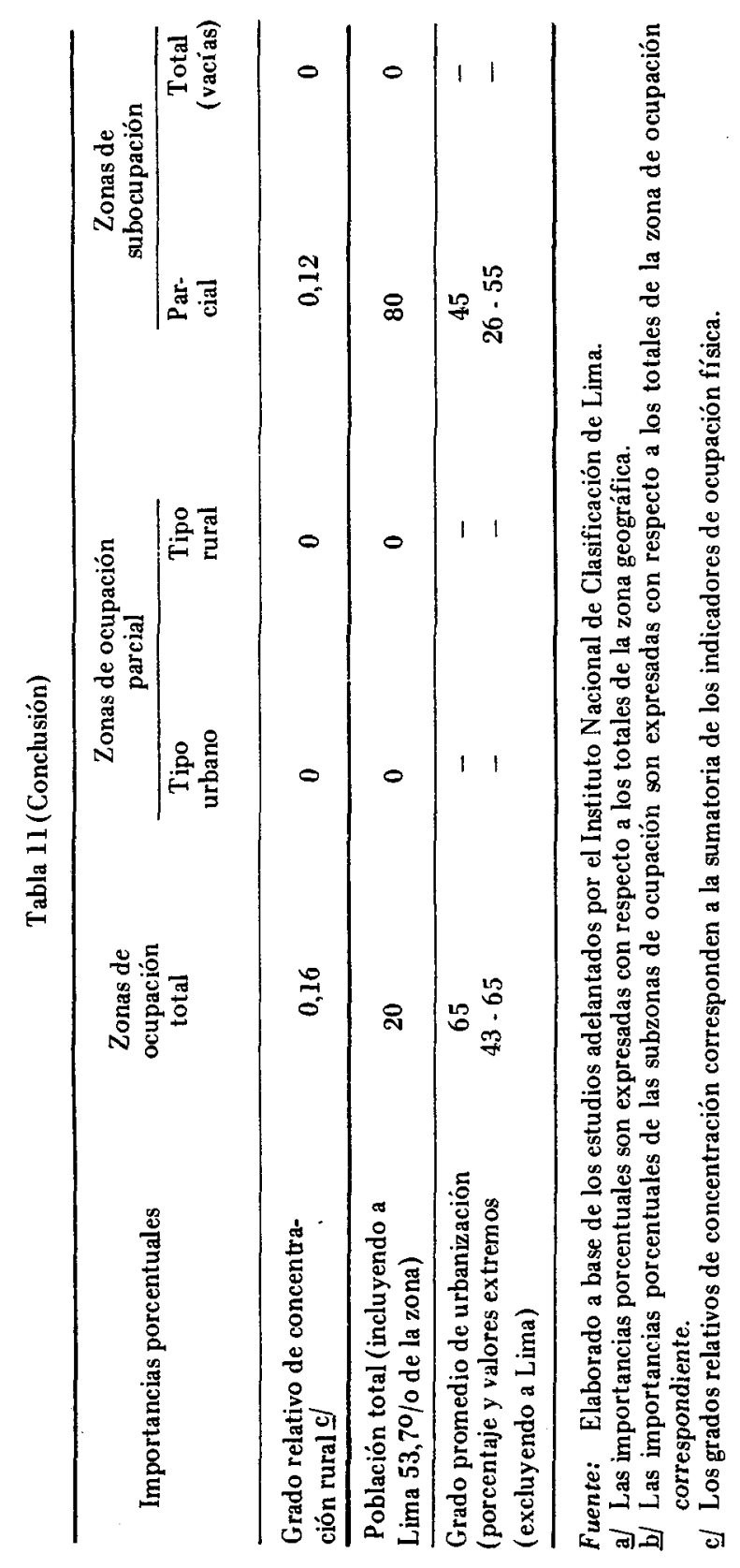

284 


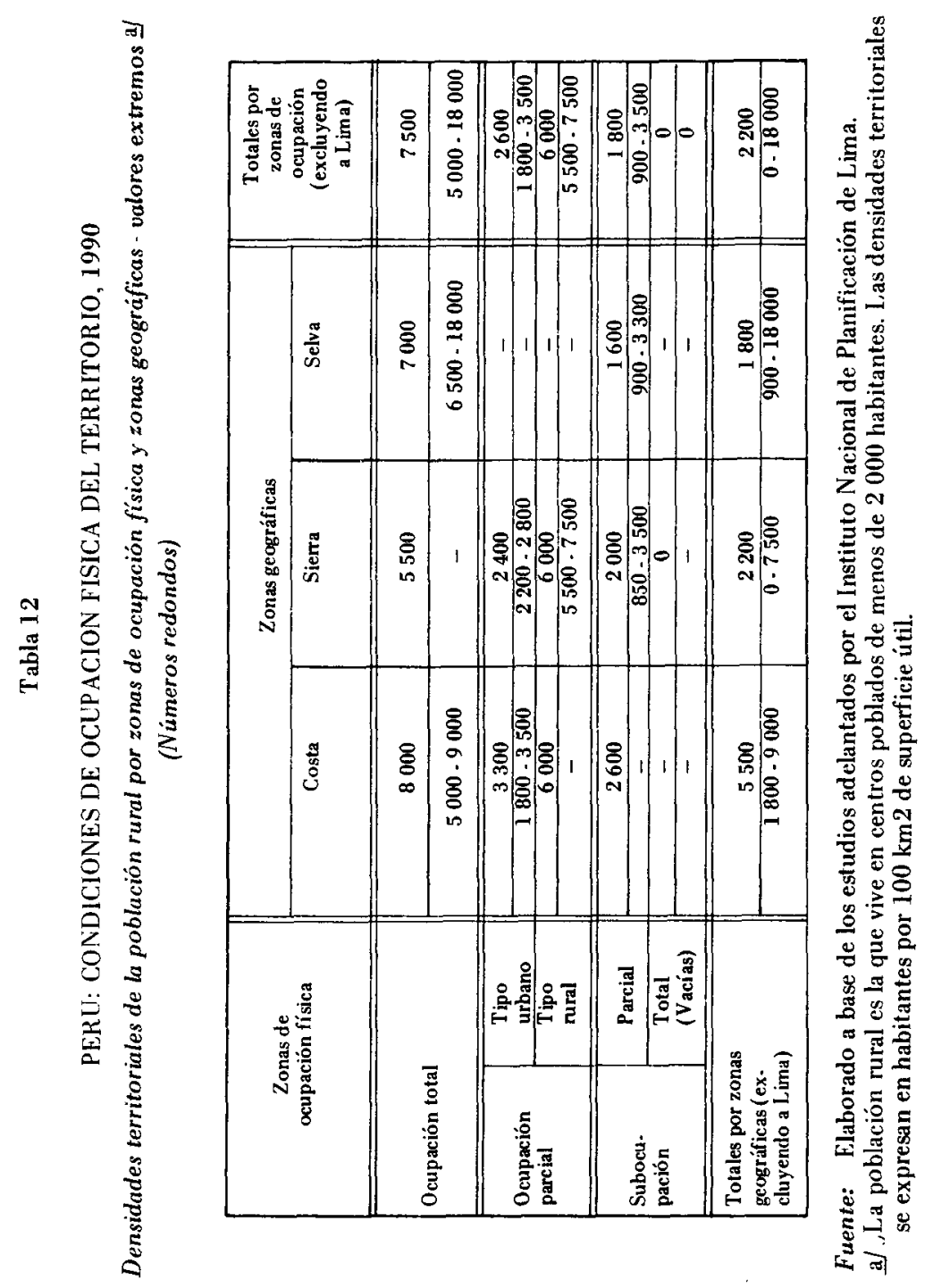




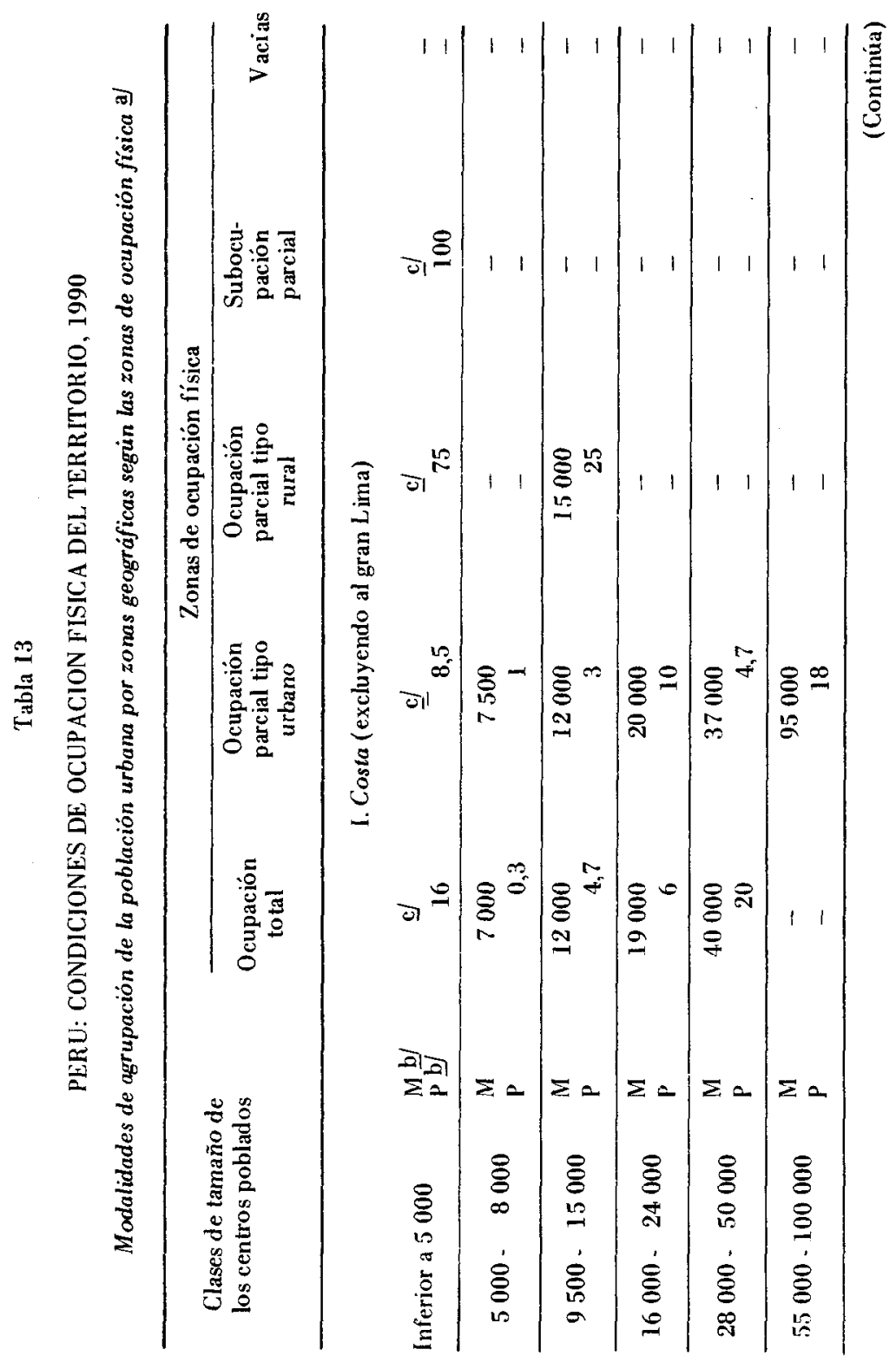




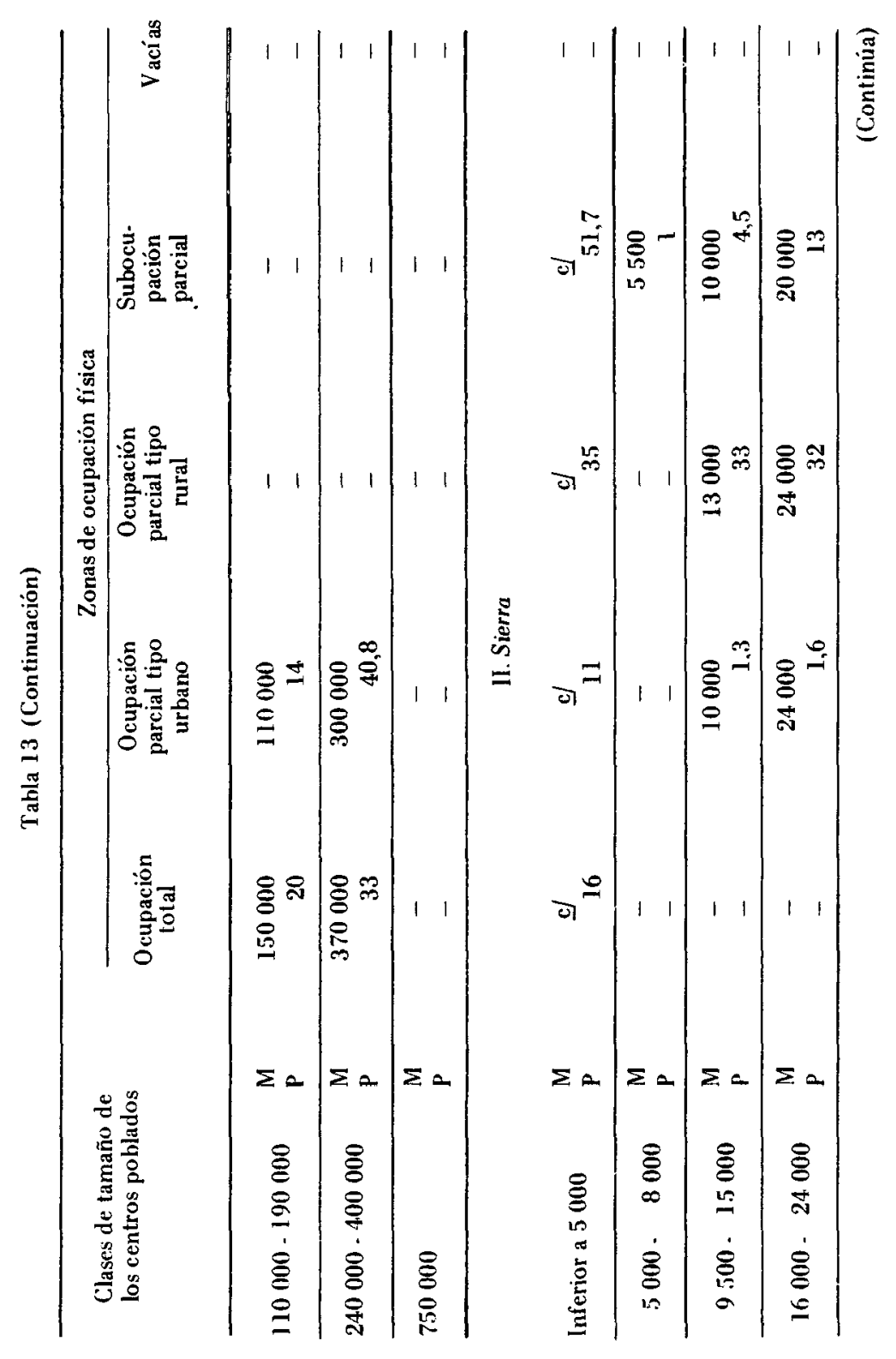




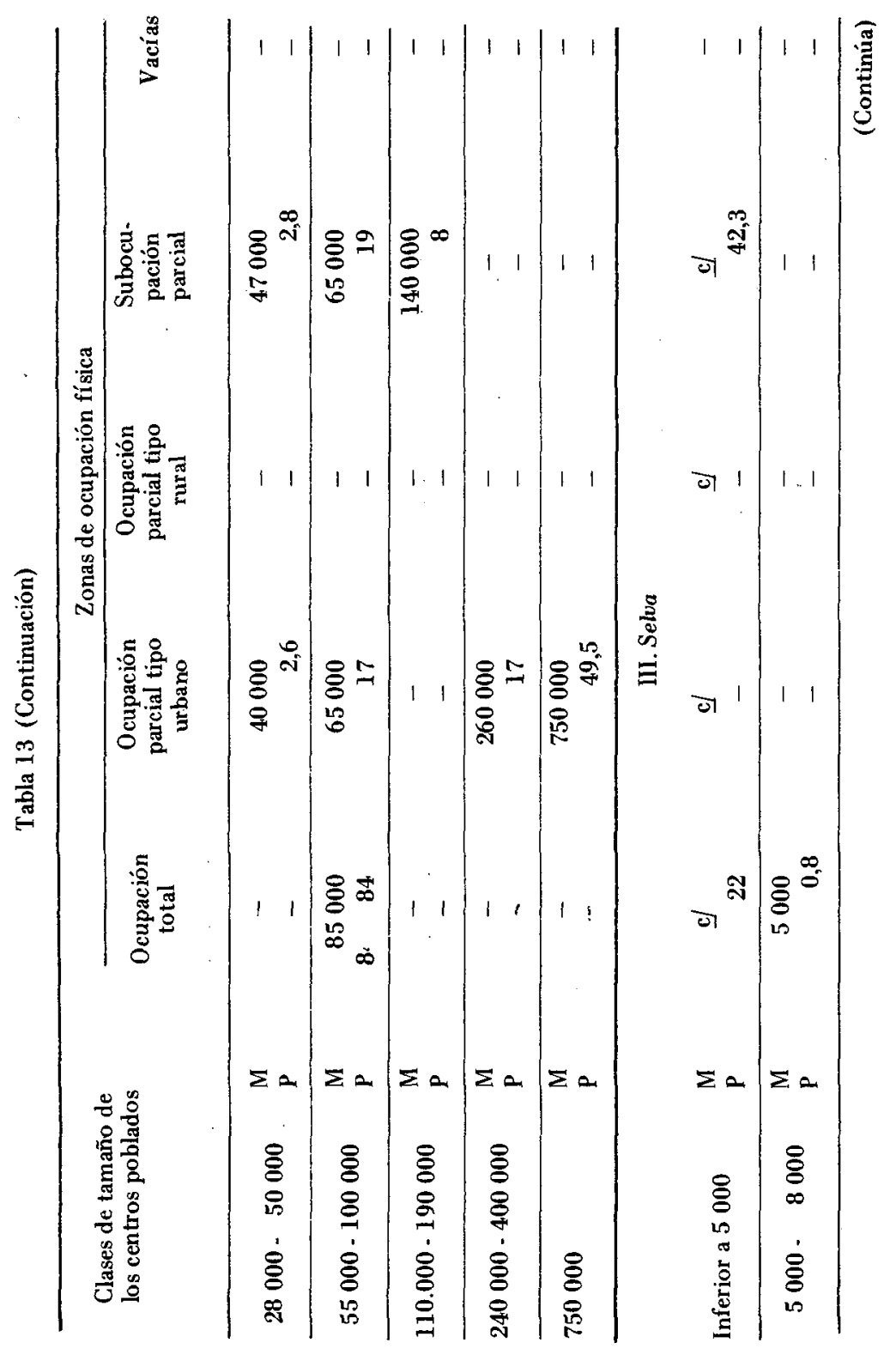




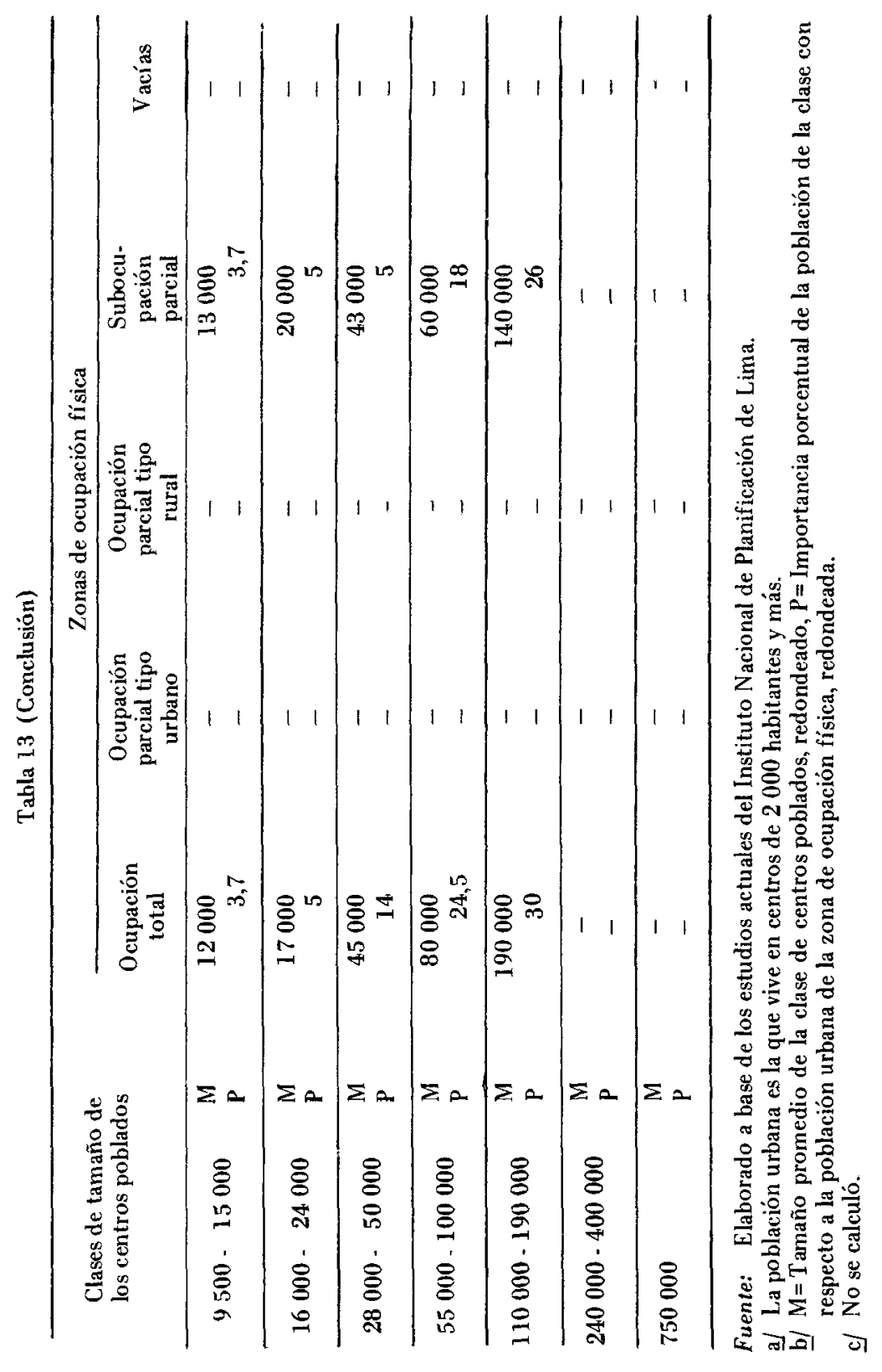




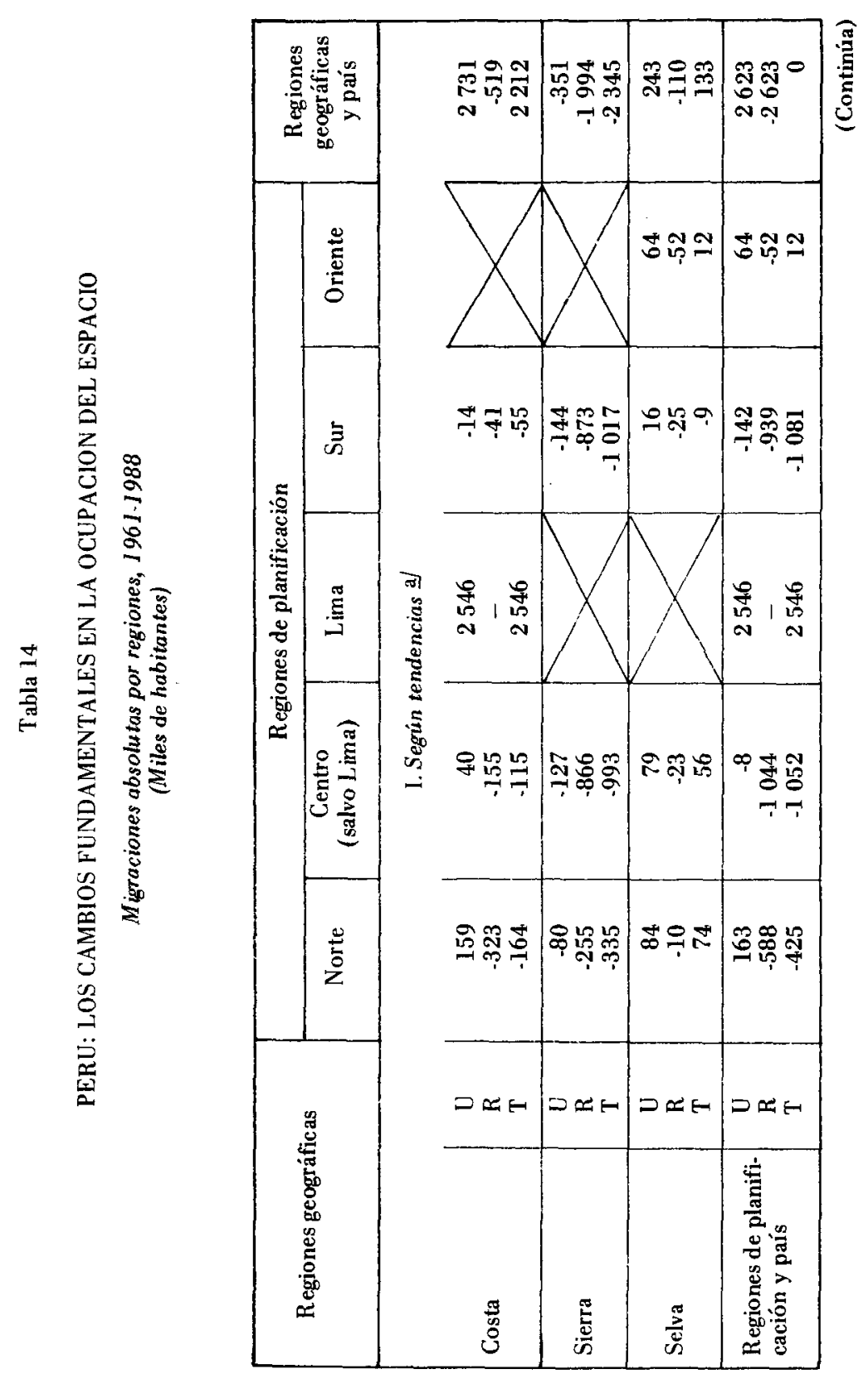




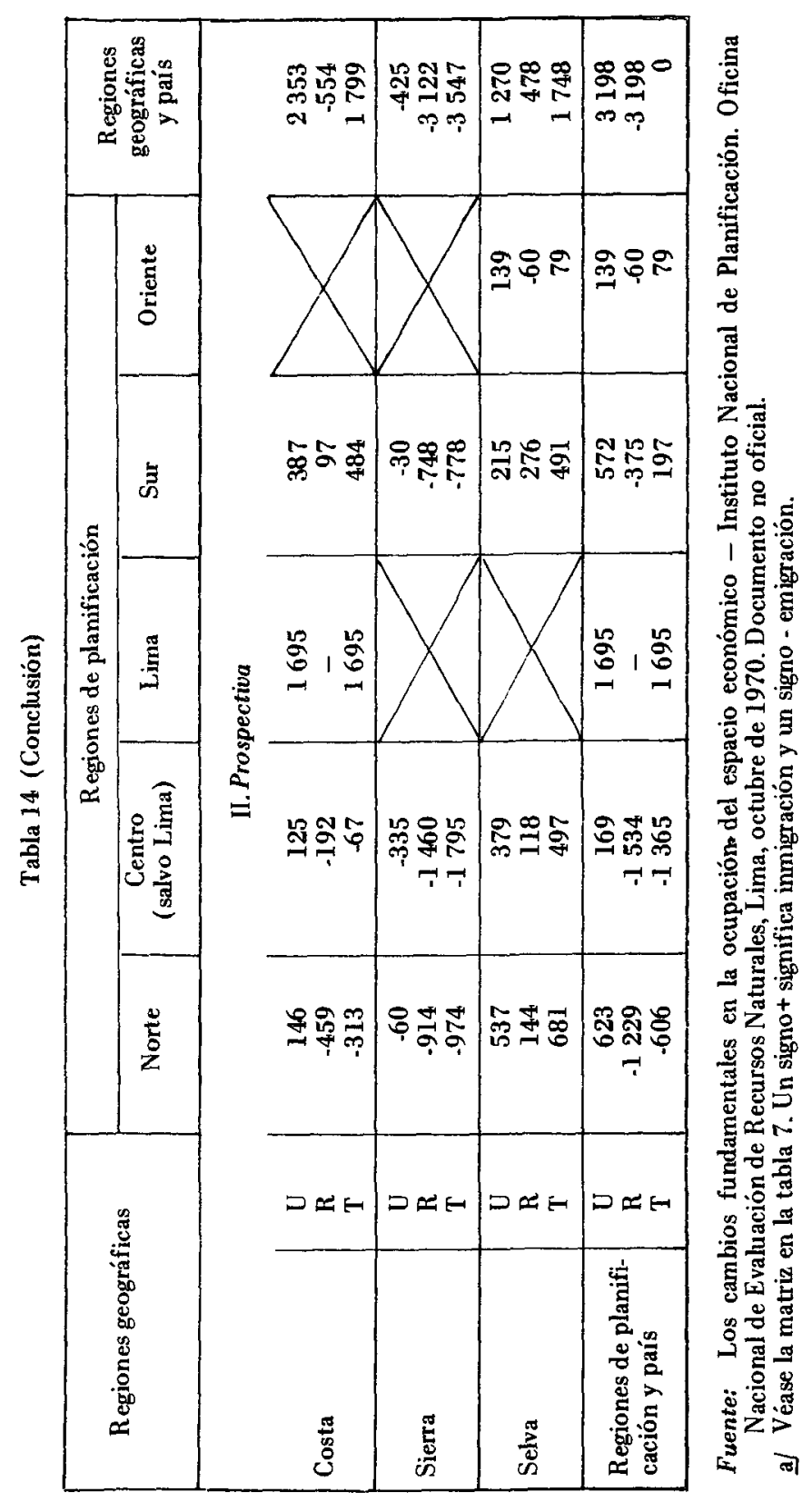




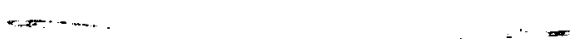




\title{
PROGRAMA IE ADIESTRAMIENTO SOBRE POBLACION Y PLANIFICACION DEL DESARROLLO
}

\author{
Luis Olivos \\ Sub Director Auxiliar, \\ Departamento de Asuntos Sociales, \\ Organización de los Estados Americanos, \\ Santiago, Chile \\ Luis Ratinoff \\ Consejero de Programas, \\ Banco Interamericano de Desarrollo \\ Washington, Estados Unidos
}




\section{ANTECEDENTES}

La experiencia de casi una década de planificación del desarrollo en América Latina y la creciente incorporación de objetivos sociales dentro de los planes y programas gubernamentales, han llevado a los organismos nacionales de planificación y a las instituciones de ayuda internacional, a prestar mayor atención a los aspectos demográficos del desarrollo.

Si se examinan los planes nacionales, se aprecia que en la mayoría de los casos se ha intensificado el uso de la información demográfica en la determinación de los grandes objetivos de política de los gobiernos.

Los organismos internacionales se han hecho eco de estos esfuerzos en sus actividades de investigación, reuniones, becas y asistencia técnica. Sin embargo, las actividades de capacitación que estas instituciones realizan en los campos de planificación y de población no han cubierto hasta ahora el área de las interrelaciones entre las variables demográficas y las económico-sociales.

Se ha señalado la existencia de este vacío en diversas oportunidades. En la reunión de expertos en población y demografía, convocada por el BID a fines de 1969, se indicó la conveniencia de que en la elaboración de planes de desarrollo se hiciera una utilización mayor de información demogrăfica, especificándose la necesidad que las oficinas nacionales de planificación incorporaran demógrafos en sus cuadros técnicos, y se realizarãn programas de capacitación para planificadores que analizaran las interrelaciones entre las variables demográficas $y$ las económico-sociales.

Paralelamente, el Comité Asesor de Población de la OEA, en su reunión de noviembre de 1969, efectuada en Bogotá, discutió la conveniencia de establecer, en colaboración con los organismos regionales especializados, algunos cursos de capacitación destinados a satisfacer esta necesidad.

El Colegio de México y el Centro de Estudios del Desarrollo de la Universidad de los Andes, de Bogotá, en colaboración con la OEA y el BID, llevaron a cabo en abril de 1970, una reunión de expertos destinada a discutir en forma preliminar la viabilidad de un programa de cursos sobre las relaciones entre las variables demográficas y económicas en la planificación del desarrollo. En esa oportunidad se analizaron las 
posibilidades de llevar a cabo una iniciativa de esta naturaleza, prestándose especial atención al contenido de los cursos. Entre las principales conclusiones de este encuentro pueden anotarse las siguientes:

1. Aun cuando los expertos reunidos en México estuvieron de acuerdo en cuanto a oportunidad y conveniencia de esta iniciativa, se recomendó realizar una reunión de personal técnico de las oficinas de planificación de los países, para examinar el uso que se hacía de las variables demográficas en la elaboración de los planes nacionales y la consideración que en los mismos se daba a las interrelaciones entre la población y los aspectos económico-sociales del desarrollo.

2. Se recomendó, además, que el plan de estudios incluyera:

a) Análisis de las interrelaciones entre las variables demográficas y las económico-sociales, en algunos campos especializados tales como el desarrollo urbano y rural, fuerza de trabajo, educación, salud, recursos humanos, ingresos, ahorro, inversión, consumo, provisión de servicios sociales, migraciones y distribución geográfica de la población.

b) Uso de metodologías aplicables a la programación de estas áreas de interrelación, tales como modelos generales y especiales.

c) Uso de algunas metodologias demográficas.

d) Utilización de información demográfica en los planes convencionales de desarrollo. 


\section{FUNDAMENTACION}

La dinámica demográfica es un factor básico en el proceso de cambio social, en el que influye por variados medios y del que a su vez recibe influencia.

Por una parte, el tamaño, el crecimiento, la composición por sexo y edad y la distribución geográfica de la población, influyen de manera importante sobre la magnitud y naturaleza de las metas de la planificación nacional. Por otra parte, la planificación tiene que tener en cuenta los efectos del desarrollo económico y social sobre la fecundidad, la mortalidad, la migración interna y la internacional, el tamaño y calificación de la fuerza de trabajo y otras variables directa o indirectamente demográficas. Estas consideraciones, que no siempre se tienen debidamente en cuenta en la elaboración de planes, son especialmente importantes en las condiciones de rápido crecimiento de la población y de migración masiva a las ciudades de la mayoría de los países de América Latina. Adicionalmente, planificar el desarrollo de una sociedad implica planificar el uso de los recursos humanos, tanto en términos de la fuerza de trabajo propiamente tal como de sectores tradicionalmente ajenos a ella, tales como los estudiantes, las dueñas de casa y otros.

En resumen, las metas del desarrollo quedan parcialmente determinadas por factores demográficos; el desarrollo contribuye a determinar las características de variables demográficas básicas, y la planificación del desarrollo implica, entre otras cosas, planificar el empleo de la capacidad de trabajo de la población. El conocimiento de estas interrelaciones entre las variables demográficas $y$ las socio-económicas es bastante deficiente y rara vez se las toma en cuenta en forma sistemática en la planificación nacional. Por otra parte, las estadísticas demográficas de los paises latinoamericanos son generalmente insuficientes, en mayor o menor medida, para suministrar la información que se necesita para estos propósitos y la que hay disponible no se usa siempre de la manera más eficiente.

En estas condiciones, la incorporación de la variable población en los planes de desarrollo requiere, en primer lugar, de adecuadas medida y proyección de las variables demográficas $y$, en segundo término, de modelos que representen las interrelaciones entre éstas y las principales variables socio-económicas del plan de desarrollo. 
A continuación se señalan algunos de los aspectos de población que es necesario tener en cuenta en la planificación sectorial y en la determinación de las metas de ahorro-inversión.

\section{EDUCACION}

La necesidad de tomar en cuenta las variables demográficas se hace evidente al planear el desarrollo del sistema educacional. Aquí, en este sector, son consideraciones de importancia fundamental el tamaño actual y estimado de la población, su composición por edades y distribución geográfica. Igualmente, deben examinarse los efectos de una mayor educación sobre la fecundidad, con el fin de coordinar las metas del desarrollo educacional con aquellas de una politica nacional de población.

En educación, no obstante el carácter nacional que deben tener los sistemas educativos, la diferenciación por regiones es indispensable por dos razones básicas: a) la estructura de la población por edades y sexos es específica para cada región y probablemente distinta de las restantes, $y$ b) las caracteristicas socio-económicas de las regiones, incluso sus niveles educativos, son distintas y, por tanto, lo son sus requerimientos educativos.

La planificación del desarrollo educativo en regiones de emigración neta plantea problemas distintos de los que se encuentran en las regiones de inmigración neta. Estas diferencias son muy significativas cuando las migraciones internas son tan intensas como en América Latina y afectan a variables tan importantes como: a) los cambios en la estructura interna del sistema educativo de acuerdo con los cambios en la estructura por edades de la población escolar, b) el volumen y composición de las inversiones y de los gastos de mantenimiento, influidos por el tamaño y crecimiento de la población escolar, c) la composición por ramas y niveles del sistema educativo determinada por el tamaño, composición por edades y vocaciones de la población escolar y por las necesidades de capacitación de la fuerza de trabajo, d) la orientación y contenido de los planes y programas de estudio de acuerdo con el papel que se le asigne a la educación de preparar para la emigración a las ciudades, para adaptar a los inmigrantes, para fines de colonización, etc.

Es. evidente, además, que las rápidas tasas de expansión de la matricula tienen consecuencias sobre la eficiencia de los sistemas escolares, manifestadas sobre todo en su capacidad de retención y condicionando, por lo tanto, el logro de las metas educativas contenidas en los planes respectivos.

Por otra parte, la repartición geográfica de los servicios educativos es un factor de radicación poblacional de gran importancia como instrumento para ayudar a cumplir las metas de reparto geográfico de la población. 
El problema de planificación de la salud en países subdesarrollados exige también un conocimiento detallado de la distribución geográfica de la población y de las tasas de incidencia de las principales causas de mortalidad y de morbilidad. Por la circunstancia de que este último fenómeno es particularmente mal detectado por nuestros sistemas estadísticos, se hace necesario diseñar encuestas específicas de amplio alcance con el fin de obtener un conocimiento adecuado del fenómeno. Ahora bien, a corto plazo, algunos de los recursos médicos y para-médicos son más o menos fijos y aun a largo plazo, su tasa de crecimiento puede estar limitada por varias restricciones, lo que exige diseñar una utilización óptima de los recursos disponibles en términos de reducir al mínimo posible alguna de las incidencias de morbilidad, no dejando que otras causas incorporadas al plan sean superiores a cierto límite acordado.

En esta forma, puede también corregirse la distribución espacial de los recursos médicos y hospitalarios, haciéndolos más acordes con la distribución geográfica de la masa total de enfermos. Es bien sabido que muchos de los paises de América Latina tienen concentrados sus escasos recursos médicos en la capital y en unas pocas ciudades principales, lo cual determina una marcada desutilización de aquéllos. Este serio problema sólo puede resolverse mediante un mejor conocimiento de los hechos demográficos y su articulación a modelos de "optimización" que son más complejos en el caso de la salud, a causa de la pluralidad de manifestaciones de la morbilidad.

\section{DESARROLLO URBANO}

Aun cuando generalmente no figuran explícitamente planes de desarrollo urbano en los programas nacionales de desarrollo económico y social, es evidente que el problema de la urbanización, en sus aspectos tanto positivos como negativos, ocupa cada día más la atención de los planificadores. La concentración urbana ha sido muy rápida en América Latina y lo seguirá siendo por mucho tiempo como parte del proceso de industrialización y como resultado del rechazo de población por el sector rural de baja productividad. Una planificación futura del crecimiento urbano como problema nacional tiene que partir de datos demográficos básicos y requiere conocer, en consecuencia, las estructuras por edades en las áreas rurales y urbanas, la estructura ocupacional y las tasas de actividad; requiere, asimismo, el conocimiento de las corrientes migratorias y sus tendencias.

Además, en los planes sectoriales figuran programas de inversión en infraestructura urbana que fundamentalmente deben obedecer tanto a cálculos del déficit preexistente como a proyecciones a base de datos 
demográficos y otros de indole económica y social. Este es el caso de planes para introducir y ampliar sistemas de agua potable y drenaje, transporte urbano, pavimentación $\mathrm{y}$ otros servicios similares (por ejemplo, teléfonos y alumbrado).

Entre los planes sectoriales, ocupan siempre un lugar muy destacado los planes de vivienda para los cuales se requieren conocimientos muy precisos de las características de la población urbana, del tamaño de la familia, de la migración a las ciudades, de la distribución ocupacional, etc., y de datos de carácter económico indicadores de la capacidad de pago.

Uno de los elementos nuevos en la planificación es la tendencia en algunos países a descentralizar la industria, lo cual supone tomar en cuenta las tasas diferenciales de crecimiento urbano por tamaños de ciudades, que se basa, nuevamente, en análisis demográfico.

\section{DESARROLLO RURAL}

En lo que concierne a los problemas del desarrollo rural, las relaciones mutuas entre las variables socio-económicas y las demográficas se encuentran condicionadas por los siguientes factores:

a) la relación "hombre-tierra";

b) los sistemas de tenencia, la tecnología productiva y el nivel de empleo;

c) la demanda global de productos agropecuarios;

d) las migraciones internas;

e) la extensión de algunos servicios básicos a las zonas rurales, y

f) la creación de fuentes de trabajo no agrícola en esas mismas zonas.

El examen de estas relaciones reviste especial importancia para el planificador. En efecto, es un aspecto estratégico de la programación del desarrollo nacional el definir con propiedad el papel de la agricultura y las implicaciones ulteriores de mantener una "agricultura campesina".

Dadas ciertas tendencias demográficas, recursos, tierras disponibles, y la naturaleza y modalidades del desarrollo nacional, una cuestión imprescindible es decidir si el papel de la agricultura sería sólo satisfacer la demanda de productos agropecuarios, o contribuir a crear fuentes de empleo y a corregir en parte algunas desigualdades en la distribución de los ingresos. Esta decisión tiene implicaciones en el sentido de favorecer o no la formación de una economía campesina.

Lo anterior lleva a la conclusión de que la relación hombre-tierra y su proyección futura es un aspecto fundamental en la elección de tecnologías productivas (densidad de capital vs. densidad de mano de obra) y determina el nivel de empleo, monto y composición de las inversiones agrícolas reproductivas, y monto del ingreso neto de las 
familias campesinas. Las implicaciones institucionales de esa relación afectan los sistemas de tenencia de la tierra y distribución de los ingresos, favoreciendo o no la formación de una demanda campesina de artículos de producción industrial.

A su vez, la reorientación de las actividades agrícolas tiene consecuencias sobre el desarrollo rural, en especial, la dotación de servicios, organización económica social, formas de participación, calificación de la fuerza de trabajo y creación de fuentes de empleo no agrícola.

\section{EMPLEO Y MANO DE OBRA}

En vista de que entre los objetivos actuales de la planificación económica y social figura el de proveer el mayor volumen posible de ocupación a nuevos ingresantes a la fuerza de trabajo, asi como reducir el desempleo y el subempleo, es indispensable en las tareas de planificación tener un conocimiento adecuado de las caracteristicas de la fuerza de trabajo y de los cambios que ocurren en ella. En particular, es necesario conocer la estructura por edades de la fuerza de trabajo masculina y femenina, urbana y rural, clasificada por ocupaciones, para obtener el perfil de calificación de la misma, y clasificada por años de educación para obtener el perfil educativo. Estos análisis necesitan reforzarse con encuestas especiales sobre la calificación del trabajo en determinadas industrias o en determinadas regiones. En la planificación sectorial y regional, y dentro de ella la de ramos industriales específicos, una de las principales incógnitas es siempre la disponibilidad de personal calificado de nivel intermedio y superior. El análisis demográfico y el de las estructuras de calificación pueden contribuir mucho a la solución de los problemas respectivos.

Además, existen métodos de proyecciones de las necesidades de fuerza de trabajo y de los niveles requeridos de calificación que han sido utilizados en varios países europeos pero todavía muy escasamente en América Latina. Se necesita ahondar en estas técnicas de proyecciones y crear mayor conciencia de la necesidad de esta clase de trabajos.

Entre varios paises latinoamericanos existen movimientos migratorios, algunos de carácter estacional, otros permanentes, derivados en gran parte de diferencias locales o regionales en las perspectivas de desarrollo y en los niveles de ingreso. Los planes de desarrollo relativos a esas áreas necesitan contar con un conocimiento detallado de las características de la población emigrante y de sus tendencias con objeto de prever, ya sea si se deberá prescindir de dichas migraciones en el futuro o si deberán considerarse como un factor permanente y necesario como contingente de fuerza de trabajo para la agricultura e industrias agrícolas u otros sectores. Cualquiera que sea la política que en definitiva siga un país respecto a la migración de 
trabajadores, para su éxito y cumplimiento se requiere conocer la situación mediante el análisis demográfico.

En algunos países latinoamericanos continúa existiendo una apreciable inmigración internacional de población de países no latinoamericanos. Rara vez existe una política explícita al respecto, pero se supone que, en general, se prefiere la inmigración de técnicos y fuerza de trabajo calificada. Sin embargo, no se ha hecho un análisis suficiente ni de las características de la población recientemente inmigrada ni de las condiciones prevalecientes en los paises europeos y otros de emigración. Es ésta un área que requiere una estrecha colaboración entre el análisis demográfico y la planificación de la calificación y oferta de fuerza de trabajo de nivel medio y superior.

Otro aspecto del trabajo del planificador, al que se debe incorporar el conocimiento de las variables demográficas, es el que se refiere a los requisitos de empleos para manter la ocupación plena o semi-plena de la futura fuerza laboral. A este propósito, además del conocimiento de la distribución de la población por sexo y edad, es necesario disponer de criterios adecuados sobre la evolución de las tasas de participación y de empleo entre los participantes, presumiblemente influidos, por los esfuerzos mismos de la planificación. Si una de las metas del plan de desarrollo es controlar el nivel de desempleo y de subempleo, será necesario propiciar actividades y tecnologías intensivas en el uso de la mano de obra, particularmente en las primeras etapas del plan.

\section{Población y ahorro}

La relación entre la capacidad de ahorro y las variables demográficas es un asunto todavía bastante controvertible. De una parte, se afirma que una elevada tasa de crecimiento vegetativo y su consecuente alta tasa de dependencia, determinan un bajo coeficiente de ahorro. Esta posibilidad puede verse contradicha en la realidad, en la medida en que exista una fuerte concentración de la capacidad de ahorro en manos de un pequeño grupo, o una considerable tasa de sustitución entre el consumo y el tiempo libre de los adultos por el consumo de los niños.

Sin embargo, es claro que dados un coeficiente de ahorro y una relación capital-producto, la eficacia del primero en impulsar el desarrollo económico varía inversamente a la tasa de crecimiento demográfico. Así, por ejemplo, con una tasa capital producto de 4,0 y una tasa de crecimiento de tres por ciento anual, sería necesario disponer del doce por ciento de coeficiente de ahorro neto simplemente para mantener constante el ingreso per cápita de la población. Ese doce por ciento del ingreso total que fuese ahorrado sería apenas suficiente para atender las necesidades del aumento de la población, sin mejorar su nivel de bienestar. Para elevar el ingreso per cápita en un uno por ciento anual, se requeriría ahorrar el 16 por ciento del producto. En otros 
términos, cada uno por ciento más en el crecimiento anual de la población, exigiría cuatro por ciento adicional en el coeficiente de ahorro neto para preservar el ritmo de crecimiento económico. Este raciocinio resulta bastante simplificado, en cuanto no incorpora los posibles cambios de la tasa capital-producto como consecuencia del crecimiento de la fuerza de trabajo, del uso de tecnologías distintas, de mejoramientos de la productividad del trabajo, de empleo de otros insumos, de economías extensas y de escalas sobrevinientes. 


\section{CONTENIDO PROVISORIO DEL CURSO}

\section{Programa de Adiestramiento sobre Población y Planificación del Desarrollo}

I.-Introducción

- Antecedentes, propósitos y métodos.

II.-Interrelaciones a nivel macro-social

- Influencia del cambio económico sobre el crecimiento demográfico

- Visión histórica

- Nivel y composición del consumo

- Hábitos naturales, sociales y culturales

- Mortalidad

- Fecundidad

- Los problemas del plazo y la indeterminación

- Influencia del cambio demográfico sobre el crecimiento económico

- El consumo, el ahorro y la inversión

- El tamaño y composición de los mercados

- De consumo

- De trabajo

- Los modelos de interrelación

- Algunos modelos seleccionados

- La "neutralidad" de los modelos

- Migraciones y desarrollo

- Migración rural-urbana e industrialización

- Productividad y empleo rurales

- Empleo, servicios y condiciones de vida urbanas

- Patrones alternativos de repartición geográfica de la población y la actividad económica

- La interpretación histórica

- Economía de exportación

- Algunas experiencias (Holanda, Israel, Inglaterra, Estados Unidos, etc.)

- Crecimiento demográfico y ocupación del suelo (C. Clark)

- Situación actual y perspectivas en América Latina 
III.-Interrelaciones y necesidades de información demográfica a nivel sectorial

t

- Educación

- Salud

- Desarrollo urbano

- Desarrollo rural

- Fuerzas de trabajo y recursos humanos

- Ahorro, inversión y empleo

IV.-Políticas de Población

- Antecedentes

- Planificación del cambio social

- El requerimiento de la coherencia interna

- Mejoramiento de los niveles de vida y crecimiento demográfico

- Nivel y distribución del ingreso, el consumo y la educación

- Planificación de la familia y bienestar

- Alternativas extremas

- La definición de Caracas

- El control de la natalidad

- Elementos para una política de desarrollo y mejoramiento de la población

- Algunas caracteristicas de la población

- El ejercicio de Burgeois-Pichat

- Inversiones demográficas

- Educación y otras condiciones de vida

- Planificación y desarrollo de los recursos humanos

- Organización y desarrollo de los mercados de trabajo

- Planificación del desarrollo y de la repartición geográfica de la población

\footnotetext{
Nota: Se espera que los organismos internacionales interesados, en consulta con los países y con la cooperación de expertos en la materia, elaboren un plan de estudios del curso que sea coherente con los lineamientos señalados en este documento.
} 
$\therefore$ 
GUIA BIBLIOGRAFICA DE ESTADISTICAS DEMOGRAFICAS Y SOCIALES

Comisión Económica para América Latina 


\section{INTRODUCCION}

1. Desde la iniciación del decenio de 1960 tanto los organismos internacionales como las instituciones nacionales de estadística, economía y planificación vienen preocupándose de la planificación del desarrollo y de las necesidades concomitantes de información. Entre éstas destacan las relativas a las variables demográficas y a aspectos tales como educación, sanidad, vivienda, hogares, mano de obra, agricultura, industria, nivel de vida, ingresos y bienestar social.

2. Las Naciones Unidas, teniendo en cuenta la necesidad de contar para estos fines con estadísticas genuinas y actualizadas, publicó el documento "Utilización de los programas nacionales de análisis de los datos de los censos de población en la formulación de planes y políticas", 1 que constituye una guia sobre esta materia.

3. Asimismo, se organizó el Seminario Interregional sobre la Aplicación de los Datos y Estudios Demográficos a la Planificación del Desarrollo (Kiev, 15 al 25 de septiembre de 1969), inspirado en el concepto de que "incumbe a los demógrafos proporcionar a políticos y planificadores un conocimiento estadístico satisfactorio de las tendencias y cambios de la población, así como de la interacción entre población y economía durante el proceso de desarrollo"..2

4. El Seminario reconoció la importancia de la guía preparada por las Naciones Unidas y subrayó la necesidad de desarrollar métodos y técnicas que permitan evaluar las relaciones recíprocas entre tendencias económicas y tendencias demográficas y que puedan ser fácilmente empleadas en los paises en desarrollo.

\section{A. La guia bibliográfica}

5. La presente guía bibliográfica se basa en la experiencia internacional vertida en el informe del Seminario de Kiev, sobre el tratamiento de la información estadística requerida para la formulación de programas de desarrollo económico y social, principalmente para los países en desarrollo, y presenta diez grandes cuadros referentes a los temas discutidos en ese Seminario.

1/ Naciones Unidas, ST/SOA/Series A/36, Nueva York 1964.

2/ Naciones Unidas, documento E/CN.9/223, 4 de octubre de 1969. 
6. El propósito de la guía es proporcionar a los investigadores y planificadores de los paises americanos un instrumento bibliográfico, por paises, que les permita conocer la naturaleza de la documentación estadística más reciente disponible, y los temas específicos que ésta contiene y que son requeridos para la formulación de programas de desarrollo.

7. Los temas son los siguientes:

I. Estado, estructura y crecimiento de la población.

II. Mano de obra.

III. Población, alimentación y agricultura.

IV. Educación.

V. Salud.

VI. Población, vivienda y hogar.

VII. Migración interna y urbanización.

VIII. Nivel de vida.

IX. Desarrollo social.

X. Fecundidad y planificación familiar.

8. Cada cuadro contiene en el encabezamiento los nombres de veinte naciones latinoamericanas $y$, en la columna matriz, los temas específicos integrantes del gran tema que corresponde al cuadro. La bibliografía señalada corresponde: i) a tèmas específicos investigados por los censos y presentados en las respectivas publicaciones en forma simple y combinada, y ii) a temas específicos de las estadísticas continuas demográficas y sociales. En contados casos se señalan estadísticas obtenidas en encuestas especiales de los países, y esto sólo cuando han sido reproducidas en una publicación de carácter internacional.

9. La denominación individual de estos temas ha sido ajustada en la mejor forma posible a la manera como son presentados los datos tabulados en la mayoria de los países. A determinados temas no corresponde información alguna, para ningún país americano considerado en la guía (por lo menos no se tiene conocimiento de que haya esa información), pero se han incluido en la columna matriz por haber sido considerados importantes.

10. Cuando los temas se presentan con una clasificación detallada de atributos se han registrado, en algunos casos, en forma: de combinaciones más simples que corresponden mejor a la forma como las han presentado en la práctica los paises en sus publicaciones. Con todo, se han anotado siempre los temas en los cuadros en su forma original, inmediatamente después de su presentación en forma más simple.

11. Por tratarse de una guía bibliográfica, estos cuadros no contienen información numérica alguna sobre los temas, pero si señalan la 
naturaleza de la fuente estadística directa, donde el investigador encontrará los datos más recientes disponibles, distinguiéndose si esa fuente es una publicación nacional o internacional y señalándose las fechas de referencia de la información y de identificación de la publicación.

12. Para facilitar la referencia bibliográfica sobre cualquier tema estadístico se han utilizado códigos los cuales emplean solamente cifras arábigas o una combinación de letras mayúsculas y de cifras arábigas. Se emplean así tres códigos diferentes, el primero de los cuales se refiere exclusivamente al año o período de tiempo al cual se refiere el dato. Los otros dos códigos se aplican uno, a la naturaleza de la publicación que contiene el dato $y$, el otro, al año de identificación de la publicación el cual puede o no puede coincidir con el de aparición de la misma. Entre código y código se han situado dos puntos para separar uno de otro y facilitar asi al lector su interpretación.

13. Para el primer código, aplicado al año o período de referencia del dato, se utilizan solamente números compuestos de dos cifras (código exclusivamente numérico) correspondientes al año respectivo; así 69 , significa el año 1969; 58, el año 1958; etc. Cuando se trata de un periodo de tiempo al cual se aplica, por ejemplo, una serie estadística de datos, se registran las dos últimas cifras del año inicial del periodo y las dos últimas cifras del año final del mismo período, separadas por un guión; así 52 - 54, significa el período 1952 - 1954;61-65, significa el periodo 1961 - 1965.

14. Para el segundo código se emplean letras mayúsculas y cifras (código literal-numérico) y siempre este código empieza con una o dos letras mayúsculas. Asi por ejemplo una "I" mayúscula, significa que se trata de una publicación de un organismo internacional y dos letras mayúsculas, corresponden a la clave elegida para sustituir el nombre completo del país al que corresponde la publicación. Inmediatamente después de la o las letras mayúsculas, separadas por un solo punto, aparece una cifra que sirve para identificar el nombre de la publicación internacional o nacional. Esta última identificación de la publicación internacional o nacional se obtiene buscando el código respectivo en el Anexo I de esta Guía. Cabe señalar que, dentro del mismo código, sus partes integrantes están separadas por un punto. En cambio, entre código y código, la separación está dada por dos puntos.

15. El tercer código está compuesto de dos cifras o de una sola. En el primer caso, las dos cifras corresponden a las dos últimas del año de identificación de la publicación; y cuando se trata de una sola cifra, ésta corresponde al número del tomo o volúmen que identifica la publicación.

16. Una flecha horizontal se usa para indicar que el código correspondiente a un país es también válido para otros países. Se ha ubicado entonces la flecha en todos los paises que corresponde. Cuando 
no se ha dispuesto de información alguna sobre un tema, en lugar del código respectivo, 'se han anotado tres puntos seguidos. (...).

17. A continuación se dan algunos ejemplos de aplicación de los códigos que se acaban de explicar:

a) Caso de publicaciones internacionales

Cuadro I. Estado, estructura y crecimiento de la población

\begin{tabular}{lr}
\hline TEMAS & \multicolumn{1}{c}{ BRASIL } \\
\hline Población censada por división administrativa & $60:$ I. $4: 70$ \\
Proyecciones de población por sexo y grupos de edades & $65-85:$ I. 12: 4 \\
\hline
\end{tabular}

18. Para el primer tema, los tres códigos significan que el último dato disponible en el país corresponde al año 1960; que dicho dato está contenido en una publicación internacional (I) individualizada en el Anexo de esta guía por la cifra 4. Buscando en el Anexo la lista de códigos, se verá que se trata de lá publicación "América en Cifras: Situación Demográfica", del Instituto Interamericano de Estadística. En cuanto al tercer código (70), indica que la fecha de aparición de esta publicación es el año 1970.

19. Para el segundo tema, el triple código significa que se trata de una serie de datos correspondientes al período comprendido entre los años 1965 y 1985; que dicha serie de datos está incluida en una publicación internacional (I), individualizada por el código 12. Buscando en la lista de códigos del Anexo se verá que tal publicación corresponde al "Boletín Estadístico de CELADE". En cuanto al tercer código (4), indica que se trata del Boletín $N^{\circ} 4$ de CELADE.

\section{b) Caso de publicaciones nacionales}

Cuadro I. Estado, estructura y crecimiento de la población

\begin{tabular}{ll}
\hline TEMAS & BRASIL \\
\hline Defunciones fetales & $66:$ BR. $3: 69$ \\
\hline
\end{tabular}

20. Para este tema, el primer código compuesto de dos dígitos indica que se trata de un dato correspondiente al año 1966; el segundo código (BR.3) señala que se trata de una publicación brasileña (BR) la que está individualizada según la lista del Anexo (cifra 3 ) como la "Actualidade Estatística do Brasil". En cuanto al tercer código (69), señala que se trata de una publicación identificada para el año 1969. 


\section{B. Comentarios sobre la información estadistica señalada por la guía}

21. Cabe señalar que estos comentarios son muy generales, pues sólo se ha tratado de dar una visión panorámica sobre la disponibilidad de determinadas estadísticas en los países americanos. Además, no tienen la finaliidad de discutir los problemas de cobertura y confiabilidad de la información estadística, pues sólo un estudio profundo, país por país, realizado por especialistas muy enterados de los propios países podría arrojar luces sobre ese asunto.

22. Por otro lado, debe tenerse presente que esta guía bibliográfica no es más que un primer intento, en manera alguna exhaustivo, y que para completar esa guía habría que recibir mayores informaciones de los propios países americanos sobre las estadísticas demográficas $y$ sociales, que son las que abarca principalmente esta guía.

23. Si bien es cierto que en la guía se hace referencia a algunas estadísticas económicas, se está lejos de haber abordado este tema en su integridad, quedando aún un buen trabajo a realizar a este respecto.

24. En lo concerniente a la producción de estadísticas demográficas los países americanos han realizado un gran avance en el último decenio, gracias en parte a los esfuerzos de las Oficinas de Población y de Estadística de las Naciones Unidas, que han preparado abundante material metodológico relacionado con el levantamiento de los censos de población y habitación y la producción de estadísticas demográficas continuas; han distribuido manuales y otras publicaciones técnicas para orientar los análisis demográficos y han creado centros para la enseñanza de la demografía de los cuales existe uno en la región americana (CELADE) con sede en Santiago de Chile, y una subsede en San José de Costa Rica. Con todo, existen aún variables demográficas no suficientemente investigadas y por tanto conocidas estadísticamente, sobre todo en cuanto a sus interrelaciones con otros temas sociales y económicos. A este último respecto se tiene una reciente y valiosa información en el informe del Seminario de Kiev.

25. En cuanto a las estadísticas sociales (educación, salud, vivienda, trabajo, etc.) la producción de información es en diversos aspectos inferior al de las estadísticas demográficas y ello se puede comprobar en los cuadros que integran la guía bibliográfica, no obstante el esfuerzo de los organismos internacionales interesados y las medidas tomadas por las entidades estadísticas de diversos países americanos.

26. Una revisión general de los diez cuadros presentados, señala entre otras, las siguientes situaciones, sobre algunas de las estadísticas demográficas, sociales y algunas económicas, que se han especificado.

27. Hay falta evidente de información sobre temas especificos diversos en todos los cuadros, para un número más o menos variado de países. De manera especial se destaca la ausencia de información sobre: 
i) nacimientos según el nivel de educación de los padres; la ocupación y la categoría de ocupación del padre; defunciones por ocupación del difunto; número de defunciones fetales urbanas y rurales; divorcios según el número de hijos dependientes; tasas netas de reproducción. (Cuadro I);

ii) población económicamente activa por nivel de instrucción y por rama de actividad económica y nivel de instrucción; indicadores de empleo; salarios en las industrias de construcción y de comunicaciones; horas trabajadas (Cuadro II);

iii) retención escolar en el segundo nivel; repitentes de primero y segundo nivel; deserción escolar en primero y segundo nivel (Cuadro IV);

iv) egresados hospitalarios según diagnóstico; condiciones de egreso hospitalario; visitas domiciliarias de servicios de salud; existencia de equipos hospitalarios y su presupuesto (Cuadro V);

v) existencia de equipos en las viviendas (radio, refrigerador, cocina, etc.) (Cuadro VI);

vi) ingreso familiar y gastos de consumo del hogar (Cuadro VIII);

vii) información sobre guarderias infantiles; estadísticas judiciales; hogares según categoría socio-económica del padre y personas a cargo (Cuadro IX).

28. La pobreza de la información es general sobre ciertos temas principales: "mano de obra" (Cuadro II); "población, alimentación y agricultura" (Cuadro III); "migración interna y urbanización" (Cuadro VII); "fecundidad y planificación familiar" (Cuadro X).

29. La mayoría de los cuadros señala una bibliografía predominantemente internacional (Cuadros I, III, IV, V, VI, VIII, IX, y $\mathrm{X})$. Esto se debe a que en la etapa de selección de la bibliografía se estimó mejor utilizar aquella que contenía simultáneamente información sobre el mayor número de países. De esta manera el investigador no tendrá que recurrir a una bibliografía múltiple para disponer de datos sobre el mismo tema para diversos países. Paralelamente se tomó en cuenta también la circunstancia de que existiera, en la misma fuente bibliográfica, la mayor variedad de temas especificos para diversos países. En general estas condiciones son satisfechas por las publicaciones de los organismos internacionales.

30. Los cuadros restantes contienen, en cambio una bibliografía predominantemente nacional (Cuadros II y VII). Dentro del mismo planteamiento seguido para el caso anterior, esta situación se debe al hecho de no haberse encontrado una misma fuente bibliográfica que contenga información para diversos países, sobre los temas específicos de los dos cuadros señalados. Por ese motivo, ha debido concretarse la 
guía a señalar las diversas fuentes nacionales que contienen la información requerida. En estos casos el investigador tendrá que utilizar necesariamente una bibliografía múltiple.

31. Aunque la mayor o menor producción de estadísticas en los países americanos es asunto de organización interna y también de recursos económicos y técnicos entre los que merecen especial mención la dotación de personal capacitado, hay un aspecto negativo relativamente fácil de subsanar. Se trata de lo tardio de la presentación de las estadísticas existentes, o sea, que para diversos temas específicos están muy lejos de ser oportunas y por tanto de actualidad.

32. Esto se puede comprobar al analizar los diez cuadros de la guía. Con excepción de las estadisticas censales que, por razones obvias, están disponibles en lo que concierne al decenio de 1960 , las estadísticas continuas acusan un general retraso en cuanto a su-fecha de referencia. Se tienen asi:

i) estadísticas demográficas con antigüedad de cuatro a seis años (Cuadro I);

ii) estadísticas de mano de obra con antigüedad de tres a seis años. Para los países que las tienen más actualizadas, acusan dos años de antigüedad (Cuadro II);

iii) muy pocas estadísticas de población, alimentación y agricultura tienen una antigüedad de dos y íres años. Para la mayoría de los países es mayor (Cuadro III);

iv) estadísticas de educación cuya antigüedad oscila entre los dos y diez años (Cuadro IV);

v) estadísticas de salud con antigüedad de tres a siete años (Cuadro V);

vi) estadísticas de población, vivienda y hogar, con tres y cuatro años de antigüedad, entre las más recientes (Cuadro VI);

vii) estadísticas de migración interna y urbanización, la mayoría de las cuales corresponden a alrededor del año 1960 (Cuadro VII);

viii) estadísticas de seguro social con cuatro años de antigüedad y otras estadísticas vinculadas con el nivel de vida, con cinco y seis años de antigüedad.

ix) estadísticas sobre desarrollo social con cinco años de antigüedad. Contadas estadísticas se refieren a los años 1967 y 1969 (Cuadro IX);

x) las estadísticas sobre fecundidad acusan más o menos la misma antigüedad que las ya señaladas para el Cuadro I.

33. Como se ve, la situación es mucho más grave en lo que concierne al conjunto de estadísticas sociales.

34. La comparabilidad internacional de los datos estadísticos demográficos y sociales -en el supuesto de que no existan deficiencias 
en cuanto a su cohertura geográfica o su referencia al grupo humano al cual se aplican-por lo general esta garantizada por la existencia de definiciones y estándares de investigación y de clasificaciones especiales, oportuna y sistemáticamente revisadas y publicadas por los organismos internacionales interesados, como las Naciones Unidas (Oficinas de Estadística y de Población); la Organización de las Naciones Unidas para la Agricultura y la Alimentación (FAO); la oficina Internacional del Trabajo (OIT); y la Organización Mundial de la Salud (OMS). Sin embargo, en algunos casos se hace indispensable al investigador la prudente revisión de las definiciones o normas de recopilación estadística seguidas por los países en determinados campos (por ejemplo, los periodos de referencia en la investigación de la población económicamente activa) a fin de garantizar las conclusiones derivadas de sus comparaciones o análisis. 
I. ESTADO, ESTRUCTURA Y CRECIMIENTO DE LA POBLACION

\begin{tabular}{|c|c|c|c|c|c|c|c|c|c|c|}
\hline Temas & Argentina & Bolivia & Brasil & Colombia & Chile & Ecuador & Paraguay & Perú & Uruguay & Venezuela \\
\hline $\begin{array}{l}\text { Población censada } \\
\text { Total } \\
\text { Por División Administrativa } \\
\text { Por arrea urbana rural } \\
\text { Menor de } 25 \text { años por sexo y años simples } \\
\text { Por sexo y grupos de edades }\end{array}$ & $\begin{array}{l}\text { 60:I.27:71 } \\
60: I .4: 70 \\
60: I .27: 71 \\
\text { 60:I.15:70 } \\
\text { 60:Ar.6:60 }\end{array}$ & $\begin{array}{l}\text { 50:I.27:71 } \\
50: \text { BO.4:50 } \\
50: I .27: 71 \\
\text { 50:I.15:70 } \\
50: \text { Bo.4:50 }\end{array}$ & $\begin{array}{l}\text { 60:I.27:71 } \\
60: I .4: 70 \\
60: I .27: 71 \\
60: I .15: 70 \\
60: B r .2: 60\end{array}$ & $\begin{array}{l}\text { 64:I.27:71 } \\
\text { 64:I.4:70 } \\
\text { 64:I.27:71 } \\
\text { 64:I.15:70 } \\
\text { 64:Co.6:64 }\end{array}$ & $\begin{array}{l}\text { 60:I.27:71 } \\
\text { 60:I.4:70 } \\
\text { 60:I.27:71 } \\
\text { 60:I.15:70 } \\
\text { 60:Ch.8:60 }\end{array}$ & $\begin{array}{l}\text { 62:I.27:71 } \\
62: 1.4: 70 \\
62: I .27: 71 \\
62: 1.15: 70 \\
62: \text { Ec.7:62 }\end{array}$ & $\begin{array}{l}\text { 62:I.27:71 } \\
\text { 62:1.4:70 } \\
\text { 62:I.27:71 } \\
\text { 62:I.15:70 } \\
\text { 62:Pr.3:62 }\end{array}$ & $\begin{array}{l}\text { 61:I.27:71 } \\
61: 1.4: 70 \\
\text { 61:I.27:71 } \\
\text { 61:I.15:70 } \\
\text { 61:Pe.4:61 }\end{array}$ & $\begin{array}{l}\text { 63:I.27:71 } \\
63: 1.4: 70 \\
63: 1.27: 71 \\
63: 1.15: 70 \\
63: \text { Ur.2:63 }\end{array}$ & $\begin{array}{l}\text { 61:I.27:71 } \\
61: 1.4: 70 \\
61: I .27: 71 \\
61: I .15: 70 \\
61: \text { Ve.3:61 }\end{array}$ \\
\hline $\begin{array}{l}\text { Por características educativas } \\
\text { Por características económicas }\end{array}$ & $\longleftarrow$ & & & & $\longrightarrow \begin{array}{l}\text { Ver } \\
\text { Ver }\end{array}$ & $\begin{array}{l}\text { 62:Ec.7:62 } \\
\text { Ver tema IV } \\
\text { Ver tema II }\end{array}$ & 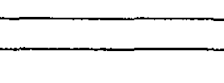 & & & $\longrightarrow$ \\
\hline $\begin{array}{l}\text { Población estimada } \\
\quad \text { Total } \\
\text { Por sexo y edad } \\
\text { Por área urbana y rural }\end{array}$ & $\begin{array}{c}\text { 60-69:I.1:69 } \\
70: I .2: 70 \\
\ldots\end{array}$ & $\begin{array}{c}\text { 60-69:I.1:69 } \\
70: I .2: 70 \\
\ldots\end{array}$ & $\begin{array}{c}\text { 60-69:I.1:69 } \\
\ldots \\
\cdots\end{array}$ & $\begin{array}{c}\text { 60-69:I.1:69 } \\
\text { 68:I.4:70 } \\
\ldots\end{array}$ & $\begin{array}{l}\text { 60-69:I.1:69 } \\
\text { 69:I.2:70 } \\
\text { 69:I.1:69 }\end{array}$ & $\begin{array}{c}\text { 60-69:I.1:69 } \\
\text { 69:I.2:70 } \\
\cdots\end{array}$ & $\begin{array}{c}\text { 60-69:I.1:69 } \\
\ldots \\
\ldots\end{array}$ & $\begin{array}{l}\text { 60-69:I.1:69 } \\
68: I .1: 69 \\
\text { 69:I.1:69 }\end{array}$ & $\begin{array}{c}\text { 60-69:I.1:69 } \\
\text { 68:I.4:70 } \\
\ldots\end{array}$ & $\begin{array}{l}\text { 60-69:I.1:69 } \\
68: I .1: 69 \\
69: I .1: 69\end{array}$ \\
\hline $\begin{array}{l}\text { Proyecciones de población } \\
\text { Total } \\
\text { Por sexo y grupos de edades } \\
\text { Menor de } 25 \text { años por sexo y años simples }\end{array}$ & $\begin{array}{c}\text { 20-2000:I.12:7 } \\
655-85: I .12: 4 \\
85-200: I .12: 6 \\
65-85: I .12: 5\end{array}$ & $\begin{array}{c}\text { 20-2000:I.12:7 } \\
65: 85: I .12: 4 \\
\text { 85-200:I.12:6 } \\
\text { 65-85.I.12:5 }\end{array}$ & $\begin{array}{c}20-2000: I .12: 7 \\
65-85: I .12: 4 \\
85-2000: I .12: 6 \\
65-85 . I .12: 5\end{array}$ & $\begin{array}{c}\text { 20-2000:I.12:7 } \\
\text { 65-85:I.12:4 } \\
\text { 85-2000:I.12:6 } \\
\text { 65-85:I.12:5 }\end{array}$ & $\begin{array}{l}\text { 20-2000:I.12:7 } \\
\text { 65-85:I.12:4 } \\
\text { 85-2000:I.12:6 } \\
\text { 65-85:I.12:5 }\end{array}$ & $\begin{array}{l}\text { 20-2000:I.12:7 } \\
65-85: I .12: 4 \\
\text { 85-2000:I.12:6 } \\
65-85: I .12: 5\end{array}$ & $\begin{array}{c}20-2000: I .12: 7 \\
65-85: I .12: 4 \\
\text { 85-2000:I.12:6 } \\
\text { 65-85.I.12:5 }\end{array}$ & $\begin{array}{c}\text { 20-2000:I.12:7 } \\
65-85: I .12: 4 \\
85-200: 1.12: 6 \\
65-85 . I .12: 5\end{array}$ & $\begin{array}{c}\text { 20-2000:I.12:7 } \\
65-85: I .12: 4 \\
\text { 85-200:I.12:6 } \\
\text { 65-85.I.12:5 }\end{array}$ & $\begin{array}{c}\text { 20-2000:I.12:7 } \\
\text { 65-85:I.12:4 } \\
\text { 85-200:I.12:6 } \\
\text { 65-85.I.12:5 }\end{array}$ \\
\hline $\begin{array}{l}\text { Nacidos vivos } \\
\text { Total } \\
\text { Por zonas urbana y rural } \\
\text { Por edad de la madre } \\
\text { Por orden de nacimiento } \\
\text { Por nivel de instrucción de los padres } \\
\text { Por ocupación del padre } \\
\text { Por categoría ocupacional del padre } \\
\text { Por legitimidad y sexo }\end{array}$ & $\begin{array}{c}\text { 67:I.16:71 } \\
\text { 66:I.1:69 } \\
\ldots \\
\ldots \\
\ldots \\
\text { 66:I.1:69 }\end{array}$ & $\begin{array}{c}\text { 67:II.16:71 } \\
\text { 65:I.4:70 } \\
\text { 65:1.4:70 } \\
\ldots \\
\ldots \\
\ldots \\
\ldots \\
\text { 65:1.4:70 }\end{array}$ & $\begin{array}{c}\text { 69:1.10:71 } \\
\ldots \\
\ldots \\
\ldots \\
\ldots \\
\ldots \\
\ldots\end{array}$ & $\begin{array}{c}\text { 68:I.16:71 } \\
\ldots . . \\
\text { 67:I.4:00 } \\
\text { 67:I.1:69 } \\
\ldots \\
\ldots \\
\text { 67:I.1:69 }\end{array}$ & 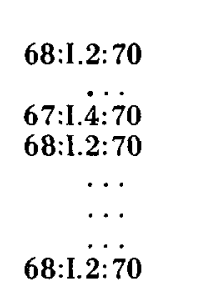 & $\begin{array}{c}\text { 68:I.16:71 } \\
\text { 68:I.2:70 } \\
\text { 68:1.2:70 } \\
\ldots \\
\ldots \\
\text { 66:I.1:69 }\end{array}$ & $\begin{array}{c}\text { 69:Pr.1:69 } \\
\ldots 0: 1.4: 70 \\
\ldots \\
\ldots \\
\ldots \\
\text { 69:PR.1:69 }\end{array}$ & $\begin{array}{c}\text { 67:I.16:71 } \\
\text { 65:I.1:69 } \\
\text { 65:1.1:69 } \\
\ldots \\
\ldots \\
\text { 65:I.1:69 }\end{array}$ & $\begin{array}{c}\text { 68:I.16:71 } \\
\ldots 3: 1.4: 70 \\
\ldots \\
\ldots \\
\ldots \\
\text { 63:I.1:69 }\end{array}$ & $\begin{array}{l}\text { 68:1.16:71 } \\
\text { 67:1.4:70 } \\
67: 1.1: 69 \\
67: 1.1: 69 \text { a/ } \\
67: 1.1: 69\end{array}$ \\
\hline $\begin{array}{l}\text { Defunciones } \\
\text { Total } \\
\text { Por zona urbana y rural } \\
\text { Por sexo y edad } \\
\text { Por ocupación }\end{array}$ & $\begin{array}{c}\text { 67:I.16:71 } \\
\text { 63:I.1:67 } \\
\text { 67:Ar.1:69 } \\
\ldots\end{array}$ & $\begin{array}{l}\text { 67:Bo.6:67 b/ } \\
\text { 65:I.4:70 } \\
\text { 66:I.1:69 } \\
\quad \cdots\end{array}$ & $\begin{array}{c}64: \text { Br. } 1: 70 \\
\ldots \\
\ldots \\
\ldots\end{array}$ & $\begin{array}{c}\text { 67:1.16:71 } \\
\text { 67:I.1:70 } \\
\text { 67:I.4:70 } \\
\ldots\end{array}$ & $\begin{array}{c}\text { 68:I.2:70 } \\
\text { 65:I.1:67 } \\
\text { 68:I.2: } 70 \\
\ldots\end{array}$ & $\begin{array}{c}\text { 68:I.2:70 } \\
\text { 65:1.1:67 } \\
\text { 68:I.2:70 } \\
\ldots\end{array}$ & $\begin{array}{c}\text { 69:Pr.1:69 } \\
\text { 69:Pr.1:69 } \\
69: \text { Pr.1:69 } \\
\ldots\end{array}$ & $\begin{array}{l}\text { 67:1.16:71 } \\
63: 1.1: 67 \\
64: 1.1: 69\end{array}$ & $\begin{array}{c}\text { 67:I.16:71 } \\
\text { 63:I.1:67 } \\
\text { 66:I.4:70 } \\
\ldots\end{array}$ & $\begin{array}{l}\text { 68:I.16:71 } \\
\text { 66:I.1:67 } \\
\text { 67:I:4:70 } \\
\text { 67:I.2:69 }\end{array}$ \\
\hline $\begin{array}{l}\text { Defunciones de menores de un año } \\
\text { Total } \\
\text { Por zona urbana y rural } \\
\text { Por sexo y edad }\end{array}$ & $\begin{array}{c}\text { 67:I.16:71 } \\
\text { 66.I.2:70 }\end{array}$ & $\begin{array}{c}\text { 67:Bo.6:67 b/ } \\
\text { 65:1.4:70 } \\
\ldots\end{array}$ & $\begin{array}{l}\text { 69:Br.1:70 } \\
\text { 69:I.1:70 } \mathrm{c}\end{array}$ & $\begin{array}{l}67: 1.16: 71 \\
67: 1.4: 70 \\
67: 1.2: 68 d\end{array}$ & $\begin{array}{c}68: 1.2: 70 \\
68: 1.2: 70\end{array}$ & $\begin{array}{l}\text { 68:I.2:70 } \\
\text { 66:I.4:70 } \\
\text { 68:I.2:70 }\end{array}$ & $\begin{array}{c}\text { 69:Pr.1:69 } \\
\text { 69:Pr.1:69 }\end{array}$ & $\begin{array}{c}67: 1.16: 71 \\
\ldots \\
\ldots\end{array}$ & $\begin{array}{c}67: I .16: 71 \\
66: I .2: 68\end{array}$ & $\begin{array}{l}68: \text { Ve.2:69 } \\
\text { 66:I.:2:68 e }\end{array}$ \\
\hline $\begin{array}{l}\text { Defunciones fetales } \\
\text { Total } \\
\text { Por zonas urbana y rural } \\
\text { Por edad de la madre } \\
\text { Por orden del nacimiento } \\
\text { Por período de gestación } \\
\text { Por legitimidad }\end{array}$ & $\begin{array}{c}\text { 67:I.1:69 } \\
\text { 66:I.2:69 } \\
\ldots \\
\text { 66:1.1:69 }\end{array}$ & $\begin{array}{l}\cdots \\
\cdots \\
\cdots \\
\cdots \\
\cdots\end{array}$ & $\begin{array}{c}66: \text { Br.3:69 } \\
\ldots \\
\ldots \\
\ldots \\
\ldots \\
\ldots\end{array}$ & $\begin{array}{l}\text { 67:I.1:69 } \\
67: 1.2: 68 \\
67: C 0.3: 214 \\
67: I: 1: 1: 9 \\
67: 1.1: 69\end{array}$ & $\begin{array}{l}\text { 68:I.2:70 } \\
\text { 68:1.2: } \\
\text { 68:I.2:70 } \\
\text { 67:I.1:69 }\end{array}$ & $\begin{array}{c}\text { 68:1.2:70 } \\
\text { 68:I.:. }: 70 \\
\text { 68:I.2:70 } \\
\text { 68:I.2:70 } \\
\ldots\end{array}$ & $\begin{array}{c}\text { 69:Pr.1:69 } \\
\ldots \\
\ldots \\
\ldots \\
\ldots \\
\ldots\end{array}$ & $\begin{array}{c}65: 1.1: 69 \\
\ldots \\
\cdots \\
\ldots \\
\ldots\end{array}$ & $\begin{array}{l}\text { 67:I.1:69 } \\
\text { 67:I.2:68 } \\
\text { 66:I.2:68 } \\
\text { 66:I.1:1:99 } \\
\text { 67:I.1:69 }\end{array}$ & $\begin{array}{l}\text { 67:L1:69 } \\
\text { 67:I.1: } 69 \\
\text { 67:L.1:69 } \\
\text { 67:I.1:69 } \\
\text { 67:I.1:69 }\end{array}$ \\
\hline
\end{tabular}


I. ESTADO, ESTRUCTURA Y CRECIMIENTO DE LA POBLACION (Continuación)

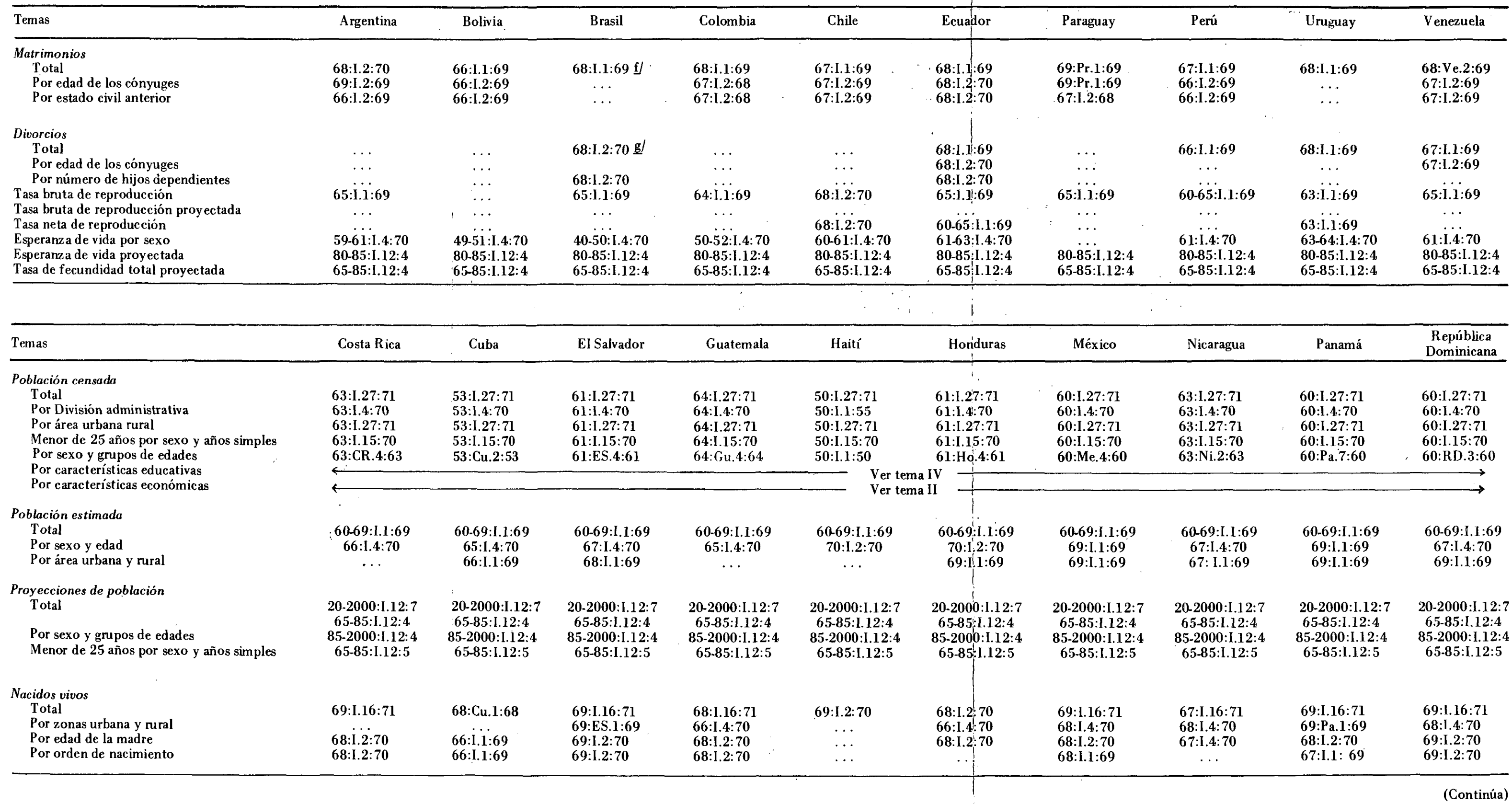


I. ESTADO, ESTRUCTURA Y CRECIMIENTO DE LA POBLACION (Conclusión)

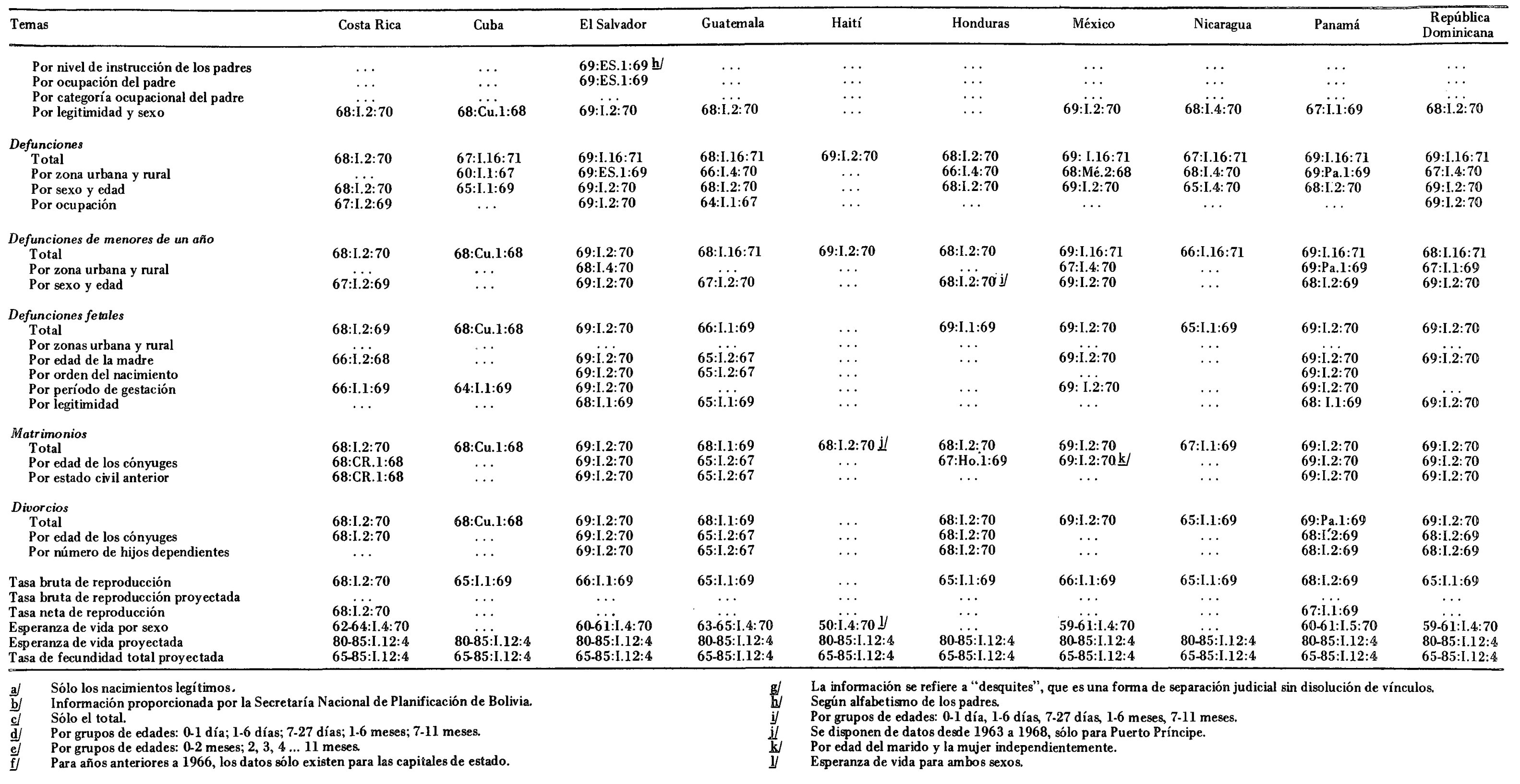


II. MANO DE OBRA

\begin{tabular}{|c|c|c|c|c|c|c|c|c|c|c|}
\hline Temas & Argentina & Bolivia & Brasil & Colombia & Chile & Ecuador & Paraguay & Perú & Uruguay & Venezuela \\
\hline Proyecciones de población activa & 50-85:I.12:3 & 50.85:I.12:3 & 50-85:I.12:3 & 50-85:I.12:3 & $50-85: I .12: 3$ & 50-85:I.12 & 50-85:I.12:3 & 50-85:I.12:3 & 50-85:I.12:3 & 50-85:I.12:3 \\
\hline \multicolumn{11}{|l|}{ Población económicamente activa censal } \\
\hline Total & 60:Ar.6:60 & $\begin{array}{l}\text { 50:Bo.4:50 } \\
\text { 58-67:Bo.2:67 }\end{array}$ & $\begin{array}{l}60: \mathrm{Br} .2: 60 \\
60: \mathrm{Br} .2: 60\end{array}$ & $\begin{array}{l}\text { 64:Co.6:64 } \\
\text { 64:Co.6:64. }\end{array}$ & $\begin{array}{l}\text { 60:Ch.8:60 } \\
\text { 60:Ch.8:60 }\end{array}$ & $\begin{array}{l}\text { 62:Ec.7:6: } \\
\text { 62:Ec.7:6 }\end{array}$ & $\begin{array}{l}\text { 62:Pr.3:62 } \\
62: \operatorname{Pr} 3: 62\end{array}$ & $\begin{array}{l}\text { 61:Pe.1:66 } \\
61: \ln 1: 66\end{array}$ & $\begin{array}{l}\text { 63:Ur.2:63 } \\
\text { 63: }\end{array}$ & 61:Ve.3:61 \\
\hline $\begin{array}{l}\text { Ocupados } \\
\text { Desocupados }\end{array}$ & $\begin{array}{l}\text { 60:Ar.6:60 } \\
60: A r .6: 60\end{array}$ & $\begin{array}{l}\text { 58-67:Bo.2:67 } \\
58-67: B 0.2: 67\end{array}$ & $\begin{array}{l}\text { 600:Br.2:60 } \\
60: B r .2: 60\end{array}$ & $\begin{array}{l}\text { 64:Co.6:64 } \\
\text { 64:0.0. }\end{array}$ & 60:Ch.8:60 & 62:Ec.7:6 & 62:Pr.3:62 & $\begin{array}{l}\text { 01:P. } 1: 00 \\
\text { 61:Pe.1:66 }\end{array}$ & $\begin{array}{l}\text { 63:Ur.2:63 } \\
63: \mathrm{Ur}_{r} \cdot 2 \cdot 63\end{array}$ & 61:Ve.3:61 \\
\hline $\begin{array}{l}\text { Desocupados } \\
\text { Por sexo y edad }\end{array}$ & $\begin{array}{l}\text { 60:Ar.6:60 } \\
\text { 60:Ar.6:60 }\end{array}$ & $\begin{array}{l}\text { 58-67:Bo.2:67 } \\
50 . \mathrm{Bo} .4: 50\end{array}$ & $60: \mathrm{Br} .2: 60$ & 64:Co.6:64 & 60.Ch.8:60. & 62:Ec.7:6 & 62:Pr.3:62 & $61: \mathrm{Pe} 1: 66$ & 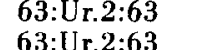 & 61:Ve.3:61 \\
\hline $\begin{array}{l}\text { Por sexo y edad } \\
\text { Por ocupación y sexo a/ }\end{array}$ & $\begin{array}{l}\text { 60:Ar.6:60 } \\
\text { 60:Ar.6:60 }\end{array}$ & $\begin{array}{l}\text { 50.Bo.4:50 } \\
50: B o .4: 50\end{array}$ & $60: \mathrm{Br} .2: 60$ & & 60:Ch.8:60 b/ & 62:Ec. $7: 6$ & 62:Pr.3:62 & 61:Pe.1:66 & $\begin{array}{l}\text { 63:Ur.2:63 } \\
\text { 63:Ur.263 }\end{array}$ & $\begin{array}{l}\text { 61:Ve.3:61 } \\
61: \text { e.3:61 }\end{array}$ \\
\hline $\begin{array}{l}\text { Por ocupación y sexo a/ } \\
\text { Por rama de actividad y sexo }\end{array}$ & 60:Ar.6:60 & $50: B o .4: 50$ & $60: B r .2: 60$ & 64:Co.6:64 & 60:Ch.8:60 & 62:Ec. $7 \div 6$ & $\begin{array}{l}\text { 62:Pr.3:62 } \\
.02: 302\end{array}$ & 61:Pe.1:66 & $\begin{array}{l}\text { 03:0r.2:03 } \\
\text { 63:Ur.2:63 }\end{array}$ & $\begin{array}{l}\text { 61:Ve.3:01 } \\
\text { 61:Ve.3:61 }\end{array}$ \\
\hline Por categoría ocupacional y sexo & 60:Ar.6:60 & $50:$ Bo. $4: 50$ & $60: \mathrm{Br} .2: 60$ & 64:Co.6:64 & 60:Ch.8:60 & 62:Ec.7:6 & 62:Pr.3:62 & 61:Pe.1:66 & 63:Ur.2:63 & 61:Ve.3:61 \\
\hline $\begin{array}{l}\text { Por nivel de instrucción } \\
\text { Por }\end{array}$ & $60.4 r 6.60$ & $\ldots$ & $\cdots$ & $\begin{array}{l}\text { 64:Co.6:64 } \\
\text { 64:Co.6:64 }\end{array}$ & 60:Ch.8:60 & 62:Ec.7:6 & 62:Pr.3:62 & & & 61:Ve.3:61 \\
\hline & 60:Ar.6:60 & .. & $\cdots$ & $\begin{array}{l}\text { 64:Co.6:64 } \\
\text { (a) }\end{array}$ & 60:Ch.8:60 & 62:Ec. $7: 6$ & 62:Pr.3:62 & $\because$ & 63:Ur.2:63 $\mathrm{c}$ & $\begin{array}{l}\text { 61:Ve.3:61 } \\
61: V_{2}: 61\end{array}$ \\
\hline $\begin{array}{l}\text { Por ocupación y nivel de instrucción } \\
\text { Por rama de actividad sexo y edad }\end{array}$ & 60:Ar.6:60 & 50: Bo.4:50 & $60: 1.2: 68$ & 60:Co.6:64 & $60: \mathrm{Ch} .8: 60$ & 60:Ec.7:6 & 62:Pr.3:62 & $\cdots$ & 63:Ur.2:63 & $\begin{array}{l}\text { 61:Ve. } 3: 01 \\
\text { 61:Ve.3:61 }\end{array}$ \\
\hline $\begin{array}{l}\text { Por rama de actividad sexo y edad } \\
\text { Por rama de actividad y nivel de instrucción }\end{array}$ & & & (20.6- & & & $62:$ Ec. $7: 6$ & 62:Pr.3:62 & $\cdots$ & & 61:Ve.3:61 \\
\hline Por ocu pación, categoría ocupacional y sexo & 60:Ar.6:60 & 50:Bo.4:50 & .. & 64:Co.6:64 & 60:I.1:64 & 62:Ec. $7 ! 6$ & 62:Pr.3:62 & 61:I.1:64 & 63:Ur.2:63 & 61:Ve.3:61 \\
\hline \multicolumn{11}{|l|}{ Población económicamente inactiva } \\
\hline Total & 60:Ar.6:60 & 50:Bo.4:50 & $60: B r .2: 60$ & 64:Co.6:64 & 60:Ch.8:60 & 62:Ec.7!6 & 62:Pr.3:62 & 61:Pe.1:66 & 63:Ur.2:63 & 61:Ve.3:61 \\
\hline Por tipo de inactividad & 60:Ar.6:60 & 50:Bo.4:50 & $\cdots$ & 64:Co.6:64 & & & & .. & & 61:Ve.3:61 \\
\hline \multicolumn{11}{|l|}{ Indices de empleo } \\
\hline $\begin{array}{l}\text { General } \\
\text { Fn sertoges arícolas }\end{array}$ & $\cdots$ & $\cdots$ & .. & 68:Co.3:231 & ‥ & $\cdots 1$ & $\cdots$ & 65:I.24:70 & $\cdots$ & .. \\
\hline $\begin{array}{l}\text { En sectores agrícolas } \\
\text { En sectores no agrícolas }\end{array}$ & 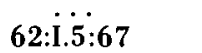 & $\ldots$ & $\cdots$ & 68:Co.3:231 & & $\cdots$ & $\cdots$ & 65:I 24: 70 & $\cdots$ & \\
\hline $\begin{array}{l}\text { En sectores no agricolas } \\
\text { En manufactura }\end{array}$ & 64:I.I.5:67 & $\ldots$ & $\cdots$ & 68:I.24:70 & 67:I.24:70 $\frac{\mathrm{d} /}{}$ & $67: \mathrm{I} .24: 7 \mathrm{C}$ & ... & 67:I.24:70 & $59: 1.5: 67$ & 69:I.24:70 \\
\hline En industrias extractivas & 62:1.5:67 & $\ldots$ & ... & 68:I.24:70 $\mathrm{e} /$ & 67:1.24:70 $\stackrel{d}{d} /$ & $67: I .24: 71$ & $\ldots$ & $67: 1.24: 70 \mathrm{~g} /$ & .. & 69:1.24:70 \\
\hline En construcción & .. & $\cdots$ & $\ldots$ & 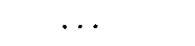 & .. & . & .. & $67: \mathrm{I} .24: 70 \mathrm{~g} /$ & .. & $\cdots$ \\
\hline En transporte, almacenaje y comunicaciones & ... & $\ldots$ & ... & & .. & $\cdots$ & .. & 67:I.24:70g/ & ... & .. \\
\hline Indices de desempleo & $\cdots$ & $\cdots$ & $\ldots$ & 68:Co.7:70 & $\ldots$ & $\cdots$ & ... & .. & $\cdots$ & .. \\
\hline \multicolumn{11}{|l|}{ Indices de salarios } \\
\hline $\begin{array}{l}\text { General } \\
\text { En sectores no agrícolas }\end{array}$ & 59:I.11:67 & $\ldots$ & $\cdots$ & $\begin{array}{l}\text { 67:Co.2:68 } \\
\text { 67:Co.2:68 }\end{array}$ & 67:I.11:67 & . & $\begin{array}{l}\text { 61:1.11:67 } \\
61: I .22: 67\end{array}$ & $\begin{array}{l}\text { 68:I.24:70 } \mathrm{h} / \\
68: I .24: 70 \mathrm{~g} /\end{array}$ & $\begin{array}{l}\text { 67:1.24:70i } \\
62: 1.22: 67\end{array}$ & $58: 1.11: 67$ \\
\hline $\begin{array}{l}\text { En sectores no agncolas } \\
\text { En industrias manufactureras }\end{array}$ & 69:I.24:70 & 63:I.11:67 & 69:I.24:70 & 68:1.24:70 & 68:1.24:70 & $67: 1.24: 7$ & ... & 68:I.24:70 h & 66:Ur.1:66 & 69:1.24:70 \\
\hline En minas y canteras & & & & 68:I.24:70 & 68:1.24:70 & $67: 1.24 ! 7$ & ... & 64:I.11:67 & $\ldots$ & 69:I.24:70 \\
\hline En construcción & 69:I.24:70 & $64: 1.11: 67 \mathrm{j} / \mathrm{l}$ & 64:I.11:67 & 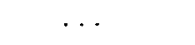 & & $\cdots$ & $\cdots$ & 68:I.24:70 g/ & $\cdots$ & $66: 1.11: 67 \mathrm{k}$ \\
\hline En transporte almacenaje y comunicaciones & 69:I.24: 70 & $64: 1.11: 67 \overline{\mathrm{I}} /$ & & & & & & 68:I.24:70 g/ & .. & 66:I.11:67 \\
\hline En agricultura & 69:I.24:70 & $\ldots$ & 66:I.11:67 & 68:I.24:70 & 68: I.24:70 & . & 61:1.11:67 & 62:I.11:67 & .. & 67:I.11:67 \\
\hline \multicolumn{11}{|l|}{ Horas trabajadas } \\
\hline Todos los sectores & $\cdots$ & $\cdots$ & $\cdots$ & $\cdots$ & $\cdots$ & $\cdots$ & $\cdots$ & 65:I.5:67 h/ & $\cdots$ & $\cdots$ \\
\hline $\begin{array}{l}\text { En agricultura } \\
\text { Sector no agrícola }\end{array}$ & $\cdots$ & $\cdots$ & $\cdots$ & $\cdots$ & $\cdots$ & $\therefore$ & $\cdots$ & $68 \cdot 124: 70$ & $\cdots$ & .. \\
\hline $\begin{array}{l}\text { Sector no agrícola } \\
\text { Sector industrias manufactureras }\end{array}$ & $\cdots$ & $\cdots$ & 61:1.5:67 & 61:I.5:67 & $\cdots$ & $68: 1.24: 7$ & $\ldots$ & 65:I.24:70 $\underline{\mathrm{h} /}$ & $\cdots$ & 69:I.24:70 \\
\hline $\begin{array}{l}\text { Productividad del trabajo } \\
\text { Paso }\end{array}$ & $\cdots$ & $\ldots$ & $\ldots$ & 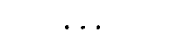 & $\cdots$ & $\cdots$ & $\cdots$ & $\cdots$ & .. & ... \\
\hline \multirow{3}{*}{$\begin{array}{l}\text { Produccion de la renta nacional que corres- } \\
\text { ponde a remuneraciones de asalariados } \\
\text { Trabajadores sindicalizados } \\
\text { Conflictos de trabajo }\end{array}$} & $\ldots$ & 68:I.24:70 & & $68: 0.24: 70$ & $68: 1.24: 70$ & $68: I .24: 7$ & 70 & 66:I.24:70 & 67:I.24:70 & 68:I.24:70 \\
\hline & $\cdots$ & 00.1 .24 .10 & 65:Br.1:67 & $\begin{array}{l}0.0 .24 .60 \\
\ldots\end{array}$ & & ... & & & . & \\
\hline & 69:1.24:70 $\underline{-} /$ & $\ldots$ & $\ldots$ & $\ldots$ & 69:I.24:70 & & 68:I.24:70 & 69:I.24:70 & - & 69:I.24:70 \\
\hline & & & & & & & & & & (Continúa) \\
\hline \multicolumn{11}{|l|}{320} \\
\hline
\end{tabular}


II. MANO DE OBRA (continuación)

\begin{tabular}{|c|c|c|c|c|c|c|c|c|c|c|}
\hline Temas & Costa Rica & Cuba & El Salvador & Guatemala & Haití & Honduras & México & Nicaragua & Panamá & $\begin{array}{c}\text { República } \\
\text { Dominicana } \\
\end{array}$ \\
\hline Proyecciones de población activa & 50-85:I.12:3 & $50.85: 1.12: 3$ & 50-85:1.12:3 & $50-85: I .12: 3$ & $50-85: 1.12: 3$ & 50-85:I.12:3 & 50-85:I.12:3 & 50-85:I.12:3 & 50-85:1.12:3 & 50-85:I.12:3 \\
\hline \multicolumn{11}{|l|}{ Población económicamente activa censal } \\
\hline Total & 63:CR.4:63 & 53:Cu.2:53 & 61:ES.4:61 & 64:Gu.4:64 & 50:I.1:55 & 61:Ho.4:61 & 60:Mé.4:60 & $63: \mathrm{Ni}, 2: 63$ & 60:Pa.7:60 & 60:RD.3:60 \\
\hline Ocupados & 63:CR.4:63 & $53: \mathrm{Cu} .2: 53$ & 61:ES.4:61 & 64:Cu.4:64 & $\ldots$ & 61:Ho.4:61 & 60.Mé.4:60 & . & $60: P a .7: 60$ & $\ldots$ \\
\hline Desocupados & 63:CR.4:63 & $\begin{array}{l}\text { 53:Cu.2:53 } \\
\text { 53:.5u }\end{array}$ & 61:ES.4:61 & 64:Cu.4:64 & $\ldots$ & 61:Ho.4:61 & 60:Mé.4:60 & & 60:Pa.7:60 & $\cdots$ \\
\hline Por sexo y edad & 63:CR.4:63 & $53: 1.22: 67$ & 61:ES.4:61 & $64: G u .4: 64$ & $50: I .1: 55$ & 61:Ho.4:61 & 60:Mé.4:60 & 63:Ni.2:63 & 60:Pa.7:60 & $60: 1.22: 67$ \\
\hline Por ocupación y sexo $\mathbf{a}$ / & 63:CR.4:63 & 53:I.5:67 & 61:ES.4:61 & 64:Gu.4:64 & 50:I.1:56 & 61:Ho.4:61 & 70:Mé.5:70 & $63: \mathrm{Ni} .2: 63$ & 60:Pa.7:60 & 60:I.5:67 \\
\hline Por rama de actividad y sexo & 63:CR.4:63 & $53:$ I.5:67 & 61:ES.4:61 & 64:Gu.4:64 & 50:I.1:55 & $\begin{array}{l}61: H o .4: 61 \\
6\end{array}$ & 70:Mé.5:70 & 63:Ni.2:63 & 60:Pa.7:60 & 60:I.5:67 \\
\hline Por categoría ocupacional y sexo & 63:CR.4:63 & 53:I.5:67 & 61:ES.4:61 & 64:Gu.4:64 & 50:I.1:55 & 61:Ho.4:61 & 70:Mé.5:70 & $63: \mathrm{Ni} .2: 63$ & $60: P a .7: 60$ & $60: 1.5: 67$ \\
\hline Por nivel de instrucción & 63:CR.4:63 & ... & & $\ldots$ & $\ldots$ & & $\ldots$ & $\ldots$ & $60: \mathrm{Pa} .7: 60$ & $\ldots$ \\
\hline Por ocupación, sexo y edad & 63:CR.4:63 & & 61:I.1:64 & $\cdots$ & $\cdots$ & 61:I.1:64 & $\cdots$ & $\ldots$ & 60:Pa.7:60 & $\ldots$ \\
\hline Por ocupación y nivel de instrucción & $\cdots$ & $\ldots$ & & & & & .. & & & \\
\hline Por rama de actividad sexo y edad & $\cdots$ & $\cdots$ & 61:ES.4:61 & 64:Gu.4:64 & $\ldots$ & 61:Ho.5:66 & $\ldots$ & ... & .. & $60: \mathrm{RD} .3: 60$ \\
\hline $\begin{array}{l}\text { Por rama de actividad y nivel de instrucción } \\
\text { Por ocupación categoría ocupacional y sexo }\end{array}$ & $\cdots$ & & & 64:Gu.4:64 & $\ldots$ & & & & & \\
\hline Por ocupación, categoría ocupacional y sexo & $\cdots$ & 53:Сu.2:53 & 61:ES.4:61 & 64:Gu.4:64 & $\cdots$ & 61:I.1:64 & $\therefore$ & $\cdots$ & 60:I.1:64 & 60:RD.3:60 \\
\hline \multicolumn{11}{|l|}{ Población económicamente inactiva } \\
\hline $\begin{array}{l}\text { Total } \\
\text { Por tipo de inactividad }\end{array}$ & $\begin{array}{l}\text { 63:CR. } 4: 63 \\
\text { 63:1.1:64 }\end{array}$ & $\begin{array}{l}\text { 65:Estimac. } \\
53: \mathrm{Cu} .2: 53\end{array}$ & $\begin{array}{l}\text { 61:ES.4:61 } \\
61: E S .4: 61\end{array}$ & $\begin{array}{c}\text { 64:Gu. } 4: 64 \\
\quad \ldots\end{array}$ & $\begin{array}{c}50: 1.1: 56 \\
\ldots\end{array}$ & $\begin{array}{l}\text { 61:Ho.4:61 } \\
\text { 61:I.1:64 }\end{array}$ & $\begin{array}{l}\text { 60:Mé.4:60 } \\
\text { 60:I.1:64 }\end{array}$ & 63:Ni.2:63 & $\begin{array}{l}\text { 60:Pa.7:60 } \\
\text { 60:I.1:64 }\end{array}$ & $\begin{array}{l}\text { 60:RD.3:60 } \\
\text { 60:RD.3:60 }\end{array}$ \\
\hline \multicolumn{11}{|l|}{ Indices de empleo } \\
\hline General & $\cdots$ & .. & .. & .. & $\cdots$ & $\cdots$ & $\cdots$ & $\ldots$ & 68:I.24:70 & \\
\hline En sectores agrícolas & $\cdots$ & $\cdots$ & $68.24 .70 \mathrm{~m} /$ & $\cdots$ & $\cdots$ & $\cdots$ & $\cdots$ & $\cdots$ & $60.134-70$ & \\
\hline En sectores no agrícolas & $\cdots$ & $\cdots$ & $\begin{array}{l}68: 1.24: 70 \mathrm{~m} / \mathrm{m} \\
68 \cdot 2 a \cdot 70 \mathrm{~m} /\end{array}$ & & $\cdots$ & & & $\cdots$ & 68:1.24:70 & 65:I.5:67 \\
\hline $\begin{array}{l}\text { En manufactura } \\
\text { En industrias extractivas }\end{array}$ & $\cdots$ & $\cdots$ & 68:I.24:70 $\underline{\mathrm{m} /}$ & 69:I.24: $70 \underline{n} / \underline{n}$ & $\cdots$ & $66: 1.24: 70$ & 65:I.5:67 & $\cdots$ & $68: 1.24: 70$ & $67: 1.24: 70$ \\
\hline En industrias extractivas & $\cdots$ & $\cdots$ & $67 \cdot 24: 70 \mathrm{~m} /$ & 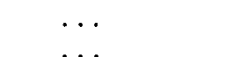 & $\cdots$ & $\ldots$ & & $\cdots$ & $\cdots$ & $67: 1.24: 70$ \\
\hline $\begin{array}{l}\text { En construcción } \\
\text { En transoorte almacenaie y comunicaciones }\end{array}$ & $\cdots$ & $\cdots$ & $\begin{array}{l}\text { 67:I.24:70 } \frac{\mathrm{m} /}{6} \\
67: 1.24: 70 \mathrm{~m} /\end{array}$ & $\cdots$ & $\cdots$ & $\cdots$ & 62:1.5:67 & $\cdots$ & & $\ldots$ \\
\hline $\begin{array}{l}\text { En transporte, almacenaje y comunicaciones } \\
\text { a }\end{array}$ & $\cdots$ & $\cdots$ & & & $\cdots$ & .. & $\cdots$ & $\cdots$ & 68:I.24:70 & .. \\
\hline Indices de desempleo & $\cdots$ & $\cdots$ & $\cdots$ & $\cdots$ & $\cdots$ & $\cdots$ & $1 \quad \ldots$ & $\cdots$ & $\cdots$ & $\cdots$ \\
\hline \multicolumn{11}{|l|}{ Indices de salarios } \\
\hline General & 63:I.11:67 & $\cdots$ & .. & ... & $\cdots$ & 60:I.11:67 & $\cdots$ & $\cdots$ & 67:Pa.2:69 & $65: 1.11: 67$ \\
\hline $\begin{array}{l}\text { En sectores no agricolas } \\
\text { En industrias manufactureras }\end{array}$ & $\begin{array}{l}\text { 63:1.22:67 } \\
\text { 63:I.11:67 }\end{array}$ & 68:Cu.1:68 o/ $\mathrm{p} /$ & 69:1.24:70 $\underline{m} /$ & 69:I.I.24:70 $\underline{n}$ & $\ldots$ & $66: I .24: 70$ & 69:1.24:70 & 67:I.24:70 & 68: I.24: 70 & 68:1.24:70 \\
\hline En minas y canteras & 62:I.11:67 & 68:Cu.1:68 of & & $\ldots$ & $\ldots$ & $\ldots$ & $68: 1.24: 70$ & $67: I .24: 70$ & 66:I.11:67 & 67:1.24:70 \\
\hline En construcción & 61:I.11:67 & & $69: 1.24: 70$ & $\ldots$ & ... & $\ldots$ & 68:1.24:70 & 67:I.11:67 & 64:1.11:67 & 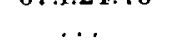 \\
\hline En transporte, almacenaje y comunicaciones & 62:I.11:67 & $66: C u .1: 68$ of & $\ldots$ & $\ldots$ & $\ldots$ & $\ldots$ & 68:I.24:70 & $\ldots$ & $67: \mathrm{Pa} .2: 69$ & $\ldots$ \\
\hline En agricultura & 69:1.24:70 & 66:Cu.1:68 of & $\ldots$ & $\ldots$ & $\ldots$ & $\ldots$ & 68:I.24:70 & & 66:I.11:67 & $\ldots$ \\
\hline \multicolumn{11}{|l|}{ Horas trabajadas } \\
\hline Todos los sectores & $\cdots$ & $\cdots$ & $\cdots$ & $\cdots$ & 60:I.5:67 & $\cdots$ & 64:I.5:67 & $\cdots$ & .. & ... \\
\hline En agricultura & $\cdots$ & $\cdots$ & $\cdots$ & $\cdots$ & $\cdots$ & $\cdots$ & $\cdots$ & $\cdots$ & $\cdots$ & $\cdots$ \\
\hline $\begin{array}{l}\text { Sector no agrícola } \\
\text { Sector industrias manufactureras }\end{array}$ & $\ldots$ & $\ldots$ & 69:ES.3:70g/ & 69:I.24:70 $\underline{\mathrm{n}} / \tilde{\tilde{N}}$ & $60: 1.5: 67$ & $\cdots$ & 68:Mé. 2:68 & $\ldots$ & $\cdots$ & $\cdots$ \\
\hline Productividad del trabajo & $\ldots$ & $\ldots$ & $\ldots$ & & $\ldots$ & $\ldots$ & $\ldots$ & $\ldots$ & $\ldots$ & $\ldots$ \\
\hline
\end{tabular}


II. MANO DE OBRA (conclusión)

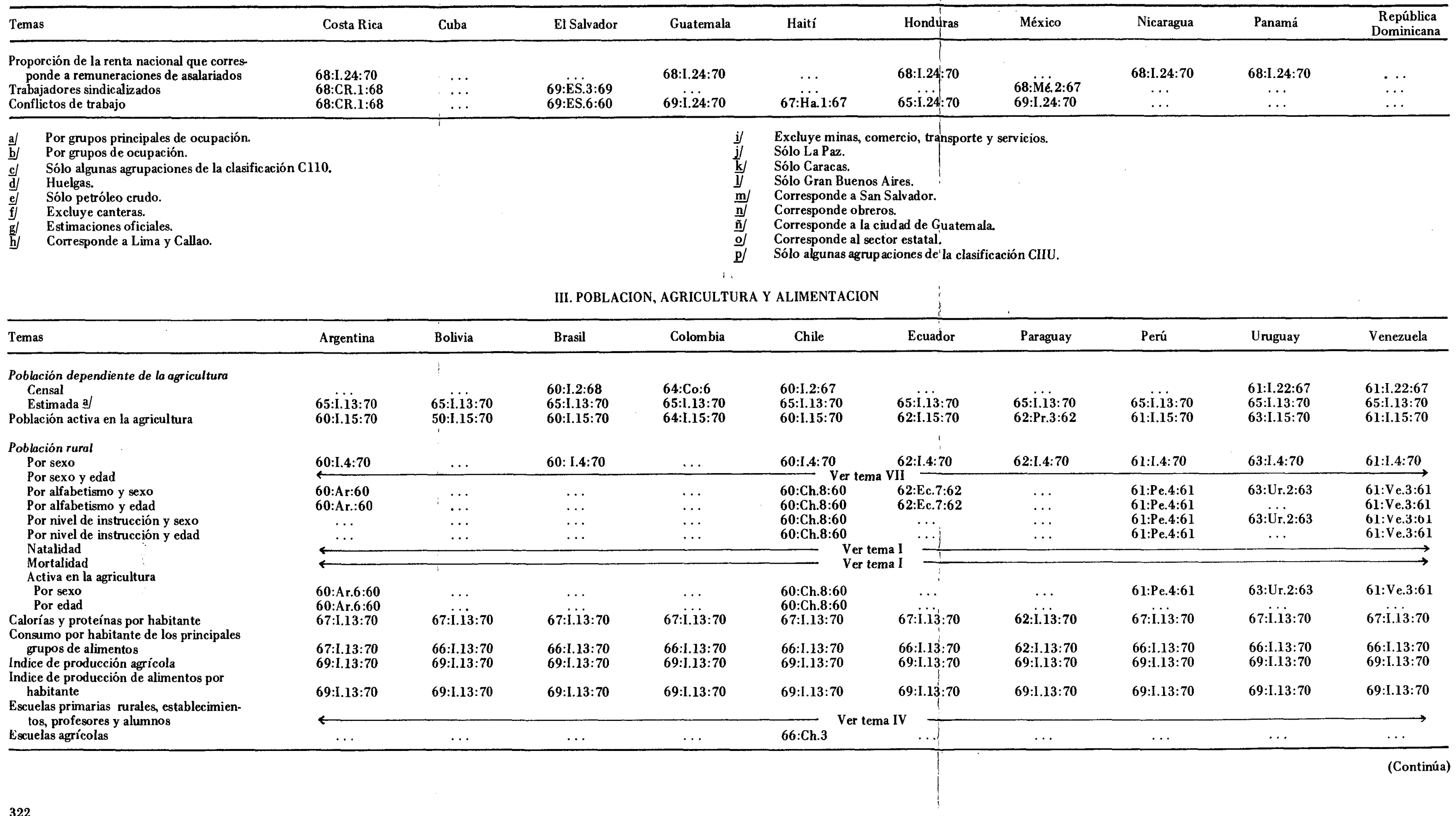


III. POBLACION, AGRICULTURA Y ALIMENTACION (Conclusión)

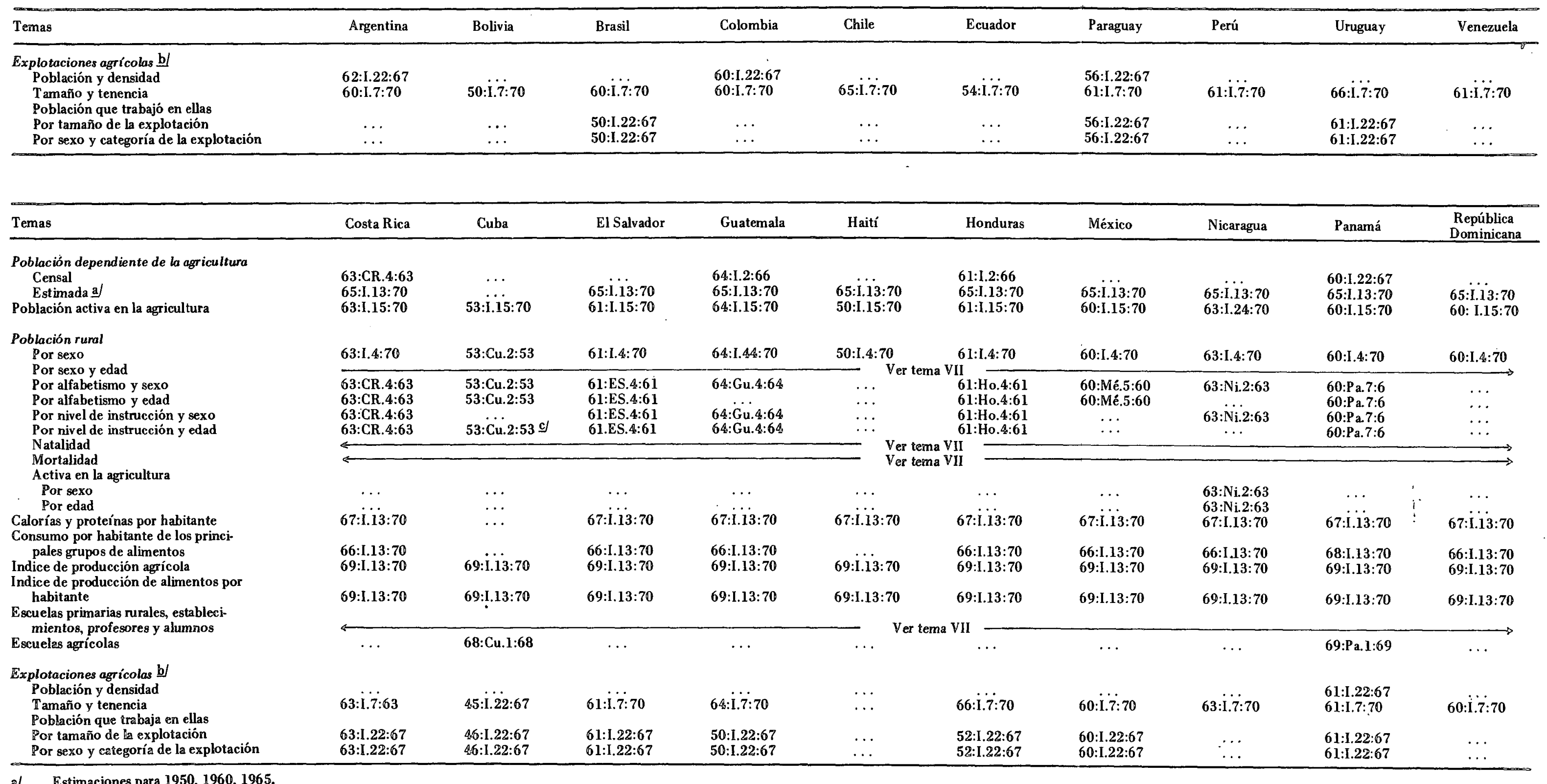


IV. EDUCACION

\begin{tabular}{|c|c|c|c|c|c|c|c|c|c|c|}
\hline Temas & Argentina & Bolivia & Brasil & Colombia & Chile & Ecuädor & Paraguay & Perú & Uguguay & Venezuela \\
\hline $\begin{array}{l}\text { Población por alfabetismo } \\
\text { Por sexo } \\
\text { Por sexo y edad } \\
\text { Por sexo y área urbana y rural }\end{array}$ & $\begin{array}{l}\text { 60:Ar.6:60 } \\
60: 1.6: 67 \\
60: 1.6: 67\end{array}$ & $\begin{array}{l}50: B o .4: 50 \\
50: 1.6: 67 \\
50: 1.6: 67\end{array}$ & $\begin{array}{l}60: \mathrm{Br} .2: 60 \\
50: \mathrm{I} .6: 67 \\
50: 1.6: 67\end{array}$ & $\begin{array}{l}\text { 64:Co.6:64 } \\
\text { 64:1.6:67 } \\
64: 1.6: 67\end{array}$ & $\begin{array}{l}60: \text { Ch.8:60 } \\
60: I .6: 67 \\
60: 1.6: 67\end{array}$ & $\begin{array}{l}\text { 62: Ed. } 7: 62 \\
62: 1.6: 67 \\
62: 1.6: 67\end{array}$ & $\begin{array}{l}\text { 62:Pr.3:62 } \\
\text { 62:1.6:67 } \\
62: 1.6: 67\end{array}$ & $\begin{array}{l}\text { 61:Pe.4:61 } \\
\text { 61:I.6:67 } \\
\text { 61:1.6:67 }\end{array}$ & $\begin{array}{l}\text { 63:Ur.2:63 } \\
\text { 63:I.6:67 } \\
\text { 63:1.6:67 }\end{array}$ & $\begin{array}{l}\text { 61:Ve.3:61 } \\
\text { 61:1.6:67 } \\
61: 1.6: 67\end{array}$ \\
\hline $\begin{array}{l}\text { Población por nivel de instrucción } \\
\quad \text { Total } \\
\text { Por último curso aprobado } \\
\text { Por sexo } \\
\text { Por sexo y edad } \\
\text { Por tipo de enseñanza }\end{array}$ & $\begin{array}{l}\text { 60:I.6:67 } \\
\cdots \\
\text { 60:Ar.6:60 } \\
\text { 60:Ar.6:60 } \\
\text { 60:Ar.6:60 }\end{array}$ & $\begin{array}{l}50: I .6: 67 \\
50: \text { Bo.4:50 } \\
50: \text { Bo.4:50 } \\
\ldots \\
\cdots \\
\cdots\end{array}$ & $\begin{array}{c}50: I .6: 67 \\
\ldots \\
60: B r .2: 60 \\
\cdots \\
\cdots\end{array}$ & $\begin{array}{l}\text { 64:I.6:67 } \\
\text { 64:Co.6:64 } \\
\text { 64:Co.6:64 } \\
\text { 64:Co.6:64 } \\
\text { 64:Co.6:64 }\end{array}$ & $\begin{array}{l}60: I .6: 67 \\
60: 1.1: 63 \\
60: \text { Ch.8:60 } \\
60: 1.1: 63 \\
60: C h .8: 60\end{array}$ & $\begin{array}{l}\text { 62:I. } 6: 67 \\
62: E \mathrm{c} .7: 62 \\
62: \mathrm{Ec} .7: 62 \\
62: \mathrm{Ec} .7: 62 \\
62: \mathrm{Ec} .7: 62\end{array}$ & $\begin{array}{l}\text { 62:I.6:67 } \\
\ldots \\
\text { 62:Pr.3:62 } \\
\ldots \\
\ldots\end{array}$ & $\begin{array}{l}\text { 61:I.6:67 } \\
\text { 61:I.1:63 } \\
\text { 61:Pe.4:61 } \\
\text { 61:I.1:63 } \\
\quad \ldots\end{array}$ & $\begin{array}{l}\text { 63:1.6:67 } \\
\text { 63: Ur.2:63 } \\
\text { 63:Ur.2:63 } \\
\text { 63:Ur.2:63 }\end{array}$ & $\begin{array}{l}\text { 61:I.6:67 } \\
\text { 61:Ve.3:61 } \\
\text { 61:Ve.3:61 } \\
\text { 61:Ve.3:61 } \\
61: \text { Ve.3:61 }\end{array}$ \\
\hline $\begin{array}{l}\text { Población que asiste a institucio. } \\
\text { nes de enseñanza regular } \\
\text { Por sexo y edad } \\
\text { Por grado } \\
\text { Por nivel de instrucción }\end{array}$ & $\begin{array}{l}\text { 60:Ar.6:60 } \\
\text { 60:Ar.6:60 } \\
\text { 60:Ar.6:60 }\end{array}$ & $\begin{array}{c}\text { 50: } \mathrm{Bo} .4: 50 \\
\quad \ldots \\
\quad \cdots\end{array}$ & $\begin{array}{c}50: \text { Br.2:60 } \\
\cdots \\
\cdots\end{array}$ & $\begin{array}{l}\cdots \\
\cdots \\
\cdots\end{array}$ & $\begin{array}{l}\text { 60:Ch.8:60 } \\
\text { 60:Ch.8:60 } \\
\text { 60:Ch.8:60 }\end{array}$ & $\begin{array}{c}\text { 62:Ec.7:62 } \\
\ldots \\
\ldots\end{array}$ & $\begin{array}{c}\text { 62:Pr.3:62 } \\
\ldots \\
\ldots\end{array}$ & $\begin{array}{c}\text { 61:Pe.4:61 } \\
\ldots \\
\ldots\end{array}$ & $\begin{array}{l}\cdots \\
\cdots \\
\cdots\end{array}$ & $\begin{array}{l}\text { 61:Ve.3:61 } \\
\text { 61:Ve.3:61 } \\
\text { 61:Ve.3:61 }\end{array}$ \\
\hline $\begin{array}{l}\text { Alumnos, profesores y establec. } \\
\text { En nivel preescolar } \\
\text { En primer nivel } \\
\text { En segundo nivel } \\
\text { En educación superior }\end{array}$ & $\begin{array}{l}\text { 70:Ar.2:70 } \\
\text { 70:Ar.2:70 } \\
\text { 70:Ar.2:70 } \\
\text { 70:Ar.2:70 }\end{array}$ & $\begin{array}{l}\text { 69:Bo.3:70 a/ } \\
\text { 69:Bo.3:70 } / \\
\text { 69:Bo.3:70 } / \\
66: 1.14: 69 \text { c } /\end{array}$ & $\begin{array}{l}\text { 62:I.14:69 } \\
\text { 67:I.14:67 } \\
\text { 68:I.14:69 } \\
\text { 67:I.14:69 }\end{array}$ & $\begin{array}{l}\text { 66:I.14:69 } \\
\text { 66:I.14:69 } \\
66: I .14: 69 \\
\text { 66:I.14:69 }\end{array}$ & $\begin{array}{l}\text { 67:I.14:69 } \\
\text { 68:I.14:69 } \\
\text { 67:I.14:69 } \\
\text { 6:I:I.14:69 }\end{array}$ & $\begin{array}{l}\text { 67:I.14:69 } \\
\text { 67:I.14:69 } \\
\text { 67:I.14:69 } \\
\text { 67:I.14:69 }\end{array}$ & $\begin{array}{l}\text { 66:I.14:69 } \\
\text { 69:Pr.1:69 } \\
\text { 69:Pr.1:69 } \\
\text { 69:Pr.1:69 } 9\end{array}$ & $\begin{array}{l}\text { 67:1.14:69 } \\
\text { 67:1.14:69 } \\
67: 1.14: 69 \\
67: 1.14: 69\end{array}$ & 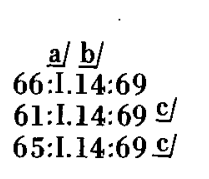 & $\begin{array}{l}\text { 67:I.14:69 a/ } \\
\text { 67:I.14:69 } \\
\text { 67:I.14:69 } \\
\text { 67:I.14:69 }\end{array}$ \\
\hline $\begin{array}{l}\text { Escuelas primarias.rurales } \\
\text { Establecimientos } \\
\text { Profesores } \\
\text { Alumnos } \\
\text { Matrícula y profesores en segundo }\end{array}$ & $\begin{array}{c}\cdots \\
\text { 65:I. } \dddot{6}: 67\end{array}$ & $\begin{array}{l}\text { 65:I.6:67 } \\
\text { 67:I.6:67 }\end{array}$ & $\begin{array}{c}\text { 67:I.6:67 } \\
\text { 67:I.6:67 } \\
\ldots\end{array}$ & $\begin{array}{l}\text { 66:I.6:67 } \\
\text { 65:I.6:67 } \\
\text { 66:I.6:67 }\end{array}$ & $\begin{array}{c}\cdots \\
67: 106: 67\end{array}$ & $\begin{array}{l}\text { 66:I.6:67 } \\
\text { 66:I.6:67 } \\
\text { 66:I.6:67 }\end{array}$ & $\begin{array}{l}69: \operatorname{Pr} .1: 69 \\
66: 1.6: 67\end{array}$ & $\begin{array}{l}\cdots \\
\cdots \\
\cdots\end{array}$ & $\begin{array}{l}\cdots \\
\cdots \\
\cdots\end{array}$ & $\begin{array}{l}\text { 67:1.6:67 } \\
\text { 67:I.6:67 } \\
\text { 67:I.6:67 }\end{array}$ \\
\hline $\begin{array}{l}\text { nivel, por tipo de enseñanza } \\
\text { Matricula en primer y segundo } \\
\text { nivel, por sexo y edad } \\
\text { Tasas de matrícula en primer y } \\
\text { segundo nivel }\end{array}$ & $\begin{array}{l}\text { 70:Ar.2:70 } \\
\text { 67:Ar.3:70 } \mathrm{d} / \\
\text { 67:I.14:69 }\end{array}$ & $\begin{array}{c}68: 1.14: 69 \\
66: 1.6: 67 \mathrm{~s} \\
-67: 1.14: 69\end{array}$ & 68:1.14:69 & $\begin{array}{l}66: 1.14: 69 \\
66: \text { Co.3:234 } \\
67: 1.14: 69\end{array}$ & $\begin{array}{l}\text { 67:I.14:69 } \\
67: I .14: 69 \text { f } \\
67: I .14: 69\end{array}$ & $\begin{array}{l}67: I .14: 69 \\
66: I .14: 69 \\
67: I .14: 69\end{array}$ & $\begin{array}{l}69: \text { Pr.1:69 } \\
66: 1.14: 69 \\
67: I .14: 69\end{array}$ & $\begin{array}{l}67: I .14: 69 \\
65: I .14: 69 \\
\text { 67:I.14:69 }\end{array}$ & $\begin{array}{l}65: I .14: 69 \mathrm{c} / \\
64: I .6: 67 \mathrm{~g} / \\
67: I .14: 69\end{array}$ & $\begin{array}{l}\text { 67:I.14:69 } \\
\text { 67:I.14:69f } \\
\text { 67:I.14:69 }\end{array}$ \\
\hline $\begin{array}{l}\text { Retención } \\
\quad \text { En primer nivel } \\
\text { En segundo nivel }\end{array}$ & $\begin{array}{l}\text { 59-65:I.15: } 70 \\
\text { 65:I.6:67 }\end{array}$ & $\begin{array}{c}\text { 61-66:I.15:70 } \\
\ldots\end{array}$ & 60-65:I.15:70 & $\begin{array}{l}\text { 61.65:I.15:70 } \\
\text { 65:I:6:67 }\end{array}$ & 60-67:I.15:70 & $\begin{array}{l}\text { 60.65:1.15:70 } \\
66: 1.6: 67\end{array}$ & $\begin{array}{l}\text { 60-65:I.15: } 70 \\
\text { 62:1.6:67 }\end{array}$ & 61-65:I.15:70 & $\begin{array}{c}60-65: I .15: 70 \\
\ldots\end{array}$ & $\begin{array}{c}60-65: I .15: 70 \\
\ldots\end{array}$ \\
\hline $\begin{array}{l}\text { Repitentes } \\
\quad \text { En primer nivel } \\
\text { En segundo nivel }\end{array}$ & $\begin{array}{l}\text { 65:Ar.5:67 } \\
\text { 65:Ar.5:67 }\end{array}$ & $\begin{array}{l}\cdot \\
\cdots \\
\cdots\end{array}$ & $\begin{array}{l}\cdots \\
\cdots\end{array}$ & $\begin{array}{l}\cdots \\
\cdots\end{array}$ & $\cdots$ & $i$ & $\begin{array}{c}\text { 69:PR.1:69 } \\
\quad \ldots\end{array}$ & $\cdots$ & $\cdots$ & $\begin{array}{c}67: \text { Ve.1:67 } \\
\quad \cdots\end{array}$ \\
\hline $\begin{array}{l}\text { Deserciones } \\
\quad \text { En primer nivel } \\
\text { En segundo nivel }\end{array}$ & $\cdots$ & $\ldots$ & $\cdots$ & $\begin{array}{c}\text { 63:Co.1:67 } \\
\ldots\end{array}$ & $\cdots$ & $\cdots$ & $\cdots$ & $\cdots$ & $\begin{array}{l}\cdots \\
\cdots\end{array}$ & $\begin{array}{l}\cdots \\
\cdots\end{array}$ \\
\hline 324 & & & & & & & & & & (Continúa) \\
\hline
\end{tabular}


IV. EDUCACION (Continuación)

\begin{tabular}{|c|c|c|c|c|c|c|c|c|c|c|}
\hline Temas & Argentina & Bolivia & Brasil & Colombia & Chile & Ecuador & Paraguay & Perú & Uruguay & Venezuela \\
\hline $\begin{array}{l}\text { Graduados } \\
\text { En primer nivel } \\
\text { En segundo nivel } \\
\text { Titulados en la universidad, por } \\
\text { disciplina } \\
\text { Gastos pubblicos en educación }\end{array}$ & $\begin{array}{l}\text { 64:Ar.4:68 } \\
\text { 66:I.6:67 } \\
\text { 66:I.14:69 } \\
\text { 66:I.14:69 }\end{array}$ & 67:I.14:69 & $\begin{array}{c}\cdots \\
\cdots \\
64: 1.14: 69 \\
66: I .25: 69\end{array}$ & $\begin{array}{l}\text { 66:Co.3:67 } \\
\text { 66:I.14:69 } \\
\text { 66:I.14:69 }\end{array}$ & $\begin{array}{c}\cdots \\
\text { 66:Ch. } 3: 66 \\
66: 1,14: 69\end{array}$ & $\begin{array}{l}\text { 65-66:I.6:67 } \\
\text { 68:Ec.6:68 } \\
\text { 67:1.14:69 }\end{array}$ & $\begin{array}{l}\cdots \\
\cdots \\
69: \operatorname{Pr} .1: 69 \underline{h} / \\
64: 1.25: 69\end{array}$ & $\begin{array}{c}\cdots \\
\cdots \\
\text { 65:Pe.1:66 } \\
\text { 64:I.25:69 }\end{array}$ & $\begin{array}{c}\cdots \\
\cdots \\
\text { 65:1.14:69 } \\
\text { 67:1.14:69 }\end{array}$ & $\begin{array}{c}\cdots \\
\cdots \\
66: 1.14: 69 \\
67: 1.14: 69\end{array}$ \\
\hline Temas & Costa Rica & Cuba & El Salvador & Guatemala & Haití & Honduras & México & Nicaragua & Panamá & $\begin{array}{c}\text { República } \\
\text { Dominicana } \\
\end{array}$ \\
\hline $\begin{array}{l}\text { Población por alfabe tismo } \\
\text { Por sexo } \\
\text { Por sexo y edad } \\
\text { Por sexo y área urbana y rural }\end{array}$ & $\begin{array}{l}\text { 63:CR.4:63 } \\
63: 1.6: 67 \\
63: 1.6: 67\end{array}$ & $\begin{array}{l}\text { 53:Cu. } 2: 53 \\
\qquad 33: I .6: 67 \\
53: I .6: 67\end{array}$ & $\begin{array}{l}\text { 61:ES.4:61 } \\
\text { 61:I.6:67 } \\
\text { 61:I.6:67 }\end{array}$ & $\begin{array}{l}\text { 64:Gu. } 4: 64 \\
\text { 64:1.6:67 } \\
64: 1.6: 67\end{array}$ & $\begin{array}{l}\text { 50:I.6:67 } \\
\text { 50:I.6:67 } \\
\text { 50:I.6:67 }\end{array}$ & $\begin{array}{l}\text { 61:Ho.4:61 } \\
\text { 61:I.6:67 } \\
\text { 61:I.6:67 }\end{array}$ & $\begin{array}{l}\text { 70:Mé.5:70 } \\
\text { 60:1.6:67 } \\
\text { 60:1.6:67 }\end{array}$ & $\begin{array}{l}\text { 63:Ni.2:63 } \\
\text { 63:1.6:67 } \\
\text { 63:I.6:67 }\end{array}$ & $\begin{array}{l}\text { 60:Pa.7:60 } \\
\text { 60:I.6:67 } \\
\text { 60:I.6:67 }\end{array}$ & $\begin{array}{l}\text { 60:RD.3:60 } \\
\text { 60:1.6:67 } \\
\text { 60:1.6:67 }\end{array}$ \\
\hline $\begin{array}{l}\text { Población por nivel de instrucción } \\
\text { Total } \\
\text { Por último curso aprobado } \\
\text { Por sexo } \\
\text { Por sexo y edad } \\
\text { Por tipo de enseñanza }\end{array}$ & $\begin{array}{l}\text { 63:1.6:67 } \\
63: \text { CR.4:63 } \\
63: \text { CR. } 4: 63 \\
63: \text { CR. } 4: 63 \\
63: \text { CR.4:63 }\end{array}$ & $\begin{array}{l}53: 1.6: 67 \\
53: \mathrm{Cu} .2: 53 \\
53: \mathrm{Cu} .2: 53 \\
53: \mathrm{Cu} .2: 53\end{array}$ & $\begin{array}{l}\text { 61:1.6:67 } \\
\text { 61:1.1:63 } \\
\text { 61:ES.4:61 } \\
\text { 61:1.1:63 } \\
\text { 61:ES.4:61 }\end{array}$ & $\begin{array}{l}\text { 64:I.6:67 } \\
\quad \ldots \\
\text { 64:Gu. } 4: 64 \\
\quad \cdots \\
\cdots\end{array}$ & $\begin{array}{c}50: 1.6: 67 \\
\ldots \\
50: 1.6: 67 \\
\ldots \\
\cdots\end{array}$ & $\begin{array}{l}\text { 61:1.6:67 } \\
61: I .1: 63 \\
61: H 0.4: 61 \\
61: 1.1: 63 \\
\quad \ldots\end{array}$ & $\begin{array}{l}\text { 60:I.6:67 } \\
\text { 70:Mé.5:70 } \\
\text { 70:Mé.5:70 } \\
\text { 70:Mé.5:70 } \\
\text { 70:Mé.5:70 }\end{array}$ & $\begin{array}{c}\text { 63:I.6:67 } \\
\text { 63: } \mathrm{Ni} .2: 63 \\
\cdots \\
\cdots\end{array}$ & $\begin{array}{l}\text { 60:I.6:67 } \\
\text { 60:1.1:63 } \\
\text { 60:Pa.7:60 } \\
\text { 60:I.1:63 } \\
\text { 60:Pa.7:60 }\end{array}$ & $\begin{array}{l}\text { 60:1.6:67 } \\
\text { 60:RD.3:60 } \\
\text { 60:RD.3:60 } \\
\text { 60:RD.3:60 }\end{array}$ \\
\hline $\begin{array}{l}\text { Población que asiste a instituciones } \\
\text { de enseñanza regular } \\
\text { Por sexo y edad } \\
\text { Por grado } \\
\text { Por nivel de instrucción }\end{array}$ & $\begin{array}{l}\text { 63:CR. } 4: 63 \\
63: C R .463 \\
63: C R .4: 63\end{array}$ & $\begin{array}{c}53: \text { Cu. } 2: 53 \\
\ldots \\
\ldots\end{array}$ & $\begin{array}{c}\text { 61:ES.4:61 } \\
\text { 61:ES.4:61 } \\
\ldots\end{array}$ & $\begin{array}{c}\text { 64:Gu. } 4: 64 \\
64: G u .4: 64 \\
\ldots\end{array}$ & $\begin{array}{l}\cdots \\
\cdots \\
\cdots\end{array}$ & $\begin{array}{c}\text { 61:Ho.4:61 } \\
\ldots \\
\text { 61:Ho.4:61 }\end{array}$ & $\begin{array}{c}\text { 60:Mé.4:60 } \\
\quad \ldots \\
\quad \ldots\end{array}$ & $\begin{array}{c}\text { 63: } \mathrm{Ni}, 2: 63 \\
\ldots \\
\ldots\end{array}$ & $\begin{array}{l}\text { 60:Pa.7:60 } \\
\text { 60:Pa.7:60 } \\
60: P a .7: 60\end{array}$ & $\begin{array}{c}\text { 60:RD.3:60 } \\
\ldots \\
\ldots\end{array}$ \\
\hline $\begin{array}{l}\text { Alumnos, profesores y establec. } \\
\text { En nivel preescolar } \\
\text { En primer nivel } \\
\text { En segundo nivel } \\
\text { En educación superior }\end{array}$ & $\begin{array}{l}\text { 66:I.14:69 } \\
67: C R .1: 68 \\
66: I .14: 69 \\
66: I .14: 69\end{array}$ & $\begin{array}{l}\text { 67:I.14:69 a } \\
68: \operatorname{Cu} 1: 1: 68 \\
68: C u=1: 68 \\
68: C u .1: 68\end{array}$ & $\begin{array}{l}\text { 70:ES.3:70 } \\
70: \text { ES.3:70 } \\
69: \text { ES.169 } \\
\text { 67:1.14:69 } d\end{array}$ & $\begin{array}{l}\text { 67:I.14:69 } \\
\text { 68:Gu.1:68 } \\
\text { 67:II.14:69 } d] \\
\text { 68:I.14:69 }\end{array}$ & $\begin{array}{l}\text { 66:I.14:69 } \\
\text { 66:I.14:69 } \\
\text { 66:I.14:69 }\end{array}$ & $\begin{array}{l}\text { 67:Ho.1:69 } \\
69: \text { Ho.3:70 } \\
69: \text { Ho.3:70 } / \\
\text { 67:Ho.1:69 }\end{array}$ & $\begin{array}{l}\text { 68:Mé. } 2: 68 \\
\text { 68:Mé.2:68 } \\
\text { 67:I.14:69 } \\
\text { 67:I.14:69 } \mathrm{c}\end{array}$ & $\begin{array}{l}\text { 66:I.14:69 } \mathrm{c} / \\
\text { 66:1.14:69 } \\
\text { 66:I.14:69 } \\
\text { 66:I.14:69 }\end{array}$ & $\begin{array}{l}\text { 69:Pa.1:68 } \\
\text { 69:Pa.1:68 } \\
69: P a .1: 68 \mathrm{j} / \\
\text { 69:Pa.1:68 J]/ }\end{array}$ & 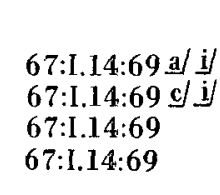 \\
\hline $\begin{array}{l}\text { Escuelas primarias rurales } \\
\text { Establecimientos } \\
\text { Profesores } \\
\text { Alumnos } \\
\text { Matrícula y profesores en segundo } \\
\text { nivel, por tipo de enseñanza } \\
\text { Matrícula en primer y segundo } \\
\text { nivel, por sexo y edad } \\
\text { Tasas de matrícula en primer y } \\
\text { segundo nivel }\end{array}$ & $\begin{array}{l}\text { 65:I.6:67 } \\
65: 1.6: 67 \\
65: 1.6: 67 \\
66: 1.14: 69 \\
67: C R .1: 68 \text { d/ } \\
67: 1.14: 69\end{array}$ & $\begin{array}{c}\cdots \\
\cdots \\
67: 1.14: 69 \\
67: 1.14: 69 \\
67: 1.14: 69\end{array}$ & $\begin{array}{l}\text { 67:1.6:67 } \\
67: 1.6: 67 \\
67: 1.6: 67 \\
69: \text { ES.2:70 } \\
69: \text { ES.2:70 k/ } \\
67: 1.14: 69\end{array}$ & $\begin{array}{l}66: 1.6: 67 \\
66: 1.6: 67 \\
67: 1.6: 67 \\
67: 1.14: 69 \mathrm{~d} / \\
67: G u .2: 67 \\
67: 1.14: 69\end{array}$ & $\begin{array}{c}65: 1.6: 67 \\
\ldots \\
\cdots \\
66: 1.14: 69 d] \\
\ldots \\
67: 1.14: 69\end{array}$ & $\begin{array}{l}\text { 66:I.6:67 } \\
66: I .6: 67 \\
65: I .6: 67 \\
67: \text { Ho.1:69 } \\
\text { 67:Ho.1:69 } \\
\text { 67:Ho.1:69 }\end{array}$ & $\begin{array}{l}\text { 68:Mé.2:68 } \\
\text { 65:I.6:67 } \\
\text { 67:I.6:67 } \\
\text { 67:I.23:69 } \\
\text { 65:I.6:67 } \\
\text { 67:I.14:69 }\end{array}$ & $\begin{array}{c}\text { 67:I.6:67 } \\
\text { 67:I.6:67 } \\
\text { 67:I.14:69 } \\
\ldots \\
\text { 67:I.14:69 }\end{array}$ & $\begin{array}{l}\text { 69:Pa.1:68 } \\
\text { 66:I.6:67 } \\
\text { 69:Pa.1:68 } \\
\text { 67:I.14:69 } \\
\text { 68:Pa.6:68 } \\
67: I .14: 69\end{array}$ & $\begin{array}{c}\cdots \\
\cdots \\
67: 1.14: 69 \\
66: 1.14: 69 \\
67: 1.14: 69\end{array}$ \\
\hline
\end{tabular}


IV. EDUCACION (Conclusión)

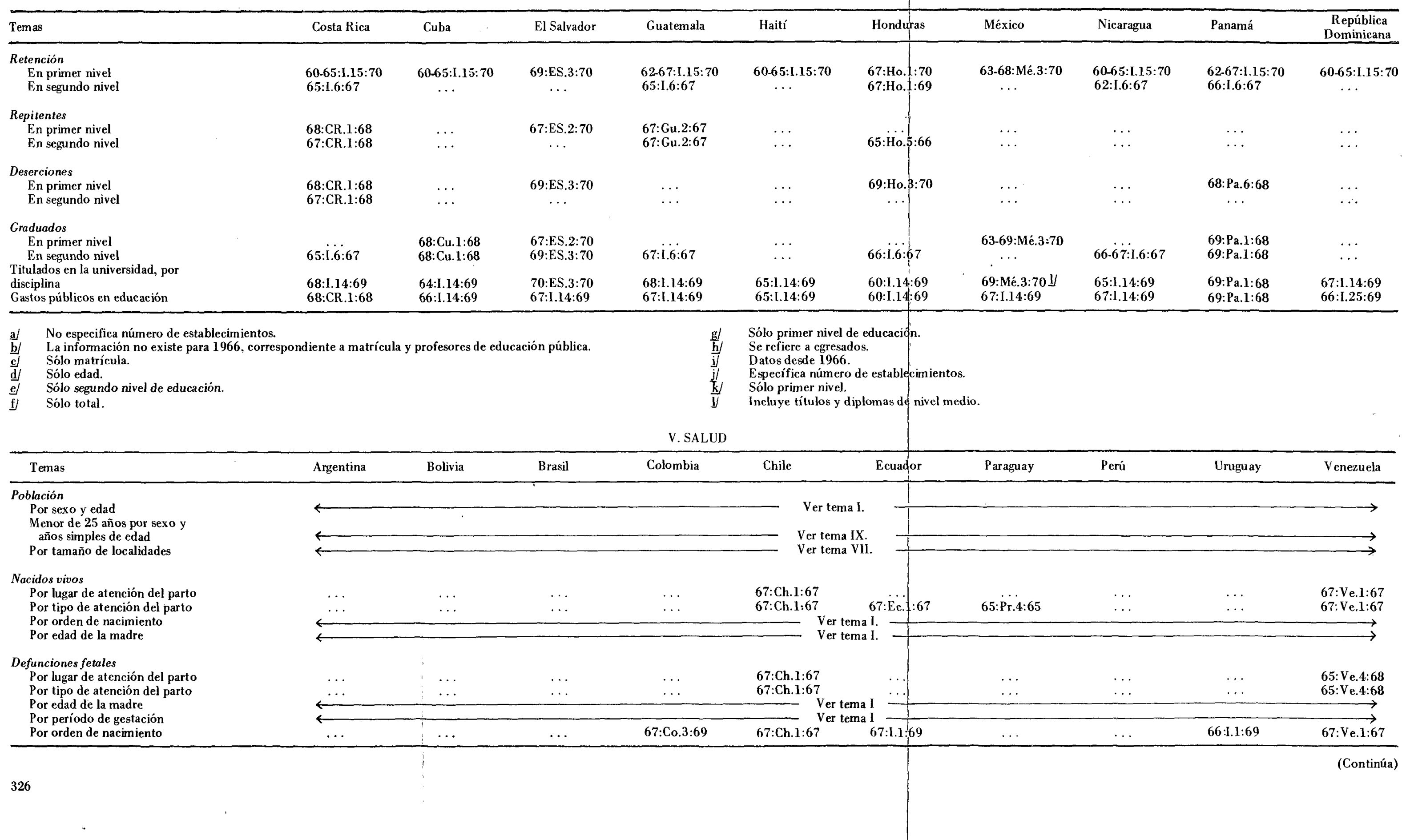


V. SALUD (Continuación)

\begin{tabular}{|c|c|c|c|c|c|c|c|c|c|c|}
\hline Temas & Argentina & Bolivia & Brasil & Colormbia & Chile & Ecuador & Paraguay & Perú & Uruguay & Venezuela \\
\hline $\begin{array}{l}\text { Defunciones } \\
\text { Por causas de muerte }\end{array}$ & 66:I.2:69 & 66:I.2:69 & $\cdots$ & 67:I.2:68 & 68:I.2:70 & 68:I.2: 70 & 69:I.2:70 & \multicolumn{2}{|c|}{ Defunciones } & 67:Ve.1:67 \\
\hline $\begin{array}{l}\text { Por sexo y edad según causas } \\
\text { de muerte }\end{array}$ & $66: 1.2: 69$ & $66: 1.2: 69$ & $\ldots$ & $67: 1.2: 68$ & 67:Ch.1:67 & 68:I.2:70 & 69:I.2:70 & 64:I.2:68 & $66: 1.2: 68$ & $67: 1.2: 68$ \\
\hline $\begin{array}{l}\text { Por tipo de certificación según } \\
\text { causas de muerte }\end{array}$ & $\cdots$ & $\ldots$ & $\ldots$ & 67:I.2:68 & 67:Ch.1:67 & 68:I.5: 70 & 65:Pr.4:65 & 63:Pe.2:64 & $\ldots$ & 67:Ve.1:67 \\
\hline \multicolumn{11}{|l|}{ Egresos hospitalarios } \\
\hline $\begin{array}{l}\text { Por especialidad } \\
\text { Por sexo y edad segín diagnóstico }\end{array}$ & $\cdots$ & $\cdots$ & $\cdots$ & $67 . C_{0} 3.68$ & $67: \operatorname{Ch} 6: 67$ & $67 . E_{c} 2.67$ & .. & 65:Pe.1:66 & .. & $\cdots$ \\
\hline $\begin{array}{l}\text { Por sexo y e edad seguin diagnóstico } \\
\text { Por días de estada }\end{array}$ & $60: 1.5: 67$ & $\cdots$ & & $\begin{array}{l}\text { 67:Co.3:68 } \\
\text { 67:Co.2:68 }\end{array}$ & $\begin{array}{l}\text { 67:Ch.6.67 } \\
\text { 67:Ch.6:67 }\end{array}$ & $\begin{array}{l}\text { 67:Ec.2:67 } \\
67: \text { : } 2: 67\end{array}$ & $60: 10: 67$ & $\begin{array}{l}\text { 65:Pe.1:66 a/ } \\
62.15: 67\end{array}$ & & \\
\hline Por condición al egresar & & $\cdots$ & 68: Br.1:70 & $67: C o .3: 68$ & 67:Ch.6:67 & 67:Ec.2:67 & $\ldots$ & 65:Pe.1:66 & 60:I.5:67 & 63:I.5:67 \\
\hline \multicolumn{11}{|l|}{ Consultas } \\
\hline Nuevas y repetidas & 64:I.5:67 & $64: 1.5: 67$ & $65: \mathrm{Br} .1: 67$ & 67:Co.3:68 & $64: 1.5: 67$ & 64:I.5:67 & 69:Pr.1:69 & $63: 1.5: 67$ & $\ldots$ & 64:I.5:67 \\
\hline $\begin{array}{l}\text { Por sexoo y edad } \\
\text { Por diagnóstico }\end{array}$ & $\begin{array}{l}\text { 64:I.5:67 } \\
64: I .5: 67\end{array}$ & $\cdots$ & $\begin{array}{l}\ldots \\
\ldots\end{array}$ & $\cdots$ & $\ldots$ & $\cdots$ & $\begin{array}{l}\text { 69:Pr.1:69 } \frac{\mathrm{b}}{\mathrm{f}} \\
\text { 69:Pr.1:69 } \mathrm{b}\end{array}$ & 64:I.20:61-64 & $\ldots$ & $\cdots$ \\
\hline Por sexo, edad y diagnóstico & 64:I.5:67 & $\ldots$ & $\ldots$ & $\ldots$ & $\ldots$ & $\ldots$ & $\ldots$ & $\ldots$ & $\ldots$ & $\cdots$ \\
\hline $\begin{array}{l}\text { Nuevas y repetidas por sexo, } \\
\text { edad y diagnóstico }\end{array}$ & & & & 66:Co.8:68 & & & 60. $\operatorname{Pr} 1.60$ b & & & \\
\hline De menores de 5 años & 64:I.5:67 & 64:1.5:67 & 68: $\because 18$ r.1:70 & $64: 1.5: 67$ & 70:Ch.6:70 $\mathrm{s}$ & 63:İ: $: 67$ & 64:I.5:67 & $63: \because \because .5: 67$ & $\ldots$ & $\cdots$ \\
\hline Pre y post natales & $64: 1.5: 67$ & 64:I.5:67 & $\ldots$ & 64:I.5:67 & $70: \mathrm{Ch} .6: 70$ & 63:I.5:67 & 64:1.5:67 & 63:I.5:67 & $\cdots$ & $\cdots$ \\
\hline $\begin{array}{l}\text { Visitas domiciliarias por médico, } \\
\text { matrona y enfermera }\end{array}$ & .. & ... & $68: B r .1: 70$ & $\ldots$ & 70:Ch.6:70 & $\ldots$ & 69:Pr.1:69 & $\ldots$ & $\ldots$ & $\ldots$ \\
\hline \multicolumn{11}{|l|}{ Atenciones dentales } \\
\hline $\begin{array}{l}\text { Total } \\
\text { Por tipo }\end{array}$ & $\begin{array}{l}\text { 64:I.20:61-64 } \\
\ldots\end{array}$ & $\begin{array}{l}\text { 64:I.20:61-64 } \\
\ldots\end{array}$ & $\begin{array}{c}\text { 68:Br.1:70 } \\
\ldots\end{array}$ & $\begin{array}{c}\text { 67:Co.3:68 } \\
\quad \ldots\end{array}$ & $\begin{array}{l}\text { 70:Ch.6:70 } \\
\text { 70:Ch.6:70 }\end{array}$ & $\begin{array}{l}\text { 63:I.20:61-64 } \\
\quad \ldots\end{array}$ & $\begin{array}{l}\text { 69:Pr.1:69 d/ } \\
\quad \ldots\end{array}$ & 63:I.20:61-64 & $\cdots$ & 64:I.20:61-64 \\
\hline Por sexo y edad & & $\ldots$ & & & & & $\ldots$ & $\ldots$ & $\ldots$ & $\ldots$ \\
\hline $\begin{array}{l}\text { Recetas y prescripciones } \\
\text { Vacunas por tipo } \\
\text { Exámenes de laboratorio por tipo }\end{array}$ & 67:I.5:67 & $\begin{array}{c}67: 1.5: 67 \\
\ldots\end{array}$ & $\begin{array}{l}69: \mathrm{Br} .1: 70 \\
67: \mathrm{I} .5: 67 \\
68: \mathrm{Br} \cdot 1: 70\end{array}$ & $\begin{array}{l}\text { 67i.5:67 } \\
\text { 64:1.20:61-64 }\end{array}$ & $\begin{array}{l}\text { 70:Ch.6:70 } \\
70: \text { Ch.6:70 } \\
70: \text { Ch.6:70 }\end{array}$ & $\begin{array}{l}\text { 67:I.5:67 } \\
\text { 60:1.5:67 }\end{array}$ & $\begin{array}{l}\text { 69:Pr.1:69 } \\
\text { 64:I.20:61-64 }\end{array}$ & $\begin{array}{l}\text { 67:I:.5:67 } \\
63: 1.20: 61-64\end{array}$ & $67: 1.5: 67$ & $\begin{array}{l}\text { 67:1.5:67 } \\
\text { 64:I.20:61-64 }\end{array}$ \\
\hline \multicolumn{11}{|l|}{$\begin{array}{l}\text { Población servida } \\
\end{array}$} \\
\hline $\begin{array}{l}\text { urbana rural } \\
\text { Por alcantarillado }\end{array}$ & $\begin{array}{l}\text { 67:I.5:67 } \\
\text { 63:I.5:67 }\end{array}$ & $\begin{array}{l}\text { 67:I.5:67 } \\
64: 1.5: 67\end{array}$ & $\begin{array}{l}\text { 67:I.5:67 } \\
\text { 64:I.5:67 }\end{array}$ & $\begin{array}{l}\text { 67:I.5:67 } \\
\text { 60:1.5:67 }\end{array}$ & $\begin{array}{l}\text { 67:I.5:67 } \\
\text { 64:I.5:67 }\end{array}$ & $\begin{array}{l}\text { 67:I.5:67 } \\
\text { 64:I.5:67 }\end{array}$ & $\begin{array}{l}\text { 67:I.5:67 } \\
\text { 64:I.5:67 }\end{array}$ & $\begin{array}{l}\text { 67:1.5:67 } \\
\text { 64:1.5:67 }\end{array}$ & $\begin{array}{l}67: 1.5: 67 \\
64: 1.5: 67\end{array}$ & $\begin{array}{l}\text { 67:1.5:67 } \\
\text { 64:I.5:67 }\end{array}$ \\
\hline \\
\hline $\begin{array}{l}\text { De atención abierta } \\
\text { De atención cerrada }\end{array}$ & 64:1.20:61-64 & 64:I. 20:61-64 & $\begin{array}{l}65: \mathrm{Br} .1: 67 \\
67 \cdot \mathrm{Br}: 69\end{array}$ & 64:I.20:61-64 & 70:Ch.6:70 & 64:I.20:61-64 & 64:I.20:61-64 & 64:I. $20: 61-64$ & 62.90 .6160 & $64: 1.20: 61-64$ \\
\hline $\begin{array}{l}\text { De atención cerrada } \\
\text { Centros de salud materno }\end{array}$ & $62: 1.20: 61-64$ & & & & 70:Ch.6:70 & & & 64:1.20:61-64 & $63: 1.20: 61-64$ & $63: 1.20: 61-64$ \\
\hline infantil & 64:I.15: 70 & 64:I.15:70 & $68: B r .1: 70$ & 64:I.15:70 & $\cdots$ & 63:I. $15: 70$ & $64: I .15: 70$ & 63:I.15:70 & $\ldots$ & 64:I.15:70 \\
\hline \multicolumn{11}{|l|}{ Camas de hospital } \\
\hline Por especialidad & $62: 1.20: 61-64$ & 62:I.20:61-64 & $68: \mathrm{Br} .1: 70$ & 64:I.20:61-64 & 70:Ch.6:70 & $67:$ Ec.2:67 & $64: I .20: 61-64$ & 64:I. $20: 61-64$ & $66: U r .1: 66$ & $65:$ Ve.4:68 \\
\hline Pediátricas y obstétricas & 62:I.15:70 & & 66:I.15:70 & & 67:I.15: 70 & 65:I.15:70 & 65:I.15:70 & 63:I.15:70 & 62:1.15:70 & $65: 1.15: 70$ \\
\hline Por 1000 habitantes & 63:I.5:67 & 67:1.19:67 & 67:I.19:67 & 67:I.19:67 & $70:$ Ch.6:70 & 67:I.19:67 & 68:I.19:67 & 67:I.19:67 & 67:I.19:67 & $67:$ I.19:67 \\
\hline
\end{tabular}


V. SALUD (Continuación)

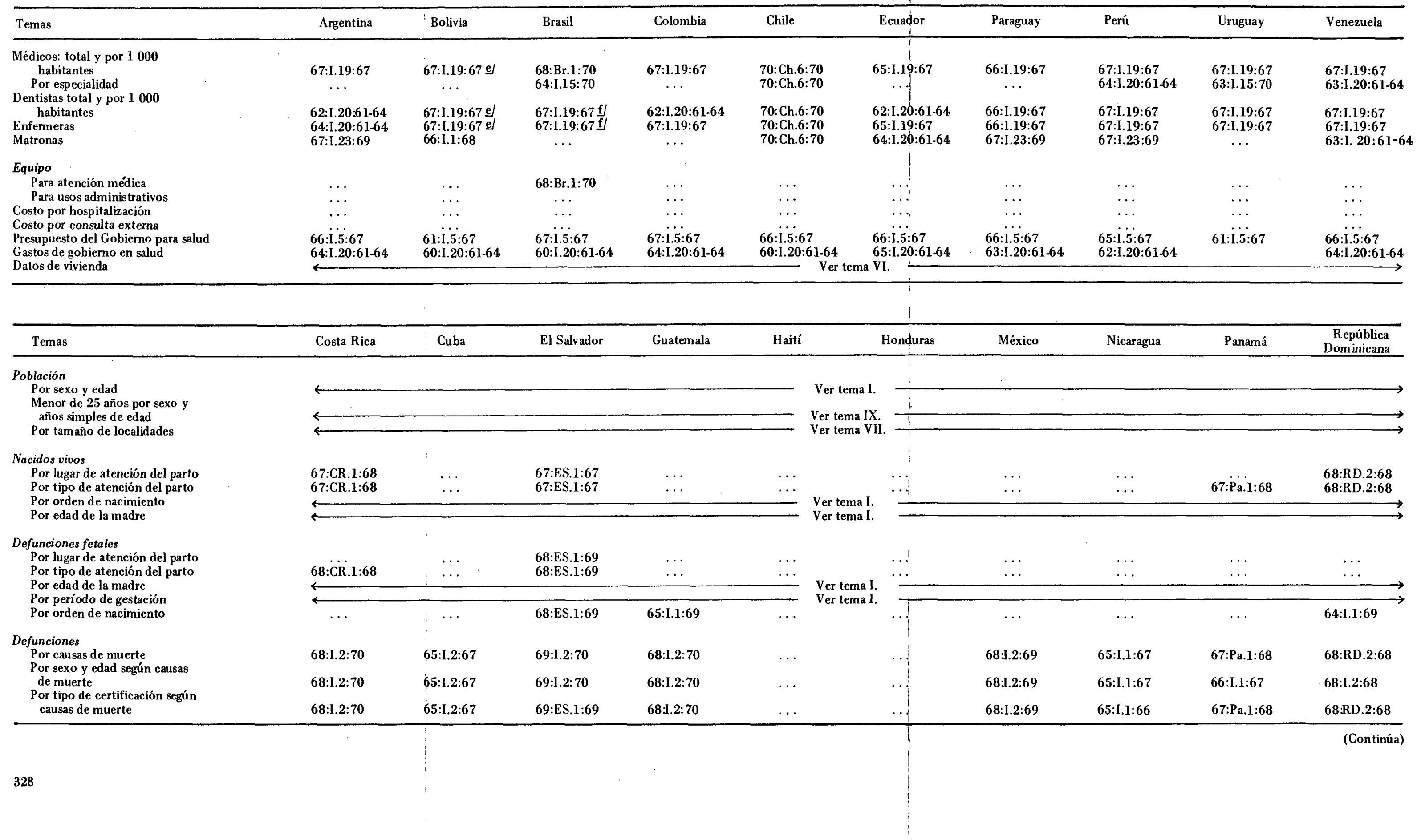


V. SALUD (Continuación)

\begin{tabular}{|c|c|c|c|c|c|c|c|c|c|c|}
\hline Temas & Costa Rica & Cuba & El Salvador & Guatemala & Haití & Honduras & México & Nicaragua & Panamá & $\begin{array}{c}\text { República } \\
\text { Dominicana }\end{array}$ \\
\hline \multicolumn{11}{|l|}{$\begin{array}{l}\text { Egresos hospitalarios } \\
\text { Por especialidad }\end{array}$} \\
\hline $\begin{array}{l}\text { Por especialidad } \\
\text { Por sexo y edad según diagnóstico }\end{array}$ & & $\ldots$ & 67:ES.1:67 & $\cdots$ & $65: \mathrm{Ha.1}: 67 \mathrm{~g} !$ & $\cdots$ & $\cdots$ & $\cdots$ & 66:Рa $3: 68$ & .. \\
\hline $\begin{array}{l}\text { Por días de estada } \\
\text { Por diagnostico }\end{array}$ & 67:СR.1:68 & $\cdots$ & 69:ES.3:70 & 68:Gu.1:68 & 65:Ha.1:67 & 67:Ho.1:69 & $60: 1.5: 67$ & $\ldots$ & 66:Pa.3:68 & 60:1.5:67 \\
\hline Por condición al egresar & & & 67:ES.1:67 & $\cdots$ & $\cdots$ & $\cdots$ & $\cdots$ & $\cdots$ & 66:Pa.1:68 & $\cdots$ \\
\hline \multicolumn{11}{|l|}{ Consultas } \\
\hline Nuevas y repetidas & 68:CR.1:68 & $64: 1.5: 67$ & $67: 1.5: 67$ & 68:Gu.1:68 & $62: I .5: 67$ & $67: I .5: 67$ & :64:I.5:67 & 63:I.5:67 & 66:Рa.2:69 & 62:I.5:67 \\
\hline $\begin{array}{l}\text { Por sexo y edad } \\
\text { Por diagnóstico }\end{array}$ & $\cdots$ & $\cdots$ & $\begin{array}{l}\text { 68:ES.3:70 } \mathrm{h} / \\
67: \text { ES.1:67 }\end{array}$ & $\cdots$ & $\cdots$ & 66:Ho.5:66 & $\ldots$ & $\cdots$ & 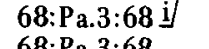 & $\cdots$ \\
\hline & & & $\begin{array}{l}\text { 0.ES.1.06 } \\
\text { 67:ES.1:67 }\end{array}$ & $\cdots$ & & $\ldots$ & $\cdots$ & $\cdots$ & 68:Pa.3:68 & $\cdots$ \\
\hline $\begin{array}{l}\text { Por sexo, edad y diagnóstico } \\
\text { Nuevas y repetidas por sexo, }\end{array}$ & & & 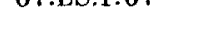 & $\cdots$ & $\cdots$ & $\cdots$ & $\cdots$ & $\cdots$ & $\cdots$ & $\cdots$ \\
\hline edad y diagnóstico & & & $67:$ ES.1:67 & & $\ldots$ & & $\ldots$ & $\ldots$ & & .. \\
\hline De menores de 5 años & $64: 1.5: 67$ & 64:1.5:67 & 64:I.5:67 & $63: 1.5: 67$ & $\cdots$ & 64:1.5:67 & $\cdots$ & $\ldots$ & 68:Pa.3:68 & . \\
\hline $\begin{array}{l}\text { Pre y post natales } \\
\text { Visitas domiciliarias por médico. }\end{array}$ & 64:1.5:67 & 64:I.5:67 & 64:1.5:67 & 63:L.5:67 & . & 64:I.5:67 & $\cdots$ & ... & 65:I.5:67 & .. \\
\hline matrona y enfermera & & & 69:ES.3:70 & $\cdots$ & ... & $\ldots$ & $\ldots$ & $\ldots$ & $68: P a .1: 68$ & $\cdots$ \\
\hline \multicolumn{11}{|l|}{ Atenciones dentales } \\
\hline Total & 68:CR.1:68 & 64:1I.20:61-64 & 69:ES.3:70 & 63:I.20:61-64 & $60: 1.20: 61-64$ & 64:1.20:61-64 & 64:1.20:61-64 & $\cdots$ & 64:I.20:61-64 & $60: 1.20: 61-64$ \\
\hline $\begin{array}{l}\text { Por tipo } \\
\text { Por sexo y edad }\end{array}$ & $\cdots$ & $\cdots$ & $\cdots$ & $\cdots$ & $\cdots$ & $\cdots$ & $\cdots$ & $\cdots$ & $\ldots$ & $\cdots$ \\
\hline $\begin{array}{l}\text { Por sexo y edad } \\
\text { Recetas y prescripciones }\end{array}$ & $\cdots$ & $\cdots$ & $\cdots$ & $\cdots$ & .. & $\cdots$ & $\cdots$ & $\cdots$ & $\cdots$ & $\cdots$ \\
\hline Vacunas por tipo & 68:CR.1:68 & 68:Cu.1:68 & 69:ES.3:70 & $67: 1.5: 67$ & 67:I.5:67 & $67: 1.5: 67$ & $66: 1.5: 67$ & $67: 1.5: 67$ & 69:Pa.1:68 & 67:1.5:67 \\
\hline Exámenes de laboratorio por tipo & 64:1.20:61-64 & $63: 1.20: 61-64$ & 69:ES.3:70 & $60: 1.5: 67$ & $60: 1.5: 67$ & 64:I.5:67 & 64:I.20:61-64 & 60:1.5:67 & $64: I .20: 61 \cdot 64$ & $60: 1.5: 67$ \\
\hline \multicolumn{11}{|l|}{ Población servida } \\
\hline $\begin{array}{l}\text { Por agua potable según área } \\
\text { urbana rural }\end{array}$ & $67: 1.5: 67$ & $67: 1.5: 67$ & $67: 1.5: 67$ & 67:I.5:67 & $67: 1.5: 67$ & 67:I.5:67 & $67: 1.5: 67$ & $67: L 5: 67$ & 67:I.5:67 & 67:I.5:67 \\
\hline Por alcantarillado & 64:I.5:67 & 64:I.5:67 & $64: 1.5: 67$ & 64:1.5:67 & 64:1.5:67 & 64:1.5:67 & 64:1.5:67 & 64:1.5:67 & 64:I.5:67 & 64:I.5:67 \\
\hline \multicolumn{11}{|l|}{ Establecimientos } \\
\hline De atención abierta & 64:1.20:61-64 & 64:1.20:61-64 & 69:ES.3:70 & $64: 1.20: 61-64$ & 64:1.20:61-64 & 64:1.20:61-64 & 64:I.20:61-64 & 63:1.20:61-64 & 64:I.20:61-64 & 62:I.20:61-64 \\
\hline $\begin{array}{l}\text { De atención cerrada } \\
\text { Centros de salud materno }\end{array}$ & 64:1.20:61-64 & $65: 1.20: 61-64$ & 69:ES.3:70 & $64: 1.20: 61-64$ & 65:1.20:61-64 & 69:Ho.3:70 & 67:Mé.1:67 & 65:I.20:61-64 & 64:1.20:61-64 & $64: 1.20: 61-64$ \\
\hline infantil & 64:I.15:70 & 64:I.15:70 & $64: 1.15: 70$ & 63:I.15:70 & $\ldots$ & 64:I.15:70 & $\ldots$ & $\ldots$ & 64:I.15:70 & $\ldots$ \\
\hline \multicolumn{11}{|l|}{ Camas de hospital } \\
\hline $\begin{array}{l}\text { Por especialidad } \\
\text { Pediátricas y obstétricas }\end{array}$ & $\begin{array}{l}\text { 68:CR.1:68 } \\
\text { 66:L15:70 }\end{array}$ & 68:Cu.1:68 & $\begin{array}{l}\text { 69:ES.3:69 } \\
\text { 63:L15:70 }\end{array}$ & $\begin{array}{l}\text { 64:I. } 20: 61-64 \\
64: 125: 70\end{array}$ & $\begin{array}{l}\text { 65:I.20:61-64 } \\
65: 25: 70 \text { if }\end{array}$ & 64:I.20:61-64 & 63:I.20:61-64 & 65:I.20:61.64 & $\begin{array}{l}\text { 68:Pa.2:69 } \\
\text { 64:L } 5: 70\end{array}$ & $\begin{array}{l}64: 1.20: 61-64 \\
64: 115: 70\end{array}$ \\
\hline Por 1000 habitantes & 67:I.19:67 & 67:I.19:67 & 67:I.19:67 & 67:1.19:67 & 67:I.23:68 $\mathrm{k}$ & 67:I.19:67 & 67:1.19:67 & 65:I.19:67 & $67: 1.19: 67$ & 67:I.19:67 \\
\hline \multicolumn{11}{|l|}{ Médicos: total y por 1000} \\
\hline $\begin{array}{l}\text { habitantes } \\
\text { Por especialidad }\end{array}$ & 63:I.20:61-64 & 00.1 .19 .06 & $09 . \mathrm{ES} .3 .09$ & 0.19 .08 & $\begin{array}{l}\text { 06.1.19.08 } \\
\ldots\end{array}$ & $09: 10.3 \div 60$ & $\begin{array}{c}\text { ar.1.19:0 } \\
\ldots\end{array}$ & $\begin{array}{c}03.1 .19 .06 \\
\ldots\end{array}$ & 68:Pa.2:69 & $\begin{array}{c}67: 1.19: 67 \\
\ldots\end{array}$ \\
\hline \multicolumn{11}{|l|}{ Dentistas total y por 1000} \\
\hline $\begin{array}{l}\text { habitantes } \\
\text { Enfermeras }\end{array}$ & $\begin{array}{l}\text { 67:1.19:67 } \\
67: 19: 67\end{array}$ & $\begin{array}{l}67: 1.19: 67 \\
67.10 \cdot 67\end{array}$ & $\begin{array}{l}\text { 69:ES.3:69 } \\
60 \cdot \text { SS } 3 \cdot 60\end{array}$ & $\begin{array}{l}67: 1.19: 671 / \\
67.10 \cdot 67\end{array}$ & 67:1.19:67 & 69: Но.3: 70 & 67:I.19:67 & 65:1.19:67 & 68:Pa.1:68 & $64: 1.20: 61-64$ \\
\hline $\begin{array}{l}\text { Enfermeras } \\
\text { Matronas }\end{array}$ & $\begin{array}{l}\text { 67:I.19:67 } \\
\text { 67:I.23:69 }\end{array}$ & 67:1.19:67 & 69:ES.3:69 & 67:I.19:67 & 67:I.19:67 & 69: Ho.3:70 & 67:I.19:67 & 65:1.19:67 & 68:Pa.1:68 & $64: I .20: 61-64$ \\
\hline Matronas & 67:1.23:69 & & & & $67: 1.23: 69$ & $63: 1.20: 61-64$ & $61: I .19: 64$ & 60:1.19:64 & $64: 1.20: 61-64$ & 64:I.20:61-64 \\
\hline
\end{tabular}


V. SALUD (Conclusión)

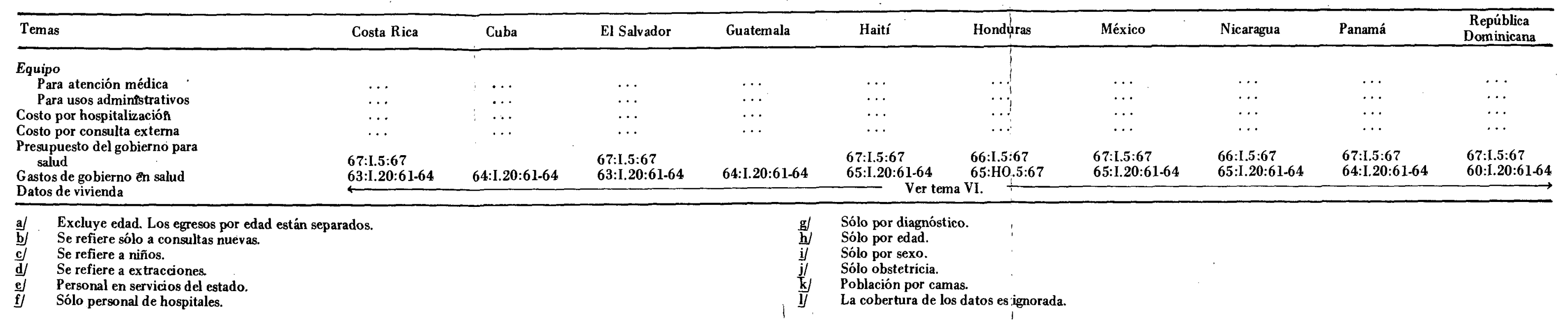

VI. POBLACION, VIVIENDA Y HOGARES

\begin{tabular}{|c|c|c|c|c|c|c|c|c|c|c|}
\hline Temas & Argentina & Bolivia & Brasil & Colombia & Chile & Ecuador & Paraguay & Perú & Uruguay & Venezuela \\
\hline \multicolumn{11}{|l|}{ Viviendas } \\
\hline Ocupadas y desocupadas & 60:Ar.6:60 & $\cdots$ & & 64:Co.6:64 & 60:Ch.8: 60 & & 62:Pr.3:62 & 61:Pe.4:61 & & 61:Ve.3:61 \\
\hline $\begin{array}{l}\text { Ocupadas y desocupadas por área urbana y rural } \\
\text { Permanentes, semipermanentes e improvisadas }\end{array}$ & 60:Ar.6:60 & $\cdots$ & $60: \mathrm{Br} .2: 60 \mathrm{a} /$ & 64:Co.6:64 & 60:Ch.8:60 & $\begin{array}{l}\text { 62: Ec.7:62 a } \\
\text { 62:Ec.7:62 }\end{array}$ & 62:Pr.3:62 & 61:Pe.4:61 & 63:Ur.2:63 & 61:Ve.3:61 \\
\hline $\begin{array}{l}\text { Por material de construcción } \\
\text { Por año de construcción }\end{array}$ & 60:Ar.6:60 & .. & & 64:Co.6:64 & 60:Ch.8:60 & $\begin{array}{l}\text { 62:Ec.7:62 } \\
\ldots .1\end{array}$ & 62:Pr.3:62 & 61:I.5:67 & 63:Ur.2:63 & 61:Ve.3:61 \\
\hline $\begin{array}{l}\text { Por abastecimiento de agua } \\
\text { Por sistema de eliminación de excretas }\end{array}$ & $\begin{array}{l}\text { 60:I.5:67 } \\
\text { 60:Ar.6:60 }\end{array}$ & 50:I.5:67 & $\begin{array}{l}\text { 60:I.5:67 } \\
\text { 60:Br:2:60 }\end{array}$ & $\begin{array}{l}\text { 64:I.5:67 } \\
\text { 64:Co.6:64 }\end{array}$ & $\begin{array}{l}\text { 60:I.5:67 } \\
\text { 60:Ch.8:60 }\end{array}$ & $\begin{array}{l}\text { 62:1.5:67 } \\
62: \text { Ec.7:62 }\end{array}$ & $\begin{array}{l}\text { 62:1.1:67 } \\
\text { 62:Pr.3:62 }\end{array}$ & 61:1.5:67 & $\begin{array}{l}\text { 63:I:.5:67 } \\
\text { 63:Ur:2:63 }\end{array}$ & $\begin{array}{l}\text { 61:1:.5:67 } \\
\text { 61: }: \text { e. } 3: 61\end{array}$ \\
\hline Por disponibilidad de luz eléctrica & $60: 1.5: 67$ & & $60: 1.5: 67$ & $64: 1.5: 67$ & $60: 1.23: 69$ & 62:1.5:67 & $62: 1.5: 67$ & 61:1.5:67 & $63: 1.5: 67$ & 61:1.5:67 \\
\hline $\begin{array}{l}\text { Por disponibilidad de baño } \\
\text { Por disponibilidad de cuarto de cocina }\end{array}$ & 60:Ar.6:60 & $50:$ Bo.4: 50 & & 64:I.5:67 & $\begin{array}{l}\text { 60:1.23:69 } \\
\text { 60:Ch.8:60 }\end{array}$ & 62:Ec.7:62 & $\begin{array}{l}\text { 62:I.5:67 } \\
\text { 62:Pr.3:62 }\end{array}$ & 61:I.5:67 & $\begin{array}{c}63: 1.5: 67 \\
\ldots\end{array}$ & $\begin{array}{l}\text { 61:1.5:67 } \\
\text { 61:Ve.3:61 }\end{array}$ \\
\hline $\begin{array}{l}\text { Por tipo de tenencia } \\
\text { Por alquiler mensual }\end{array}$ & 60: Ar.6:60 & 50:Bo.4:50 & $\begin{array}{l}\text { 60:Br.2:60 } \\
60: B r .2: 60\end{array}$ & $\begin{array}{c}\text { 64:C0.6:60 } \\
\quad \ldots\end{array}$ & $\begin{array}{l}\text { 60:Ch.8:60 } \\
\text { 60:Ch.8:60 }\end{array}$ & $\begin{array}{l}\text { 62:Ec.7:62 } \\
\text { 62:Ec.7:62 }\end{array}$ & $\cdots$ & $\begin{array}{l}\text { 61:Pe.4:61 } \\
\text { 61:Pe.4:61 }\end{array}$ & $\begin{array}{l}\text { 63:Ur.2:63 } \\
\quad \ldots\end{array}$ & $\begin{array}{l}\text { 61:Ve.3:61 } \\
\text { 61:Ve.3:61 }\end{array}$ \\
\hline \multicolumn{11}{|l|}{ Viviendas particulares ocupadas } \\
\hline Por número de cuartos & $60: 1.23: 69$ & 50:Bo.4:50 & $60: I .23: 69$ & 64:I.23:69 & 60:I.23:69 & 62:I.23:69 & 62:1.23:69 & 61:I.23:69 & 63:I.23:69 & $61: 1.23: 69$ \\
\hline $\begin{array}{l}\text { Por número de ocupantes } \\
\text { Por número de ocupantes según número de cuartos }\end{array}$ & 60:1.5:67 & $50: B 0.4: 50$ & $60: 1.23: 69$ & $\begin{array}{l}64: 1.23: 69 \\
64: \operatorname{Co.6:64}\end{array}$ & 60:1.5:67 & 62:I.23:69 & $\begin{array}{l}\text { 62:1.23:69 } \\
\text { 62:Pr.3:62 }\end{array}$ & $\begin{array}{l}\text { 61:I.23:69 } \\
\text { 61:Pe.4:61 }\end{array}$ & & $\begin{array}{l}\text { 61:1.23:69 } \\
\text { 61:Ve.3:61 }\end{array}$ \\
\hline $\begin{array}{l}\text { Por número de ocupantes según número de cuartos } \\
\text { Promedio de cuartos por vivienda }\end{array}$ & 60:I.15:70 & 50:1.15:70 & 50:I.15:70 & $\begin{array}{l}\text { 64:Co.6:64 } \\
\text { 64:I.15:70 }\end{array}$ & 60:I.15:70 & $62: 1.15: 70$ & $\begin{array}{l}\text { 62:Pr.3:02 } \\
\text { 62:1.15:70 }\end{array}$ & 61:1.15:70 & 63:1.15:70 & 61:1.15:70 \\
\hline $\begin{array}{l}\text { Promedio de personas por cuarto } \\
\text { Por disponibilidad de agua potable }\end{array}$ & 60:I.15:70 & 50:1.15:70 & 50:1.15:70 & 64:I.15:70 & 60:I.15:70 & 62:I.15:70 & $62: 1.15: 70$ & 61:I.15:70 & $\ldots$ & 61:1.15:70 \\
\hline $\begin{array}{l}\text { y número de ocupantes } \\
\text { Según tenencia y área urbana y rural }\end{array}$ & $\begin{array}{l}\text { 60:Ar.6:60 } \\
\text { 60:1.5:67 }\end{array}$ & $50: 1.5: 67$ b/ & $\begin{array}{l}\text { 60: Br.2:60 } \\
60: 1.5: 67\end{array}$ & $\begin{array}{l}\text { 64:Co.6:64 } \\
\text { 64:1.5:67 }\end{array}$ & 60:1.5:67 & $\begin{array}{l}\text { 62:Ec.7:62 } \\
\text { 62:1.5:67 }\end{array}$ & $\begin{array}{l}\text { 62:Pr.3:62 } \\
\text { 62:Pr.3:62 }\end{array}$ & 61:I.5:67 & 63:1.5:67 & $\begin{array}{l}\text { 61:Ve.3:61 } \\
\text { 61:1.5:67 }\end{array}$ \\
\hline
\end{tabular}


VI. POBLACION, VIVIENDA Y HOGARES (Continuación)

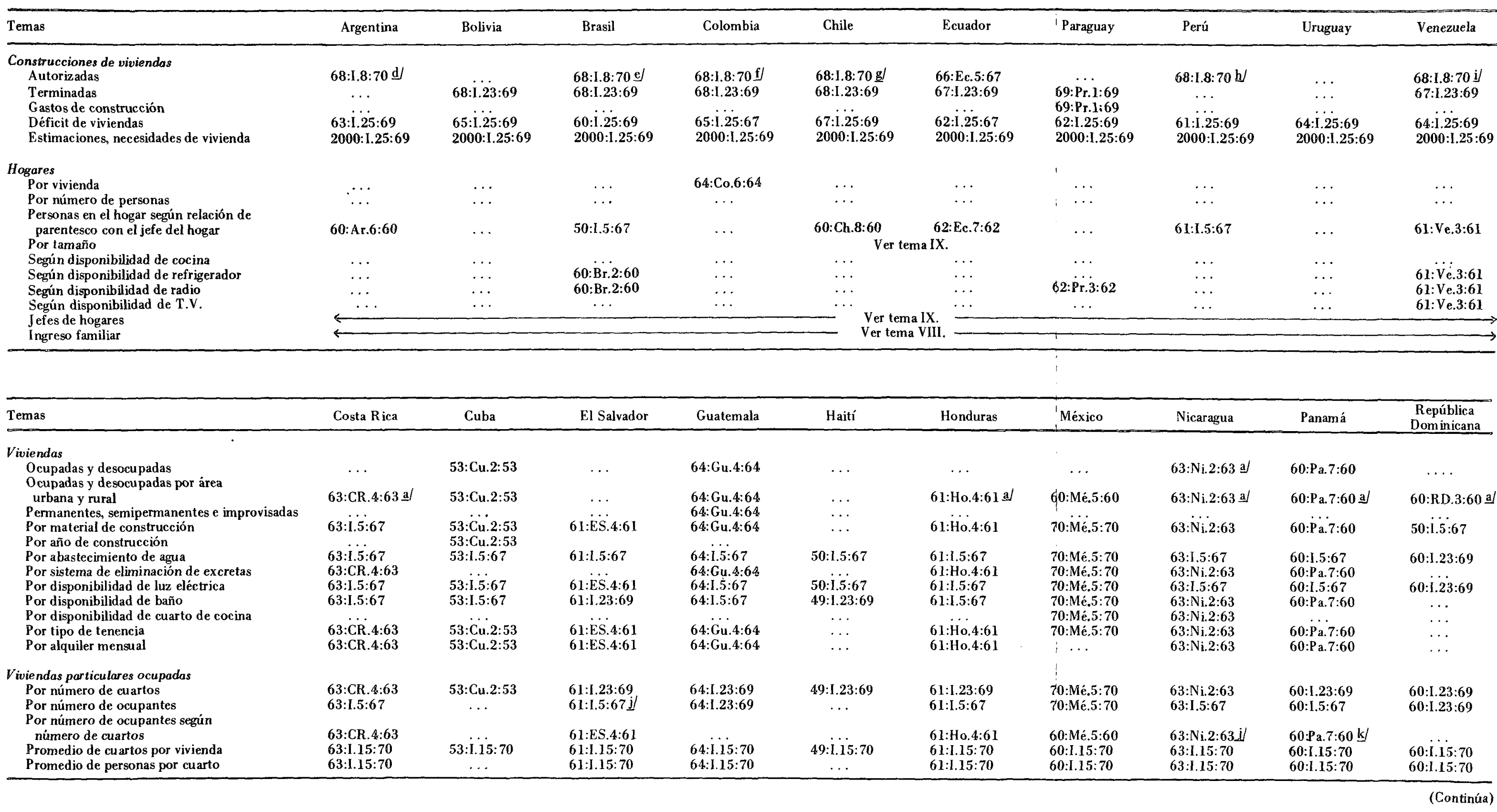


VI. POBLACION, VIVIENDA Y HOGARES (Conclusión)

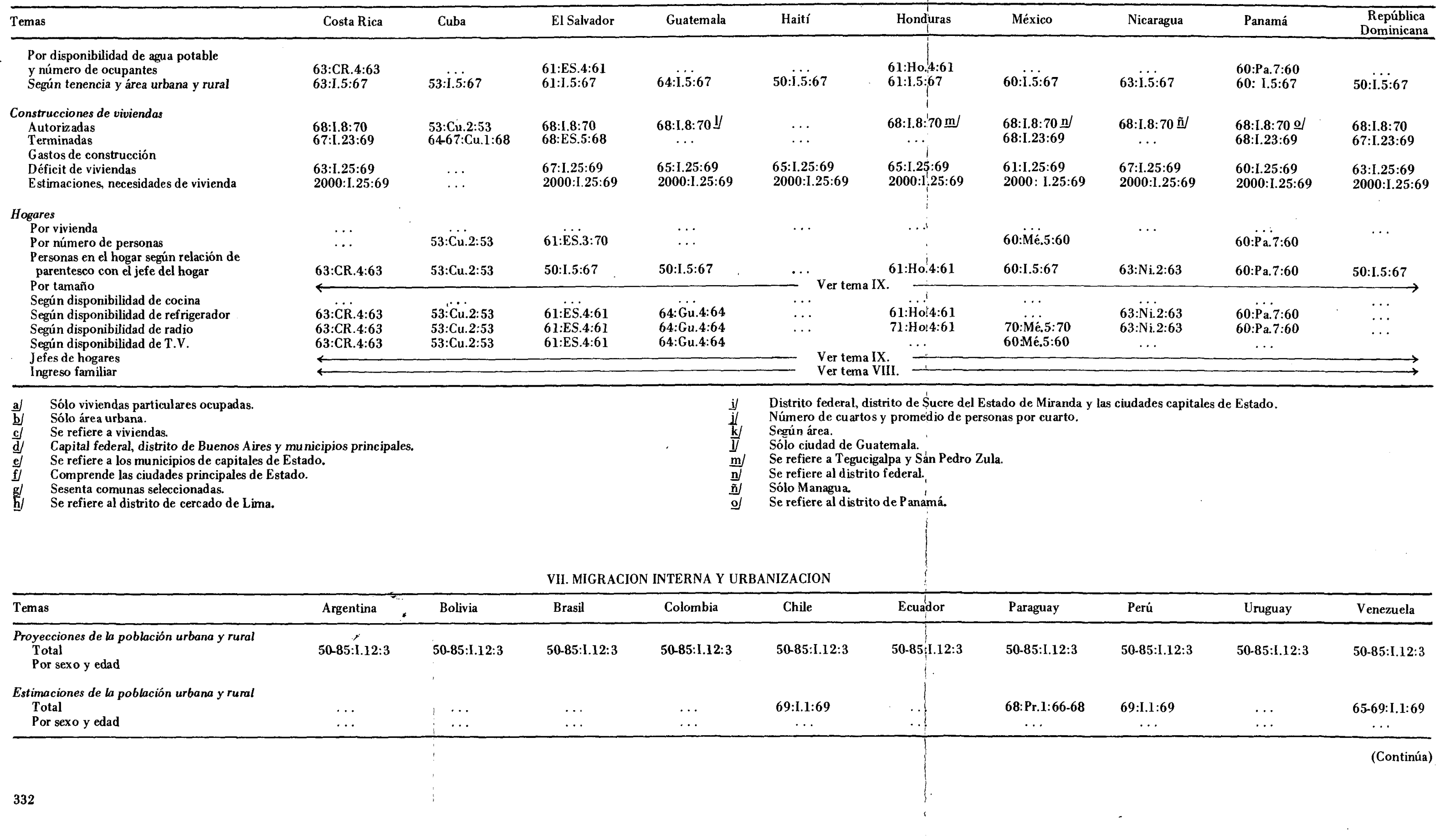


VII. MIGRACION INTERNA Y URBANIZACION (Continuación)

\begin{tabular}{|c|c|c|c|c|c|c|c|c|c|c|}
\hline Temas & Argentina & Bolivia & Brasil & Colombia & Chile & Ecuador & Paraguay & Perú & Uruguay & Venezuela \\
\hline \multicolumn{11}{|l|}{ Población urbana y rural } \\
\hline Por sexo y edad & 60:Ar.6:60 & $\ldots$ & 60:I.2:68 & & \multirow{3}{*}{$\begin{array}{l}\text { 60:Ch.8:60 } \\
60: 1.2: 67\end{array}$} & 62:Ec.7:62 & 62:Pr.3:62 & 61:Pe.1:66 & 63:Ur.2:63 & 61:Ve.3:61 \\
\hline $\begin{array}{l}\text { Población por tamaño de localidades } \\
\text { Por área urbana y rural }\end{array}$ & 60:1.2:67 & $\cdots$ & $60: \mathrm{Br} .2: 60$ & 64:Co.6:64 & & 62:Ec.7:62 & $\cdots$ & 61:Pe.1:66 & 63:I.2:66 & 61:Ve.3:61 \\
\hline Población de ciudades capitales de & & & $\cdots$ & $\cdots$ & & & & $\cdots$ & $\cdots$ & \\
\hline 100000 y más habitantes & 60:I.1:69 & 69:1.1:69 a/ & $68: 1.1: 69$ & 69:I.1:69 & 68:1.1:69 & 69:I.1:69 & 68:1.1:69 & 69:I.1:69 & 63:I.1:69 & 69:1.1:69 \\
\hline \multicolumn{11}{|l|}{$\begin{array}{l}\text { Población de las divisiones administrativas } \\
\text { por área urbana y rural }\end{array}$} \\
\hline Total & 60:Ar.6:60 & 50:Bo.4: 50 & $60: B r .2: 60$ & 64:Co.6:64 & \multirow{3}{*}{$\begin{array}{l}\text { 60:Ch.8:60 } \\
\text { 60:Ch.8:60 b/ } \\
\text { 60:Ch.8:60 }\end{array}$} & 62:Ec.7:62 & 62:Pr.3:62 & 61:Pe.1:66 & $\ldots$ & 61:Ve.3:61 \\
\hline Por sexo y edad & 60:Ar.6:60 & 50:Bo.4: 50 & & 64:Co.6:64 & & 62:Ec.7:62 & $\cdots$ & 61:Pe.1:66 & $\cdots$ & $\cdots$ \\
\hline $\begin{array}{l}\text { Por nivel de instrucción } \\
\text { Por tipo de actividad }\end{array}$ & $60: \ddot{A r} .6: 60$ & $\cdots$ & $\cdots$ & 64:Co.6:64 & & 62:Ё.7:62 & 62:Pr.3:62 & 61:Pe.4:61 & $\cdots$ & $\ldots$ \\
\hline Por rama de actividad & $\ldots$ & ... & $\ldots$ & $\ldots$ & $\cdots$ & $\ldots$ & $\ldots$ & $\therefore$ & $\cdots$ & $\ldots$ \\
\hline Por categoría ocupacional & $\cdots$ & $\cdots$ & $\cdots$ & $\cdots$ & $\cdots$ & $\cdots$ & $\cdots$ & $\cdots$ & $\cdots$ & $\cdots$ \\
\hline Por ocupación & $\cdots$ & $\cdots$ & $\cdots$ & $\cdots$ & $\cdots$ & $\cdots$ & $\cdots$ & $\cdots$ & $\cdots$ & $\cdots$ \\
\hline \multicolumn{11}{|l|}{$\begin{array}{l}\text { Población nativa e inmigrante en las } \\
\text { divisiones administrativas }\end{array}$} \\
\hline $\begin{array}{l}\text { Total } \\
\text { Por sexo y edad }\end{array}$ & 60:Ar.6:60 & $\cdots$ & $\cdots$ & 64:Co.6:64 & \multirow{2}{*}{$\begin{array}{l}\text { 60:Ch.8:60 } \\
\text { 60:Ch.8:60 b/ }\end{array}$} & $\cdots$ & $\cdots$ & 61:Pe.4:61 & $\cdots$ & $\cdots$ \\
\hline $\begin{array}{l}\text { Por sexo y edad } \\
\text { Por nivel de instrucción }\end{array}$ & $\ldots$ & $\ldots$ & $\cdots$ & $\cdots$ & & $\cdots$ & $\begin{array}{l}\cdots \\
\cdots\end{array}$ & 61:Pe.4:61 & $\cdots$ & $\cdots$ \\
\hline Por ocupación & ... & $\ldots$ & $\ldots$ & 64:Co.6:64 & $\ldots$ & $\cdots$ & $\cdots$ & $\cdots$ & $\cdots$ & $\ldots$ \\
\hline Por rama de actividad & $\ldots$ & $\ldots$ & $\ldots$ & 64:Co.6:64 & $\ldots$ & $\therefore$ & $\ldots$ & $\ldots$ & $\ldots$ & $\ldots$ \\
\hline $\begin{array}{l}\text { Por categoría ocupacional } \\
\text { Por número de hijos nacidos vivos }\end{array}$ & $\cdots$ & $\cdots$ & $\cdots$ & $\ldots$ & $\cdots$ & $\cdots$ & $\cdots$ & $\cdots$ & $\cdots$ & $\cdots$ \\
\hline $\begin{array}{l}\text { Por número de hijos nacidos vivos } \\
\text { de las mujeres }\end{array}$ & $\cdots$ & $\cdots$ & $\cdots$ & $\cdots$ & $\cdots$ & $\cdots$ & $\ldots$ & $\ldots$ & $\ldots$ & $\ldots$ \\
\hline \multirow{3}{*}{$\begin{array}{l}\text { Población por lugar de residencia habitual } \\
\text { Según lugar de residencia anterior y sexo } \\
\text { Segín tiempo de residencia }\end{array}$} & & & & \multirow{3}{*}{ 64:Co.6:64 } & & & & & & \\
\hline & $\ldots$ & $\ldots$ & $\ldots$ & & $\ldots$ & \multirow{2}{*}{$\begin{array}{l}\text { 62:Ec.7:62 } \\
\text { 62:Ec.7:62 }\end{array}$} & $\ldots$ & 61:Pe.4:61 & $\ldots$ & 61:Ve.3:61 \\
\hline & $\cdots$ & $\cdots$ & $\cdots$ & & $\cdots$ & & $\cdots$ & 61:Pe.4:61 & $\cdots$ & $\cdots$ \\
\hline \multicolumn{11}{|l|}{ 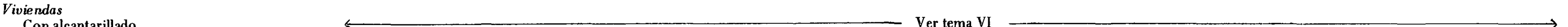 } \\
\hline \multirow{2}{*}{$\begin{array}{l}\text { Con alcantarillado } \\
\text { Con agua potable } \\
\text { Con alumbrado eléctrico } \\
\text { Con pavimentación }\end{array}$} & \multicolumn{5}{|c|}{ 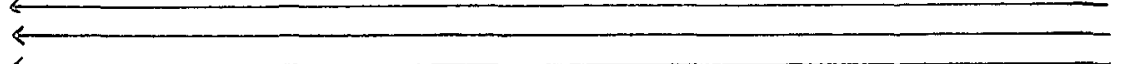 } & VI & - & $\longrightarrow$ & - & $\longrightarrow$ \\
\hline & 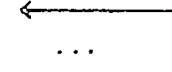 & $\ldots$ & $\ldots$ & $\cdots$ & $\ldots$ Ver tem & VI $\ldots$ & $\cdots$ & $\ldots$ & $\cdots$ & $\ldots$ \\
\hline \multirow{5}{*}{$\begin{array}{l}\text { Población por división administrativa } \\
\text { Según lugar de nacimiento y sexo } \\
\text { Longitud de líneas férreas y su relación con } \\
\text { el territorio y la población } \\
\text { Longitud de carreteras } \\
\text { Capacidad de energia eléctrica: } \\
\text { instalada y producida } \\
\end{array}$} & & & & & \multirow{3}{*}{ 60:Ch.8:60 } & & & & & \\
\hline & $\cdots$ & $\cdots$ & $\cdots$ & 64:Co.6:64 & & $\cdots$ & $\cdots$ & 61:Pe.4:61 & $\cdots$ & 61:Ve.3:61 \\
\hline & \multirow{2}{*}{\multicolumn{10}{|c|}{ 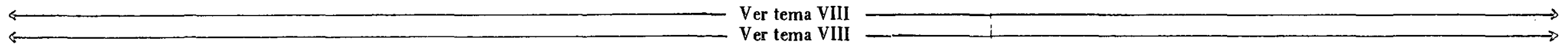 }} \\
\hline & & & & & & & & & & \\
\hline & 68:I.8:70 & 68:1.8:70 & 68:I.8:70 & 68:1.8:70 & 68:I.8:70 & 66:I.8:70 & 68:I.8:70 & 67:I.8:70 & $66: I .8: 70$ & 68:I.8:70 \\
\hline
\end{tabular}


VII. MIGRACION INTERNA Y URBANIZACION (Continuación)

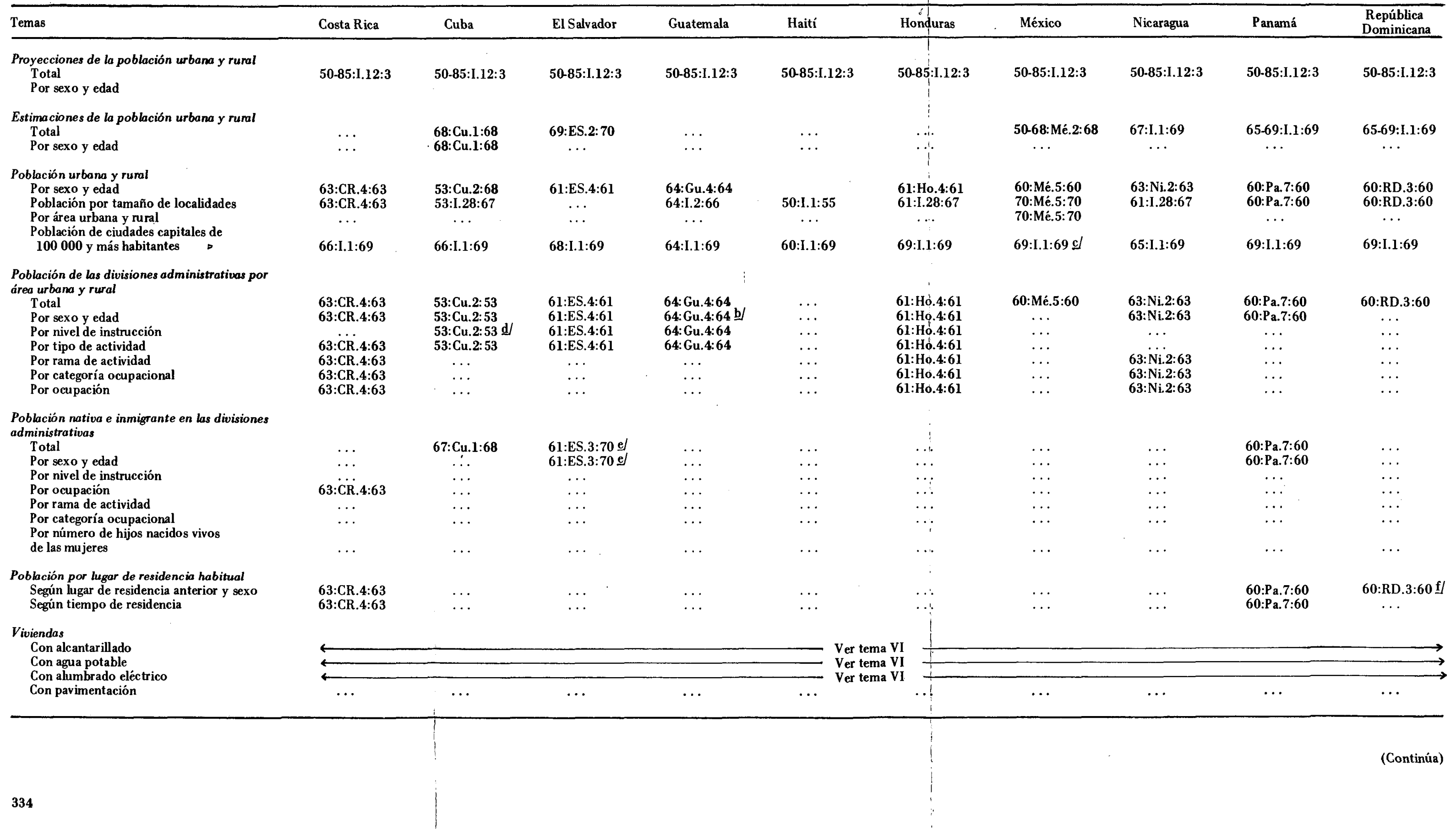


VII. MIGRACION INTERNA Y URBANIZACION (Conclusión)

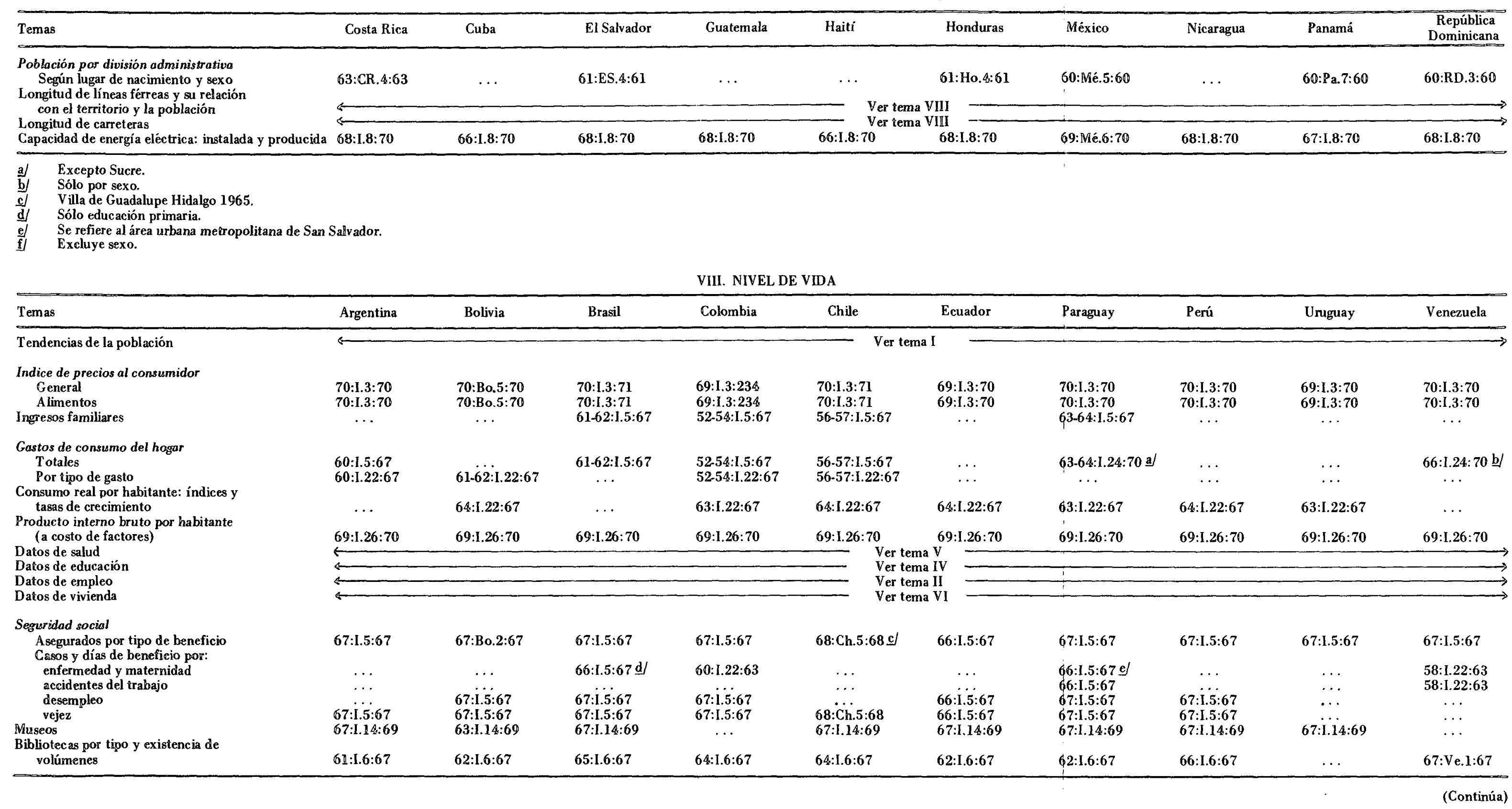


VIII. NIVEL DE VIDA (Continuación)

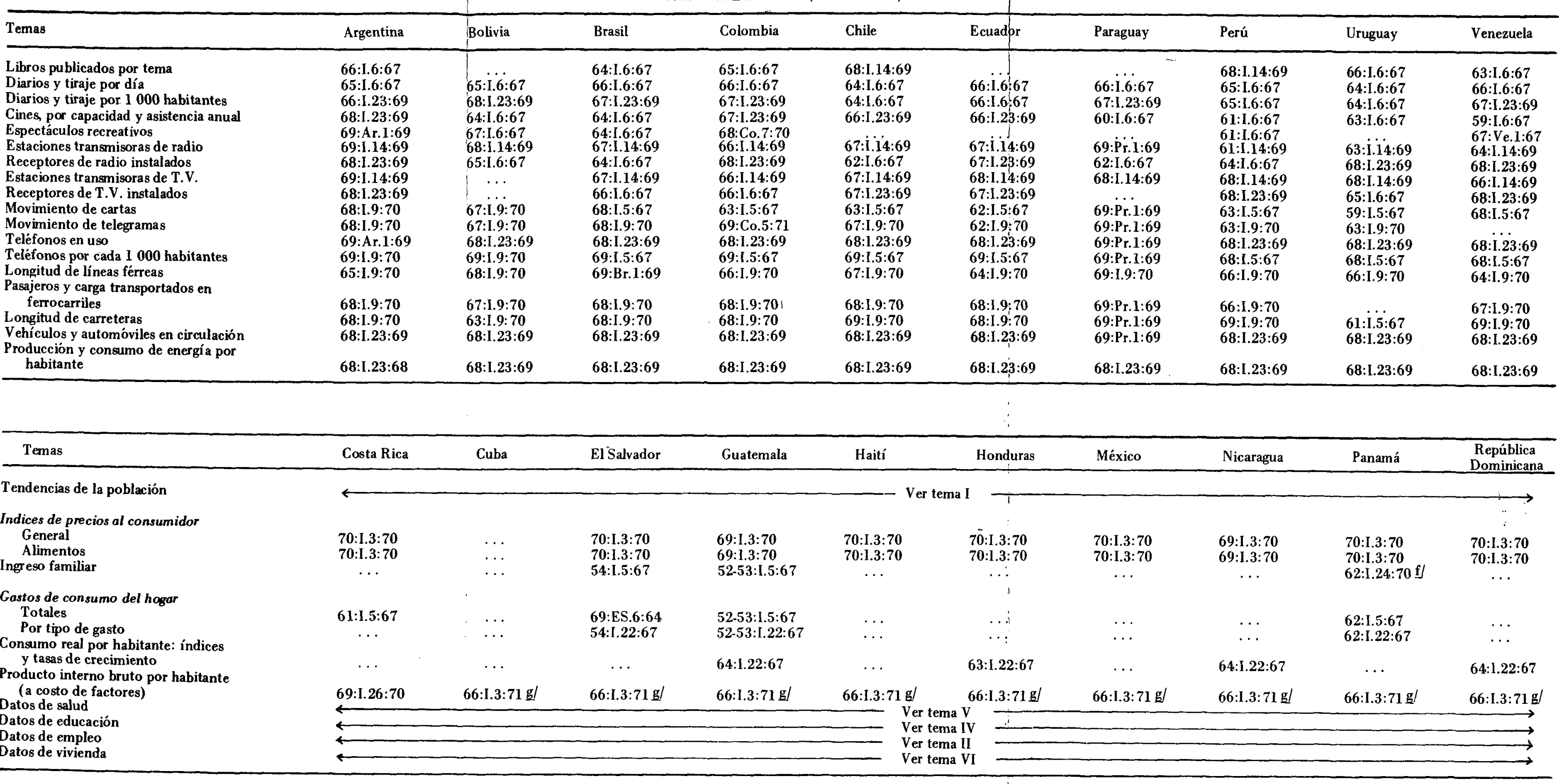


VIII. NIVEL DE VIDA (Conclusión)

\begin{tabular}{|c|c|c|c|c|c|c|c|c|c|c|}
\hline Temas & Costa Rica & Cuba & EI Salvador & Guatemala & Haití & Honduras & México & Nicaragua & Panamá & $\begin{array}{c}\text { República } \\
\text { Dominicana }\end{array}$ \\
\hline \multicolumn{11}{|l|}{ Seguridad social } \\
\hline \multirow{3}{*}{$\begin{array}{l}\text { Asegurados por tipo de beneficio } \\
\text { Casos y días de beneficio por: } \\
\text { enfermedad y maternidad } \\
\text { accidentes del trabajo } \\
\text { desempleo }\end{array}$} & 68:CR.1:68 & $\ldots$ & 69:ES.3:69 & $67: 1.5: 67$ & $66: I .5: 67$ & 67:1.5:67 & 68:Mé.2:68 & 67:I.5:67 & 69:Pa.1:68 & $67: 1.5: 67$ \\
\hline & $\begin{array}{l}\text { 68:CR.1:68 } \\
68: C R .168\end{array}$ & $\ldots$ & $\begin{array}{l}67: 1.5: 67 \mathrm{~h} / \\
66: I .5: 67\end{array}$ & $67: 1.5: 67 \mathrm{i} /$ & $\cdots$ & $\begin{array}{l}\text { 65:1.5:67 } \\
\text { 65:1.5:67 }\end{array}$ & $\begin{array}{l}59: 1.22: 63 \mathrm{j} / \\
59: 122: 63\end{array}$ & $66: 1.5: 67$ & $69: \mathrm{Pa} .1: 68$ & 66:I.5:67 \\
\hline & b8:CK.1:68 & $\cdots$ & $67: 1.5: 67$ & & $66: 1.5: 67$ & 67:1.5:67 & 67:I.5:67 & 67:I.5:67 & $69: \dddot{\mathrm{Pa}} 1: 68$ & $\begin{array}{l}\text { 65:1.5:67 } \\
67: 1.5: 67\end{array}$ \\
\hline vejez & 68:CR.1:68 & & & & & & 67:I.5:67 & 67:1.5:67 & 69:Pa.1:68 & $67: 1.5: 67$ \\
\hline \multicolumn{11}{|l|}{$\begin{array}{l}\text { Mibliotecas por tipo y existencia de } \\
\text { Bibles }\end{array}$} \\
\hline volúmenes & $64: 1.6: 67$ & 68:Cu.1:68 & 69:ES.1:69 & 64:I.6:67 & 64:1.6:67 & 62:1.6:67 & 64:I.6:67 & 62:1.6:67 & 62:I.6:67 & 64:I.6:67 \\
\hline Libros publicados por tema & 68:I.14:69 & 68:1.14:69 & 66:I.6:67 & $66: 1.6: 67$ & $65: 1.6: 67$ & 62:1.6:67 & 68:I.14:69 & & & 63:I.6:67 \\
\hline $\begin{array}{l}\text { Diarios y tiraje por día } \\
\text { Diariog hatantes }\end{array}$ & 67:I.23:69 & 61:1.6:67 & 69:ES.1:69 & 66:I.6:67 & 65:I.6:67 & 67:1.23:69 & $66: 1.6: 67$ & 65:1.6:67 & $66: I .6: 67$ & $66: 1.6: 67$ \\
\hline Diarios y tiraje por 1000 habitantes & 64:1.6:67 & 61:1.6:67 & $66: 1.6: 67$ & 66:I.6:67 & 65:I.6:67 & 64:I.6:67 & $66: 1.6: 67$ & 65:I.6:67 & 67:I.23:69 & 66:1.6:67 \\
\hline $\begin{array}{l}\text { Cines, por capacidad y asistencia anual } \\
\text { Espectáculos recreativos }\end{array}$ & 60:1.23:69 & 61:1.6:67 & $\begin{array}{l}\text { 62:1.6:67 } \\
\text { 69:ES.1:69 }\end{array}$ & $68: 1.23: 69$ & 64:I.6:67 & 60:1.23:69 & $\begin{array}{l}\text { 68:Mế. } 2: 68 \\
\text { 68:Mé.2:68 }\end{array}$ & 63:1.6:67 & 68:I.23:69 & 67:L.23:69 \\
\hline Estaciones transmisoras de radio & 60:I.14:69 & 61:I.14:69 & 63:I.14:69 & $68: 1.14: 69$ & 65:I.14:69 & 63:I.14:69 & 68:I.14:69 & 60:I.14:69 & 68:I.14:69 & 64:1.14:69 \\
\hline Receptores de radio instalados & $65: 1.6: 67$ & $64: 1.6: 67$ & $68: 1.23: 69$ & & $68: I .23: 69$ & $68: 1,23: 69$ & 68:Mé.2:68 & 68:1.23:69 & $65: 1.6: 67$ & $68: 1.23: 69$ \\
\hline Estaciones transmisoras de T.V. & 68:I.14:69 & 63:I.14:69 & $66: 1.14: 69$ & 68:I.14:69 & 68:I.14:69 & 68:I.14:65 & 68:I.14:69 & 68:I.14:69 & 68:1.14:69 & 67:I.14:69 \\
\hline Receptores de T.V. instalados & 68:I.23:69 & 68:I.23:69 & 67:I.1.23:69 & 68:1.23:69 & 68:I.23:69 & 68:1.23:69 & 68:I.23:69 & $67: 1.23: 69$ & 67:I.23:69 & 68:I.23:69 \\
\hline \multirow{4}{*}{$\begin{array}{l}\text { Movimiento de cartas } \\
\text { Movimiento de telegramas } \\
\text { Teléfonos en uso } \\
\text { Teléfonos por cada } 1000 \text { habitantes } \\
\text { Longitud de lineas férreas } \\
\text { Pasajeros y carga transportados en }\end{array}$} & 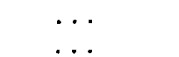 & $\cdots$ & $\begin{array}{l}\text { 68:I.5:67 } \\
67: I .9: 70\end{array}$ & 68:I.23:69 & & $60 \cdot \mathrm{Ho} 3 \cdot 70$ & 69:Mé.6:70 & & & 63:1.5:67 \\
\hline & 68:I.23:69 & 68:I.23:69 & $\begin{array}{l}\text { b7:.9: } 76 \\
69: E S .1: 69\end{array}$ & 68:23:69 & $68: 23: 69$ & 68:23:69 & $\begin{array}{l}\text { 69:Mé.6:70 } \\
\text { 69:Mé.6:70 }\end{array}$ & $68: 1.23: 69$ & 68:I.23:69 & $\begin{array}{l}\text { 63:I.9:70 } \\
\text { 68:I.23:69 }\end{array}$ \\
\hline & $69: 1.5: 67$ & 69:I.5: 67 & 69:I.5:67 & $69: 1.5: 67$ & 69:I.5:67 & 69:Ho.3:70 & 69:1.5:67 & 69:1.5:67 & $69: \mathrm{Pa} .1: 68$ & 69:I.5:67 \\
\hline & 68:CR.1:68 & 63:I.9:70 & 66:I.9:70 & 65:I.9:70 & 64:1.9:70 & $67: 1.9: 70$ & 69:Mè.3:70 & 64:1.9:70 & $66: I .9: 70$ & $66: 1.9: 70$ \\
\hline \multirow{4}{*}{$\begin{array}{l}\text { Pasajeros y carga transportados en } \\
\text { ferrocarriles } \\
\text { Longitud de carreteras } \\
\text { Vehículos y automóviles en circulación } \\
\text { Producción y consumo de energía por } \\
\text { habitante }\end{array}$} & 68:CR.1:68 & 68:Cu.1:68 & 70:ES.3:70 & 67:I.9:70 $\mathrm{l}$ & & $67:$ Ho.1:69 & 69:Mé,3:70 & 68:I.9:70 & & \\
\hline & $68: 1.9: 70$ & & 68:1.9:70 & $69: 1.9: 70$ & 69:I.9:70 & $69:$ Ho. $3: 70$ & $69: 1.9: 70$ & $68: 1.9: 70$ & 69:Pa.1:68 & 68:1.9:70 \\
\hline & $68: 1.23: 69$ & 68:I.23:69 & 69:ES.3: $70 \underline{m} /$ & 68:I.23:69 & 68:1.23:69 & 68:1.23:69 & 68:1.23:69 & 67:I.23:69 & 69:Pa.1:68 & 68:1.23:68 \\
\hline & 68:I.23:69 & 68:I.23:69 & $68: 1.23: 69$ & 68:I.23:69 & 68:1.23:69 & 68:I.23:69 & 68:I.23:69 & 68:I.23:69 & 68:1.23:69 & $68: 1.23: 69$ \\
\hline
\end{tabular}

\footnotetext{
a/ Sólo Asunción.

Sólo participantes

Sólo participan tes.
Sólo casos.

Maternidad, estimaciones.

Ciudad de Panamá.

Sólo área de San Salvador y municipios de Sonsonate y Acayutl

We mujeres as

Lestimaciones.

Estimaciones.
Número total

Número total de asegurado

m/ Vehículos de pasajeros.
} 
IX. DESARROLLO SOCIAL

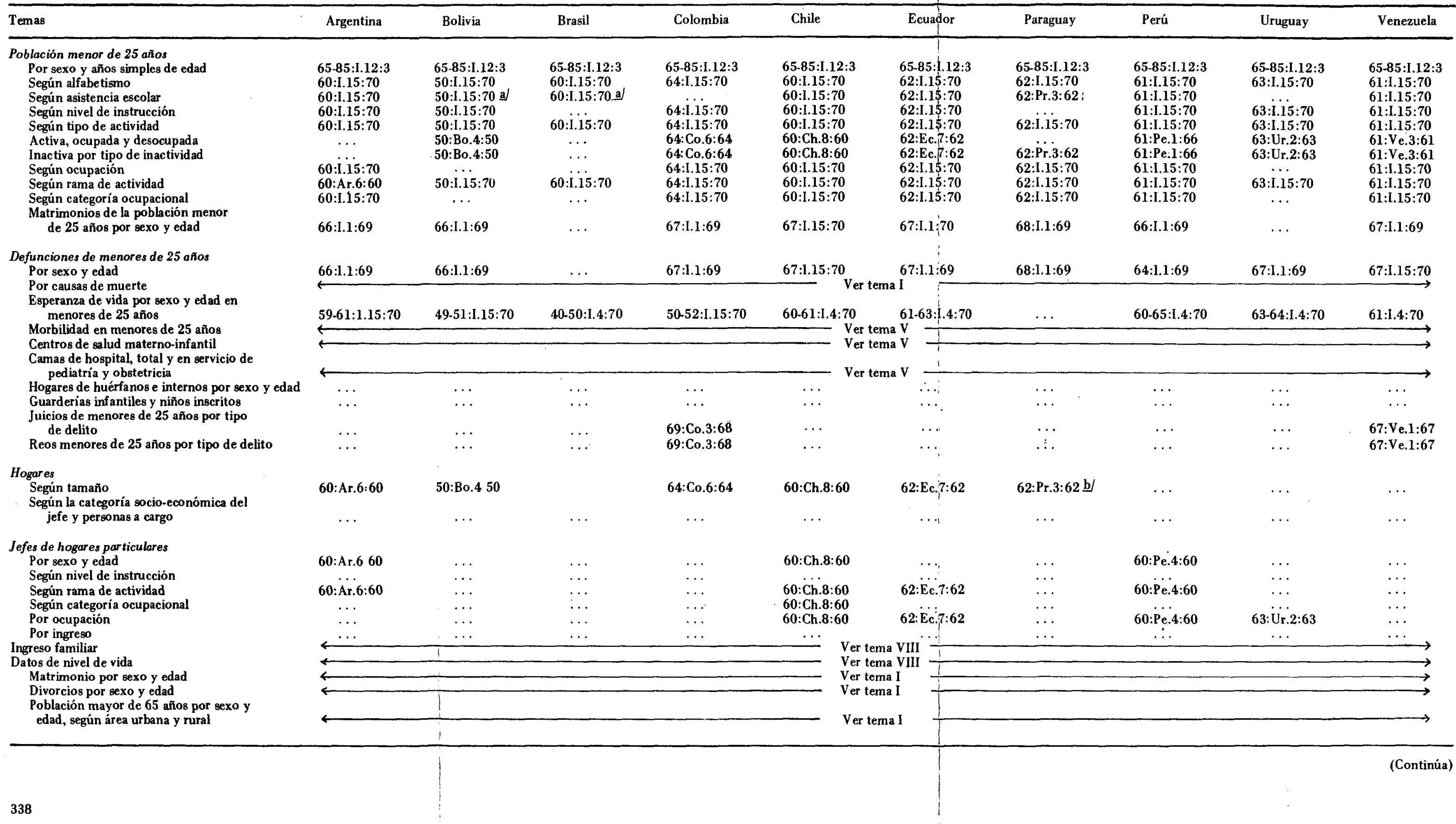


IX. DESARROLLO SOCIAL (Continuación)

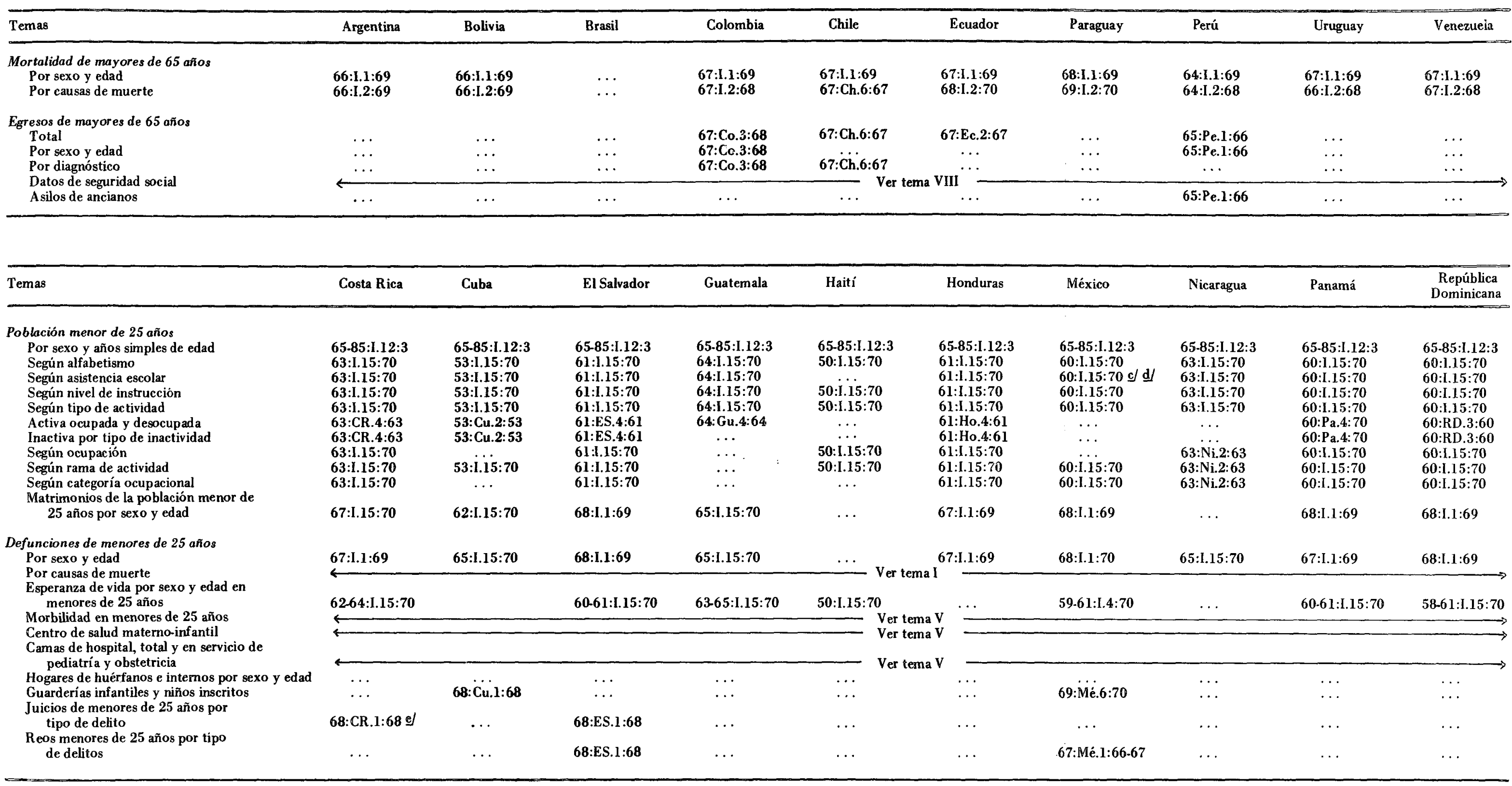


IX. DESARROLLO SOCIAL (Conclusión)

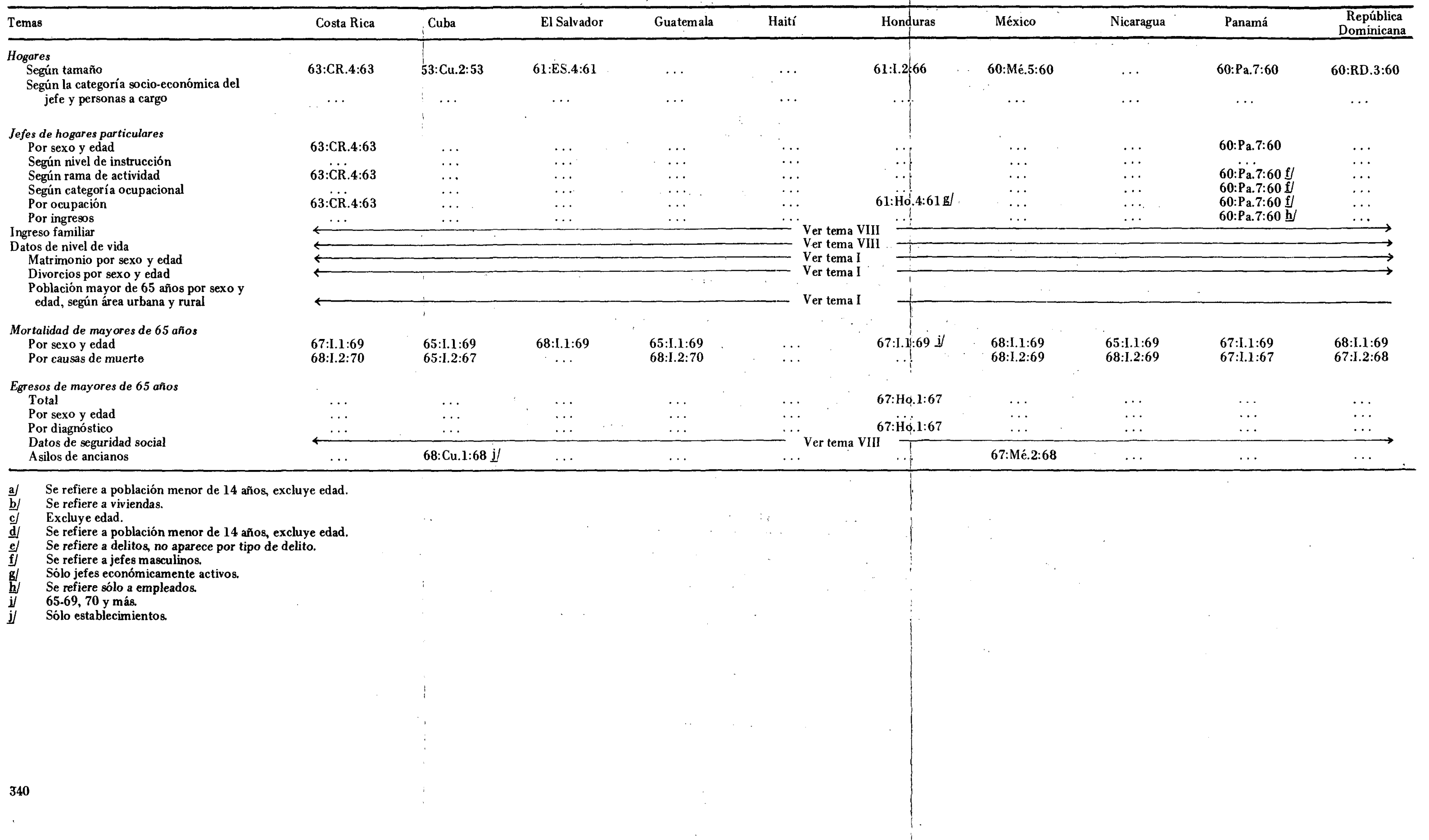


X. FECUNDIDAD Y PLANIFICACION FAMILIAR

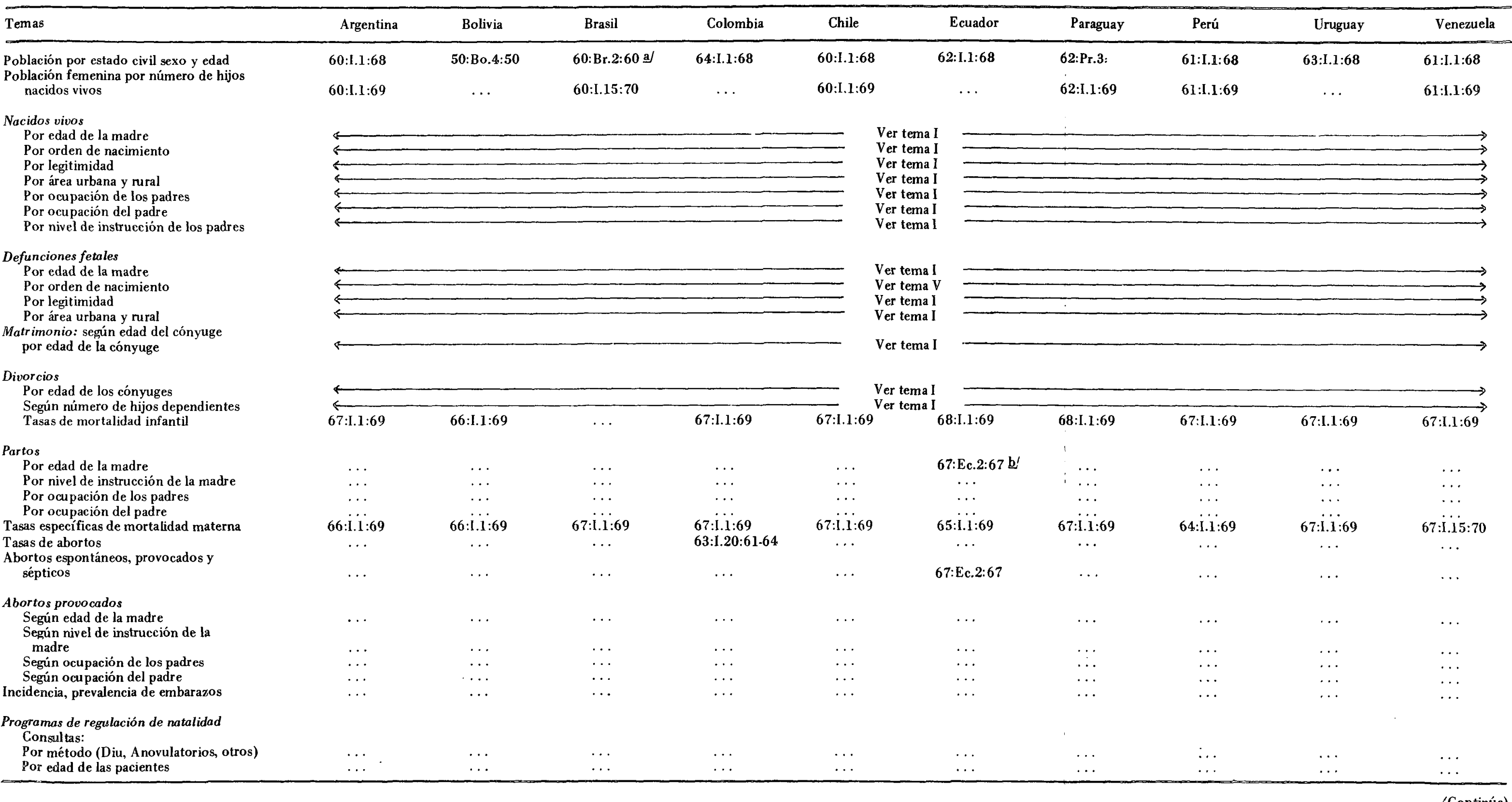


X. FECUNDIDAD Y PLANIFICACION FAMILIAR (Continuación)

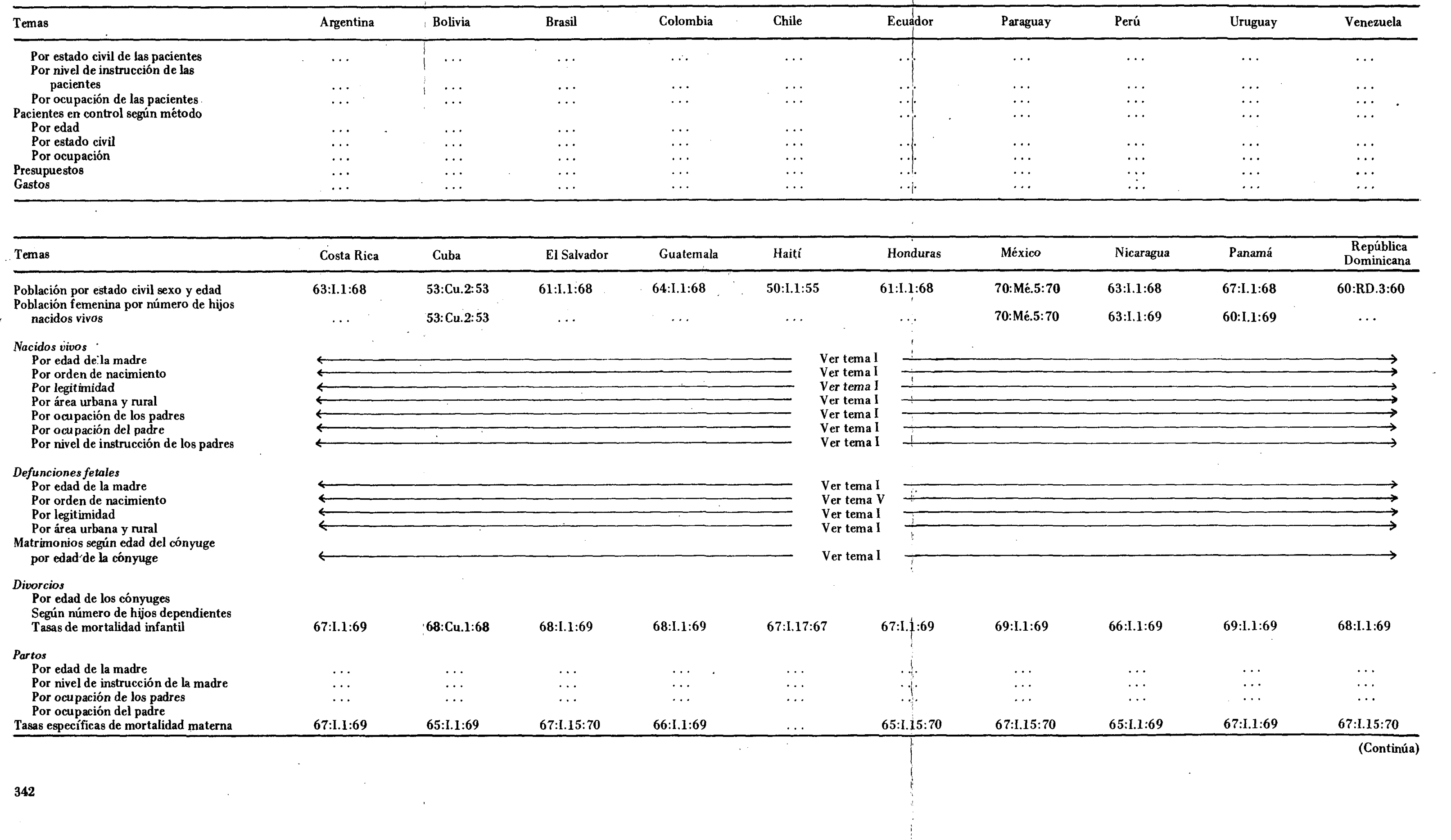


X. FECUNDIDAD Y PLANIFICACION FAMILIAR (Conclusión)

\begin{tabular}{|c|c|c|c|c|c|c|c|c|c|c|}
\hline Temas & Costa Rica & Cuba & El Salvador & Guatemala & Haití & Honduras & México & Nicaragua & Panamá & $\begin{array}{l}\text { República } \\
\text { Dominicana }\end{array}$ \\
\hline $\begin{array}{l}\text { Tasas de abortos } \\
\text { Abortos espontáneos, provccados y }\end{array}$ & $64: 1.20: 61-64 \mathrm{a} /$ & $\ldots$ & $\ldots$ & $\ldots$ & $\ldots$ & $64: 1.20: 61-64$ a & . & $\ldots$ & $\ldots$ & $\ldots$ \\
\hline sépticos & $\cdots$ & $\cdots$ & $69:$ ES.5:69 & $\cdots$ & $\cdots$ & $\cdots$ & $\cdots$ & $\ldots$ & $\cdots$ & $\cdots$ \\
\hline \multicolumn{11}{|l|}{ Abortos provocados } \\
\hline $\begin{array}{l}\text { Según edad de la madre } \\
\text { Semin nivel de instrución de la madre }\end{array}$ & $\cdots$ & $\cdots$ & $\cdots$ & $\cdots$ & $\cdots$ & $\cdots$ & $\cdots$ & $\ldots$ & ... & ... \\
\hline $\begin{array}{l}\text { Según nivel de instrucción de la madre } \\
\text { Según ocupación de los padres }\end{array}$ & $\cdots$ & $\ldots$ & $\ldots$ & $\cdots$ & $\cdots$ & $\cdots$ & $\ldots$ & $\cdots$ & $\cdots$ & $\cdots$ \\
\hline $\begin{array}{l}\text { Según ocupación del padre } \\
\text { S }\end{array}$ & $\ldots$ & $\cdots$ & $\ldots$ & $\ldots$ & $\ldots$ & $\ldots$ & ... & $\ldots$ & $\ldots$ & $\ldots$ \\
\hline Incidencia, prevalencia de embarazos & ... & $\cdots$ & $\cdots$ & $\cdots$ & $\cdots$ & $\cdots$ & $\cdots$ & $\cdots$ & $\cdots$ & $\cdots$ \\
\hline \multirow{2}{*}{\multicolumn{11}{|c|}{$\begin{array}{l}\text { Programas de regulación de natalidad } \\
\text { Consultas: }\end{array}$}} \\
\hline Por método (Diu, Anovulatorios, otros) & $\ldots$ & $\ldots$ & $\ldots$ & $\ldots$ & $\ldots$ & $\ldots$ & $\ldots$ & & & \\
\hline Por edad de las pacientes & $\ldots$ & ... & ... & $\ldots$ & $\cdots$ & .. & .. & .. & $\cdots$ & ... \\
\hline Por estado civil de las pacientes & ... & ... & ... & $\ldots$ & .. & .. & $\ldots$ & $\ldots$ & .. & .. \\
\hline Por nivel de instrucción de las pacientes & $\ldots$ & $\ldots$ & $\ldots$ & ... & .. & .. & .. & ... & .. & ... \\
\hline $\begin{array}{l}\text { Por ocupación de las pacientes } \\
\text { Pont }\end{array}$ & $\ldots$ & $\ldots$ & $\ldots$ & ... & ... & $\ldots$ & $\ldots$ & $\ldots$ & ... & ... \\
\hline $\begin{array}{l}\text { Pacientes en control según método } \\
\text { Por edad }\end{array}$ & $\cdots$ & $\ldots$ & ... & $\ldots$ & .. & .. & $\ldots$ & $\cdots$ & $\cdots$ & ... \\
\hline Por estado civil & $\ldots$ & $\ldots$ & $\ldots$ & $\ldots$ & $\ldots$ & $\ldots$ & $\ldots$ & $\ldots$ & $\ldots$ & $\ldots$ \\
\hline Por ocupación & ... & ... & ... & $\ldots$ & ... & ... & ... & ... & ... & ... \\
\hline $\begin{array}{l}\text { Presupuestos } \\
\text { Pris }\end{array}$ & $\ldots$ & $\ldots$ & $\ldots$ & ... & ... & ... & ... & ... & ... & ... \\
\hline Gastos & ... & . & ... & ... & ... & ... & $\ldots$ & $\ldots$ & 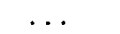 & $\ldots$ \\
\hline
\end{tabular}

a/ Excluye edad de la madre

xcluye edad. 



\section{ANEXO I}

\section{SIMBOLOGIA UTILIZADA}

1. Los códigos que figuran en cada casillero de los diversos cuadros son tres, y están separados entre sí por dos puntos, con el siguiente significado:

a) El primer código (dos cifras), que representan las dos últimas del año de referencia del último dato disponible para el tema. Cuando se trata de un período de tiempo se señalan los años ex tremos de éste, separados por un guión.

b) El segundo código (compuesto de una o dos letras mayúsculas y de una o dos cifras) representa el nombre de la publicación (Ver listas de códigos a continuación).

La letra "I" representa una publicación internacional. Para las publicaciones nacionales el nombre del pais se representó por dos le tras mayúsculas.

c) El tercer código (una o dos cifras) representan, según el caso, el volumen (ver lista de códigos) o el año de la publicación respectivamente.

2. Una flecha $(\rightarrow)$ horizontal a continuación de un código señala que el dato para ese país se halla en la misma publicación indicada para el país anterior.

3. Tres puntos (...) indican que no se dispone del dato o que no se conoce la fuente que lo contiene. 


\title{
BIBLIOGRAFIA INTERNACIONAL
}

\author{
Códigos
}

I.1. United Nations:

Demographic yearbook, 1955, 1963, 1964, 1965, 1966, 1967, 1968, 1969.

I.2. Archivo de formularios para el Anuario Demográfico, 1970.

I.3. . Monthly Bulletin of statistics, June, 1971.

OEA; Instituto Interamericano de Estadística, Secretaria General.

I.4. América en cifras:

Situación demográfica: Estado y movimiento de la población, 1970.

I.5. Situación social: Hogar, habitación, mejoramiento urbano, previsión social, asistencia médica y de salud y trabajo, 1967.

I.6. Situación cultural: Educación y otros aspectos culturales, 1967.

I.7. Situación económica: I: Agricultura, ganadería, silvicultura, caza y pesca.

I.8. Situación económica: 2: Industria, 1970.

1.9. Situación económica: 3: Comercio, transportes, comunicaciones y turismo, 1970.

1.10. Situación económica: 4: Balanza de pagos, producto e ingresos nacionales y finanzas.

I.11. Situación económica: 5: Precios, salarios, consumo y otros, 1967.

I.12:1 CELADE

Boletín Demográfico; Año 1, vol. II; América Latina: Población menor de 70 años, total económicamente activa por sexo y grupos de edades: año 1965, Santiago de Chile, octubre 1968.

I.12:2. Boletín Demográfico; Año 2, vol. III; América Latina: Tasas de actividad por sexo y grupos de edades en el tramo 10-69 años: Áno 1965, Santiago de Chile, enero de 1969.

1.12:3. Boletín Demográfico; Año II, No 4; América Latina: Nivel de la mortalidad: Tasas brutas anuales de mortalidad en la población estacionaria y en la población real, por países. Periodo 1965-1970, Santiago de Chile, julio de 1969. 
1.12:4. Boletín Demográfico; Año III, No 5; América Latina: Población total y tasas anuales de natalidad, mortalidad y crecimiento según proyecciones recomendadas por CELADE, 1960-2000, Santiago de Chile, enero de 1970.

I.12:5. Boletín Demográfico; Año III, No 6; América Latina: Población total por países: Año 1970, Santiago de Chile, julio de 1970.

I.13. FAO

The state of food and agriculture, 1970.

I.14. UNESCO

Statistical yearbook, 1969.

I.15. Naciones Unidas:

Estadisticas sobre la infancia y la juventud en América Latina, 1970.

I.16. Population and vital statistics report, Series A, vol. XXIII, No $1,1^{\circ}$ January, 1971.

I.17. OMS:

World health statistics annual, 1967.

Volume I: Vital statistics and causes of death.

1.18. Volume II: Infectidus deseases: cases, deaths and vaccinations.

1.19. Volume III: Health personnel and hospital establishments.

OPS: Organización Panamericana de la Salud, Oficina sanitaria panamericana, Oficina regional.

1.20. Condiciones de salud en las A méricas, 1961-1964.

1.21. Casos notificados de enfermedades de declaración obligatoria en las A méricas, 1965.

I.22. Naciones Unidas: Compendium of social statistics, 1963, 1967.

I.23. Statistical yearbook, 1969.

1.24. OIT:

Anuario de estadísticas del trabajo, 1970.

Banco Interamericano de Desarrollo:

1.25. Progreso socio-económico en América Latina, Fondo Fiduciario de Progreso Social, noveno informe anual, 1969.

1.26. Naciones Unidas:

Estimaciones de la CEPAL en base a estadisticas oficiales.

1.27. Boletín Estadístico de A mérica latina, Vol. VIII-1,1971.

I.28. Boletín Estadistico de América Latina, Vol. IV-2. 


\section{BIBLIOGRAFIA NACIONAL}

Argentina: Ar.

\section{Códigos}

1. Instituto Nacional de Estadística y Censos: Boletin de Estadística, 1969.

2. Secretaria de Estado de Cultura y Educación: Estadística Educativa, 1970.

3. Secretaría de Estado de Cultura y Educación: Estadística Educativa, (comunicado para la Prensa) 1970.

4. Secretaría de Estado de Cultura y Educación: Estadística Educativa, (Boletín Informativo) 1968.

5. Secretaría de Estado de Cultura y Educación: Educación en Cifras, 1967.

6. Poder Ejecutivo Nacional, Secretaría de Estado de Hacienda; Dirección Nacional de Estadística y Censos: Censo Nacional de Población y Vivienda, 1960. Total general.

(Poblacion: 9 Tomos; Tomo I, Total del país, desde el Tomo II al IX se refiere al total por provincia, Vivienda: 3 Tomos).

Bolivia: Bo

1. Secretaria Nacional de Planificación y Coordinación: Bolivia en Cifras, 1967.

2. Caja Nacional de Seguridad Social: Estadística, 1967.

3. United States Agency for International Development-Bolivia: Estadisticas Económicas, 1970.

4. Dirección General de Estadística y Censos. Ministerio de Hacienda y Estadística: Censo Demográfico, 1950.

5. Ministerio de Planificación y Coordinación; Instituto Nacional de Estadística: Indices de Precios al Consumidor, Hoja Informativa No 20 , Diciembre, 1970.

6. Información Directa - 67 .

Brasil: Br.

1. Fundaçao IBGE: Instituto Brasileiro de Estadística: Anuario Estadístico do Brasil, 1969.

2. IBGE - Serviço Nacional de Recenseamento: VII Recenseamento Geral do Brasil, 1960, Sinopse preliminar do censo demográfico (2 volúmenes). 
3. Fundaçao - IBGE: Instituto Brasileiro de Estatística: Actualidade Estatística do Brasil, 1969.

Colombia: Co.

1. DANE: Departamento Administrativo Nacional de Estadística: Anuario General de Estadistica, 1966-1967, Tomo IV-V.

2. DANE: Informe al Congreso Nacional, 1968.

3. DANE: Boletín mensual de Estadística, enero 1969, No 214, junio 1968 , No 207 , febrero 1971 , No 234 , mayo 1968 , No 206 , octubre 1968, No $^{\circ} 211$.

4. Banco de La República: Revista del Banco de La República, octubre 1970.

5. DANE: Indicadores socioeconómicos, vol. 2, No 6, enero 1971.

6. DANE: XIII Censo Nacional de Población y II Censo Nacional de Edificios y Vivienda, julio 15 de 1964, Resumen General.

7. Banco de La República - Departamento Investigaciones Económicas: Síntesis Estadística, 1970.

Chile: Ch.

1. Dirección de Estadística y Censos: Demografía, 1967.

2. Instituto Nacional de Estadística: Estadística de Salud, Tomo I, Recursos y Atenciones, 1970.

3. Dirección de Estadística y Censos: Educación y Justicia, 1966.

4. Superintendencia de Educación: Matrícula, 1968.

5. Superintendencia de Seguridad Social: Estadistica de Seguridad Social, 1968.

6. Banco Central: Boletín mensual, junio 1971.

7. Banco Central: Boletín mensual, julio-diciembre, 1967.

8. Dirección de Estadística y Censos: XIII Censo de Población y II Censo de Vivienda, 29 de noviembre de 1960, Serie A. Total del País, (25 Tomos, Serie B. Total por provincias).

Ecuador: Ec.

1. Junta Nacional de Planificación y Coordinación: Anuario de Estadísticas Vitales, 1967.

2. Junta Nacional de Planificación y Coordinación: Anuario de Estadísticas Hospitalarias, 1967.

3. Junta Nacional de Planificación y Coordinación: Anuario de Estadísticas Educacionales, 1967-1968.

4. Junta Nacional de Planificación y Coordinación: Estadisticas del Trabajo, $1^{\circ}$ y $2^{\circ}$ trimestre 1968.

5. Junta Nacional de Planificación y Coordinación: Estadísticas de Permisos de Construcción, 1967.

6. Universidad Central del Ecuador, Instituto de Investigaciones Económicas y Financieras: Estadisticas Universitarias, 1968. 
7. Junta Nacional de Planificación y Coordinación, División de Estadística y Censos: Segundo Censo de Población y Primer Censo de Vivienda, 1962, (Tomos: I, II, III, IV).

Paraguay: Pr.

1. Dirección General de Estadística y Censos: Anuario Estadístico del Paraguay.

2. Dirección General de Estadística y Censos: Educación Paraguaya, 1968.

3. Ministerio de Hacienda: Dirección General de Estadística y Censos: Censo de Población y Vivienda, 1962.

4. Ministerio de Salud Pública y Bienestar Social - Dirección de Servicios Informativos: Estadísticas Vitales en el Paraguay, 1965.

Perú: Pe.

1. Dirección Nacional de Estadística y Censos: Anuario Estadistico del Perú, 1966.

2. Instituto Nacional de Planificación, Dirección Nacional de Estadística y Censos: Boletín de Estadistica Peruana, (Demografia) 1964.

3. Dirección Nacional de Estadística y Censos; Boletin de Análisis Demográfico, 1970.

4. Instituto Nacional de Planificación; Dirección Nacional de Estadística y Censos: VI Censo Nacional de Población, 1961.

Uruguay: Ur.

1. Direccion General de Estadística y Censos: Anuario Estadístico, 1964-1965-1966.

2. Ministerio de Hacienda, Dirección General de Estadistica y Censos: Muestra de Anticipación de Resultados Censales. IV Censo General de Población y II de Vivienda, 1963.

3. Ministerio de Hacienda; Dirección General de Estadística y Censos: Boletín Estadístico, No 3 .

Venezuela: Ve.

1. Dirección General de Estadística y Censos Nacionales: Anuario Estadistico, 1967.

2. Dirección General de Estadística y Censos Nacionales: Boletín Mensual (Trimestral) de Estadistica, No 37, enero-marzo, 1970.

3. Dirección General de Estadística y Censos Nacionales: Noveno Censo General de Población, 1961, Resumen General de la Republica, Partes A, B y C.

4. Dirección General de Estadística y Censos Nacionales: Compendio Estadistico, 1968. 
Costa Rica: CR.

1. Dirección General de Estadística y Censos: Anuario Estadístico, 1968, Volumen II (Demografía y salud), Volumen V (Educación, cultura y justicia).

2. Dirección General de Estadística y Censos: Estadísticas Vitales, 1967.

3. Dirección General de Estadistica y Censos: Población Total de la República, 1969.

4. Dirección General de Estadística y Censos: Censo de Población y Vivienda, 1963.

Cuba: $\mathrm{Cu}$

1. Dirección General de Estadística: Boletín Estadístico, 1968.

2. Tribunal Superior Electoral, Oficina Nacional de los Censos Demográfico y Electoral: Censos de Población, Viviendas y Electoral, 1953, Informe General.

El Salvador: ES.

1. Dirección General de Estadística y Censos: Anuario Estadístico, vols, II-IV.V, 1969.

2. Dirección General de Estadística y Censos: Avance Estadístico, $\mathrm{N}^{\circ} 64$, agosto $1970, \mathrm{~N}^{\circ} 54$, marzo 1970.

3. CONAPLAN (Sección de Investigaciones Estadísticas): Indicadores Económicos y Sociales, septiembre-diciembre 1970.

4. Ministerio de Economía, Dirección General de Estadística y Censos: Tercer Censo Nacional de Población y Segundo Censo Nacional de Habitación Urbana, 1961.

5. Dirección General de Estadística y Censos: El Salvador en Gráficas, 1968.

Guatemala: Gu.

1. Dirección General de Estadística: Guatemala en Cifras, 1968.

2. Ministerio de Educación; Oficina de Planeamiento Integral de Educación, Sección de Estadística Educacional: Anuario Estadístico de la Educación, 1967.

3. Banco de Guatemala: Boletín Estadistico, 1967.

4. Dirección General de Estadística; Departamento de Censos y Encuestas: Censo de Población y Vivienda, 1964: Resultados de Tabulación por muestreo.

Haiti: Ha.

1. Département des Finances et des Affaires Economiques; Institut Haitien de Statistique: Bulletin Trimestriel de Statistique, 3ème Trimestre, 1967. 
Honduras: Ho.

1. Secretaría de Economía y Hacienda; Dirección General de Estadística y Censos: Anuario Estadístico, 1969.

2. Secretaría de Economía y Hacienda; Dirección Genéral de Estadística y Censos: Estadísticas Educacionales, 1965.

3. Banco Central de Honduras; Departamento de Estudios Económicos: Indicadores de la Economía de Honduras, julio, 1970.

4. Secretaria de Economía y Hacienda, Dirección General de Estadística y Censos: Decimotercer Censo Nacional de Población y Segundo Censo Nacional de Vivienda, 1961.

5. Secretaría de Economía y Hacienda; Consejo Superior de Planificación Económica y Dirección General de Estadística y Censos: Compendio Estadístico, 1966.

México: Mé.

1. Secretaría de Industria y Comercio; Dirección General de Estadística y Censos: Anuario Estadístico de los Estados Unidos mexicanos, 1966-1967.

2. Secretaría de Industria y Comercio; Dirección General de Estadística y Censos: Anuario Estadístico compendiado, 1968.

3. Secretaría de Industria y Comercio; Dirección General de Estadística y Censos: Revista de Estadística, julio, 1970.

4. Secretaria de Industria y Comercio; Dirección General de Estadística y Censos: VIII Censo General de Población. 1960. Resumen General.

5. Secretaría de Industria y Comercio; Dirección General de Estadística y Censos: IX Censo General de Población, 1970.

6. Secretaría de Industria y Comercio; Dirección General de Estadística y Censos: Agenda Estadistica, 1970.

Nicaragua: Ni.

1. Dirección General de Estadística y Censos: Resumen Estadístico, 1950-1960.

2. Ministerio de Economía; Dirección General de Estadística y Censos: Censos Nacionales 1963. Población y Vivienda, Características Generales por Departamentos y Municipios.

(Población: Volumen I y II. Vivienda: Volúmenes I y II).

Panamá: Pa.

1. Contraloría General; Dirección General de Estadística y Censo: Panamá en Cifras, 1968, (Compendio Estadístico: Años 1963 a 1967).

2. Contraloría General; Dirección General de Estadística y Censo: Estadistica Panameña: Demografía, 1969.

3. Contraloría General: Dirección General de Estadística y Censo: Estadistica Panameña: Estadisticas Vitales, 1968. 
4. Contraloría General; Dirección General de Estadística y Censo: Estadística Panameña: Estadistica del Trabajo, 1968.

5. Contraloría General: Dirección General de Estadística y Censo: Estadística Panameña, Año XXIX: Población y Asistencia Social, 1968.

6. Contraloría General; Dirección General de Estadística y Censo: Estadística Panameña XXIX: Educación, 1968.

7. Contraloría General; Dirección General de Estadística y Censo: Sexto Censo de Población y Segundo de Vivienda, 1960.

República Dominicana: RD.

1. Oficina Nacional de Estadística: República Dominicana en Cifras, 1969.

2. Oficina Nacional de Estadística: Estadística Demográfica, 1968.

3. Oficina Nacional de Estadística: Cuarto Censo Nacional de Población, 1960. (Resumen en general). 


\section{ANEXO II}

\section{INFORMACION ADICIONAL SOBRE LAS PRINCIPALES PUBLICACIONES ESTADISTICAS INTERNACIONALES Y NACIONALES EN LOS CAMPOS DEMOGRAFICO Y SOCIAL}

\section{A. Publicaciones internacionales}

1. Existen varias publicaciones cuyo contenido es de bastante actualidad. Entre otras cabe citar las siguientes:

- Demographic Yearbook (Naciones Unidas)

- América en Cifras. Situación Demográfica (IASI)

- Monthly Bulletin of Statistics (Naciones Unidas)

- Population and Vital Statistics Report (Naciones Unidas)

- Boletín Estadístico de América Latina (CEPAL)

- Boletín Demográfico (CELADE)

También es bastante oportuna la información del Anuario de Estadisticas del Trabajo de la OIT y aunque en menor grado, la del Anuario Estadístico de la UNESCO.

2. Hay otros Anuarios que se publican oportunamente, pero contienen escasa información en el campo social. Así, por ejemplo, el Estado Mundial de la Agricultura y de la Alimentación de la FAO sólo proporciona datos sobre calorias y proteinas por habitante y sobre consumo aparente de diversos alimentos, también por habitante, basados en las estadísticas de producción y comercio externo.

3. El Statistical Yearbook de las Naciones Unidas contiene información sobre diversos temas, pero de carácter muy general. Por ejemplo, sobre salud, da el número total de médicos y de algún personal paramédico y el número de establecimientos hospitalarios y de camas. No se detallan por especialidad, ni se presenta in formación sobre atenciones.

4. Existen varias publicaciones sobre otros temas, que contienen bastante información, pero que se publican con mucho atraso. Por ejemplo, el Anuario de Estadísticas de Salud, 1967, de la OMS, se publicó solamente en 1971; por otra parte, ese Anuario aparece cada tres o cuatro años.

5. Esta situación se repite en el caso de otras publicaciones que tratan el tema de la salud. Así, el último número del Compendium of Social Statistics, que contiene también una selección de otros temas sumamente útiles, corresponde a 1967 y sus datos se refieren al año 
1964; el número anterior se publicó en 1963. El último número de América en Cifras: Situación Social, que también contiene datos de salud, corresponde a 1967, y muchos de sus datos se refieren a 1964 , 1965 y 1966.

6. Las Estadísticas sobre la Situación de la Infancia y la Juventud en América Latina, recopilada por primera vez por la CEPAL (con el auspicio de UNICEF) no es una publicación periódica.

7. La publicación del BID. Progreso Socio-Económico en América Latina, contiene datos muy generales, pero bastante recientes. No obstante, como algunas de sus informaciones provienen de organismos nacionales distintos de las Direcciones de Estadística, ellas difieren de las estadísticas oficiales.

8. Cabe señalar que, la oportunidad de las publicaciones estadísticas de los organismos internacionales depende también de la oportunidad con que los organismos nacionales pertinentes proporcionen los datos.

\section{B. Publicaciones nacionales}

1. Algunos países no publican un anuario general de estadísticas que incluya la mayor parte de los temas demográficos y sociales, sino boletines o anuarios que comprenden solamente algunos de esos temas. Argentina: "Boletín de Estadísticas". No incluye temas sobre salud ni educación; otros temas se tratan parcialmente. "Argentina Estadística". No publica datos sobre salud ni hechos vitales; otros temas se tratan sólo parcialmente. Además solamente se conoce un ejemplar de esta publicación.

Bolivia: "Boletín Estadístico". Sólo publica índices de precios. "Bolivia en Cifras". Sólo contiene datos de población total y empleo.

Chile: "Síntesis Estadística" (mensual) presenta datos estadísticos muy generales; no incluye algunos temas importantes, como salud.

"Boletín" (semestral). No incluye datos sobre demografía, salud y educación. A traso en la publicación.

Ecuador: Sólo se dispone de una "Síntesis Estadística del Ecuador" para el período 1955-1962. Se tiene conocimiento de la existencia de un "Anuario Estadístico" 1963-1968 del cual no se dispone aún.

Haití: Sólo publica el Bulletin Trimestriel de Statistique, que contiene solamente algunos datos demográficos y sociales, varios de los cuales abarcan sólo un trimestre. Ultimo número publicado: tercer trimestre de 1968.

2. Algunos paises publican anuarios generales, pero con mucho atraso: 
Colombia: El último anuario es de 1967 y sólo contiene algunos temas; el anterior es de 1963.

Perú: $\quad$ El último anuario se publicó en 1966.

Uruguay: El último anuario corresponde a 1964-1966 y se publicó en 1970.

El anterior correspondió al periodo 1961-1963.

Venezuela: El último anuario es de 1967.

Costa Rica: El último anuario apareció en 1968.

Cuba: $\quad$ El último Boletín Estadístico es de 1968.

Guatemala: Guatemala en Cifras, último número publicado en 1968; Boletin Estadistico (anteriormente Trimestre estadistico) el último número corresponde a 1967.

Honduras: Anuario Estadístico; la última edición es de 1966. Compendio Estadistico; último número, 1966.

Hay datos más actuales en Indicadores de la Economía de Honduras, cuya última edición es de julio de 1970.

México: El último Anuario Estadístico Compendiado es de 1968; el anterior Anuario Estadístico 1966-1967, se publicó en 1969.

Nicaragua: El últimoResumen Estadístico corresponde a 1950-1960. 3. Otros países publican anuarios generales con frecuencia y oportunidad aceptables:

El Salvador: Anuario Estadístico; el último número apareció en 1969. Indicadores Económicos y Sociales; último número es de sep tiembre-diciembre 1970.

El Salvador en Cráficas; última edición 1969.

Panamá: Panamá en Cifras; último número 1965 a 1969; aparece

República anualmente $y$ abarca un periodo de 5 años.

Dominicana: República Dominicana en Cifras; último número, 1969.

Paraguay: Sus anuarios aparecían antes en forma esporádica, pero se está regularizando su publicación. Se dispone ya del Anuario 1969.

4. Los 8 paises siguientes tienen publicaciones especiales sobre Demografia: Chile, Ecuador, Paraguay, Perú, Venezuela, Costa Rica, Panamá, República Dominicana.

5. Otras publicaciones nacionales versan sobre los siguientes temas: Educación: Argentina, Chile, Ecuador, Paraguay, Guatemala; Salud: Chile, Ecuador; Edificación: Argentina, Chile, Guatemala; Seguridad Social: Bolivia, Chile;Trabajo: Ecuador;Justicia: Chile.

6. Un caso especial lo constituye Panamá, que en la serie Estadística Panameña ha publicado, aunque no en forma periódica, datos sobre salud, educación, asistencia social, migración y empleo.

7. Nueve países no tienen publicaciones especiales sobre estadísticas demográficas o sociales. 
LA INFORNACTON Y LOS ESTUDIOS DEMOGRAFICOS EN ANIERICA LATINA

\author{
Carmen Arretx
}




\section{LA INFORMACION Y LOS ESTUDIOS DEMOGRAFICOS EN AMERICA LATINA}

La disponibilidad de informaciones y estudios demográficos, a través del tiempo, depende en forma sustancial de:

a) el desarrollo y utilización de las fuentes de información básica, en particular los censos de población;

b) los progresos en las técnicas de análisis demográficos, especialmente aquéllas que se refieren a la utilización de informaciones insuficientes para la determinación de las variables demográficas, y

c) las necesidades de estudios de población que sirvan a los fines de la programación del desarrollo económico y social.

Parece poco oportuno, y resultaría muy extenso para este documento, dar un panorama cronológico de los principales hechos que han caracterizado el desarrollo de la Demografía en América Latina. En cambio, se presentarán, en forma resumida, las características que han tenido las tres determinantes mencionadas con antelación, en dos épocas que pueden distinguirse claramente: la primera, que cubre el periodo anterior al levantamiento del Censo de las Américas, en 1950; la segunda, que se inicia ese año.

\section{FUENTE DE INFORMACION}

\section{a) Período anterior a 1950}

En varios de los países de América Latina se vienen levantando censos de población desde hace más de 100 años: el primer censo de Chile corresponde a 1835; el de Argentina, a 1869; el de Brasil, a 1872, etc. Hacia 1950, algunos países contaban con 5 a 11 censos de población: Colombia 11, Chile 11, Venezuela 7, México 6, el Brasil 5.

Las técnicas empleadas, los fines para los que fueron programados y la utilización de los resultados han variado en forma considerable entre los primeros y los últimos censos de población. En general, en los censos levantados con anterioridad a 1950, los conceptos y definiciones sobre los tópicos que se investigaban, generalmente se establecían sin relación con la teoría y las aplicaciones de la economía, la sociología y otras ciencias sociales, ya que los censos constituían meros recuentos de la población y la descripción de algunas de sus características. 
Los resultados sobre la población por sexo, a niveles geográficos muy detallados, pueden considerarse como aportes significativos al cu adro de estadísticas nacionales, pero no podrían considerarse apropiados como fuentes de información para el análisis demográfico, salvo escasas excepciones, como los Censos de la Argentina del siglo pasado y el de 1914, del Brasil de 1940 y acaso el de Chile de 1940. En el caso de los censos de la Argentina cabe destacar que a base de ellos ha sido posible el estudio de las tendencias pasadas de la mortalidad, fecundidad, y migraciones, estudios que han respondido al interés actual del análisis demográfico por reconstruir esas tendencias con miras a una mejor comprensión del comportamiento de las variables demográficas. En el caso del Brasil, la utilización de los censos anteriores a 1950, se debe especialmente a la iniciativa del profesor Giorgio Mortara, que a partir de 1940 inicia en Brasil una serie de estudios sobre la población brasileña. 1$]$

\section{b) Período que se inicia en 1950}

Hacia 1950, existía conciencia en los países de mayor desarrollo de la necesidad y utilidad de los censos de población. La experiencia de la crisis de 1930, las necesidades surgidas en el período de post-guerra, etc. fueron estimulos importantes en la realización de censos en el período 1940-1950 en la mayoría de los países desarrollados. Para los países de América Latina, que contaban con estadísticas básicas heterogéneas, en cuanto a cantidad y calidad, esos antecedentes y en especial el censo de Estados Unidos de 1940, tuvieron influencia decisiva en las actividades relacionadas con algunas de las acciones tomadas con miras al mejoramiento de las estadísticas. Así, por ejemplo, en la creación del Instituto Interamericano de Estadística (IASI) que tuvo como propósitos patrocinar el mejoramiento de estadísticas básicas, estimular la utilización de técnicas apropiadas en la recolección y elaboración de las informaciones y promover su utilización.

El IASI patrocinó más adelante la organización de la Comisión del Censo de las Américas (COTA) $\stackrel{2}{ }$, que se levantaría en 1950, siguiendo más bien las ideas impuestas a niveles internacionales, antes que respondiendo a necesidades manifestadas de los paises de América Latina.

1/ Mortara, G., "Comparacao entre os números de brasileiros natos apurados pelos censos de 1940 e de 1920, e os cálculos conforme determinadas hipótesis acerca da natalidade e da mortalidade", en IBGE, Revista Brasileira de Estadística, año $\mathrm{X}, \mathrm{N}^{0} 39$.

2) IASI, Relato del Censo de las Américas de 1950, W ashington D.C. 1953. Primera sesión de la Comisión del Censo de las Américas de 1950. 1947.

Segunda sesión de la Comisión del Censo de las Américas de 1950. 1949. 
Desde el punto de vista que nos preocupa - los avances logrados en la producción de datos y estudios demográficos - la realización del Censo de las Américas en 1950, marca la iniciación de los censos con contenido y finalidad más modernos, convirtiéndose en fuentes valiosas de análisis demográficos. Entre los primeros estudios basados en dichos resultados, merece destacarse las proyecciones de población, por sexo $y$ edad, para los países de América Latina 3/ elaborados por la División de Población de las Naciones Unidas, que emprendían esta labor "atendiendo a las necesidades de tales proyecciones de los países subdesarrollados como ayuda en la planificación de sus programas de desarrollo económico y social" (E/2359, pág. 7).

Esta afirmación pone de manifiesto el interés que estaban adquiriendo los estudios demográficos, dirigidos a los fines de la planificación económica y social.

Se hacía evidente la necesidad de estimular a los países en la utilización de los resultados censales. Con este propósito se realizó el Seminario sobre Evaluación y Aprovechamiento de los resultados censales en América Latina, 4 en particular los relativos a los censos de población que se levantarian en torno a 1960.

La introducción de equipos modernos en la elaboración de los datos ha permitido ampliar considerablemente la producción de datos en general, y en particular la confección de tabulaciones especificas sobre determinados temas que requieren cruces de varios atributos y variables. Cabe señalar además que ha sido posible preparar programas especiales a base de muestras de censos con propósitos analíticos determinados que, en general, no están considerados en los programas nacionales de tabulaciones censales. 5 /

Paralelamente al progreso de las técnicas censales, y respondiendo a la preocupación nacional, se intensifica, en este período, el uso de las informaciones provenientes de los registros de hechos vitales, que en el pasado cumplían principalmente funciones legales. Se reconoce por ejemplo, en el seminario mencionado "que es necesario que los datos censales y los registros de las estadísticas vitales mantengan una coordinación estrecha con el fin de que pueda hacerse una mayor utilización de la información recolectada a través de ambos procesos".

3/ Naciones Unidas,Future Population Estimates by Sex and Age, Report I: The population of Central America (including Mexico), 1950.1980 (1954); report II: The Population of South America, 1950.1980 (1955).

4/ Seminario sobre Evaluación y aprovechamiento de los resultados censales en América Latina, Santiago, Chile.1959.

5] A este respecto cabe destacar el programa de tabulaciones censales preparado en CELADE, a base de las muestras de los censos de población de alrededor de 1960 de los paises latinoamericanos. Véase, por ejemplo, CELADE, Banco de datos, Boletín Informativo $\mathrm{N}^{\circ} 4$, Nov. 1970. 
Sin embargo, aún hoy, las estadísticas de registro, en la mayoría de los países latinoamericanos, siguen siendo de calidad poco satisfactoria, $y$, en consecuencia, de utilización limitada.

A las dos fuentes de información mencionadas anteriormente -los censos de población y las estadísticas de registros de hechos vitales hay que agregar la explotación de una tercera: las encuestas por muestreo. Es a partir del censo de 1950 , y en particular en la década 1960-1970, cuando se recurre con mayor frecuencia a este tipo de fuentes con el fin de estudiar con mayor cantidad y calidad de información aspectos específicos de la población. Por vía de ejemplo pueden mencionarse los programas de Encuestas Comparativas de Fecundidad en América Latina en áreas urbanas y rurales, llevadas a cabo por el Centro Latinoamericano de Demografía (CELADE); 6 J encuestas de mano de obra que se realizan periódicamente en algunos países; $[$ encuestas de inmigración a áreas metropolitanas,,$\sqrt{ }$ y encuestas destinadas a la determinación de tasas demográficas básic as, 9 ] etc.

\section{TECNICAS DE ANALISIS DEMOGRAFICO UTILIZADAS EN LOS PAISES DE AMERICA LATINA}

\section{a) Periodo anterior a 1950}

Los Servicios Nacionales de Estadísticas y Censos tenían, en ese periodo, como principal función y responsabilidad la de realizar los censos de acuerdo a disposiciones legales establecidas, y la de estimar la población total en los años comprendidos en los periodos intercensales.

Los estudios demográficos de este periodo son descriptivos; en general en ellos no intervienen técnicas de análisis demográfico, salvo la importante excepción que constituye el Brasil, especialmente los estudios llevados a cabo bajo la dirección del Profesor Giorgio Mortara a base de los censos de el Brasil de 1920 y 194010 / y que se comenzaron a llevar a cabo a partir de 1940. Aunque de naturaleza diferente a éstos, cabe señalar también, como aportes importantes en aquella época al conocimiento de la mortalidad de algunos paises, la elaboración de

\section{6/ PECFAL.}

7) Ejemplo: Encuesta de Mano de obra en Chile, Panamá, Argentina, etc.

8) Ejemplo: Encuesta de Migración al Gran Santiago, CELADE A/15.

9/ Ejemplo: CELADE, A/4. Brasil: Encuesta demográfica experimental de Guanabara.

Ejemplo: CELADE, Encuesta Demográfica Experimental de Cauquenes.

10/ Véase nota 1/. 
tablas de vida, (para algunos países) $11 /$ y los estudios sobre las causas de muerte llevados a cabo por los Departamentos de Higiene y Medicina Preventiva.

La falta de aplicación de las técnicas demográficas ya conocidas en esa época, 12 / y que sirven para estimar las variables determinantes de los cambios de población, en cuanto a tamaño y estructura, está asociada con el escaso desarrollo alcanzado por las fuentes de información y con la falta de personal capacitado para desarrollar este tipo de estudios.

\section{b) Periodo que se inicia en 1950}

La mayor disponibilidad de informaciones sobre la población de los paises de América Latina pone en evidencia algunos hechos importantes como el relacionado con su elevada tasa de crecimiento, que en este período alcanza altos niveles, jamás igualados en ninguna región en épocas anteriores. Hay preocupación, a niveles internacionales, por el análisis del comportamiento de la población, lo que estimula el desarrollo de técnicas aplicables a los casos de países que aún no disponen de informaciones suficientes. Le cabe a las Naciones Unidas especialmente, la preparación de una serie de manuales sobre diferentes aspectos del problema de la utilización de las informaciones. Así se publican manuales sobre métodos para: evaluación de las estadísticas básicas, estimaciones de indicadores demográficos a partir de informaciones insuficientes e incompletas, el análisis de los resultados censales, etc. $\underline{13 /}$

Con el próposito de promover, a nivel de los países latinoamericanos, la necesidad de emprender estudios demográficos, especialmente en relación con los programas de desarrollo económico y social, las Naciones Unidas organizan en 1955,14/ el Seminario de Población de

11) Por ejemplo: Kern E., La mortalidad en la ciudad de Buenos Aires, Instituto de Biometría, F acultad de Ciencias Económicas, Buenos Aires. 1948.

Cabello O. Vildósolo y Latorre M., Tablas de vida para Chile 1920, 1930 y 1940. Revista Chilena de Higiene y Medicina Preventiva, vol. VIII, No 3, 1946.

12) Lotka, Alfred J., Theorie Analytique des Asociations Biologiques, 1939.

13/ Por ejemplo: Naciones Unidas,S.T./SOA/Serie A/23 Manual II Métodos para evaluar la calidad de los datos básicos destinados a los cálculos de población.

Naciones Unidas,S.T./SOA/Serie A/42, Manual IV, Métodos para establecer mediciones demográficas fundamentales a partir de datos incompletos.

Naciones Unidas,S.T./SOA/Serie A/43, Methods of Analysing Census Data on Economic Activities of the Population.

14/ Naciones Unidas,S.T./TAA/SER.C/33, América Latina, Seminario sobre población, Rio de Janeiro, diciembre, 1955. Nueva York, 1959. 
América Latina, en el que se trata de determinar las necesidades de estudios demográficos y los mejores métodos para llevarlos a cabo.

Ya sea a través de los procedimientos descritos en los manuales mencionados anteriormente, $o$ a través de procedimientos ortodoxos en que intervienen estadísticas de registros, se comienza a conocer en forma más cabal las condiciones demográficas de los países de América Latina. Estudios de este tipo fueron desarrollados principalmente por CELADE, respondiendo en general a las demandas de los países y como parte de los programas de docencia e investigación del Centro, o como colaboración a las Unidades de Análisis Demográficos que se establecieron en los Servicios de Estadísticas Nacionales, o en algún organismo oficial vinculado a las actividades de planificación económica y social.

En este período se observa entonces, un desarrollo importante en el conocimiento de las variables demográficas $y$ sus factores determinantes. 15/ Contribuyeron a este desarrollo diversas circunstancias; derivadas en gran parte de las aspiraciones de los países por el mejoramiento de sus condiciones de vida, y de los problemas que plantea el rápido crecimiento de la población, redundando en el mejoramiento de las fuentes de información en cuanto a contenido y utilización, en la aplicación de técnicas apropiadas a las condiciones de los países de la región y en la formación de personal idóneo - tarea que le ha correspondido fundamentalmente a CELADE; EI Colegio de México.16/

Se puede decir que el estado del conocimiento de las variables demográficas alcanza madurez y solidez durante este período y que del análisis de variables exclusivamente demográficas se pasa a la realización de estudios dé población que no sólo requieren conocer las variables demográficas, sino además; explicar sus cambios dentro del complejo contexto económico y social en que evoluciona la población.

La introducción de modernas tecnologías, no exclusivas del campo demográfico sino de aplicabilidad en todo el ámbito científico, facilitan la labor de emprender estudios de mayor complejidad y alcance.

15 Naciones Unidas, S.T./SOA/Ser. A/17, Factores determinantes y consecuencias de las tendencias demográficas, Nueva York, 1953.

16. CELADE ha adiestrado a más de 300 estudiantes en técnicas de análisis demográfico a través de sus cursos regulares, en Santiago, y de cursos intensivos realizados en algunos países. El Colegio de México creó en 1964 el Centro de Estudios Económicos y Demográficos, donde imparte cursos de Demografía de dos años de duración. 


\section{NECESIDADES DE ESTUDIOS DE POBLACION PARA LOS FINES DE LA PROGRAMACION DEL DESARROLLO ECONOMICO Y SOCIAL}

Como se ha señalado en otro documento presentado a este seminario, 17 el insumo de informaciones demográficas en el proceso de planificación correspondía especialmente a la etapa de diagnóstico y se vinculaba con proyecciones de población: tamaño y crecimiento de la población. Hemos anotado antes que las primeras proyecciones elaboradas por las Naciones Unidas en 1954-1955, para los países de América Latina, respondían a los fines de la planificación económica y social. Con el transcurso del tiempo, las au toridades responsables de los programas de desarrollo han prestado un interés creciente a los problemas de población; por una parte los problemas planteados por el rápido aumento de la población, y por otra los que surgen en la planificación del desarrollo de nuestros países, plantean interrogantes que deben dilucidarse a través de estudios de población en que se analicen las relaciones entre variables demográficas y económicas.

La realización de este tipo de estudios exige la coordinación de esfuerzos y el trabajo conjunto de profesionales de campos diferentes: economistas, sociólogos, médicos, educadores y demógrafos, entre otros. En otras palabras, la formación de grupos de trabajo interdisciplinarios. Es en esta dirección hacia la que se encaminan las actuales investigaciones demográficas. Los centros de estudios demográficos y estudios relativos al desarrollo económico y social incluyen dentro del equipo de trabajo a profesionales de las diferentes esferas científicas, que en el pasado se dedicaban a estudios específicos dentro de sus respectivos campos de acción, o establecen una coordinación que les permite un mejor aprovechamiento de sus recursos. Un ejemplo de esta labor conjunta es el trabajo del ILPES-CELADE. 18/

En la actualidad se inicia una etapa de estudios tendientes a dar conocimiento amplio y cabal de las interrelaciones entre las variables demográficas y las de naturaleza económico-social; se ha creado conciencia de su existencia y de que revisten importancia en la formulación práctica de un programa de desarrollo integral.

Los primeros estudios que se han llevado a cabo han debido obviar obstáculos difíciles, como los derivados de falta de informaciones suficientes y adecuadas, en especial los que se derivan del

17) Seminario sobre utilización de estudios y datos demográficos en la planificación.

18/ ILPES-CELADE, Elementos para la elaboración de una política de desarro. llo con integración para Amérioa Latina, 1968. 
desconocimiento de la naturalza misma de las complejas relaciones que intervienen en el proceso de cambio demográfico y económico-social. Los nuevos censos de población, que se vienen levantando a partir de 1970, y las encuestas por muestreo sobre tópicos específicos aportarán indudablemente, elementos valiosos para el progreso de nuevos estudios de población, dentro del enfoque que las circunstancias actuales imponen.

\section{EJEMPLO ILUSTRATIVO DE UTILIZACION DE DATOS CENSALES. ESTIMACION DEL SUBEMPLEO}

La subutilización de la mano de obra constituye un problema importante en el sistema económico-social de los países de América Latina y los planes de desarrollo incluyen entre sus metas, en general, la absorción eficiente de la mano de obra.

Es necesario conocer entonces, aunque sea en forma aproximada, la magnitud de la población económicamente activa que, no obstante participar en la producción de bienes y servicios, lo hace durante jornadas inferiores a lo normal; o con baja productividad muy inferior a la media de la población económicamente activa (PEA) en su conjunto, percibiendo, en consecuencia, ingresos inferiores también al salario promedio de la PEA en su conjunto. Sin pretender que sean éstos los únicos y mejores criterios de naturaleza económica que caracterizan al subempleo; pueden considerarse como elementos útiles para reconocer dentro de la población económicamente activa al grupo de sube mpleados.

Junto a estas características, que pueden considerarse netamente económicas, el grupo de subempleados presenta otras de naturaleza demográfico-social y cultural, que cabe esperar derivan de las primeras o están asociadas a ellas. Puede pensarse, por ejemplo, que en una familia de ingresos bajos algunos de sus miembros se incorporen a las actividades económicas siendo de corta edad y, en consecuencia, tengan niveles educativos insuficientes y lo hagan por salarios bajos, o que teniendo edades avanzadas realicen actividades en jornadas incomple tas de trabajo. Como este ejemplo, pueden encontrarse muchos más que ilustrarian las características demográfico-sociales de los subempleados; en todos ellos se encontrarían algunos elementos comunes: bajos niveles de instrucción, edades marginales de actividad económicá - menores de 15 años y mayores de 65 - posiciones ocupacionales típicas de baja remuneración - como ayudantes familiares -, ocupaciones que pueden implicar o bajos ingresos o jornadas de trabajo discontinuas. Sobre estas características de la población económicamente activa, los censos de población, a través de los tópicos tradicionales que investigan, aportan valiosa información que puede utilizarse en la estimación del subempleo. Es preciso convenir sobre los atributos pertinentes de la 
población económicamente activa, para identificar dentro de ella al sector subempleado, y además sobre los límites dentro de los cuales es razonable esperar que tales atributos se presenten en ese grupo.

En un primer ensayo se han elegido los atributos que se señalan a continuación, después de analizar algunas informaciones relativamente escasas, y en el entendimiento que en estudios que se realicen más adelante deberán encontrarse justificaciones empíricas a esta elección o bases para tomar en cuenta otros criterios.

\section{A. Atributos que se consideran}

Es pertinente analizar en relación al subempleo de la Población Económicamente Activa (PEA) los siguientes atributos:

a) Nivel de instrucción alcanzado

b) Edad

c) Categoría ocupacional

d) Ocupación.

a) Existe asociación entre el nivel de instrucción alcanzado por la PEA y la productividad. Se observa que a niveles superiores de instrucción corresponden productividades mayores. Cabe esperar, por lo tanto, que la PEA con bajos niveles de instrucción tenga, en promedio, productividades inferiores. En los países de América Latina,el promedio de años de estudio de la población alcanza sólo a 3 o 4 años, y es un promedio muy bajo si se lo compara con los alcanzados por los países desarrollados, de más de 10 años. Dentro de la región hay grandes variaciones, por lo tanto el promedio del conjunto no representa casos particulares. Para los propósitos de este primer ensayo de medición del subempleo con datos censales, se ha adoptado como límite de lo que se entenderá por bajo nivel de instrucción un promedio de 4 años de estudio. La PEA, en consecuencia, se clasifica en dos subgrupos: los de bajo nivel de instrucción (4 años o menos de estudio) y los de nivel de instrucción mayor (más de 4 años de estudio).

b) Una segunda variable de la PEA que interesa analizar es la edad. La PEA con edades entre 15 a 70 años es la que con mayor probabilidad está efectivamente participando en la producción de bienes y servicios, en cambio la de edades menores de 15 años y mayor es de 70 , lo hace por circunstancias que podrán ir desapareciendo a medida que los paises se desarrollen. Por una parte los menores de 15 años deberán ser absorbidos por el sistema educativo, lo que implicará que su ingreso al mercado de trabajo se postergue; por otra, los mayores de 70 años se acogerán a los sistemas de previsión social. Claro está que parte importante de la PEA en estas edades marginales, en los países de América Latina, participa efectivamente en actividades económicas, de modo que no seria real incluir a todo este subgrupo entre los subempleados. Dentro de él aquéllos con bajo nivel de instrucción se 
considerarán subempleados, y los que tienen niveles de instrucción superior serán analizados con respecto a la ocupación y a la categoría ocupacional que tengan, de la misma forma que se analizará el primer subgrupo que tiene edades entre 15 y 70 años.

c) Algunas categorías ocupacionales son receptoras, en mayor proporción, de subempleados, así por ejemplo, los trabajadores por cuenta propia, y los trabajadores familiares no remunerados. No todos los incluidos en estas categorías son subempleados, es razonable pensar que dentro de ellas los que tienen bajo nivel de instrucción lo sean, así como entre los que tienen niveles de instrucción superior sean subempleados aquellos que tengan determinadas ocupaciones que los identifiquen como receptores de bajos niveles de ingresos, vendedores ambulantes, agricultores, trabajadores en servicios, etc.

La identificación de subempleados dentro de otras categorías ofrece mayores dificultades. Es así, por ejemplo, que dentro de los asalariados existe gran heterogeneidad y no se pueden establecer criterios rígidos. Se ha considerado que parte importante de los asalariados que trabajan en servicios personales son subempleados; entre éstos se incluyen los que desempeñan servicios personales dentro de hogares particulares.

d) Con respecto a la ocupación, hay acuerdo en reconocer algunas ocupaciones como típicas de bajos niveles de ingreso, y otras que de acuerdo a la categoría ocupacional y al nivel de instrucción del que la desempeña también lo son. Así por ejemplo, el agricultor que trabaja por cuenta propia, los dependientes de tiendas que trabajan como ayudantes familiares, los vendedores de tiendas que trabajan por cuenta propia, etc.

La PEA clasificada según dos o más atributos de los mencionados, permite la formación de clases excluyentes; cuya suma constituye el total de subempleados dentro de la PEA.

\section{B. Identificación del conjunto de subempleados dentro de la PEA}

En el cuadro l se presenta la clasificación de la población económicamente activa, según nivel de instrución, en dos grandes grupos de edades, categorías ocupacionales y determinadas ocupaciones, que permiten la identificación de los subempleados en cada clase y aparecen subray ados.

La descripción de cada una de estas clases se da a continuación:

a) Todos los activos menores de 15 años y mayores de 70 con menos de cuatro años de estudios aprobados;

b) Entre los activos de 15 a 70 años se considerarán subempleados:

1) Los trabajadores por cuenta propia con menos de cuatro años de estudios

2) Los trabajadores familiares no remunerados con menos de cuatro años de estudios. 


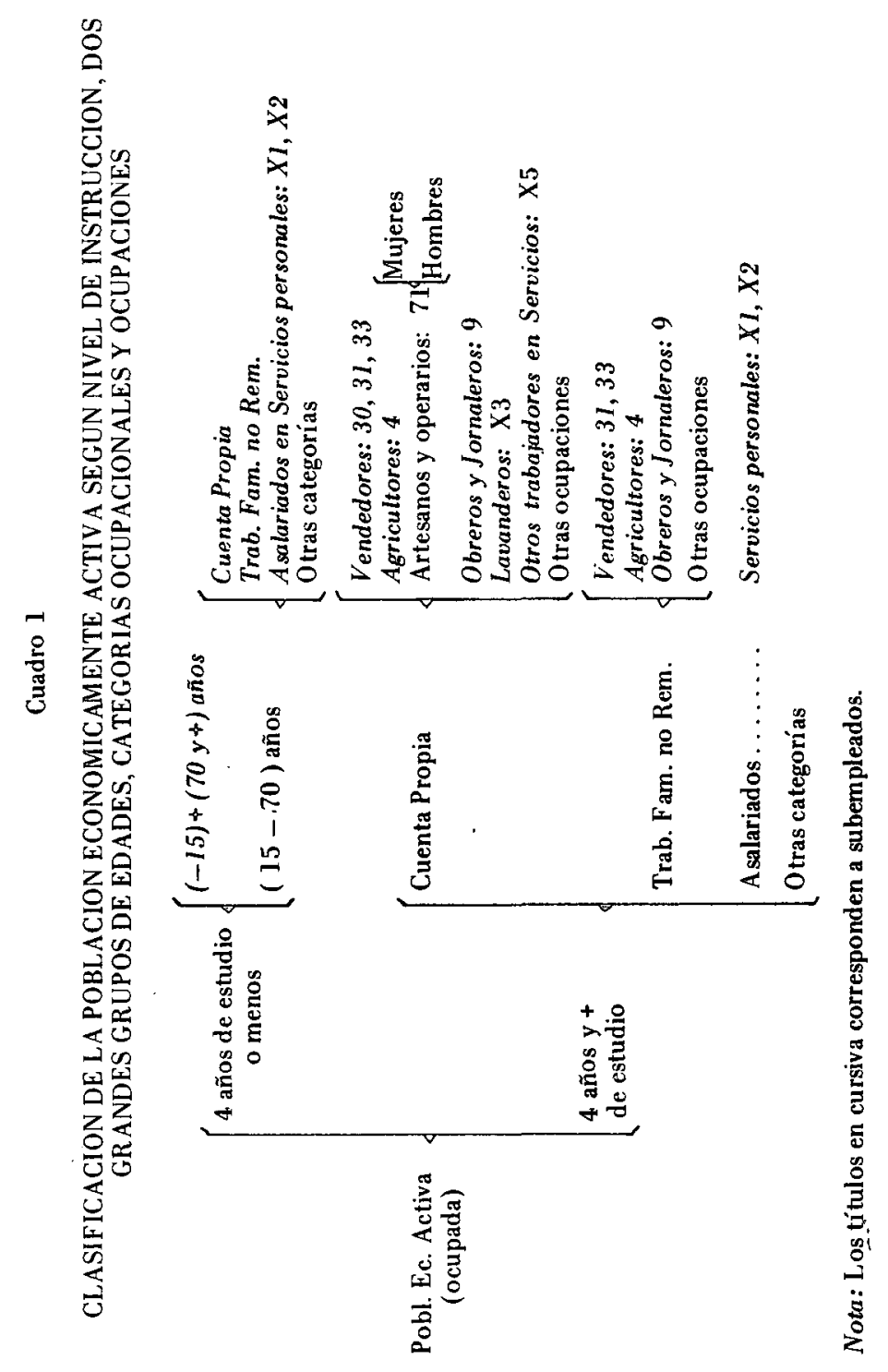


3) Los trabajadores por cuenta propia con más de cuatro años de estudios ocupados en las siguientes actividades:

i) Vendedores, codificados según la clasificación ocupacional del IASI para el censo de 1960, con: 30,31 y 32 dentro del grupo principal 3 de las ocupaciones. Los tres subgrupos se refieren a:

30: Vendedores-propietarios en el comercio al por mayor y en el comercio al por menor.

31: Dependientes de tiendas y vendedores ambulantes

33: Otros vendedores y personas en ocupaciones afines

ii) Agricultores: con código 4 en el grupo principal y que comprende los subgrupos siguientes:

40: Agricultores, ganaderos y administradores de explotaciones agrícolas.

41: Pescadores y personas en ocupaciones afines.

42: Trabajadores agropecuarios y jardineros.

43: Cazadores, tramperos y personas en ocupaciones afines.

44: Madereros, caucheros y personas en ocupaciones afines.

iii) Artesanos y operarios del sexo femenino codificados con 71 dentro del grupo principal 7. Se refiere a: sastres, modistas, peleteros y personas en ocupaciones afines relacionadas con la confección de los productos a base de tela y piezas de cuero para vestuarios.

iv) Obreros y jornaleros codificados en el grupo principal 9 que comprende los siguientes subgrupos:

90: Obreros y jornaleros de construcción.

91: Estibadores, cargadores y otros jornaleros del transporte.

92: Lavanderos, aplanchadores, tintoreros de establecimientos de limpieza y jornaleros afines.

93: Otros jornaleros y obreros.

v) Lavanderosy aplanchadores del subgrupo X3, dentro del grupo principal $\mathrm{X}$.

vi) Cocineros y otros trabajadores en servicios, por cuenta propia, codificados con X5, dentro del grupo principal X.

4) Los trabajadores familiares no remunerados con más de cuatro años de estudios ocupados en las siguientes actividades:

i) Vendedores: con código 31 y 33.

ii) Agricultores del grupo principal: 4 .

iii) Obreros y jornaleros del grupo principal: 9 .

5) Los activos asalariados cuyas ocupaciones sean servicios personales codificados con $\mathrm{X} 1$ y $\mathrm{X} 2$, dentro del grupo principal X. Se refieren a: X1: Cocineras y otros sirvientes o criados en hogares particulares. X2: Lavanderos y aplanchadores empleados en hogares particulares. 
c) Entre los activos menores de $\mathbf{1 5}$ años y mayores de 70, con más de cuatro años de estudios aprobados, se considerarán como subempleados los correspondientes a los clasificados con los números 1), 2), 3), 4) y 5), especificados en el caso de los activos con edades entre 15 y 70 años.

\section{Resultados}

Sc hìo una estimación del subempleo de la Población Económicamente Activa, siguiendo los criterios anteriores, a base de muestras de los censos de ocho países: Costa Rica, Chile, El Salvador, Ecuador, Cuatemala, Honduras, Panamá y la República Dominicana. La elección de estos países obedece sólo al hecho de contar para ellos con las informaciones necesarias. No puede pretenderse que el conjunto formado por los ocho países sea una buena muestra de las características del subempleo en América Latina; la inclusión de México, la Argentina y el Brasil hubiera dado a los resultados mayor validez. En el caso de México, no fue posible utilizar la muestra disponible debido a las incompatibilidades que presenta con los resultados del censo. No obstante las limitaciones señaladas, puede considerarse que los resultados obtenidos constituyen una aproximación razonable al nivel y características del subempleo en. América Latina.

En el cuadro 2 aparecen los porcentajes que dentro de la PEA representa el subempleo en cada país y en los ocho países en conjunto. Se presenta además, en este mismo cuadro, la composición del subempleo por cuatro grupos (excluyentes): 1) los subempleados que tienen edades inferiores a 15 años y superiores a 70 , y cuyo nivel de instrucción es inferior a cuatro años de estudios. 2) Los subempleados en la categoría Cuenta Propia y que no se incluyen en 1). 3) Los subempleados en la categoría Trabajador Familiar no remunerado, no incluidos en 1). 4) Los subempleados en la categoría Asalariados, no incluidos en 1).

La estimación del subempleo obtenida en el conjunto de los ocho paises considerados es consistente con la eliminación elaborada por ILPES, 19 utilizando criterios económicos - la coincidencia en el resultado no implica que ambas estimaciones se refieran al mismo grupo. Puede suceder que cualitativamente sean diferentes los subempleados definidos en un caso y en otro. No se dispone, por ahora, de elementos de juicio para comparar las dos estimaciones, sin embargo, estudios como el que se presenta en esta oportunidad facilitarían la mejor comprensión y estimación del subempleo y en consecuencia la formulación de políticas de empleo adecuadas.

19/ ILPES-CELADE, Elementos para ... op. cit. 


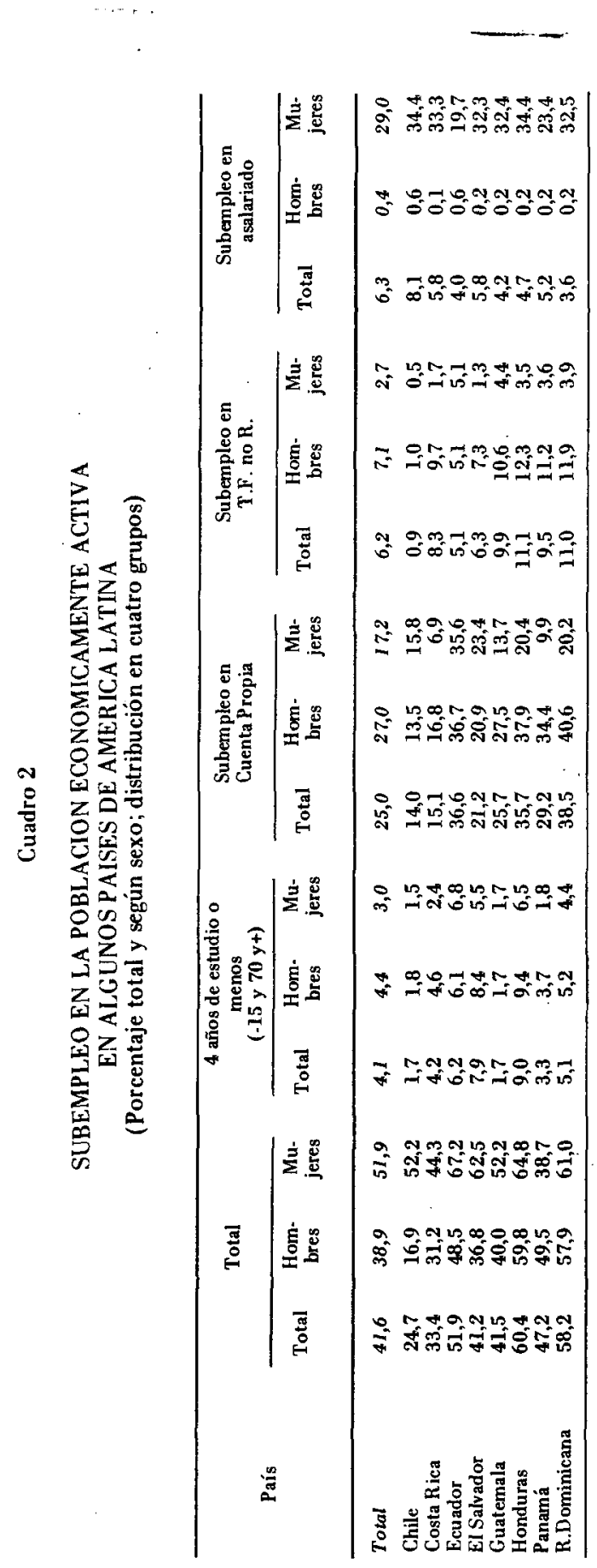




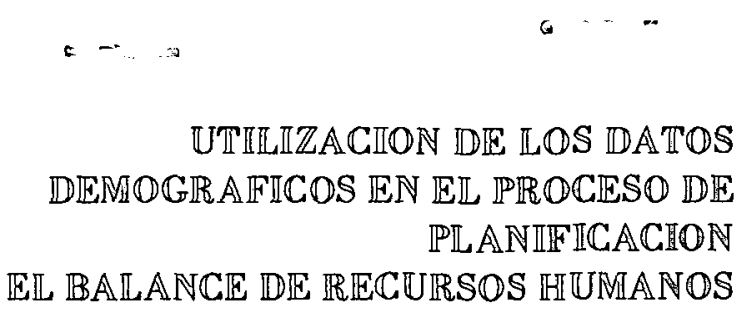

Boris Chacón F.

Jefe, Unidad Recursos Humanos, Oficina de Planificación Nacional,

Santiago, Chile 
$\infty$ 


\section{EL BALANCE DE RECURSOS HUMANOS}

\section{ASPECTOS GENERALES}

El problema de la distribución y utilización de los recursos de mano de obra del país debe resolverse en estrecha relación con los problemas más generales del desarrollo económico. Los planes de desarrollo a corto plazo y sobre todo los de largo plazo, deben tener en cuenta los recursos de mano de obra disponible para ser utilizados en el proceso productivo y, a la vez, contener estimaciones sobre el aumento de dichos recursos.

La me ta final de la planificación de la mano de obra en la economía nacional es la de alcanzar un equilibrio, es decir, que exista concordancia entre los aumentos de los recursos de mano de obra y el desarrollo de las necesidades de los mismos.

Para lograr este equilibrio se usa como herramienta fundamental el balance de mano de obra $1 /$ en que se distinguen, por un lado, todos los recursos de mano de obra según su origen y, por otro, se clasifican de acuerdo con las necesidad es por tipos de utilización.

El balance de recursos humanos es una descripción de cómo se distribuye la fuerza de trabajo entre los sectores económicos de un país y de cómo debiera distribuirse para alcanzar metas especificas de desarrollo. Comparando la situación alcanzada con la deseada, es posible identificar, por una parte, la necesidad de cambios en la localización de la fuerza de trabajo, el déficit de algunas calificaciones, la mano de obra desocupada y, por otra, será posible corregir las deficiencias detectadas y que estén impidiendo alcanzar las metas previstas.

El balance se hace para un momento determinado en el tiempo y en su expresión más simple muestra, por un lado, la composición de los recursos disponibles de mano de obra y por otro la distribución del empleo por ocupaciones, ramas de actividad, nivel de calificación y otras características. En este sentido es un instrumento muy valioso para la planificación a corto plazo ya que permite visualizar los desajustes ocasionados por la desocupación u otros desequilibrios a nivel de sectores o regiones.

1/En esta oportunidad se usan como sinónimo: balance de recursos humanos y balance de mano de obra. 
A base de los balances, es posible elaborar y formular políticas de planificación en relación a:

- Redistribuir los recursos de mano de obra entre los diversos sectores económicos, así como también entre zonas geográficas del país.

- Planificar las migraciones de la población.

-Formar graduados en las diversas especialidades para cubrir los déficit de personal calificado.

- Absorber los contingentes de cesantes buscando una redistribución adecuada entre los diferentes sectores económicos.

En general, contando con la información oportuna y adecuada, podrán construirse balances para períodos inferiores a un año cuando se desean conocer las variaciones estacionales que afectan la composición del empleo y la distribución del trabajo, o balances anuales para estimar el volúmen, composición y distribución de las nuevas entradas a la fuerza de trabajo durante un año dado.

\section{TIPOS DE BALANCES}

En el cuadro 1 , se muestra un esquema dentro del cual se puede enmarcar un balance de mano de obra, tanto para el país como para una región determinada. Se ha clasificado la población desde dos puntos de vista al mismo tiempo: disponibilidad y no disponibilidad de mano de obra, y participación en las actividades económicas.

El nivel de desagregación de un balance puede llegar hasta donde sea necesario; en este caso sólo se ha presentado un resumen. Se puede construir también una serie de sub-balances, los cuales normalmente están enfocados en alguna característica específica como el nivel educacional o de calificación de la mano de obra, distribución por edades o regiones, etc.

En este sentido, es necesario destacar por su importancia el Balance de Recursos Humanos del Sector Público, donde se muestra la evolución de la ocupación en ese sector, dividida fundamentalmente en dos grandes grupos:

- Gobierno general.

- Empresas estatales.

En el cuadro 2 se muestra otro tipo de balance que está enfocado más bien demográficamente y divide fundamentalmente la población por edades.

Será necesario contar también con otro balance que desagregue la parte correspondiente a la fuerza de trabajo y se refiera exclusivamente a esta variable. Un posible esquema de este tipo de balance se muestra en el cuadro 3. En la vertical se han colocado los sectores económicos y la variación experimentada en un año y se reserva la horizontal para colocar un total y un desglose que puede ser por nivel de calificación, 
tipos de ocupación, u otra característica, dependiendo del tipo de información que se quiere proporcionar.

En este sentido, las principales "aperturas laterales" de los balances serían:

i) Nivel de calificación.

ii) Categorías ocupacionales.

iii) Nivel de instrucción.

iv) Nivel regional.

En relación al nivel de calificación, es necesario destacar los profesionales, técnicos, personal administrativo, trabajadores calificados y trabajadores no calificados. Por su parte, las principales categorías ocupacionales serían las de empleadores, trabajadores por cuenta propia, empleados y obreros. En cuanto al nivel de instrucción, es necesario hacer una apertura considerando un nivel universitario, medio profesional, secundario, primario o básico, ninguna enseñanza y analfabetos. Finalmente, la apertura a nivel regional puede ser por regiones, provincias o áreas específicas.

Existe otro tipo de balance (véase 'el cuadro 4) que describe la magnitud de los flujos brutos hacia y fuera de la fuerza de trabajo durante un periodo determinado. Este balance puede ser construido tanto para el total de la fuerza de trabajo como para sectores económicos' o grupos ocupacionales, dependiendo también de las necesidades de información y de la disponibilidad de datos. En todo caso, es una buena descripción de la dinámica del crecimiento de la fuerza de trabajo.

\section{TAREAS EN LA PREPARACION DE LOS BALANCES}

La principal tarea en la preparación de los balances de mano de obra es la de estimar en qué medida puede el desarrollo proyectado de la economía y de la construcción social y cultural, asegurar la utilización de los recursos humanos y en qué medida los recursos disponibles de mano de obra permitirán alcanzar el volumen de producción proyectado.

Por el lado de la disponibilidad de mano de obra, será necesario estimar para el año base del plan y para los próximos años, la población considerada como fuerza de trabajo. Será necesario, también, destacar aquellos contingentes de mano de obra aptos para el trabajo y no incluidos en la fuerza de trabajo (dueñas de casa o inactivos en edad de trabajar). Será necesario contar también con la información sobre el sexo, la edad y los niveles de calificación y educación de las disponibilidades y, en general, la desagregación necesaria para poder comparar con los requerimientos de formación profesional y técnica de los sectores económicos. 
En cuanto a la asignación de los recursos de mano de obra, será necesario cuantificar para el año base y en las estimaciones para los años siguientes, la ocupación y desocupación. La primera deberá distinguirse por sexos, grupos ocupacionales, nivel de formación y sectores económicos. Es conveniente reparar dentro de cada sector económico en los contingentes de mano de obra que corresponden al sector público y las empresas estatales. Por su parte, la desocupación deberá cuantificarse en valores absolutos con un cierto grado de desagregación. A la cantidad de desocupados de la fuerza de trabajo será necesario agregar la de los inactivos que tienen intenciones de trabajar (parte de la población en edad de trabajar y no incluida en la fuerza de trabajo) y la subocupación o desocupación disfrazada.

Con estos elementos se constatarán las limitaciones que existen a corto plazo para solucionar los desajustes entre las disponibilidades de recursos humanos calificados y sus necesidades.

La escasez de mano de obra calificada y la abundancia de la no calificada deberá irse alterando paulatinamente. En este sentido, el balance de mano de obra cumple una función fundamental dado que puede ayudar a formular políticas para solucionar este problema y, al mismo tiempo, va evaluando cuantitativamente la eficacia de esas políticas. 
Cuadro 1

BALANCE DE MANO DE OBRA

Resumen

Año 1 Año $1+\mathbf{n}$

I. RECURSOS HUMANOS DEL PAIS

I.1 Disponibilidad de mano de obra

1. Población en edad de trabajar (15-64 años)

2. Población que trabaja, mayor de 64 años

3. Población que trabaja, menor de $\mathbf{1 5}$ años

I.2. Recursos humanos no disponibles

1. Población que no trabaja, menor de 15 años de edad

- Párvulos que no estudian (0-6 años)

- Estudiantes en edad pre-básica (5-6 años)

- Estudiantes de enseñanza básica y media (7-14 años).

- Población en edad escolar (7-14 años) que no asisten a la escuela, menos población que trabaja, menor de 15 años.

2. Población que no trabaja, mayor de 64 años.

II. UTILIZACION DE LA MANO DE OBRA DISPONIBLE

II.1. Población activa

1. Población ocupada

- Agricultura

- Minería

- Industria

- Construcción

- Electricidad, gas, agua

- Comercio

- Transporte

- Servicios

2. Población desocupada

II.2. Población inactiva en edad de trabajar (15-64 años)

1. Estudiantes

2. Labores de hogar

3. Otros

III. DESOCUPACION ABIERTA ENTRE LOS INACTIVOS

- Miles de personas

- Tasa de desocupación

IV. DESOCUPACION EQUIVALENTE DERIVADA

DEL SUBEMPLEO EN LOS OCUPADOS

- Miles de personas

- Tasa de desocupación 


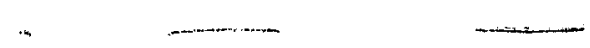


EXIPRIENCIA ECUATORIANA

Dr. Néstor Vega Moreno

Director Técnico

Junta de Planificación del Ecuador 


\section{CONCEPTOS BASICOS}

\section{EL HOMBRE SUJETO DEL DESARROLLO}

Que el hombre es el rey de la creación no es una simple metáfora de la Biblia sino que efectivamente es el ser más importante que habita este planeta, que ha escrito con sus actos una larga historia y ha formado una admirable civilización. Los descubrimientos científicos actuales son realmente asombrosos tanto en la conquista del espacio, como en la electrónica, la computación, la química, la física y la mecánica que han procurado hacer realmente agradable la vida del hombre en la civilización moderna. Sin embargo, estos beneficios de la ciencia y de la técnica son aprovechados y participados solamente por un porcentaje menor de la población mundial, quedando la mayoría de ella completamente marginada de esos beneficios y de estos progresos al llevar la misma vida primitiva de la Edad Media.

La planificación del desarrollo económico y social, garantizando el desarrollo científico y tecnológico y el crecimiento económico de las sociedades modernas, tiene sin embargo la obligación ineludible de buscar un mejoramiento en el nivel de vida para los grupos marginados. Todo el esfuerzo de la planificación moderna tiene que estar orientado al beneficio del sujeto del desarrollo, el hombre.

\section{EL HOMBRE ACTOR DEL DESARROLLO}

Si el hombre ha sido el creador de esta maravillosa civilización, tenemos que admitir que el mayor recurso que tiene un pais es el recurso humano y que por consiguiente debe planificarse con sumo cuidado la utilización de su capacidad y de su esfuerzo. Cuando un país encuentra dentro de su territorio recursos naturales organiza y planifica su explotación hasta el mínimo detalle y con la máxima eficiencia; en cambio quizá no ha habido la suficiente acción para la óptima utilización de los recursos humanos en beneficio del propio hombre. Inclusive en los planes de desarrollo,de invención relativamente reciente en los países modernos,tal vez no se ha dado toda la atención al aspecto humano. La reacción actual es hacer de la planificación la servidora del hombre. 


\section{NECESIDAD DEL CONOCIMIENTO DE LA SITUACION DEMOGRAFICA DE UN PAIS}

Si el hombre es sujeto de desarrollo y actor del desarrollo es imprescindible su conocimiento en los aspectos generales de la demografía y sus actitudes frente al medio que lo rodea y en el que debe actuar. El conocimiento más elemental se refiere a los aspectos demográficos que comprende el estudio del volumen de población de un país y su tasa de crecimiento, como diferencia de la tasa de natalidad y de mortalidad; su composición por edades y sexos; su distribución geográfica entre población urbana y rural y las migraciones internas; el conocimiento de la población económicamente activa y la población dependiente; el grado de alfabetismo y el de instrucción;'sus posibilidades de empleo y su situación de subempleo o desempleo, etc.

\section{PROBLEMAS DEMOGRAFICOS DE MAYOR IMPORTANCIA PARA LA PLANIFICACION DEL DESARROLLO}

Las variables demográficas anteriormente establecidas permiten determinar los factores positivos para la planificación del desarrollo, así como los principales problemas demográficos que es preciso resolver. En primer lugar, el volumen total de la población y su tasa de crecimiento nos indican las necesidades totales de alimentación, vestido, vivienda que es preciso crear y proveer para esa poblaciön. La relación entre la población activa y la población dependiente y pasiva demuestra el esfuerzo que cada persona potencialmente activa debe hacer para proveer los elementos que satisfacen las necesidades básicas. Asimismo, el conocimiento de la población total y su división por edades y sexos, combinados con la tasa de crecimiento, nos indican las necesidades totales de empleo y el número de nuevos empleos que es necesario crear anualmente. Son puntos elementales que uno no puede descuidar.

\section{EL HOMBRE Y EL MEDIO: PROGRAMACION REGIONAL Y NACIONAL}

La distribución geográfica de la población es otro elemento sumamente importante dentro de la planificación porque la estructura del empleo y la provisión de servicios básicos son distintas en el medio urbano y en el medio rural. Los movimientos migratorios son factores a tomarse en cuenta dentro de la programación urbana y regional, porque a causa de ello ciertas ciudades o ciertas regiones pueden experimentar un crecimiento más acelerado que otras. 


\section{LA PROGRAMACION SECTORIAL CON RELACION \\ AL HOMBRE}

a) Si el conocimiento de los datos y relaciones demográficas es importante para ciertos aspectos de la programación global y regional no lo es menos importante para la programación sectorial. La atención de la salud comprende a la población total pero no cabe duda de que los infantes tienen una propensión mayor a enfermarse y requieren de cuidados de especialistas. El volumen de la población infantil por lo tanto debe ser considerado dentro de la programación de la salud. Asimismo se debe tomar en cuenta el número de mujeres en edad biológicamente activa para la programación de la salud. El medio ambiente, las estadísticas de salud y la tasa misma de morbilidad permitirán un adecuado reajuste de las diversas especialidades médicas.

b) Los niños en edad escolar determinarán las necesidades de aulas, equipos y profesores; lo mismo pasa con los jóvenes de nivel secundario y superior de acuerdo a la propensión de la población a seguir este tipo de estudios y las necesidades de profesiones especializadas para el desarrollo.

c) A más de las necesidades de vivienda y los servicios conexos de agua potable, luz y alcantarillado; servicios de teléfonos, comunicaciones y transporte, que se requieren para toda la población, no cabe duda que la proyección de las nuevas viviendas debe hacerse en función de los nuevos matrimonios y la necesidad de cubrir déficit habitacionales anteriores.

d) La producción industrial de diversos tipos de artículos de hogar o de oficina, de centros educacionales o de salud, de uso individual o colectivo, está dependiendo de la población total, de su organización económica, de su sistema de vida, de sus costumbres. Ya se ha mencionado que la producción de alimentos o la importación de los mismos está en función de la población total y de sus hábitos de consumo.

e) En definitiva se podría decir que no hay una sola actividad que pueda programarse prescindiendo del sujeto del desarrollo que a su vez es el actor principal del mismo. Su preparación y su educación para vivir dentro de la sociedad moderna es una de las inversiones básicas que debe hacer cada país. 


\section{EXPERIENCIA EN EL ECUADOR EN LA UTILIZACION DE DATOS Y ESTUDIOS DEMOGRAFICOS EN LA PLANIFICACION}

\section{LOS CENSOS DE POBLACION DE 1950 Y 1962}

a) El primer censo de población en el Ecuador se realizó en 1950; sólo en dicho año pudimos tener un conocimiento cierto del número total de habitantes del país y su composición por edades y sexo. Para muchos constituyó una verdadera sorpresa que en dicho año la población del Ecuador fuera únicamente de 3270000 personas, porque habíamos creído que la cifra era mayor. Inclusive el Registro Civil que permite inscribir nacimientos, matrimonios, y defunciones, se estableció solamente a principios de siglo, de modo que antes de ello el único registro que se llevaba era el de la Iglesia, a base de fe de bautismo, de matrimonio y defunción. Con el censo de 1962 en que la población del Ecuador llegó a 4476000 personas, se pudo establecer la tasa de crecimiento entre los dos censos y hacer las correcciones respectivas de las estimaciones a base del registro civil, que nos hizo conocer que había también un subregistro no del todo despreciable. Desde 1950 se lleva, de todas maneras, una estadística continua de la población que permite disponer de las diversas variables demográficas en cada año y establecer las proyecciones correspondientes de acuerdo a la tasa experimental de crecimiento. El tercer censo nacional de población se proyecta para 1972.

b) Aparte del conocimiento total de la población y su distribución por edad y por sexo, los censos permitieron conocer la población econónicamente activa, su distribución ocupacional y el índice de alfabetismo, entre otras cosas. Desgraciadamente, debido a la interpretación de los empadronadores y de la población censada, la población efectivamente ocupada en labores económicas quizá no se refleje exactamente en los datos estadísticos. Tampoco conocemos su distribución racial y la distribución por el tipo de vestido que daría zlementos importantes dentro del estudio de la estructura sociológica del país, debido a ciertos tabús de la población por los que parecería orohibido el mencionar la raza, a pesar de que existen tres razas completamente diferenciadas, blanca, india y negra y una rama ndefinida de todo tipo de mestizajes. 


\section{EL PLAN INMEDIATO DE DESARROLLO 1962-1963}

Fl primer plan de desarrollo presentado por la Junta de Planificación no fue un plan general sino más bien un plan de inversiones públicas en los sectores de mayor urgencia, en que a más de obras públicas se daba alguna atención a la agricul tura. En dicho plan definitivamente el uso de datos y estudios demográficos fue mínimo.

\section{PLAN GENERAL DE DESARROLLO 1964-1973}

a) El plan general de desarrollo 1964-1973, es muy frondoso pues comprende 21 libros en seis tomos. Sin embargo, el énfasis en dicho plan está dado en la programación sectorial frente a necesidades evidentes en lo que respecta a agricultura, ganadería, explotación forestal, pesca, industria fabril $y$ artesania, transporte $y$ comunicaciones, energía, riego, etc. A pesar de que se establecen metas sociales relacionadas directamente con el hombre en lo que respecta a alimentación, vestido, calzado, ocupación, vivienda y salud pública, no existe un estudio socio-económico profundo y quizá la utilización misma de los datos demográficos es insuficiente. Sin embargo, es importante anotar que entre las transformaciones estructurales que se preconizan constan los programas de reforma agraria que plantean el reasentamiento de 170000 familias en casi 2000000 de hectáreas de tierra laborable y el desplazamiento de 68100 familias hacia 2000000 de hectáreas de tierras de colonización.

b) En el resumen revisado del plan realizado en 1966 se concede, sin embargo, bastante importancia a la política de recursos humanos, cuando se dice: "El recurso humano se ha de considerar, en primer término, como el contexto que encuadra y exige una política planificada de crecimiento económico y social, es decir, como la población que ha de concebir, ejecutar y se ha de beneficiar con los programas de desarrollo. El hombre, en consecuencia, aparece como uno de los factores básicos de producción, al tiempo que en él han de incidir las metas económicas y sociales del desarrollo".

Se hace un análisis demográfico y de los recursos humanos y se establece que, "en la política de recursos humanos tienen fundamental importancia los programas destinados a dirigir la migración, a crear ocupación y los que incrementarán la productividad por ocupado". En realidad la preocupación de la política de población surgió con posterioridad a la iniciación misma del plan y fue tomando mayor forma a partir de 1966. 


\section{PLAN ECUATORIANO PARA EL DESARROLLO DE LOS RECURSOS HUMANOS}

a) La preocupación de la Junta Nacional de Planificación del Ecuador por la planificación de los recursos humanos se hizo evidente en 1970 con la presentación del "Plan Ecuatoriano para el Desarrollo de los Recursos Humanos", preparado con la ayuda financiera de la Agencia de los Estados Unidos para el Desarrollo Internacional y con la asistencia técnica de la Universidad de Ohio. En el prólogo del mencionado Plan se establece que "el Plan Ecuatoriano para el Desarrollo de los Recursos Humanos forma parte de un esquema mucho más amplio de planificación que el papel del hombre en el contex to del desarrollo económico y social". Asimismo plantea una aspiración de que el plan "mueva a reflexionar seriamente en la urgencia de reorientar los sistemas de desarrollo de los recursos humanos para que respondan eficazmente a las necesidades de desarrollo económico y del cambio social". El objetivo fundamental por otra parte es doble; conseguir un índice de desarrollo económico asociado con un incremento permanente de bienestar general, por una parte, y por otra, lograr empleo pleno y productivo para la población económicamente activa. Lógicamente para ello es necesario eliminar los problemas y cuellos de botella que se presentan en el proceso de desarrollo de los recursos humanos.

b) A más de las proyecciones demográficas hasta 1980, a fin de tener en cuenta sus implicaciones en los diversos aspectos y sectores en los que intervienen los recursos humanos, el Plan hace un análisis sociológico de los recursos humanos en el desarrollo económico y social y luego concentra su esfuerzo en la política de empleo estableciendo los requerimientos sectoriales de la mano de obra y luego las necesidades de reformar el sistema educativo para atender esos requerimientos sectoriales de la mano de obra. Finalmente, establece las necesidades de inversión en el sistema educativo para formar la mano de obra requerida.

Por consiguiente, tampoco este plan de recursos humanos es completo, pues está orientado fundamentalmente a establecer proyecciones demográficas de distinta naturaleza y los requerimientos de mano de obra con un diseño de política de empleo. No contempla en cambio aspectos de alimentación y nutrición y todos los problemas conexos de producción, industrialización $\mathrm{y}$ : comercialización de alimentos que ello conlleva, como tampoco los problemas de subalimentación y desnutrición que involucran problemas conexos de salud, vivienda, vestido, higiene, recreación, etc. 


\section{SEMINARIO SOBRE POBLACION Y DESARROLLO, ABRIL DE 1971}

a) El interés de la Junta de Planificación del Ecuador por estudiar los problemas demográficos y los aspectos socio-económicos que pudieran dirigir el nuevo Plan de Desarrollo, la llevó a auspiciar, conjuntamente con la Organización de Estados Americanos, el Seminario sobre Población y Desarrollo que se realizó en Quito, en abril de 1971.

El documento preparado por la Junta de Planificación para dicho evento no es un plan, pero la amplitud del estudio de los problemas es mayor que en el Plan Ecuatoriano para el Desarrollo de los Recursos Humanos. Está concebido en dos partes, la primera dedicada específicamente al estudio demográfico, que incluye las principales características demográficas del Ecuador, ell análisis de los principales componentes del crecimiento demográfico, una proyección de la población ecuatoriana a 1980 en que el Ecuador tendría una población total de 8590000 personas, y un análisis de la población económicamente activa: y luego, una segunda parte que incluye estudios especiales sobre los recursos humanos y específicamente referentes a la política de empleo y luego análisis de los fenómenos y servicios intimamente relacionados con el desarrollo social del hombre, a saber educación, salud, seguridad social, vivienda, desarrollo urbano y desarrollo rural.

b) En el Acta Final del mencionado evento se estableció que el objetivo general del seminario fue analizar con la atención debida las múltiples interrelaciones entre las tendencias del crecimiento de la población y sus variables conexas del desarrollo social y económico, colaborando asi en la consideración de políticas de población que sean consistentes con las necesidades y metas dell país y las cuales puedan operar armonicsamente dentro del contexto del Plan Nacional de Desarrollo. En sus conclusiones y recomendaciones, entre otras, se llegó a las siguientes: propender hacia una sociedad que garantice iguales oportunidades para todos, por medio del empleo pleno de los recursos humanos y dentro de una estructura de poder que asegure la justicia social, y además integrar estructuralmente el análisis demográfico a la problemática del subdesarrollo, a fin de asegurar el tratamiento prioritario que debe tener la variable población en la planificación del desarrollo. 


\section{NUEVA ESTRATEGIA PARA LA PLANIFICACION DEL DESARROLLO}

\section{LA FILOSOFIA DEL NUEVO PLAN}

La filosofía básica que guía el nuevo Plan de Desarrollo es la de incorporar a la masa marginada de la población a la economía monetaria y al progreso. Ello implica desde luego una serie de objetivos como la eliminación de la marginalidad y una mejor distribución del ingreso, la creación de iguales oportunidades para todos los ciudadanos, una mejor ocupación del espacio económico, la ampliación de mercados, la intensificación de la industrialización y urbanización del país y la superación de desequilibrios externos; objetivos que, a su vez, implican una serie de políticas de acción y reformas estructurales, como un replanteo de la reforma agraria, una reforma del sistema educativo, una nueva política de comercio exterior, una nueva estrategia de industrialización y reformas tributarias, institucionales, legales y financieras.

\section{EL PROBLEMA DE LA MARGINALIDAD}

De la población total del Ecuador que en 1970 se estima en 6177000 personas, el 53 por ciento, o sea 3274000 personas se encuentran marginadas de la economía moderna y del progreso, viven de un sistema de producción para autoconsumo, con escasa o nula utilización del dinero, o tienen ingresos monetarios tan bajos que no les permiten llevar un nivel de vida que se compadezca con los mínimos requerimientos compatibles con la dignidad humana. La marginación económica trae automáticamente el discrimen social y eventualmente racial y la imposibilidad de superarse por medio de la educación. Sería inconcebible hacer un Plan de Desarrollo sin tomar en cuenta este problema, que es el mayor con que se enfrentan los pueblos y sin buscarle una solución.

\section{LOS PROGRAMAS EN FUNCION DEL DESARROLLO HUMANO}

Por tanto se propugna que toda la programación esté en función del desarrollo humano y de la eliminación de la marginalidad, estableciendo políticas y sistemas organizativos que favorezcan el empleo pleno y a 
tiempo completo de la población económicamente activa, para que adquiera mejores remuneraciones por su trabajo y lleve a una mejor distribución del ingreso. No solamente los programas sociales de educación, salud, seguridad social, vivienda, desarrollo urbano y rural, sino los programas de producción agricola, ganadera, e industrial y los programas de infraestructura económica, deben estar en función del desarrollo humano y no sacrificar esto por obras espectaculares que eventualmente no son las que más lo favorecen.

\section{LA PREPARACION DE PERSONAL}

Desde luego este mejoramiento del hombre tiene que ser realizado por él mismo a base de su mejor preparación, por lo que es preciso dar especial atención a los programas de educación diversificada en los distintos niveles y a la protección de la salud, no sólo con la medicina curativa sino campañas preventivas y el mejoramiento de servicios sanitarios, así como los programas de alimentación e higiene. Mientras más preparado, educado y sano sea el elemento humano y mejor y mayor ocupación remunerada tenga, favorecerá todos los programas de producción y desarrollo, porque será mejor productor y mejor consumidor. 

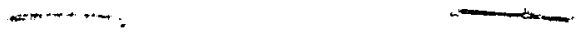

\section{CONCLUSION}

De lo expuesto se puede ver que la planificación en el Ecuador ha dado un giro marcado por el énfasis a los programas sociales y la atención de los recursos humanos frente a una actitud anterior de la búsqueda de un crecimiento económico más que de un desarrollo social. Esperamos tener éxito en la formulación del nuevo plan, así como también en la ejecución del mismo y la obtención de las metas y objetivos deseados, de modo que en un periodo de 20 años eliminemos la marginalidad y todos los ecuatorianos, sin discrimen, tengan una mayor participación en los beneficios del progreso. 
USO DE DATOS Y ESTUDTOS

DEMOGRAIFICOS EN IAA PLANIFICACION

ECONOMICA Y SOCIAL DE HONDURAS

Lic. Conrado Osorio

Jefe, Sección de Análisis Estadístico del Consejo Superior de Planificación Económica, Honduras 
. 
Los estudios demográficos, y en especial las proyecciones de población derivan en gran parte su importancia de la necesidad de elaborar los planes y programas de desarrollo económico y social de un país. La tasa de crecimiento poblacional y el tamaño y composición actual y futura de la población son variables básicas en dichos análisis y estudios. Asimismo, basándose en el incremento y estructura de la población, debe estimarse la fuerıa de trabajo con que contará el pais; el crecimiento de población en edad escolar, para la planificación de la educación nacional; la distribución de la población, con el fin de permitir la implementación de las políticas gubernamentales en cuanto a localización y expansión de los servicios de salubridad, educación y vivienda etc. Es decir que, en cualquier ámbito de la planificación del desarrollo de un país, deberán considerarse directa o indirectamente algunos supuestos con relación a la población y su composición. $1 /$ Por otra parte, las proyecciones demográficas constituyen la base para el cálculo de la futura capacidad productiva (bienes y servicios) del país, mediante la determinación de la oferta de trabajo y las necesidades de los consumidores.

Las proyecciones de población que se requieren en el proceso de la planificación económica-social, varían de un pais a otro, según el desarrollo que se ha alcanzado y según las características demográficas, económicas y sociales del país. Las posibilidades de elaborar proyecciones útiles y confiables varia de acuerdo a los datos básicos disponibles y al alcance de las investigaciones realizadas. Influyen también los recursos humanos existentes y de otro tipo que se destinen a este trabajo. En países de menor grado de desarrollo se observa la falta y desconfiabilidad de las estadísticas, limitándose a investigaciones básicas sobre las tendencias características de la población y sus relaciones con las variables económicas y sociales, y a proyecciones modestas; la escasez de especialistas en este ramo es un factor importante.

1/ Tendencias futuras de la población, Centro de Estudios Económicos y Demográficos, Colegio de México. 
Honduras: Proyecciones existentes en uso

A continuación se citan las proyecciones que actualmente se utilizan en Honduras:

Población total

1961-1980

Población urbana y rural 1961-1980

Población por sexo 1961-1980

Población por edades 1961-1980

Población económicamente

activa por nivel educativo

1961-1980

De estas proyecciones puede calcularse el ingreso per cápita, variable importante para plantear las metas globales de desarrollo económico a cumplirse mediante un plan nacional. Asinismo, este indicador permite evaluar el progreso de un país

Históricamente, el primer recuento de la población de Honduras se levantó en 1791 con un total de 93501 habitantes, y un segundo en 1801 con 130000 habitantes. El primer Censo de la Población se realizó en 1881, levantándose el último en 1961; en total se han levantado 13 censos de población.(Véanse los cuadros 2 y 3 ).

En los primeros ocho censos (incluyéndose los dos recuentos) no se obtuvo una regularidad que permita hacer comparaciones entre uno y otro, transcurriendo períodos de 4 a 23 años entre los diversos censos citados: 10 años entre el primero y segundo, 8 entre el segundo y tercero, 6 años entre el tercero y cuarto, 23 años entre el cuarto y quinto, 6 años entre el quinto y sexto, 10 años entre sexto y séptimo $y$ 4 años entre séptimo y octavo. Asimismo, se observó una variación en las tasas anuales de crecimiento entre cada época: 1,5 por ciento de 1910-1916 y 1916-1926; 5,1 por ciento para $1926-1930 ; 2,4$ por ciento de 1930-1935; 2,9 por ciento para $1935-1940 ; 1,6$ por ciento para $1940-1945 ; 2,7$ por ciento para $1945-1950$, y finalmente, 3,0 por ciento para 1950-1961.

Las fluctuaciones que se observan en las tasas de crecimiento de los periodos intercensales evidencian las deficiencias de los censos anteriores a 1945, como consecuencia de las técnicas utilizadas, la calidad de los registros de los sucesos vitales, la extensión territorial, produciéndose márgenes de error considerables. Otros factores, como las constantes revoluciones políticas de ese período, también causaron distorsiones en las secuencias censales al reducir considerablemente la población joven.

Las anomalías mencionadas han sido parcialmente superadas con las estimaciones de CELADE. Las proyecciones de población para 1961-1981,, actualmente en uso, están basadas en información inás

2/ Proyecciones de la población de Honduras por sexa y grupos de edad $1961-81$, Serie A, No 70, junio de 1967. 
adecuada y exacta y en hipótesis más razonables. Estas indican que para 1961, la tasa de natalidad fue de 50 por mil y la tasa de mortalidad 18 por mil, las que tomando en cuenta un pequeño margen de inmigración, dieron una tasa anual de crecimiento aproximado de 3,3 por ciento.

De las cuatro proyecciones de CELADE, basadas en hipótesis diferentes sobre la fecundidad e inmigración, la Hipótesis $B$ que considera inmigración y fecundidad en descenso, fue la aceptada por la Dirección General de Estadísticas y Censos. Debe anotarse que dicha hipótesis fue aceptada, no porque existe la probabilidad de una disminución en la fecundidad, sino porque los resultados obtenidos fueron más acordes con la realidad.

Entre los países del Area Centroamericana, Honduras, con una tasa anual de 3,4 por ciento, ocupa el segundo lugar en lo que al crecimien to de la población se refiere, superada únicamente por Costa Rica con una tasa de 3,7 por ciento, y seguida por El Salvador con 3,07 por ciento, Nicaragua, 2,97, Guatemala 2,77, Panamá 3,27. En conjunto, Centro América exhibe una tasa promedio de 3,0 por ciento. Este rápido crecimiento de la población constituye un factor que ejerce presiones sobre la planificación del desarrollo, ya que involucra la expansión de los servicios de salubridad, vivienda y educación,la satisfacción de las necesidades vitales de la población creciente, la creación de fuentes de trabajo remu nerativo, etc.

\section{Determinación del crecimiento demográfico}

El crecimiento de la población está determinado por el crecimiento natural o vegetativo. Número de nacimientos menos número de defunciones más la migración neta (inmigrantes menos emigrantes). El cuadro 4 revela que la tasa de natalidad, para el período 1950-1968, ha aumentado de 39,9 por mil a 44,5 por mil. La tasa de mortalidad general, calculada sobre la base de cada 1000 habitantes en el período de los 19 años mencionados, ha disminuido considerablemente; de 11,8 personas por mil que se observó en 1950 descendió en 1968 a 8,5 personas por mil. Este descenso se debe fundamentalmente a la notable disminución de la mortalidad infantil, que en 1950 registró una tasa de 85,6 niños por mil nacidos vivos hasta llegar a 34,0 por mil nacidos vivos en 1968. Dicha disminución, de más de un 50 por ciento, da una idea del esfuerzo que se ha hecho en nuestro país en el campo de la salubridad y la atención médica, especialmente a las madres y los niños. La tasa bruta de crecimiento vegetativo, que se calculó sobre la base de cada mil habitantes, nos muestra que en los últimos 19 años el zrecimiento natural vegetativo ha sido constante, incrementando de 28,0 por mil en 1950 a 35,9 por mil en 1968 . 
El crecimiento constante y rápido de la población de Honduras es u na característica que comparte con los demás países centroamericanos, que según el estudio sobre Recursos Humanos del Consejo Superior Universitario Centroamericano, ha registrado un promedio de 3,3 por ciento anual. La Dirección General de Estadísticas y Censos estableció para 1961 una tasa anual de crecimiento de 3,0 por ciento; si comparamos esta tasa que aún está por debajo del promedio de la región centroamericana, con el promedio de crecimiento poblacional del mundo, que según estudios realizados por Naciones Únidas es de 1,8 por ciento anual, nuestro crecimiento resulta alto.

\section{Honduras: Crecimiento estimado para 1969}

La población de Honduras al 30 de junio de 1969 se estimaba en 2494,9 miles de personas de ambos sexos, con una tasa de crecimiento anual para 1961 de 3,0 por ciento, registrándose una variación anual de 0,04 por ciento. En 1969 se observó un crecimiento de 3,4 por ciento, indicando el aumento progresivo de la población que ejerce su mayor impacto en los núcleos donde se concentra la población.

Haciendo un análisis comparativo de las tendencias del crecimiento de la población centroamericana, se presenta en el cuadro 1 el total por países y por quinquenios desde 1945 hasta 1969.

\section{Cuadro 1}

AMERICA CENTRAL Y PANAMA.

ESTIMACIONES DE POBLACION DE 1945-1969

(En miles a mitad de año)

\begin{tabular}{|c|c|c|c|c|c|c|c|}
\hline Año & $\begin{array}{r}\text { Costa } \\
\text { Rica }\end{array}$ & $\begin{array}{c}\text { El } \\
\text { Salvador }\end{array}$ & Guatemala & Honduras & s Nicaragua & Panamá & Región \\
\hline 1945 & 714 & 1736 & 2586 & 1234 & 983 & 675 & 7928 \\
\hline 1950 & 849 & 1921. & 3040 & 1388 & 1133 & 765 & 9096 \\
\hline 1955 & 1025 & 2175 & 3512 & 1.589 & 1308 & 882 & 10491 \\
\hline 1960 & 1.235 & 2509 & 4013 & 1847 & 1511 & 1021 & 12136 \\
\hline 1965 & 1491 & 2917 & 4586 & 2181 & 1745 & 1197 & 14117 \\
\hline $1969^{*}$ & 1700 & 3300 & 5000 & 2500 & 2000 & 1400 & 15900 \\
\hline
\end{tabular}

Fiuente: CELADE, Boletín Demográfico, Vol. $1, N^{\circ} 1$. Santiago de Chile, enero 1968, cuadro 1 .

* Population Reference Bureau, abril 1969.

Durante este periodo la población de la región se duplicó, observándose la misma tendencia en Honduras, Nicaragua, El Salvador, Guatemala y Panamá; en Costa Rica casi se triplica. La aceleración del ritmo de crecimiento demográfico puede calcularse por el número de 
años que una población tardará en duplicarse, bajo el supuesto que se mantendrá la tasa anual media en un determinado período. (Véanse los cuadros 5 y 6 ). En el cuadro 6 se observa una ligera reducción en el número de años requeridos para duplicar la población de la región centroamericana. En Honduras esta tendencia es evidente al pasar de un período de 30 años para 1945-1950 a 20 años para 1965-1969. (En los países donde los movimientos de migración internacional no muestran mucha importancia, los únicos componentes del crecimiento de la población son, desde luego, la natalidad y la mortalidad).

\section{Honduras: Población por grupos de edades}

La estructura de la población hondureña por edades, representada en los cuadros 7 y 8 , muestra una concentración de población menor de 15 años, que en términos absolutos asciende según estimaciones para 1969 a 1172,5 miles de personas, equivalente al 47,1 por ciento de la población total (473,5 miles de $0-4$ años). Esta característica de la estructura por edades nos indica que la población de Honduras es joven y de fuerte poder reproductivo. Comparado con otros grupos de la población, tenemos que es muy superior al grupo que va de 15 a 39 años, ya que éste alcanza únicamente el 37,0 por ciento de la población total. La población potencialmente activa, que está comprendida entre los 15 y 64 años, asciende a un total de 1262,6 miles que representa el 50,6 por ciento de la población total; toda la población activa y no activa de trabajo de 15 años y más suma 1322,4 miles, representando el 53,0 por ciento de la población total.

\section{Honduras: Poblaciôn urbana y rural}

La población urbana, según el censo de 1961 y corregido por CELADE, ascendió a un total de 444,0 miles y la rural a 1465,9 miles de personas: esta última representa el 76,8 por ciento de la población total. Para los efectos del Censo de 1961 se definió como población urbana la de los centros poblados de mil habitantes o más, que tuvieran por lo menos los siguientes servicios públicos:

1. Escuela primaria completa (6 grados);

2. Uno de los siguientes servicios: Correo, telégrafo o teléfono público;

3. Comunicación terrestre (carretera o ferrocarril) o servicio regular aéreo o marítimo;

4. Servicio de agua potable, y

5. Servicio de alumbrado eléctrico.

Los departamentos que registraron el mayor porcentaje de población urbana fueron: el departamento de Cortés con 53,5 por ciento, Francisco Morazán con el 49,4 por ciento y Atlántida con 42,7 por 
ciento. El departamento de Lempira es el que tiene la menor población urbana ya que apenas representa el 1,7 por ciento, equivalente a 1654 personas de un total de 111546 que viven en el departamento, o sea, el 98,3 por ciento es población rural; en ese orden le siguen los departamentos de Intibucá, Copán, Valle, La Paz, Ocotepeque y Colón.

Analizando el cuadro 9 se observa que la población de Honduras es eminentemente rural, con promedio general del 76,8 por ciento del total de población; únicamente cuatro de los 18 departamentos evidencia una población urbana considerable: el resto es rural. El porcentaje de población rural fluctúa entre 80,3 por ciento en el departamento de Yoro, 98,3 por ciento de Lempira y 100 por ciento de Gracias a Dios.

Para 1969 tenemos una población urbana de 664,8, miles que representa el 26,6 por ciento del total y la rural de 1830,1 , o sea, el 73,4 por ciento del total. Para 1975 se estima que la componente urbana ascenderá a 29 por ciento, llegando a constituir el 30,8 por ciento de la población total en 1980.

Uso de datos demográficos en la planificación regional

La planificación regional es la forma de asegurar que se considere en el proceso de planificación no únicamente lo que se va a hacer sino también el lugar donde se hará. Por ejemplo, para guiar el desarrollo del país, no es suficiente determinar que el país necesita construir 500 aulas escolares cada año, sino que hay que determinar donde son necesarias, ya que poco valdría que se construyeran todas en un departamento despoblado. Es decir, el desarrollo económico de un país no es un proceso que puede llevarse a cabo en cualquier punto del territorio nacional, sino algo que tiene que repartirse entre las aldeas y ciudades de ese territorio, y su progreso dependerá en gran parte de la eficiencia de la repartición.

En cuanto a la distribución regional de población y su actividad económica, Honduras adopta una división de diez regiones y diez polos regionales, los cuales están diseñados para que puedan ser usados de tres maneras diferentes: 1) como áreas de datos e información, en términos de los cuales se pueden llevar a cabo estudios y se pueden acumular y analizar datos; 2) como regiones y polos de servicios, para ser usados en la programación de la infraestructura física y social por parte de agencias gubernamentales y 3) como regiones de programación de desarrollo, en términos de las cuales puedan organizarse planes nacionales y sub-nacionales de desarrollo,de acuerdo a la distribución espacial de las actividades cuyo desarrollo se está planificando.

En Honduras dos terceras partes de la población está dedicada a la actividad agrícola. Se ha dicho que ningún pais puede desarrollarse 
económicamente con la mayoria de su poblacion en la agricultura, y existe una correlación definitiva entre el porcentaje de la población de un país que es urbano o semiurbano, y el nivel de vida de la población de ese país.

Para disminuir la proporción de la población en agricultura es necesario aumentar los rendimientos por trabajador agrícola y probablemente por unidad de tierra. Gran parte del territorio de Honduras, dada su topografía, no es muy apropiado para cultivos; así vemos que existen regiones muy montañosas y zonas semi-desérticas.

Por lo tanto, los esfuerzos deben concentrarse en las áreas de mayor potencial agrícola-donde los rendimientos por trabajador agrícola y por unidad de tierra pueden ser los más altos y los más baratos de lograr- liberando gente de la necesidad de trabajar en agricultura y permitiendo el apoyo de una may or población no agrícola. Areas que no son apropiadas para la agricultura deben de ser encaminadas hacia otras actividades, disminuyendo así su importancia económica relativa, lo cual reduciría la dependencia nacional en agricultura y también permitiría a las poblaciones agrícolas en áreas marginales y sub-marginales, iniciar labores no agrícolas, o emigrar a áreas más apropiadas.

En términos generales, la población agrícola de Honduras vive y trabaja en las áreas de menor potencial agricola, mientras que las áreas de mayor potencial agrícola son, en la mayor parte, despobladas e inexplotadas.

Las regiones de Tegucigalpa, Choluteca, Santa Rosa y Zonas Fronterizas contienen 45,72 por ciento de la población nacional que trabaja en agricultura y 55,06 por ciento de áreas en cultivos, pero solamente poseen el 19,03 por ciento de la tierra clasificada como cultivable, el 9,96 por ciento de la tierra buena y el 14,18 por ciento de los bosques del país. Sin embargo, las regiones de La Ceiba, Juticalpa y Gracias a Dios, con solamente 16,25 por ciento de la población nacional agrícola y 20,41 por ciento de la tierra en cultivos, contienen el 58,59 por ciento de la tierra buena, el 46,73 por ciento de la tierra clasificada como cultivable, y el 65,19 por ciento de los bosques.

Industria, comercio, servicios y centros urbanos

En ocho de las diez regiones se ha designado un centro urbano como un polo de crecimiento para la región. Estos centros urbanos servirán como focos de servicios gubernamentales locales (es decir, regionales) y de centros regionales de comercio. Además, nueve de las diez regiones contienen poblaciones designadas para ser sub-polos; éstos serán primeramente centros de comercio local que servirán una área subregional. Se han seleccionado lugares en cuatro regiones para desarrollo urbano-industrial. 
A medida que se mejora el transporte en el país se harán mas cortas las distancias, haciendo así impráctico un mayor número de focos centrales mayores. De antemano, se tienen dudas sobre el potencial para el desarrollo de algunos de los polos y sub-polos, una vez que los caminos mejorados los sitúen más cerca a centros mayores y de mayor potencia. Se acepta que cuatro focos de desarrollo urbano-industrial pueden ser un máximo práctico.

Honduras es pequeña en área (especialmente, a medida que mejora el transporte) y en población y un mayor número de focos centrales may ores no sería práctico.

Además, no se ha demostrado que haya un tamaño máximo para una ciudad eficiente $y$ aun si existe tal límite, ninguna población se encontraría cerca de ese límite al presente. Sin embargo, ciudades más grandes pueden absorber y soportar una mayor variedad de mercaderías y servicios y las economías de escala y las economías externas pueden aumentar la eficiencia de operaciones en ciudades más grandes. La necesidad de ciudades más grandes es particularmente evidente en Honduras.

La migración de agricultores a la vida urbano-industrial debería promoverse para aumentar la producción industrial del país y el nivel de vida de la gente.

La región de Tegucigalpa contiene, por supuesto, la ciudad más grande del país. Aunque la región tiene el porcentaje más bajo de población en agricultura de todas las regiones (34,6 por ciento), el porcentaje ocupacional más alto está en "Servicios" ( 38,8 por ciento), y solamente 19,0 por ciento en industria. Este porcentaje en industria, aunque también es el más alto en el país, deja a la región de Tegucigalpa por debajo de la región de San Pedro Sula. Tegucigalpa es uno de los cuatro lugares en el país designado para desarrollo industrial, siendo sus ventajas principales la comparativamente alta población actual, la presencia de la capital nacional y su proximidad relativa a la Carretera Panamericana. Servicios, particularmente de naturaleza gubernamental y semi-gubernamental, continuarán empleando más personas que la industria, pero Tegucigalpa puede esperar algún crecimiento industrial, lo que evitará que sea una ciudad capital de una sola industria. Sin embargo, este crecimiento industrial tendrá que ser en industrias con grandes mercados locales (opuesto a mercados de exportación). En general, Tegucigalpa no debería ser forzada a crecer industrialmente, o generalmente, a la misma tasa que San Pedro Sula y La Ceiba, donde el acceso a puertos y transporte terrestre, potencialmente buenos y la proximidad de vastas áreas subordinadas agrícolas (para el desarrollo de industrias verticamente integradas, basadas en la agricultura) dan a estas ciudades ventajas considerables.

Frecuentemente se cita el caso de Medellín para mostrar que una ciudad, aun como Tegucigalpa, interior y aislada en las montañas, puede 
desarrollarse industrialmente. Debe tenerse en cuenta, sin embargo, que Medellín se desarrolló a pesar de su aislamiento y no a causa de él, y dada la existencia de ciudades en Honduras que son mucho más apropiadas que Tegucigalpa para crecimiento rápido y desarrollo de tipo industrial, Tegucigalpa no debería forzar el desarrollo de industrias que puedan establecerse más eficientemente en otra parte.

Sin embargo, el desarrollo por ocupaciones de "Servicios" continuará y, debido al atractivo físico de Tegucigalpa y a su proximidad a la Carretera Panamericana, puede ser posible planificar y desarrollar turismo a cierta escala.

La región de Tegucigalpa, a causa de su tamaño físico, su potencial agrícola relativamente bajo y la falta de sub-centros existentes, tendrá solamente un sub-polo, Talanga, el cual servirá de centro de comercio local para el Valle de Talanga y deberá beneficiarse de su población futura en el empalme de las Carreteras Central y Oriental.

La región de San Pedro Sula contiene en la actualidad el mayor número de trabajadores industriales de todas las regiones, y goza del crecimiento industrial más rápido del país. Este crecimiento se concentra en San Pedro Sula, pero otras áreas del Valle de Sula, (el cual ya contiene siete poblaciones de más de 5000 personas), se han beneficiado también, particularmente a lo largo de la Carretera Norte-Sur en el corredor Puerto Cortés-Potrerillos. Esta área continuará siendo el centro industrial del país.

San Pedro Sula, como el polo regional, es y será el centro de servicios y de comercio para la región; Progreso, Puerto Cortés y Tela continuarán como sub-polos comerciales y un desarrollo industrial menor proseguirá en los tres. Puerto Cortés, como el primer puerto del pais, puede llegar a ser la segunda ciudad del Valle y podría desarrollarse como un centro industrial orientado hacia el puerto. Cuando se termine la Carretera al Oeste de Puerto Cortés, hacia Guatemala, Puerto Cortés y Honduras, podría beneficiarse al servir una región interior portuaria mucho más grande. Las facilidades en Puerto Cortés deberán continuar mejorándose para poder competir efectivamente con Puerto Barrios, una competencia que se desarrollará cuando se termine la carretera entre los puertos.

Santa Bárbara y Quimistán se han designado como sub-polos de comercio local. Cuyamel, aunque actualmente pequeño y aislado, puede llegar a desarrollarse cuando el plano y fértil llano de Cuyamel cambie de ser un área de pasto extensiva a una de agricultura más productiva, y cuando la carretera a Guatemala pase por allí.

La región de La Ceiba posee la tercera ciudad del país y es una de las regiones de mayor potencial para el desarrollo. La Ceiba continuará siendo el tercer centro industrial y comercial del país y crecerá considerablemente a medida que sus zonas interiores se vuelvan más productivas y que nuevos caminos reduzcan su aislamiento. Desarrollo 
industrial adicional ocurrirá también en lugares cercanos a recursos naturales, como por ejemplo la Planta de pulpa y papel en Mame. Con el aumento de producción en la región, el uso de los puertos de La Ceiba y Trujillo aumentará también, y deberán programarse mejoras en sus facilidades. Se han designado como sub-polos para comercio local a Olanchito, San Esteban, Trujillo y Yoro; todos estos sub-centros podrán gozar un crecimiento acelerado cuando sus respectivas áreas de servicios desarrollen una producción mayor. Olanchito particularmente, ubicado en el extenso y fértil Valle del Aguán, puede desarrollarse considerablemente $\mathbf{y}$ hasta puede esperar cierto desarrollo industrial, aunque La. Ceiba continuará dominando la región. Esta región, así como la región de San Pedro Sula, tiene un potencial considerable para el desarrollo de una industria pesquera e industrias de elaboración de pescado, particularmente en las Islas de la Bahía y en los puertos de La Ceiba y Trujillo. Las Islas de la Bahía constituyen una de las áreas más importantes del país para el desarrollo de una industria turística que debería promoverse. De hecho, la pesca y el turismo probablemente tendrán que ser las bases de la economía de las Islas de la Bahía, por lo menos en el futuro cercano.

La región de Choluteca contiene la cuarta zona que se ha designado para desarrollo industrial. Un desarrollo de este tipo es particularmente importante para esta región, en vista de su alta densidad de población agrícola. Este tipo de desarrollo debería ocurrir en la zona de San Lorenzo, donde se recomienda que se construyan las facilidades portuarias (para servir tanto al Sur como a Tegucigalpa) y que se desarrolle un complejo industrial en la misma zona. Con una facilidad portuaria, San Lorenzo, sobre la Carretera Panamericana, se encontrará en una situación muy favorable para recibir y generar insumos de producción industrial. Sin embargo, Choluteca es actualmente tan dominante en la región en términos de servicios, transporte y comercio, que continuará siendo el polo regional en el futuro cercano, pero a medida que se desarrolle San Lorenzo, éste puede reemplazar a Choluteca como el centro dominante de la región, tanto para servicios y comercio, como para actividades industriales y terciarias. Nacaome y San Marcos de Colón continuarán siendo los sub-polos comerciales para sus zonas de servicios inmediatos. Tal como en las regiones del Norte, existe aquí un potencial para el desarrollo de la pesca comercial y para el procesamiento del pescado. San Lorenzo sería la mejor ubicación para este tipo de actividades, particularmente cuando se haya construido el puerto y se pueda servir Tegucigalpa con más facilidad.

El patrón general, es de un verdadero desarrollo urbano-industrial en cuatro lugares: El Valle de Sula, Tegucigalpa, La Ceiba y San Lorenzo; y cierto desarrollo industrial, principalmente basado en agricultura, en otras áreas. Los ocho polos regionales deberían desarrollarse como 
centros de servicios gubemamentales y de comercio, con los sub-polos funcionando en forma igual, pero en menor escala.

A medida que se desarrolla la agricultura, se mejora el transporte y se aumenta la movilidad de personal, el tamaño de Honduras puede hacer posible una migración acelerada a las áreas urbanas y la consecuente dominación particular de los cuatro polos de crecimiento y desarrollo urbano-industrial.

La distribución espacial de recursos económicos en Honduras indica que las concentraciones de población y de actividad económica actualmente en áreas aisladas y de bajo potencial agricola, deberían trasladarse a las áreas de mayor potencial agrícola, áreas que son bastante extensas en Honduras. Es decir, se deberían aprovechar mejor los considerables recursos naturales del país.

Aunque el tamaño de Honduras (en extensión física y en población), imposibilita el desarrollo de todos los polos regionales al nivel de centros urbanos de gran escala, los cuatro lugares que han sido designados para desarrollo urbano-industrial deberían crecer a una tasa acelerada. Honduras tiene alrededor de un 10 por ciento de su población en lugares que podrían llamarse ciudades (T'egucigalpa y San Pedro Sula), y aun estas ciudades son todavía pequeñas en términos mundiales. Además, no se ha demostrado que las ciudades grandes son, ipso facto, malas. Las deficientes condiciones de vivienda que se asocian con las ciudades grandes, son los resultados del crecimiento urbano no planificado, y no del crecimiento urbano en sí. Y, en todo caso, las condiciones de vivienda en los peores tugurios de San Pedro Sula, por ejemplo, probablemente no son, excepto tal vez por su mayor densidad, peores que las condiciones de pobreza rural local de la cual vienen los migrantes urbanos. Sin embargo, Honduras, con una población urbana actualmente tan pequeña, tiene una oportunidad ideal para evitar tales condiciones de vida y para planificar un desarrollo urbano nacional. 


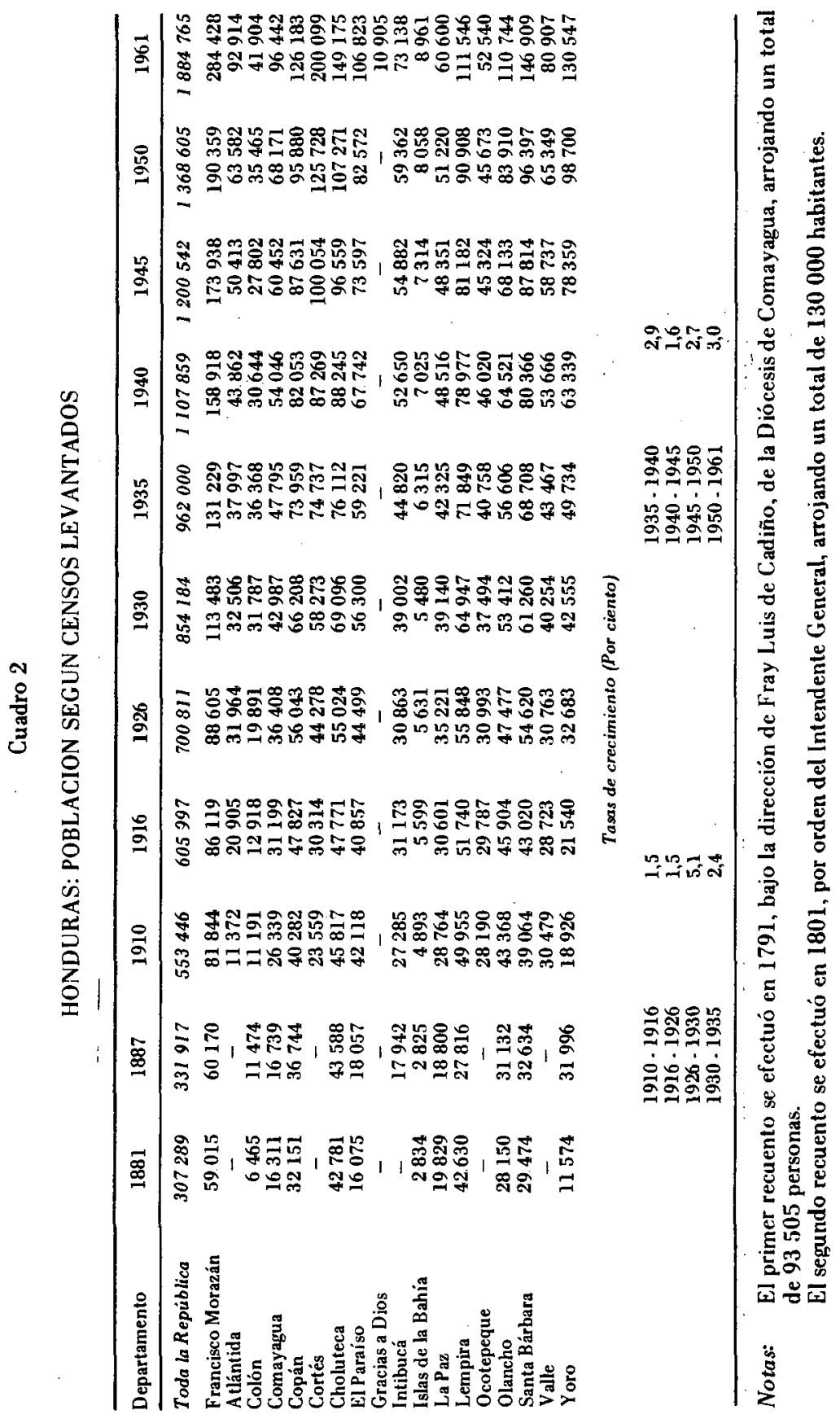


Cuadro 3

HONDURAS: POBLACION TOTAL SEGUN CENSOS LEVANTADOS Y ESTIMACIONES PARA 1980

\begin{tabular}{cccc}
\hline Años & $\begin{array}{c}\text { Recuento o } \\
\text { censos de } \\
\text { población }\end{array}$ & $\begin{array}{c}\text { Población } \\
\text { corregida y } \\
\text { estimada a } \\
\text { mediados de año }\end{array}$ & $\begin{array}{c}\text { Tasas de } \\
\text { crecimiento } \\
\text { medio anual } \\
\text { (Por ciento) }\end{array}$ \\
\hline 1791 & $93501 \mathrm{a} /$ & - & - \\
1801 & $130000 \mathrm{~b} /$ & - & - \\
1881 & $307289 \mathrm{c} /$ & - & - \\
1887 & $331917 \mathrm{~d} /$ & - & - \\
1910 & 553446 & - & - \\
1916 & 605997 & - & 1,5 \\
1926 & 700811 & - & 5,1 \\
1930 & 854184 & - & 2,4 \\
1935 & 962000 & - & 2,9 \\
1940 & 1107859 & - & 2,6 \\
1945 & 1200542 & $1909,9 *$ & 3,0 \\
1950 & 1368605 & 2108,9 & 3,3 \\
1961 & 1894765 e/ & - & - \\
1964 & - & 2181,2 & - \\
1965 & - & 2333,0 & - \\
1966 & - & 2412,9 & 3,4 \\
1967 & - & 2494,9 & - \\
1968 & - & 2981,9 & 3,6 \\
1969 & - & 3556,8 & \\
1975 & - & - &
\end{tabular}

Fuente: Dirección General de Estadística y Censos.

a/ Primer recuento a cargo Fray Luis de Cadiño prelado de la Diócesis de Comayagua.

b/ Segundo recuento.

c/ Primer censo a cargo de Don Francisco Cruz, fundador y primer director de Estadística.

d/ Segundo censo a cargo de Antonio R. Vallejo.

e/ Ultimo censo levantado.

*) Estimaciones del CELADE. 
Cuadro 4

HONDURAS: TASAS BRUTAS DE CRECIMIENTO VEGETATIVO. 1950 - 1968

\begin{tabular}{|c|c|c|c|c|}
\hline Años & $\begin{array}{c}(1) \\
\text { Tasa } \\
\text { Natalidad } \\
\frac{B}{p} K=1000\end{array}$ & $\begin{array}{c}(2) \\
\text { Tasa } \\
\text { Mortalidad } \\
\frac{D}{p} K=1000\end{array}$ & $\begin{array}{c}(3) \\
\text { Tasa Bruta } \\
\text { Crecimiento } \\
\text { Vegetativo } \\
\frac{B \cdot D}{p} \times \quad 1000\end{array}$ & $\begin{array}{c}\text { (4) } \\
\text { Mortalidad } \\
\quad \text { Infantil } \\
\frac{I}{p} 1000\end{array}$ \\
\hline $\begin{array}{l}1950 \\
1951 \\
1952 \\
1953 \\
1954 \\
1955 \\
1956 \\
1957 \\
1958 \\
1959 \text { a } \\
1960 \\
1961 \\
1962 \\
1963 \\
1964 \\
1965 \\
1966 \\
1967 \\
1968\end{array}$ & $\begin{array}{l}39,9 \\
41,0 \\
39,7 \\
41,7 \\
41,7 \\
43,0 \\
40,7 \\
43,2 \\
43,1 \\
42,0 \\
42,4 \\
42,9 \\
44,5 \\
43,8 \\
45,5 \\
43,7 \\
44,4 \\
44,0 \\
44,5\end{array}$ & $\begin{array}{r}11,8 \\
11,1 \\
12,5 \\
11,6 \\
11,1 \\
11,3 \\
10,1 \\
10,4 \\
11,1 \\
9,5 \\
9,3 \\
9,0 \\
9,0 \\
9,1 \\
9,3 \\
8,6 \\
9,1 \\
8,4 \\
8,5\end{array}$ & $\begin{array}{l}28,0 \\
29,8 \\
27,1 \\
30,1 \\
30,5 \\
31,6 \\
30,5 \\
32,7 \\
31,9 \\
34,5 \\
34,7 \\
35,5 \\
37,2 \\
36,3 \\
37,9 \\
36,8 \\
35,4 \\
35,6 \\
35,9\end{array}$ & $\begin{array}{l}85,6 \\
54,7 \\
64,3 \\
64,0 \\
60,0 \\
54,9 \\
53,0 \\
59,4 \\
65,1 \\
53,5 \\
52,0 \\
49,9 \\
43,6 \\
47,0 \\
45,4 \\
41,2 \\
37,8 \\
35,5 \\
34,0\end{array}$ \\
\hline
\end{tabular}

Fuente: Dirección General de Estadística y Censos.

a Cifras corregidas a partir de 1959 , población total, fuente CELADE.

$\mathrm{B}=$ Nacimientos

$\mathbf{p}=$ Población total

$\mathrm{D}=$ Defunciones

I = Mortalidad Infantil 
Cuadro 5

AMERICA CENTRAL Y PANAMA.

TASAS ANUALES DE CRECIMIENTO 1945 - 1969

\begin{tabular}{lccccc}
\hline & \multicolumn{5}{c}{ Períodos } \\
\cline { 2 - 6 } Países & $\mathbf{1 9 4 5 - 5 0}$ & $\mathbf{1 9 5 0 - 5 5}$ & $\mathbf{1 9 5 5 - 6 0}$ & $\mathbf{1 9 6 0 - 6 5}$ & $\mathbf{1 9 6 5 - 6 9}$ \\
\hline Costa Rica & 3,45 & 3,76 & 3,72 & 3,76 & 3,8 \\
El Salvador & 2,02 & 2,48 & 2,85 & 3,00 & 2,2 \\
Guatemala & $\mathbf{3 , 2 2}$ & 2,88 & 2,66 & 2,66 & 2,8 \\
Honduras & 2,35 & 2,70 & 3,08 & 3,28 & 3,4 \\
Nicaragua & 2,83 & 2,86 & 2,88 & 2,87 & 3,0 \\
Panamá & 2,50 & 2,84 & 2,92 & 3,17 & 3,2 \\
Región & 2,74 & 2,85 & 2,92 & 3,01 & 3,1 \\
\hline
\end{tabular}

Cuadro 6

AÑOS PARA DUPLICAR LA POBLACION

\begin{tabular}{lccccc}
\hline & \multicolumn{5}{c}{ Periodos } \\
\cline { 2 - 6 } Países & $1945-50$ & $1950-55$ & $1955-60$ & $1960-65$ & $\begin{array}{c}1965-69 \\
*\end{array}$ \\
\hline Costa Rica & 20 & 19 & 19 & 19 & 20 \\
El Salvador & 35 & 28 & 25 & 23 & 19 \\
Guatemala & 22 & 24 & 26 & 26 & 23 \\
Honduras & 30 & 26 & 23 & 21 & 20 \\
Nicaragua & 25 & 24 & 24 & 24 & 20 \\
Panamá & 28 & 25 & 24 & 22 & 22 \\
Región & 26 & 25 & 24 & 23 & 23 \\
\hline
\end{tabular}

* Population Reference Bureau, abril 1969. 
Cuadro 7

HONDURAS: DISTRIBUCION ABSOLUTA Y RELATIVA

DE LA POBLACION, SEGUN GRUPOS DE EDADES, 1969

\begin{tabular}{ccc}
\hline $\begin{array}{c}\text { Grupos } \\
\text { de edades }\end{array}$ & $\begin{array}{c}\text { Población } \\
\text { en miles }\end{array}$ & $\begin{array}{c}\text { Distribución } \\
\text { relativa } \\
\text { (por cien) }\end{array}$ \\
\hline Total & 2494,9 & 100,0 \\
0.4 & 473,5 & 19,0 \\
$5 \cdot 9$ & 377,2 & 15,1 \\
$10-14$ & 321,8 & 13,0 \\
$15-19$ & 278,8 & 11,1 \\
$20-24$ & 211,0 & 8,4 \\
$25-29$ & 168,0 & 6,7 \\
$30-34$ & 144,7 & 5,8 \\
$35-39$ & 121,5 & 4,9 \\
$40-44$ & 106,4 & 4,3 \\
$45-49$ & 83,3 & 3,3 \\
$50-54$ & 61,5 & 2,5 \\
$55-59$ & 49,9 & 2,0 \\
60.64 & 37,5 & 1,5 \\
$65-69$ & 26,0 & 1,0 \\
70 y más & 33,8 & 1,4 \\
\hline
\end{tabular}

Fuente: Dirección General de Estadística y Censos en base a las proyecciones del CELADE. 
Cuadro 8

HONDURAS: POBLACION POR ESTRUCTURA DE EDAD ESTIMADA

AL 30 DE JUNIO DE 1969

(Miles de habitantes)

\begin{tabular}{ccccr}
\hline $\begin{array}{c}\text { Grupos de } \\
\text { edades }\end{array}$ & Ambos sexos & Por ciento & Masculino & Femenino \\
\hline Total & $2.494,9$ & 100,0 & $1.245,9$ & $1.249,0$ \\
$0-4$ & 473,5 & 19,0 & 240,0 & 233,5 \\
$5 \cdot 9$ & 377,2 & 15,1 & 190,3 & 186,9 \\
$10-14$ & 921,8 & 13,0 & 161,8 & 160,0 \\
$15-19$ & 278,8 & 11,1 & 139,6 & 139,2 \\
$20-24$ & 211,0 & 8,4 & 105,1 & 105,9 \\
$25-29$ & 168,0 & 6,7 & 83,3 & 84,7 \\
$30-34$ & 144,7 & 5,8 & 71,6 & 73,1 \\
$35-39$ & 121,5 & 4,9 & 60,0 & 61,5 \\
$40-44$ & 106,4 & 4,3 & 52,4 & 54,0 \\
$45-49$ & 83,3 & 3,3 & 40,8 & 42,5 \\
$50-54$ & 61,5 & 2,5 & 30,1 & 31,4 \\
$55-59$ & 49,9 & 2,0 & 24,4 & 25,5 \\
$60-64$ & 37,5 & 1,5 & 18,1 & 19,4 \\
$65-69$ & 26,0 & 1,0 & 12,5 & 13,5 \\
70 y más & 33,8 & 1,4 & 15,9 & 17,9 \\
\hline
\end{tabular}

Fuente: Dirección General de Estadística y Censos en base a estimaciones del CELADE. 


$$
\leq x+2=
$$

Cuadro 9

HONDURAS: POBLACION URBANA Y RURAL POR DEPARTAMENTOS SEGUN CENSO DE 1961

\begin{tabular}{|c|c|c|c|c|c|c|}
\hline \multirow[b]{2}{*}{ Departamentos } & \multirow[b]{2}{*}{ Total } & \multirow[b]{2}{*}{ Urbana } & \multirow[b]{2}{*}{ Rural } & \multicolumn{3}{|c|}{ Por ciento } \\
\hline & & & & Total & Urbana & Rural \\
\hline Total & 1884765 & 437818 & 1446947 & 100,0 & 23,2 & 76,8 \\
\hline $\begin{array}{l}\text { Francisco Morazán } \\
\text { Atlántida } \\
\text { Colón } \\
\text { Comayagua } \\
\text { Copán } \\
\text { Cortés } \\
\text { Choluteca } \\
\text { ElParaíso } \\
\text { Gracias a Dios } \\
\text { Intibucá } \\
\text { Islas de la Bahía } \\
\text { La Paz } \\
\text { Lempira } \\
\text { Ocotepeque } \\
\text { Olancho } \\
\text { Santa Bárbara } \\
\text { Valle } \\
\text { Yoro } \\
\quad 1969^{*} \\
1975^{*} \\
1980^{*}\end{array}$ & $\begin{array}{r}284428 \\
92914 \\
41904 \\
96442 \\
126183 \\
200099 \\
149175 \\
106.823 \\
10905 \\
73138 \\
8961 \\
60600 \\
111546 \\
52540 \\
110744 \\
146909 \\
80907 \\
130547 \\
24949 \\
30691 \\
36609\end{array}$ & $\begin{array}{r}140375 \\
39645 \\
4499 \\
14.466 \\
12241 \\
106992 \\
17933 \\
13770 \\
- \\
6.027 \\
2844 \\
6533 \\
1854 \\
5702 \\
14048 \\
17101 \\
8119 \\
25669 \\
6648 \\
8906 \\
11284\end{array}$ & $\begin{array}{r}144.053 \\
53269 \\
37405 \\
81976 \\
113942 \\
93107 \\
131242 \\
93053 \\
10905 \\
67111 \\
6177 \\
54067 \\
109692 \\
46838 \\
96696 \\
129808 \\
72788 \\
104878 \\
18301 \\
21785 \\
2.5325\end{array}$ & $\begin{array}{l}100,0 \\
100,0 \\
100,0 \\
100,0 \\
100,0 \\
100,0 \\
100,0 \\
100,0 \\
100,0 \\
100,0 \\
100,0 \\
100,0 \\
100,0 \\
100,0 \\
100,0 \\
100,0 \\
100,0 \\
100,0 \\
100,0 \\
100,0 \\
100,0\end{array}$ & $\begin{array}{r}49,4 \\
42,7 \\
10,7 \\
15,0 \\
9,7 \\
53,5 \\
12,0 \\
12,9 \\
- \\
8,2 \\
31,7 \\
10,8 \\
1,7 \\
10,9 \\
12,7 \\
11,6 \\
10,0 \\
19,7 \\
26,6 \\
29,0 \\
30,8\end{array}$ & $\begin{array}{r}50,6 \\
57,3 \\
89,3 \\
85,0 \\
90,3 \\
46,5 \\
88,0 \\
87,1 \\
100,0 \\
91,3 \\
68,3 \\
89,2 \\
98,3 \\
89,1 \\
87,3 \\
88,4 \\
90,0 \\
80,3 \\
73,4 \\
71,0 \\
69,2\end{array}$ \\
\hline
\end{tabular}

* Estimaciones del CELADE.

Gráfico No 1

HONDURAS: POBLACION TOTAL SEGUN GRUPOS DE EDAD Y SEXO

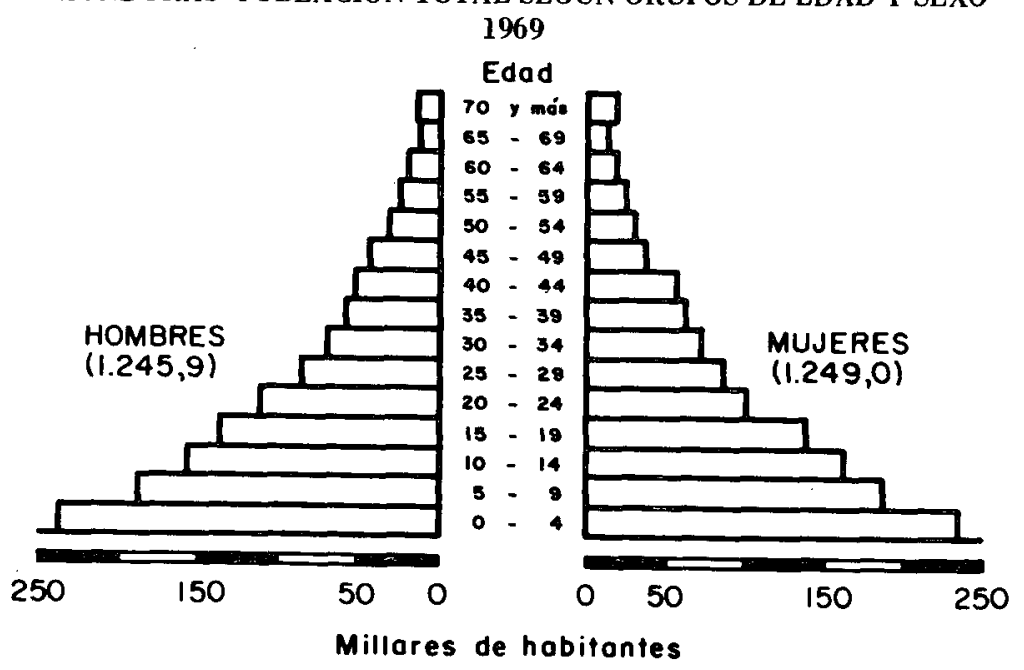

414 
ALGUNOS MODELOS SENGILLOS PARA

$\mathbb{E L}$ ANALISIS DE LAS

INTERDEPENDENCIAS ENTTRE LOS

CAMBBIOS ECONOMRCOS Y LOS

DEMOGRAFICOS

Lic. Eliézer Tijerina Garza Consejero Ejecutivo, Dirección de Estudios Económicos, Secretaria de la Presidencia, México 



\section{EL ANALISIS DE LAS INTERACCIONES DE LOS FACTORES ECONOMICOS Y DEMOGRAFICOS REGIONALES EN MEXICO}

Para analizar las interdependencias entre los factores económicos y demográficos regionales en México, se ha seleccionado el método de Análisis Factorial, en su acepción de Componentes Principales. $1 /$ El propósito de su aplicación es determinar la magnitud del bienestar económico por entidades federativas, mediante la consideración de variables representativas, del consumo de bienes privados y públicos y de la estructura económica, por una parte, y de los aspectos demográficos más relevantes, por la otra. Aunque ya el método se ha aplicado a 1960 y 1970 , se está desarrollando actualmente un análisis más exhaustivo con la información de 1960, que es más numerosa y en algunos aspectos más confiable.

\section{DESCRIPCION DEL METODO DE COMPONENTES PRINCIPALES}

Debido a la disponibilidad de los programas de cómputo electrónico para el método de Componentes Principales y tomando en cuenta la poca diferencia que existe con el Análisis Factorial (en su acepción clásica), se decidió trabajar con aquella variante.

El primer paso fue buscar la descripción del método adaptada a la elaboración de un índice de bienestar económico. De la literatura consultada 2 se utilizó la discusión de $\mathrm{F}$. V. Waugh, por ser la más cercana a nuestros propósitos. La exposición siguiente sigue muy de cerca a la de este autor, esperando que la discusión detallada del método, contribuya a su mayor difusión.

1/ La comparación de ambos métodos y una aplicación para medir el bienestar colectivo estatal y sus relaciones con el desarrollo agrícola y la política económica en México, se puede consultar en: Tijerina Garza, E., Aspectos regionales del desarrollo agrícola mexicano, bienestar económico y acción pública, 1940-1960. Trabajo inédito presentado en el Research Workshop on Problems of Agricultural Development in Latin America, Caracas, Venezuela, mayo 17-19, 1971, organizado por The Ford Foundation.

2/ Algunas obras importantes son: H.H. Harman, Modern Factor Analysis, University of Chicago Press, Chicago, 1970. M.G. Kendall "Factor Analysis as a Statistical Technique", en Journal of the Royal Statistical Society, Serie B, 1961. G. Tintner, Econometrics, J. Wiley, N. York, 1965. F.V. Waugh, "F actor Analysis Some Basic Principles and An Application", Agricultural Economics Research, July, 1962. 
El propósito principal de la aplicación del análisis de Componentes Principales al caso de México en 1940, 1950, 1960 y 1970, es determinar: a) ¿cuánto vale el índice de bienestar económico estatal?, b) ¿qué interdependencias existen entre las variables económicas generales, las demográficas y las representativas de la disposición de los servicios públicos?, c) ¿̨cuál es su dinámica espacial y temporal? y d) ¿qué se puede decir del impacto de las diferentes partidas del gasto público incluidas en el análisis? Procederemos enseguida a exponer, paso a paso, el método estadístico de referencia.

Para simplificar la exposición, se supondrán tres variables únicamente. Tenemos pues:

\section{1) $I=k+b_{1} X_{1}+b_{2} X_{2}+b_{3} X_{3}$}

Donde $k$ y las $b_{i}$, son constantes que se estimarán. $I$ es el indice que se quiere medir, y las $X_{i}$ son las variables observadas.

Si especificamos el índice para los valores promedio de las variables conocidas tenemos:

2) $\bar{I}=k+b_{1} \bar{X}_{1}+b_{2} \bar{X}_{2}+b_{3} \bar{X}_{3}$

Donde $\bar{X}_{i}$ son las medias aritméticas de $X_{i}$.

Si deducimos 2) de 1):

$I-\bar{I}=b_{1}\left(X_{1}-\bar{X}_{1}\right)+b_{2}\left(X_{2}-\bar{X}_{2}\right)+b_{3}\left(X_{3}-\bar{X}_{3}\right)$

y definimos:

$$
i=I-\bar{I}, \text { y } X_{i}^{d}=X_{i}-\bar{X}_{i}
$$

obtenemos:

3) $\quad i=b_{1}\left(X_{1}^{d}\right)+b_{2}\left(X_{2}^{d}\right)+b_{3}\left(X_{3}^{d}\right)$

Como las variables empleadas en nuestro caso están medidas en diferentes unidades, se estandarizaron para hacerlas comparables y evitar así los problemas introducidos por unidades distintas en la medición de la variancia total. Con tal efecto, se dividieron las $X_{i}^{d}$ por sus desviaciones estándar:

4) $i_{Z}=w_{1} Z_{1}+w_{2} Z_{2}+w_{3} Z_{3}$

Donde $Z_{i}$ son las variables estandarizadas y $W_{i}$ las nuevas ponderaciones. Se está en condiciones ahora de definir el objetivo del análisis. 
5) Maximizar la variancia de $i_{Z}=\frac{1}{n} \Sigma i_{Z}^{2}$

$$
\begin{aligned}
=\frac{1}{n} \sum\left(W_{I}^{2} Z_{1}^{2}\right. & +2 W_{1} W_{2} Z_{1} Z_{2}+2 W_{1} W_{3} Z_{1} Z_{3}+W_{2}^{2} Z_{2}^{2} \\
& \left.+2 W_{2} W_{3} Z_{2} Z_{3}+W_{3}^{2} Z_{3}^{2}\right)
\end{aligned}
$$

Como el coeficiente de correlación simple puede considerarse como la suma de productos de dos variables estandarizadas (es decir, deduciendo sus medias y dividiéndolas entre sus desviaciones estándar, para hacer el coeficiente independiente del origen y de la escala) dividida entre el número de observaciones, tenemos:

6) $r_{i j}=\frac{I}{n} \frac{\Sigma\left(X_{i}-\bar{X}_{i}\right)\left(X_{j}-\bar{X}_{j}\right)}{S_{i} S_{j}}$

donde $S_{i}$ y $S_{j}$ son las desviaciones estándar de $X_{i}$ y $X_{j}$.

De acuerdo con la definición de las $Z_{i}$

7) $r_{i j}=\frac{1}{n} \Sigma Z_{i} Z_{j}$

Cuando $i=j$, tenemos:

8) $r_{i i}=\frac{1}{n} \Sigma\left(Z_{i}\right)^{2}=\frac{\Sigma\left(X_{i}-\bar{X}\right)\left(X_{i}-\bar{X}\right)}{n S_{x i} S_{x i}}$

$$
\begin{aligned}
& =\frac{\sum\left(X_{i} \cdot \bar{X}\right)^{2}}{n} \frac{1}{S_{x i}^{2}} \\
& =\frac{S_{x i}^{2}}{S_{x i}^{2}}=1
\end{aligned}
$$

Si se eleva al cuadrado la ecuación 4), obtenemos:

9) $i^{2}=\left(W_{1} Z_{1}+W_{2} Z_{2}+W_{3} Z_{3}\right)\left(W_{1} Z_{1}+W_{2} Z_{2}+W_{3} Z_{3}\right)$

$$
\begin{aligned}
=W_{1}^{2} Z_{1}^{2} & +2 W_{1} W_{2} Z_{1} Z_{2}+2 W_{1} W_{3} Z_{1} Z_{3}+W_{2}^{2} Z_{2}^{2} \\
& +2 W_{2} W_{3} Z_{2} Z_{3}+W_{3}^{2} Z_{3}^{2}
\end{aligned}
$$

* En adelante, con el fin de simplificar la notación, $i$, cuando represente el indice de bienestar, será empleado en lugar de $i_{z}$. 
10) Sumando y dividiendo entre $n$, obtenemos:

$$
\begin{aligned}
\frac{1}{n} \Sigma\left(w_{1}^{2} Z_{1}^{2}\right. & +2 W_{1} W_{2} Z_{1} Z_{2}+2 W_{1} W_{3} Z_{1} Z_{3}+W_{2}^{2} Z_{2}^{2} \\
& \left.+2 W_{2} W_{3} Z_{2} Z_{3}+W_{3}^{2} Z_{3}^{2}\right)
\end{aligned}
$$

Considerando 6), 7) y 8) y haciendo operaciones con 10)

$$
\begin{aligned}
W_{1}^{2} \frac{1}{n} \Sigma Z_{1}^{2} & +2 W_{1} W_{2} \frac{1}{n} \Sigma Z_{1} Z_{2}+2 W_{1} W_{3} \frac{1}{n} \Sigma Z_{1} Z_{3} \\
& +W_{2}^{2} \frac{1}{n} \Sigma Z_{2}^{2}+2 W_{2} W_{3} \frac{1}{n} \Sigma Z_{2} Z_{3} \\
& +W_{3}^{2} \frac{1}{n} \Sigma Z_{3}^{2}
\end{aligned}
$$

11)

$$
W_{1}^{2}+2 r_{12} W_{1} W_{2}+2 r_{13} W_{1} W_{3}+W_{2}^{2}+2 r_{23} w_{2} W_{3}+w_{3}^{2}
$$

Por lo tanto maximizar 11) es lo mismo que maximizar la variancia del índice (ecuación 5).

Es preciso introducir una restricción a la maximización de 11), pues de otra manera podría incrementarse sin límite, simplemente incrementando las ponderaciones.

En consecuencia el problema es maximizar la variancia del indice con la condición lateral $\Sigma w_{i}^{2}=1$. Esta restricción significa, como se verá en 15), que la transformación lineal es normalizada.

12) $\operatorname{Max} V \lambda=w_{1}^{2}+2 r_{12} W_{1} W^{2}+2 r_{13} w_{1} w_{3}+W_{2}^{2}+2 r_{23} w_{2} w_{3}$

$$
+W_{3}^{2}-\lambda\left(W_{1}^{2}+W_{2}^{2}+W_{3}^{2}-1\right)
$$

Condiciones necesarias para el valor extremo:

$$
\begin{aligned}
\frac{\partial V \lambda}{\partial W_{1}} & =2 W_{1}+2 r_{12} W_{2}+2 r_{13} W_{3}-2 \lambda W_{1}=0 \\
\frac{\partial V \lambda}{\partial W_{2}} & =2 r_{12} W_{1}+2 W_{2}+2 r_{23} W_{3}-2 \lambda W_{2}=0 \\
\text { 13) } \frac{\partial V \lambda}{\partial W_{3}} & =2 r_{13} W_{1}+2 r_{23} W_{2}+2 W_{3}-2 \lambda W_{3}=0
\end{aligned}
$$




$$
\frac{\partial V \lambda}{\partial \lambda}=W_{1}^{2}-W_{2}^{2}-W_{3}^{2}-1=0
$$

Dividiendo las tres primeras ecuaciones por 2 y despejando $\lambda W_{i}$ :

14) $W_{1}+r_{12} W_{2}+r_{13} W_{3}=\lambda W_{1}$

$r_{12} W_{1}+W_{2}+r_{23} W_{3}=\lambda W_{2}$

$r_{13} W_{1}+r_{23} W_{2}+W_{3}=\lambda W_{3}$

Desde luego, $\Sigma W_{i}^{2}=1$ debe también cumplirse.

Estas condiciones necesarias pueden expresarse alternativamente -obteniendo factores comunes-:

15) $(1-\lambda) W_{1}+r_{12} W_{2}+r_{13} W_{3}=0$

$r_{12} W_{1}+(1-\lambda) W_{2}+r_{23} W_{3}=0$

$r_{13} W_{1}+r_{23} W_{2}+(1-\lambda) W_{3}=0$

nos define una transformación lineal normalizada de $W_{1}^{2}+W_{2}^{2}+W_{3}^{2}-1=0$ las variables iniciales en valores factoriales no correlacionados.

Esto es, en forma matricial:

$(R-\lambda I)(W)=0$

Se especifica asi un sistema de cuatro ecuaciones con cuatro incógnitas: $W_{1}, W_{2}, W_{3}$ y $\lambda$. Las tres primeras ecuaciones del 15), al ser un sistema sin constantes independientes diferentes de cero conocidas, es homogéneo, por lo que se resuelve iterativamente, y, en general, las soluciones no son únicas.

Esta es la razón por la cual los $\lambda_{i}$ no son únicos ni, en consecuencia, los vectores asociados a ellos (es decir, las ponderaciones). Sin embargo, se puede demostrar que el primer eigenvalue $\rightarrow$ y su vector asociado- es cl que contribuye a explicar más la variancia del índice. (Ver los escritos de Kendall mencionados en la bibliografía). Consecuentemente, se puede hacer el análisis con el primer eigenvalue $\left(\lambda_{1}\right)$ y sus ponderaciones asociadas, o bien, considerar los más importantes, dependiendo de la magnitud de la variancia que se intenta explicar y de la bondad de los resultados estadísticos. (Posteriormente, se menciona el criterio empleado en este estudio).*

* Para simplificar la interpretación de los distintos componentes es recomendable rotar la matriz de componentes, buscando que dentro de cada componente quede un número reducido de variables con ponderaciones significativas. 
Las condiciones suficientes se definen por la matriz Hessiana, que debe ser negativa definida. Esto significa que los elementos de la diagonal principal deben ser negativos, lo que implica que las soluciones $\left(\lambda_{i}\right)$ que satisfagan la función objetivo deben ser mayores que uno.

16) $\left[\begin{array}{lll}1+\lambda & r_{12} & : r_{13} \\ r_{12} & 1-\lambda & r_{23} \\ r_{13} & r_{23} & 1-\lambda\end{array}\right]$

Con el propósito de encontrar una interpretación de $\lambda$, sumamos las ecuaciones 14) multiplicándolas previa y respectivamente por $W_{1}, W_{2}$, y $W_{3}$, obtenemos:

17) $W_{1}^{2}+r_{12} w_{1} w_{2}+r_{13} w_{1} w_{3}=\lambda w_{1}^{2}$

$$
\begin{aligned}
& r_{12} w_{1} w_{2}+w_{2}^{2}+r_{23} w_{2} w_{3}=\lambda W_{2}^{2} \\
& r_{13} w_{1} w_{3}+r_{23} w_{2} w_{3}+w_{3}^{2}=\lambda W_{3}^{2}
\end{aligned}
$$

18) Sumándolas, obtenemos:

$$
\begin{aligned}
W_{1}^{2} & +2 r_{12} W_{1} W_{2}+2 r_{13} W_{1} W_{3}+2 r_{23} W_{2} W_{3}+W_{2}^{2} \\
& +W_{3}^{2}=\lambda\left(\Sigma W_{i}^{2}\right)
\end{aligned}
$$

pero, de acuerdo con 11), el lado izquierdo de 18) es precisamente la variancia de $i$, observando la restricción $\Sigma W_{i}^{2}=1$, por lo tanto:

19) $\lambda=$ variancia de $i$

Para encontrar las correlaciones entre las variables y el índice, se procede asi:

\section{0) Definición del índice $i$}

$i=W_{1} Z_{1}+W_{2} Z_{2}+W_{3} Z_{3}$

Multiplicando $i$ sucesivamente por $Z_{1}, Z_{2}$ y $Z_{3}$ 
21) $i Z_{1}=W_{1} Z_{1}^{2}+W_{2} Z_{1} Z_{2}+W_{3} Z_{1} Z_{3}$

$i Z_{2}=W_{1} Z_{1} Z_{2}+W_{2} Z_{2}^{2}+W_{3} Z_{2} Z_{3}$

$i Z_{3}=W_{1} Z_{1} Z_{3}+\mathbb{W}_{2} Z_{2} Z_{3}+W_{3} Z_{3}^{2}$

puede expresarse de acuerdo con 11):

22) $\frac{1}{n} \sum i Z_{1}=\mathbb{W}_{1}+W_{2} r_{12} * \mathbb{W}_{3} r_{13}$

$\frac{1}{n} \Sigma i Z_{2}=W_{1} r_{12}+W_{2}+W_{3} r_{23}$

$\frac{1}{n} \Sigma i Z_{3}=W_{1} r_{13}+W_{2} r_{23}+W_{3}$

La suma de las tres ecuaciones anteriores es igual a $\lambda W_{1}+\lambda W_{2}+\lambda W_{3}$, de acuerdo con las condiciones necesarias.

Dividiendo por $\sqrt{\lambda}$ cada ecuación de 19) (las $Z_{i}$ tienen como desviación estándar la unidad):

23)

$$
\begin{aligned}
& \frac{W_{1}+W_{2} r_{12}+W_{3} r_{13}}{\sqrt{\lambda}}=\frac{\lambda W_{1}}{\sqrt{\lambda}} \equiv \sqrt{\lambda} W_{1}=\frac{1}{n} \Sigma \frac{i}{\sqrt{\lambda}} Z_{1} \\
& \frac{W_{112} W_{2} W_{323}}{\sqrt{\lambda}}=\frac{\lambda W_{2}}{\sqrt{\lambda}} \equiv \sqrt{\lambda} W_{2} \frac{1}{n} \Sigma \frac{i}{\sqrt{\lambda}} Z_{2} \\
& \frac{W_{113} W_{223} W_{3}}{\sqrt{\lambda}}=\frac{\lambda W_{3}}{\sqrt{\lambda}} \equiv \sqrt{\lambda} \mathbb{W}_{3}=\frac{1}{n} \Sigma \frac{i}{\sqrt{\lambda}} Z_{3}
\end{aligned}
$$

Para encontrar:

24) $r Z_{1} i=\sqrt{\lambda} W_{1}$, y asi para $2, \mathrm{y} 3$

De 24) sabemos que las ponderaciones, $W_{i}^{2}$, son iguales a la proporción de la variancia total representada por el coeficiente de determinación, $r Z_{i} 2_{i}$, con respecto a la variable estandarizada $i$ y el índice.

Es decir,

25) $w_{i}=\frac{r Z i i}{\sqrt{\lambda}}$ 


$$
w_{i}^{2}=\frac{r i^{2} i}{\sqrt{\lambda}}
$$

La suma de las correlaciones cuadradas, de 25),

26) $\Sigma r^{2} Z i i=\Sigma \lambda W_{i}^{2} \equiv \lambda \Sigma W_{i}^{2}$

como se encontró por la restricción, $\Sigma w_{i}^{2}=1$, por lo tanto:

27) $\lambda=\Sigma r^{2} Z i i$

Esto es, que el multiplicador de Lagrange es también igual a la suma de las correlaciones cuadradas entre el índice y las variables estandarizadas.

Para el diseño de la escala del índice se procedió de acuerdo con Waugh:

28) $I=\frac{W_{1}}{S_{1}} \quad X_{1}^{d}+\frac{W_{2}}{S_{2}} \quad X_{2}^{d}+\frac{w_{3}}{S_{3}} \quad X_{3}^{d}$

Donde $S_{i}$ son las desviaciones estándar, y $X_{1}^{d}=X_{i}-\bar{X}_{i}$

Se sustituyó en 28) las $X_{i}^{d}$ por las $X$ correspondientes al país, y el valor del índice así obtenido se hizo igual a 100 (para así referir los índices de las entidades a esta base común).

29) $I^{n}=\frac{W_{1}}{S_{1}} X_{1}^{n}+\frac{W_{2}}{S_{2}} X_{2}^{n}+\frac{W_{3}}{S_{3}} X_{3}^{n}$

Donde $I^{n}=$ valor del indice nacional

$X_{i}^{n}=$ variables de bienestar correspondientes al país.

A continuación se modificaron las ponderaciones para lograr la referencia de los indices estatales al valor del indice nacional:

$$
\begin{aligned}
& I \frac{100}{I^{n}}=\frac{W_{1}}{S_{1}} \quad \frac{100}{I^{n}} X_{1}+\frac{W_{2}}{S_{2}} \frac{100}{I^{n}} X_{2} \\
& +\frac{W_{3}}{S_{3}} \cdot \frac{100}{I^{n}} X_{3}
\end{aligned}
$$


O sea:

30) $I^{l}=\frac{W_{1}}{S_{1}} k X_{1}+\frac{W_{2}}{S_{2}} k X_{2}+\frac{W_{3}}{S_{3}} k X_{3}$

Donde $\quad I^{I}=I \frac{I 00}{I^{n}} \quad I k$

De esta manera, el índice es 100 para los valores nacionales y cero para las entidades que observaron ceros en cada variable del bienestar.

Una vez que se ha expuesto el método de análisis indicado para el estudio de las interacciones demográficas y económic as, en el tiempo y en el espacio, conviene precisar algunas relaciones importantes. Los vectores normalizados de los componentes principales pueden ser convertidos en la estructura factorial (factor pattern) de la manera siguiente:

31) $A i j=W_{i j} \lambda_{j}$

Donde, $A$ ij es el elemento $i$ del factor $j$

Wij es el elemento $i$ del componente principal $j$

$\lambda j$ es la raiz característica correspondiente al componente principal $i$

Además

32) $A i j=r_{i j}$, que es el coeficiente de correlación simple entre la variable $i$ y el factor $j$.

La llamada comunalidad, que expresa la proporción de la variancia total de la variable $i$ explicada por el conjunto de factores $j$ es:

33) $\Sigma^{p} A i j^{2}=h i^{2}$

$$
j=1
$$

Asimismo, es posible retornar a la expresión de las variables estandarizadas, en términos de los puntajes de los factores (factor scores):

34) $Z j i=A j 1 F I i+A j 2 F 2 i+A j 3 F 3 i$

Donde $A i l$ es el coeficiente factorial del factor $1 ; F l$, es el puntaje o valor factorial (factor score) para el Estado $i$ en el primer factor. Por último el valor o puntaje factorial se obtiene asi: 
35) $F 1 i=A 11 Z 1 i+A 21 Z 2 i+\ldots \ldots \ldots+A p i Z p i$

Para concluir la discusión, el problema de la selección de variables de análisis será abordado a la luz de las conclusiones de I. Adelman y C.T. Morris. 3 /

3/ I. Adelman and C. T. Morris, Society, Politics and Economic Development. A Quantitative Approach, The Johns Hopkins University Press, Baltimore, 1967, pp. 145-146. 


\section{EL DESARROLLO ECONOMICO GLOBAL Y EL CRECIMIENTO DE LA PRODUCCION Y OCUPACION SECTORIALES}

En esta sección se describirá un modelo sencillo para el análisis y proyecciones de la producción y ocupación sectoriales. El esquema analítico ha sido diseñado tomando en cuenta las grandes deficiencias existentes en las estadísticas actuales de empleo de los factores productivos (especialmente de la mano de obra) y de los pagos a los factores productivos (en particular de los salarios). Asimismo, se han considerado las dificultades de especificación de las funciones de producción agregadas y de la naturaleza del cambio tecnológico.

El modelo siguiente opera enlazado a un modelo macroeconómico de la economía mexicana; en éste se determina el nivel del producto bruto interno $\mathrm{y}$ de sus componentes externos $\mathrm{e}$ internos básicos. A continuación se expone el modelo sectorial.

1) $\log _{P E A^{t}}=\partial P B I^{b}{ }_{t}(1+\lambda)$

2) $P E A^{s} \equiv P E A^{t}-P E A^{a g}-P E A^{i}$

3) $P E A^{a g} \equiv P B I^{a g} \div P B I^{a g} / P E A^{a g}$

4) $P E A^{i} \equiv P B I^{i} \div P B I^{i} / P E A^{i}$

5) $P B I^{a g} / P E A^{a g}=a+b \log P B I$

6) $\log P B I^{i} / P E A^{i}=a+b \log P B I$

7) $P B I^{a g} \equiv\left(P B I^{a g} / P B I^{t}\right) P B I^{t}$

8) $P B I^{a g} / P B I^{t}=\frac{1}{a+b P B I}$

9) $P B I^{i} \equiv \frac{P B I^{i}}{P^{i} I^{t}} P B I^{t}$

10) $\frac{P B I^{i}}{P B I^{t}}=a+b \log P B I$

11) $P B I^{s} \equiv P B I^{t}-P B I^{a g}-P B I^{i}$ 
donde
$P E A^{t}$ población económicamente activa total
$P B I$ produc to bruto interno total
$P E A^{a g}$ población económicamente activa en el sector agropecuario
$P E A^{s}$ población económicamente activa en el sector servicios
$P E A^{i}$ población económicamente activa en el sector industrial
$P B I^{a g}$ producto bruto interno por persona económicamente
$P E A^{a g}$ activa en el sector agropecuario
$P B I^{i}$ producto bruto interno por persona económicamente
$\overline{P E A^{i}}$ activa en el sector industrial
$P B I^{a g}$ proporción que representa el producto bruto interno
$\overline{P B I}$ agropecuario del producto interno total
$\underline{P B I^{i}}$ proporción que representa el producto bruto interno
$\frac{P B I^{t}}{}$ industrial del producto bruto interno total
$P B I^{S} \quad$ producto bruto interno del sector servicios
$P B I^{i} \quad$ producto bruto interno del sector industrial
$P B I^{\text {ag }}$ producto bruto interno del sector agropecuario.

El modelo anterior capta las tendencias sectoriales de largo plazo, proporcionando un elemento de juicio para la evaluación de las disparidades sectoriales que, en general, se observan en América Latina. Actualmente, en la Dirección de Estudios Económicos de la Secretaría de la Presidencia, se dispone de modelos más sofisticados, en los cuales se emplea la programación lineal y el esquema de insumo-producto. 


\section{EL ANALISIS ESTADISTICO DE LOS CAMBIOS REGIONALES Y SECTORIALES EN LA OCUPACION DE LA MANO DE OBRA 4}

Un modelo simple, útil en el análisis de los componentes sectoriales y regionales de la ocupación de mano de obra, es el siguiente.

Supongamos que se desea analizar el cambio en la ocupación sectorial por regiones:

1) $P E A_{i j}^{*}-P E A_{i j}$

Donde $P E A_{i j}^{*}$ es la población económicamente activa del sector $i$ región $j$ en el año final del período de tiempo estudiado. $P E A_{i j}$ es esta misma variable, sólo que en el año inicial.

El cambio registrado en la ecuación 1) puede examinarse a la luz de la siguiente identidad:

$$
\text { 2) } \begin{aligned}
& P E A_{i j}^{*}-P E A_{i j}=P E A_{i j}\left(\frac{P E A^{*} . .-P E A \ldots}{P E A}\right) \\
& +P E A_{i j}\left(\frac{P E A_{i .}^{*}-P E A_{i .}}{P E A_{i .}}-\frac{P E A^{*} \ldots-P E A \ldots}{P E A \ldots}\right) \\
& +P E A_{i j}\left(\frac{P E A_{i j}^{*}-P E A_{i j}}{P E A_{i j}}-\frac{P E A_{i .}^{*}-P E A_{i .}}{P E A_{i .}}\right)
\end{aligned}
$$

Las variables con asterisco corresponden al año final del periodo y las que no lo tienen al inicial. $P E A$.. es la población económicamente activa total nacional, $P E A_{i}$ es la correspondiente al sector $i$ en el país.

En el análisis de los componentes del cambio ocupacional, es conveniente definir el primer elemento a la derecha de la ecuación 2):

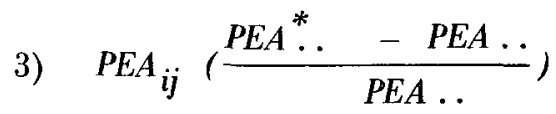

4/ La bibliografía relacionada con este método puede encontrarse en E. Tijerina G., The Components of Change in the Value of Agricultural Production in México, 1940-1950, 1950-1960, 1960-1963, M.S.

Thesis, lowa State University, Department of Economics, Amex, 1970. 
Este componente se define como crecimiento nacional, y representa el crecimiento hipotético de la región $j$ debido al sector $i$, en el supuesto de que la tasa de crecimiento de este sector fuera idéntica a la observada como promedio en el país. Es decir, corresponde al caso en el cual existe semejanza completa en los crecimientos sectoriales y regionales. La contribución total de este componente a la región $j$ está definida por la $\Sigma$.

Para determinar los indicadores de especialización ocupacional, se define el segundo componente, denominado composición de la ocupación:

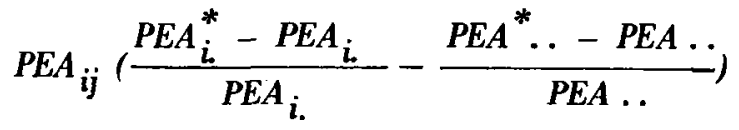

Esto nos permite determinar si la ocupación regional recibe beneficios o perjuicios debido a la estructura de la ocupación. Si la región está especializada en sectores productivos con dinámica ocupacional más acelerada en el pats, la ocupación de esta región se incrementará en mayor medida, y a la inversa. De manera que si $\sum_{i}$ es mayor que cero, la región tendrá ventajas ocupacionales debido a especialización productiva, y a la inversa.

En seguida, se define el componente participación regional:

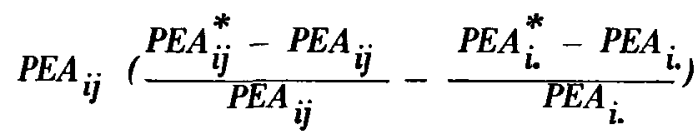

Este indicador define el crecimiento ocupacional regional, en términos del crecimiento diferencial en cada sector en la región con relación a su correspondiente en el país. La interpretación de las cifras resultantes en un país con mayor perfección en el mercado de trabajo que la prevaleciente en América Latina, es radicalmente distinta. Por ejemplo, si la $\sum_{i}$ es mayor que cero, en un país desarrollado con baja desocupación crónica, se puede colegir que la región tiene ventajas comparativas en los sectores para los cuales el efecto aquí medido es positivo; si es menor que cero, la interpretación sería lógicamente la contraria. Esta interpretación no es válida cuando existe desempleo y subempleo crónicos. En este caso, el mayor incremento de la ocupación regional debido a mayores incrementos sectoriales $\mathbf{y}$ regionales en relación con los nacionales, puede indicar, en vez de un mejoramiento, un empeoramiento en las condiciones ocupacionales. Obviamente, si se contara con cifras fidedignas de desocupación, este problema no 
existiría. En las circunstancias prevalecientes en México, es indispensable complementar el análisis aquí expuesto con el relativo a la productividad y los ingresos sectoriales y regionales.

Para determinar si el crecimiento ocupacional regional en el sector es más rápido, igual o más lento, que el crecimiento de la ocupación total en el pais, se define el componente crecimiento neto relativo. Este es igual a la suma de los componentes composición de la ocupación y participación regional.

Finalmente, es posible definir, de acuerdo con el valor algebraico del crecimiento neto relativo, si la entidad es ascendente, descendente o proporcional según sea mayor, menor o igual a cero, respectivamente. Asimismo, el signo de la participación regional determinará si el crecimien to ocupacional regional es rápido, proporcional o lento. 
$+$

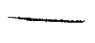


OBJETIVOS DE LAS POLITICAS DE

DESARROLLO ECONOMICO

Lic. Luis de Pablo Serna

Jefe, Departamento de Planeación de la Dirección de Estudios Económicos, Secretaria de la Presidencia,

México 


\section{INTRODUCCION}

Puede afirmarse que los lineamientos y objetivos básicos de la política económica del Ejecutivo constituyen una nueva estrategia global de desarrollo cuya orientación esencial radica en conseguir una participación más equitativa de la población del país en los beneficios del crecimiento económico.

Este propósito orienta las medidas de política económica que han de tomarse; su realización supone el uso más racional y eficiente de todos nuestros recursos humanos y naturales, la multiplicación y eficacia de los instrumentos de que se dispone y la coordinación de todos quienes participan en la tarea del desarrollo. Por ello surge la necesidad de investigar cuáles son y cómo surgieron los factores determinantes del tipo y nivel de desarrollo que nos caracteriza, cuál ha sido la tendencia del comportamiento de tales factores y cuál será el comportamiento futuro de los mismos si evaluamos las modificaciones resultantes de la implantación de políticas por la actual Administración.

El presente proyecto tiene como objetivo fundamental el proponer las bases de un análisis que permita evaluar la eficacia de los instrumentos de política disponibles en función de las metas señaladas por el Presidente.

Las características más relevantes de este estudio son: su generalidad y su pragmatismo. En cuanto a la primera, la modernización y el desarrollo del país, incluyen aspectos tanto económicos como políticos y sociales; tomaremos una perspectiva que incluy a a estos ámbitos hasta donde sea posible, lo cual a su vez impone un criterio de selección en los elementos que deben ser observados. Respecto a la segunda, se pretende analizar el desarrollo del país para presentar recomendaciones prácticas que enriquezcan los elementos de juicio necesarios en el trazo de políticas.

En términos generales, se acostumbra definir al desarrollo económico tanto como un incremento sostenido de la producción real per cápita, como cualquier aumento en el ingreso real por persona, sin que importe la fuente de la cual proviene tal aumento. Ambas perspectivas tienen la misma limitación: se trabaja con medidas de tendencia central, las cuales dicen bastante poco acerca del rango y distribución del producto entre la población, además del sesgo que se introduce al medir valores afectados por las condiciones de mercado, subestimándose la producción de sectores poco comercializados o de subsistencia. 
Puede también caracterizarse el desarrollo comparando el ingreso per cápita con ciertas variables de contenido social y político, en diferentes épocas en un mismo país o entre diferentes países; a partir de los resultados de estas comparaciones se infieren ciertas peculiaridades que tipifican a un grupo de países como desarrollados y a otros que no lo son. La limitación de esta última perspectiva radica en la base de su construcción: es esencialmente descriptiva, en sí no contiene los elementos que permiten integrar un sistema conceptual que defina univocamente al desarrollo.

Todo lo anterior junto con la necesidad de aportar sugerencias viables, invitan a recapitular el tratamiento del concepto desarrollo.

Suponemos que existen componentes básicos en todo sistema económico que de una u otra manera intervienen en el procesode desarrollo, éstos son: el nivel de pobreza, la desocupación y el subempleo, el grado de desigualdad (social, cultural y política), y el patrón de distribución del ingreso. Estos componentes, o variables básicas, no sufren alteraciones drásticas en corto plazo, y permiten suponer ciertos patrones de interdependencia entre ellos. La hipótesis que proponemos es que un cierto "arreglo" de las interdependencias corresponde, si no al proceso de desarrollo mismo, si al menos a un proceso para-desarrollista. Esto es: un programa gubernamental que disminuya efectivamente los índices de pobreza, de sub o desempleo, de desigualdad, y que logre un reparto más equitativo de ingreso, estará operando con una orientación al desarrollo, aun cuando el ingreso nacional no muestre alteraciones significativas. Podemos decir que trabajar en este sentido proporciona el "potencial" básico de cualquier pauta de desarrollo que se desee.

Tal hipótesis es consistente también con la necesidad de lograr un marco político que soporte las nuevas decisiones que se tomen en función del desarrollo. Es decir, un sistema económico con un gran número de desocupados, con grandes desigualdades sociales $\mathbf{y}$ con poblaciones marginales viviendo en la mịseria, nunca podrá proveer una base firme para los derechos políticos y para el orden civil. A su vez, éstos últimos son condición necesaria pero no suficiente para la efectividad de las decisiones concernientes a la nueva orientación de política económica gubernamental; es necesario asociarles criterios que optimicen la relación instrumento-objetivos dentro del marco de tal política económica.

Una vez propuesto lo anterior, podemos pasar a la conceptualización de las variables que hemos referido, señalando que de ninguna manera agotan por sí solas el ámbito de la definición del desarrollo; fueron escogidas justamente para incluir "al menos" los componentes mínimos en una definición de tal naturaleza. 


\section{Pobreza}

La necesidad básica que se presenta es la de abastecerse de comida suficiente, es decir, alimentos. Es un hecho comprobado que bajo ciertos niveles de nutrición, en el caso de los adultos no puede esperarse ni buena salud, ni fortaleza física ni capacidad de trabajo, en el caso de los niños, un mal régimen nutricional, sobre todo en los primeros años, causa perjuicios irreparables no sólo físicos sino mentales. En este renglón deben incluirse también los indicadores de calzado y vestido, así como el tipo de vivienda, condiciones de sanidad e higiene.

\section{Desocupación y subempleo}

Otra de las necesidades básicas que debe satisfacer un individuo (quizá de tipo psicológico y seguramente de tipo social) es cumplir un rol funcional, cualquiera que éste sea. La mayoría de las veces dicho rol es institucional y puede ser concebido como una ocupación o un empleo (contractual) pero también deben ser incluidos los trabajadores que laboran por cuenta propia.

\section{Distribución del ingreso}

La distribución del ingreso se concibe como la liga directa entre el ingreso per cápita y el número de gentes que viven en pobreza.

Generalmente, por los reducidos cambios en este factor, se le considera como una constante dentro de ciertos límites de tiempo. Sin embargo, en el caso de México, las oscilaciones en la distribución del ingreso han sido bastante significativas y su comportamiento invita a incluirlo como una variable que refleja, en parte, el tipo de participación en los beneficios del crecimiento económico.

\section{Estructura de desigualdades}

Por último vamos a referirnos a la estructura de desigualdades que presenta el país, básicamente en cuanto a patrones culturales, políticos y sociales. En el primer caso (patrones culturales) podemos referirnos al alfabetismo, al nivel educativo alcanzado, al tipo de lenguas o dialecto que se hable y a la filiación religiosa. En cuanto al aspecto político debemos atender a la participación política mediante el voto y a todas aquellas de tipo formal, tales como la filiación sindical y la participación en partidos políticos. Por último, en cuanto a las desigualdades sociales podemos referir al tipo de tareas ocupacionales que se desempeñan y el status asociado a ellas, al tipo de fuente de los ingresos, categorías de localización ecológica, tipología de la estructura familiar, movilidad social (vertical) experimentada, movilidad 
horizontal, participación de servicios sociales comunitarios, participación de la información a través de los medios de comunicación, etc. indicadores todos encaminados a señalar el tipo de desigualdades existentes bajo las variables propuestas. 


\section{POBREZA}

La primera variable a la que nos vamos a referir, la pobreza, tiene como una característica importante su dependencia a un marco referencial. Muchas veces al hablar de un tipo específico de pobreza, o de pobreza en gemeral, nos estamos refiriendo en realidad a la necesidad que existe -con respecto a un marco de referencia o dentro de un contexto especifico- de ciertos elementos escasos. Así, en un contexto urbano o en un país desarrollado el poseer televisión a automóvil puede significar una necesidad importante cuya falta puede relacionarse con pobreza física. En una comunidad aislada los mismos artículos son altamente prescindibles y para hablar de pobreza física hay que referirse, por ejemplo, a lo adecuado del habitat, al tipo de alimentación, o a la existencia de instalaciones sanitarias domésticas.

Esta manera de concebir la pobreza nos permite hablar de ella como una necesidad manifiesta (sentida) la cual se objetiviza en un individuo justamente al entrar en contacto con cierto grupo de referencia, antes de lo cual no existia tal necesidad. Sin embargo, la pobreza asi definida sería exclusivamente un fenómeno de tipo social y su alcance conceptual -al depender de un marco relativo- resultaria muy restringido; frente a esta limitación, es posible hablar también de pobreza con respecto a ciertos indicadores absolutos en los cuales es posible discinguir ciertas prioridades y límites básicos que satisfacer.

Talles prioridades y sus límites correspondientes constituyen un continum jeraryuizado de tal forma que, partiendo de necesidades exclusivarnente físico-biológicas, puede llegar a ser tan complejo y sofisticado que incluya necesidades de tipo social y cultural; estas úlcimas, prescindibles desde el punto de vista del compromiso frísico-biológico inicial.

Por otro lado, all tratar a la pobreza como variable, es necesario proponer un índice que logre medir el grado de pobreza de una problación y que permita además efectuar comparaciones en tiempo y espacio. $\underline{1} / \mathbb{E s}$ aqui donde pueden surgir algunos problemas de tipo metodológico: cuando se utiliza el ingreso económico como un

$\mathbb{1} /$ James Wilkie propone un índice de pobreza para México construido a partir de siete íterns censales: a) analfabetos, b) quienes hablan sólo una lengua indígena, c) quienes viven en una comunidad de menos de 2500 habitantes, d) quienes van descalzos, e) quienes usan huaraches, f) quienes comen tortillas en lugar de pan y g) quienes no tienen drenaje en su casa. 
indicador de niveles de pobreza -como muchas veces se hacegeneralmente no se toman en cuenta elementos como los beneficios no monetarios, o algunas diferencias regionales en precios y otras condiciones -como el clima por ejemplo- que determinan significativamente los niveles de vida de una localidad. Por ello utilizar el ingreso per cápita como discriminante de quienes son pobres y quienes no lo son resulta bastante unilineal y finalmente poco confiable. 2 Por esta razón preferimos concebir la pobreza como un indice que podamos desagregar en por lo menos tres indicadores operacionales básicos: alimentación, vestido y vivienda.3/ Dentro de éstos, la alimentación, concebida como una dieta alimenticia suficiente para lograr un mínimo de salud física y mental, guardará un carácter principal por ser el indicador más importante con respecto a la determinación de niveles mínimos de subsistencia.

Corresponde ahora aclarar cuáles son los límites que nos permitirán discernir entre una situación de pobreza efectiva y las que no lo son. A este respecto podemos proponer básicamente dos tipos de criterios: a) criterios jurídico-políticos y b) criterios físico-biológicos.

Dentro de los criterios jurídico-políticos, destaca la orientación de la actual Administración, donde las metas tienen esencialmente un carácter cualitativo y están dirigidas a ampliar la igualdad de oportunidades en la participación de los beneficios del desarrollo. Esta estrategia tiene como punto de apoyo la Constitución Política Mexicana, en la cual se distinguen, bajo los Títulos Primero y Sexto, algunos criterios que pueden operar como condiciones reglamentables minimas, necesarias para llenar algunas definiciones juridico-politicas relacionadas con lo que hemos denominado pobreza. Tales criterios son:

- "La eduación primaria será obligatoria" (Artículo $3^{\circ}$, fracción VI)

- Fis un requisito para ser ciudadano "Tener un modo honesto de vivir" (Artículo 34, fracción II)

- La "vagancia consuetudinaria" suspende los derechos o prerrogativas de los ciudadanos. (Artículo 33, fracción IV)

- "Los salarios mínimos generales deberán ser suficientes para satisfacer las necesidades normales de un jefe de familia en el orden

2/ En los Estados Unidos, el gobierno federal propuso en 1964. un ingreso per cápita anual de 3000 dlls. como criterio divisor entre pobreza y no-pobreza. Junto a esto, el Council of Economic Advisers propuso como estándar mínimo oficial la cantidad de $\$ 250$ dlls.anuales para consumo per cápita de comida y 600 dils.para otros aspectos que no fueran estrictamente necesidades físicas.

3) Además de estos indicadores se incluirá también la posesión de ciertos bienes de consumo duradero, como indicador de pobreza que va más allá de registrar las necesidades puramente físic as. 
material, social y cultural, y para proveer a la educación obligatoria de los hijos" (Artículo 123, fracción VI). $4 /$

El supuesto implícito en estos artículos es que todo mexicano tiene efectivamente el derecho de ejercer una actividad lícita $y$ remunerativa, en la cual utilize una parte suficiente de su tiempo, y que le permita satisfacer sus necesidades familiares.

El emplear las disposiciones legales tiene como ventaja utilizar normas cuyo rango de aplicación incluye a todo el universo de la población con la cual se piensa trabajar, además de que tales normas garantizan su aplicación indiscriminada sobre los sujetos en quienes recae su acción.

Sin embargo, al tratar de establecer niveles mínimos de subsistencia, que a su vez refieran la pobreza efectiva de ciertos grupos de población, los criterios jurídico-políticos tienen, para los propósitos de este análisis, las siguientes limitaciones: a) no establecen el mínimo cuantitativo o cualitativo del atributo a que se refieren para llenar una definición; y b) generalmente no alcanzan a cubrir el espectro de indicadores necesario para definir conceptos como el de pobreza. Es por esto que -en nuestro caso- resulta más operativo trabajar con criterios físico-biológicos los cuales, además de distinguir límites cuantificables, permiten también implantar la estrategia que hemos señalado: hablar de satisfacer necesidades sociales o culturales sólo una vez que se hayan satisfecho ciertos límites físico-biologicos imprescindibles. Esta última afirmación descansa en el supuesto de que la satisfacción de ciertas necesidades biológicas vitales, proporciona el apuntalamiento básico no sólo para el crecimiento y desarrollo físico de los individuos, sino para la adquisición de ciertas habilidades, capacidad mental y de trabajo, e incluso posibilidades de socialización y trabajo en grupo.

Desde el punto de vista biológico, el aspecto de la pobreza que puede ser tratado más intensivamente es la alimentación y su correlato, el hambre. Mientras que al estudiar el vestido y la vivienda hay aspectos tales como la moda, la estética, o el confort, que no tienen un referente claro de tipo biológico, cualquier dieta puede ser traducida a su referente nutricional o proteico, independientemente de lo complejo de su composición, sabor, temperatura o tipo de cocción. Es por esto que con anterioridad afirmamos el carácter preponderante de la

4/ Cf. Porras y Lopez Armando, La Nueva Ley Federal del Trabajo. Textos Universitarios, S.A., Méx. 1970,Pág. 48: "Necesidades básicas que debe cubrir el salario minimo vital: a) Necesidades de orden material, habitación y manejo de casa, alimentación, vestido y transporte. . . b) Necesidades de carácter social, entre las que se incluyen la convivencia con otras familias, la práctica de deportes, la concurrencia a espectáculos y otras actividades semejantes, c) Necesidades de naturaleza cultural, asistencia a escuelas, bibliotecas y otros centros de cultura. Finalmente, ... el salario mínimo debe proporcionar al trabajador los elementos suficientes para proveer la educación de sus hijos". 
alimentación en la determinación de niveles mínimos de subsistencia, sin descuidar, por supuesto, el papel que juegan el vestido y la vivienda.

En términos generales podemos definir el hambre como la insuficiencia de todas o de algunas substancias imprescindibles para el funcionamiento orgánico de los seres humanos, para su metabolismo, su desarrollo físico y, en general, para el desempeño de la actividad que realicen. En este sentido se han distinguido desnutrición $y$ malnutrición, 5/ hambre aguda, hambre evidente y hambre oculta 6/ y se ha hablado de hambres específicas: de calorias, de proteinas, de vitaminas y de minerales. $]$

En cuanto a la alimentación, se dice que ésta debe cumplir por lo menos las siguientes cuatro funciones: a) una función plástica que consiste en asegurar el desarrollo de los órganos de un individuo así como reponer sus pérdidas y reparar los tejidos; b) una función energética, encargada de generar la energía termodinámica que permite la realización de diversas actividades a una temperatura aproximada de $37^{\circ}$ centígrados; c) una función reguladora, mediante la cual se estimulan y coordinan los procesos bioquímicos vitales que son susceptibles de control mediante sustancias directamente elaboradas por el organismo, y d) una función hidratante, encargada de reponer la pérdida constante de agua.

Para medir el valor energético de los alimentos se utiliza como unidad la kilocaloría 8 / la cual a su vez permite cuantificar los diversos tipos de necesidad calórica de un individuo. Uno de tales tipos es la llamada necesidad calórica básica o metabolismo basal.

El metabolismo basal (MB) se define como el gasto energético, por unidad de tiempo, de un individuo en condiciones basales, es decir: sano, en completo reposo físico y mental, 14 horas después del último alimento e inmediatamente después de un periodo de sueño normal. Tal necesidad representa el mínimo de energía requerida para mantener las funciones del organismo. (Para un hombre adulto, se determina por la dispersión de calor de la masa corporal metabólicamente activa (o masa magra), y se valúa en una kilocaloría por kilo de peso por hora. Así, el MB de un hombre adulto (de aproximadamente $70 \mathrm{kgs}$ ) suele calcularse sobre $1000 \mathrm{Kcal} / \mathrm{m}^{2}$ de superficie corporal, y tomando como promedio de superficie $1,7 \mathrm{~m}^{2}$, el gasto calórico básico será $1700 \mathrm{Kcal} /$ día).

5) Food and Agriculture Organization of the United Nations.

6/ De Castro, Josue, Geopolítica del Hambre. Ed. Solar-Hachette.

7) Melotti, Humberto, Sociología del Hambre. FCE.

8/ La caloría, o más propiamente, la kilocaloría, equivale a 100 pequeñas calorías, siendo esta última unidad la cantidad de calor necesaria para elevar de $14,5^{\circ}$ a $15,5^{\circ} \mathrm{C}$ la temperatura de un gramo de agua destilada. 
Otro tipo de necesidad calórica surge cuando añadimos al MB las calorías absorbidas por la actividad física de un individuo, en cuyo caso hablamos de la necesidad calórica en actividad.

La actividad física de un individuo es uno de los determiantes que más altera el gasto energético total. Varía desde, por ejemplo, 0,5 $\mathrm{Kcal} / \mathrm{minu}$ to en un indiviuo sentado leyendo, hasta $10^{\circ}$ ó más Kcal en un individuo bajo actividad física intensa. Estas diferencias confieren una alta variabilidad al gasto energético total y hacen difícil establecer una cantidad de dicho gasto, a menos que se conozca el tipo y duración de las actividades diarias. Ante esta limitación, una regla práctica generalizada consiste en añadir un 25 por ciento más de las recomendaciones de calorias cuando un individuo realiza trabajo físico intenso, y restar 25 por ciento cuando un individuo es sedentario.

Aparte de estos factores, existen otros que también son determinantes del consumo mínimo de calorías. La edad, por ejemplo: durante el crecimiento, la síntesis de tejidos y la maduración imponen al niño un gasto energético adicional de tal forma que gasta -en condiciones basales- el doble de energía por $\mathrm{Kg}$. de peso de la que se consume después de los 22 años, cuando el organismo adquiere su masa magra máxima. El sexo también impone diferencias importantes en el gasto calórico, tanto por las diferencias de crecimiento en la adolescencia, como por la diferente masa corporal total y magra, como por la diferente constitución y superficie corporal. Asimismo, el clima y la temperatura ambiental determinan las pérdidas de calor del organismo, y en casos extremos, se requiere un trabajo excesivo de los mecanismos homeostáticos para salvar ciertas diferencias cuando no existe un habitat adecuado.

La variación en los factores intervivientes en la determinación de requerimientos mínimos calóricos requirió un patrón de recomendaciones que -construido sobre una pareja tipo- operara como una norma internacional y permitiera comparaciones. Tal es el patrón de recomendaciones de la FAO (1950) en donde el "hombre de referencia" tiene 25 años, pesa $65 \mathrm{Kg}$., está sano y activo, vive en una zona cuya temperatura media anual es $10^{\circ} \mathrm{C}$, desempeña una actividad moderada durante 8 horas, camina 90 minutos, tiene actividades recreativas durante 90 minutos y descansa en su casa 4 horas. Para este individuo la FAO recomienda $3200 \mathrm{Kcal} /$ dia. La "mujer de referencia" tiene 25 años, pesa $55 \mathrm{Kg}$, realiza labores domésticas, camina 60 minutos, tiene una hora de actividades recreativas y vive en el mismo clima que el hombre de referencia; la FAO le asigna una recomendación de $2300 \mathrm{Kcal} /$ día.

La insuficiencia de esta cantidad de calorías, debida generalmente a deficiencias en la dieta alimenticia, se asocia muchas veces, sobre todo en los países subdesarrollados, a la mortalidad infantil y a la baja esperanza de vida. Si a esto añadimos que la desnutrición causa apatía en general y 
baja capacidad de trabajo, los que se alimentan mal no sólo viven menos, sino que -mientras viven- son poco aptos para desempeñar las frecuentes tareas de trabajo intensivo que demanda el desarrollo.

Por otro lado, un individuo no requiere exclusivamente calorías para desarrollar una actividad normal; es necesario hablar de un complejo alimenticio bastante más amplio en el que es posible distinguir algunos elementos imprescindibles. Para este propósito se ha estudiado la cantidad mínima de proteínas que se requieren para cubrir la cuota de desgaste (mínimo endógeno), para responder a las exigencias del equilibrio del nitrógeno (mínimo fisiológico), y para la elaboración de reservas indispensables para mantener el equilibrio en casos de emergencia (mínimo higiénico). En especial se ha estudiado el mínimo de aminoácidos indispensables para el desarrollo físico y para el equilibrio del nitrógeno que deben integrarse con las proteínas que los contienen ya que el organismo no puede sintetizarlas, tales como la isoleucina, la lisina, el triptófano, etc.

La carencia de proteínas -y en especial las de origen animal- así como la carencia de vitaminas y de oligoelementos minerales conduce al padecimiento de afecciones graves que impiden el crecimiento, afectan la funcionalidad de los órganos vitales, la capacidad procreativa, y el deterioro de la vida misma. Por esto, al hablar de pobreza, es imprescindible contar con indices que refieran los límites bajo los cuales podemos distinguir una carencia efectiva. En esta perspectiva podemos distinguir dos tipos de índices: los requerimientos nutricionales y las recomendaciones dietéticas.

Los requerimientos nutricionales, o más propiamente, las necesidades de nutrimentos son altamente individuales; son "la expresión numérica de la cantidad que un individuo dado, en un momento y condiciones específicas, necesita para mantener la salud y un estado nutricional óptimo". 9/ Por el contrario, las recomendaciones dietéticas son valores que se aplican a grandes grupos, basadas generalmente en las necesidades promedio de una población, más dos desviaciones estándar, a lo cual se agrega otra cantidad como margen de seguridad. Por esto en nuestro caso, por ser un índice estadístico (social), es preferible trabajar con recomendaciones dietéticas en lugar de requerimientos nutricionales individuales.

Las recomendaciones que vamos a utilizar en este análisis son, en un nivel desagregado, las recomendaciones para consumo diario de nutrimentos que propone -para el caso de México en particular- el Instituto Nacional de Nutrición(1970), y que se presentan en el cuadro 5.

Tales recomendaciones operan como el marco con respecto al cual podemos evaluar el patrón alimenticio de la población mexicana. Es

9/ Instituto Nacional de Nutrición, Recomendaciones Dietéticas para México, 1970, Mimeografiado. 
decir, las recomendaciones consisten en indicadores mínimos a satisfacer, por debajo de los cuales podemos afirmar que existe desnutrición crónica y consecuentemente, los individuos que caen bajo esta categoría, están en una situación de deterioro constante, la cual se refleja en su reducido tamaño corporal, poca resistencia a las enfermedades, capacidad psíquica reducida, y escasa capacidad de trabajo.10/ Así, el uso de las recomendaciones como indicador de quienes están mal alimentados en México, es uno de los aspectos relevantes en esta parte del trabajo.

Recientemente, el Instituto Nacional de Nutrición elaboró un trabajo en el cual se propone una regionalización de los problemas nutricionales del país, atendiendo a recomendaciones específicas para el caso mexicano. 11 /

En este trabajo, desde el punto de vista de la oferta de alimentos, es decir, atendiendo a la disponibilidad de alimentos o al llamado consumo aparente, las conclusiones a que se llegó son las siguientes: en los últimos 30 años ha habido en México un notable aumento en la disponibilidad de alimentos, fundamentalmente en algunos productos vegetales.

Cuadro 1

\section{CAMBIOS EN LA DISPONIBILIDAD DE ALIMENTOS} EN MEXICO

\begin{tabular}{|c|c|c|c|c|c|c|c|}
\hline Alimentos & 1940 & 1945 & 1950 & 1955 & 1960 & 1965 & 1969 \\
\hline Maíz & 95,9 & 98,1 & 106,6 & 122,3 & 121,4 & 139,3 & 121,9 \\
\hline Trigo & 28,1 & 29,2 & 36,2 & 24,3 & 36,2 & 25,0 & 38,4 \\
\hline Otros cereales & 5,9 & 5,4 & 6,7 & 6,5 & 7,1 & 7,8 & 6,9 \\
\hline Firijol & 7,2 & 7,0 & 7,9 & 13,4 & 15,1 & 17,6 & 14,1 \\
\hline Garbanzo & 1,4 & 3,7 & 2,6 & 2,3 & 2,9 & 2,6 & $\mathbf{3 , 0}$ \\
\hline Otras legumbres y oleaginosas & 1,8 & 1,9 & 3,9 & 3,1 & 4,0 & 4,2 & 3,5 \\
\hline Papa & 3,3 & 4,4 & 4,1 & 4,5 & 6,4 & 5,5 & 6,1 \\
\hline Carnote & 2,6 & 2,3 & 2,2 & 2,3 & 2,3 & 2,4 & 2,0 \\
\hline Tomate y jitomate & 7,8 & 5,0 & 7,5 & 7,1 & 5,8 & 7,9 & 8,7 \\
\hline Chiles & 2,1 & 2,0 & 2,0 & 2,5 & $\mathbf{3 , 0}$ & 3,7 & 4,7 \\
\hline Aguacate & 2,4 & 2,5 & 2.2 & 2,4 & 2,6 & 2,9 & 2,7 \\
\hline Otras verduras & 2,0 & 2.8 & 2.7 & 2,8 & 2,6 & 2,3 & 6,8 \\
\hline Naranja & 9,5 & 11,7 & 19,3 & 17,6 & 19,0 & 16,8 & 17,3 \\
\hline Plátano & 18,0 & 17,8 & 14,5 & 12,6 & 15,5 & 20,4 & 19,1 \\
\hline Melón y sandia & 2,3 & 1,7 & 1,9 & 2,9 & 3,2 & 6,1 & 3,8 \\
\hline Piña & 3,2 & 2,5 & 2,7 & 3,0 & 4.2 & 4,6 & 5,3 \\
\hline Otras frutas & 16,4 & 17,3 & 18,1 & 17,9 & 21,3 & 24.6 & 23,4 \\
\hline Carnes & 21,7 & 19,4 & 17,2 & 18,4 & 26,9 & 26.9 & 26,7 \\
\hline Pescados y mariscos & 1,9 & 1,6 & 1.8 & 3,0 & 2,3 & 3,0 & 3,1 \\
\hline Leche & 81,2 & 81,5 & 76,3 & 77,8 & 98,4 & 101,7 & 89,2 \\
\hline Huevo & 3,4 & 3,5 & 3,9 & 4,8 & 4,9 & 5,7 & 6.1 \\
\hline Azúcar & 21,8 & 22,6 & 22,6 & 27,2 & 30.8 & 32,1 & 36,1 \\
\hline Grasas & 6,5 & 7,0 & 6,2 & 6.2 & 5,6 & 6.5 & 6,5 \\
\hline
\end{tabular}

10/ Of. Melotti, H. Op. Cit. Pág, 16.

11 Instituto Nacional de Nutrición, 1970, Cuadro Mimeografiado. 
Los aumentos más significativos se registraron en productos como el maíz, trigo, frijol y papa, mientras que los aumentos más moderados correspondieron a la leche y a la carne, productos ricos en valor nutritivo.

Sin embargo, el aumento en la disponibilidad de alimentos no refleja los aumentos de producción registrados. En los últimos 30 años, la producción de alimentos ha sido mayor que el aumento de la disponibilidad y que el crecimiento de la población.

\section{Gräfico 1}

\section{TENDENCIAS DE POBLACION, PRODUCCION Y DISPONIBILIDAD DE ALIMENTOS}

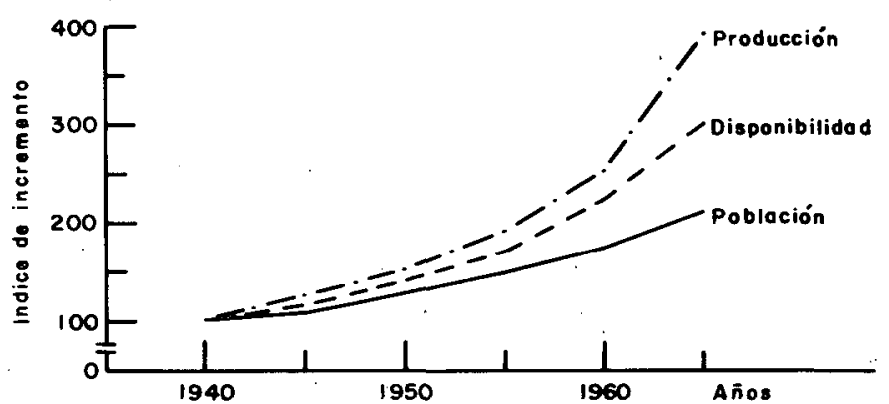

Esta diferencia se debe, por una parte, al crecimiento demográfico, y por otra, a los volúmenes de productos alimenticios que se exportan, se merman o se almacenan.

$\mathrm{Si}$ se consideran cifras globales, los cambios registrados en la producción de alimentos muestran que creció un 285 por ciento, mientras que la disponibilidad total lo hizo un 194 por ciento y la disponibilidad per cápita sólo 72 por ciento.

En cuanto a la estructura de la disponibilidad, ésta se ha mantenido prácticamente inalterada durante los últimos años. Los cereales son la principal fuente de elementos nutritivos para la población mexicana.

El gráfico muestra que la disponibilidad per cápita de alimentos alcanza 2619 calorías, 72,0 gramos de proteinas totales, de las cuales 22,7 gramos son de origen animal; cifras que son semejantes a las recomendaciones de la FAO y del INN. 


\section{ALIMENTOS FUENTES DE CA LORIAS Y PROTEINAS \\ DISPONIBILIDAD NACIONAL 1969}

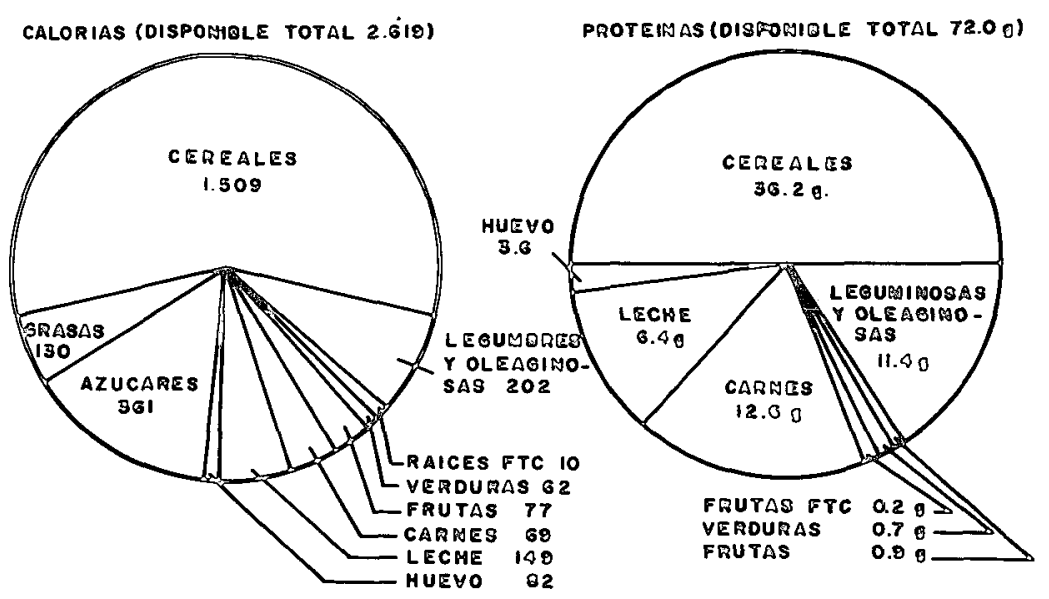

Cuadro 2

DISPONIBILIDAD Y RECOMENDACIONES DE NUTRIMENTOS EN 1969

\begin{tabular}{lccc}
\hline Nutrimentos & $\begin{array}{c}\text { Disponibilidad } \\
\text { por habitante }\end{array}$ & Recomendaciones \\
\hline Calorias & $\mathbf{2 6 1 9}$ & $2 \mathbf{6 0 0}$ & $*$ \\
Proteinas totales (g) & 72,0 & 75,0 & $*$ \\
Proteinas animales (g) & 22,7 & 25,0 & $*$ \\
Calcio (mg) & $\mathbf{6 8 9}$ & $\mathbf{6 0 0}$ & $*$ \\
Hierro(mg) & 18,89 & 18,0 & $* *$ \\
Vitamina A (mg) & 0,803 & $1 \mathbf{8 0 0} * *$ \\
Tiamina (mg) & 2,18 & $1,30 * *$ \\
Rivoflavina (mg) & 0,91 & $1,90 * *$ \\
Niacina (mg) & 26,8 & $26,0 * *$ \\
Vitamina C (mg) & $\mathbf{8 1}$ & $\mathbf{8 0 , 0} * *$ \\
\hline
\end{tabular}

* Recomendaciones de FAO para un país de escaso desarrollo.

** Recomendaciones del INN. 
El cuadro resalta también la deficiencia de vitamina A y riboflavina, carencias que reflejan la escasęz de leche y verduras respectivamente.

$\mathrm{Si}$ atendemos a los cambios en la disponibilidad de nutrimentos que hubo durante los últimos años, se nota un estancamiento relativo, lo cual puede entenderse como reflejo de una demanda satisfecha.

Cuadro 3

DISPONIBILIDAD DE CALORIAS Y PROTEINAS

EN LOS ULTIMOS AÑOS

(Por persona y por día)

\begin{tabular}{lccc}
\hline Año & \multicolumn{3}{c}{ Nutrimentos } \\
\cline { 2 - 4 } & Calorías & Proteínas & $\begin{array}{c}\text { Proteinas } \\
\text { animales }\end{array}$ \\
\hline 1958 & 2518 & 75,2 & 20,5 \\
1959 & 2320 & 69,4 & 20,6 \\
1960 & 2523 & 74,9 & 22,6 \\
1961 & 2501 & 74,4 & 20,3 \\
1962 & 2544 & 73,6 & 22,2 \\
1963 & 2674 & 76,5 & 21,4 \\
1964 & 2492 & 73,1 & 21,6 \\
1965 & 2662 & 78,1 & 23,3 \\
1966 & 2747 & 79,4 & 21,7 \\
1967 & 2625 & 76,0 & 22,9 \\
1968 & 2547. & 75,1 & 22,9 \\
1969 & 2619 & 72,0 & 22,7 \\
\hline
\end{tabular}

Tal estabilidad de la demanda puede tener explicaciones diversas: en primer término, èl poco cambio en el poder de compra de la población; en segundo término, la estructura de la población mexicana, donde existe una alta proporción de individuos con bajos requerimientos nutricionales tales como la población infantil y la población con una reducida masa corporal; en tercer término, la población con poco gasto energético ya sea por desocupación, subocupación, o subconsumo tradicional por apego a dietas típicas o por adaptación biológica a un consumo reducido de alimentos.

Estos elementos permiten concluir que en los últimos años no ha existido una sobreproducción real de alimentos, sino más bien un marcado subconsumo; es decir, no obstante la existencia de carencias alimenticias, la población no está siendo capaz de consumir volúmenes significativamente mayores de alimentos.

En esta situación, el Distrito Federal juega un papel determinante: no obstante que tiene sólo el 15 por ciento de la población del pais, dispone para su consumo entre el 22 y 58 por ciento de las 
disponibilidades nacionales, según el tipo de alimento de que se trate. Por ejemplo, el Distrito Federal dispone, por habitante, de siete veces más carne de aves, tres veces más de huevos, pescados y mariscos, y más del doble de leche y carne de ganado que el resto del pais. Además, la disponibilidad total de alimentos crece mucho más rápidamente en el D.F. que en el resto del país.

Estas desigualdades llevan a pensar en la necesidad de regionalizar los problemas nutricionales en México. Para ello utilizaremos la regionalización que propone el Instituto Nacional de Nutrición, en donde se emplearon como indicadores la mortalidad de niños de 1 a 4 años y encuestas de consumo familiar elaboradas por el propio Instituto.

La primera diferencia importante que existe se da entre la ciudad y el campo. En el medio rural, el producto con mayor aportación calórica es el maíz, proporcionando aproximadamente el 60 por ciento de la demanda calórica total. Le siguen en importancia el frijol, el azúcar y las grasas. Para el medio urbano, la aportación calórica de los componentes de la dieta se indican en la siguiente gráfica.

\section{Gráfico $N^{\circ} 3$}

\section{COMPONENTES DE LA DIETA MEXICANA SEGUN SU APORTACION EN CALORIAS}
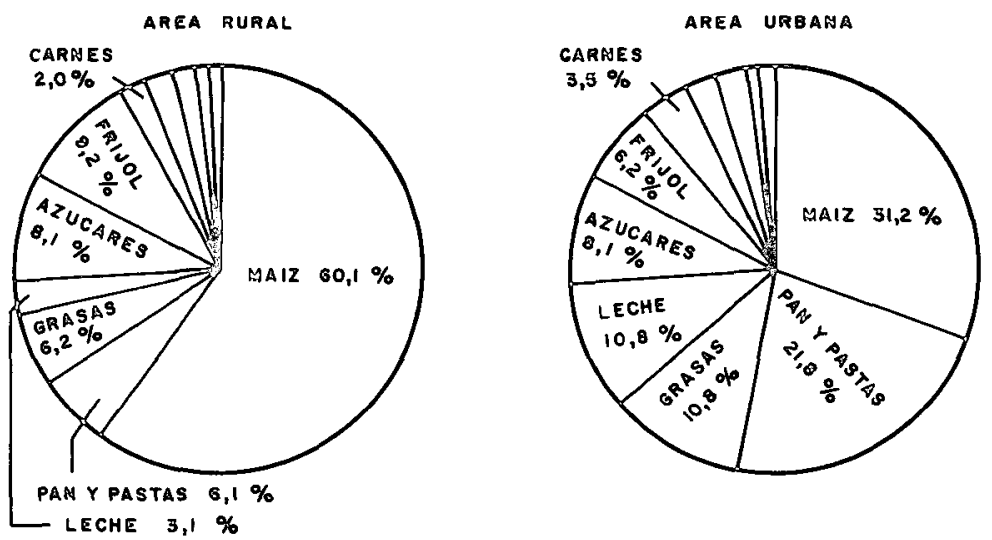

En cuanto al aporte proteico de la dieta rural y urbana, en la primera se consumen 56,2 gramos de proteínas totales, de las cuales, el 80 por ciento proceden de productos vegetales como frijol, maiz, trigo y otros; el 20 por ciento restante lo aportan la carne y muy reducidas cantidades de leche y huevo. En el área urbana la situación es sensiblemente mejor: se consumen 70,7 gramos de proteínas totales y la participación de productos animales es mayor. 
Gráfico $\mathrm{N}^{\mathrm{O}} 4$

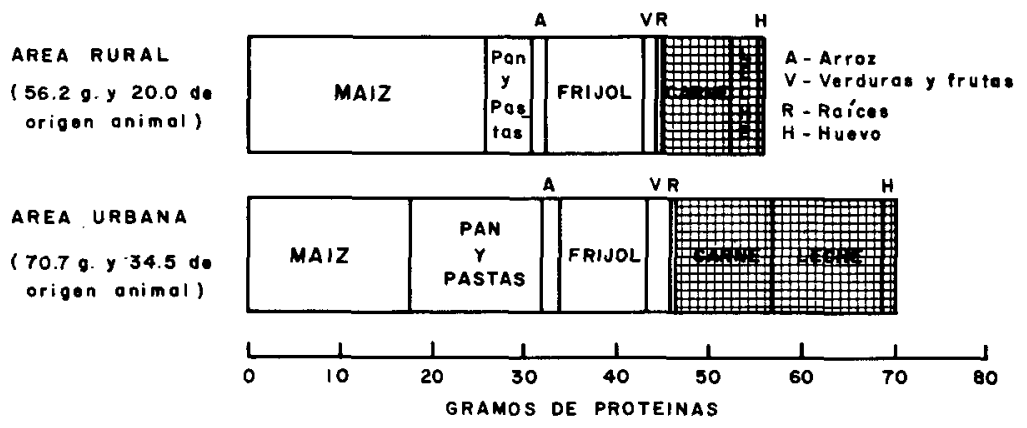

Además de estas diferencias entre las dos áreas mencionadas, existen desniveles marcados dentro de cada una de ellas, lo cual puede apreciarse mediante la desagregación correspondiente.

En el área urbana se escogieron tres niveles de observación que, de acuerdo a criterios ecológicos, corresponden aproximadamente a una distinción entre clases media baja, baja y proletarios. El área rural se subdividió en cuatro niveles, designados como zonas de buena nutrición aquellas donde la mortalidad de niños en edad preescolar fue menor de 6 por mil; cuando la mortalidad fue entre 6 y 12, la zona nutricional se calificó de regular; si fue entre 12 y 18 , se denominó mala y muy mala cuando la mortalidad fue mayor de 18 por mil. Así, en base a esta desagregación, las diferencias pueden ser mejor apreciadas.

Cuadro 4

CONSUMO DE CALORIAS Y PROTEINAS DE LOS DISTINTOS NIVELES RURALES Y URBANOS

\begin{tabular}{lccc}
\hline NIVELES & $\begin{array}{c}\text { Calorías } \\
\text { Totales }\end{array}$ & $\begin{array}{c}\text { Proteínas } \\
\text { Totales }\end{array}$ & $\begin{array}{c}\text { Proteínas } \\
\text { Animales }\end{array}$ \\
\hline URBANO & & & \\
1. Unidades Habitacionales & 2380 & 86,1 & 45,8 \\
2. Vecindades & 2320 & 67,1 & 23,5 \\
3. Barracas periféricas & 2030 & 59,0 & 14,3 \\
\hline RURAL & & & \\
1. Zonas de Buena Nutrición & 2330 & 69,0 & 20,0 \\
2. Zonas de Regular Nutrición & 2120 & 60,0 & 15,1 \\
3. Zonas de Mala Nutrición & 2060 & 56,1 & 10,0 \\
4. Zonas de Muy Mala Nutrición & 1890 & 50,2 & 7,9 \\
\hline
\end{tabular}




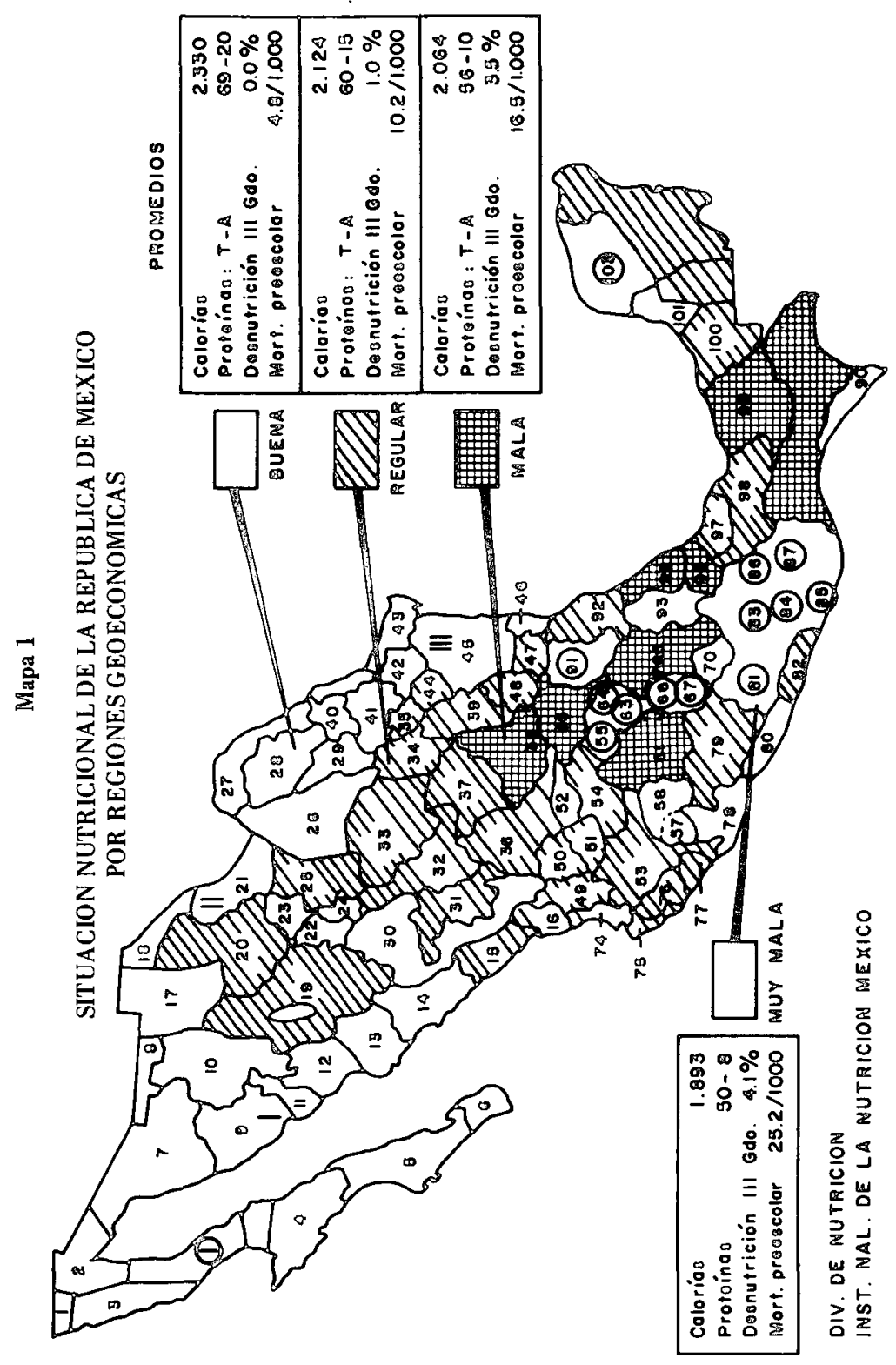


Cabe destacar que ninguna de las cifras de consumo alcanza a la cifra de disponibilidad nacional de 2600 calorias; y en particular, en el área rural, incluso aquellas zonas calificadas de nutrición regular, están bastante lejos de las recomendaciones.

En el mapa anexo se presenta la composición regional de los diversos niveles nutricionales que se señalaron para el medio rural.

En base a los requerimientos nutricionales establecidos y teniendo presente la regionalización del problema nutricional, puede proponerse una dieta tipo que funcione como el arreglo minimo entre las cantidades de ciertos alimentos, y que garantice un patrón alimenticio dentro de las recomendaciones. Al decir "ciertos" alimentos, se está pensando básicamente en un criterio de selección, así como en la posibilidad de contar con un patrón de sustituibilidad de alimentos dentro de un mismo tipo.

En cuanto al criterio de selección de alimentos, éste fue esencialmente dual: por un lado se introdujeron en la dieta los alimentos típicos con respecto a los cuales existe un marcado apego preferencial en los sectores mayoritarios de la población. Cabe en este momento aclarar que la dieta tipo que se formuló, es en primera instancia, una recomendación general que puede aplicarse al grueso de la población, independientemente de consideraciones de gusto o de producción de algunos alimentos exclusivamente regionales; es decir, el diseño de la dieta es de tal forma que busca garantizar la participación de alimentos preferidos de consumo básico, y cuyo consumo sería difícil alterar. Por otro lado, los alimentos típicamente consumidos (sobre todo en el área rural) difícilmente alcanzan a satisfacer los requerimientos recomendados, por esto fueron introducidos en la dieta alimentos de alto contenido nutricional, de los cuales se espera que exista al menos una demanda latente; es decir, que no se espera el rechazo de consumo de alimentos como ciertas variedades de carne o huevos.

Otros dos criterios intervinientes en la formulación de la dieta fueron los siguientes: se utilizó la estructura de una familia tipo (de seis miembros) para desagregar el consumo mínimo familiar, lo cual permite comparar los requerimientos alimenticios para cada uno de los miembros de dicha familia; y las recomendaciones de alimentos se hicieron en gramos de consumo diario, repartidos scgún cada una de las tres comidas usuales. Así, el diseño de la dieta tipo resultó como sigue: 


\begin{tabular}{|c|c|c|c|c|c|c|}
\hline \multirow{2}{*}{ DESAYUNO } & \multicolumn{4}{|c|}{$\begin{array}{l}\text { MENL FAMILIAR } \\
\text { (6 miembros) }\end{array}$} & \multirow[b]{2}{*}{$\begin{array}{l}\text { Pre- } \\
\text { esc. } \\
(1500 \\
\text { cals })\end{array}$} & \multirow[b]{2}{*}{$\begin{array}{l}\text { Pre- } \\
\text { esc. } \\
(1250 \\
\text { cals. }\end{array}$} \\
\hline & $\begin{array}{l}\text { Sr. } \\
(2500 \\
\text { cals })\end{array}$ & $\begin{array}{c}\text { Sra. } \\
(3000 \\
\text { cals. })\end{array}$ & $\begin{array}{l}\text { Adoles- } \\
\text { cente } \\
(3000 \\
\text { cals })\end{array}$ & $\begin{array}{c}\text { Esco- } \\
\text { lar } \\
(2000 \\
\text { cals })\end{array}$ & & \\
\hline $\begin{array}{l}\text { Café o/leche } \\
\text { Leche } \\
\text { Azúcar } \\
\text { Inf. de café }\end{array}$ & $\begin{array}{r}200 \\
15 \\
\mathrm{c} / \mathrm{s}\end{array}$ & $\begin{array}{r}200 \\
15 \\
c / s\end{array}$ & $\begin{array}{r}200 \\
15 \\
c / s\end{array}$ & $\begin{array}{r}200 \\
15 \\
c / s\end{array}$ & $\begin{array}{r}200 \\
15 \\
c / s\end{array}$ & $\begin{array}{r}200 \\
15 \\
c / s\end{array}$ \\
\hline $\begin{array}{l}\text { Huevos a la } \\
\text { Mexicana } \\
\text { Huevos } \\
\text { Jitomate } \\
\text { Cebolla } \\
\text { Aceite } \\
\text { Sal } \\
\text { Chile }\end{array}$ & $\begin{array}{l}1 \text { pza. } \\
15 \\
3 \\
5 \\
\text { c/s } \\
c / s\end{array}$ & $\begin{array}{c}2 p z a . \\
30 \\
5 \\
8 \\
c / s \\
c / s\end{array}$ & $\begin{array}{l}1 \text { pza. } \\
15 \\
3 \\
5 \\
\text { c/s } \\
\mathrm{c} / \mathrm{s}\end{array}$ & $\begin{array}{c}2 p z a \\
30 \\
5 \\
8 \\
\mathrm{c} / \mathrm{s} \\
\mathrm{c} / \mathrm{s}\end{array}$ & $\begin{array}{l}1 \text { pza. } \\
15 \\
3 \\
5 \\
\text { c/s } \\
\text { c/s }\end{array}$ & $\begin{array}{c}1 \mathrm{pza} . \\
15 \\
3 \\
5 \\
\mathrm{c} / \mathrm{s} \\
\mathrm{c} / \mathrm{s}\end{array}$ \\
\hline $\begin{array}{l}\text { Frijoles guisa- } \\
\text { dos } \\
\text { Frijol } \\
\text { Cebolla } \\
\text { Aceite } \\
\text { Sal, Agua }\end{array}$ & $\begin{array}{r}30 \\
5 \\
5 \\
\mathrm{c} / \mathrm{s}\end{array}$ & $\begin{array}{r}30 \\
5 \\
5 \\
\mathrm{c} / \mathrm{s}\end{array}$ & $\begin{array}{r}30 \\
5 \\
5 \\
\mathrm{c} / \mathrm{s}\end{array}$ & $\begin{array}{r}15 \\
3 \\
15 \\
\mathrm{c} / \mathrm{s}\end{array}$ & $\begin{array}{l}- \\
- \\
- \\
-\end{array}$ & $\begin{array}{l}- \\
- \\
- \\
-\end{array}$ \\
\hline $\begin{array}{l}\text { Fruta } \\
\text { Naranja } \\
\text { Tortillas* } \\
\text { Pan** sal } \\
\text { Pan dulce*** }\end{array}$ & $\begin{array}{l}\text { lpza. } \\
2 " \\
\text { lpza. } \\
1 " "\end{array}$ & $\begin{array}{l}\text { lpza. } \\
2 " \\
1 \text { pza. } \\
1 "\end{array}$ & $\begin{array}{l}\text { lpza. } \\
3 " " \\
2 p z a . \\
1 "\end{array}$ & $\begin{array}{l}\text { lpza. } \\
1 "= \\
\overline{1 p z a}\end{array}$ & $\begin{array}{l}\text { lpza. } \\
1 " \\
\text { 1/2pza. }\end{array}$ & $\begin{array}{l}1 \text { pza. } \\
\overline{-} \text {. } \\
1 / 2 \text { pza. } \\
1 / 2 \text {. }\end{array}$ \\
\hline $\begin{array}{l}\text { Colación matutina } \\
\text { Leche }\end{array}$ & - & 200 & - & - & 200 & 200 \\
\hline $\begin{array}{ll}\text { * } & 25 \text { gramos. } \\
\text { * } & 40 \text { gramos. } \\
\text { ** } \quad 40 \text { gramos. }\end{array}$ & & & & & & \\
\hline
\end{tabular}


MENU FAMILIAR

(6 miembros)

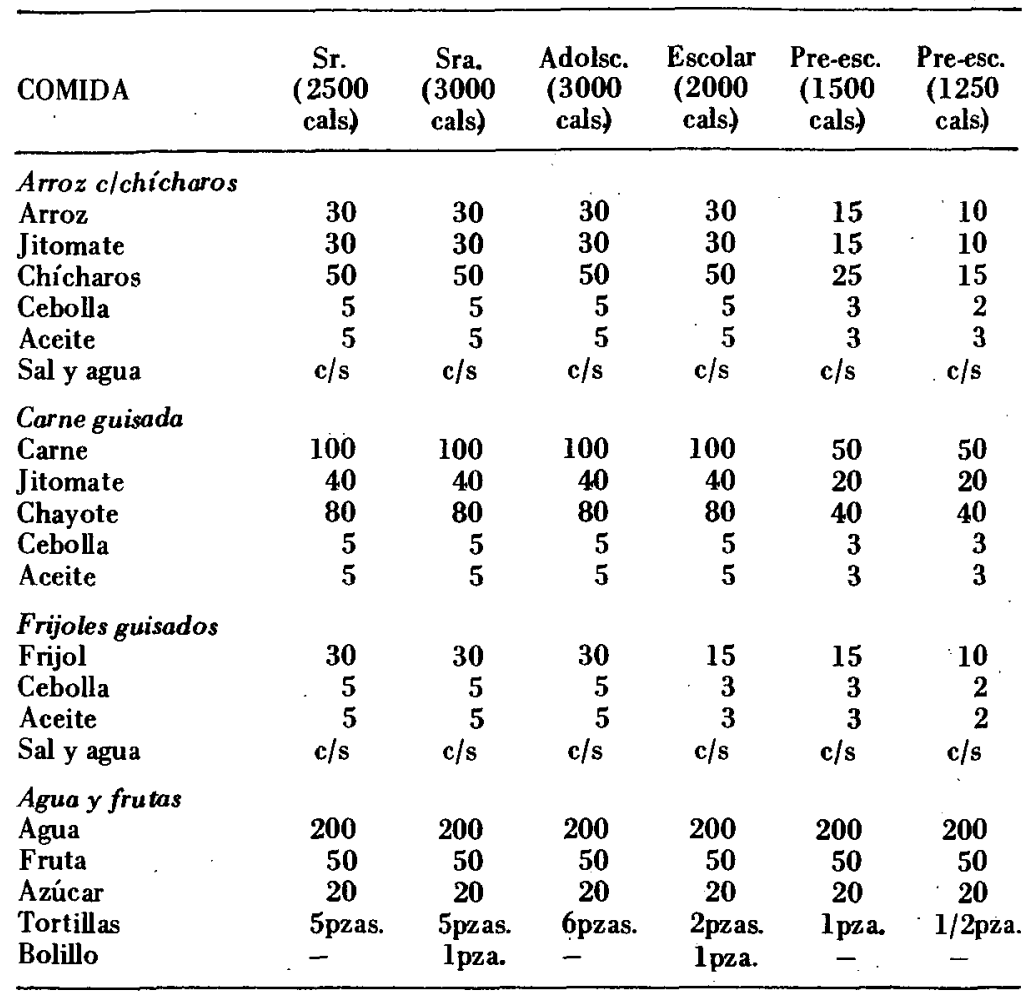

MENU FAMILIAR

(6 miembros)

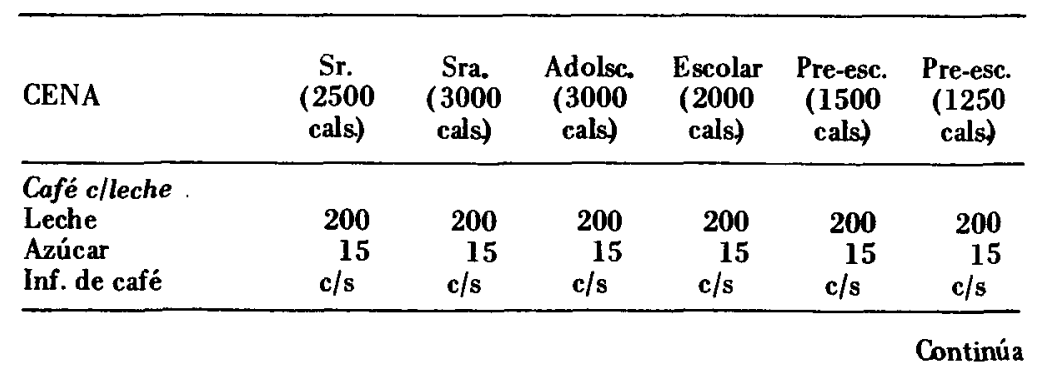


MENU FAMILIAR ( conclusión)

(6 miembros)

\begin{tabular}{|c|c|c|c|c|c|c|}
\hline CENA & $\begin{array}{l}\text { Sr. } \\
(2500 \\
\text { cals. })\end{array}$ & $\begin{array}{c}\text { Sra. } \\
\text { (3000) } \\
\text { cals.) }\end{array}$ & $\begin{array}{l}\text { Adolsc. } \\
\text { (3000 } \\
\text { cals.) }\end{array}$ & $\begin{array}{l}\text { Escolar } \\
(2000 \\
\text { cals. })\end{array}$ & $\begin{array}{l}\text { Pre-esc. } \\
(1500 \\
\text { cals. })\end{array}$ & $\begin{array}{c}\text { Pre-esc. } \\
(1250 \\
\text { cals. })\end{array}$ \\
\hline \multicolumn{7}{|c|}{ Carne con verduras } \\
\hline Aceite & 5 & $\begin{array}{r}3 \\
5\end{array}$ & $\begin{array}{r}6 \\
5\end{array}$ & -5 & -3 & -3 \\
\hline Acelgas & 40 & 40 & 40 & 40 & 20 & 20 \\
\hline Papas & 60 & 60 & 60 & 60 & 30 & 30 \\
\hline Cebolla & 5 & 5 & 5 & 5 & 3 & 3 \\
\hline Jitomate & 40 & $\Delta 0$ & 40 & 40 & 20 & 20 \\
\hline \multicolumn{7}{|c|}{ Frijoles guisados } \\
\hline Frijol & - & 30 & 30 & & & \\
\hline Aceite & - & 5 & 5 & & & \\
\hline Cebolla & - & 5 & 5 & & & \\
\hline Sal, agua & - & $\mathrm{c} / \mathrm{s}$ & $\mathrm{c} / \mathrm{s}$ & & & \\
\hline Tortillas & 2pzas. & 2pzas. & 3pzas. & lpza. & & \\
\hline Bolillo & $1 "$ & $1 "$ & $2 "$ & $1 "$ & 1pza. & 1/2pza. \\
\hline Pan Dulce & $1 "$ & $1 "$ & $1 "$ & $1 "$ & $1 / 2 \mathrm{pza}$. & - \\
\hline
\end{tabular}

La substituibilidad entre alimentos es crítica en dos tipos de productos: frutas y verduras. En la dieta, por ejemplo, la fruta que ha sido utilizada es una naranja de $\mathbf{1 5 0}$ gramos de peso bruto, la cual puede ser substituida por la misma cantidad de cualquier otra fruta que contenga diez por ciento de hidratos de carbono. Así, para substituir frutas es necesario conocer la clasificación que de ellas se tiene en cuanto a su concentración de hidratos de carbono:

Frutas con 5 por ciento de hidratos de carbono:

Lima o limón dulce, tuna, melón, papaya, sandía.

Frutas con 10 por ciento de hidratos de carbono:

Chabacano, higo, jícama, mandarina, mango, naranja, nanche, uva, toronja, piña, caimito, granada roja, pitahaya.

Frutas con 15 por ciento de hidratos de carbono:

Capulín, ciruela, chirimoya, durazno, guayaba, mamey, manzana, pera, perón, zapote blanco, zapote negro.

Frutas con 20 por ciento de hidratos de carbono:

Chico zapote, plátano, tejocote, zapote amarillo, anona.

Para efectuar la substitución de frutas se puede tomar como base el siguiente ejemplo:

Una ración de naranja (fruta al 10 por ciento) de 150 gramos, serían 300 gramos de frutas al 5 por ciento y 75 gramos de frutas al 20 por ciento. 
De igual forma, las verduras se clasifican también según su contenido de hidratos de carbono, y se substituyen de la misma forma que las frutas. Su clasificación por grupos es como sigue:

Verduras con 5 por ciento de hidratos de carbono:

Acelgas, alcachofas, calabacitas, col, coliflor, chayote, colinabo, ejotes, espárragos, espinacas, flor de calabaza, jitomate, lechuga, lengua de vaca, nabo, nopales, pepinos, rabanitos, tomate verde, verdolagas.

Verduras con 10 por ciento de hidratos de carbono:

Betabel, cebolla, poro, zanahorias, chiles para rellenar.

Verduras con 15 por ciento de hidratos de carbono:

Guaje, habas verdes, chícharos.

Verduras con 20 por ciento de hidratos de carbono:

Camote, elote tierno, papa, yuca.

Dichos patrones de substituibilidad, junto con la dieta general formulada, dan pie a que puedan generarse una serie de dietas particulares en las que se introduzcan tanto restricciones de disponibilidad de ciertos alimentos producidos sxclusivamente en una región, como restricciones referentes al precio al consumidor que se registra para ciertos alimentos en la zona. Este proceder resulta benéfico en dos sentidos: por un lado permite sofistic ar la evaluación del costo de bien alimentar a los que no lo están, por regiones; y por el otro permite sugerir cual sería la estructura óptima del gasto en alimentación por familia; es decir, se tiene tanto la cantidad requerida para satisfacer el déficit alimenticio global,como la estrategia para que la estructura de dicho gasto sea óptima desde el punto de vista de los beneficios nutricionales que pueden obtenerse.

En esta última perspectiva, si se cuenta con índices que refieran la demanda alimenticia proporcional de cada uno de los miembros de la familia tipo, y además se cuenta con conocimientos acerca de cual es la desagregación porcentual del gasto alimenticio por miembro individual, podrá verificarse la hipótesis de que generalmente los infantes preescolares consumen una proporción del gasto menor a la sugerida por las recomendaciones nutricionales correspondientes. Asi, es generalmente la población infantil la que sufre más daño con la irracionalidad y la escasez de recursos alimenticios. Si a esto añadimos que el deterioro físico y mental sufrido en los años iniciales de vida por la carencia alimenticia, es irreparable, la importancia de orientar los recursos alimenticios a la población infantil es de primer orden. 


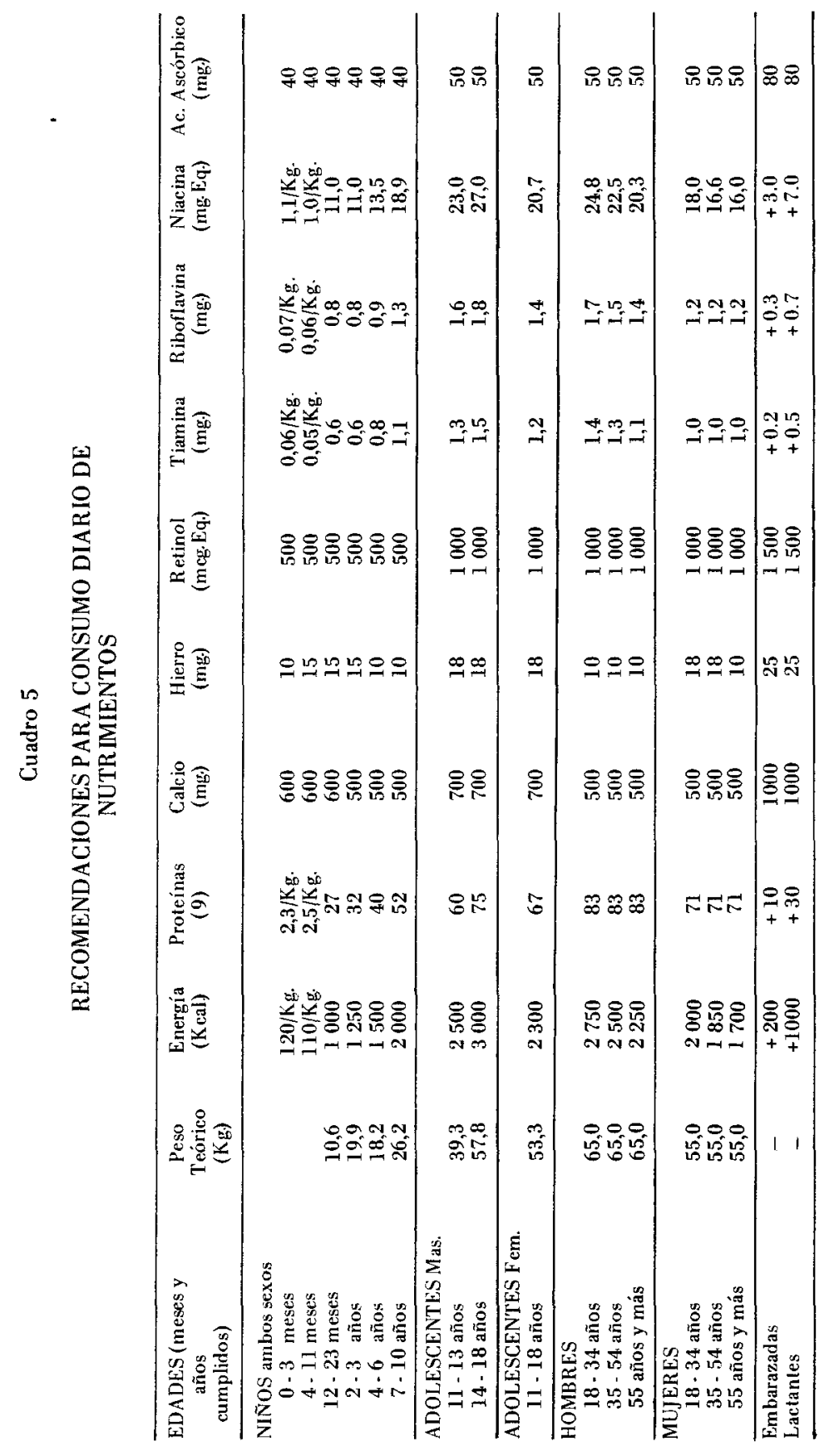




\section{LA EXPERIIENCIA VIENEZOLANA SOBBRE USO DDE $\mathbb{D A T O S ~ Y ~ E S T U D I O S ~}$ \\ DENOGRAFICOS EN LA PLANIFICACTON}

Dirección de Planificación Social y Cultural, Oficina Central de Coordinación y Planificación, República de Venezuela 

Advertencia: Las limitaciones de la información estadística disponible han dificultado ostensiblemente la elaboración realista de los planes nacionales de desarrollo económico y social. En este sentido, la experiencia venezolana de planificación no difiere grandemente de la de otros países latinoamericanos. lgualmente, quizás sea en el campo de la programación del empleo donde las dificultades estadísticas se dejan sentir con mayor énfasis, constituyendo un verdadero problema sin cuya superación difícilmente pueda hablarse de planificación del uso y formación de la mano de obra.

Las deficiencias estadísticas señaladas están, en nuestro caso, referidas básicamente al alcance o cobertura de la información, a su nivel de agregación, a su grado de exactitud y confiabilidad, a la oportunidad temporal en que se suministren los datos; y conllevan una acentuada inadecuación de la información a los propósitos de un conocimiento objetivo de las tendencias ocupacionales de la fuerza de trabajo y a los problemas que les son inherentes.

Ante tal situación, y enfrentados a la necesidad de formular un Plan Nacional de Recursos Humanos, concebido como parte integrante del proceso general de planificación, la Ofícina Central de Información y Planificación (CORDIPLAN), conjuntamente con varias instituciones públicas, promovió y realiza actualmente una investigación en materia de recursos humanos.

Esta investigación denominada proyecto de "Investigación y Planificación de Recursos Humanos" deberá concluir en la formulación de un Plan Nacional de Recursos Humanos a ser ejecutado en un plazo no menor de 15 años. La consideración explícita de diversos aspectos demográficos y ocupacionales adquiere en la investigación un carácter relevante.

Por su parte, el proyecto "Investigación y Planificación Urbana", que se lleva a cabo bajo el patrocinio de CORDIPLAN y el Fondo Especial de las Naciones Unidas, que está encaminado a examinar los fenómenos de la urbanización, tiene obvias implicaciones demográficas y ocupacionales.

A la luz del comentario anterior, pues, deben considerarse los predicados que bajo la forma de respuesta se expresan a continuación, resumiendo suscintamente la experiencia venezolana respecto al uso de datos y estudios demográficos en la planificación.

Por ley, el suministro de información estadística oficial compete al Ministerio de Fomento a través de la Dirección General de Estadística y 
Censos Nacionales. En la práctica esta Dirección puede delegar, y así lo hace, en algunas agencias gubernamentales la recolección y publicación de datos en áreas específicas de información (verbigracia, la Dirección de Estadística Laboral del Ministerio del Trabajo).

Sin embargo, por múltiples razones, un número importante de instituciones públicas $\mathrm{e}$ incluso privadas generan sus propias estadísticas. 1$]$

Los datos demográficos utilizados por CORDIPLAN para la determinación de las metas de empleo contenidas en el IV Plan de la Nación (1970-1974) son los emanados de la Dirección General de Estadística.

Las proyecciones de población utilizadas en la preparación del IV Plan de la Nación fueron elaboradas por la Dirección General de Estadística básicamente en el año 1969. Dicha elaboración implicó la tarea de actualización de proyecciones confeccionadas en años anteriores.

\section{Uso de las Proyecciones}

a) El nivel de detalle de los datos demográficos utilizados para calcular las demandas que se espera satisfacer en el periodo del Plan en materia de vivienda, educación y salud fue bastante variable y no siempre tuvieron como referencia la distribución urbana-rural de la población. Para las tres (3) áreas de programación señaladas las cifras fueron utilizadas principalmente a nivel de entidad federal (Estados) y de las principales ciudades. En algunos casos, especialmente en materia de salud, se llegó a manejar información por municipios e incluso por parroquias. Dado el carácter agregado del IV Plan, muchos de estos elementos no son observables directamente en él; sin embargo, son claros en los documentos técnicos que sirvieron de base a la elaboración del Plan General.

b) Las diversas implicaciones económico-sociales de la expansión demográfica de Venezuela y del consiguiente incremento de la oferta de trabajadores constituyeron el punto de partida de la programación del empleo, condicionando en gran parte los objetivos en materia ocupacional del Plan 1970-1974.

1/ CORDIPLAN, y en general muchas otras oficinas, están de acuerdo en que la prolongación en el tiempo de múltiples fuentes de datos estadísticos agravaría las ya serias limitaciones que dificultan la formulación y puesta en práctica de la política económica y social. Tales problemas han determinado la reciente constitución de un "Comité de Enlace" entre la Dirección General de Estadística y Censos Nacionales, el Banco Central de Venezuela y CORDIPLAN, con el propósito de lograr la adopción de medidas que permitan encarar favorablemente las dificultades existentes en esta materia. (Gaceta Oficial No 29.559 del 15 de julio de 1971). 
Cuadro 1

VENEZUELA: PERIODO Y AMBITO DE LAS PROYECCIONES DE POBLACION TOTAL Y ECONOMICAMENTE ACTIVA

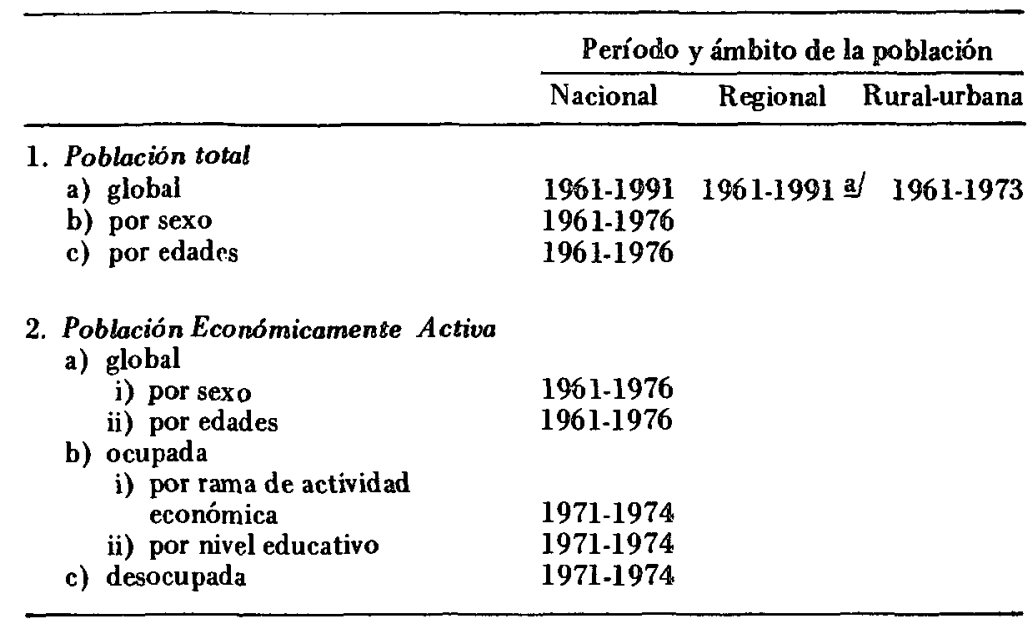

Nota: Este cuadro se refiere sólo a la información demográfica emanada de la Dirección General de Estadística y Censos Nacionales del Ministerio de Fomento. La información sobre población ocupada corresponde a las me tas contempladas en el IV Plan de la Nación.

Existen otras estimaciones, incluso con un mayor nivel de desagregación y abarcando un período más amplio, también elaboradas por instituciones públicas. Sin embargo, estos datos no fueron utilizados en los propósitos de la elaboración del IVPlan.

Una importante salvedad debe señalarse respecto a las cifras publicadas por el Ministerio de Obras Públicas a través de la Comisión del Plan de Aprovechamiento de los Recursos Hidráulicos (COPLANARH), las cuales se utilizaron especialmente para la programación agropecuaria, de infraestructura vial y en menor medida para la programación de la vivienda.

a/ A nivel de entidad federal. También existen proyecciones a nivel de distrito y municipio sólo para el período 1961-1976.

En cifras globales, el Plan prevé la generación de 597 mil nuevos empleos. Siendo esta cifra ligeramente superior al aumento proyectado de la fuerza de trabajo durante el período 1970-1974 (578 mil personas), se estima se producirá un leve descenso en el volumen absoluto de la desocupación de la mano de obra. Sin embargo, la tasa de desocupación se reducirá en forma apreciable, situándose para el último año del Plan en 6,5 por ciento de la población económicamente activa.

i) y ii) La determinación explícita de las metas ocupacionales del Plan implicó un proceso laborioso de trabajo dado que se consideró en 
forma simultánea con las metas de producción, productividad e inversión. El procedimiento utilizado fue el de aproximaciones sucesivas mediante reajustes más o menos continuos en las diversas relaciones macro-económicas cuantitativas tanto globales como sectoriales (verbigracia, coeficiente de inversión bruta, relación marginal capital-producto, producto medio por trabajadores, densidad relativa de capital, etc.).

Tal proceso de ajustes, naturalmente, implicó cambios más o menos importantes en las metas originalmente formuladas del empleo. En especial esto fue cierto para las actividades de la producción agropecuaria, del comercio y de los servicios. Sin embargo, la parcial reformulación de las metas no llevó a la conclusión de establecer políticas especiales de generación de empleo, bajo la forma, por ejemplo, de programas de ocupaciones adicionales. (En el Plan 1963-1966, se encararon, especialmente,situaciones del último tipo).

Existe, sí, una variante de las políticas especiales de empleo, empero su importancia cuantitativa en el IV Plan es realmente insignificante. Dicha variante se refiere a los ensayos en curso para generar empleos mediante programas de autogestión en actividades de reducida escala económica (el presupuesto teórico que subyace tras estos ensayos se fundamenta en el "modelo" denominado de "economias paralelas o compensatorias".

iii) En este punto debe indicarse que independientemente del nivel absoluto o relativo de las diferencias, positivas o negativas, observables entre la población económicamente activa y la población ocupada, en Venezuela, tradicionalmente y a los fines de la programación económica y social, se ha considerado la variable demográfica en forma exógena y no se han establecido polític as para influir deliberadamente sobre la dinámica poblacional.

Sólo muy recientemente se comienza a darle una interpretación diferente a la variable demográfica. Las razones de este cambio aparecen asociadas a los efectos económicos y sociales de la elevada tasa de crecimiento de la población venezolana, asi como a las diversas implicaciones de una fuerte corriente inmigratoria (gran parte de la cual asume un carácter ilegal).

En tal sentido, varios grupos de trabajo analizan bajo una perspectiva interdisciplinaria las caracteristicas y tendencia de comportamiento de la población. Los resultados de tales investigaciones con seguridad permitirán formular una comprensiva política demográfica.

\section{Evaluación de proyectos}

No obstante la importancia del sector público venezolano respecto al esfuerzo de financiamiento de los programas de inversión, bien sea a través del otorgamiento de créditos u otro tipo de facilidades a los 
sectores empresariales privados o mediante la implantación de actividades productivas, directamente bajo su responsabilidad, la programación de las inversiones no ha sido enmarcada bajo definidos criterios de evaluación de proyectos.

Esto no sólo se presenta en los casos de los programas financiados o ejecutados por el sector gubernamental sino que afecta a las actividades del sector empresarial privado.

En verdad, las instituciones públicas dedicadas a la promoción y financiamiento de programas de desarrollo suelen definir áreas prioritarias de actividad, con preferencia la industrial y agrícola, y sobre esa base examinar las demandas crediticias del sector privado.

Sin embargo, sólo en contadas ocasiones se determina adecuadamente la magnitud y características ocupacionales del empleo directamente generado por los proyectos de inversión. Menos frecuente aún es la determinación del efecto multiplicador de empleos de estos proyectos sobre el conjunto de la economia.

A los propósitos de superar dicha situación se dan actualmente pasos iniciales para la creación y puesta en funcionamiento del Sistema Nacional de Promoción y Evaluación de Proyectos, el cual operará adscrito a CORDIPLAN y, entre otras funciones, tendrá las de elaborar e implantar normas y procedimientos para la preparación uniforme de los proyectos, incluyendo criterios para la determinación de las prioridades a conceder a las alternativas de inversión.

La organización del sistema venezolano de planificación establece la existencia tanto de oficinas regionales como de oficinas sectoriales de coordinación y planificación.

Al presente, existen cuatro oficinas del primer tipo y numerosas sectoriales, siendo las principales entre estas últimas las oficinas de planificación y presupuesto de los distintos Ministerios y de los institutos autónomos y empresas del Estado.

Por supuesto, todas estas oficinas utilizan, en mayor o menor medida, diferentes estadísticas demográficas: la práctica, en este caso, consiste en atenerse a las cifras de la Dirección General de Estadística y Censos Nacionales del Ministerio de Fomento, sobre todo en lo que respecta a los datos de población por entidad federal, sexo y edad; si bien en virtud de la naturaleza específica de los datos requeridos, muchas de dichas oficinas generan algunos cálculos sobre población.

Si bien ésta es la práctica corriente, muchas veces se producen duplicaciones innecesarias o bien no se toman como base las estadísticas de la Dirección General. 


\section{A NEXO \\ INDICADORES EST ADISTICOS UTILIZADOS EN LOS \\ ANALISIS DE RECURSOS HUMANOS, FUENTES QUE \\ LOS SUMINISTR AN Y OBSER VACIONES SOBRE \\ SU CONFIABILIDAD 1 \\ (ESQUEMA)}

\section{A. Demografía y estadistica vital}

Información demográfica:

a) Población total

b) Distribución por sexo y edad

c) Estado civil y nacionalidad

d) Localización en las áreas urbanas y rurales y distribución por entidades federales.

e) Tamaño promedio de las familias

Estadistica vital:

a) Tasas de fecundidad y natalidad (global y diferencial)

b) Tasas de mortalidad

c) Tasa de crecimiento de la población

d) Esperanza de vida al nacer

Fuentes:

- Dirección General de Estadística (Ministerio de Fomento)

- División de Epidemiología y Estadística Vital (Ministerio de Sanidad).

\section{B. Población económicamente activa}

\section{Información básica:}

a) Población activa total, distribución por sexo y edad, localización urbana y rural por entidades federales

\footnotetext{
1/ Este anexo intenta resumir un marco normativo de los indicadores estadísticos utilizables (y utilizados) en los análisis de recursos humanos (criterio amplio) en Venezuela. Es, obviamente, muy incompleto y se of rece sólo a título de versión preliminar para discusión.
} 
b) Tasas de actividad e inactividad (global y específica) e índice de dependencia de la población

c) Clasificación de la población activa por grupos y categorías de ocupación y su distribución por ramas de actividad económica

d) Población ocupada (niveles absolutos y relativos) y su distribución por ramas de actividad económica según sexo y edad, localización geográfica.

e) Población desocupada: ídem

f) Población sub-empleada

Fuentes:

- Dirección General de Estadística y Censos Nacionales: Censos de población y encuestas de hogares por muestreo

- Oficina Central de Coordinación y Planificación (CORDIPLAN): encuestas industriales

- Instifuto Nacional de Cooperación Educativa (INCE): encuestas de mano de obra

- Ministerio del Trabajo: informes sobre estadísticas de trabajo.

Observaciones: La información histórica básica sobre población y fuerza de trabajo es de origen censal; la estadística vital se deriva de registros sanitarios y hospitalarios y ambas reflejan con bastante certeza la realidad. La necesidad de disponer de información continua sobre diversas variables demográficas y ocupacionales ha determinado el uso de procedimientos de muestreo. Obviamente, los datos obtenidos por este procedimiento no gozan de la misma certidumbre que los antes citados; sin embargo, a medida que se gana experiencia y se superan fallas y limitaciones en la obtención de la información, su grado de confiabilidad aumenta.

A pesar de la necesidad de disponer de estadísticas confiables sobre los niveles de desocupación, grupos de la población a los cuales afecta y su localización geográfica, esta información es posiblemente la más deficiente. Se considera conveniente que la Dirección de Empleo del Ministerio del Trabajo ofrezca información complementaria sobre los aspectos cuantitativos de la desocupación.

Con relación al sub-empleo, puede decirse que no existe la información sobre su medición.

\section{Niveles educativos de la población}

a) Perfil educativo de la población total y económicamente activa, y para esta última su distribución según ramas o sectores de actividad económica y tipo de ocupación de los trabajadores.

b) Oferta del sistema educativo formal:

i) Matricula educacional por niveles, índices de prosecución escolar. 
ii) Cifras de egresados, distribuidos por niveles educativos, según áreas urbanas y rurales, sexo y edad. En el nivel superior de educación la distribución de la matrícula se hace por especialidad.

c) Oferta del sistema educativo informal:

i) Matrícula en los centros de adiestramiento y capacitación para el trabajo conforme al tipo de especialización y según la naturaleza de la rama de actividad económica donde labora o ha de laborar el aprendiz o adiestrado.

\section{Fuentes:}

- Dirección General de Estadísticas y Censos Nacionales: Censos de Población y Encuestas de hogares

- Ministerio de Educación: Memoria Anual

- Universidades: Informes Anuales

- Instituto Nacional de Cooperación Educativa (INCE): Informe anual.

\section{Productividad de la mano de obra}

a) Producto por trabajador ocupado: global y por sectores económicos

b) Densidad de capital (capital existente por trabajador): global y sectorial.

Fuentes:

- Oficina Central de Coordinación y Planificación (CORDIPLAN):

Departamentos de recursos humanos y programación general.

- Instituto de Productividad (IMPRO): Informes varios.

Observaciones: La información existente sobre la productividad del trabajo es bastante pobre, en general se trata de una sencilla relación entre el valor del producto (global y sectorial) y el número de trabajadores ocupados en su obtención.

Sería inútil disponer de información sobre el rendimiento por hora/hombre trabajada, así como el nivel de rendimiento productivo conforme al grado educativo alcanzado por los trabajadores en los distintos sectores económicos y según las diversas regiones. En este sentido, es necesario obtener mayor información proveniente de organismos especializados en el estudio del problema (especialmente del Instituto Venezolano de la Productividad) y se debe procurar la realización de una encuesta que permita determinar la estructura sectorial de la productividad del trabajo en la economía venezolana y conduzca a la determinación de correlaciones existentes entre el valor global de la producción y los insumos de capital y trabajo (número y calidad). 
Remuneración del trabajo:

a) Sueldos y salarios pagados al personal; (salarios nominales o ganancias medias, tarifas medias de salario) por hora, día, semana o mes; por grupos ocupacionales y ramas económicas.

b) Participación de los sueldos y salarios en el ingreso nacional.

Fuentes:

- Banco Central de Venezuela: Informes anuales

- Ministerio del Trabajo: Informes estadísticos.

Observaciones: Lamentablemente, los datos sobre la remuneracion de la mano de obra en las diversas actividades económicas son muy precarios y se ofrecen por regla general a un nivel muy agregado. Los datos provenientes de las estadísticas del Seguro Social son en la actualidad muy deficientes. Sin embargo, constituyen una fuente potencial de información de utilidad.

Se ha dicho que la distribución factorial del ingreso, tal como se asienta en las estadísticas del Banco Central, posee escasa significación, ya que el carácter global de la remuneración del tralajo esconde las profundas diferencias en los niveles de ingreso.

\section{E. Demandas de mano de obra}

a) En términos totales, por industria, por ocupación y por ubicación.

b) Requerimientos ocupacionales por nivel educativo (especialmente las necesidades de personal de alto nivel).

\section{Fuentes:}

- Oficina Central de Coordinación y Planificación (CORDIPLAN): Sector de Recursos Humanos (Estimación).

- Universidades: Departamento de Programación Educativa.

Observaciones: La información existente es de escasa utilidad para los fines de una verdadera programación del empleo; la naturaleza altamente agregada de las estimaciones sólo puede conformar un marco muy general de referencia.

Convendría conocer la expresión ocupacional del gasto de inversión (multiplicador de empleo) de los diversos programas crediticios de numerosos organismos del Estado, o bien de los programas de inversión de las empresas estatales (Corporación Venezolana de Fomento, Corporación Venezolana de Guayana, Instituto Venezolano de Petroquímica, Corporación Venezolana de Petróleo), etc. 

INIFORPBE FINAL

Versión Definitiva 



\section{INTRODUCCION}

En la ciudad de Santiago de Chile se realizó el Seminario sobre Utilización de Estudios y Datos Demográficos en la Planificación, entre los días 23 y 29 de agosto de 1971, con el auspicio de las siguientes instituciones:

Banco Interamericano de Desarrollo;

Centro Latinoamericano de Demografía;

Comisión Económica para América Latina;

División de Población de las Naciones Unidas;

Institu to Latinoamericano de Planificación Económica y Social;

Organización de los Estados Americanos, Secretaría General, y

Programa Regional del Empleo de América Latina y el Caribe (OIT).

El seminario tuvo su origen en la necesidad cada vez más evidente de intensificar y perfeccionar el uso de datos y estudios demográficos en la planificación del desarrollo cconómico y social, Las instituciones auspiciadoras han ido desarrollando una actividad tendiente a responder a esa necesidad a través de seminarios, estudios, documentos, conferencias, investigaciones, docencia y asistencia técnica, interesando en esa labor a funcionarios responsables de la planificación del desarrollo en los países latinoamericanos.

Los objetivos del seminario fueron los siguientes:

1. Discutir con los funcionarios responsables de los programas de planificación nacional, las posibilidades y perspectivas del uso de los estudios y datos demográficos en la planificación del desarrollo;

2. Discutir los aspectos sustantivos y metodológicos del sistema de interrelaciones entre demografía y planificación y los métodos y técnicas requeridos para incorporar las variables demográficas en la planificación;

3. Discutir en líneas generales el posible contenido de un programa de enseñanza de dichos métodos y técnic as.

El seminario se desarrolló en dos partes. La primera estuvo destinada a identificar los problemas demográficos de mayor importancia para la planificación del desarrollo nacional; examinar la naturaleza del sistema de relaciones mutuas entre la variable "población" considerada en su doble aspecto de factor productivo y de sujeto de necesidades de consumo; especificar las implicaciones que deriven de lo anterior para los enfoques, métodos y técnicas, y definir las necesidades básicas que habría que satisfacer en materia de capacitación y asistencia técnica, 
para que los países puedan disponer, con oportunidad, de la información demográfica para la formulación de las políticas de población y diseñar métodos y técnicas de planificación adecuadas para cumplir el objetivo anterior. En esta primera parte se utilizaron como documentos de discusión los indicados con las claves L. 1 y $\mathrm{L} .1$ Addendum que figuran en la lista de documentos presentados al seminario (Anexo IV).

La segunda parte estuvo destinada al examen detallado de los puntos anteriores y de la utilización de los estudios demográficos en la planificación sectorial y regional. En esta segunda parte se utilizaron documentos de referencia cuya lista se incluye en el Anexo IV.

Durante todo el seminario la discusión se vio enriquecida por el aporte de los participantes, que en el caso de los representantes de las oficinas nacionales de planificación sirvió también de valiosa y actual ilustración de la realidad latinoamericana. En este sentido, es importante destacar que, además, algunos países presentaron al seminario, documentos relativos a las experiencias nacionales (mencionados en la lista del Anexo IV).

El seminario contó con 24 participantes de las oficinas de planificación de 15 países latinoamericanos. Como invitados especiales asistieron los señores Jean Bourgeois-Pichat, Director del Instituto Nacional de Estudios Demográficos de Francia; Dudley Seers, Director del Instituto de Estudios del Desarrollo de la Universidad de Sussex, Inglaterra, y Osvaldo Sunkel, Investigador del Instituto de Estudios Internacionales de la Universidad de Chile, que tuvieron a su cargo la exposición básica de los aspectos a discutirse en el seminario. Considerando a los observadores de los países y de los organismos internacionales, el total de las personas participantes se elevó a 56 . Una lista de ellos figura en el Anexo IlI.

Las sesiones tuvieron lugar en la sede de la CEPAL, de acuerdo con el calendario incluido en el Anexo II.

Inauguró el seminario el Secretario Ejecutivo de la CEPAL, señor Carlos Quintana, quien subrayó que el hecho de "discutir las posibilidades y perspectivas del uso de los estudios y datos demográficos en la planificación del desarrollo implica un reconocimiento que las características y cambios económicos, sociales y demográficos están estrechamente interrelacionados, aun cuando se tenga presente que el sistema de mutua dependencia no sólo es relativamente poco conocido sino que tampoco ha recibido hasta ahora la necesaria atención". 


\section{PRIMERA PARTE}

La primera parte del seminario, destinada a todos los participantes y que ocupó los dos primeros días, estuvo dedicada a la discusión del tema "Los estudios demográficos y la planificación del desarrollo". Es de gran interés reseñar algunos de los aspectos considerados.

\section{DISPONIBILIDAD Y USO DE LOS DATOS DEMOGRAFICOS}

En primer lugar, hubo acuerdo general sobre la utilidad de usar los datos de población, entre otros aspectos, en la cuantificación de las metas y en la consideración de las implicaciones de los cambios que los planes tratan de promover, posibilitando un análisis preliminar de distintas alternativas posibles. Por ejemplo, diferentes proyecciones de población permitirian evaluar la influencia que los cambios en los componentes del crecimiento demográfico podrían tener en el tamaño y la estructura de la población, determinantes éstos muy importantes de los requerimientos y posibilidades de la economía.

Muchos participantes, especialmente funcionarios de las oficinas de planificación señalaron la insuficiencia de información sobre población. La utilización más intensa y apropiada de los datos y de los estudios demográficos en los procesos de planificación puede estar limitada por su disponibilidad, especialmente con el grado de desagregación muchas veces requerido. Se señaló también que, a nivel sectorial, el uso es bastante intenso. En sectores como vivienda, salud, educación, seguridad social, la planificación no podría concebirse sin la utilización de dicha información.

Las deficiencias en cantidad, calidad y adecuación de la información fueron aspectos mencionados insistentemente por los particpantes. Se hizo notar también que la limitación de información es asimismo, motivo de preocupación de los demógrafos, pues esta circunstancia restringe la posibilidad de hacer estudios más profundos y detallados que podrían hacerse dado el grado de desarrollo del análisis demográfico.

Sin embargo, se reconoció que la información sobre población existente en la América Latina es superior en calidad y en cantidad a la disponible en otras regiones poco desarrolladas, y que a veces se presenta el caso que la información existente no se utiliza totalmente. 
Se reconoció también que la disponibilidàd y la adecuación de los datos depende en parte de las demandas que los usuarios hacen a los productores de información. Se señaló que una de las fuentes más importantes de información es el censo de población y que éste puede satisfacer muchos de los requerimientos de planificadores y demógrafos, siempre que se adopten previsiones en las distintas etapas de la elaboración del censo, empezando por la formulación misma de la cédula censal, incluyendo las preguntas y las definiciones apropiadas para el análisis ulterior.

Es conveniente también definir regiones o segmentos geográficos relevantes para cierto tipo de análisis y diseñar un programa de tabulaciones que responda a los objetivos definidos.

Se han hecho progresos, naturalmente. Sin embargo, se podría avanzar más en la medida en que planificadores y demógrafos asumieran una responsabilidad mayor en la programación de los censos. Su intervención en las distintas etapas de la preparación debería ser tomada en cuenta a fin de influir en las decisiones de los organismos encargados de levantar los censos.

Se señaló que sería muy valiosa la intensificación de la colaboración que se ha establecido con el correr de los años entre demógrafos, economistas, sociólogos, y otros científicos sociales. Esta colaboración conduciría a definir mejor las modalidades de utilización de la información demográfica.

\section{LA ELABORACION ESTADISTICA}

Muchos de los participantes estuvieron de acuerdo en cuestionar la utilidad de ciertas categorías estadísticas que se emplean y que generalmente corresponden a modelos de países desarrollados, que no expresan necesariamente la realidad de los países latinoamericanos. Un problema que suele presentarse al elaborar los datos, según se ha comentado reiteradamente, se refiere a la necesidad de disponer de información a un nivel amplio de desagregación para poder hacer análisis más detallados y precisos de esa realidad latinoamericana. Por ejemplo, se señalaron las limitaciones de la clasificación por ocupación y por categoría ocupacional que las oficinas de estadística utilizan siguiendo recomendaciones internacionales. Se observó que en algunos casos se mezclan en una sola categoria personas que pertenecen a estratos socio-económicos muy diferentes, lo que contradice en parte los propósitos que indudablemente se tuvieron en cuenta al recomendar dich as clasificasiones. 


\section{NECESIDAD DE ESTUDIOS SOBRE INTERRELACIONES}

Un tema al que se asignó mucha importancia en las discusiones fue el de las interrelaciones entre las variables demográficas, por una parte, y las económicas, sociales y culturales, por otra. Se señaló repetidas veces la necesidad de intensificar el estudio más profundo y detallado de esas relaciones mutuas. Sin disminuir la importancia de las otras disciplinas sociales, se insistió en ejemplos de relaciones entre demografía y economía. Por ejemplo, se hicieron extensas referencias en conexión con problemas de empleo, subempleo y desempleo, de calificación de la mano de obra, de distribución del ingreso, de consumo, de ahorro, etc. Se indicó como un ejercicio necesario que podrían realizar juntos economistas y demógrafos el de traducir los requerimientos de población activa, en la distribución de esa población, según ocupaciones necesarias, y comparar esta distribución con la que realmente tiene la población. Podria examinarse asi el grado de compatibilidad entre los requerimientos de un plan de desarrollo y las tareas que la población se encuentra en condiciones de desempeñar. En relación con el consumo y su planificación es necesario tomar en cuenta el tamaño y el ciclo vital de las familias, la composición por edad de la población, las corrientes migratorias, etc.

Podrían dedicarse algunos estudios a examinar las tendencias del crecimiento de la población, el tamaño de la familia y la distribución espacial en relación con el ingreso y con la distribución del mismo. Esto tendría a su vez relación con el estudio de las condiciones de las que depende la formación del ahorro. También se mencionó el interés de investigaciones sobre la rentabilidad de las inversiones sociales en campos como alimentación, salud y educación. Se sugirió, además, que en relación con ciertas políticas de población, por ejemplo, la de estímulo de la migración interna, deberian hacerse estudios que tomen en consideración esa política.

\section{LAS VARIABLES DEMOGRAFICAS INCORPORADAS A LOS PLANES COMO DATOS EXOGENOS}

Se discutió repetidas veces, tanto en la primera como en la segunda parte del seminario, el tratamiento que se da a las variables demográficas en el proceso de la elaboración de planes de desarrollo. Se incorporan como datos que no resultan afectados por los cambios económicos y sociales que generará la ejecución de los planes, como si la dinámica demográfica fuera independiente. No es ésta una actitud particular del planificador. Cuando el demógrafo plantea supuestos alternativos dentro de los rangos máximo y mínimo de la posible evolución de las variables demográficas, trata en cierto modo de contemplar los supuestos económicos, sociales y culturales, que hay 
detrás de esas alternativas, pero no pueden ser analizadas profundamente ni las causas ni las circunstancias en que pueda ser más factible la verificación de uno y otro supuesto. En realidad no es esto fruto de falta de percepción del problema por parte de planificadores y demógrafos, sino más bien del estado actual del conocimiento, que todavía no ha avanzado suficientemente en el campo de las interrelaciones entre ambos tipos de variables, según se comentó en el punto 3.

Independientemente del grado de desarrollo del conocimiento sobre interrelaciones entre variables demográficas, económicas, sociales, etc., se ha dicho que el tratamiento de las variables de la población como datos exógenos no es un inconveniente, porque dichas variables evolucionan lentamente, en general, y los cambios son poco perceptibles en el período de cuatro o cinco años a que suelen referirse los planes de desarrollo. En las reuniones se hizo notar a este respecto que muchas veces los planes incorporan medidas que producen sus efectos completos al cabo de un período muy extenso, como ocurre con los grandes proyectos de infraestructura. Sin embargo, no por ello dejan de incorporarse a los planes.

Se hizo hincapié en que los planes deberían ser complementados por análisis que consideraran explícitamente el posible cambio que las variables demográficas pueden experimentar, y su relación con el desarrollo. Más aún, no debería perderse de vista la evolución de dichas variables, porque se ha dado el caso en algunos paises de la América Latina, en que la fecundidad, por ejemplo, ha sufrido variaciones muy grandes en periodos relativamente muy cortos, lo que ha tenido como consecuencia que las estimaciones de población incluidas en los planes de desarrollo quedaran fuera de la realidad.

\section{NECESIDAD DE INTENSIFICAR LA COLABORACION ENTRE ECONOMISTAS Y DEMOGRAFOS}

Las discusiones precedentes subrayaron la necesidad de intensificar la colaboración entre economistas y demógrafos para unificar criterios en análisis interdisciplinarios. Se hizo referencia a la tendencia cada vez may or a incorporar problemas y metas sociales, como la eliminación de la marginalidad en los planes. El reconocimiento del hombre como sujeto del desarrollo abre todo un amplio panorama para los estudios de población vinculados al desarrollo mismo.

\section{DESAGREGACION NECESARIA PARA EL TRATAMIENTO DE LAS RELACIONES ENTRE VARIABLES DEMOGRAFICAS Y ASPECTOS SOCIALES Y ECONOMICOS DEL DESARROLLO}

La incorporación de objetivos sociales a los planes tiende a complementar los tratamientos más puramente económicos. El ritmo de 
crecimiento del producto bruto interno, tomado como indicador del desarrollo, no permite por sí solo apreciar determinados aspectos cualitativos sumamente importantes de este desarrollo. Suele ocurrir que, paralelamente con un ritmo alto de crecimiento económico, haya un agravamiento de determinados aspectos sociales y politicos muy importantes. Por ello es indispensable considerar también explícitamente aspectos relacionados con la calidad de la vida, en particular, la de los sectores de muy bajo ingreso, afectados por problemas de marginalidad, mala alimentación, salud, falta de educación, etc. Esto hace necesario considerar una serie de aspectos en los cuales los estudios demográficos pueden prestar una utilidad considerable si se realizan con un grado adecuado de desagregación. Hay que reconocer que los valores que toman las variables puramente demográficas en los estratos de más bajo ingreso pueden ser muy diferentes del promedio de la población. Se aprecia así que el tratamiento global de tales variables no es apropiado cuando toma la población en su conjunto.

\section{CAPACITACION DE PROFESIONALES}

Hubo acuerdo acerca de la conveniencia de capacitar profesionales para afrontar tareas de vinculación más sistemática y adecuada de la población con la planificación del desarrollo. Para ello se requeriría diseñar un programa de enseñanza que permitiera avanzar hacia la integración de las principales variables demográficas y de los estudios eñ materia de población con los problemas y las políticas de desarrollo.

Hasta ahora y hasta donde alcanza el conocimiento de los participantes en lo que a la América Latina se refiere, tanto la economía como la demografía tienden a ser enseñadas en términos de sistemas de conocimientos independientes entre sí. Sin embargo, estos aspectos tienen relaciones mutuas de indudable importancia en la explicación de

los resultados de determinado proceso. Se reconoció que sería útil un may or conocimiento por parte de economistas y demógrafos de las recíprocas disciplinas. Se trataría de formar economistas y demógrafos que, además del conocimiento específico de sus respectivos campos, tengan nociones firmes de lo que es el sistema social, económico, político, demográfico, etc.

\section{UNIDADES DE ANALISIS DEMOGRAFICO EN OFICINAS DE PLANIFICACION}

Incidentalmente se señaló la conveniencia de reforzar las oficinas de planificación con unidades de análisis demográfico, cuando éstas no existan. Se mencionó que en algunas oficinas de planificación ya operan estas unidades, algunas de ellas vinculadas al área de asuntos sociales. 


\section{SEGUNDA PARTE}

Tal como se detalla en el calendario, la segunda parte estuvo dedicada a la discusión de temas seleccionados. Cada tema estuvo tratado en un documento ad hoc que sirvió de base para la discusión. A continuación se resumen los asuntos más importantes tratados en los documentos y en las discusiones. Los temas se identifican por el título de los documentos y se comentan en el orden en que fueron considerados en el seminario.

\section{OBJETIV OS SOCIALES Y VARIABLES DEMOGRAFICAS EN LA PLANIFICACION}

En el modelo presentado se expone una metodología que trata de incorporar los aspectos sociales a los objetivos del desarrollo económico. Es un modelo que parte del análisis de brechas de financiamiento externo y de ahorro interno y el ajuste de ambas brechas se da como tarea para el planificador. En ese ajuste se señalan los montos de ahorro interno y divisas necesarias para mantener una cierta tasa de crecimiento compatible con determinados objetivos sociales. En segundo término se examinan las metas sectoriales y su coherencia con las globales. Se utiliza un modelo de mejoramiento multisectorial que determina simultáneamente el potencial máximo de crecimiento de la economía, compatible con las restricciones de recursos y la estructura de demanda, y deduce los niveles de producción, empleo, inversiones e importaciones.

Para la determinación de la demanda desde el punto de vista de la relación entre las variables económicas y sociales, por una parte, y las demográficas por otra, se examinan como componentes de importancia el consumo de las personas y del gobierno, y las inversiones. En el primer caso se determina la elasticidad de ingreso de la demanda por tamaño de la familia según sexo, edad, y su cambio a través del tiempo. El crecimiento de la población determinará la restricción de la oferta y las necesidades de mayores recursos. En relación con el consumo del gobierno, los rubros más importantes son: educación pública, salud pública y demanda de alimentos.

La inversión es otro elemento de la demanda final porque su nivel condiciona la capacidad productiva de los diferentes sectores de la economía y también por la creación de puestos de trabajo. A 
continuación se describe la compatibilidad de la demanda final con la demanda intermedia.

El empleo es uno de los aspectos importantes desde el punto de vista del uso de recursos. El problema del empleo tiene dos aspectos fundamentales. Primero, la compatibilidad de la tasa de desocupación a nivel global con los objetivos del plan; segundo, la identificación de determinados tipos de déficit de mano de obra que pudieran dificultar los programas de desarrollo.

La proyección de la población activa se relaciona directamente con el ritmo de crecimiento de la población y las tasas de actividad por sexo y grupos de edades. Se destaca que el ritmo de crecimiento de la población activa dependerá de la tasa de incorporación de jóvenes a la fuerza de trabajo.

En el documento se plantean varias proyecciones alternativas de la población activa. En una de esas alternativas se consideran transformaciones de los patrones culturales; la productividad del trabajo también juega un papel importante en el modelo, en el que se observa que el crecimiento de la ocupación tiene lugar principalmente en los sectores tradicionales y tiende a concentrarse en los sectores agricolas y de servicio. La baja productividad agrícola es el resultado del alto empleo en el sector que estimula la migración a las áreas urbanas. Se menciona también que, en general, es el sector "servicios" el que absorbe la mayor proporción de esta migración. La posibilidad de modificar el ritmo del flujo migratorio rural-urbano y de incrementar la productividad de los servicios es función de la posibilidad que ofrezca el sector industrial para absorber mano de obra en forma productiva.

Para facilitar el ajuste entre oferta y demanda de recursos humanos, es necesario asegurar: primero, una mejor organización del mercado de trabajo y una adecuada movilidad de las ocupaciones; segundo, una organización apropiada del trabajo dentro de la empresa para el mejor aprovechamiento de la mano de obra más escasa; tercero, la aceleración de la capacitación profesional especializada y, cuarto, el mejoramiento de los métodos de enseñanza para lograr mayor productividad que con la educación tradicional. Finalmente, se formulan metas regionales, las que ponen especial énfasis en los objetivos sociales del plan. Se busca una distribución igualitaria del ingreso y de las oportunidades de empleo.

Durante la discusión se destacó la importancia de incluir objetivos de naturaleza social y también respecto a la distribución regional. Se hizo notar que este modelo económico presentado es un modelo cerrado y la información demográfica es agregada como exógena. Se asocia este comentario al hecho de que el modelo considera un plazo relativamente corto, de menos de cinco años, en que las variables demográficas probablemente no van a hacer notar sus consecuencias sobre las económicas. Sin embargo, en un plazo más largo, las consecuencias 
serán perceptibles y por ello el programa debería tomarlas en cuenta. No parece conveniente que el planificador incluya decisiones con repercusiones a mediano o largo plazo, sin tener en consideración esos efectos.

Se mencionó también que entre los objetivos del plan habría convenido agregar la brecha de ocupación y las políticas de población, pues aparte de considerarse necesario, se observa que implicitamente hay en el modelo algunos aspectos que se relacionan con estos problemas. Consecuentemente con algunas discusiones de la primera parte del seminario, se insistió nuevamente aquí en la necesidad de efectuar estudios conjuntos interdisciplinarios para poder determinar de la mejor manera las interrelaciones que pueden existir entre las variables demográficas y las económicas. Se destacó, además, que el modelo era un ejemplo ilustrativo de los primeros pasos que pueden darse para utilizar datos demográficos en las distintas etapas de la formulación de un plan de desarrollo.

Se mencionó que convendría intentar prever las posibles influencias que el comportamiento demográfico puede ejercer sobre variables económicas cuya evolución dentro del plan se supone principalmente afectada por decisiones en el ámbito económico.

También sería conveniente evaluar algunos de los efectos deseados que el comportamiento de las variables demográficas podría tener sobre el plan y los efectos indeseables de esa política. A este respecto se cita como ejemplo el caso de la modernización de la industria textil que, si bien desde el punto de vista económico tiene por efecto un aumento de la producción, desde el punto de vista del empleo puede tener efectos no buscados según ciertas experiencias conocidas, pues ha originado desempleo al eliminar algunos empleos propios de la industria tradicional.

Se debería reflexionar sobre los temas de investigación de interrelaciones de variables económicas y demográficas, que quizás sería conveniente abordar en el futuro para ir dilucidando estas in terrogantes y poder contribuir a la incorporación de las variables demográficas como variables endógenas del programa.

Se señaló también la necesidad de evaluar los efectos que algunas políticas de población definidas por algunos paises, explícitamente en algunos casos y en otros de manera implícita, pueden tener sobre las otras variables y sobre las de tipo económico. En relación con el empleo y las inversiones, algunos piensan que las inversiones adicionales crean empleos, pero también eliminan otros. El crecimiento del empleo estará dado por el saldo neto entre creación y eliminación.

Una sugerencia importante fue la conveniencia de aplicar el modelo a una situación concreta de un país latinoamericano que de alguna manera se acerque, desde el punto de vista de la planificación, a un modelo de desarrollo como el presentado. 


\section{RELACIONES ENTRE VARIABLES ECONOMICAS Y DEMOGRAFICAS: ENSAYO DE UN MODELO}

En los modelos económicos suelen incorporarse los efectos de la dinámica de la población sobre las variables económicas. En el documento que sirvió como base para la discusión de este punto del temario, se presenta un modelo demográfico en el que se explican las relaciones en sentido inverso: algunas de las variables de población son funciones que dependen del proceso económico y social. Es frecuente que en las proyecciones de población no queden explícitas las relaciones que vinculan el status socio-económico con el comportamiento reproductivo, los niveles de mortalidad, los movimientos migratorios y la participación en actividades económicas.

En general esto sucede por no disponerse de información suficiente para cuantificar esas relaciones. La política de desarrollo produce cambios en las variables demográficas y a su vez este cambio afecta en sus aspectos específicos a la secuencia del proceso de desarrollo. Ásí, cambios en los niveles de vida a través de mejores niveles educativos, mejores condiciones habitacionales, mejores niveles de ingreso per cápita, etc., han de implicar cambios en los pátrones de fecundidad especialmente cuando las mejoras se registran en los grupos de fecundidad elevada. Si, al mismo tiempo, el proceso de desarrollo abre posibilidades de trabajo para la mujer, puede reforzar el efecto depresivo sobre la fecundidad, lo que a su vez puede significar mayores posibilidades de que la mujer realice trabajos fuera del hogar.

Teniendo en cuenta estas consideraciones, y mediante la utilización de datos obtenidos en algunos países de la América Latina, se determinaron relaciones entre niveles de vida por una parte, y niveles de fecundidad y tasas de participación femenina en actividades económicas, por otra. Con estas relaciones y dos supuestos alternativos de desarrollo, se prepararon proyecciones de población de América Latina que abarcan el periodo de 1970-2000.

La primera alternativa de desarrollo consistió en suponer que la tasa de crecimiento del producto latinoamericano crecería al mismo ritmo que en el pasado, es decir, 2,1 por ciento anual por persona,mientras que la distribución del ingreso permanecería durante el periodo de la proyección igual a la estimada en 1970. La segunda alternativa supone: 1) que el producto latinoamericano por persona crecerá a una tasa que partiendo de los niveles registrados en el pasado reciente, alcanzaría en 1980 el valor de 5,1 por ciento y 2) una redistribución del ingreso.

Los resultados indican que la fecundidad disminuye en cualquiera de las dos alternativas de crecimiento del producto. Esta disminución es sensiblemente más intensa cuando opera el supuesto de mayor tasa de crecimiento del producto. Relacionados con las tendencias de la fecundidad, se establecieron dos supuestos de participación de la 
población en actividades económicas. Según el primero, la participación sería constante en el tiempo y de acuerdo al segundo, la participación urbana femenina crecería a medida que disminuya la fecundidad, mientras que la masculina disminuiría. Esto da como resultado diferentes tamaños y estructuras por sexo y edad de la oferta de mano de obra. Se destaca la importancia de ejercicios de este tipo a la luz de los resultados que se obtienen. Por ejemplo se menciona que al final de los treinta años de la proyección, según la segunda alternativa en la población habría 20 millones de personas menos que según la primera. De esos 20 millones aproximadamente 18 millones serían niños menores de 15 años.

Obviamente, estas diferencias repercuten en el volumen y en la estructura del consumo de la demanda de servicios educativos, de salud, etc., que cambian en función del tamaño y de la estructura de la población. Aceptando que varían las tasas de participación urbana, aumentando en el caso de las mujeres a medida que su fecundidad decrece, y disminuyendo en el caso de los hombres a medida que evoluciona el proceso de desarrollo, se observa una oferta superior en 3,4 millones a la estimación de la oferta de mano de obra que se deriva al suponer constantes las tasas de participación. Merece subray arse que esta cifra es la composición de dos resultantes también de la proyección. La cifra de 3,4 millones es la diferencia entre 10 millones de puestos adicionales que deberían ser creados por la economía para las mujeres y la eliminación de 6,6 millones de hombres en las actividades económicas. Estas cifras indican, ciertamente, un cambio cualitativo muy importante que el planificador debe introducir explícitamente en su plan y que el demógrafo debe incorporar a sus proyecciones para esos usos específicos.

Una de las primeras preguntas que se formularon algunos participantes fue cuál sería el grado de utilidad de un modelo de simulación de este tipo para una oficina de planificación donde se necesita generalmente de decisiones rápidas y en un momento determinado o si sería mejor dejar estos modelos a nivel académico en las universidades o institutos de investigación.

Se discutió acerca de la aplicabilidad del modelo a situaciones y países específicos. El modelo presentado incluye medidas de las variables demográficas que no necesariamente corresponden a las que tendrían los países de la América Latina, sino que en algunos casos son aproximaciones o supuestos. En respuesta se señaló que el modelo, por contener una secuencia de cálculo que refleja la práctica común para efectuar las proyecciones demográficas es aplicable a situaciones específicas tal como se encuentra, para lo que deberían realizarse las adaptaciones correspondientes con los datos del caso.

Por otro lado, dado que las asociaciones efectuadas entre la fecundidad, la mortalidad, la participación en la actividad económica y 
la evolución económica no se encuentran incorporadas explícitamente en el programa de cómputos sino que se ejecutan como trabajos separados, existe una amplia flexibilidad para poder hacer hipótesis específicas en cada uno de los paises. De este modo se determinaria la posible evolución de dichas variables y se incorporarían estos resultados como datos a programas de cómputo, de tal manera que se puedan obtener resultados asociados a situaciones concretas.

Se señaló que en este modelo ya se está abordando cierto tipo de relaciones entre variables demográficas y económicas que son útiles para la formulación de políticas de empleo. También se dijo que la apreciación más correcta de los problemas del desarrollo que puede lograrse mediante un tratamiento específico de los aspectos demográficos integrados con variables económicas constituye un avance útil para las tareas de planificación. Estos análisis a largo plazo ubican mejor los problemas de mediano plazo en el contexto de una perspectiva histórica adecuada. En la formulación misma de los planes de mediano plazo parecería ser conveniente, tratar las variables de población como exógenas para el periodo de cuatro o cinco años que corresponde al plan. No puede desconocerse sin embargo que pueden darse casos de evoluciones rápidas y fuertes de variables demográficas que caen dentro de estos periodos de mediano plazo y que pueden afectar las formulaciones de políticas.

Algunos participantes sugirieron algunos temas que podrían ser incluidos en trabajos de aplicación o en modelos de esta clase. Por ejemplo, se mencionó la conveniencia de analizar las tasas de participación en las edades extremas, para descubrir de qué manera pueden resultar afectadas por la escolaridad de los jóvenes y por la jubilación o el retiro. Este tipo de consideraciones podría relacionarse con la formulación de una política de empleo. Por ejemplo, la presión sobre el mercado de trabajo podría modificarse sensiblemente si se aumenta la retención escolar o se intensifica el retiro de los activos en edades avanzadas. Desde luego, es necesario conocer las elasticidades que afectan a la participación en las variables mencionadas, como la escolaridad y la jubilación, y los índices económicos relevantes para algunos casos, como podría ser el ingreso.

Otro aspecto que debería ser incluido es el de la diferenciación urbano-rural. En lo que a distribución territorial de la población se refiere, debería, además, subrayarse la importancia del problema de la migración que parece muy relevante cuando se trabaja en políticas de empleo.

El conocimiento de las características de los migrantes y de los motivos para migrar ayudarían a definir una política de empleo. Es posible que un poblador de un "minifundio" tenga parámetros demográficos totalmente diferentes de los que tendría el poblador de un "latifundio" moderno. 
Otro tema importante, que podría ser incluido en este tipo de estudios, es el relativo a estudios demográficos específicos para grupos sociales. A pesar de no contarse con estudios y datos adecuados para la investigación demográfica de grupos sociales, pueden intentarse, sin embargo, algunas aproximaciones relacionando, por ejemplo, la mortalidad y la fecundidad con la ocupación de las personas. El problema mayor para hacer estudios más profundos y refinados es la deficicncia de la infomación estadistica. Por ejemplō, si exisisienán informaciones sobre las defunciones relacionadas con la ocupación o sobre la fecundidad de la mujer con la ocupación de los maridos, podrían hacerse estudios más refinados.

A través de encucstas, en particular las patrocinadas por el CELADE, se está proporcionando información que en parte está ya disponible. Alguna se ha incorporado ya al documento discu tido.

Trabajos de investigación de esta naturaleza son necesarios para lograr avances en el análisis de las interrelaciones de las variables demográficas y las variables de otro orden. El uso de modelos de simulación es una técnica distinta que se está utilizando a modo de laboratorio en las ciencias sociales.

\section{SECUENCIA DEL PROCESO DE FORMULACION DE METAS DE EMPLEO EN LA PLANIFICACION}

Se discutieron diferentes aspectos de los pasos metodológicos que incluyen la formulación de planes de desarrollo con objetivos de empleo. Se mencionó que la consideración de la disponibilidad de recursos humanos es el punto de partida para fijar las metas preliminares respecto a las tasas de ocupación. La información demográfica es esencial en esa etapa debiendo considerarse la necesidad de incorporar las variables de población al mismo modelo, dadas las interrelaciones que se verifican entre desarrollo y comportamiento demográfico.

La determinación del empleo en los sectores rurales es una función de la disponibilidad de recursos naturales, de la capacidad de absorción productiva de la mano de obra y de la demanda por este tipo de bienes.

En los sectores urbanos habría que distinguir entre los productores de bienes materiales y los de servicios. En relación a los primeros, la tecnología empleada representa un papel central en la estrategia de empleo. En los últimos sectores, la atención del planificador debe centrarse en las normas de prestación de esos servicios, derivando de ahí su capacidad de absorber mano de obra.

La metodología como tal no es secuencial sino formalmente dada y a cada paso habrá que estudiar la compatibilidad total entre metas y resultados. En general, los participantes estuvieron de acuerdo en que el 
balance de recursos humanos es una metodología apropiada para hacer compatibles a corto, mediano y largo plazo, la disponibilidad de recursos humanos y la capacidad de absorción de mano de obra.

La gran diferencia de los planes económicos en la América Latina tiene mucho que ver con la información demográfica insuficiente, inadecuada o rezagada en el tiempo. Esta circunstancia puede llegar hasta determinar el fracaso de modelos matemáticamente muy sofisticados y se debe en gran medida a la falta de personal especializado. En ese sentido se consideró conveniente continuar los esfuerzos por mejorar el sistema global de información, especialmente en lo que se refiere a población, y apoy ar las iniciativas de capacitación interdisciplinaria.

Desde el punto de vista de los resultados de la planificación, los planes a largo plazo poseen la ventaja de abarcar un período tal que permite coordinar todas las medidas tendientes a producir los cambios institucionales indispensables para garantizar el empleo productivo de la fuerza de trabajo.

En relación con el tema del empleo se plantearon problemas que revisten gran importancia. Uno de los determinantes de la oferta futura de la mano de obra se relaciona con el grado de utilización actual de la que existe disponible. Adquiere así gran interés el obtener las mejores mediciones del desempleo y especialmente del desempleo disfrazado y del subempleo, que se localizan principalmente en determinadas ramas de actividad como la agricultura, por ejemplo. Dos son las dificultades que se mencionaron como las fundamentales para hacer esas mediciones. Una es la falta de información adecuada. Otra, los criterios utilizados para definir el desempleo disfrazado y el subempleo. Estas mediciones son particularmente importantes para definir la política de creación de empleos, cuando el desempleo, el desempleo disfrazado y el subempleo alcanzan proporciones como las que pueden observarse en la América Latina (de un tercio a la mitad de toda la mano de obra).

La elaboración de un plan para absorber toda esa mano de obra en un plazo de cinco años tiene grandes implicaciones políticas.

Hay otro aspecto que merece amplia atención de los planificadores por sus repercusiones negativas sobre el empleo, y es el riesgo que ciertas inversiones puedan determinar una disminución del empleo, especialmente cuando se hacen en sectores modernos.

Finalmente se mencionó que la selección de tecnologías se ha basado hasta el presente en consideraciones que no toman suficientemente en cuenta aspectos de los costos y beneficios sociales de la inversión. Por otro lado, se subray a que se pueden producir discrepancias en tre costos y beneficios sociales según sean los plazos con los que se trabaje. 


\section{LA UTILIZACION DE DATOS DEMOGRAFICOS Y EL TRATAMIENTO DE LAS VARIABLES DE LA POBLACION EN PLANIFICACION DE LA SALUD}

En el sector de la planificación de la salud interesan los datos y los estudios demográficos desde un doble punto de vista, primero, con respecto a la interrelación que existe entre la población y la salud y segundo, con referencia a la población como sujeto de los servicios de salud.

En la etapa del diagnóstico de la situación de la salud de la población y en el establecimiento de las metas de salud es importante tomar en cuenta las influencias que sobre ésta ejercen las variables demográficas. Destacan entre ellas, por su relación con las condiciones de la salud, los patrones de distribución geográfica, las formas de asentamiento y las densidades rurales y urbanas, las migraciones interiores, la composición por sexo y edades y determinadas características socio-culturales y laborales.

La planificación de la salud requiere del conocimiento del nivel y de la estructura de la salud; de la explicación de éstos por medio de los factores que los afectan; de la proposición de un modelo de salud congruente con el modelo de desarrollo general hacia el que se orienta la sociedad en el futuro: de la configuración de una estrategia para alcanzar dicho modelo, que sea compatible con las estrategias de los demás sectores del desarrollo $\mathrm{y}$, finalmente, de la elaboración de los planes, la programación de las actividades, la evaluación y el reajuste permanente.

El nivel y la estructura de la salud tienen como elementos explicativos a las características de la población y dentro de un criterio epidemiológico extendido, constituyen la expresión de la susceptibilidad básica y de la exposición a los riesgos para la salud que, en interacción con el ambiente, resultan en diversos daños. La composición por sexo y edades se manifiesta a través del grado de susceptibilidad y/o exposición de acuerdo con el riesgo diferencial de las enfermedades específicas.

Los migrantes pueden modificar la estructura de la morbilidad de las áreas de atracción, como portadores de una patología nueva o por su mayor grado de susceptibilidad a enfermedades endémicas de esas zonas. Los patrones de distribución geográfica y las densidades pueden actuar indirectamente, a través de las posibilidades de provisión de servicios médicos y sanitarios, o, más directamente, por la "densidad social" cuando se trata de enfermedades mentales u otros desarreglos de la conducta.

Por último, características tales como grupo étnico, educación, ocupación e ingresos intervienen en la situación de la salud a través de la alimentación, la vivienda, los hábitos higiénicos, los riesgos profesionales directos, etc. 
En función del sexo y la edad varía necesariamente el tipo de servicios requeridos. Por otra parte, la distribución de los recursos de salud no coincide con la distribución geográfica de la población, en el sentido de que los primeros están concentrados en las áreas de mayor demanda efectiva y de mayor densidad de población. Los cambios rápidos en el volumen de la población de algunas áreas, como sería en las ciudades importantes, generalmente no hallan una respuesta rápida en la provisión de servicios de salud, por la relativa rigidez de la infraestructura de prestación de servicios del sector de la salud.

El sistema de información del sector salud es inadecuado. No obstante, en algunas áreas, bajo determinados programas de salud, se han establecido registros continuos de los hechos de la población que pueden ser utilizados para investigar diversos aspectos demográficos. Un ejemplo de estos registros se encuentra en los programas de control antimalárico.

Sin embargo, la disponibilidad de información demográfica con oportunidad y con la desagregación necesaria no es la más adecuada, aunque también puede ser cierto que en el campo de la salud no se utilizan con mayor profusión categorías de análisis de población disponibles, por las dificultades de manejo de las categorías conceptuales.

En la formulación del diagnóstico de las condiciones de la salud, es esencial tener, por lo menos, la siguiente información:

i) la población de áreas pequeñas;

ii) la clasificación urbano-rural de la población, por su relevancia respecto al tipo de problemas y de calidad o clase de servicios a brindar;

iii) la composición por sexo y edades;

iv) los aspectos socio-culturales de la población asociados al estado de salud,

v) las pautas de utilización de los servicios vinculados con distancias y aspectos psico-sociales de los usuarios.

El modelo de salud que se propone dentro del proceso de planificación tiene que ser un modelo de cambio y no tiene necesariamente que coincidir con el pasado. Si es así, tanto el impacto de las acciones de salud sobre la mortalidad y sobre la fecundidad, como el impacto de las acciones provenientes de otros sectores, tendrían que ser evaluados por el sector salud y tomados en cuenta para las estimaciones y proyecciones de la población.

La salud, considerada como sector social, no puede limitarse a evaluar el impacto de sus acciones en términos de mortalidad. Su misión va más allá, puesto que le corresponde prevenir la enfermedad, aliviar el dolor, curar al enfermo, rehabilitar al incapacitado y prolongar la vida. Todo esto se traduce en conocer la magnitud de los problemas y disponer de los recursos para llevar a cabo las actividades que se concentran en los grandes campos de la previsión y de la atención de la demanda. 
En cualquier caso, la información acerca de la población es imprescindible puesto que permite evaluar los problemas y estimar las dimensiones de los recursos para resolverlos.

En los objetivos de salud deberían tenerse presentes los problemas particulares de cada país y de cada región y sus posibilidades generales y formas de desarrollo económico social. Deberían considerarse, además, con enfoques distintos aquellos problemas que pueden tener solución por aplicación de los adelantos tecnológicos, como puede ser el control de las enfermedades infecciosas y parasitarias, y aquéllos que, en buena medida, están estrechamente vinculados a los niveles de vida, como son, por ejemplo, el tratamiento de las enfermedades crónicas, la salud materno infantil y otras situaciones.

Existen también algunos aspectos de importancia a considerar, como los efectos de las acciones de salud sobre la mortalidad y la fecundidad. Las investigaciones médicas que realice el sector de la planificación de la salud sobre los factores médicos y sociales de la morbilidad y la mortalidad serán de gran provecho para la formulación de proyecciones de la mortalidad.

Las prácticas higiénicas y la asistencia médica que hacen posible reducir la mortalidad infantil, podrían, a través de un cambio de actitud de las madres hacia el cuidado de los hijos, facilitar cambios en el número de hijos tenidos $\mathrm{y}$, en consecuencia, en el nivel de la fecundidad.

La fecundidad no es un efecto importante para el sector salud salvo que se considere de manera tangencial. Su inclusión dentro de la planificación de la salud se justifica siempre que tenga características de política expresa, $y$ en este caso es sólo informativa para la programación de actividades destinadas a la atención de la demanda espontánea. En cambio, si existe política definida, las acciones de planificación de la familia podrían incorporarse al contenido de la planificación sectorial y, por lo tanto, se podrían fijar metas, asignar recursos, programar actividades y medir los efectos. En este caso, es imprescindible el uso de la información y de las técnicas demográficas.

\section{ASPECTOS DEMOGRAFICOS DE LA PLANEACION DE LA EDUCACION}

Dado el grado de desarrollo de la planificación de la educación es en las etapas del diagnóstico y del pronóstico en las que se hace un uso más intenso de la información demográfica. También aquí, como en otros sectores de la planificación, puede observarse que en la etapa del pronóstico se utiliza la información demográfica como si el proceso de la evolución de la población estuviera dado fuera del sistema o del proceso de la planifícación de la educación, sin tomar en cuenta los posibles cambios derivados en la dinámica demográfica, introducidos 
por el propio proceso de la planificación y que, por otro lado, no recoge las posibles alternativas derivadas del cambio demográfico inducido. Tanto en el diagnóstico como en el pronóstico, existe la posibilidad de que el demógrafo colabore con el planificador de la educación en otros aspectos que van más allá de la proyección de la población escolar.

La medida del analfabetismo, ligada con características demográficas de la población, como sexo, edad y lugar de residencia, permiten hacer inferencia sobre la situación educativa actual y la pasada. Estas deducciones sirven además para el análisis de las tendencias y para la extrapolación de las mismas. A través de técnicas específicas es posible realizar la evaluación de la situación educativa.

Se dice también que el conocimiento de la situación educativa, en relación con la distribución territorial de la población, es indispensable para la cvaluación de los requerimientos y para la formulación de metas a nivel regional.

Un aspecto muy importante es el efecto que el comportamiento demográfico puede tener sobre algunas medidas del rendimiento educativo. Por ejemplo, cuando mediante la utilización de indicadores, como las tasas de analfabetismo o el número medio de años de instrucción, se trata de evaluar la eficiencia de la capacidad instalada del sistema escolar en diferentes zonas del territorio. Esos indicadores dan una medida aproximada de la eficiencia del sistema, en términos cuantitativos. Es parcialmente aproximada porque los valores que alcanzan esos indicadores, por ejemplo en la zona urbana y en la zona rural, están afectados por el proceso de migración interna.

En varios casos analizados, se verificó que el grupo migrante de la zona rural a la zona urbana parece tener un nivel de instrucción más elevado que el de la población de origen, pero más bajo que el de la población de destino. Esta circunstancia explica que el movimiento migratorio deteriore simultáneamente los niveles de instrucción de la zona ru ral, de origen, y de la urbana, de destino.

Este tipo de hallazgo mueve a algunas reflexiones. Cuando el planificador de la educación especifica las metas, trata de eliminar las diferencias de nivel de instrucción entre las diversas regiones del país y asigna una mayor cantidad de inversiones de todo tipo a las zonas donde el nivel de instrucción es más deficiente. Surge la duda de si el planificador verá cumplidas sus metas si no' toma en cuenta el efecto que la migración interna puede tener en los resultados del programa.

Finalmente se formulan algunas preguntas. Si se eleva el nivel de instrucción en las zonas rurales, ¿se estará estimulando al mismo tiempo la migración interna? Esa migración, ¿facilitará o dificultará el proceso? Estas y otras preguntas sugieren la necesidad de investigar más profundamente la relación entre la demografía y la planificación de la educación. 
Durante la discusión se mencionó que al comparar la población en edad escolar con la población escolar en la América Latina, se hace evidente una demanda de educación todavía insatisfecha. Por el alto volumen actual que tiene esa demanda parece muy difícil que pueda ser cubierta con los métodos tradicionales de enseñanza. Existe hoy la posibilidad de cambiar sustancialmente los métodos tradicionales de enseñanza por otros que tendrían la gran ventaja de llegar más lejos y más masivamente. Fntre otros, se menciona como un ejemplo el proyecto de educación por satélite apoyado por varios países y por organizaciones internacionales. Un método de este tipo permitiría llegar a las regiones apartadas de un país y aparentemente las más necesitadas, dado que el nivel de instrucción es más bajo cuanto más dispersa es la población.

Desde luego, el análisis de la demanda de servicios educativos requiere proyecciones de población escolar y se subraya que es necesario ser muy cuidadoso en la realización de las proyecciones. La preocupación por las variables macroeducativas debe complementarse con el análisis de las variables microeducativas. Para la adopción de decisiones se requiere información cada vez más detallada y de disponibilidad más rápida. Sería conveniente disponer de oficinas de investigación muestral como un medio de mantener información actualizada en el momento en que se necesite.

También hay acuerdo en la necesidad de discutir el significado de términos como "urbano" o "rural". El criterio numérico que generalmente se utiliza para hacer la diferencia de núcleos de distintos tamaños que tienen ciertas características, no es el adecuado. También deberían hacerse esfuerzos para revisar el concepto de alfabetismo que debería incluir más requisitos que los de ser capaz de leer y escribir.

La relación entre la educación y la migración interna motivó diferentes reacciones entre los participantes. Algunos expresaron que tal vez pudieran estimularse $y$ dirigirse los movimientos migratorios interiores a través de la educación. Otros manifestaron sus temores de que pudiera pensarse en términos restrictivos desde el punto de vista de la instrucción, con el propósito de frenar los movimientos migratorios, si alguna política se fijara ese objetivo.

Algunos participantes expusieron que, siendo la educación un derecho por sí misma no debería utilizarse como un medio de satisfacer determinadas políticas de población. Se mencionaron otros requerimientos que el planificador de la educación podría hacer al demógrafo. Por ejemplo, colaboración para medir la eficiencia del sistema pedagógico a partir de las entradas y salidas del sistema educativo; cómo medir las pérdidas, la repetición, el abandono, etc.

A corto y a mediano plazo, el planificador de la educación necesita conocer los resultados de la influencia de hechos determinantes, precisa enterarse de los datos relativos a la población en edad escolar, según 
por el propio proceso de la planificación y que, por otro lado, no recoge las posibles alternativas derivadas del cambio demográfico inducido. Tanto en el diagnóstico como en el pronóstico, existe la posibilidad de que el demógrafo colabore con el planificador de la educación en otros aspectos que van más allá de la proyección de la población escolar.

La medida del analfabetismo, ligada con características demográficas de la población, como sexo, edad y lugar de residencia, permiten hacer inferencia sobre la situación educativa actual y la pasada. Estas deducciones sirven además para el análisis de las tendencias y para la extrapolación de las mismas. A través de técnicas específicas es posible realizar la evaluación de la situación educativa.

Se dice también que el conocimiento de la situación educativa, en relación con la distribución territorial de la población, es indispensable para la evaluación de los requerimientos y para la formulación de metas a nivel regional.

Un aspecto muy importante es el efecto que el comportamiento demográfico puede tener sobre algunas medidas del rendimiento educativo. Por ejemplo, cuando mediante la utilización de indicadores, como las tasas de analfabetismo o el número medio de años de instrucción, se trata de evaluar la eficiencia de la capacidad instalada del sistema escolar en diferentes zonas del territorio. Esos indicadores dan una medida aproximada de la eficiencia del sistema, en términos cuantitativos. Es parcialmente aproximada porque los valores que alcanzan esos indicadores, por ejemplo en la zona urbana y en la zona rural, están afectados por el proceso de migración interna.

En varios casos analizados, se verificó que el grupo migrante de la zona rural a la zona urbana parece tener un nivel de instrucción más clevado que el de la población de origen, pero más bajo que el de la población de destino. Esta circunstancia explica que el movimiento migratorio deteriore simultáneamente los niveles de instrucción de la zona rural, de origen, y de la urbana, de destino.

Este tipo de hallazgo mueve a algunas reflexiones. Cuando el planificador de la educación especifica las metas, trata de eliminar las diferencias de nivel de instrucción entre las diversas regiones del país y asigna una mayor cantidad de inversiones de todo tipo a las zonas donde el nivel de instrucción es más deficiente. Surge la duda de si el planificador verá cumplidas sus metas si no toma en cuenta el efecto que la migración interna puede tener en los resultados del programa.

Finalmente se formulan algunas preguntas. Si se eleva el nivel de instrucción en las zonas rurales, ¿̇se estará estimulando al mismo tiempo la migración interna? Esa migración, ¿́facilitará o dificultará el proceso? Estas y otras preguntas sugieren la necesidad de investigar más profundamente la relación entre la demografía y la planificación de la educación. 
Durante la discusión se mencionó que al comparar la población en edad escolar con la población escolar en la América Latina, se hace evidente una demanda de educación todavía insatisfecha. Por el alto volumen actual que tiene esa demanda parece muy difícil que pueda ser cubierta con los métodos tradicionales de enseñanza. Existe hoy la posibilidad de cambiar sustancialmente los métodos tradicionales de enseñanza por otros que tendrían la gran ventaja de llegar más lejos y más masivamente. Fntre otros, se menciona romo un ejemplo el proyecto de educación por satélite apoyado por varios países y por organizaciones internacionales. Un método de este tipo permitiría llegar a las regiones apartadas de un país y aparentemente las más necesitadas, dado que el nivel de instrucción es más bajo cuanto más dispersa es la población.

Desde luego, el análisis de la demanda de servicios educativos requiere proyecciones de población escolar y se subraya que es necesario ser muy cuidadoso en la realización de las proyecciones. La preocupación por las variables macroeducativas debe complementarse con el análisis de las variables microeducativas. Para la adopción de decisiones se requiere información cada vez más detallada y de disponibilidad más rápida. Sería conveniente disponer de oficinas de investigación muestral como un medio de mantener información actualizada en el momento en que se necesite.

También hay acuerdo en la necesidad de discutir el significado de términos como "urbano" o "rural". El criterio numérico que generalmente se utiliza para hacer la diferencia de núcleos de distintos tamaños que tienen ciertas caracteristicas, no es el adecuado. También deberian hacerse esfuerzos para revisar el concepto de alfabetismo que debería incluir más requisitos que los de ser capaz de leer y escribir.

La relación entre la educación y la migración interna motivó diferentes reacciones entre los participantes. Algunos expresaron que tal vez pudieran estimularse $\mathrm{y}$ dirigirse los movimientos migratorios interiores a través de la educación. Otros manifestaron sus temores de que pudiera pensarse en términos restrictivos desde el punto de vista de la instrucción, con el propósito de frenar los movimientos migratorios, si alguna política se fijara ese objetivo.

Algunos participantes expusieron que, siendo la educación un derecho por sí misma no debería utilizarse como un medio de satisfacer determinadas políticas de población. Se mencionaron otros requerimientos que el planificador de la educación podría hacer al demógrafo. Por ejemplo, colaboración para medir la eficiencia del sistema pedagógico a partir de las entradas y salidas del sistema educativo; cómo medir las pérdidas, la repetición, el abandono, etc.

A corto y a mediano plazo, el planificador de la educación necesita conocer los resultados de la influencia de hechos determinantes, precisa enterarse de los datos relativos a la población en edad escolar, según 
edades, sexo, discribución urbano-rural. Además, para la planificación regional, requiere información de la distribución geográfica a nivel distrital, municipal, etc.

Todas estas características son importantísimas si se considera la necesidad de incorporar anualmente un gran volumen de población en edad escolar, al proceso educativo de los países de la América Latina, lo que significa asignar recursos humanos, físicos y financieros que representan una proporción importante de los recursos disponibles. Sin embargo, las variables demográficas no son las únicas que deberian tenerse en cuenta. Variables como repetición y deserción son seguramente de mayor significación, ya que su incidencia en el alfabetismo es uno de los problemas que tienen que resolver los planificadores.

Alguien señaló la importancia de distinguir entre número de años de instrucción y educación. La primera es una medición de tipo formal, mientras que la segunda sería no solamente la cantidad de conocimientos adquiridos dentro o fuera de la escuela, sino la aptitud y el desarrollo de las personas para desenvolverse y sobrevivir.

Ante la preocupación expresada por otros participantes en el sentido de que sería conveniente disponer de proyecciones de población por áreas pequeñas, se mencionó que todavía hay dificultades de tipo metodológico para poder hacer buenas proyecciones, dificultades que arrancan desde las fuentes de información, que suelen no ser lo suficientemente detalladas como para hacer estudios profundos que permitan mejorar los métodos de estimación.

Es necesario también, estudiar el impacto que el cambio en las variables demográficas, como por ejemplo la fecundidad o la mortalidad, tendría sobre la capacidad instalada del sistema. Un descenso rápido de la fecundidad, como ha ocurrido en algunos países de la América Latina, ha significado una merma de la presión que la población hacia sobre el sistema educativo.

6. EL USO DE DATOS Y ESTUDIOS DEMOGRAFICOS

EN LA PLANIFICACION DEL DESARROLLO REGIONAL

Este tema fue tratado en dos partes. La primera se refiere a las variables demográficas requeridas por la planificación regional. Se considera que la información demográfica es un elemento importante, tanto para la caracterización de las unidades territoriales como para el análisis de los flujos de factores de producción entre esas unidades. Desde el diagnóstico inicial hasta la evaluación y el control de la realización de un plan regional es necesario usar datos y estudios demográficos. Hay una importantísima limitación que las fuentes de datos de población suelen presentar. Estos datos generalmente se refieren a unidades político-administrativas que difícilmente coinciden con regiones 
definidas para la planificación. De ahí que es esencial obtener la información con el mayor grado de desagregación posible para que pueda ser reagrupada convenientemente. Probablemente, en ningún sector es más indispensable el conocimiento de las corrientés migratorias, de las características de los migrantes y de los factores determinantes y asociados con la migración. Sé señaló la importacia de los censos para las mediciones necesarias, pero el conocimiento más profundo dependerá en gran medida de estudios por muestreo.

En el proceso de la urbanización es fundamental la distinción entre población urbana y población rural. Ambas poblaciones difieren con frecuencia en sus modalidades de producción y de consumo y en sus requerimientos de obras de infraestructura. También difieren en sus características personales, culturales, económicas, etc. Sin embargo, esta dicotomía no es suficiente para fines más específicos del desarrollo regional. Es necesario estudiar la forma de asentamiento de la población en localidades de diferente tamaño, de distinta organización económica, etc.

La parte de fondo del documento es un caso de aplicación concreta de ciertas metodologías al Perú y un modelo que responde a la formulación de una nueva estrategia regional. Entre los males profundos figuran los grandes desequilibrios regionales, no solamente en cuanto a la satisfacción de las necesidades de la población, sino también respecto a las condiciones de aprovechamiento de todos los recursos potenciales y a la utilización de los recursos humanos disponibles. Uno de los factores más importantes del desequilibrio se refiere a las condiciones de ocupación física del territorio y a las tendencias de los movimientos migratorios. Entre las soluciones adoptadas figura la promoción de importantes cambios en las condiciones de ocupación del espacio nacional que requerirá la adopción de complejas políticas específicas con el fin de enfrentar a largo plazo grandes movimientos migratorios.

La metodología usada se basa en un indicador que mide el grado de concentración de la población que vive en las distintas unidades territoriales, con respecto a la población total. Dicho indicador se expresa como el cociente entre la densidad de una unidad territorial y la suma de las densidades de todas las unidades territoriales. Mediante el uso de diferentes combinaciones del indicador es posible clasificar a las unidades territoriales en tres grandes grupos:

a) Zonas de ocupación total, donde existe sobreocupación física relativa en las dos zonas, urbana y rural;

b) Zonas de ocupación parcial, con sobrepoblación relativa en una sola de las zonas, clasificadas en dos subgrupos: urbano y rural;

c) Zonas de subocupación, que presentan una condición de subpoblación relativa total en ambas zonas. Según el valor de la densidad rural con respecto al valor crítico de un habitante por $\mathrm{Km}^{2}$, pueden clasificarse en dos subgrupos: zonas de subocupación y zonas 
vacías. Con el propósito de tener una imagen tan real como sea posible, es conveniente tomar en cuenta las superficies aprovechables.

A fin de precisar los objetivos fijados en la estrategia nacional se definió un objetivo imaginario de las zonas urbana y rural para el año 1990 sobre la base de una serie de supuestos demográficos y económicos que configurarían los cambios de la población en el futuro. Se incluyeron 40 variables y cerca de 35 parámetros y el tipo de análisis utilizado corresponde a un modelo de planificación que no presenta relaciones matemáticas. Los resultados obtenidos muestran cambios drásticos en la distribución territorial de la población del Perú, que se supone que satisfarán los fines del desarrollo regional.

Se formularon observaciones relacionadas con los fundamentos de los cálculos efectuados para el caso del Perú. Además, otras observaciones con algunos aspectos de tipo general sobre el tratamiento demográfico en la planificación regional.

A este respecto se acentuó la necesidad de efectuar un análisis más estrecho entre la población y el proceso de migración. Es también necesario un análisis detallado de la población y las condiciones de ocupación y de asentamiento específico en áreas regionales. Este análisis se debe vincular a las condiciones socio-económicas generales que inciden en la distribución geográfica de las poblaciones.

Es útil contar con datos relacionados con la población agrícola y no solamente rural, de modo de tener una visión directa sobre la población sustentada por las actividades agrícolas.

Otro aspecto mencionado fue el referente al tratamiento de la migración de manera de relacionarla no sólo con las transferencias rurales-urbanas, sino, además, con los desplazamientos rurales-rurales. Además, estos desplazamientos, como parte de la política de desarrollo, habrían de estar unidos necesariamente con las condiciones de una planificación urbana. Es una necesidad urgente contar con análisis que permitan aclarar cómo lograr esos desplazamientos de población en forma planificada. Se necesitan estudios sociológicos para comprobar la viabilidad de esos desplazamientos. Debe tenerse cuidado en el uso de coeficientes del tipo hombre/tierra, por su carácter agregado.

Un trabajo como éste debería incluir consideraciones sobre el desarrollo urbano. Existen problemas de demandas en lo urbano, en la vivienda, en el transporte, etc., y se requiere la participación de demógrafos para realizar estudios de esta naturaleza.

No puede tomarse ninguna decisión de planificación que pueda basarse en las tasas, sino que ellas dependen de las decisiones políticas. Se requiere muchos más conocimientos para interpretar las tasas que comúnmente se utilizan en la planificación regional.

La reforma agraria en los asentamientos campesinos altera la relación entre ciudad y zona rural. En la etapa del diagnóstico previo a la planificación del desarrollo debe hacerse un estudio de las tendencias y 
de la estructura de la población, en el cual la desagregación espacial tuviera un papel destacado y que debiera incluir la consideración de los siguientes temas:

i) el crecimiento de la población y su redistribución geográfica;

ii) las tendencias de las variables demográficas que determinan esa dinámica;

iii) la estructura por sexo y edad de la población en diferentes áreas $y$ localidades;

iv) el proceso de urbanización y las formas de asentamiento rural y urbano de la población, $y$

v) las tendencias de la participación en la actividad económica.

Los datos y estudios demográficos son útiles para el trabajo en otras etapas de la planificación del desarrollo regional, como el establecimiento de objetivos y su cuantificación, y la evaluación de los planes. Se reconoció la gran utilidad de los distintos tipos de proyecciones demográficas.

Los resultados de los estudios demográficos mencionados deberían incluir factores económicos, sociales, culturales, etc., que determinan los cambios en las variables demográficas o están influidos por ellas.

En particular se destacó la necesidad de que en el estudio de la migración interna (que se consideró el campo más necesario e importante en el aporte de la demografía) se tratara de determinar, no solamente los flujos migratorios y algunas características de los migrantes, sino también sus motivaciones para migrar y la forma en que se realice el proceso de integración al medio urbano.

Es importante establecer el volumen de los recursos naturales y humanos a fin que al determinar la localización de los mismos se puedan planificar los flujos migratorios necesarios para alcanzar las metas propuestas en los planes.

Es importante incluir la categoría población agrícola en el análisis de la distribución espacial de la población.

\section{PROGRAMA DE ADIESTRAMIENTO SOBRE POBLACION Y PLANIFICACION DEL DESARROLLO}

El conocimiento de las relaciones entre las variables demográficas y las socio-económicas es insuficiente y, por eso mismo, rara vez se las toma en cuenta de manera sistemática en la planificación nacional. Hay diferentes campos en los que debería hacerse esfuerzos para incorporar esas interrelaciones. En algunos de esos campos, educación, salud, desarrollo urbano y rural y empleo, se percibe la intensidad de la interacción sin que pueda cuantificarse adecuadamente para servir a los propósitos del planificador.

Tal situación ha sido considerada en los últimos años en reuniones promovidas por algunas instituciones de la región y se ha sugerido la 
conveniencia no sólo de incorporar demógrafos a las oficinas de planificación, sino también la de establecer cursos de capacitación para planificadores, dirigidos a mejorar el tratamiento de estas interrelaciones en las tareas de planificación.

Parece pertinente, entonces, recoger la idea y adelantar sugerencias sobre lo que podría ser contenido de los programas de capacitación. Valdría la pena considerar tres enfoques diferentes:

i) las interrelaciones a niveles macro-sociales;

ii) las interrelaciones y necesidades de información y de estudios demográficos a niveles sectoriales, y

iii) la política de población.

El primer enfoque destaca netamente la importancia del estudio de las influencias del cambio económico según el crecimiento demográfico y, a su vez, la influencia del cambio demográfico según el crecimiento económico.

En el segundo se requiere escoger aquellos sectores en que es más relevante la interacción y también, que sean los considerados como de primera prioridad por el planificador.

Por último, el tercero se impone como necesario, pues la política de población deberá integrarse con las políticas definidas a nivel nacional. La conveniencia de realizar un curso, como el sugerido en el documento que sirvió de base para la discusión, fue señalada repetidas veces durante el seminario.

En esta sesión, y orientada por el documento mencionado, se originó un interesante debate que versó sobre aspectos que podrían resumirse en seis preguntas: ¿por qué es conveniente realizar un curso? ¿para qué? ¿cuál sería su contenido? ¿a quiénes estaría destinado? ¿cómo empezar? ¿qué acciones complementarias convendría llevan adelante?

\section{a) ¿Por qué es conveniente realizar un curso y para qué?}

La cantidad de demógrafos que trabajan en las oficinas de planificación de los países de la región es insuficiente. Además, la comunicación profesional entre demógrafos y planificadores todavía no se ha dado al nivel deseable. Tal como se reconoce en algunos de los documentos presentados a este seminario, actualmente se ve la posibilidad de afianzar esa comunicación entre demógrafos y planificadores y la de difundir en todos los paises de la región las ventajas de incorporar las variables demográficas dentro del proceso de planificación.

Estas consideraciones, y también las necesidades expresadas por muchos de los participantes, refuerzan la idea de organizar un curso como el que se sugiere.

Este curso tendría por objetivo dar a cierto tipo de profesionales una visión amplia de las interrelaciones entre demografía y economía, de tal suerte que se considere este tipo de interrelaciones en los planes de desarrollo. 


\section{b) Contenido}

Durante el seminario no se definió concretamente, y con precisión, el programa.

Sin embargo, es posible plantear un esquema surgido de las diferentes opiniones de los participantes. En general, estas opiniones han mostrado dos matices, más que dos posiciones, de pensamiento.

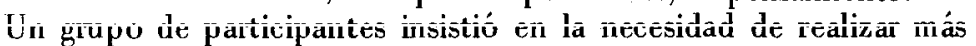
investigación básica en demografía. El curso debería orientarse más bien hacia el uso de datos y estudios demográficos en la planificación, porque de esta manera se cubrirían las necesidades a corto plazo de las oficinas de planificación.

Una variante de este enfoque estaría representada por la opinión que el curso debería fundamentarse más en las necesidades específicas de información de los diferentes países. Esto implicaría cierta selectividad por áreas, porque las experiencias de la planificación de los diferentes países guardan discrepancias en cuanto a la intensidad del proceso mismo y de los logros obtenidos. Si se hace esta selectividad por áreas y por experiencia en la planificación, se podria ayudar a los diferentes países a superar sus limitaciones informativas. En otras palabras, no se dehería empezar montando un curso que responda a un ideal que contenga todos aquellos elementos que desde cierto punto de vista constituyen la base fundamental del conocimiento de interrelaciones económicas, demográficas, sociales, políticas, etc., sino que trate de enfocar la solución de problemas concretos.

Otros participantes señalaron que aspectos como el estudio de las interrelaciones entre economía y demografía deberían ser incluidos en un programa. Convendría estudiar, por ejemplo, la relación de dependencia de las variables económicas en función de las variables demográficas. Podría examinarse cómo se modifican el consumo y el ahorro ante cambios de algunas variables demográficas.

El documento en general constituye una respuesta adecuada a las cuestiones planteadas durante el seminario. Se plantea un curso de tipo sectorial, pero se recomienda también otro de contenido más global, La interpretación de todos los aspectos sectoriales debería reunirse después en un estudio más global de desarrollo y de población. Por otro lado, no debería dejarse a un lado en el programa la consideración del manejo de las fuentes de información y la posible generación de otras nuevas.

Se intentó hacer un esquema del contenido posible de los cursos.

En primer lugar, convendría identificar el contex to de los problemas sociales de la América Latina incluyendo problemas relativos al campo de la población, examinando los diferentes modos de afrontar esos problemas y las posibles soluciones. Los problemas a los que se hace referencia se relacionan con la vivienda, la nutrición, la educación, la 
salud. Convendría incluir, un sumario de la dinámica de la interacción entre los problemas sociales y económicos; el proceso de crecimien to de los últimos años y los problemas derivados de este proceso. Deberían intervenir en el análisis economistas, demógrafos, sociólogos e incluso elementos de la ciencia política para contribuir a la explicación del contexto.

Un segundo punto tendría relación con la dinámica de la población. Además de esta dinámica, podría considerarse la vinculación entre las variables demográficas natalidad, mortalidad, migración, y estructura por edad y sexo; estructura de la fuerza de trabajo; la relación entre dependientes y población total, etc., con el propósito de dar una estructura técnica que permita entender el papel de las políticas.

Un tercer punto se refiere a las interrelaciones entre las variables de diferentes disciplinas, especialmente aquéllas que pueden considerarse como "círculos viciosos".

Para el estudio de las interrelaciones es necesario considerar la información mencionada en el segundo punto en relación con todas las implicaciones que tiene frente a la mano de obra, el ingreso, el consumo, etc. Tal vez una manera conveniente, aunque compleja, de enfocar el tema de las interrelaciones es dirigir la atención sobre grupos de problemas, más que sobre sectores o una disciplina particular. Por ejemplo, podría considerarse que el tamaño de la familia puede originar problemas de vivienda, de nu trición, de ausen tismo en las escuelas, etc. Pero debería considerarse simultáneamente que el nivel cultural tiene relación con el tamaño de la familia. Otro ejemplo se refiere a la condición de vida rural. Esta condición suele ser causa de la migración de las personas jóvenes y educadas, pero a su vez esta migración contribuy e a determinar las condiciones de la vida rural. También podría considerarse que el desempleo es una de las causas más fuertes de la concentración del ingreso, pero a su vez la concentración del ingreso es una de las causas de desempleo.

Un cuarto punto estaría relacionado con las técnicas de obtención de datos y de medidas para que este conocimiento estuviera puesto al alcance de los planificadores y finalmente habría que considerar la forma de incorporar esta información dentro de la elaboración de los planes. Entre las técnicas para obtener información se mencionan los censos, las encuestas y, en general, las investigaciones específicas.

Un quinto punto debería referirse al papel de las políticas y de la estrategia de los planes de desarrollo del pasado.

Y un sexto punto debería tratar sobre las.ideologías de la población.

Finalmenté, se consideró un séptimo punto relacionado con políticas de población. Cuando se habla de políticas de población no se está haciendo necesariamente mención implícita de las llamadas políticas de planificación de la familia, o de regulación de los nacimientos. Nadie desconoce la importancia de los problemas derivados de la morbilidad y 
de la mortalidad, que por regla general no ocupan mucho la atención de los estudiosos, pero con los progresos médicos que contribuyen cada vez más a extender la duración de la vida media, se genera un problema con implicaciones controvertibles. También es necesario considerar otras políticas que aunque no se pudieran definir como políticas de población, tienen implicaciones en relación con la cantidad y calidad de la población.

Estos cursos podrían estar dirigidos, no solamente a funcionarios de las oficinas de planificación y organismos centrales de planificación, sino también a profesionales ubicados en institutos de investigación y, en general, ubicados en instituciones que tengan influencia sobre las decisiones de política de desarrollo que se adopten en los paises de la región incluyendo funcionarios que están en otros organismos responsables de algunos sectores.

Otro aspecto dentro de este problema que se ha discutido ha sido el de la formación que deberían tener las personas invitadas. En general parece haber acuerdo en que esa formación será heterogénea, es decir, serán profesionales con diversos tipos de formación. Habrá demógrafos, economistas, sociólogos, médicos, planificadores, etc.

Es obvio que la América Latina enfrenta una problemática compleja. De ahi que convendria empezar atendiendo a las diferencias intraregionales de todo tipo señaladas, hasta llegar a las necesidades específicas de grupos de países. La definición del programa definirá también automáticamente el tipo de profesionales requerido.

En principio las organizaciones interesadas podrian preparar un diseño del curso.

Se sugirió el siguiente esquema: desarrollar dos cursos de tipo nacional para probar el programa, al que se invitaría a personas de diferentes oficinas de planificación. Después de la realización de los dos cursos de prueba, se podría hacer una evaluación de los mismos y finalmente tomar decisiones sobre la continuación de los cursos atendiendo a los resultados de la evaluación. La duración convendría que no fuera inferior a dos meses ni mayor de tres. Hay razones para creer que un curso que durara menos de dos meses no alcanzaría a cubrir un contenido que pueda considerarse básico para la formación de profesionales y por otra parte si excediera los tres meses seguramente impediría la participación de profesionales de posiciones jerárquicas elevadas.

Hay un aspecto, sin embargo, que los cursos no podrían resolver de inmediato. Ciertos problemas de carácter muy específico, y cuy a solución es relativamente urgente, suelen presentarse en los diferentes países cuando se plantea el uso de los datos demográficos en la planificación. Probablemente, en cada caso los problemas sean diferentes y no sería posible esperar que se formaran personas capacitadas para resolverlos. Se consideró que deberían tomarse acciones complementarias en forma 
de asistencia técnica. Esa asistencia tendría como objetivo ayudar a resolver los problemas más inmediatos de las oficinas de planificación. Tal vez podria pensarse en términos de la formación de un pequeño equipo técnico que dependiera de alguna de las instituciones auspiciadoras y que estuviera en condiciones de asistir a los países en sus necesidades específicas en el momento en que esa asistencia sea requerida. Se trataría, en una primera etapa, de satisfacer las necesidades más inmediatas, que posteriormente se cubrirían a través de los cursos.

\section{8. "GUIA BIBLIOGRAFICA DE ESTADISTICAS DEMOGRAFICAS $Y$ SOCIALES" $Y$ "LA INFORMACION DEMOGRAFICA Y LOS ESTUDIOS DEMOGRAFICOS EN LA AMERICA LATINA"}

Por último en el seminario se hizo la presentación de dos documentos informativos con el fin que los participantes conocieran el estado de la información existente y supieran a donde dirigirse para obtener datos adicionales. 


\section{ANEXO I.}

EXPOSICION DEL SEÑOR CARLOS QUINTANA, SECRETARIO EJECUTIVO DE LA COMISION ECONOMICA PARA AMERICA LATINA, HECHA EN EL ACTO INAUGURAL DEL SEMINARIO SOBRE UTILIZACION DE ESTUDIOS Y DATOS DEMOGRAFICOS EN LA PLANIFICACION

No obstante los progresos alcanzados en la teoría y en la práctica de la planificación. del desarrollo, aún existen aspectos $y$ problemas importantes en cuya consideración es fundamental el aporte de las diferentes disciplinas sociales, entre ellas la demografía. La preocupación central en este seminario, será el examen de algunos aspectos metodológicos que intervienen en la elaboración de los planes, en relación con el uso de los datos y los estudios demográficos. No debería interpretarse, sin embargo, esta definición del alcance de las discusiones del seminario como limitado a lo puramente metodológico, desde el momento en que surgen importantes implicaciones sobre el contenido de las metas y de los objetivos de los planes y, en general, sobre las mismas modalidades del desarrollo.

Discutir las posibilidades y las perspectivas del uso de los estudios y de los datos demográficos en la planificación del desarrollo -primer objetivo del seminario- implica un reconocimiento de que las características y cambios económicos, sociales y demográficos están estrechamente interrelacionados, aun cuando se tenga presente que el sistema de mutua dependencia - segundo objetivo de las discusionesno sólo es relativamente poco conocido sino que tampoco ha recibido hasta ahora la necesaria atención.

Deberíamos atribuir esta situación a un divorcio desafortunado entre la economia y la demografía. Los economistas manejan muchos problemas que tienen importantes aspectos demográficos, sin que muchas veces tengan una apreciación cabal de las contribuciones que el análisis demográfico podría rendir a sus estudios.

A su vez, los demográfos, con bastante frecuencia, no toman en cuenta los problemas que son de interés para los economistas, o en todo caso, su trabajo no está orientado por las necesidades del análisis económico. Ciertamente, esta desvinculación también afecta a la formulación de políticas, como ocurre con ciertas medidas económicas que necesariamente irán a tener implicaciones en la distribución espacial de la población, como son los planes regionales de inversión, o aquéllas 
que al afectar la distribución del ingreso podrían modificar la tasa de crecimiento de la población, sin tomar en cuenta en uno y otro caso tales consecuencias. En el mismo sentido se podrian mencionar muchas medidas de política social (servicios médicos, seguridad social, educación, etc.) que son tomadas sin expresar las consecuencias económicas que se derivarian de los cambios demográficos que dichas políticas probablemente provoquen.

Podemos decir que cada día se presta más atención a las variables demográficas en los planes gubernamentales y en la elaboración de políticas. La tasa de crecimiento de la población de nuestros paises, al igual que en otras regiones en desarrollo económico, sin paralelo en la historia de la humanidad, ha traído como consecuencia una mayor apreciación de la complejidad del problema de desarrollo y la necesidad de conocer más sobre las relaciones recíprocas de la situación demográfica y las tendencias sociales y las políticas si se desea encontrar soluciones prácticas a ese problema.

La creciente incorporación de objetivos sociales en la concepción y elaboración de los planes, abre nuevas y promisorias perspectivas al uso de los datos y de los estudios demográficos. En efecto, la planificación de los servicios que los gobiernos deben proporcionar a la población en materias como educación, salud pública, seguridad social, vivienda y la de otros aspectos de la infraestructura económica y social, debería apoyarse en un profundo y detallado conocimiento de la estructura y de la dinámica demográficas en la medida en que tales servicios están destinados a unidades de consumo como el individuo, la familia y otros segmentos de la población. Las demandas potenciales dependen en estas situaciones, entre otros factores, del número, de la estructura por sexo y edad, de la distribución espacial y de ciertas características sociales básicas, intimamente ligadas a las condiciones y a las tendencias demográficas.

Por otra parte, son muchos los problemas que debe afrontar el desarrollo de estos países que reclaman estudios en los que deberían trabajar en forma coordinada planificadores y demográfos, pero seguramente habría que dar prioridad a aquellos que tienen que ver con la utilización económica de los recursos humanos frente a la incapacidad de absorción de mano de obra que caracteriza a su desarrollo. También sería deseable abordar desde un doble ángulo -económico y demográfico- el problema de las migraciones interiores frente a los desequilibrios de las oportunidades economicas, asunto de vital importancia en la planificación regional.

Un somero examen de los planes gubernamentales mostraria que en la práctica de la planificación se hace un uso relativamente intenso de información demográfica,especialmente en la etapa de diagnóstico. Sin embargo, las variables demográficas intervienen en los planes como "datos" establecidos en forma exógena. Incluso en modelos de desarrollo 
con un alto grado de sofisticación, los datos de la población son determinados externamente y en consecuencia sin posibilidad alguna que puedan reflejar, en las proyecciones, los efectos de los cambios económicos y sociales previstos; dicho de una manera más general, los modelos no incorporan sistemas de interrelaciones de variables económicas, sociales y demográficas.

Por otro lado, sería poco realista esperar que las proyecciones demográficas, elaboradas muchas veces ignorando los planes gubernamentales, puedan describir, con un grado aceptable de seguridad la evolución futura de la población en sus aspectos cuantitativos y seguramente en menor medida todavía los cualitativos. ¿Cómo podría anticiparse, por ejemplo, la disponibilidad de los recursos humanos si no existen bases sólidas para inferir el grado de participación en el mercado de trabajo de ciertos segmentos de la población, su localización geográfica y su calificación educativa? ¿Cómo hacer un pronóstico confiable de la tasa de crecimiento demográfico (piénsese en tendencias de la fecundidad) cuando no se establecen hipótesis sobre cambios inducidos o previsibles en la distribución del ingreso y, en general, del acceso de una importante masa de población a formas modernas de vida?

En el documento presentado como Base de Discusión, se señalan dos grandes líneas de relaciones entre desarrollo y población, que deberian ser examinadas en este seminario. La primera de ellas se refiere al impacto de la tecnología moderna sobre los determinantes del crecimiento demográfico, la movilidad espacial y las tendencias de la urbanización con un alto grado de independencia respecto del nivel de vida de una gran mayoría de la población. La segunda línea emerge más bien de las formas que presenta el desarrollo latinoamericano $y$, por consiguiente, aquel tipo de relaciones podría ser graduado y quizás en parte modificado por nuevas modalidades que se impusieran a este proceso.

Quisiera señalar una vez más la necesidad de mayores investigaciones sohre las mutuas relaciones entre los cambios demográficos y los económicos y sociales. A los demógrafos les compete profundizar el análisis de las variables demográficas en el contex to económico y social y perfeccionar las fuentes de información de datos básicos de la población teniendo en cuenta las necesidades de la planificación. Por otra parte, los planificadores deberán perfeccionar la metodología que utilizan para elaborar los planes, introduciendo en ella, de manera adecuada, las variables demográficas. Es de esperar que, como consecuencia de este seminario, se promueva una mayor colaboración entre los especialistas en ambos campos. Un último punto a que deseo hacer referencia tiene relación con la necesidad de capacitar profesionales en este nuevo campo de especialización dentro del arte de planificar, materia sobre la cual esperamos la contribución de todos ustedes, durante este seminario. 


\section{ANEXO Il}

\section{CALENDARIO}

PRIMERA PARTE DEL SEMINARIO

Lunes 23

$9.00 \cdot 10.50$ Inscripción de los participantes

11.00 - 11.15 Sesión inaugural :

Discurso de bienvenida del Secretario Ejecutivo de la CEPAL, señor Carlos Quintana.

11.15 - 13.00 Primera sesión:

Los estudios demográficos y la planifiación del desarrollo.

Moderadores: Señores Norberto González y Aníbal Pinto.

Documentos de referencia: L.1 y L.1 Addendum.

15.30 - 17.00 Segunda sesión: Continuación.

Martes 24

9.30-12.30 Tercera sesión: Continuación.

14.30 - 17.30 Cuarta sesión: Continuación. Final de la primera parte.

\section{SEGUNDA PARTE DEL SEMINARIO}

Miercoles 25

9.30 - 12.30 Primera sesión :

Discusión sobre el dorumento "Objetivos sociales y variables demográfic as en la planificación económica" de Alejandro Fioxley (1...3).

Moderadores: Señor Pedro Esparza y señorita Carmen A. Miró.

14.30 - 17.30 Segunda sesión :

Discusión sobre los documentos "Relaciones entre variables económicas y demográficas. Ensayo de un modelo". de Angel fucaraccio y Carmen Arretx (I.4) y "Sccuencia del proceso de formulación de metas de empleo en la planificacion", de listeban Lederman (I..5). Moderadores: Señores Angel Fucaraccio, Norberto González y Paulo Souza. 
Jueves 26

$9.30-12.30$ Tercera sesión : Continuación

14.30 - 17.30 Cuarta sesión:

Discusión sobre los documentos "La utilización de los datos demográficos y el tratamiento de las variables de la población en planificación de la salud", de Raúl Vargas (L.2) y "Aspectos demográficos en la planeación de la educación" de Jorge A révalo e Iric Corvalín (L.6).

Moderadores: Señores Juan Carlos Elizaga y César Peláez.

Viernes 27

9.30 - 13.00 Quinta sesión :

Discusión sobre el documento "El uso de datos y estudios demográficos en la planificación del desarrollo regional" de Henri Meot y César Peláez (L.7).

Moderadores: Señores Juan Carlos Elizaga y Esteban Lederman.

Presentación de los documentos "Guía Bibliográfica de estadísticas demográficas y sociales", de CEPAL (L.8) y "La información y los estudios demográficos en la América Latina", de Carmen Arrext (L.9).

Sabado 28

9.30 - 13.00 Sexta sesión :

Discusión sobre el documento "Programa de adiestramiento sobre población y planificación del desarrollo" de Luis Olivos y Luis Ratinoff. (L.13).

Moderadores: Señorita Carmen A. Miró y señor Luis Ratinoff.

Discusión del proyecto de Informe Final.

Moderador: Señor Jorge Arévalo. 


\section{ANEXO III \\ LISTA DE PARTICIPANTES DEL SEMINARIO SOBRE \\ UTILIZACION DE ESTUDIOS Y DATOS \\ DEMOGRAFICOS EN LA PLANIFICACION}

Sr. Waldo Beltrán Aguilar

Economista Técnico

Ministerio de Planificación y Coordinación

BOLIVIA

Sr. René Bustamante

Director Oficina Nacional de Planificación

Presidencia de la República

NICARAGUA

Sr. Guillermo Caram

Subdirector

Oficina Nacional de Planificación

REPUBLICA DOMINICANA

Sr. Boris Chacón

Jefe Unidad Recursos Humanos

ODEPLAN

CHILE

Sr. Omar Chible

Asesor Oficina Nacional de Planificación

Presidencia de la República

NICARAGUA

Sr. Luis de Pablo Serna

Jefe de Programación Económica

Palacio Nacional

MEXICO

Sr. Gilbert Duperval

Director Asistente

División Estudios y Planificación - CONADEP

Palacio Ministerial

HAITI 
Sra. Cecilia Granados Ramírez de Solórzano

Economista

Oficina de Planificación

COSTA RICA

Sr. José Illescas

Director de Programación Social

ivinisterio de Pilanificación y Coordinación

BOLIVIA

Sr. Alberto Insúa

Director Servicio de Empleo y Recursos Humanos

Ministerio del Trabajo

PERU

Sra. Maritza Izaguirre

Director Planificación Social y Cultural

Palacio Blanco

VENEZUELA

Sr. Marco A. López

Director de Planificación

Casa Presidencial

COSTA RICA

Sra. Loreley Lorenzi de Reig

Técnico Ayudante en Demografía

Oficina de Planeamiento y Presupuesto

URUGUAY

Sr. Emile Macajoux

Tecnicien de ler. classe

CONADEP

HAITI

Sr. Gonzalo Martner

Director

Oficina de Planificación Nacional

CHILE

Sr. Conrado Osorio

Jefe Sector Estadístico

Consejo Superior de Planificación Económica

HONDURAS 
Sr. José Enrique Páez

Programador General

Secretaría Técnica de Planificación

PARAGUAY

Sr. Armando Baltazar Rivera

Jefe Departamento Programación Global CONAPLAN

Casa Presidencial

EL SALVADOR

Sr. Eudoro Sánchez y Sánchez

Secretario Técnico

Presidencia de la República

REPUBLICA DOMINICANA

Sr. Pedro Salazar Ch.

Planificador-Director

Sección de Planificación Regional

Dirección de Planificación

Presidencia de la República

PANAMA

Sr. Eliézer.Tijerina $G$ arza

Consejero Ejecutivo de la Presidencia

Palacio Presidencial

MEXICO

Sr. Héctor Valecillos T.

Adjunto al Coordinador

Departamento de Recursos Humanos

Palacio Blanco

VENEZUELA

Sr. Jorge Váscones C.

Sociólogo-Demógrafo

Instituto Nacional de Planificación

PERU

Sr. Néstor Vega Moreno

Director Técnico

Junta de Planificación

ECUADOR 


\section{ESPECIALISTAS INVITADOS}

Sr. Jean Bourgeois-Pichat

Director

Instituto Nacional de Estudios Demográficos

FRANCIA

Sr. Dudley Seers

Director

Instituto de Estudios del Desarrollo

Universidad de Sussex

INGLATERRA

Sr. Osvaldo Sunkel

Investigador del Instituto de Estudios Internacionales

Profesor de la Facultad de Ciencias Económicas

de la Universidad de Chile

CHILE

PARTICIPANTES DE ORGANIZACIONES INTERNACIONALES

Sra. Carmen Arretx

Profesor-Investigador

CELADE

Sr. Angel Fucaraccio

Profesor-Investigador

CELADE

Sr. Esteban Lederman

Programador Recursos Humanos (OIT)

ILPES

Sr. Aníbal Pinto

Director

División Investigación y Desarrollo Económico

CEPAL

Sr. Paulo Renato Souza

Economista

PREALC

Sr. Raúl Vargas

Jefe División Información

Centro Panamericano de Planificación en Salud

OPS/OMS 
OBSERVADORES

Sr. Roque García Frías

Jefe Sección Estudios Demográficos

CEPAL

Srta. María Esther González Antelo

Socióloga

Oficina Sectorial de Recursos Humanos

Ministerio del Interior

ARGENTINA

Sr. Eduardo Miranda

Experto

Oficina Regional

UNESCO

Sr. Bolivar Nieto Terán

Demógrafo

CELADE-Subsede

COSTA RICA

Sr. Carlos Noriega

Consultor

División Estadística

CEPAL

Srta. Graciela Echegoyen

Sectorialista en Educación

ODEPLAN

CHILE

Srta. Georgina Ortiz $\mathbb{P}$.

Sectorialista en Salud

ODEPLAN

CHILE

Sr. Agustín Porras M.

Demógrafo

El Colegio de México

MEXICO

Sr. Jorge Riquelme

Director Programa Interamericano del

Desarrollo Social

OEA 
Sr. Estevam Strauss

Profesor del Programa de

Cooperación Económica para

América Latina

ILPES

Sr. Víctor E. Tokman

Asesor Económico

CIAP - ILPES

Sr. Edu ardo Troncoso Langlois

Director Adjunto

PREALC (OIT)

Sr. Jan Versluis

Experto

OIT

Sr. Sergio Zubicueta

Planificación Regional

ODEPLAN

CHILE

COMITE ORGANIZADOR

Sr. Jorge Arévalo

Demógrafo

CELADE

Sr. Juan Ayza

Subdirector del Programa de Investigaciones

ILPES

Sr. Juan Carlos Elizaga

Coordinador Técnico

CELADE

Sr. Pedro Esparza

Economista

División Investigáciones

ILPES

Sr. Norberto González

Director del Programa de Investigaciones

ILPES 
Srta. Carmen A. Miró

Directora

CELADE

Sr. Luis Olivos

Subdirector Auxiliar

Departamento de Asuntos Sociales

OEA

Sr. César Peláez

Demógrafo

División de Asuntos Sociales

CEPAL

Sr. Luis Ratinoff

Program Adviser

BID 


\section{ANEXO IV}

LIST A DE DOCUMENTOS

\section{Calendario}

Los estudios demográficos en la planificación del desarrollo (Base de discusión) (ILPES - CELADE)

Posibilidades y perspectivas del uso de los datos y estudios demográficos (Algunos puntos de discusión) (ILPES - CELADE)

Objetivós sociales y variables demográficas en la planificación económica (Señor Alejandro Foxley)

Relaciones entre variables económicas y demográficas. Ensayo de un modelo (Señor Angel Fucaraccio y señora Carmen Arretx)

Secuencia del proceso de formulación de metas de empleo en la planificación (Señor Esteban Lederman)

La utilización de los datos demográficos y el tratamiento de las variables de la población en planificación de la salud (Dr. Raúl Vargas)

Aspectos demográficos en la planeación de la educación (Señor Jorge Arévalo y señorita Iris Corbalán)

El uso de datos y estudios demográficos en la planificación del desarrollo regional. CEPAL

Programa de adiestramiento sobre población y planificación del desarrollo (Señores Luis Olivos y Luis Ratinoff)

Guía Bibliográfica de estadísticas demográficas y sociales. CEPAL

La información y los estudios demográficos en la América Latina (Señora Carmen Arretx) 
Algunos modelos sencillos para el análisis de las interdependencias entre los cambios económicos y los demográficos (Licenciado Eliézer Tijerina)

Uso de datos y estudios demográficos en la planificación económica y social de Honduras (Licenciado Conrado Osorio)

Utilización de los datos demográficos en el proceso de planificación. El balance de recursos humanos (Señor Boris Chacón)

Objetivos de las políticas de desarrollo económico (Señor Luis de Pablo Serna)

La experiencia ecuatoriana (Señor Néstor Vega M.)

La experiencia venezolana sobre uso de datos y estudios demográficos en la planificación. (Dirección de Planificación Social y Cultural. Oficina Central de Coordinación y Planificación).

Informe Final

Final Report. 

SEMINAR ON THE UTHE IZATION OF STUDIRS AND DEROGRAPMTC DATA

IN PLANNRNG

Final Report 



\section{INTRODUCTION}

The Seminar on the Utilization of Demographic Data and Studies in Planning took place in Santiago, Chile, from August 23-29, 1971, and was sponsored by the following institutions:

Inter-American Development Bank;

Latin American Demographic Centre;

Economic Commission for Latin America;

United Nations Population Division;

Latin American Institute for Economic and Social Planning;

Organization of America States, General Secretariat, and

Regional Programme for Latin American and Caribbean Employment (ILO)

The origins of the Seminar can be found in the ever-growing need to intensify and improve the use of demographic studies and data in the planning of the economic and social development. The sponsoring institutions, have tended to develop activities aimed at fulfilling that need through seminars, studies, papers, conferences, research, teaching and technical assistance, stimulating interest in this task among the officials responsible for the development planning in Latin American countries.

The aims of the Seminar were the following:

1. To discuss the possibilities and prospects of using demographic studies and data for development planning with the officials responsible for national planning programmes.

2. To discuss the substantive and methodological aspects of the system of interrelations between demography and planning, and the methods and techniques required to incorporate demographic variables into planning.

3. To discuss, in general terms, the possible contents of a teaching programme of these methods and techniques.

The Seminar was conducted in two parts. The first part, was intended to identify the demographic problems of major importance for national development planning; to examine the nature of the system of mutual relationships of the variable "population", both in terms of its productive factor and subject to consumption needs. Part one was also concerned with specifying the implications of demographic problems particularly regarding approaches, methods and techniques, and defining the basic needs to be satisfied, as far as training and 
technical assistance are concerned. This is so that at the opportune moment countries may have demographic information available to formulate population policies and design adequate planning methods and techniques, thus fulfilling the previously mentioned objective. In this first part, papers marked with the key L.1 and L.1 Addendum shown in the list of documents presented to the Seminar, (Appendix IV), were used as discussion papers.

The second part was intended to examine the previous point in greater detail and to also examine the utilization of demographic studies in the sectorial and regional planning. A list of reference documents for the second part is included in Appendix IV.

Throughout the Seminar, discussions were enriched by the contribution of the participants, which in the case of representatives of the national planning bureaus, were also a valuable and timely illustration of the Latin American reality. It is important to point out here that some countries also presented papers related to their national experiences to the Seminar. (See the list in Appendix IV).

Twenty-four participants in the Seminar represented the planning bureaus of 15 Latin American countries. Special guests attending were, Mr. Jean Bourgeois-Pichat, Director of the National Institute for Demographic Studies of France; Mr. Dudley Seers, Director of the Institute for Development Studies of the University of Sussex, England; and, Mr. Osvaldo Sunkel, Researcher from the Institute for International Studies of the University of Chile. These gentlemen were responsible for presenting the basic subjects to be discussed in the Seminar. The total number of participants was 56 , including observers from various countries and international organizations. A list of participants appears in Appendix III.

The sessions were held at ECLA's headquarters, according to the schedule included in Appendix II.

The Seminar was inaugurated by the Executive Secretary of ECLA, Mr. Carlos Quintana, who emphasized the fact "discussing the possibilities and prospects of using demographic studies and data in development planning, implies a recognition that economic, social and demographic charasteristics and changes are closely interrelated, even when we realize that the system of mutual dependance is not only relatively little-known, but also that it has not received the necessary attention". 


\section{PART ONE}

The first part of the Seminar, lasting two days and intended for all participants, was devoted to the discussion of the subject "Demographic studies and development planning". It is useful to summarize some of the aspects considered.

\section{AVAILABILITY AND USE OF DEMOGRAPHIC DATA}

Initially, there was general agreement on the usefulness of population data, among other aspects, for the quantification of the goals and for considering the implications of the changes that development plans try to promote, thereby enabling a first analysis of different possible alternatives. For example, different population projections would allow to evaluate the influence that the changes in the components of the demographic growth could have on the population's size and structure. These are very important determinants of the requirement and possibilities of the economy.

Many participants, especially officials from the planning bureaus noted the lack of sufficient information on population. More extensive and adequate utilization of the data from demographic studies in the planning processes, can be limited by its availability especially given the degree of separation often required. It was also noted that at the sectorial level, use of demographic data is quite intensive. In sections such as housing, health, education, social security, planning could not be conceived of without the utilization of this information. Defficiencies in quality, quantity and adequacy were aspects persistently mentioned by participants. It was also pointed out that the limitation of information is likewise a concern for demographers, since this situation restricts the possibility of carrying out detailed and deeper analyses. However, it was acknowledged that in quality as well as in quantity, the existent information on population in Latin America, is greater than that available in other developing regions, and that occasionally existing information is not entirely used.

It was also recognized that the availability and the adequacy of the data depends, in part, on the demands made by users upon the information-producing sources. It was noted that one of the most important sources of information is the population census, and that this can satisfy many of the planners' and demographers' requests, provided 
that some measures are taken at the different stages of the census elaboration, beginning with the drawing up of the census form itself, and including the adequate questions and definitions for the further analysis.

It is also necessary to define relevant geographic regions or segments for certain kinds of analyses, and to design a tabulation programme which can fit the defined objectives.

Progress has been made, naturaily. However, we could advance even more provided that planners and demographers assume a greater responsibility for census programming. Increased involvement of planners and demographers at the different stages of the process should be taken into account, so that their influence can affect the decisions of the organizations in charge of taking a census.

It was noted that the increased collaboration established throughout the years among demographers, economists, sociologists and other social scientists, could be very valuable. This collaboration would lead to a better definition of the ways in which demographic information may be utilized.

\section{THE STATISTICAL ELABORATION}

Many participants agreed that it is necessary to question the utility of certain statistical categories used. These generally correspond to models from the developed countries which do not necessarily express the Latin American countries' reality. A frequent problem when working out the data, as has been repeatedly commented, is the necessity of having the information available at modely separated points, so that more detailed and accurate analysis of the Latin American reality can be made. For example, participants noted the limitations of the international classification by occupation and by occupational categories which the statistical bureaus use. It was pointed out that in some cases, individuals belonging to very different socio-economic strata are mixed together under one category, which somehow contradicts the purposes that were undoubtedly taken into account when recommending those classifications.

\section{NECESSITY OF STUDIES ON INTERRELATIONS}

A subject accorded much importance during the discussions, was that of the interrelations between demographic variables on one hand, and the economic, social and cultural variables on the other. The necessity of intensifying the deeper and detailed study of those mutual relations was repeatedly pointed out. Without diminishing the importance of other social disciplines, examples of relations between demography and economy, were insisted in. For instance, lengthy references were made 
in connection with problems such as employment, sub-employment and unemployment, labour qualification, income distribution, consumption, savings, etc.

It was pointed out, that as a necessary exercise, economists and demographers could work together in translating the economically active population's requirements into the distribution of that population according to job needs and compare this distribution with the real one. We could thus examine the degree of compatibility between the requirements of a development plan and the tasks the population is in position to perform. In relation to consumption and its planning, we must take into account the family size and life cycle, the age structure of the population, migration streams, etc.

Some studies could be devoted to examining population growth trends of family size and spatial distribution in relation to income and to income distribution. In turn this would be related to the study of the conditions upon which the accumulation of savings depend. Also mentioned was interest in the returns of social investments in fields such as food, health and education. Moreover, it was suggested that in relation to certain population policies, such as, for instance, encouraging internal migration, some studies should be conducted which take that policy into account.

\section{THE DEMOGRAPHIC VARIABLES INCORPORATED TO PLANS AS EXTERNAL DATA}

The treatment given to the demographic variables in the development plan's elaboration process, was discussed several times during the first as well as in the second part of the Seminar. These variables are incorporated as data which are not affected by the economic and social changes generated by the execution of the plans, as if the demographic dynamics were independent. This attitude is not unique to the planner. When the demographer states some supposed alternatives within a maximum and minimum range of the demographic variables' possible evolution, he is somehow trying to consider the economic, social and cultural assumptions that are behind those alternatives, but neither the causes nor the circumstances in which one or the other assumption may be more feasible, can be deeply analized. Actually this is not a result of the demographers' and planners' lack of perception but is rather the present state of knowledge, which has not yet moved forward sufficiently in the field of interrelations between both kind of variables, as was commented in point 3 .

Apart from the level of knowledge existing about the interrelations between economic, social, demographic and other variables, it has been said that treatment of the population variables as external data is not an obstacle, since those variables in general, evolve very slowly, and the 
changes are hardly noticeable during the four or five year-periods often referred to in the development plans. In this regard, during the meetings it was noted that frequently development plans incorporate measures, the effects of which are only felt after an extensive time-lapse, as is the case with big infrastructure projects. Nevertheless, this does not keep from being incorporated into the plans.

It was emphasized that the plans should be complemented by anaty ocs which clearly conoider the possible changes that the yariables may undergo and the relation of this development. Moreover, the evolution of those variables must be kept in mind, for it has been the case in some Latin American countries where fertility, for example, has suffered a great many variations in relatively short periods of time, the population estimates included in the development plans were far from the reality.

\section{NECESSITY OF INTENSIFYING THE COLLABORATION BETWEEN ECONOMISTS AND DEMOGRAPHERS}

The above discussion underlined the need to intensify the collaboration between economists and demographers and to unify the criteria for interdisciplinary analyses. Reference was made to the growing tendency to incorporate problems such as the elimination of marginality, and other social goals of this nature, into the plans. This recognition of man as the subject of the development, opens a whole wide panorama for the population studies related to developtment itself.

\section{NECCESARY DISAGGREGATION FOR THE TREATMENT \\ OF THE INTERRELATIONS BETWEEN THE DEMOGRAPHIC VARIABLES AND THE SOCIAL AND ECONOMIC ASPECTS OF DEVELOPMENT}

The incorporation of social goals into the plans is achieved as a complement to almost purely economic considerations. The rhythm of growth of the internal gross product taken as a development indicator, does not alone allow us to appreciate certain qualitative aspects very important to the development process. It of ten occurs that together with a high rhythm of economic growth, there is a worsening of some certain important social and economic aspects. That is why it is very important also to clearly consider some aspects related to the quality of life, particularly that of the low-income sectors, affected by problems of marginality, food deficiencies, health, lack of education, etc. This makes necessary the consideration of a series of aspects, in which demographic studies may be of great use if applied with an adequate level of disaggregation. It must be acknowledged that values taken by 
purely demographic variables, in the lowest income strata, can be very different from the population average. Thus, it can be seen that the general treatment of those variables, is not adequate when the population is taken as a whole.

\section{TRAINING OF PROFESSIONALS}

There was general agreement regarding the convenience of training professionals to make more adequate and systematic efforts at linking population with development planning. A teaching programme would have to be designed, for this purpose which would allow advances toward the integration of population studies and major demographic variables with development policies and problems. As far as we know, until now economics and demography in Latin America tend to be taught, in terms of systems of mutually independant knowledge. These aspects, however, have mutual relationships of undoubted importance in the explanation of the results of a determined process. It was recognized that a greater knowledge of the disciplines involved would be very useful to economists and demographers. We would try to train economists and demographers who in addition to the specific competence in their respective fields, also have firm notions of what social, economic, political, demographic and other systems are all about.

\section{UNITS OF DEMOGR APHIC ANALYSIS IN PLANNING BUREAUS}

The advisability of strengthening planning bureaus with units of demographic analysis when lacking, was incidentally pointed out. It was mentioned that in some planning bureaus, these units are already operating, some of them linked to the social affairs area. 


\section{PART TWO}

As detailed in the schedule, the second part of the Seminar was intended for the discussions of selected topics. Each topic was dealt with an ad-hoc document used as a basis for the discussions. The most important issues presented in the documents and during the discussions are summarized as follows. The topics are identified by the title of the documents and are commented upon in the order in which they were considered during the Seminar.

\section{SOCIAL GOALS AND DEMORAPHIC VARIABLES \\ IN PLANNING}

In the model presented, a methodology attempting to incorporate the social considerations into the objectives of economic development, was described. It is a model beginning with the analysis of external financing gaps, and of internal saving gaps. Adjusting both gaps is a task given to the planner. In this process, the amounts of internal savings and the foreign exchange necessary to keep a growth rate somewhat compatible with certain social objectives, are pointed out. Secondly, sectorial goals and their coherence with the general goals are examined. A model of multisectorial improvement is used, which simultaneously determines the maximum economic growth potential compatible with the limitations on resources and the structure of the demand, and deduces the levels of production, employment, investment and imports.

- To determine the demand from the point of view of the relation between the social and economic variables on one hand, and demographic variables on the other, investments and consumption habits of the people and of the government, are examined as important components. In the first case we determine the income resiliency of the demand by family size, according to sex, age and its change through time. Population growth will determine the limitations of the supply and the needs for greater resources. The most important fields of government consumption are: public education, public health, and food demands.

Investment is another aspect of final demand, since its level conditions the productive capacity of different sections of the economy, and also the creation of job vacancies. The compatibility of the final demand with the intermediate demand is described below. 
From the point of view of resource use employment is an important factor. The employment problem has two fundamental aspects. Firstly, the compatibility of the unemployment rate at a general level, with the aims of development plans; secondly, the identification of certain kinds of labour drain which could hinder development programmes.

The projection of the economically active population is directly related to the population's rhythm of increase and the sex-age-specific activity rate. It is pointed out that the rhythm of increase of the economically active population, will depend on the rate of the incorporation of the youth into the working force.

Several alternative projections of the economically active population, are presented in the paper. In one of those alternatives transformations in the cultural pattern are considered. The productivity of labour also plays an important role in the model, where it is observed that an increase in employment occurs, mainly in the traditional sectors, and tends to concentrate in the agricultural, and service area. Low agricultural productivity is a result of the high employment in the area and this stimulates migration towards urban areas. It is also mentioned that in general, the "service" sector absorbs the highest proportion of this migration. The possibility of modifying the rhythm of the rural-urban migratory flow and of increasing the productivity of the services depend on the capacity of the industrial sector to absorb labour productively.

To facilitate the adjustment between the supply and demand of human resources, it is necessary first to be sure of a better organization of the labour market and an adequate mobility between jobs; second, a suitable organization of labour within the enterprise for more profitable use of scarce labour: third, the acceleration of specialized professional training and, fourth, improved teaching methods to achieve productivity higher than that achieved with traditional education. Finally, regional goals are formulated which put special emphasis on the social objectives of the plans. An even distribution of the income and of employment opportunities are what we are seeking.

During the discussions, the importance of including social objectives was underlined, as were objectives related to regional distribution. It was noted that the economic model presented is a closed model and the demographic information added is exogenous. This observation is associated with the fact that the model contemplates a relatively short period of less than five years, where the consequences of the demographic variables will not be as apparent as the economic variables. However, in a longer term the consequence will be perceptible suggesting the reason why the programme should take them in to account. It does not seem advisable for the planner to include decisions with mid-term and long-term consequences without taking into account those effects. 
It was also mentioned that it would be advisable to add, among the subjectives of the plans, the gap between employment and population policies. Besides considering it necessary within the model there are certain aspects implicitly related to these problems. Following the thread of discussions held during the first part of the Seminar, it was the necessity of accomplishing interdisciplinary studies to better determine the interrelations which may exist between the demographic and economic yariables was again insisted upon. It was also pointed ont that the model was an illustrative example of the first steps which can be taken towards using demographic data in different stages of the drawing up of a development plan.

It was mentioned that it would be advisable to try to foresee the possible influence which demographic behaviour may have on economic variables, since the evolution of these variables within the plan is supposed to be affected mainly by decisions in economic field.

It would also be advisable to evaluate some of the desired effects that the behaviour of the demographic variables might have on development plans, as well as the undesirable effects of a policy. We quote as an example of this, the case of the modernization of the textile industry, which although having as an economic effect an increase in production may have undesired employment effects. Experience has demonstrated that modernization has resulted in unemployment when eliminating some occupations inherent to traditional industry.

Thought should be given to the research topics regarding the interrelations between demographic and economic variables which would be advisable to begin in the future as part of the effort to elucidate these questions, and to be able to contribute to the incorporation of the demographic variables as endogenous variables of the programme.

Also mentioned was the necessity of evaluating the effects that some contries' definition of population policies, clearly explained in some cases and implicit in others, may have on economic and other variables. In terms of employment and investment, some people think that additional investments create jobs but at the same time eliminate others. The increase in employment will be determined by the net balance between creation and elimination.

An important suggestion made was the advisability of applying the model to a concrete situation in a Latin American country, somehow approaching a development plan like the one presented from a planning viewpoint. 


\section{RELATIONS BETWEEN ECONOMIC AND DEMOGRAPHIC VARIABLES: ATTEMPT AT A MODEL}

The effects of population dynamics upon economic variables are usually incorporated into economic models. In the paper used as a basis for the discussion of this point, we find a demographic model in which the relations are explained in the opposite way: some of the variables are functions which depend on the social and economic process. In population projections, we usually find unclear relations which unite socio-economic status with reproductive behaviour, levels of mortality, migratory movements and participation in economic activities.

In general, this occurs due to a lack of sufficient information to quantify these relations. The development policy produces changes in demographic variables which affect the sequence of the development process in specific terms. Thus, changes produced in the standard of living, brought about through better educational levels, better housing conditions, better levels of income per capita, etc., will definitely imply changes in fertility patterns, specially when these improvements have been registered among groups with high fertility. If, at the same time, the development process offers the possibility of work to women, it may increase the depressive effect upon fertility, which concurrently may result in greater possibilities for women to seek employment.

Taking these considerations into account and by using data obtained in some Latin American countries, relations were stated between the standard of living on the one hand and fertility levels and rates of female participation in economic activities on the other. With these relations and two alternative approaches to development, population projections for Latin America were prepared for the period between 1970-2000.

The first approach to development assumes that the crude rate of increase of the Latin American product would increase at the same rate as in the past, that is to say, 2.1 per cent per year per person, while the income distribution would remain equal to the one estimated in 1970 during the projection period. The second alternative assumes: 1) that the Latin American product per capita will reach a rate which, starting from the registered levels in the recent past, would reach 5.1 per cent in 1980 , and 2) a redistribution of the income.

Results indicate that fertility decreases in either alternative to product increase. This decrease is significantly deeper assuming a greater product rate increase. Two participation approaches were set up in connection with the population engaged in economic activities, in order to look at fertility trends: according to the first one, participation would be constant in time, and according to the second one, urban female participation would increase as fertility decreased, while the male participation would decrease. This results in different dimensions 
and different age and sex structures of labour supply. This kind of exercises is regarded as very important because of the results obtained. For example, it has been pointed out that at the end of the projection -lasting thirty years- according to the second alternative there would be twenty million persons less in the population than those calculated according to the first projection. Out of those twenty million, approximately eighteen million would be children under the age of iifieen.

These differences obviously have an influence on the supply and on the structure of the consumption demand of educational services, health, etc, which vary according to population structure and size. Assuming that rates of urban participation vary, increasing for women as their fertility decreases and decreasing for men as the development process evolves, we note a labour supply 3.4 million people greater than if we were to make an estimation supposing constant participation rates. It is important to point out that this figure is drawn from two figures resulting from this projection. The figure of 3.4 million is the difference between ten million additional jobs which should be created for women and the removal of 6.6 million men in economic activities. These figures obviously indicate an important qualitative change which should be clearly introduced by the planner in his planning and should be incorporated by the demographer in his projections. One of the first questions raised by some participants was to what extent a model of this kind would prove useful for a planning office where quick decisions are needed, or whether these models should be left to Universities and Research Institutes.

The possibility of applying the model to specific situations and countries was discussed. The model includes measurements of demographic variables which may not correspond to Latin American countries, but they may be, in some cases, only approximations or assumptions. On the other hand, it was pointed out that since the model has a sequence in calculations, reflecting the usual practice in demographic projections, it is also applicable to specific situations after adapting it to the specific data available.

On the other hand, since the associations between fertility, mortality, participation in economic activity and evolution are not clearly incorporated in the measurement programme, but are carried out as separate tasks, a wide flexibility exists in order to form specific hypotheses in each country. Thus, the probable evolution of such variables would be determined and these results would be incorporated as data for measurement-programmes. In this way, results to concrete situations may be obtained.

It was pointed out that in this pattern some relations between demographic and economic variables have already been tackled. These variables are useful to formulate employment policies. The best 
appraisal of development problems constitutes a useful advancement in planning. These long-term analyses set the medium-range problems in the context of an adequate historical perspective. On the other hand, in the formulation of medium-range plans, it would be advisable to tackle the population variables as exogenous, for a four or five year period which corresponds to the plan. It is important to bear in mind that we may find cases of quick and strong demographic evolution of variables which are included within this medium-range period. These evolutions may affect the formulation of policies.

Some of the participants suggested some topics which could be included either in applied work or in models. For example the advantage of analysing the participation rates of groups at the outer edges scale was mentioned. This analysis would be done in order to find out to what extent these groups may be affected by education of youths and by retirement. These kind of considerations could be related to the formulation of an employment policy. For example, the pressure on the labour market could be noticeably modified if school continuation is increased, or if the retirement of economically active old people is intensified. Of course it is necessary to know the degree of flexibility which affects the participation in the variables mentioned, such as education, retirement and the relevant economic indexes, applied to some cases such as for example of income.

Another aspect which should be included is the one concerning urban and rural differentiation. As far as geographical distribution of the population is concerned, we should stress the importance of the migration problem which seems to be relevant when working on employment policies.

The knowledge of the migrant's characteristics and his reasons for migration would help to define an employment policy. It is possible that an inhabitant of a "minifundio" may have population parameters entirely different from those of an inhabitant of a modern "latifundio".

Another important subject which could be included in this kind of study is the one related to specific demographic studies for social groups. In spite of not having adequate studies and data for demographic research on social groups, some approximations could be attempted at, relating, for example, mortality and fertility to occupation. The biggest problem when carrying out deep and accurate studies is the deficiency of statistical information. For example, more accurate studies could be carried out if there were information on deaths related to occupation or on female fertility related to husbands' occupation.

Information is being supplied by surveys, particularly those sponsored by CELADE. Some information has already been incorporated in to the paper discussed here. 
Research works of this kind are necessary to improve the analyses on interrelation of demographic variables and other kinds of variables. The use of simulation models is a different technique which is being used as a "laboratory" in social sciences.

\section{SEQUENCE OF FORMULATING EMPLOYMENT OBJECTIVES}

\section{IN PLANNING}

Different methodological aspects including the formulation of development plans with employment objectives, were discussed. The availability of human resources was considered the starting point to set preliminary goal as far as occupation rates are concerned. Demographic information is essential at this stage, taking into account the need for incorporating population variables into the same model, considering the inrerrelations between development and demographic behaviour.

The determination of employment in rural areas is a function of the availability of natural resources, the capacity of productive absortion, labour and the demand for these kinds of goods.

In urban areas, a distinction should be made between producers of material goods and services. Regarding the former, the technology applied plays an important role in employment strategy. In the latter areas, the planner's attention should be centered upon the rules supplying those services, hence deriving the capacity of absorbing labour.

Methodology as such is not sequentially but formally given, and at each stage, the total compatibility between objectives and achievements should be examined. In general, the participants agreed on the fact that the oscillation of human resources is an adequate methodology to make compatible both the availability of human resources and the capacity of labour absorption. This should be a short, medium and long-term compatibility.

The wide difference among economic plans in Latin America is due to insufficient, inadequate and out-of-date demographic information. This fact may even bring about the failure of mathematically sophisticated models. This is due, to a large extent, to the lack of skilled staff. With regard to this, it was considered as advisable, to strive for an improvement in the global system of information, specially as far as population is concerned, and also to support the initiatives of inter-disciplinary training.

Concerning the results of planning, long-term plans have the advantage of including a period which allows a coordination of all measures tending to produce all the necessary institutional changes which ensure the productive work of the labour force.

Problems of great importance concerning employment were stated. One of the determinants of future labour supply refers to the degree of 
present use. Thus, it is interesting to obtain the best measurements of unemployment and specially of disguised unemployment and urder-employment, which is found mainly, for example, in branches of activity such as agriculture. Two fundamental difficulties in carrying out these measurements were mentioned. One is the lack of adequeate information. The other is the criteria used in order to define the disguised unemployment and the under-employment. These measurements are particularly important in order to define the policy of creating employment, when unemployment, disguised unemployment and under-employment reach the proportions such as those found in Latin America (one third to one half of the labour force).

Elaborating a plan to absorb all that labour in a five-year term has great political implications.

Another aspect which should draw the attention of planners, because of its negative impact on employment, is the risk of an employment decrease brought about by certain investments, specially when investments are made in modern areas.

Finally, it was pointed out that the choice of technology used, up to now, has been made on the basis of considerations which have not sufficiently taken into account aspects such as the cost and social benifits of investment. On the other hand, discrepancies between costs and social benefits may occur, according to the terms previously established.

\section{THE USE OF DEMOGRAPHIC DATA AND TREATMENT OF POPULATION VARIABLES IN HEALTH PLANNING}

In health planning, demographic data and studies are important for two reasons: firstly, regarding the interrelation existing between population and health; and secondly, with reference to population as subject of health services.

In diagnosing the situation of population health, it is important to take into account the influence exerted by demographic variables. Among them, the following aspects stand out: patterns of geographical distribution; forms of settlement and both rural and urban densities; internal migration; sex and age factors; and some socio-cultural and labour characteristics.

Health planning requires: knowledge of the level of health; an explanation of these levels by means of the factors which exert an influence on them; a proposed health model congruent with a general development model towards which society will aim in the future. Health planning also requires the outline of a strategy in order to achieve the model compatible with the strategy of the rest of the development areas. Finally, health planning needs: the elaboration of plans; programming activities; and constant evaluation and readjustment. 
The level of health and the structure of health services have population characteristics based on epidemiological criteria which are explanatory elements and constitute the expression of the basic susceptibility and the exposure to health risks which, through interaction with the environment, may lead to damage of different kinds. Sex and age structure is stated by means of the degree of susceptibility and/or exposure according to the differential risk of specific diseases.

Migrants may modify the structure of morbidity in heaping areas, either as carriers of a new pathology or through their higher degrees of susceptibility to endemic diseases of those areas. The patterns of spatial distribution and density may either act indirectly, through the supply of sanitary and health services or in a more direct way, through "social density", as far as mental illness and other behaviour disorders is concerned.

Lastly, characteristics such as ethnic groups, education, employment and income, take part in the health situation through feeding, housing conditions, health habits, direct professional risks, etc.

According to sex and age, the kind of services needed will undoubtedly vary. On the other hand, the distribution of health resources does not fit in with the spatial distribution of the population, to the degree that health resources cluster in areas of a higher real demand and of higher population density. Sudden changes in population density in some areas, as in the case of important cities, do not generally find a prompt solution in the supply of health services, since the infra-structure of the supply of health services is relatively rigid.

The information system about health is inadequate. Nevertheless, in some areas under some health programmes, continuous records have been set up. These may be used in order to do research on various demographic aspects. An example of these records is found in antimalarial-control programmes.

Nevertheless, the availability of suitable demographic information, with the needed separation, is not adequate, though it may be true that in health, categories of available population analysis are not widely used due to the difficulties in handling conceptual categories.

It is essential to have, at least, the following information when formulating a diagnosis of health conditions:

i) population of small areas;

ii) the urban-rural classification of population, because of its relevance to types of problems and to quality or kind of service;

iii) the sex and age structures;

iv) the socio-cultural aspects of population, associated with their state of health; 
v) guidelines to the use of services according to distances and psycho-social characteristics of users.

The health model stated with the planning process must be a model implying change, and does not necessarily have to coincide with the past. If this is so, both the impact of health actions on mortality and fertility and the impact of actions belonging to other areas should be evaluated by the health sector and taken into account for population estimates and projections.

Health considered as a social sector, cannot be restricted to the evaluation of the impact of health measures on mortality. Its aims should go further: to prevent illness, to soothe pain, to treat the sick, to train the handicapped, and to extend life. This means recording the importance of the problems and having the resources needed in order to carry out the activities centered in the large fields of anticipating the demand and of providing it.

In any case, information about population is essential since this information allows an evaluation of problems and an estimate of the availability of resources necessary to solve the problems.

With regard to health objectives, particular problems of each country and area should be borne in mind, together with their general possibilities and forms of socio-economic development. Besides, those problems which may be solved by means of technological achievements should be tackled in a different way. An example of this is the control of infectious and parasitic diseases. Other problems which should be tackled in a different way are those concerning the treatment of chronic diseases, maternal and child health, and other situations.

Other important aspects to be considered are the effects of health policy upon mortality and fertility. Medical research conducted according to health planning concerned with social and medical factors of morbidity and mortality would be of great help in order to formulate mortality projections.

Hygienic measures and medical assitance which help to reduce infant mortality might facilitate, through a change of attitude among mothers towards the care of the children, changes in the number of children and therefore in fertility level.

Fertility is not an important effect for the health sector, except when considered in a tangential way. Its inclusion within health planning is justified only when having characteristics affecting a specific policy. In this case, it is only a piece of information to help in the programming of activities perfomed to satisfy a spontaneous demand. Nevertheless, if we had a definite policy, the possible solution of family planning could be incorporated within sectorial planning and therefore, goals could be fixed, resources distributed, activities programmed, and their effects could be measured. Essential, in this case, is the use of demographic information and techniques. 


\section{DEMOGRAPHIC ASPECTS OF EDUCATION PLANNING}

In education planning, at diagnostic and forecasting stages, demographic information is used intensely. As in other areas of planning, the forecasting stage makes use of demographic information as if the process of population evolution were outside the process of education planning. The possible changes resulting in population dynamics introduced by the pianning process itself are not taken into account. On the other hand, the possible alternatives derived from the induced demographic change are not considered. Both in the diagnosis and forecasting, the demographer may collaborate with the education planner in other aspects which go beyond the school population projection.

Measures taken against illiteracy, together with demographic characteristics of population such as sex, age and place of residence, allow us to make inferences about the present educational situation and the previous one. These inferences are also used to analize tendencies and to extrapolate from them. By using specific techniques, it is possible to evaluate the educational situation.

It is also said that knowledge of the educational situation in relation to the territorial distribution of the population is essential in order to evaluate requirements and to formulate goals at a regional level.

A very important aspect is the effect demographic behaviour may have upon some measurements of educational attainment. For example, through the use of indicators such as illiteracy rates or the average number of school years, we can attempt to evaluate the efficiency of the establisched school system in different areas of the country. Those indicators render an approximate measurement of the systems' efficiency in quantitative terms. It is approximate partly because the values reached, for example, in the urban and rural areas, are affected by the process of internal migration.

In several analized cases, the migration group from the rural area to the urban area seems to have a higher level of instruction than that of the native population, but a lower one than that of the new population. This situation explains that the migratory movement damages simultaneously both instruction levels of the urban area where it has settled.

This kind of discovery makes us wonder about many points. When the education planner sets goals, he tries to eliminate differences in levels of instruction among the various areas of the country, and to allot a higher number of investments of all kinds to those areas where the instruction level is most deficient. It is doubtful that the planner will see his goals achieved if he does not account for the effect that internal migration may have on the results of the programme. 
Finally, the following questions were raised: if the level of instruction is raised in rural areas, will internal migration be encouraged? ; will that migration facilitate or complicate the process? . These and other questions suggest the need for deeper research on the relation between demography and educational planning.

During the discussions, it was mentioned that when comparing school-age population to school population in Latin America, an unsatisfied demand for education is evident. Since that demand is high it seems very difficult that it will be absorbed by traditional methods of teaching. Nowadays it is possible to change traditional methods of teaching and introduce others wich may have the great advantage of making greater studies and reaching more people. Among others, an example of this, is the education by satellite project, sponsored by different countries and by international organizations. A method of this kind would reach distant areas of a country and apparently, the most needed, since the more scattered the population, the lower the level of instruction.

Obviously, the analysis of the demand for educational services requires projections of school population and it is necessary to be extremely careful when making projections. A concern is that macro-educational variables should be complemented with the analysis of micro-educational variables. For making decisions, more detailed information and quick availability is required. It would be convenient to have offices for sampling research as a means of keeping up-to-date information.

Everybody agrees on the need for discussing the meaning of terms such as "Urban" or "Rural". The numerical criteria generally used in order to differentiate nuclei of different sizes with certain characteristics, are not adequate. These could be defined either as urban or rural. Besides, an effort should be made in order to revise the literacy concept which should include more requirements than those of being able to read and write.

The relation between education and internal migration brought about different opinions among participants. Some of them held the opinion that internal migratory movements might perhaps be encouraged and guided through education. Others were against usign restrictive terms, as far as education is concerned, with the purpose of stopping migratory movements, if a given policy aimed at that.

Some participants even expressed that since education is a right in itself, it should not be used as a means of satisfying certain population policies. Other requirements which the education planner should demand from the demographer were mentioned. For example, collaboration to measure the efficiency of the pedagogical system from the input and output of the educational system; how to measure losses, failures, drop-outs, etc. 
At short and medium range, the education planner must be aware of results derived from the influence of determinant factors. He must also be aware of data concerning school age population, according to age, sex, and urban-rural distribution. Besides, in order to direct regional planning, he requires information on spatial distribution at district levels, municipal levels, etc.

All these characteristics mentioned are very important since in Latin American countries there is a need for incorporating a great number of the school-age population into the education process. This means to allot human, physical and financial resources which represent an important proportion of available resources. Nevertheless, demographic variables are not the only ones which should be considered. Variables such as failure and drop-out are probably more meaningful since their effect on literacy is one of the problems to be solved by planners.

The importance of distinguishing between number of years of instruction and education was pointed out. The former is a measurement of a formal type, whereas the latter would render not only the amount of acquired knowledge at school and outside, but also the people's aptitudes and development in order to live and survive.

Some participants considered the advisability of doing projections in small areas. There are however methodological difficulties to making good projections. These difficulties arise from sources of information which are not often detailed enough to enable deep studies which may improve estimation methods.

It is also necessary to study the impact brought about by a change of demographic variables upon the estabished capacity of the system. Variables of this type are, for example, fertility and mortality. As has happened in Latin America, a quick decrease in fertility weakens the pressure exerted by the population on the educational system.

\section{THE USE OF DEMOGRAPHIC DATA AND STUDIES IN REGIONAL DEVELOPMENT PLANNING}

This subject was treated in two parts. The first part deals with the demographic variables needed for regional planning. Demographic information is considered an important element both in the characterization of territorial units and in the analysis of the flow of production factors among those units. From the initial diagnosis to the evaluation and control of a regional plan, it is necessary to use demographic data and studies. There is an important drawback in the sources of population data. These data usually have to do with political-administrative units which rarely coincide with definite areas included in the planning. Thus it is therefore essential to obtain information as separated as possible, thus enabling a proper regrouping. It is probably in this area where it is essential to have a knowledge of 
migratory movements, migrants' characteristics and the factors associated with migration. The importance of censuses as a means of making the necessary measurements was pointed out. Neverthesless, a deeper knowledge of these measurements will largely depend on sampling studies.

In the urbanization process, it is fundamental to distinguish between urban and rural population, and these two should not be confused. Both populations usually differ in their production and consumption patterns and in their infrastructural requirements. They also differ in their personal, cultural and economic characteristics, etc. Nevertheless, this dichotomy is not sufficient for more specific objetives of regional development. It is necessary to study the population settlement's forms in conglomerations of different size, economic organization, etc.

The main point of the paper is to exemplify the concrete application of various methodologies to Peru and a model concerning the formulation of a new regional strategy. One of the worst defects is great regional misproportion, not only as far as satisfying population needs is concerned, but also concerning making good use of all potential resources and the use of human resources available. One of the most important factors involving misproportion concerns the conditions of physical use in the country and trends of migratory movements. Among. the solutions chosen, we may find that important changes have been promoted concerning conditions of use of national land capacity. This will require complex and specific policies in order to face great migratory movements on a long term basis.

The methodology used is based on an indicator which measures the degree of grouping of the population living in various territorial units compared to the whole population. Such indicator is expressed as the quotient between density of one territorial unit and the sum of densities of all territorial units. According to the use of different combinations of the indicator, it is possible to classify territorial units into three great groups:

a) Areas of total population, where there is relative physical over-population both in urban and rural areas;

b) Areas of partial population, with relative over-population in one of the areas, classified into two subgroups: urban and rural;

c) Areas of subpopulation, with relative subpopulation in both areas.

According to the value of rural density compared to the value of one inhabitant per $\mathrm{km}^{2}$, these may be classified into two groups: areas of subpopulation and non-populated areas. For the purpose of having a clear and honest idea of these groups it is advisable to consider areas of possible use.

In order to state objectives for the national strategy, an imaginary objective of the urban and rural area was considered for 1990. This was 
done on the basis of a demographic and economic assumption which will produce population changes in the future. Forty variables and nearly thirty-five parameters were included. The type of analysis used corresponds to a planning model which does not present mathematical relations. The results obtained show radical changes in the territorial distribution of the Peruvian population; and these changes will probably satisfy the objectives of regional development.

Some remarks concerning the basis of calculations used in Peru were made. In addition, other general remarks were made concerning the demographic treatment of regional planning.

The need for doing a more detailed analysis comparing population and the migratory process was emphasized. There is also a need for an analysis comparing population and occupational conditions and specific settlement in regional areas. This analysis should be bound to general socioeconomic conditions which influence the geographical distribution of the population.

It is useful to have data regarding agricultural population, not only rural, in order to have a clear idea about population depending on agricultural activities.

Migration should be treated not only in the context of rural-urban transfer but also rural-rural transfer. Moreover, these transfers, elements of a development policy, should necessarily be bound to urban planning conditions. There is an urgent need for an analysis in order to achieve transfers in a planned way. Sociological studies are needed to test the viability of those transfers. Care should be taken in the use of rates such as man/land, because of their attached characteristics.

A work of this kind should include considerations related to urban development. There are demand problems in cities, in housing, in transport, etc., and demographers are needed in order to carry out studies of this kind.

We cannot make any planning decisions based on rates; on the contrary, rates are based on political decisions. More knowledge is required in order to interpret the rates which are usually used in regional planning.

The Agrarian Reform in peasants' settlements alters the relation between city and rural area. At the diagnostic stage, prior to development planning, a study should be made of population trends and structure. This study should stress the important role of spatial separation and should consider the following subjects:

i) Population growth and its geographical redistribution;

ii) Trends in demographic variables which determine population dynamic;

iii) Sex and age structure in different areas and districts;

iv) The process of urbanization and the patterns of rural and urban settlement of the population; 
v) Trends of participation in economic activity.

Demographic data and studies are useful for the work carried out at other stages of regional development planning, such as determining objectives, quantifying them and evaluating plans. Related to this, various types of demographic projections are considered useful.

Results of the mentioned demographic studies should include economic, social and cultural factors, etc., which affect demographic variables or are influenced by them.

In internal migration studies (considered the most necessary and important field of demography) an attempt should be made not only to determine migratory flows and some characteristics of migrants, but also their reasons for migrating and the way in which they assimilate in to the urban area.

The flow of natural and human resources is important, because by locating them, we are able to plan migratory flows necessary to achieve the desired goals.

It is important to include agricultural population in the analysis of the spatial distribution of the population.

\section{TRAINING PROGRAMME ON POPULATION AND DEVELOPMENT PLANNING}

The knowledge of the relations between demographic and socio-economic variables is insufficient. For this reason, they are seldom taken into account in a systematic way in national planning. These interrelations should be included in different fields. In some of those fields, education, health, urban and rural development, and employment, the interaction is observed but not adequately measured so that planners may take advantage of it.

This situation has been discussed in recent years during meetings sponsored by various regional institutions. It has been suggested not only that demographers should be incorporated into planning offices but also that training courses be set up for planners, in order to improve the treatment of these interrelations in the planning activities.

Thus, it seems relevant to suggest in advance the contents of training programmes. It is necessary to consider three different approaches:

i) Interrelations at macro-social levels;

ii) Interrelations and need for information and for demographic studies at sectorial levels;

iii) Population policy.

The first approach clearly reveals the importance of studying the influence of economic change according to demographic growth and, conversely, the influence of demographic change according to economic growth. 
In the second approach, it is necessary to choose those areas in which interactions are more important and those which the planner gives first priority.

Finally, the third approach is necessary because population policy should be integrated with definite policies at the national level. The advisability of carrying out a course like the one suggested in the paper used as the basis for discussion was pointed out many times during the Seminināis.

During this session, there was an interesting debate on different aspects which could be summed up in six questions: why is it advisable to offer a course? In what purpose? What should be the contents? For whom will this course be intended? How to begin? Which complementary actions should be carried out?

\section{a) Why is it advisable to offer a course?}

The number of demographers working in the planning offices of the countries of this region is insufficient. Moreover, the professional contact between demographers and planners has not been effective at the desired level. Nowadays, it is possible to make that contact and strengthen it, as was mentioned in this Seminar. It is also possible to indicate for all countries of the region, the advantage of including demographic variables into the planning process.

Thus, the idea of offering a course was suggested by most of the participants.

The aim of this course would be to provide professionals with a clear idea of the interrelation between demography and economics, so that this type of interrelation is included in development planning.

\section{b) Contents}

During the Seminar, the contents of this course was not specifically stated.

It is nevertheless possible to suggest a syllabus resulting from the different opinions given by participants. In general, these opinions indicated two shades of thought rather than two different approaches.

Some participants thought it was necessary to carry out more basic research on demography. The course should aim at the use of demographic data and studies in planning, since, in this way, short-term needs of planning offices would be satisfied.

Some participants in this group stated that the course should be based instead on specific needs of different countries. Areas should be selected since there are differences in planning experiences, as regards the intensity of the process itself and the objectives achieved. With a selective arrangement of areas and of experiences in planning, we could 
be able to help different countries to overcome their lack of sufficient information. In other words, we should not start by carrying out a course which represents an ideal containing all those elements constituting the fundamental basis of knowledge on economic, demographic, social and political interrelations and others. On the contrary, we should carry out a course where the solution of concrete problems is studied.

Another group of participants was in favour of including interrelations between economics and demography in the syllabus. For instance, the dependency relation of economic variables should be studied according to demographic variables. Besides, changes in consumption and savings, brought about by changes in some demographic variables, could also be examined.

The document, in general, satisfies the problems stated during the Seminar. A sectorial course was suggested, but another more global approach also was recommended instead. All these sectorial aspects would be explained and later ordered in a more global study of development and population. On the other hand, the syllabus should not leave out either handling information sources or the possibility of creating new ones.

A draft of the courses' possible contents was attempted.

First, the context of social problems in Latin America could be examined, including problems in the field of population. Various ways of facing these problems and possible solutions should also be studied. Problems mentioned concern: housing, nutrition, education and health. A summary of the dynamics of interaction between social and economic problems should also be included. Besides, the growth process in the last few years and those problems brought about by this process could also be included. In order to help explain the context, economists, demographers, sociologists and some elements of political science could participate in the analysis.

The second stage should deal with population dynamics. Moreover, the course could also include the relation between demographic variables of birth, mortality, migration and age and sex structure; labour force structure; the relation between dependants and population, etc. This is done to provide a technical structure which helps in understanding the role of politics.

The third stage deals with the interrelations between variables of different disciplines, specially those considered "vicious circles".

To study interrelations one must consider all the information mentioned in the second stage. This information is important in terms of its influence on labour, income and consumption. A suitable but perhaps complex way to approach interrelations is to draw attention to groups of problems rather than to areas or a specific discipline. For instance, the number of members of a family may cause housing and 
nutrition problems, and also absenteeism from schools. At the same time, the cultural level is related to the number of members in a family. Another example deals with rural residence. This situation is usually the cause of migration among young or well-educated people, but, at the same time, this migration helps determine rural living conditions. One could say that unemployment is one of the most important causes of income concentration, but at the same time, income concentration is one of the causes of unemployment.

The fourth stage would deal with the techniques used to obtain data and the steps taken to provide planners with this knowledge. Finally, the ways to incorporate this information into the elaboration of plans should be considered. Among the techniques used to obtain information we find censuses, surveys and specific research.

The fifth stage should deal with the role of politics and the strategy of development plans of the past.

The six th stage should deal with the population ideologies.

Finally, the seventh point concerns population policies. When speaking of population policies, those policies such as family planning or birth control are not clearly stated. Everyone acknowledges the importance of problems caused by morbidity and mortality, but studies about them are not generally conducted by specialists. A controversial problem results from this since life is constantly lengthened due to medical achievements. We must examine other policies which, though not defined as population policies, have implications for quantity and quality of the population.

These courses could be intended not only for officials from planning offices and central offices but also for professionals from research institutes and other institutions related to development policies in the countries of the area. The course should even include officials working in other offices.

Another aspect treated concerned the training of the participants invited. This was not discussed at length but everyone agreed that their training should be heterogeneous. That is to say, guests should be professionals with different training: demographers, economists, sociologists, doctors, planners, etc.

Since Latin America obviously faces complex problems, the course should begin by looking at interregional differences of all kinds and then go on to specific needs for groups of countries. The definition of a programme would almost automatically define the type of professional required.

Those organizations interested in the course could prepare a syllabus of the course.

The following syllabus was suggested: to develop two national courses to test the programme. People of various planning offices would be invited. These two trial courses could be evaluated. Decisions 
on the continuation of the courses should be made according to the results obtained in the evaluation. The course could last not less than two months and not more than three. A course lasting less than two months would not cover the basic contents for training professionals. On the other hand, a course lasting more than three months would encounter difficulty in obtaining high-level participants.

There is one aspect which could not be solved immediately by the courses. With regard to the use of demographic data in planning, different countries often face problems with very specific characteristics and which need relatively urgent solutions. These problems are probably different in each case and it would be difficult to train skilled people to solve them. Complementary steps should be taken to provide technical aid which would lead to solving more urgent problems. A small technical team could be formed under the supervision of sponsoring institutions and this team could help countries to face specific needs when required. The first stage would attempt to satisfy the most urgent needs which would be dealt with later during the courses.

8. "BIBLIOGRAPHICAL GUIDE TO DEMOGRAPHIC AND SOCIAL STATISTICS" AND "DEMOGRAPHIC INFORMATION AND DEMOGRAPHIC STUDIES IN LATIN AMERICA"

Finally, during the Seminar, two papers about the state of available information were delivered. They also included information on sources of additional data, to which the participants may refer. 


\section{APPENDIX I \\ STATEMENT BY MR. CARLOS QUINTANA, EXECUTIVE \\ SECRETARY FOR THE ECONOMIC MISSION IN LATIN AMERICA, DELIVERED IN THE OPENING OF THE SEMINAR ON: "THE USE OF DEMOGRAPHIC STUDIES AND DATA IN PLANNING".}

23rd August 1971

In spite of the advances in the theory and practice of development planning, there are still important aspects and problems where the help provided by different social disciplines, such as demography, is essential. This Seminar's main concern will be the study of some methodological aspects which have to do with the elaboration of plans in relation to the use of demographic data and studies. This approach is not a purely methodological one, since there are important implications as regards plans' aims and objectives and development itself.

The first aim of the Seminar, i.e. the discussion of possibilities and future development of the use of demographic studies and data in development planning, implies the acknowledgement of close interrelations between economic, social and demographic characteristics and changes. This is so, even when bearing in mind that the system of reciprocal dependency - the second aim of the Seminar- is not well-known; and furthermore, little attention has been paid to it.

We could say that this situation has been caused by the unfortunate separation between economics and demography. Economists deal with many problems containing demographic aspects, without being aware (most of the time) of the help that demographic analy sis could provide to their studies.

On the other hand, demographers do not usually take into account those problems which interest economists, nor does their work include needs for economic analysis. Obviously, this separation also affects the formulation of policies, as occurs with certain economic steps taken, which will influence the spatial distribution of population. Other steps taken are: regional plans of investment, economic steps which could modify the rate of population increase by change of income distribution. In this respect, we could mention many measures of social 
policy (health services, social security, education, etc.) taken without clarifying the economic results derived from demographic changes which these policies would probably bring about.

More attention is paid each day to demographic variables as far as government plans and the elaboration of policies is concerned. The rate of population increase in our countries, similar to other areas with the same level of development, has brought about a deep interest in the complex development problem. It also has brought about the need for getting acquainted with reciprocal relations between the demographic situation and social and political trends, in order to solve that problem.

The increasing incorporation of social objectives in the elaboration of plans, gives way to the use of demographic data and studies. In fact, the planning of services which are provided by governments should be based on a thorough and detailed knowledge of demographic structure and dynamics. This should be so, since services such as education, health, social security, housing and other aspects of the economic and social infra-structure are provided for the consumption of the individual family and other elements of the population. In this situation, potential demands depend, among other factors, on number, age and sex structure, spatial distribution and certain social basic characteristics intimately bound to demographic conditions and trends.

On the other hand, there are many problems which need studies done by planners and demographers together. We should give first priority to those problems dealing with economic use of human resources and the inability to absorb labour. Besides, the problem of internal migrations related to the unbalanced condition of economic opportunities (of vital importance in regional planning) should be approached from a double point of view, i.e. economic and demographic.

A brief study of government plans would show that demographic information is used in the practice of planning, specially at the diagnostic stage. Nevertheless, demographic variables are included in plans as "data" obtained in an exogenous way. Even in highly sophisticated development models, population data are externally determined. Thus, there is no possibility for projections to reveal the effects of economic and social changes already foreseen. That is to say, models do not include systems of interrelations between economic, social and demographic variables.

On the other hand, it would not be realistic to expect that demographic projections, often made without knowledge of government plans, could adequately describe the future evolution of population in its quantitative aspects; and even less in its qualitative ones. For example, how could the availability of human resources be foreseen if there are no solid bases to infer the degree of participation in the labour market of certain population segments, their geographical 
distribution and their educational qualification? How could a reliable forecast of the crude rate of demographic increase (concerning fertility trends) be made if there are no hypotheses either on guided changes or possible changes in income distribution, or on the incorporation of an important mass of population into modern ways of living?

Two important lines of relation between development and population appear in the document used as a basis for discussion. These

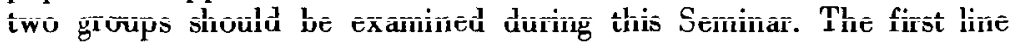
refers to the impact of modern technology upon the determinants of demographic growth, spatial mobility and the urbanization trends with a high degree of independence with regard to the standard of living of a great majority of the population. The second line arises from the characteristics of Latin American development and therefore, the kind of relations which could be graded and perhaps partly modified by new patterns.

I would like to point out, once again, the need for more research on reciprocal relations between demographic changes and economic and social changes. Demographers have to do with the analysis of demographic variables in economic and social contexts. They should also improve the sources of information and basic data about population, bearing in mind planning needs. On the other hand, planners should improve the methodology used in order to elaborate plans, including demographic variables in a adequate way. We hope that this Seminar will encourage a greater collaboration of specialists of both fields. Finally, I would like to refer to the need for training professionals in this new field of specialization within the art of planning.

We do hope to receive valuable collaboration from all of you during the Seminar. 


\section{APPENDIX II}

\section{PART ONE OF THE SEMINAR}

\section{Schedule}

Monday 23

9.00 - 10.50 Participants enrolment

11.00 - 11.15 Inaugural session:

Welcoming speech by the Executive Secretary for ECLA, Mr. Carlos Quintana.

11.15 - 13.00 Session One:

Demographic studies and development planning.

Moderators:

Mr. Norberto González and Mr. Aníbal Pinto.

Reference documents:

L.1 and L.1 Addendum.

15.30 - 17.00 Session Two:

Continuation

Tuesday 24

9.30 - 12.30 Session Three:

Continuation

14.30 - 17.30 Session Four:

Continuation. End of part one.

\section{PART TWO OF THE SEMINAR}

Wednesday 25

9.30 - 12.30 Session One:

Discussion of the paper "Social objectives of demographic variables in economic planning" by Alejandro Foxley (L.3).

Moderators:

Mr. Pedro Esparza and Miss Carmen A. Miró.

14.30 - 17.30 Session Two:

Discussion of papers "Relations between economic and demographic variables. Attempt at a model" by Angel 
Fucaraccio and Carmen Arretx (L.4) and "Sequence in the process of formulating employment objectives in planning", by Esteban Lederman (L.5).

Moderators:

Messrs. Angel Fucaraccio, Norberto González and Paulo Souza.

Thursday 20

9.30 - 12.30 Session Three:

Continuation.

14.30 - 17.30 Session Four:

Discussion of papers "The use of demographic data and treatment of population variables in health planning", by Raúl Vargas (L.2) and "Demographic aspects of education planning" by Jorge Arévalo and Iris Corbalán. (L.6).

Moderators:

Mr. Juan Carlos Elizaga and Mr. César Peláez.

Friday 27

9.30 - 13.00 Session Five:

Discussion of the paper "The use of data and demographic studies in the regional development planning" by Henri Meot and César Peláez. (L.7).

Moderators:

Mr. Juan Carlos Elizaga and Mr. Esteban Lederman.

Presentation of papers "Bibliographical guide to demographical and social statistics" by CEPAL (L.8) and "Demographic information and demographic studies in Latin America", by Carmen Arretx (L.9).

Saturday 28

9.30 - 13.00 Session Six:

Discussion of the paper "Training programme on population and development planning" by Luis Olivos and Luis Ratinoff (L.13).

Moderators:

Miss Carmen A. Miró and Mr. Luis Ratinoff.

Discussion on final report.

Moderator:

Mr. Jorge Arévalo. 
APPENDIX III

PARTICIPANTS OF THE SEMINAR ON THE USE OF DEMOGRAPHIC STUDIES AND DATA IN PLANNING

Mr. Waldo Beltrán Aguilar

Technical Economist

Ministry of Planning and Coordination

BOLIVIA

Mr. René Bustamante

Head of the National Office for Planning

Presidencia de la República

NICARAGUA

Mr. Guillermo Caram

Sub-Director

National Office for Planning

DOMINICAN REPUBLIC

Mr. Boris Chacón

Head of the Human Resources Unit

ODEPLAN

CHILE

Mr. Omar Chible

Supervisor of the National Office for Planning

Presidencia de la República

NICARAGUA

Mr. Luis de Pablo Serna

Head of Economic Programming

Palacio Nacional

MEXICO

Mr. Gilbert Duperval

Assistant Director

Division for Studies and Planning - CONADEP

Palacio Ministerial

HAITI 
Mrs. Cecilia Granados Ramírez de Solórzano

Economist

Planning Office

COSTA RICA

Mr. José Illescas

Director of Service Programming

Ministry of Planning and Coordination

BOLIVIA

Mr. Alberto Insúa

Director of Employment and Human Resources

Ministry of Labour

PERU

Mrs. Maritza Izaguirre

Director of Social and Cultural Planning

Palacio Blanco

VENEZUELA

Mr. Marco A. López

Director of Planning

Casa Presidencial

COSTA RICA

Mrs. Loreley Lorenzi de Reig

Assistant Technician in Demography

Planning and Budget Office

URUGUAY

Mr. Emile Macajoux

First Class Technician

CONADEP

HAITI

Mr. Gonzalo Martner

Director

Office for National Planning

CHILE

Mr. Conrado Osorio

Head of Statistical Area

Council for Economic Planning

HONDURAS 
Mr. José Enrique Páez

General Programmer

Technical Secretary for Planning

PARAGUAY

Mr. Armando Baltazar Rivera

Head of the Department for Global Programming

CONAPLAN

Casa Presidencial

EL SALVADOR

Mr. Eudoro Sánchez y Sánchez

Technical Secretary

Presidencia de la República

DOMINICAN REPUBLIC

Mr. Pedro Salazar Ch.

Planner-Director

Regional Planning Department

Planning Office

Presidencia de la República

PANAMA

Mr. Eliezer Tijerina Garza

Executive Adviser of Presidency

Palacio Presidencial

MEXICO

Mr. Héctor Valecillos T.

Coordinator Assistant

Human Resources Department

Palacio Blanco

VENEZUELA

Mr. Jorge Váscones C.

Sociologist-Demographer

National Institute for Planning

PERU

Mr. Néstor Vega Moreno

Technical Director

Planning Office

ECUADOR 


\section{INVITED SPECIALISTS}

Mr. Jean Bourgeois-Pichat

Director

National Institute for Demographic Studies

FRANCE

Mr. Dudley Seers

Director

Institute for Development Studies

University of Sussex

ENGLAND

Mr. Osvaldo Sunkel

Researcher of the Institute for International Studies

Professor of the Faculty of Economic Sciences

University of Chile

CHILE

PARTICIPANTS OF INTENATIONAL ORGANIZATIONS

Mrs. Carmen Arretx

Professor-Researcher

CELADE

Mr. Angel Fucaraccio

Professor-Researcher

CELADE

Mr. Esteban Lederman

Programmer of Human Resources (ILO)

Mr. Aníbal Pinto

Director

Research and Economic Development Division

ECLA

Mr. Paulo Renato Souza

Economist

PREALC

Mr. Raúl Vargas

Head of Information Division

Pan American Centre of Health Planning

Pan American / WHO 


\section{OBSERVERS}

Mr. Roque García Frías

Head of Demographic Studies Department ECLA

Miss María Esther González Antelo Sociologist

Sector Office for Human Resources

Home Office

ARGENTINA

Mr. Eduardo Miranda

Expert

Regional Office

UNESCO

Mr. Bolívar Nieto Terán

Demographer

CELADE

COSTA RICA

Mr. Carlos Noriega

Consultant

Statistical Division

ECLA

Miss Graciela Echegoyen

Expert on Education Sectors

ODEPLAN

CHILE

Miss Georgina Ortiz

Expert on Heal th Sectors

ODEPLAN

CHILE

Mr. Agustín Porras

Demographer

El Colegio de México

MEXICO

Mr. Jorge Riquelme

Director of the Interamerican Program for Social Development

OAS 
Mr. Estevam Strauss

Professor of the Program for Economic Cooperation

for Latin America

Latin America

ILPES

Mr. Víctor E. Tokman

Economic Supervisor

CIAP - ILPES

Mr. Eduardo Troncoso Langlois

Assistant Director

PREALC (ILO)

Mr. Jan Versluis

Expert

ILO

Mr. Sergio Zubicueta

REGIONAL PLANNING

ODEPLAN

CHILE

ORGANIZING COMMITTEE

Mr. Jorge Arévalo

Demographer

CEL.ADE

Mr. Juan Ayza

Sub-Director of the Research Programme

ILPES

Mr. Juan Carlos Elizaga

Technical Coordinator

CELADE

Mr. Pedro Esparza

Economist

Research Division

ILPES

Mr. Norberto González

Director of the Research Programme

ILPES 
Miss Carmen A. Miró

Director

CELADE

Mr. Luis Olivos

Assistant Sub-Director

Social Affairs Department

OAS

Mr. César Peláez

Demographer

Social Affairs Division

ECLA

Mr. Luis Ratinoff

Program Adviser

BID 
APPENDIX IV

LIST OF DOCUMENTS

Schedule

Demographic Studies in Development Planning (Basis for discussion) ILPES/CELADE

Possibilities and Perspectives on the Use of Demographic Data and Studies. (Some discussion points). ILPES/ CELADE

The Use of Demographic Data and the Treatment of Population Variables in Health Planning. (Dr. Raúl Vargas)

Social Aims and Demographic Variables in Economic Planning (Mr. Alejandro Foxley)

Relations between Economic and Demographic Variables: Attempt at a model. (Mr. Angel Fucaraccio and Mrs. Carmen Arretx)

Sequence in the Process of Formulating Employment Objectives in Planning. (Mr. Esteban Lederman)

Demographic Aspects in Education Planning. (Mr. Jorge Arévalo and Miss Iris Corbalán)

The Use of Demographic Studies and Data in Regional Planning. ECLA

Bibliographical Guide to Demographic and Social Statistics. ECLA.

Information and Demographic Studies in Latin America (Mrs. Carmen Arretx) 
Some Simple Models for the Analysis of Interdependences between Economic Changes and Demographic ones. (Eliezar Tijerina)

Use of Demographic Data and Studies in the Economic and Social Planning of Honduras. (Graduate Conrado Osorio)

Aims of Economic Development Policies. (Pablo Cerda)

Training Programme of Population and Development Planning (Mr. Luis Olivos and Mr. Luis Ratinoff)

Use of Demographic Data in the Planning Process. The Availability of Resources. (Mr. Boris Chacón).

The experience in Ecuador. (Mr. Néstor Vega M.)

The Experience in Venezuela on Use of Demographic Data and Studies in Planning. (Social and Cultural Planning Office. Central Office for Coordination and Planning)

Final Report 
Impresos Offset Ltda. - Mallinkrodt 102 - Teléfono 775618 - Santiago-Chile. 

